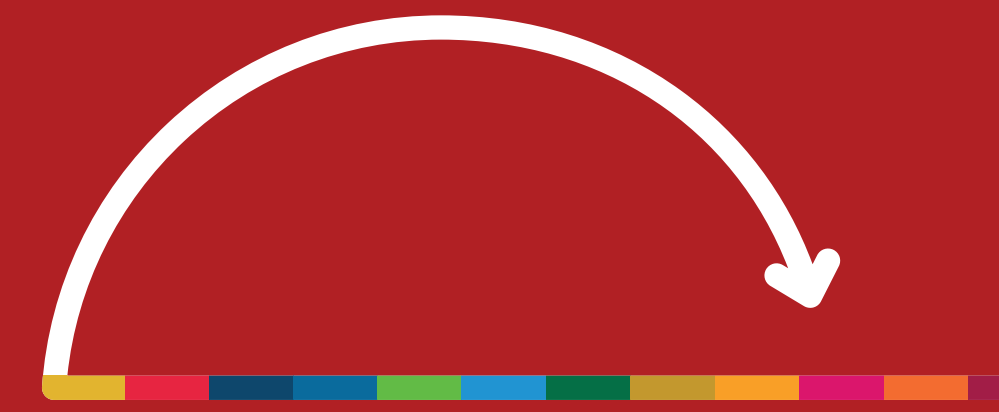

\title{
The Inefficiency \\ of Inequality
}

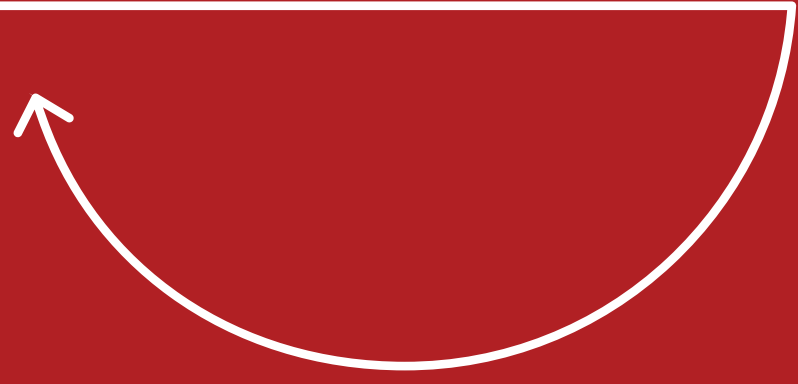

2018

THIRTY-SEVENTH SESSION OF ECLAC

Havana

7-11 May

UNITED NATIONS

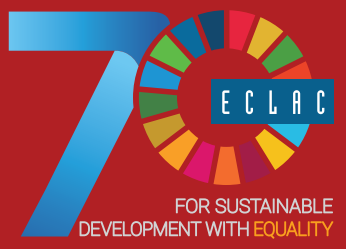




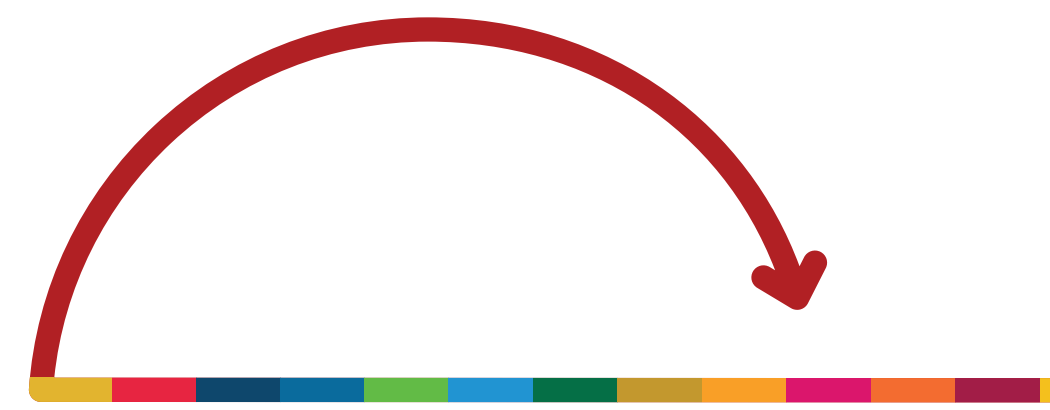

\section{The Inefficiency \\ of Inequality}

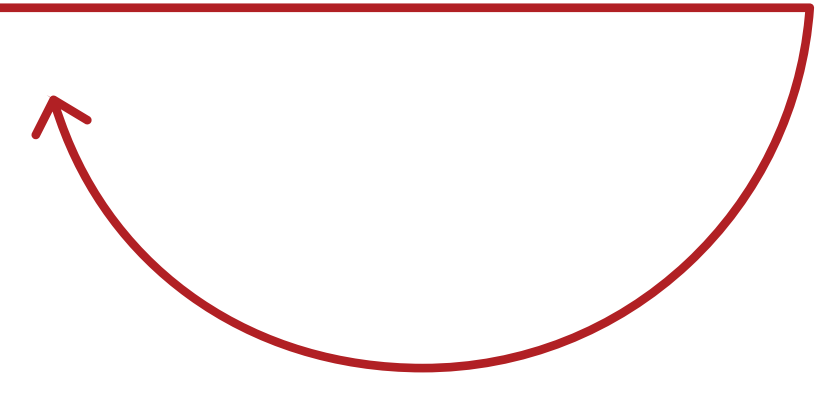

2018

THIRTY-SEVENTH SESSION OF ECLAC

Havana

7-11 May

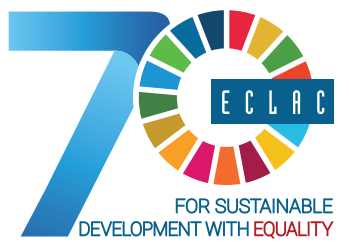




\section{Alicia Bárcena}

Executive Secretary

Mario Cimoli

Deputy Executive Secretary a.i.

Raúl García-Buchaca

Deputy Executive Secretary for Management

and Programme Analysis

\section{Ricardo Pérez}

Chief, Publications and Web Services Division

Work on this document was coordinated by Alicia Bárcena, Executive Secretary of the Economic Commission for Latin America and the Caribbean (ECLAC), with the collaboration of Mario Cimoli, Deputy Executive Secretary a.i.

The drafting committee comprised Martín Abeles, Verónica Amarante, Simone Cecchini, Wilson Peres, Esteban Pérez, Gabriel Porcile, Joseluis Samaniego and Pablo Yanes of ECLAC, and Martín Hopenhayn, former ECLAC staff member, who were assisted by Cielo Morales, Jeannette Sánchez, Romain Zivy, Vianka Aliaga and Vera Kiss.

The following chiefs of substantive divisions, subregional headquarters and country offices of ECLAC also participated in the preparation of this document: Daniel Titelman, Chief of the Economic Development Division; Pascual Gerstenfeld, Chief of the Statistics Division; Paulo Saad, Chief of the Latin American and Caribbean Demographic Centre (CELADE)-Population Division of ECLAC; Cielo Morales, Chief of the Latin American and Caribbean Institute for Economic and Social Planning (ILPES); Laís Abramo, Chief of the Social Development Division; Joseluis Samaniego, Chief of the Sustainable Development and Human Settlements Division; Jeannette Sánchez, Chief of the Natural Resources and Infrastructure Division; Nieves Rico, Chief of the Division for Gender Affairs; Osvaldo Sunkel, Chair of the Editorial Board of the CEPAL Review, Hugo Beteta, Chief of the ECLAC subregional headquarters in Mexico; Diane Quarless, Chief of the ECLAC subregional headquarters for the Caribbean; Juan Carlos Ramírez, Chief of the ECLAC office in Bogota; Carlos Mussi, Chief of the ECLAC office in Brasilia; and Inés Bustillo, Chief of the ECLAC office in Washington, D.C.

The authors are particularly grateful to the following staff members of ECLAC: José Eduardo Alatorre, Andrés Arroyo, David Barrio, Pablo Chauvet, Martín Cherkasky, Rodrigo Contreras, Felipe Correa, Manlio Coviello, Carlos de Miguel, Ernesto Espíndola, Jimy Ferrer, Tania García-Millán, Sebastián Herreros, Raúl Holz, Azhar Jaimurzina, Valeria Jordan, Andrei Jouravlev, Luiz Fernando Krieger Merico, Jeannette Lardé, Mauricio León, Karina Martínez, Antonio Martins, Luis Méndez, Beatriz Morales, Gabriel Pérez, María Cecilia Plottier, Verónica Quiroz, Luis Riffo, Adrián Rodríguez, Edwin Fernando Rojas, Miryam Saade, Ricardo Sánchez, Silvana Sánchez, Nunzia Saporito, Lucía Scuro, Valeria Torres, Daniela Trucco, Heidi Ullmann, Hugo Ventura and Soledad Villafañe.

The following ECLAC consultants also provided input for the preparation of the document: Hugo Altomonte, Rafael Aramendis, Bernardo Atuesta, Martín Brum, Fedora Carbajal, Maira Colacce, Nicole Favreau-Negront, Noemí Giosa Zuazúa, Pilar Manzi, Sebastián Valdecantos, Juan Pablo Valenzuela and Eduardo A. Vasconcellos.

The authors wish to thank Cristóbal Budnevitch, Facundo Grimberg and Alicia Pita for their assistance.

Gratitude is also due to the Governments of France, Germany, Norway, Spain and the Republic of Korea, and to the European Commission, for their support for the substantive work of ECLAC, which contributed analysis and proposals to the preparation of this document.

The boundaries and names shown on the maps included in this publication do not imply official endorsement or acceptance by the United Nations.

United Nations publication

ISBN: 978-92-1-121990-6 (print)

ISBN: 978-92-1-058628-3 (pdf)

ISBN: 978-92-1-358084-4 (ePub)

Sales No.: E.18.II.G.11

LC/SES.37/3-P

Distr: General

Copyright (@) United Nations, 2018

All rights reserved

Printed at United Nations, Santiago

S.18-00058

\section{Explanatory notes}

- Three dots (...) indicate that data are missing, are not available or are not separately reported.

- A dash (-) indicates that the amount is nil or negligible.

- A full stop (.) is used to indicate decimals.

- The word "dollars" refers to United States dollars unless otherwise specified.

- A slash (/) between years (e.g., 2013/2014) indicates a 12-month period falling between the two years.

- Individual figures and percentages in tables may not always add up to the corresponding total due to rounding.

This publication should be cited as: Economic Commission for Latin America and the Caribbean (ECLAC), The Inefficiency of Inequality (LC/SES.37/3-P), Santiago, 2018

Applications for authorization to reproduce this work in whole or in part should be sent to the Economic Commission for Latin America and the Caribbean (ECLAC), Publications and Web Services Division, publicaciones@cepal.org. Member States and their governmental institutions may reproduce this work without prior authorization, but are requested to mention the source and to inform ECLAC of such reproduction. 


\section{contents}

Foreword

\section{Chapter I}

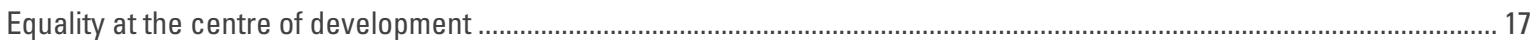

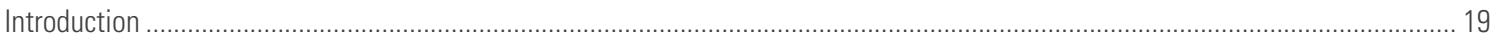

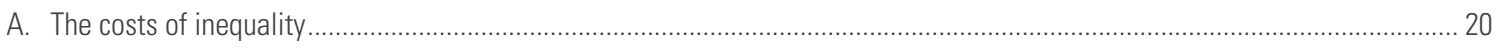

1. Unequal access to capacities: a barrier to productivity growth that the market does not correct .................................... 22

2. The destruction of the environment: a manifestation of both intra- and intergenerational inequality ................................. 24

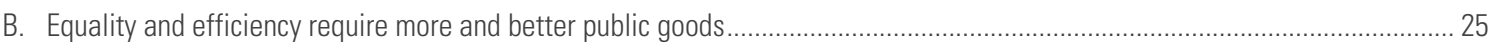

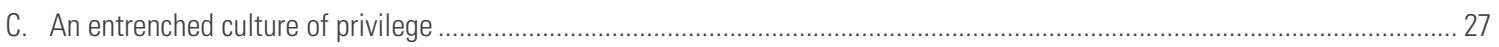

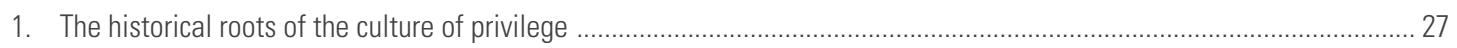

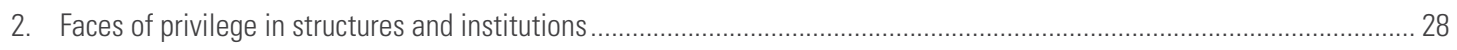

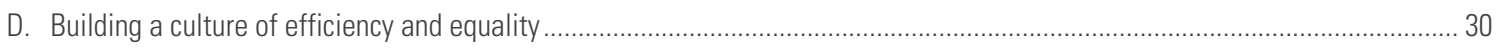

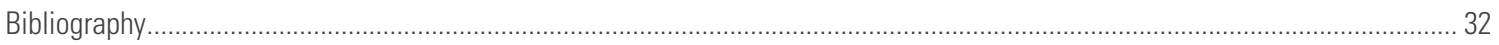

\section{Chapter II}

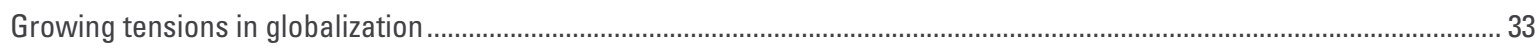

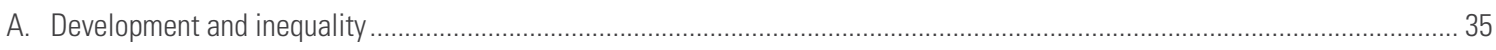

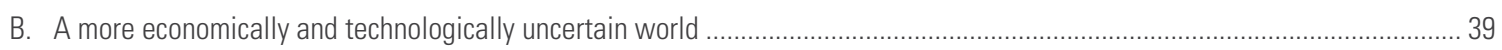

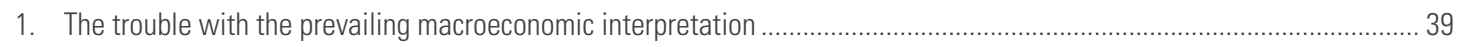

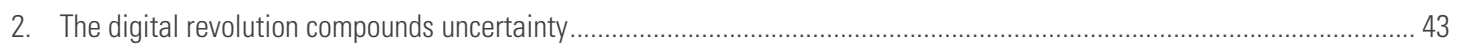

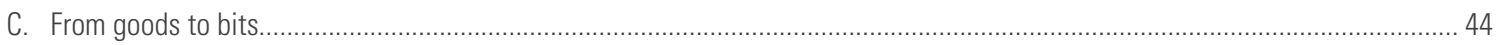

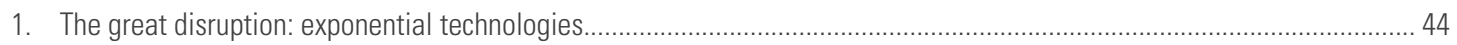

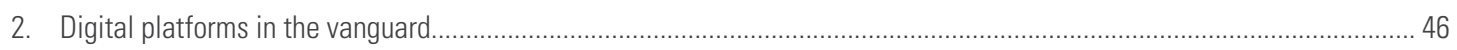

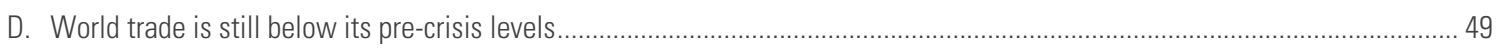

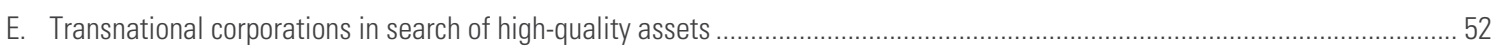

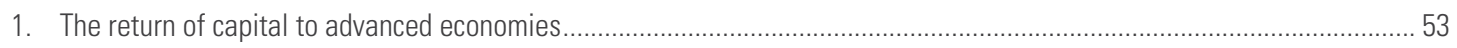

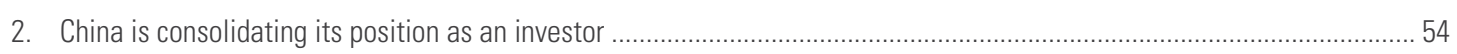

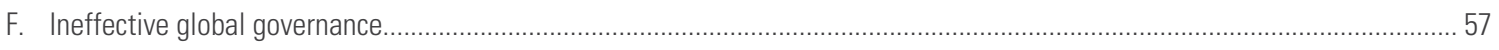

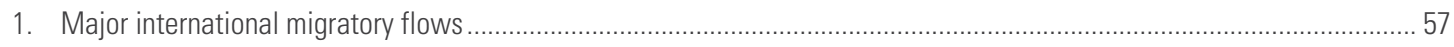

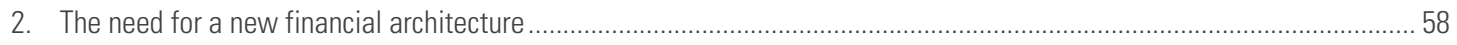

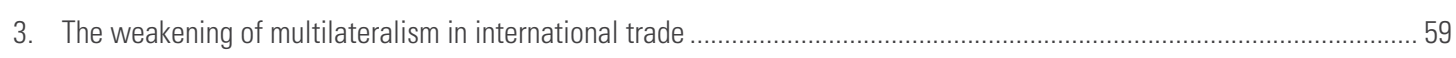

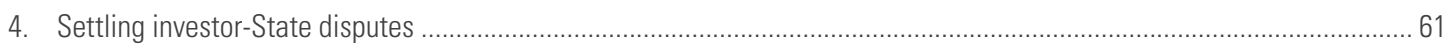

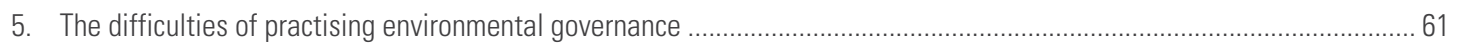

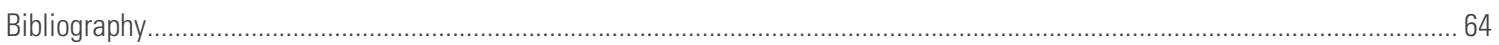




\section{Chapter III}

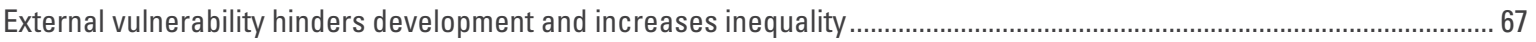

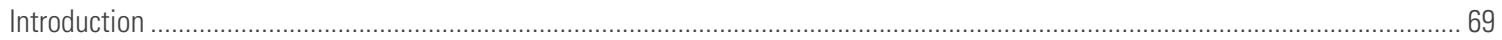

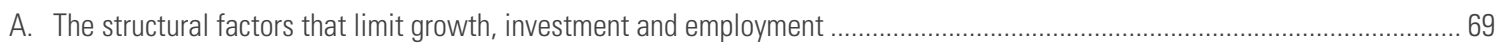

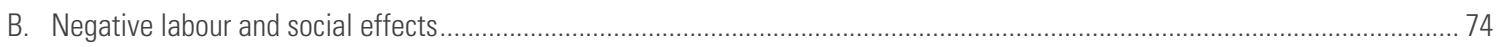

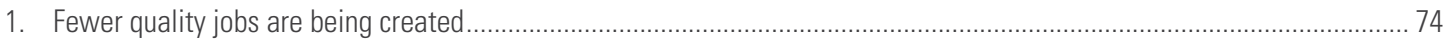

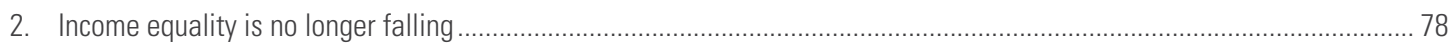

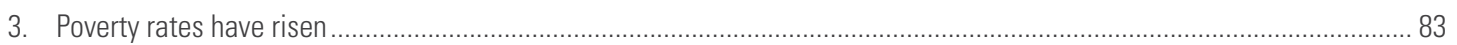

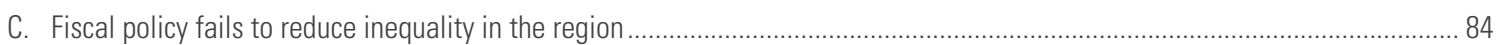

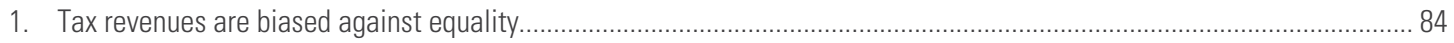

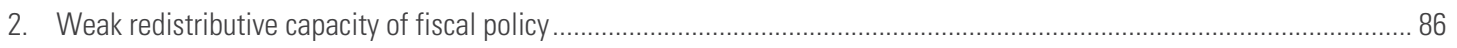

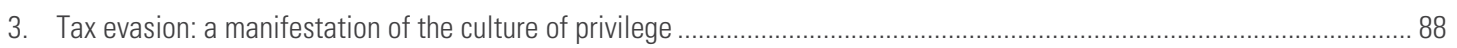

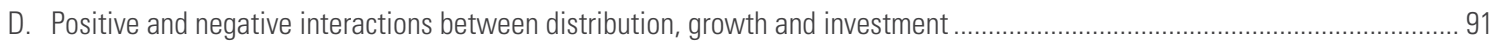

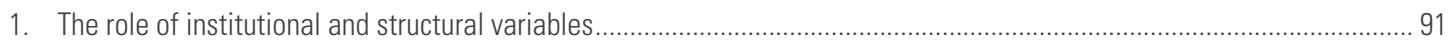

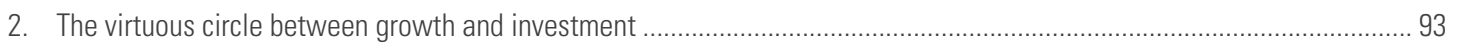

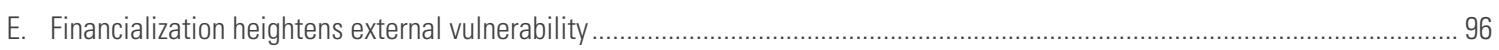

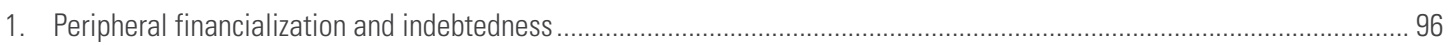

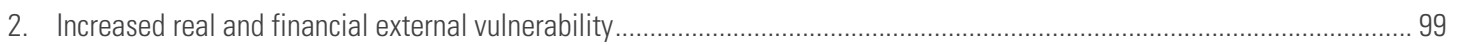

3. Obstacles to growth, investment and production diversification in the long term .................................................... 101

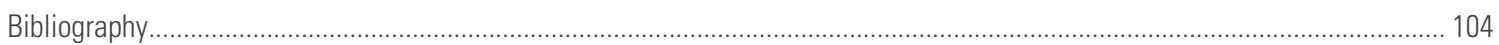

\section{Chapter IV}

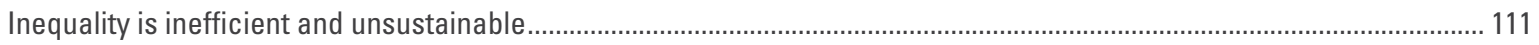

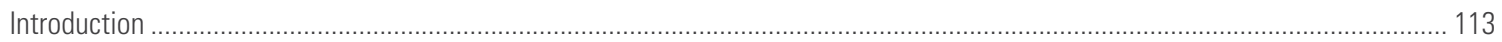

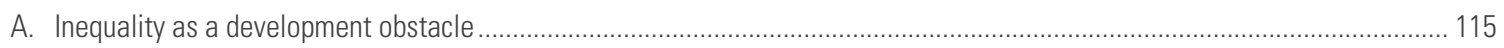

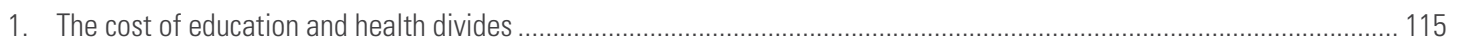

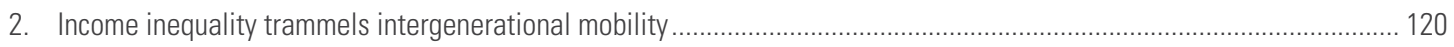

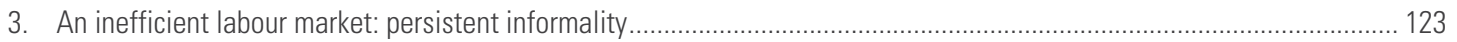

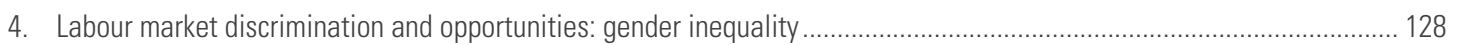

5. The positive effects of social protection and care on growth and employment ...................................................... 131

B. Future challenges: demographic changes and the technological revolution .................................................................. 135

1. The effects of ageing, female labour force participation and education ..................................................................... 135

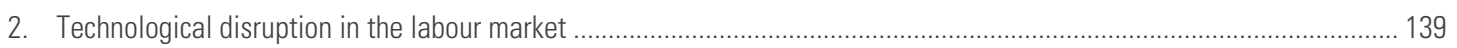

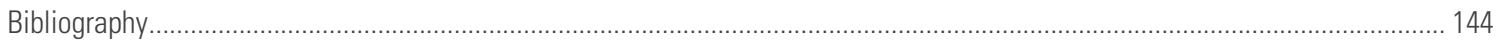

\section{Chapter V}

Inequalities that cause segregation and deterioration: territory and the environment ................................................... 151

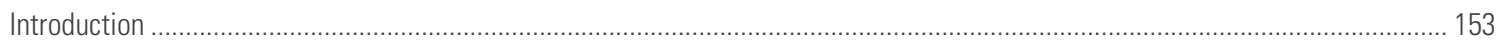

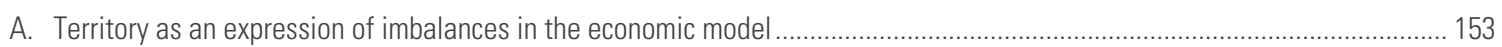

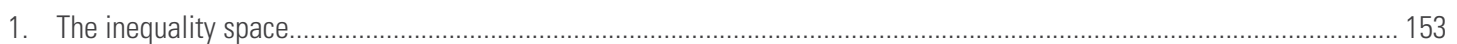

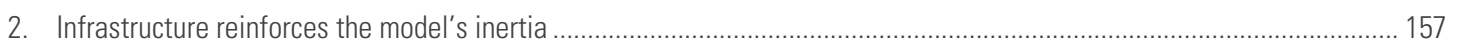

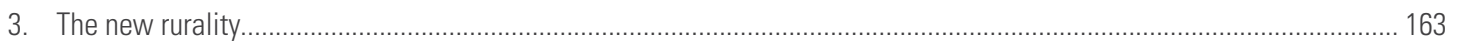

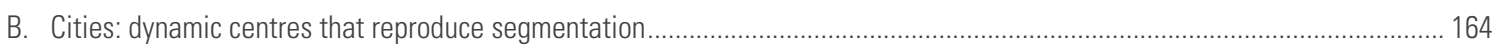

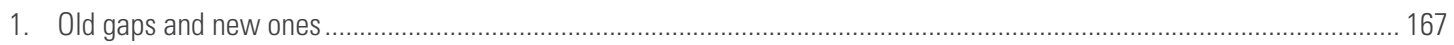

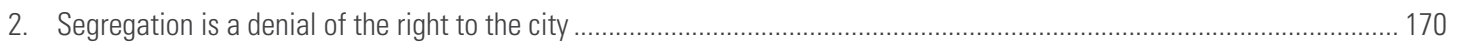

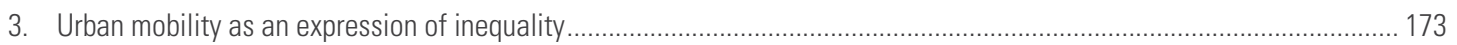


C. The development pattern erodes its own environmental foundations ......................................................................... 176

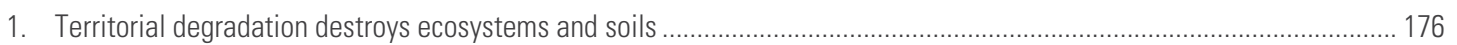

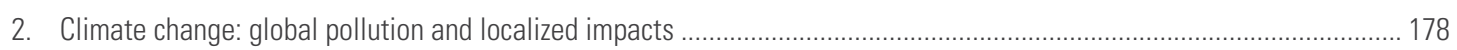

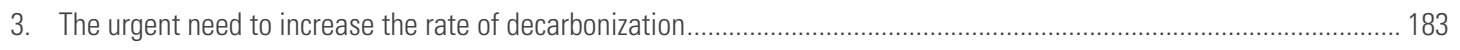

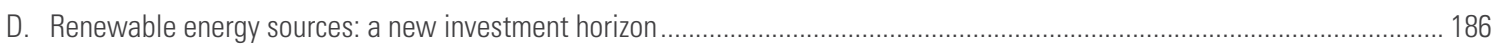

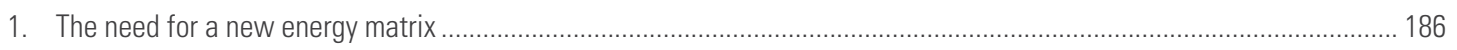

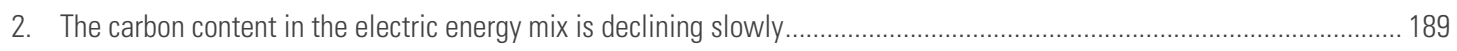

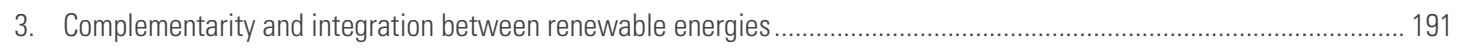

E. The foundations of a structure that is inefficient in terms of energy and production ..................................................... 193

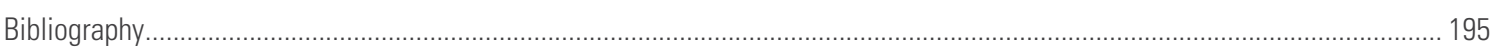

\section{Chapter VI}

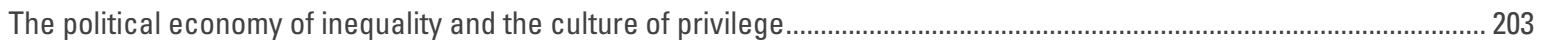

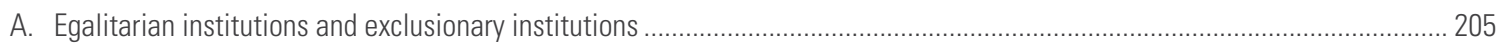

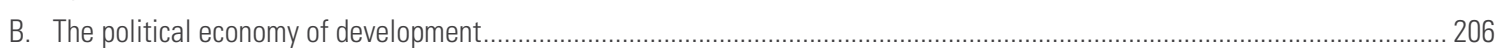

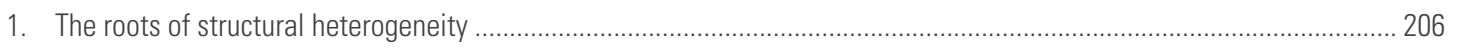

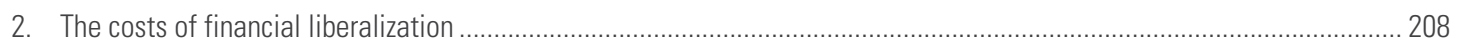

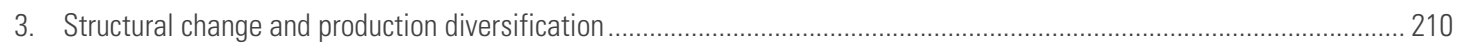

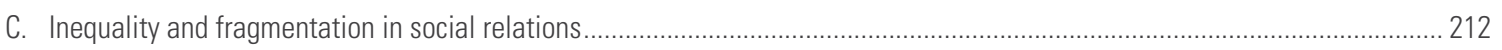

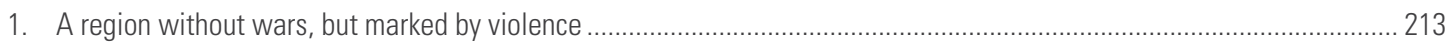

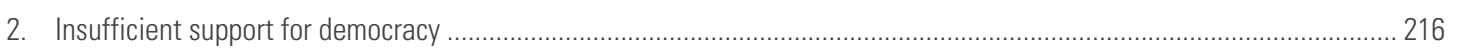

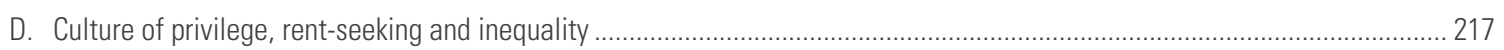

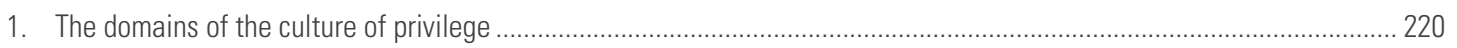

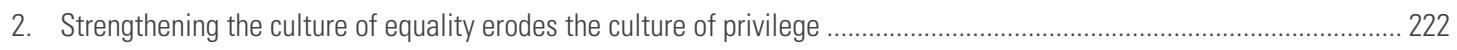

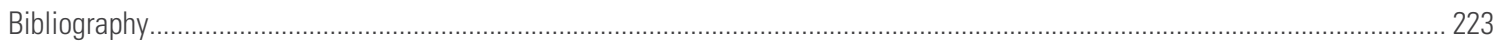

\section{Chapter VII}

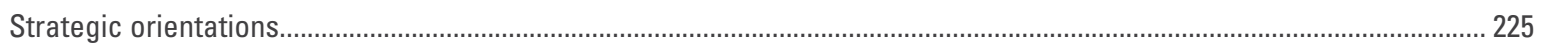

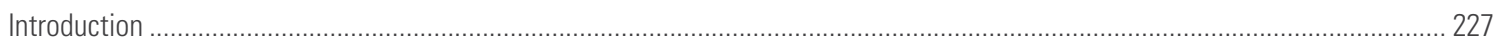

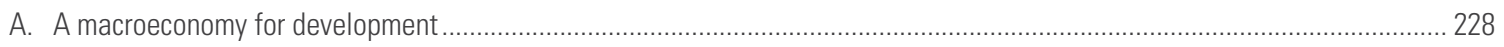

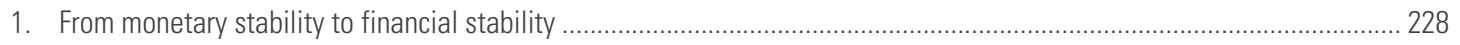

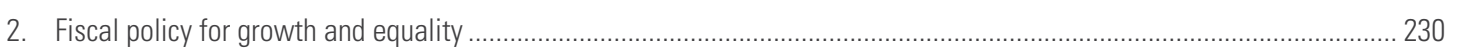

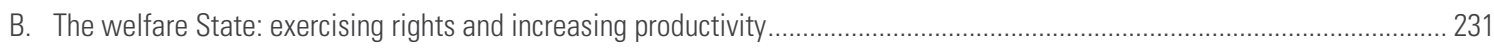

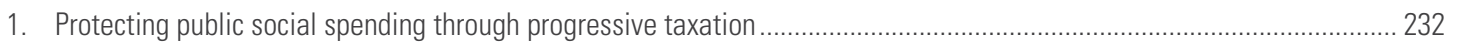

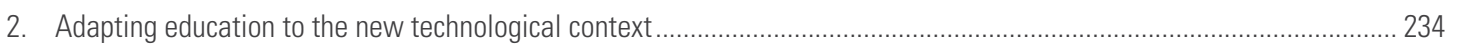

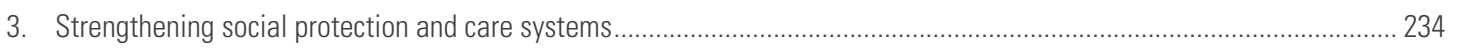

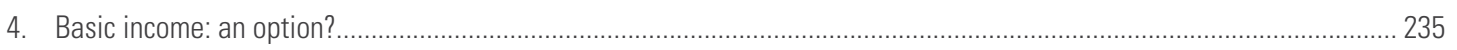

C. Three pillars of decarbonization: digitalization, sustainable cities and renewable energies ................................................. 237

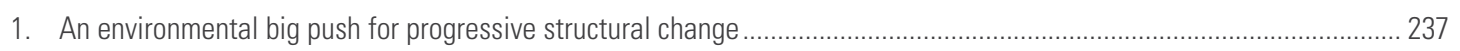

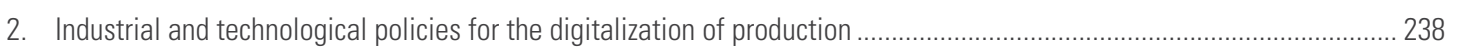

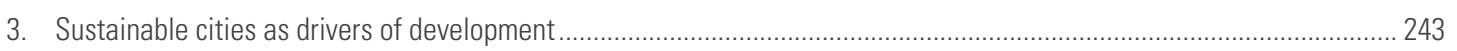

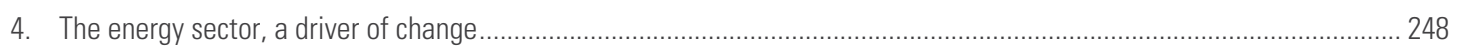

D. Transparency and trust in institutions facilitate the implementation of policies to promote the environmental big push .......... 251

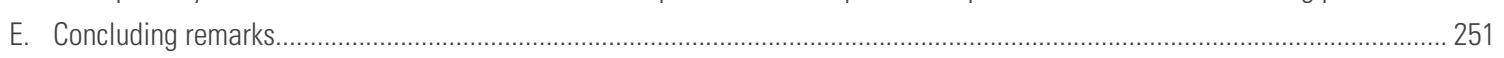

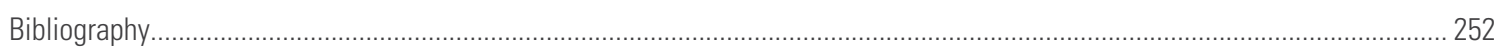




\section{Tables}

Table III.1

Table III.2

Table III.3

Table III.4

Table IV.1

Table IV.2

Table IV.3

Table V.1

Table VI.1

Table VII.1

\section{Figures}

Figure I.1

Figure 1.2

Figure 1.3

Figure II.1

Figure II.2

Figure 11.3

Figure 11.4

Figure II.5

Figure II.6

Figure II.7

Figure 11.8

Figure 11.9

Figure II.10

Figure II.11

Figure II.12

Figure 11.13

Figure III.1

Figure III.2

Figure III.3

Figure III.4

Figure III.5

Figure III.6

Figure III.7

Figure III.8

Figure III.9

Figure III.10

Figure III.11

Latin America (selected countries): foreign trade elasticity ratios, 1999-2008 and 2007-2016. 71 Latin America (18 countries): collection and relative share of corporate and personal income tax, around 2011 ......... 87 National financial wealth in tax havens, 2013 90 Latin America: annual rate of change in investment and GDP, 1990-2015 94 Latin America (9 countries): productivity and social security contributions, around 2016 124 Latin America (9 countries): wage differential relative to low-productivity workers who do not contribute to social security, around 2016 . 125 Anticipated effects of automation on employment 142 Latin America and the Caribbean: pollutant emission by transport mode. 175 Latin America (18 countries): frequency with which people think they could become victims of a crime................. 215 Measures to support the integration of MSMEs in the digital economy

Productivity and Gini index, 2014

Latin America (selected countries): average monthly labour income among employed persons aged 15 and over, by sex, race or ethnicity and years of schooling, national totals, around 2015. 23 Global surface temperature anomaly, 1900-2100, compared with the average for 1986-2005.................................. 24 Gini index, five-year averages . 36 Real income growth per adult by income percentile in the global distribution, 1980-2016 ........................................ 37

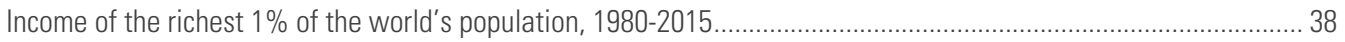
World, United States, eurozone, Japan and selected countries: different economic variables ................................... 40

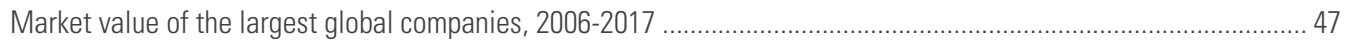

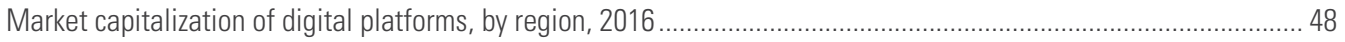
Annual variation in the volume of global trade in goods and in world GDP, and the ratio between them, 1981-2018. 50

China: share of parts and components in total imports (excluding oil) from the rest of the world and selected partners, 2000-2016. 51

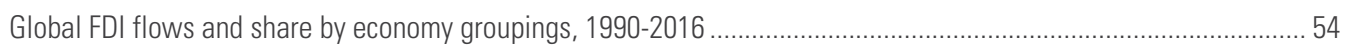
Net value of global cross-border mergers and acquisitions, 2005-2016 .............................................................. 55 Share of net cross-border mergers and acquisitions, by value, by country or region, 2016 ...................................... 55 United States and China: share of global FDI inflows and outflows, 2006-2016 ................................................... 56

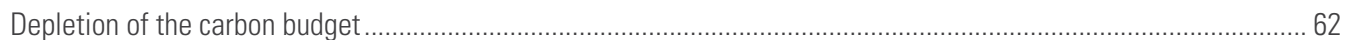

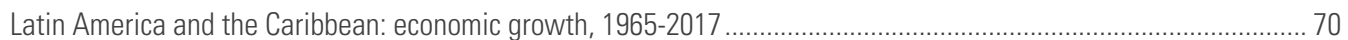
Latin America and the Caribbean: subregional growth rates and external determinants, 2004-2017 ........................ 70 Latin America and the Caribbean: growth and investment rates, 1960-2017 ...................................................... 72 Latin America and the Caribbean (as a whole and by subregions): effective growth rate and rate of growth consistent with employment rate equilibrium, 2000-2016......

Latin America (14 countries): ratio between growth consistent with external equilibrium and growth consistent with stable employment, 2000-2016

Latin America and the Caribbean (overall and by subregion): adjusted employment rate, 1991-2000.....

Latin America and the Caribbean (overall and by subregion): contribution of components to average annual change in the adjusted employment rate, 2000-2008 and 2012-2016

Latin America and the Caribbean: average annual change in the adjusted employment rate by component, by sex, selected periods. 77 Latin America and the Caribbean (overall and by subregion): share of waged employment in GDP, 1950-2014 _......... 79 Latin America and other regions: wage earners' participation in total income, around 2008 


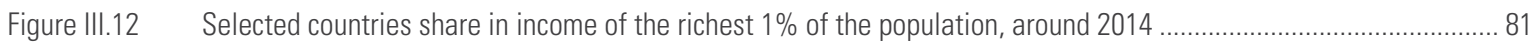

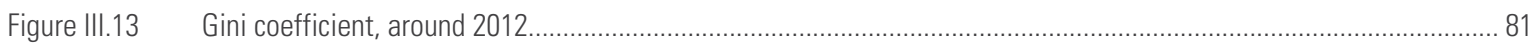

Figure III.14 Latin America and the Caribbean (15 countries): inequality measured by the Gini coefficient of per capita

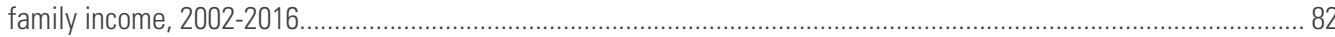

Figure III.15 Latin America and subregions (15 countries): incidence of poverty in households, 2002-2017 ................................. 83

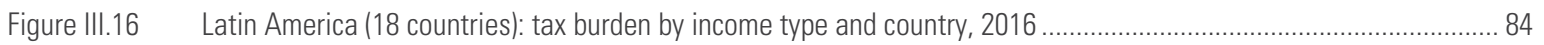

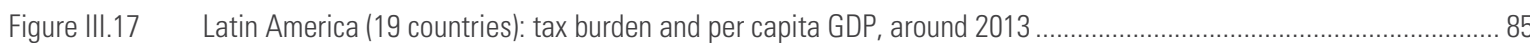

Figure III.18 Latin America (18 countries), OECD (34 countries) and European Union (15 countries): composition

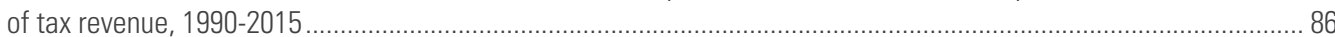

Figure III.19 Latin America and the Caribbean (16 countries): inequality reduction by fiscal policy instruments,

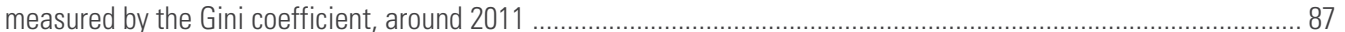

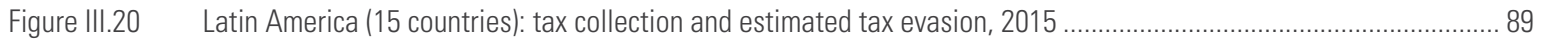

Figure III.21 Latin America and the Caribbean: estimated value of trade misinvoicing, 2004-2015 .............................................90

Figure III.22 Latin America and the Caribbean: average distribution and growth by period, 1950-2014 …................................... 93

Figure III.23 Latin America: moving correlation coefficient between the rates of change in gross fixed

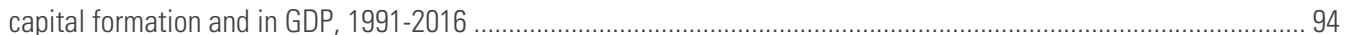

Figure III.24 Selected developed countries: wage share of income and investment rate, 1970-2010 ....................................... 95

Figure III.25 Latin America (selected countries): debt flows (bonds) and bank lending (total and non-financial

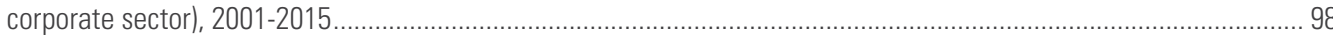

Figure III.26 Proportion of companies in Ponzi, speculative and hedged situations in international bond markets,

$2009-2015$. 98

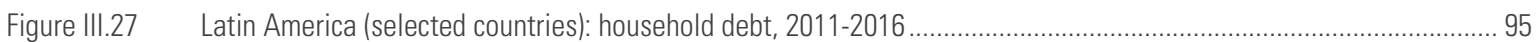

Figure III.28 Latin America and the Caribbean: real and financial external vulnerability, 2005-2007 and 2012-2014 ................... 100

Figure III.29 Latin America (14 countries): growth conditions compatible with external equilibrium, for the 2000-2016 period

Figure III.30 Latin America and the Caribbean: relationship between financialization and wage share of income,

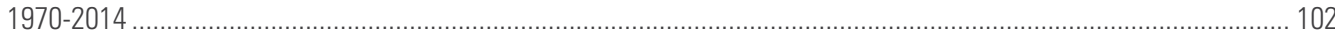

Figure III.31 Latin America and the Caribbean: relationship between financialization and investment, 1970-2014 .................... 102

Figure III.32 Latin America and the Caribbean (selected countries): macroeconomic policy responses to recessions and slowdowns, 2010-2016.

Figure IV.1 Latin America (17 countries): wages of employees aged 20 and over working for 20 or more hours a week, by years of education, around 2015 .

Figure IV.2 Latin America (17 countries): people aged over 18 who have completed the first cycle of secondary education, by income quintile, around 2016

Figure IV.3 Latin America (17 countries): increase in household income if completion of the first cycle of secondary education were universal, around 2016

Figure IV.4

Student performance in PISA tests by region and competence (mathematics, reading and science), 2015

Figure IV.5

Contribution of annual changes in life expectancy to total income, by region, 1990-2000 and 2000-2011

Figure IV.6

Latin America (7 countries): average years' education of women aged 25 to 35 who did and did not become mothers in adolescence, 2008-2015

Figure IV.7 Intergenerational mobility and income inequality.

Figure IV.14 Latin America (5 countries): distribution of paid and unpaid work in households containing a couple, 
Figure IV.15 Latin America (5 countries): income of households containing a couple, scenarios 1 and 2 ................................ 131

Figure IV.16 Latin America (5 countries): evolution of the activity rate, by country and scenario, 2015-2050 ............................ 137

Figure IV.17 Productivity per inhabitant, by country and scenario, 2015-2050 ................................................................ 138

Figure IV.18 Brazil and Mexico: average cost of a welding robot and of manufacturing labour, 2015-2032 .............................. 140

Figure V.1 Degree of income dispersion (trend in subnational disparities in per capita GDP), 1995-2015 .............................. 154

Figure V.2 Latin America (8 countries): selected indicators of RDI 2015, by development level............................................ 156

Figure V.3 South America (9 countries): exports, imports and physical trade balance, 2002-2016 ........................................ 158

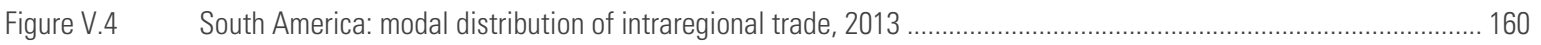

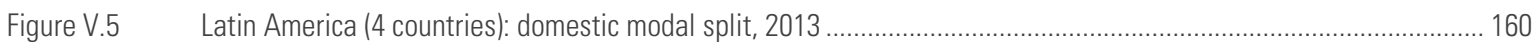

Figure V.6 Latin America (6 countries): infrastructure investment by sector (public and private), 1980-2015 .......................... 161

Figure V.7 Per capita investment in transport infrastructure: roads and railways, 2008-2015 .............................................. 162

Figure V.8 Latin America: infrastructure investment by mode of transport, 2008-2015 ..................................................... 162

Figure V.9 Infrastructure investment by mode of transport, 2008-2015 ........................................................................ 163

Figure V.10 Global urbanization trends: urban population as a percentage of the total, 1950-2050 ...................................... 165

Figure V.11 Latin America and the Caribbean: proportion of the total urban population living in cities of over

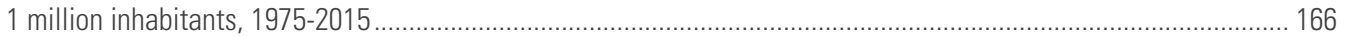

Figure V.12 Latin America and the Caribbean (18 countries): Gini coefficient by geographic area, 2013 ................................... 166

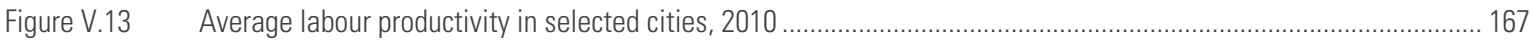

Figure V.14 Latin America and the Caribbean (17 countries): differences in sanitation coverage between urban

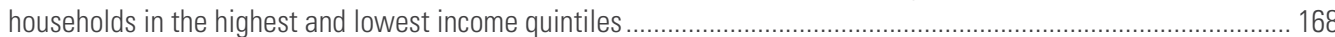

Figure V.15 Latin America and the Caribbean (15 countries): access to electric power among urban households in the highest and lowest income quintiles .............................................................................. 168

Figure V.16 Latin America (9 countries): households with Internet access by income quintile, around 2011 and 2015 ............... 169

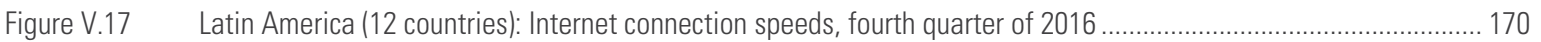

Figure V.18 Latin America: urban density in selected cities, 1990-2014 ..................................................................... 171

Figure V.19 Latin America and the Caribbean: urban population living in slums, 1990-2014 …........................................... 172

Figure V.20 Latin America (13 countries): motorization rate, per capita GDP and comparison with trends

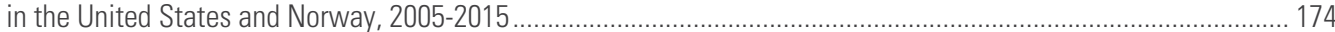

Figure V.21 Latin America (12 metropolitan areas): travel time in private cars and buses, 2014 ......................................... 174

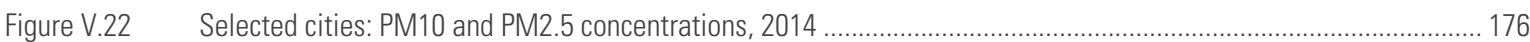

Figure V.23 Latin America and the Caribbean: lost forest area and expansion of agricultural area, 1990-2014 ........................ 177

Figure V.24 Latin America and the Caribbean (11 countries): territories desertified or in process of desertification ................... 178

Figure V.25 Latin America and the Caribbean: cost of extreme weather events, 1961-2015 ............................................... 179

Figure V.26 Latin America and the Caribbean: economic impact of a $2.5^{\circ} \mathrm{C}$ rise in temperature according to different

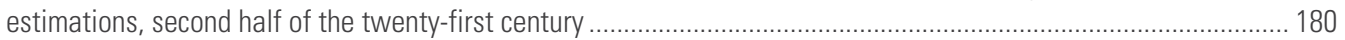

Figure V.27 Latin America and the Caribbean: estimated annual costs of climate change adaptation, by sector to 2050 ............. 181

Figure V.28 Latin America and the Caribbean: per capita emissions of $\mathrm{CO}_{2}$ equivalent, 1990-2014 ........................................ 183

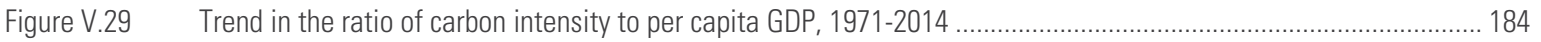

Figure V.30 Trend of the ratio of per capita GDP to energy intensity, 1971-2014 …......................................................... 185

Figure V.31 Latin America and the Caribbean: share of renewables in the total energy supply, 1990-2015 .............................. 188

Figure V.32 South America: distribution of investments in the electric energy matrix by generating sources,

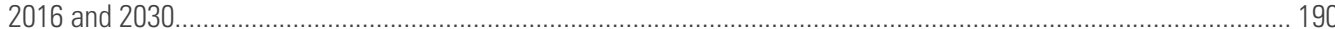

Figure V.33 South America: installed power and effective generation of non-conventional renewable energies,

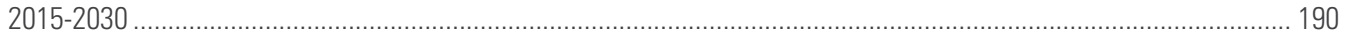

Figure V.34 Latin America and the Caribbean: investments in renewable energies, 2004-2016 .............................................. 191

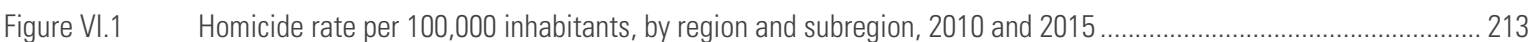


Figure VI.2 Latin America (18 countries): homicide rate per 100,000 inhabitants and Gini index (values between 0 and 1), 2014...

Figure VI.3

Latin America (18 countries): perception of security in the country, 2007-2015 ........

Figure VII.1 Latin America (19 countries): public sector social spending by function, 2000-2015......

Figure VII.2 Latin America and countries of the Organization for Economic Cooperation and Development (OECD): public social spending, tax burden and per capita GDP, 1990-2015.

\section{Boxes}

Box I.1

Box II.1

Estimating the impact of inequality on the dynamic efficiency of the economy ... 21

Box IV.1

The United States' new tax reform

Box IV.2

Income inequality constrains poverty reduction.

Box IV.3

Measuring intergenerational mobility..... 121

Box IV.4

The effects of non-contributory social protection on final indicators of human capabilities...

\section{Diagrams}

\section{Maps}

Map V.1

Latin America (8 countries): regional development index (RDI) 2015 155 


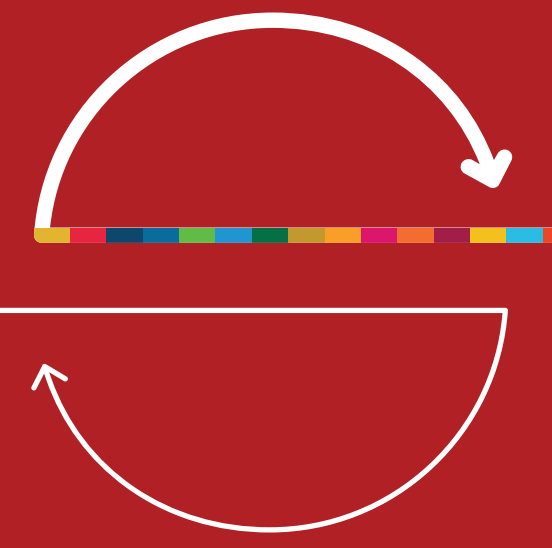

Foreword 

The Latin American and Caribbean region is facing a scenario that offers opportunities, yet is also shadowed by global uncertainties at a time when the region's economies are in need of profound and urgent changes. Moving towards greater equality is not only an ethical obligation in a region with multiple social gaps, but also a necessary condition for accelerating productivity growth, internalizing and disseminating the digital revolution, making the transition to environmental sustainability and establishing an institutional framework for action in a world in which major imbalances exist alongside enormous potential.

Although economic growth has picked up in most of the countries of the region in the last year, its long-run dynamics remain limited by a macroeconomy that does not encourage investment or diversification of production, and constrained by insufficient incorporation of technologies, wide social gaps and increasing environmental costs. It is vital to undo these limitations and explore more fully the complementarities that exist between equality, production efficiency and environmental sustainability. Accordingly, and in line with the 2030 Agenda and the Sustainable Development Goals, this document focuses on three pillars of action and the synergies between them: a macroeconomy for development; a welfare State based on rights and productivity gains; and decarbonization of the production structure, cities and energy sources.

The global risks today make a change in the prevailing model of development all the more urgent. They are elements of a crisis which, like all crises, holds both threats and opportunities. Climate change is the greatest risk facing the world today. Estimates of the costs of the adverse effects of climate change show that it will have not only repercussions on economic growth, but also great social consequences, since it will affect the most vulnerable sectors most. Future generations will not benefit from the environmental services that helped to spur the development of yesteryear. The absence of efficient global governance for controlling these processes and preventing and mitigating their effects increases the risk that environmental degradation will become irreversible.

To tackle global warming, changes must be made in the energy and transport matrices, as well as in production and consumption patterns, as set forth in the 2030 Agenda, which also urges reflection on the different dimensions of development within a comprehensive approach. It was along those lines that, several decades ago, ECLAC called for re-thinking the development model; in other words, how a society is structured and organized for the production, distribution and consumption of goods and services, how its cities are inhabited, and how economic growth fits in with quality of life. This document draws attention to the many ways in which environmental issues intersect with matters relating to land, infrastructure and urban planning and reasserts the idea that an environmental big push must be a strategic focus of industrial and technological policy, as well as of the creation of public goods and services, the transition to less segregated territories and cities, progress towards the digital economy and the change in the energy matrix.

The region must move beyond a development model characterized by environmental inefficiencies such as the depletion of resources and loss of natural resources productivity, an energy matrix based on fossil fuels, a highly polluting and inefficient transport model, loss of work hours and erosion of well-being in big cities, the costs of climate change and poor waste management.

Poor diversification of production, dependence on natural resources, specialization in low-value-added activities and vulnerability to external shocks hurt equality because they stifle the labour market, restrict the dissemination of skills and result in an unequal distribution of the benefits of growth and the costs of economic volatility. At the same time, education gaps and territorial, ethnic and gender inequalities hamper innovation and the spread of technological advances in the production system.

From an environmental perspective, if GDP growth remains tied to greenhouse emissions, the very sustainability of growth and employment will be compromised by negative externalities. Segregation of cities - where limited endowments of good-quality public goods and services (transport, education, security, healthy environments) are spread over large areas - erodes productivity because of lengthy travel times, lack of timely healthcare, violence-related morbidity and mortality and environments that are not conducive to learning and skill-building. Lastly, inequalities related to consumption, travel and settlements affect investment 
decisions in terms of the location and type of infrastructure in which investments are made, which leads to energy, environmental and production inefficiencies. These are all negative interdependencies of the prevailing development model.

The environmental big push requires a radical shift. The interdependence between ownership of technological progress, creation of a denser production fabric, quality of life and environmental sustainability is now stronger than ever. New fields are opening up where technological innovation can lead to new synergies -these include managing sustainable digital cities, the expansion of mass transport, biodiversity management, development of biomaterials and renewable energy production. These are areas in which a range of production activities are possible, creating new material conditions for inclusion and social equity and redirecting investment towards a low-carbon growth trajectory.

The 2008 crisis showed the dangers of a financial economy that is not only independent of the production sector, but also overrides and distorts it. The crisis enshrined the consensus that a bloated financial economy created a global risk. The world economy is reeling from the imbalances caused by financial bubbles - such as those related to real estate, commodities or cryptocurrencies - that move across sectors, countries and activities. As discussed in this document, the region is particularly exposed to financialization ${ }^{1}$ that holds veto power over economic policy alternatives. The dominant vision is myopic and procyclical, which does not augur well for investments in the production sectors and entrenches secular obstacles to industrial development in the region. Thus, one of the central ideas presented in this document is that countering the process of financialization is both a matter of urgency and a strategic challenge in the face of this global risk.

The global imbalances caused by an increasingly complex and underregulated financial system exacerbate problems in a region where volatility and limited endogenous manoeuvring room increase the exposure to risk and the opaqueness of its assessment by international rating agencies. Latin America and the Caribbean has entered a phase of peripheral financialization, which may be described as a set of economic practices that are subordinate to the global financial cycle - and to the internal and external actors determining its dynamics - and that change the behaviour of local economic and political actors, reinforcing the pattern of specialization and increasing external vulnerability.

The region must therefore adopt a more proactive stance that is less vulnerable to the influence of actors in the financial sector, both domestic and international. This requires implementing a macroeconomic policy that goes beyond controlling inflation, with better management of the capital account, combining countercyclical policies with a strategy of production diversification and sound fiscal policy for generating public goods and services and building indigenous capacity.

There is a third global risk associated with the conflicts and imbalances caused by the concentration of wealth, both nationally and globally. In an ever more connected world, increasing wealth concentration generates potentially explosive imbalances, which are most tellingly seen in migration flows and governance crises. The concentration of wealth and the growing asymmetries between States and regions also aggravate the "identity conflict" or "clash of civilizations", which is expressed through violence and poses a threat to security. The obstacles to understanding between peoples and faiths are often underpinned by profound differences in opportunities and living conditions.

Although income distribution improved over the last decade in Latin America and the Caribbean, the past three years have seen those gains come to a standstill and the region's income inequality remains one of the worst in the world. All of this reflects the stigma of inequality, whose various forms ECLAC has chronicled: inequalities of income, physical and financial assets, capabilities, opportunities, productivity, housing and urban conditions, power, access to welfare, networking and enjoyment of rights.

In previous documents, ECLAC has posited that social issues are not played out in the social sphere alone, insofar as social gaps have determinants that are rooted in issues of macroeconomics, production and institutions, territory, culture and gender relations. ECLAC has emphasized that equality is an inescapable

The process of financialization is defined as a situation where financial markets, financial institutions and financial elites are increasingly important in the workings of economies and their institutions of governance, both nationally and internationally (Epstein, 2006). 
ethical obligation and that equal rights, which are an intrinsic value of citizenship and modern humanism, must be consolidated in institutions, structures and policies that help to close gaps.

This document shows the other side of the coin: social gaps and lags have a negative impact on productivity, fiscal policy, environmental sustainability and the spread of the knowledge society. In other words, inequality is inefficient and is an impediment to growth, development and sustainability.

Lags in capacities, caused by lags in learning and educational trajectories, and by an outdated education that is unable to provide the skills required in a changing production sector, are an obstacle to innovation and the diffusion of technological progress. Undernutrition incurs huge productivity costs and also has repercussions on lifelong health spending, whether privately or publicly funded. Social protection deficits affect capacities and, at the same time, tend to defer and increase costs, meaning that allowing them to accumulate is a bad investment in the medium term. Informal employment places serious constraints on the funding of pension systems, particularly in the light of the ageing of societies. The care burden shouldered by women not only restricts women's autonomy, but also limits what they can contribute in labour income to the well-being of their households and to the economy as a whole. Inequality is a huge waste of human talent and capacity. Furthermore, it attacks and erodes political legitimacy, democratic discussion and peaceful coexistence as it worsens violence and human rights violations.

It is therefore indispensable to link up the production structure and the welfare system in a new way. As their per capita GDP rises, the countries of the region must boost their social spending and their capacity to finance social policies in order to build and strengthen the welfare State as they undergo profound transformations in the world of work and the demographic transition and deal with increased migration. To achieve this they will have to move towards progressive tax systems, address tax evasion and avoidance, limit tax incentives and make social spending more effective.

The impact of new technologies — in particular, robotics and artificial intelligence- on the dynamics and quality of employment warrants special mention. The increasing overlap between new technologies and the restructuring of the world of work has left the region with high levels of endemic insecurity and informality in employment. Coupled with increased migration flows and population ageing, occupational restructuring poses challenges for social protection and its financing. It is essential to improve the complementarity between contributory social protection, based on formal employment, and non-contributory systems, examine basic income alternatives and treat care systems as a pillar of social protection systems.

As noted in this document, there is strong interdependence between taxation, provision of public goods, social solidarity and environmental sustainability. A robust fiscal framework combined with the provision of quality public goods and services promotes and facilitates increased ridership of public transport, utilization of suitable education and public health services and the coming together of society as a whole in shared public spaces. This enhances social cohesion, solidarity and mutual recognition through a broader sense of belonging to a society; it also prevents (or reverses) residential segregation, the recourse to private and exclusive services by the privileged and the fragmentation and stratification of society characterized by huge gaps in the quality and timeliness of services. In addition, the mass use of public infrastructure and transport has positive environmental impacts and makes it easier to transform the energy matrix. Evidence from Scandinavian countries, for example, points to virtuous circles between taxation, the welfare State, the provision of quality public goods and services and social cohesion around the universal use of those goods and services. In addition, those societies boast high-quality democracy, with greater environmental sustainability, a better energy matrix and very low levels of violence and insecurity compared with Latin America and the Caribbean.

In Latin America and the Caribbean, convergence around public services and environmentally sustainable practices tends to be weak, owing primarily to a culture of privilege that reinforces the consumption pattern of the region's elites. Examples include the increasing desertion of public transport in favour of private cars, the replacement of open public space by enclosed shopping centres and the multiplication of private security services and gated neighbourhoods. This document shows that the political economy of highly unequal societies and the culture of privilege are obstacles to progress in development with equality. 
There are longstanding institutions in the region that perpetuate the behaviour of those who hold most of the economic and political power; this makes it difficult to advance industrial and innovation policies, as well as those aimed at strengthening the tax system or at equality. There is a rentier tendency, bred originally of privileged access to ownership of natural resources, which today is encouraged by the financial economy and oligopolistic positions in markets where there is little competition.

Moreover, the region still bears the colonial vestiges of a culture of privilege that normalizes social hierarchies and highly unequal access to the fruits of progress, political participation and production assets. This culture of privilege is the symbolic substrate underlying territorial segregation, weak taxation and the appropriation of rents by power groups.

Conversely, greater political democracy, redistributive policies and expansion of the knowledge society tend to consolidate a culture of equal rights, which is the direct opposite of the culture of privilege. In this regard, it is worth noting the progress made in the region in the 2000s, which saw greater awareness of civil, political and social rights, but also heightened tension and conflict between those who demanded greater access to the fruits of progress and others who isolated themselves from the rest of society as they sought to protect their privileges. Between the culture of rights and the culture of privileges, politics has been marked by crises and demands for legitimacy.

This document begins by stating that unless there is a shift from vicious to virtuous circles of development, global risks will increase the region's vulnerability. This is particularly relevant not only for facing risks, but also for tuning in, as a region, to the potential of the transition from the analog age to the digital age. With the exponential acceleration in technological change and its spread to all production sectors and spheres, the current industrial revolution is not just radical, but fraught with uncertainty. The only way to address this is to activate the positive interdependencies of the environmental big push to drive a new development model, with sustainability and equality at its core.

The risks facing the world and the region represent tectonic shifts that require transformations of a similar magnitude in politics and public policy. The region must therefore speed up and consolidate its efforts to keep pace with the changes in the world.

ECLAC has warned emphatically and repeatedly that the region is losing weight and importance in the global economy. Reversing that will require a big push in policy and politics. The further the region's dynamics lag behind developments elsewhere in the world, the more urgent that change becomes.

Undeniably, driving the policies proposed in this document will take significant resource mobilization and action engaging all stakeholders. However, as this document also posits, the cost of inaction would be greater. Continuing with the current development model —which, moreover, erodes social harmony and political systems - would carry even greater costs for economic growth, environmental sustainability, human capacities and talents and people's quality of life. The cost of inaction is greater than the cost of action and simply mortgages the future.

The 2030 Agenda provides a suitable and timely framework for launching a new generation of policies such as those proposed in this document and moving towards a new development model that will spark a virtuous circle of growth, equality and sustainability for current and future generations. The Latin American and Caribbean region has a wellspring of resources and capacities with which to meet the global challenges and difficulties it faces. This paper discusses those challenges and proposes strategic guidance on how to overcome them.

\author{
Alicia Bárcena \\ Executive Secretary \\ Economic Commission for \\ Latin America and the Caribbean (ECLAC)
}



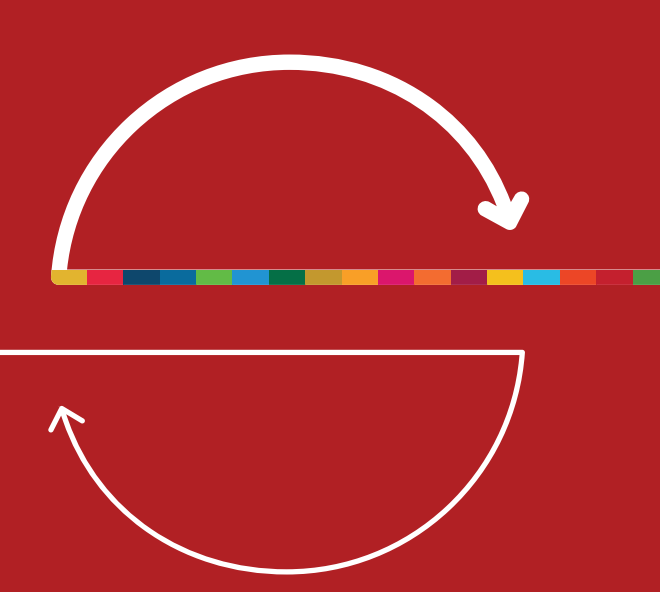

\section{CHAPTER}

I

\section{Equality at the centre of development}

Introduction

A. The costs of inequality

1. Unequal access to capacities: a barrier to productivity growth that the market does not correct

2. The destruction of the environment: a manifestation of both intra- and intergenerational inequality

B. Equality and efficiency require more and better public goods

C. An entrenched culture of privilege

1. The historical roots of the culture of privilege

2. Faces of privilege in structures and institutions

D. Building a culture of efficiency and equality

Bibliography 



\section{Introduction}

The Economic Commission for Latin America and the Caribbean (ECLAC) has proposed strategic paths towards development throughout its seven decades of existence. Since 2010, equality has had a central focus in that undertaking, as can be seen in the principal documents submitted for consideration by the countries of the region at the Commission's four most recent sessions. Thus, for almost a decade, ECLAC has identified equality as a foundational value of development and as a non-negotiable ethical principle, in keeping with the increasing importance of the topic in public demands and policy debates.

Equality stands at the centre of development for two reasons. First, because it endows policies with a rights-based approach at their very foundation, along with a vocation of humanism that embodies the most treasured legacy of modernity. Second, because equality is also a prerequisite for progress with a development model that focuses on closing structural gaps and on convergence towards higher levels of productivity, economic and environmental sustainability for future generations, the dissemination of the knowledge society and the strengthening of democracy and full citizenship.

Equality is also a historical construct. As a foundational milestone, it implies the abolition of privileges and the institution of an order based on equal rights that includes all members of society. As a necessary counterpart, however, equality of rights demands the construction of greater substantive equality, achieved by closing gaps in incomes, capacities, opportunities and access to well-being. Civil, political and cultural rights are framed by an institutional structure that promotes freedom, political participation, citizenship, equal treatment, equality of justice and the recognition of differences in characteristics such as sex, gender, ethnicity, place of origin, culture and socioeconomic status. Social and economic rights are made a reality through benefits that are accessible to all and through policies that foster, at all levels of society, the development of capacities and inclusion in the productive world through innovation, education and work. Equality of rights, social justice and the recognition of diversity or equality in differences are pillars of the same platform for equality.

There are therefore two components to advancing equality: equality of rights and substantive equality. At the core of modern welfare States is the idea that individuals use those two aspects of equality as the foundation for building their sense of societal belonging and their adherence to democratic life. The virtuous circles that arise between equality and that belonging and adhesion are, in turn, the key to addressing an increasingly complex world in which it is ever more difficult to interconnect exogenous determinants and endogenous forces in national societies.

Equality encompasses equality of means, opportunities, capacities and recognition (ECLAC, 2014). Equality of means translates into a fairer distribution of income and wealth and into a wage bill that accounts for a greater share of domestic output. Equality of opportunities entails the absence of all forms of discrimination in access to social, economic and political positions. Equality of access to capacities covers the skills, knowledge and capabilities that individuals acquire and that enable them to embark on life plans they consider worthwhile. It involves equality in the fields of quality education, health, digital access, nutrition and better living conditions through reduced overcrowding and greater access to consumer goods. At the same time, equality as mutual recognition is expressed in different actors' shares of caregiving, work and power, in the distribution of costs and benefits among present and future generations and in the visibility and affirmation of collective identities. Understood as relational equality, it refers to how people perceive the equality and inequality of the collective order in which they live, as well as to various forms of social interaction, such as coexistence in cities or in schools. Thus, as will be seen below, the culture of privilege operates as an obstacle to equality in all its dimensions. ${ }^{1}$

This document takes that definition of equality as its starting point before moving on to explore a complementary perspective that examines equality as a driving force for the economic system's efficiency — defined as the

One example of this is the territorial self-segregation of high-income sectors in Latin American cities, combined with their reluctance to use public transport in order to avoid proximity with "others" and their preference for schools where their children encounter others only from families belonging to their same social circles. Closed elites understand privilege not only as an advantage but also as exclusivity: it is both exclusive and excluding. 
full utilization of capacities and resources - and sustainability. Inequality is not only the result of how the economy functions, it is also a key determinant of that functioning, in that it defines economic agents' access to capacities and opportunities and shapes the rules that govern their decisions. The core message is that inequality entails major costs in efficiency, which means that it must be overcome if development is to be attained. In the following chapters, each of the areas where inequality restricts or limits economic efficiency are discussed in detail, together with the mechanisms through which it does so. This document therefore offers an empirical basis for studying the effects of inequality on economic efficiency in Latin American and Caribbean economies. Not only do pro-equality policies have a positive impact on social well-being, they also help create an economic system that is more propitious for learning, innovation and higher productivity.

\section{A. The costs of inequality}

The historian Alfred Cobban (1965) succinctly identified the reason why the Government of France, in the 1950s and early 1960s, adopted economic development plans that radically transformed the country's economy: "poverty is inefficient." For a long time, however, an opposing view prevailed among economists: they maintained that efficiency and equality were at odds with each other, to the extent that Okun (1975) termed the relationship between the two variables "the big trade-off". It was thought that society had to pay an economic-growth cost to reduce the asymmetries and inequalities that arose from market competition. Increasingly, that idea is being challenged in economic literature, and now a new consensus is emerging that inequality is in fact a barrier to development. This new understanding differs from the older one in at least two respects. First, it takes a longer-term view: it aims to explain the performance of economies over decades rather than years. Second, in addition to the usual economic variables identified as the determinants of innovation and productivity, it includes social, cultural and political factors, which play a prominent role in the "new economics of inequality and redistribution" (Bowles, 2012).

The traditional models held that inequality was conducive to growth because the concentration of resources in the hands of a few would raise their capacity to save and, consequently, their capacity to invest. Conversely, correcting inequality would undermine growth by reducing the incentives for individual effort (the fruits of which were to be captured and redistributed by the government) and by causing losses of income in the redistributive transfer of resources from one person to another. Doubt has been cast on this view not only by the empirical evidence (Acemoglu and others, 2013; Ostry, Berg and Tsangarides, 2014) but also by the new economics of equality, which recognizes the favourable effects of equality on effective demand and emphasizes its positive impact on the supply side. Equality can improve the efficiency of an economic system, defined in dynamic terms as the pace at which innovations can be made, those generated in other parts of the world can be absorbed, technology gaps can be reduced, innovations can permeate the production fabric and, as a result, productivity can be increased and new areas for investment can be established.

Figure I.1 shows the negative relationship that exists between inequality and productivity in a broad spectrum of countries. That relationship does not involve just one direction of causality between the two variables; on the contrary, causality comes from both inequality and productivity and their complex interaction, as argued throughout this and other chapters. To obtain a more precise estimate of the impact of inequality on the economic system's dynamic efficiency, a simple econometric exercise is presented in box l.1. It takes productivity growth over time as an approximation of that efficiency. The exercise was limited to the countries of Latin America and the Caribbean and covers the period between 1980 and 2014. The results indicate that inequality has an adverse effect on productivity growth. A one percentage point difference in the Gini index between two sample countries was associated with a drop of two percentage points in the rate of productivity growth in favour of the less unequal country during the study period. 
Figure I.1

Productivity and Gini index, 2014

(Purchasing power parity (PPP) dollars and percentages)

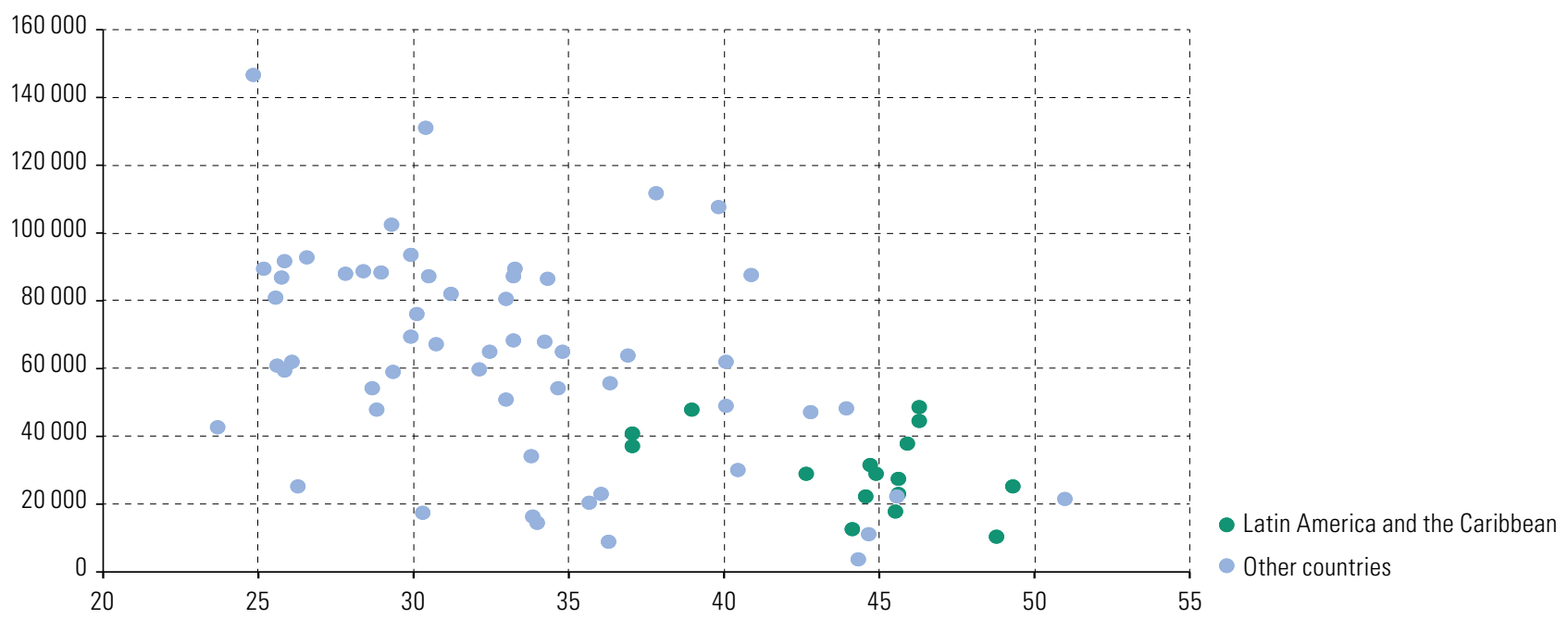

Source: Economic Commission for Latin America and the Caribbean (ECLAC), on the basis of University of Groningen, Penn World Table [online database] https://www. rug.nl/ggdc/productivity/pwt/, and Harvard University, Standardized World Income Inequality Database (SWIID) [online database] https://dataverse.harvard. edu/dataset.xhtml?persistentld=hdl:1902.1/11992.

Note: The Gini index is expressed in percentage terms. Productivity is expressed in output per employee in 2011 PPP dollars.

Equality is a necessary condition for maximizing the dynamic efficiency of the economy in that it creates a framework of institutions, policies and efforts that place the highest priority on innovation and capacity-building. From that perspective, equality is more important today than in the past because of the impact of the technological revolution, which makes building capacities and closing gaps a more urgent and unavoidable task. That urgency is heightened by the unsustainable nature of the current pattern of growth, which requires that the technological revolution be put to work in transforming the energy mix and channelling production processes along low-carbon paths in order to preserve the environment and its productive services for future generations.

This examination of the role of equality from the supply side helps showcase its positive impact on effective demand. As examined in chapter III, income distribution is more likely to drive the expansion of demand in a country with a more diversified and competitive production structure. By encouraging the spread of technologies and increased productivity, equality contributes to that diversification. Thus, the traditional Keynesian view of distribution and effective demand is complemented by the Schumpeterian approach to equality, innovation and skills.

Box I.1

Estimating the impact of inequality on the dynamic efficiency of the economy

The variable to be explained is the dynamic efficiency of the economy as measured by the annual growth rate of productivity between 1980 and 2014. In addition to the Gini coefficient (representing inequality), the right side of the equation includes other explanatory variables that economic theory has identified as determinants of productivity growth, such as the investment rate and the levels of human capital (this is part of what ECLAC terms "human capacities"). The inclusion of the Gini coefficient in the regression is intended to reflect the impact of inequality on learning and innovation; the coefficient of this variable is expected to be negative (as inequality rises, productivity growth falls). The control variables are intended to indicate the effects of both incorporated (physical capital) and unincorporated (human capital) technical progress, in addition to the effects of "learning by doing" associated with expanding investment. In both cases, positive coefficients are expected. 


\section{Box I.1 (concluded)}

As in any econometric exercise in which the variables are part of a system of simultaneous equations, the results are preliminary and should be interpreted with care. To address the endogeneity problems in the model's estimate, the generalized method of moments (GMM) was used (selecting the number of lags of the variables in accordance with the Hansen test). The results are shown in table 1.

Table 1

Dynamic panel: productivity growth and Gini coefficient, generalized method of moments

\begin{tabular}{|c|c|}
\hline \multicolumn{2}{|c|}{ Productivity growth } \\
\hline Productivity $_{\mathrm{t}-1}$ & $\begin{array}{r}-0.51^{* * *} \\
(0.0603)\end{array}$ \\
\hline Gini coefficient ${ }_{t-1}$ & $\begin{array}{l}-0.02^{* * *} \\
(0.00566)\end{array}$ \\
\hline Human capital $_{\mathrm{t}-1}$ & $\begin{array}{l}0.30^{* * *} \\
(0.0976)\end{array}$ \\
\hline Investment/GDP ${ }_{\mathrm{t}-1}$ & $\begin{array}{l}0.27^{* *} \\
(0.122)\end{array}$ \\
\hline Observations & 620 \\
\hline Number of countries & 23 \\
\hline Number of instruments & 30 \\
\hline $\operatorname{AR}(2)$ & -1.17 \\
\hline Second order correlation & $(0.243)$ \\
\hline Hansen & 18.67 \\
\hline Overidentification & (0.850) \\
\hline
\end{tabular}

Source:Economic Commission for Latin America and the Caribbean (ECLAC), on the basis of University of Groningen, Penn World Table [online database] https:// www.rug.nl/ggdc/productivity/pwt/ (for data on investment, human capital, GDP and purchasing power parity), and Harvard University, Standardized World Income Inequality Database (SWIID) [online database] https://dataverse.harvard.edu/dataset.xhtml?persistentld=hdl:1902.1/11992 (for the Gini coefficient).

Note: Human capital is measured using an index based on Barro-Lee Educational Attainment Dataset [online database] http://www.barrolee.com/ and G. Psacharopoulos, "Returns to investment in education: a global update", World Development, vol. 22, No. 9, 1994. Productivity is measured as real output in 2011 purchasing power parity dollars over the number of employees (Penn Tables). Investment/GDP is gross fixed-capital investment as a percentage of GDP (Penn Tables). Standard deviation values are shown between parentheses.

All the coefficients of the explanatory variables show the expected signs. The exercise adequately passed the specification tests indicated in table 1.

Source: Economic Commission for Latin America and the Caribbean (ECLAC).

\section{Unequal access to capacities: a barrier to productivity growth that the market does not correct}

Unequal access to capacities and opportunities — such as that caused by inequalities in access to education and health-compromises innovation and productivity. When people drop out of school before completing primary or secondary education, their productive potential suffers for the rest of their working lives. The lower wages that, all other things being equal, they will receive compared to workers with more years of formal education is an indicator of the productivity and well-being lost through curtailed schooling. Over the long term, the magnitude of those losses is extremely high. The cost to society goes beyond the lost future income of the worker who drops out of school, because there are positive externalities that arise from interactions between persons with high levels of education; ${ }^{2}$ in other words, the benefits to society of investing in education outstrip the private benefits. Inequality in education access has a hampering effect that, rather than remaining localized, spreads across the economic system as a whole.

For this reason, researchers and scientists are attracted by institutions of excellence and congregate there instead of spreading themselves around others that lack the complementary capacities demanded by their research. 
In highly unequal societies, the decision to drop out of school does not depend solely on differences in talent or effort, but also on reduced opportunities for access to education: for example, financial constraints, a limited supply of quality education facilities in a given neighbourhood or geographical region, or the need for early entry into the labour market. The correlation between the levels of education attained by parents and their children over several generations is an expression of that inequality: it is much higher in unequal economies, such as those of Latin America and the Caribbean, than in more egalitarian societies (see chapter IV). If society were to offer the same education access opportunities from the outset, there would be no reason for that correlation. Inequality in education is an intergenerational transmitter of unequal capacities and opportunities, and it is a key factor in the perpetuation of low productivity. ${ }^{3}$

But it is not just asymmetries in access that have an impact. Even if everyone had equal access to capacities at the start of life, discrimination would affect their employment opportunity expectations. In societies characterized by sexual, racial or ethnic discrimination, people who are discriminated against know that they will come up against ceilings in their careers or, at the very least, will be at a disadvantage compared to a peer of another sex, racial or ethnic identity. Figure 1.2 shows that on average, Afrodescendent ${ }^{4}$ and indigenous people complete fewer years of schooling and earn significantly less than their non-Afrodescendent and non-indigenous counterparts. This is a disincentive for women, Afrodescendants and indigenous people, whose educational achievements do not afford them better prospects in the job market. Any disincentive to learning poses an obstacle to innovation and productivity, which adds to the more direct and immediate loss inherent in neglecting a talented individual.

\section{Figure I.2}

Latin America (selected countries): average monthly labour income among employed persons aged 15 and over, by sex, race or ethnicity and years of schooling, national totals, around 2015

(Purchasing power parity dollars at constant 2010 prices)

A. 9 countries, by ethnic origin (indigenous or non-indigenous) ${ }^{a}$

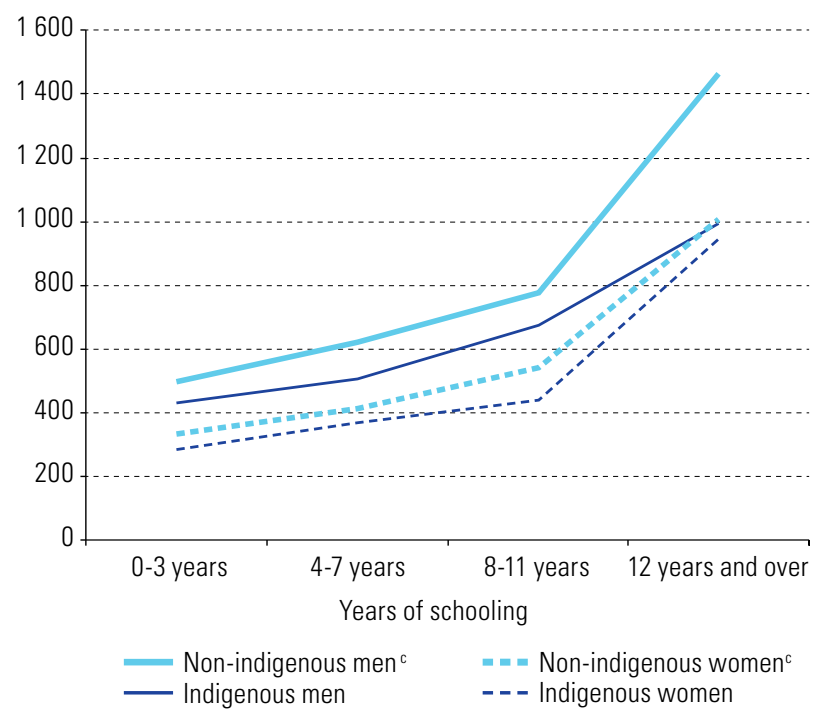

B. 4 countries, by racial origin (Afrodescendent or non-Afrodescendent) ${ }^{b}$

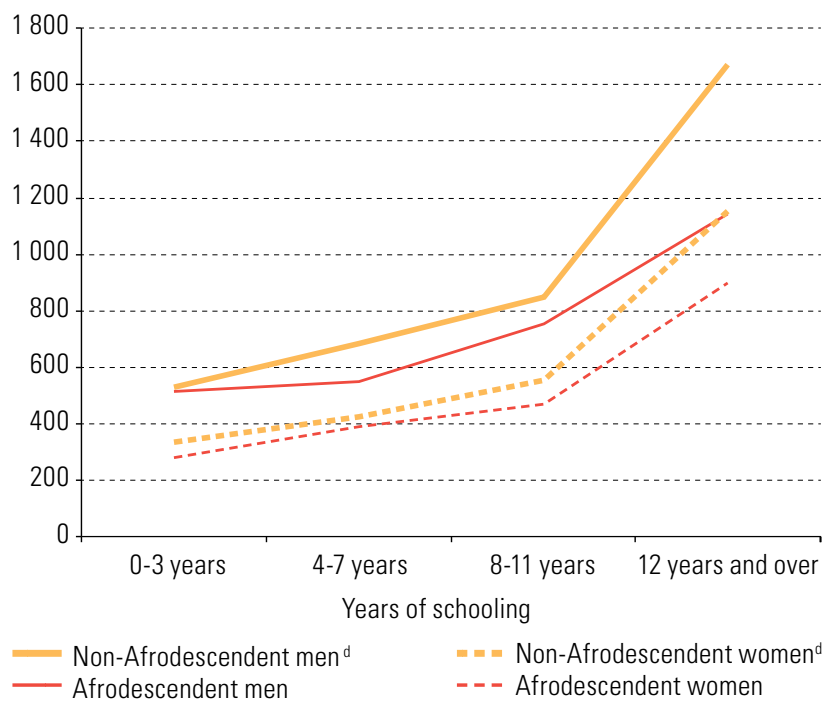

Source: Economic Commission for Latin America and the Caribbean (ECLAC), on the basis of Household Survey Data Bank (BADEHOG).

a Includes: Brazil (2015), Chile (2015), Ecuador (2016), Guatemala (2014), Mexico (2016), Nicaragua (2014), Peru (2016), Plurinational State of Bolivia (2015) and Uruguay (2016).

b Includes: Brazil (2015), Ecuador (2016), Peru (2016) and Uruguay (2016).

${ }^{\mathrm{c}}$ Does not include Afrodescendent population.

d Does not include indigenous population.

3 Chapter IV explores how inequalities of capacities and opportunities affect a system's productivity and efficiency, which is a particularly serious phenomenon when access to health is at play. Then, chapter $V$ discusses mechanisms relating to unequal infrastructure access and to the creation of centre-periphery systems in national economies.

4 The term "Afrodescendent" is considered acceptable in some countries but not in others. ECLAC acknowledges that this debate exists and that the concept is not universally accepted. 
Accordingly, rather than a luxury that only high-income countries can afford, correcting inequality is a necessary precondition for assisting those countries that lag behind to attain the productivity levels enjoyed by the former.

\section{The destruction of the environment: a manifestation of both intra- and intergenerational inequality}

Environmental sustainability can be examined as an intergenerational justice issue that cannot be reduced to finding an appropriate discount rate for present versus future consumption (Beltratti, Chichilnisky and Heal, 1993). Also at play is a trajectory of growth that affords future generations the right to enjoy the same level of well-being as the present generation, and that right is undermined by the destruction of the ecosystem. At a time when that destruction is already occurring and average global temperatures are rising at higher rates than expected (see figure I.3), intergenerational equality is an imperative.

Figure 1.3

Global surface temperature anomaly, 1900-2100, compared with the average for 1986-2005

(Degrees Celsius)

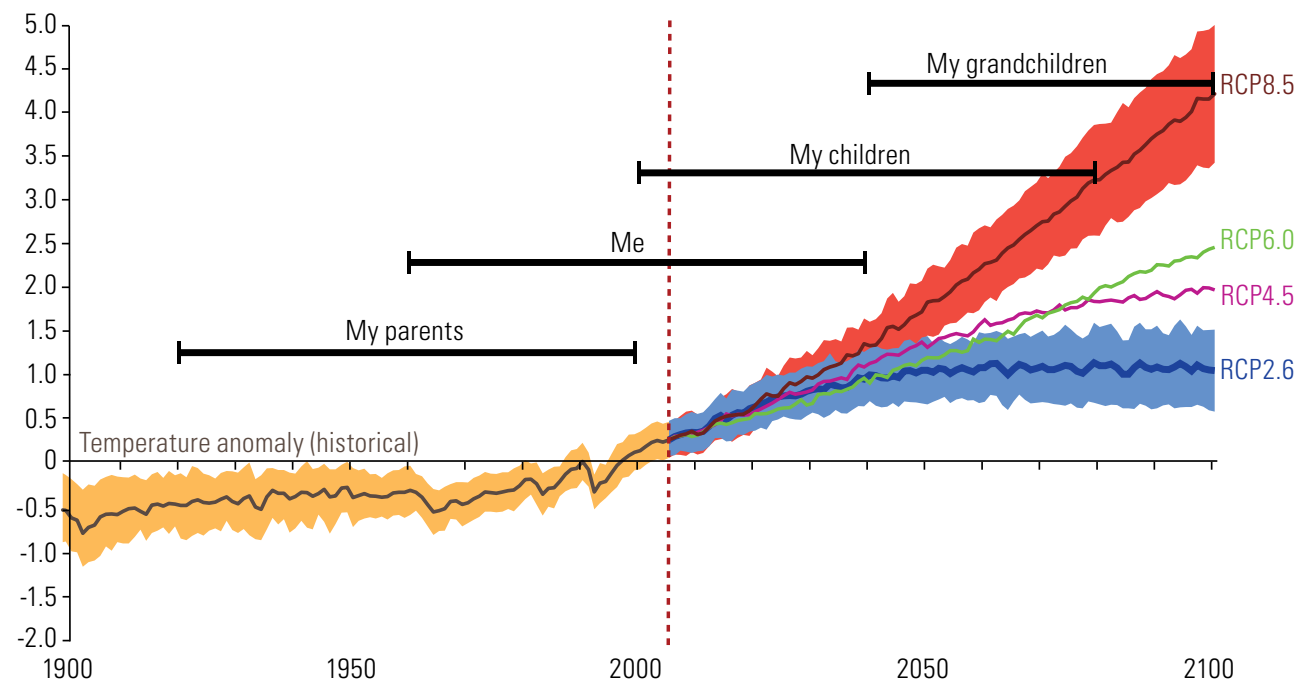

Source: Economic Commission for Latin America and the Caribbean (ECLAC), on the basis of Intergovernmental Panel on Climate Change (IPCC), Climate Change 2014: Impacts, Adaptation, and Vulnerability. Part B: Regional Aspects. Contribution of Working Group II to the Fifth Assessment Report of the Intergovernmental Panel on Climate Change, V. R. Barros and others (eds.), Cambridge, Cambridge University Press, 2014, and D. Weston, "State of the planet, Kyoto and technical fixes", The Political Economy of Global Warming: The Terminal Crisis, London, Routledge, 2013.

Note: RCP: Representative Concentration Pathway; RCP2.6: mitigation scenario leading to a very low forcing level; RCP4.5 and RCP6.0: stabilization scenarios; RCP8.5: scenario with a very high level of greenhouse gas emissions.

In line with the ideas set out in this document, inequality between generations entails a cost in future productivity as the production services of the ecosystem fall. Meanwhile, inequality within current generations also has an impact on the environment and productivity.

One example of this is the pollution emitted in cities —and the significant health impact it causesdepending on the means of transport used. ${ }^{5}$

Inequality and segregation in the region's policies for urban infrastructure and land use severely penalize the public transport on which lower-income sectors depend. By favouring individual modes of transport, inequality has negative environmental consequences; at the same time, however, its negative repercussions on people's productivity are accentuated, given that lower-income sectors are forced to make longer journeys and often inhabit neighbourhoods that are more exposed to pollution. The absence of intergenerational justice in environmental matters (with the associated costs for well-being and productivity) is compounded by the asymmetry in the total pollution generated by different income segments and in their exposure to its effects within the same generation.

5 The productivity costs of environmental destruction are discussed in detail in chapter $\mathrm{V}$. 


\section{B. Equality and efficiency require more and better public goods}

One common determinant of problems caused by inequality is the non-existence or poor quality of public goods such as security, education, health and the environment, along with the absence of systems of rules to guarantee equal opportunities.

Perhaps the chief public good that the State originally provided —and which today remains a powerful driver in building its capacities - was defence. Many of the innovations deployed by commercial market-leaders originated in or were heavily influenced by defence research. Meanwhile, the governments of the developed nations increasingly set about producing the public goods demanded by the welfare State, and this shift did not entail any negative impact on their technological capabilities (as measured by its levels of productivity). ${ }^{6}$ The type of political system in place is a powerful determinant in the production of public goods: controlling for the effect of countries' income levels, there is a statistically robust, positive relationship between democracy and the provision of public goods (Deacon, 2009). ${ }^{7}$

Similar to what happens at the national level, inequalities of income and power in the international system hamper the transition towards a new model with increased provision of global public goods. From this perspective, hyperglobalization - full commercial and financial liberalization with no rules other than those needed to minimize transaction costs between countries - is incompatible with the simultaneous existence of nation States and democracy (Rodrik, 2011). That is because hyperglobalization constrains the questions on which a country's inhabitants can decide. Under hyperglobalization, nation States see their powers reduced to merely legitimizing market-imposed rules. In particular, given their ability to transfer resources quickly and flexibly between countries, financial markets can arbitrate not only between rates of profit and bond yields in different currencies, but also between policies. The effects of those movements (with no obvious links with the fundamentals of the economy) on currency values, borrowing capacities and the expansion or reduction of credit bring a strong influence to bear on decision-making and even on the announcements that national authorities can make. To paraphrase one of De Gaulle's ministers, this is an "exorbitant privilege" at the policy level that the international system confers on a handful of financial investors. No less importantly, that resource mobility reduces the ability of States to collect taxes, which are systematically evaded through the use of tax havens located in developing and developed countries alike. ${ }^{8}$ Thus, the culture of privilege is also clearly present in the international system's rules of play.

This document provides examples of the inadequate provision of public goods that illustrate (albeit not exhaustively) the widespread exclusion in Latin American and Caribbean societies. One feature that distinguishes developed countries from developing ones is the variety — and levels of penetration into the social fabric- of networks and public and private organizations that provide public goods and generate externalities (North, Wallis and Weingast, 2009). This necessarily raises the question of why peripheral economies do not produce the public goods needed for development.

Answering that question requires looking beyond the immediate determinants of productivity and growth and addressing the interrelations between unequal societies' political economies, institutions and culture. The production of public goods has a cost and a distributive impact. While the provision of public goods allows the economic system to attain a new configuration with greater levels of efficiency and well-being, the transition towards that new equilibrium demands a complex and highly divisive political process that has, as its corollary, the redistribution of income and power among actors. Those who are in more favourable positions under the existing situation will tend to invest their resources and energies in obstructing or preventing the transition.

6 Even in a high-impact technology such as the Internet — which originally stemmed from the military research of the United States Department of Defense's ARPANET project - other stakeholders (particularly universities and, subsequently, companies) influenced the path of its development. The research efforts' diversity, flexibility and decentralization made a decisive contribution to the technology's success and spread (Abbate, 1999).

7 Alesina, Reich and Ribboni (2017) argue that the large-scale provision of public goods was the way that States found to ensure the population's effective engagement in war efforts. A discussion from the viewpoint of distributive justice and political philosophy can be found in Kallhoff (2011). See also Acemoglu and others (2013).

8 Recent document leaks about accounts held in tax havens, such as the Panama Papers and the Paradise Papers, reveal the extent of those privileges. 
This is because, first, public goods mostly benefit lower-income groups and are financed through taxes on higher-income sectors; and, second, because by expanding opportunities for market access and encouraging innovation and change in production sectors, the transition opens the door to competition from new players who threaten the profits of incumbents.

In all those cases, actors in a position of advantage — simply stated, those at the apex of the distribution curve- have reasons to oppose the new equilibrium; and the higher the initial economic and political inequality, the greater will be their power and their incentives for resisting the transition. That is why democracy and political equality are necessary for development: they provide opportunities for forming coalitions favourable to an equilibrium where there is an increased supply of public goods. They are necessary conditions but they are not enough alone, because actors' reactions are not automatically determined by the positions they would achieve under the new equilibrium. The political dynamics, culture and heritage of each society have a role to play in facilitating or delaying the transition, as discussed in chapter VI.

The relationship between the State, the market and society therefore needs to be analysed from a different angle (ECLAC, 2014). A State that is effective in the production of public goods goes hand-in-hand with a highly organized and diverse civil society and with a market where cooperation coexists with innovation and competition. In the orthodox economic literature, it is frequently assumed that the only institution that matters is respect for property rights, and it is generally understood that this implies a reduction in the State's presence and weight within the economy (Chang, 2006). However, the countries with the best records of respecting private contracts are those that impose higher taxes (Besley and Persson, 2010). This is because taxes are essential in funding the development of the State's capacities and, accordingly, the production of public goods. Without that capacity, markets would weaken or expand only intermittently, constrained by the absence of public goods or by fierce social conflicts fuelled by inequality, which could be exacerbated by the absence of effective regulatory regimes. As far back as the early nineteenth century, one keen observer of his time showcased the role of inequality in creating economically inefficient institutions. Alexis de Tocqueville (1835) described the impact of inequality (in one of its most brutal manifestations: slavery) by comparing the economies on the two sides of the Ohio River: the right bank, where slavery had been abolished, and the left bank, where it had not.

"Thus, the traveler who floats down the current of the Ohio to the spot where that river falls into the Mississippi may be said to sail between liberty and servitude; and a transient inspection of surrounding objects will convince him which of the two is more favorable to humanity.

"Upon the left bank of the stream the population is sparse; from time to time one descries a troop of slaves loitering in the half-desert fields; the primeval forest reappears at every turn; society seems to be asleep, man to be idle, and nature alone offers a scene of activity and life.

"From the right bank, on the contrary, a confused hum is heard, which proclaims afar the presence of industry; the fields are covered with abundant harvests; the elegance of the dwellings announces the taste and activity of the laborers; and man appears to be in the enjoyment of that wealth and contentment which is the reward of labor." (Tocqueville, 1835, chap. XVIII, p. 38)

The relationship between inequality and institutions is enduring. The intergenerational transmission of poverty reflects and reinforces the intergenerational transmission of exclusive institutions. One factor in explaining that persistence is that inequality permeates a society's culture, which sees certain groups' enjoyment of rights that are denied to others as something natural. As will be seen below, this gives rise to a culture of privilege that is implicitly accepted by both the entitled and the disadvantaged.

Ultimately, the direct impact of inequality on learning and capacities is compounded by another effect, perhaps less visible but no less powerful or ubiquitous: inequality weakens the State's capacities and saps the effectiveness of public policies. The political economics of inequality and their close relationship with the institutions and culture that govern social relations pose a barrier to increased productivity and growth by limiting the supply of public goods needed for the existence of competitive markets and innovative players. To view 
the combat against inequality and poverty as a sacrifice of efficiency is to ignore their key role in determining the high levels of inefficiency found in the social relations and production structures of unequal economies. On the contrary, in a democratic society, public goods are a manifestation of equality and belonging. ${ }^{9}$

\section{An entrenched culture of privilege}

\section{The historical roots of the culture of privilege}

The culture of privilege serves as the bedrock for inequality and its reproduction in Latin America and the Caribbean. Its origin is inseparably linked to conquest and colonization, through which indigenous peoples and people of African descent were subjected to forced labour and slavery, their property and wealth were expropriated, their beliefs and values were suppressed and they were systematically mistreated and denied all status of citizenship. This culture of denial of the other was concomitant with economic, political and social privileges tied to ascriptive and semi-ascriptive differences: racial or ethnic identity, gender, origin, culture, language and religion (Calderón, Hopenhayn and Ottone, 1994 and 1996). It laid the historical foundation for the culture of privilege that, with different manifestations and degrees, continues to this day.

During the colonial period, the denial of the other applied not only to indigenous and African peoples, but also to persons of mixed blood and women; then, as independent republics emerged, it was extended to immigrants, peasants, the illiterate, slum dwellers and domestic workers. The colonial experience established a form of dominance whereby those imposing the differences simultaneously set themselves up as the judges responsible for determining the hierarchical structure of that differentiation: conqueror, colonizer, Creole, landowner, dignitary, aristocrat, politician.

The culture of privilege can be understood through three basic features that date back to the rationale of colonial times and that were preserved, albeit with modifications, into the post-independence period. The first of these is the normalization of difference as inequality. Ascriptive and semi-ascriptive features serve to justify inequalities in property rights, power, standards of living, access to assets, networks of influence and status of citizenship. That hierarchical equating of the different with the unequal was enshrined in the common mindset of the elites and dominant groups: in other words, it came to be considered part of the natural order. The hegemonic nature of this form of domination stems from the internalization of an historic construct (the hierarchy of races, genders, peoples or populations) as an almost natural reality.

The second feature of the culture of privilege is that the person establishing the hierarchy is not an impartial judge: instead, the hierarchy is determined by one actor among many who, in order to secure the benefits accruing from the privilege, sets himself or herself up as both judge and party. Such individuals obtain their positions of privilege through their class of birth or bloodlines, their socioeconomic status, their race or gender, their birthplace, their culture, their belonging to the elites that wield power or any combination thereof.

The third defining feature of the culture of privilege is that to function and perpetuate itself, the hierarchy must be propagated through actors, institutions, rules and practices. In this way, a dialectic is established between the normalization of difference as inequality on the one hand and, on the other, the reproduction of inequalities through social structures and institutions. Within this dialectic, the culture of privilege leads inexorably to asymmetries in numerous aspects of collective life, such as access to privileged positions in business and finance, decision-making and deliberative power, greater or lesser presence in the channels through which ideas, ideologies and political agendas are conveyed, the appropriation of public resources for private benefit, special conditions in matters of justice and taxation, contacts for accessing better jobs and services, and ease in securing the best places to dwell, acquire supplies and receive schooling and care.

9 "As goods which are open to the public, the provision of public goods is not only a visible sign of solidarity, but also rather a joint commitment to make collective achievements available to each citizen. Public good regimes encapsulate societal progress (...)", Kallhoff, 2014. 
Through the culture of privilege, past inequalities are transmitted to the present, where they reproduce. Thus, for example, Afrodescendent populations, whose forebears were enslaved and pressed into forced labour, continue to suffer from deeper poverty, lower levels of schooling, increased exposure to the adverse effects of territorial segregation and employment in the most precarious niches of the labour market. Poverty rates among indigenous and Afrodescendent populations remain well above those of the rest of the population while, at the same time, poor income distribution underscores the connection between ethnicity and social inequality, with a much higher percentage of people of African descent and indigenous origin located in the poorest quintile (ECLAC, 2016b).

The overrepresentation of people of African descent in prisons is another example of difference as inequality and it is a reality in countries where the prison population is among the highest in the world, such as the United States and Brazil. In the latter, the number of prison inmates rose by $74 \%$ between 2005 and 2012, and the number of people of African descent who were arrested was 1.5 times higher than the number of whites taken into custody. ${ }^{10}$

\section{Faces of privilege in structures and institutions}

The culture of privilege is a key element in the pursuit of development with equality because it normalizes the relationship between a person's place on the social ladder and his or her greater or lesser access to education, health, work, security and comfortable living conditions. This dynamic permeates multiple areas where structural and institutional factors come together to perpetuate or recreate an unequal order: taxation, the appropriation of income from natural resources or financialization, the blocking of political and policy regulations by de facto powers, territorial segregation and the provision of infrastructure, segmentation in the quality of urban life, the costs that populations pay for environmental degradation and climate change, rigidities in intergenerational social mobility, or the segregation of capacities and access to well-being according to ascriptive factors or considerations of origin.

The more that families' levels of schooling, access to good health services, employment stability and mobility, physical security and quality of life correlate with their incomes and property, the more all those characteristics acquire the hallmark of privilege. Conversely, looser ties between the socioeconomic conditions of families and their levels of welfare, protection, quality of life and capacity-building indicate a weakening of the culture of privilege. That is the logic that underpins the welfare State in developed societies. ${ }^{11}$

The culture of privilege is related to structural aspects of the reproduction of inequalities. The structural heterogeneity of the region's production systems gives rise to an authentic social factory where gaps in productivity, incorporation of technical progress and access to expanded markets are forged into inequality in education and knowledge, income, career paths, engagement in the knowledge society and access to social protection systems. In other words, there is a systemic reinforcement between the emergence of inequalities and the replication of gaps, the core of which is the structural heterogeneity (ECLAC, 2010, 2012 and 2014).

As explained in chapter $\mathrm{VI}$, structural heterogeneity is rooted in the culture of privilege and it arises from a combination of privileged access to natural resources, the appropriation of public rents or quasi-rents by actors with greater economic and political power, and the coexistence of little diversified and knowledge-poor structures alongside inefficient institutions. The channelling of investment into that traditional structure is based on the incentives provided by relative prices, spending structures, subsidies, infrastructure policies and access to financing, which reinforce the unequal distribution of primary resources. And then taxation is subsequently unable to redress that inequality because the culture of privilege itself maintains a system with extensive fiscal exemptions and low rates of income tax.

10 See Brazil, General Secretariat of the Office of the President of the Republic (2014).

11 The less dependent that access to social welfare and protection systems is on family origin and the market, the more universal, equal and civic it becomes (Esping-Andersen and others, 2003). 
The institutional framework can reinforce structural heterogeneity as a factory of inequality or it can revert its effects through industrial, technological, fiscal, social and employment policies. The more robust the culture of privilege, the less space there will be for innovation in the dialectic between institutions and structures. The power of privileged sectors to veto policies that pursue innovation and resource redistribution reduces that space. Furthermore, within a culture of privilege, the interests of economic and political elites come together to hinder pro-equality reforms. This is clear in economies that depend on the extraction of raw materials, where the privileges derived from obtaining large profits through low wages and the overexploitation of natural resources lead to the prevalence of a rentier culture in the public and private sectors alike.

Another key area where the culture of privilege can be seen in Latin America and the Caribbean is the region's pronounced income inequality and wealth concentration. In Brazil, Chile, Colombia and Mexico, for example, the richest $1 \%$ of the population takes more than $20 \%$ of the total income. The region's average Gini coefficient is much higher than in other parts of the world, and the least unequal country in Latin America and the Caribbean is more unequal than any of the members of the Organization for Economic Cooperation and Development (OECD) located outside the region. One key institutional pillar of the culture of privilege, dealt with in greater depth in chapter III, is the low redistributive impact of taxation.

In Latin America and the Caribbean, fiscal privileges persist in the shape of exemptions, evasion and low rates of income tax. Much of the tax burden is indirect and falls on consumption, while income tax rates are lower than the average for OECD countries. The region's average tax burden is half the average reported by 15 European Union countries, and personal income tax levels account for most of the difference. While the bulk of the tax burden in the region comes from consumption taxes and is regressive in nature, the effective rate of the tax burden on the tenth decile of incomes was $4.8 \%$ in 2014 , compared to an average of $21.3 \%$ in the countries of the European Union.

The meagre redistributive impact of taxation — be it because of the composition of taxes and the total burden, because of the lack of effective oversight or because of the royalties that exist- is part of a system of privileges in which the most advantaged remain untouched by the social obligation to contribute to the common good through taxes. This reinforces the culture of privilege. Instead of this, fiscal responsibility within politics and public institutions should go hand-in-hand with a greater sense of social responsibility on the part of those sectors of society with the highest incomes. Taxation with a clear redistributive impact —which could be seen as a societal norm - is not only essential for promoting more equality: it also serves to draw attention to and raise awareness about equal rights.

Another area where the culture of privilege crystallizes in social relations is the rigidity of intergenerational social mobility. As already noted, in Latin America and the Caribbean, the educational achievements of children are still much more determined by those of their parents than in European countries. The intergenerational reproduction of inequality continues to be marked by gaps in educational achievement, which in turn lead to differentials in employment patterns and access to social protection. At the same time, educational segregation serves as a mechanism for social isolation and differentiation in networks of relationships. This reinforces class endogamy in the higher-income sectors, which in turn preserves and reproduces a system of inheritances and privileges that operates when members of one group defend the allegiances of their origins.

Privilege in the region has two unmistakeable territorial components. One is the map of inequalities in capacities, productivity and access to infrastructure, services and markets between different regions of a country. The other is territorial segregation in large conurbations, which is heightened by new real-estate dynamics and clearly portrays the map of privilege. In such cities, there are urban areas with mutually reinforcing vulnerabilities: school failure, precarious employment and early motherhood. Place determines the distribution of opportunities, drawing a dividing line that inexorably shapes life's path. In addition, as will be seen in chapter $\mathrm{V}$, the matrix of infrastructure, transport, utilities and environmental costs reflects a pattern of inclusion and exclusion that often dates back to the time of enclave economies.

While this document's focus is on the entrenched nature of the culture of privilege in Latin America and the Caribbean, that does not mean that such privileges are not found across the world. The lack of intergenerational solidarity regarding carbon footprints is regrettably universal. The culture of privilege is also 
present, or re-emerging, in the concentration of wealth in the world, which is taking place with unprecedented levels of intensity and at increasing speed. The same can be said of the relationship between the exercise of privileges and the realignment of powers that is reinforcing global asymmetries in terms of technological progress, financial power and capital flows.

\section{Building a culture of efficiency and equality}

In Latin America and the Caribbean, the first decade of the twenty-first century was marked by positive developments in the social arena, such as reduced poverty, various pro-solidarity reforms to social protection systems, growth in consumption and a slight improvement in income distribution. This was accompanied by a shift in the civic culture that affirmed dignity and associated it with effective rights and reciprocal treatment. That progress is not irreversible, however. In the second decade of the twenty-first century, a greater resistance towards furthering equal rights and deepening social reforms has emerged. In some countries, the pendulum is beginning to swing back, with cuts to social spending, limitations on labour rights and the repeal of tax reforms.

On the other hand, the progress attained in social rights, coupled with the greater penetration of the information society and new dynamics of upward mobility, is also producing cultural changes that are raising public awareness and expectations of equality. The public is examining the culture of privilege more closely. To a large extent, the crisis of legitimacy in the region's political systems and governments was the result of a critical scrutiny of entrenched privileges in certain sectors of society, as well as in relations between power and money.

Strengthening democracy threatens the culture of privilege. At the same time, however, it raises questions about the coherence between the symbolic and material progress of democracy towards a culture of equal rights. Symbolic progress entails democratic institutions and forums for discussion that instil, in the collective awareness, the idea of a community of citizens with equal rights. Material progress involves effective tools that translate that idea into actions that promote equality and penalize privileges.

In this conflict between the culture of equal rights and the culture of privilege, the three pillars on which equality is built must be strengthened. First, pro-equality policies and institutions must be accompanied by progress in policies and institutions for the recognition of differences. By doing so, the idea that inequality and difference as two sides of a single coin will no longer be considered natural. In its vision of equality as a foundational value for development, ECLAC identifies social rights and cultural rights as the hinge that interconnects material equality and symbolic equality (ECLAC, 2010 and 2014). Recognition policies have, in turn, an egalitarian and democratic basis. Privilege - when associated with gender, culture, ethnicity, race or place of origin - is facing increasing challenges and resistance from a rationale of recognition. Greater public and political visibility of groups that have traditionally been disregarded, and of their demands and rights, reaffirms the culture of equality.

Second, democracies must combat the characteristic practices of the culture of privilege whereby a single actor serves as both judge and party. This requires an independent justice system that affords equal access, so that abusive practices can be punished in a timely manner and clear signals can be given in response to offences arising from the exercise of privilege: tax evasion, illegal appropriation of rent or abuses in labour relations. In parallel, justice must empower those who require judicial institutions to uphold their political, social, labour and cultural rights. Non-discrimination policies must be enshrined in institutions established by the State and must be capable of countering the culture of privilege in specific fields and actions.

The third element is the introduction of institutional changes to revert the culture of privilege through social compacts for equality, as ECLAC proposed to its member countries in the position paper it presented at its thirty-fifth session (ECLAC, 2014). The construction of compacts, embodied in law and State policies, in areas that have traditionally been subject to the culture of privilege can permeate the collective awareness and revert deeply entrenched cultural hallmarks. Such compacts are both an end and a means: as the fruits of a deliberative process in pursuit of equality and democratic learning they are ends in themselves and, as instruments of public policy, they are a means for the ongoing and progressive implementation of pro-equality policies. The construction of compacts and their institutional consecration both produce a collective learning process in which the culture of 
equal rights is instilled in the community's awareness and, consequently, the exercise of privilege is curtailed. In this way, the "foundational milestones" through which democracy creates pro-equality institutions are developed.

Promoting a culture of equality requires institutions that permeate structures and modify habits. A fiscal compact that shifts consumption patterns so as to improve the delivery of public services and bring different sectors together in using them is necessary to promote both the culture of equality and environmental sustainability. With respect to the environment, the culture of privilege manifests itself in the disregard of negative environmental externalities. Patterns of consumption and dynamics of the cities that emphasize gratification, exclusivity and distinction for privileged sectors denote a lack of concern for society as a whole and for future generations. This phenomenon extends beyond the borders of our region and an expression of global negligence rooted in the exercise of privilege.

The culture of equality is bolstered when the well-being of society is addressed as a whole, with the delivery of public services and goods that everybody uses and consumes. If the State can provide good health, education, transport, security, utilities and environmental services with universal coverage, the willingness to engage in reciprocal commitments will increase. That is one of the most valuable accomplishments of advanced welfare States. In contrast, entrenched consumption of those goods and services by few in the private sector feeds the culture of privilege. When the most privileged groups isolate themselves in different, high-cost consumption patterns centred on the private sector, relational equality is seriously affected (ECLAC, 2014): cross-cutting relations between groups are hampered and gaps in well-being are cemented and this, in turn, reinforces the culture of privilege.

The culture of equality is essential for advancing towards collective agreements, which are an imperative in view of the complexity of challenges in which external constraints and internal margins for manoeuvre must be harmonized strategically. This document repeats the call for an environmental big push that ECLAC made at its thirty-sixth period (ECLAC, 2016a): in other words, a strategic approach for the future that interconnects industrial, macroeconomic and social policies to address the urgency of environmental sustainability. That demands broad social and political coalitions. Likewise, our societies must evolve from a culture of privilege to a culture of equality, since equal rights impregnate the social fabric with a greater sense of belonging and engagement in the great challenges of the future.

The equality-based approach is in alignment with the demands for capacity-building of a world marked by ever-accelerating technological change; however, it goes beyond that. It is also in alignment with the emphasis afforded to equality in the 2030 Agenda for Sustainable Development and the Sustainable Development Goals, adopted by the international community in 2015. The growing concern at high levels of inequality expressed in domestic policies thus has a correlation in the 2030 Agenda. Equality has been acknowledged as a key factor in international stability and defusing conflicts. The 2030 Agenda's watchword of "leaving no one behind" clearly underscores its universalist and inclusive focus.

The international community reached this consensus not only on the back of technical analyses, but also through discussions between governments, international organizations and civil society. One example of that dialogue was the first meeting of the Forum of the Countries of Latin America and the Caribbean on Sustainable Development, held in Mexico City in April 2017. On that occasion, governments, international organizations, academics and civil society organizations discussed and quantified the region's progress towards equality and the implementation of the 2030 Agenda. It was also agreed that those would be addressed at the second meeting of the Forum, to be held in Santiago in April 2018.

This document is a contribution to those discussions and dialogue. By analysing the high costs of inequality, the efficiency losses it entails and its impact on institutions and culture, it shows that the objectives of assured equality and acknowledged rights are not part of a nostalgic harking back to stability and, in general, to the world before hyperglobalization. On the contrary: they are the gateway to the technological revolution and to the propagation of the knowledge and skills on which increased output, employment and trade depend. As such, they can also help prevent the worsening of international political conflicts and environmental degradation through cooperation among nations in pursuit of the sustainable development to which the countries gave their commitment in the 2030 Agenda for Sustainable Development. 


\section{Bibliography}

Acemoglu, D. and others (2013), "Democracy, redistribution and inequality", National Bureau of Economic Research (NBER) Working Paper, No. 19746, Cambridge, Massachusetts, December [online] http://www.nber.org/papers/w19746.

Abbate, J. (1999), Inventing the Internet, MIT Press, Cambridge, Massachusetts.

Alesina, A., B. Reich and A. Ribboni (2017), "Nation-building, nationalism and wars", Working Paper, No. 23435, Cambridge, Massachusetts, National Bureau of Economic Research, May [online] http://www.nber.org/papers/w23435.

Beltratti, A., G. Chichilnisky and G. Heal (1993), "Sustainable growth and the green golden rule", NBER Working Paper, No. 4430, National Bureau of Economic Research, August [online] http://www.nber.org/papers/w4430.

Besley, T. and T. Persson (2010), "State capacity, conflict and development", Econometrica, vol. 78, No. 1, The Econometric Society, January.

Bowles, S. (2012), The New Economics of Inequality and Redistribution, New York, Cambridge University Press.

Brazil, General Secretariat of the Presidency of the Republic (2014), Mapa do encarceramento: os jovens do Brasil, Brasilia.

Calderón, F., M. Hopenhayn and E. Ottone (1996), Esa esquiva modernidad: desarrollo, ciudadanía y cultura en América Latina y el Caribe, Caracas, Nueva Sociedad/United Nations Educational, Scientific and Cultural Organization (UNESCO). (1994), "A cultural view of the ECLAC proposals", CEPAL Review, No. 52, (LC/G.1824-P), Santiago, April.

Chang, H. J. (2006), "Understanding the relationship between institutions and economic development: some key theoretical issues", Discussion Paper, No. 2006/05, World Institute for Development Economics Research (UNU-WIDER), July.

Cobban, A. (1965), A History of Modern France. Volume 3: 1871-1962, Harmondsworth, Penguin Books, January.

Deacon, R. (2009), "Public good provision under dictatorship and democracy", Public Choice, vol. 139, No. 1-2, April [online] https://link.springer.com/article/10.1007/s11127-008-9391-X.

ECLAC (Economic Commission for Latin America and the Caribbean) (2016a), Horizons 2030: Equality at the Centre of Sustainable Development (LC/G.2660/Rev.1), Santiago, July.

(2016b), The Social Inequality Matrix in Latin America (LC/G.2690(MDS.1/2)), Santiago, October.

(2014), Compacts for Equality: Towards a Sustainable Future (LC/G.2586(SES.35/3)), Santiago, April.

(2012), Structural Change for Equality: An Integrated Approach to Development (LC/G.2524(SES.34/3)), Santiago, July. (2010), Time for Equality: Closing Gaps, Opening Trails (LC/G.2432(SES.33/3)), Santiago, May.

Esping-Andersen, G. and others (2003), Why We Need a New Welfare State, Oxford, Oxford University Press, November [online] http://www.oxfordscholarship.com/view/10.1093/0199256438.001.0001/acprof-9780199256433.

Kallhoff, A. (2014), "Why societies need public goods", Critical Review of International Social and Political Philosophy, vol. 17, No. 6, April.

(2011), Why Democracy Needs Public Goods, Plymouth, Lexington Books.

North, D., J. J. Wallis and B. Weingast (2009), Violence and Social Orders: A Conceptual Framework for Interpreting Recorded Human History, New York, Cambridge University Press, February.

Okun, A. (1975), Equality and Efficiency: The Big Tradeoff, Washington, D.C., Brookings Institution Press.

Ostry, J., A. Berg and C. Tsangarides (2014), "Redistribution, inequality, and growth", IMF Staff Discussion Note, No. SDN/14/02, Washington, D.C., International Monetary Fund (IMF), April.

Rodrik, D. (2011), The Globalization Paradox: Democracy and the Future of the World Economy, New York, W.W. Norton \& Company, February.

Tocqueville, A. (2007), Democracy in America, New York, W. W. Norton \& Company. 

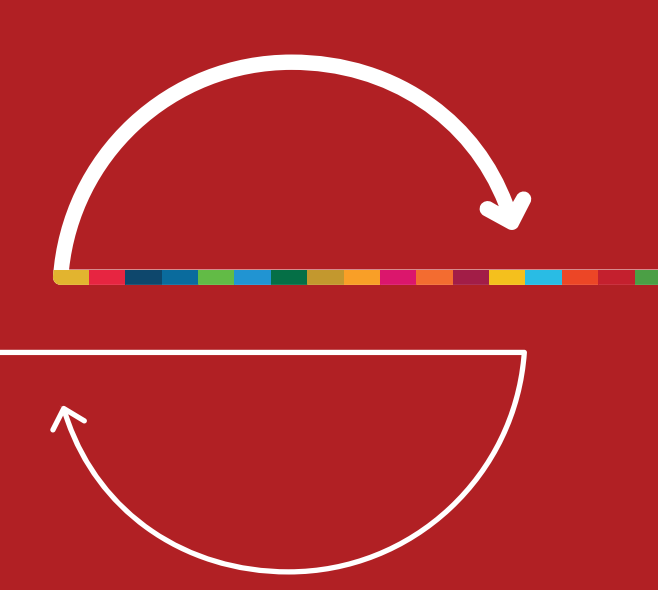

\section{CHAPTER}

|

\section{Growing tensions in globalization}

A. Development and inequality

B. A more economically and technologically uncertain world

1. The trouble with the prevailing macroeconomic interpretation

2. The digital revolution compounds uncertainty

C. From goods to bits

1. The great disruption: exponential technologies

2. Digital platforms in the vanguard

D. World trade is still below its pre-crisis levels

E. Transnational corporations in search of high-quality assets

1. The return of capital to advanced economies

2. China is consolidating its position as an investor

F. Ineffective global governance

1. Major international migratory flows

2. The need for a new financial architecture

3. The weakening of multilateralism in international trade

4. Settling investor-State disputes

5. The difficulties of practising environmental governance

Bibliography 



\section{A. Development and inequality}

Significant economic, technological and geopolitical changes have taken place on the world stage in the last biennium. Nearly a decade after the global financial crisis began, the three large economic blocs (the United States, Europe and East Asia) are all growing simultaneously for the first time, albeit at very different paces, while growth in developing countries has been boosted by the upturn in commodity prices. Meanwhile, the digital revolution is picking up speed, driven by the development of global digital platforms and the scale and network effects of extending access to digital services to nearly two thirds of the world population and the increasing importance of those platforms across the economy. The combination of different response rates to the crisis, sustained economic growth in China and the struggle for control of the nerve centres of the digital economy has led to unexpectedly strong geopolitical tensions.

Competition in global markets has exposed all countries, but particularly the transition economies, to the effects of globalization, as a result of policies to liberalize international trade and FDI flows, intensified by technological progress, particularly in digital technologies, which helped to reduce transaction costs and develop global production chains. The opening of international markets to the flow of goods, services and investments, and the dissemination of technology have boosted economic growth and employment in all the regions and helped hundreds of millions of people to escape poverty. However, ever greater interdependence at the global level has led to growing uncertainty about the functioning of the economy and the factors affecting key economic variables. It also spreads the impact of potential crises more broadly.

Globalization and rapid growth in some developing economies (particularly in China and East Asia) have significantly reduced the income gap among countries. However, not all countries have benefited equally from globalization. Income distribution within many countries became more unequal between the early 1980s and the mid-2010s, despite economic growth (see figure II.1). This inequality and its possible causes and impacts have heightened concerns about the concentration of income and wealth, an issue that has risen high on the international agenda. ${ }^{1}$ In January 2017, Oxfam International reported that just eight men own the same wealth as the poorest 3.6 billion people, that is half of humanity. ${ }^{2}$

Although inequality has declined between countries, it has reached its highest level in decades within the more developed regions, and the Gini index (the most commonly used measure of inequality) has increased in almost all regions of the world. The coefficient for the countries of the Organization for Economic Cooperation and Development (OECD) was 0.32 in 2014, its highest value since the 1980s; while in China it rose from 28.6 in the 1980s to 48 in 2012 (according to latest available data). Latin America was the only exception to this trend, as it has seen income concentration reach an all-time low over the last decade, albeit it remains the world's most unequal region.

Worldwide, the number of social, economic and behavioural sciences publications on inequality and social justice per year went from just under 1,000 in 1991 to close to 6,000 in 2014. Researchers in the economic, social and behavioural sciences publish the highest number of articles on inequality. The number of articles accelerated after 2007/2008 (ISSC/IDS/UNESC0, 2016).

2 See [online] https://www.oxfam.org/en/pressroom/pressreleases/2017-01-16/just-8-men-own-same-wealth-half-world. 
Figure II.1

Gini index, five-year averages
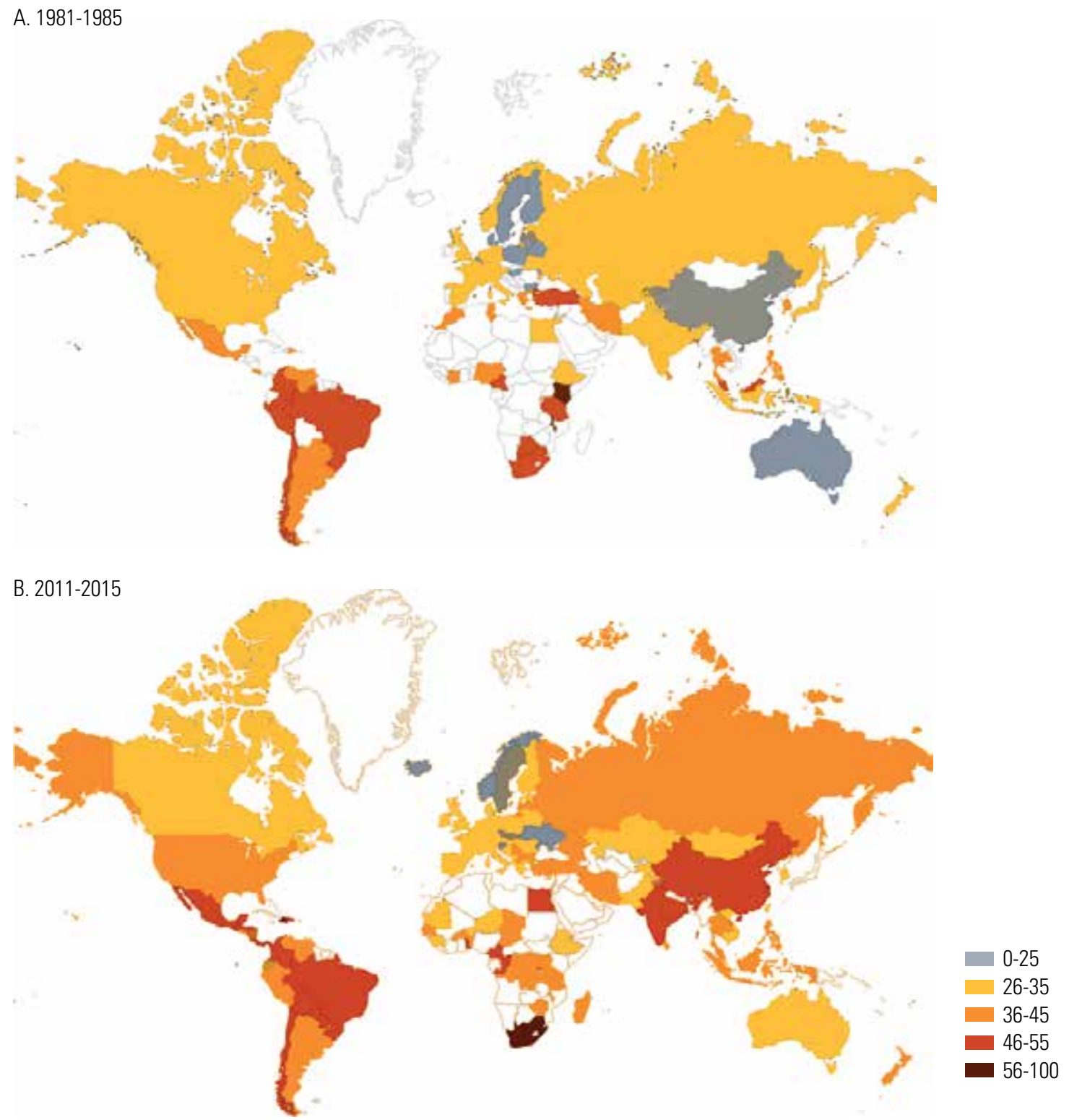

Source: World Institute for Development Economics Research (UNU-WIDER), "World Income Inequality Database (WIID 3.4)" [online database] https://www.wider. unu.edu/database/world-income-inequality-database-wiid34.

Given the multitude of variables that affect individuals' income and the distribution of resources among countries, it is impossible to quantify the respective contributions of economic globalization and global trade liberalization to growing inequality. However, global income distribution analysis can help to identify the impact of globalization on different parts of the world and income groups. On the basis of data from the World Inequality Report 2018 (Alvaredo and others, 2018), figure II.2 portrays the cumulative growth in mean income in each of the percentiles of global income distribution over the period 1980-2016. ${ }^{3}$ As the figure shows, globalization and market opening drove a significant increase in real per capita income in all countries. However, this growth occurred at different rates, creating winners and losers. The winners in terms of real per capita income growth

3 Income per adult is reported on the basis of the total national income distribution per adult (Alvaredo and others, 2018). 
were people with average income around percentiles 20 and 60 -most of them from China or India, whose economies have expanded at unprecedented rates over the past 30 years - and those with average income around percentile 99, i.e. the world's richest $1 \%$. Those left further behind were those with average per capita income between percentile 70 and percentile 90 of the global distribution, most of them belonging to the (old) middle classes in the most advanced countries.

Figure II.2

Real income growth per adult by income percentile in the global distribution, 1980-2016 (Percentages)

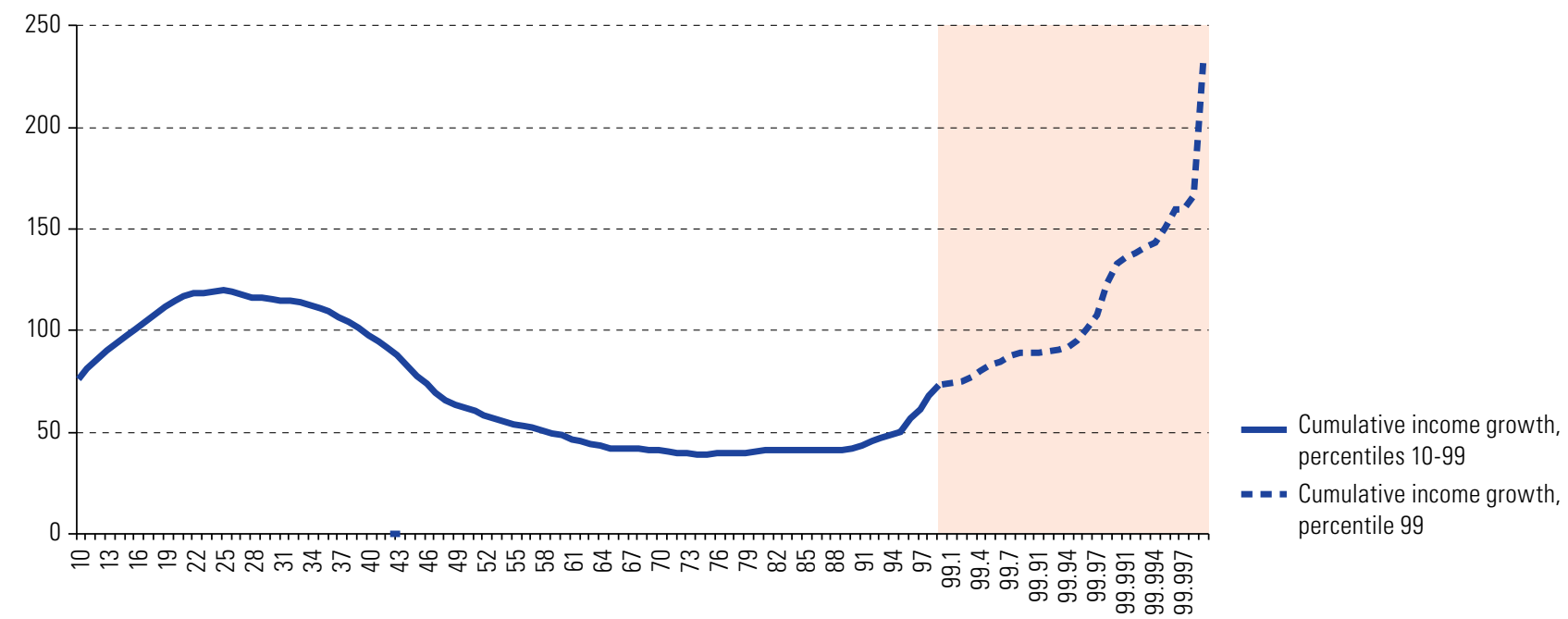

Source: Economic Commission for Latin America and the Caribbean (ECLAC), on the basis of F. Alvaredo and others, World Inequality Report 2018, World Inequality Lab, 2018 [online] http://wir2018.wid.world/files/download/wir2018-full-report-english.pdf.

This analysis yields strong evidence that the benefits of globalization have been polarized in favour of the rich. The world's richest $1 \%$ captured $27 \%$ of the total cumulative growth in income between 1980 and 2016, while $50 \%$ of the distribution captured only $12 \%$ (Alvaredo and others, 2018). This trend is confirmed in figure II.3, which shows that the richest $1 \%$ of the population seen its income rise steadily in most countries.

While many factors have contributed to rising inequality, income polarization can be largely explained by changes in wage distribution (OECD, 2011). In most developed and transition economies, top earners have seen their wages grow more than others. Various factors explain the drop in the wages of lower-skilled workers, including globalized production processes, cross-border movements of capital, technological change and automation. These processes were reinforced by political factors, such as trade unions' loss of power and the weakening of minimum wage regulations (Autor, 2014). Greater wage inequality is partly responsible for the global financial crisis of 2008-2009 and the slow recovery thereafter, first in the United States and then worldwide (Setterfield, 2013).

Although it is difficult to distinguish empirically between the effects of the various forces interacting within the economic system, the conclusions drawn by Alvaredo and others (2018) and Milanovic (2016) and those arising from the analysis of income share by decile above help to understand why globalization is being questioned in advanced countries. Income polarization depressed the wages of the middle class, forcing families to resort to borrowing to maintain their levels of well-being before the crisis. At the same time, those whose incomes grew the most invested more in financial assets than in productive activities. The growing indebtedness of the middle class, coupled with the disproportionate expansion of financial assets, led to the collapse of subprime mortgage securities, which was a key factor in the 2008 crisis. The high level of inequality and inability to stimulate wage growth depressed consumer demand and hampered the recovery of the global economy. 


\section{Figure II.3}

Income of the richest $1 \%$ of the world's population, 1980-2015

(Percentages of total income)

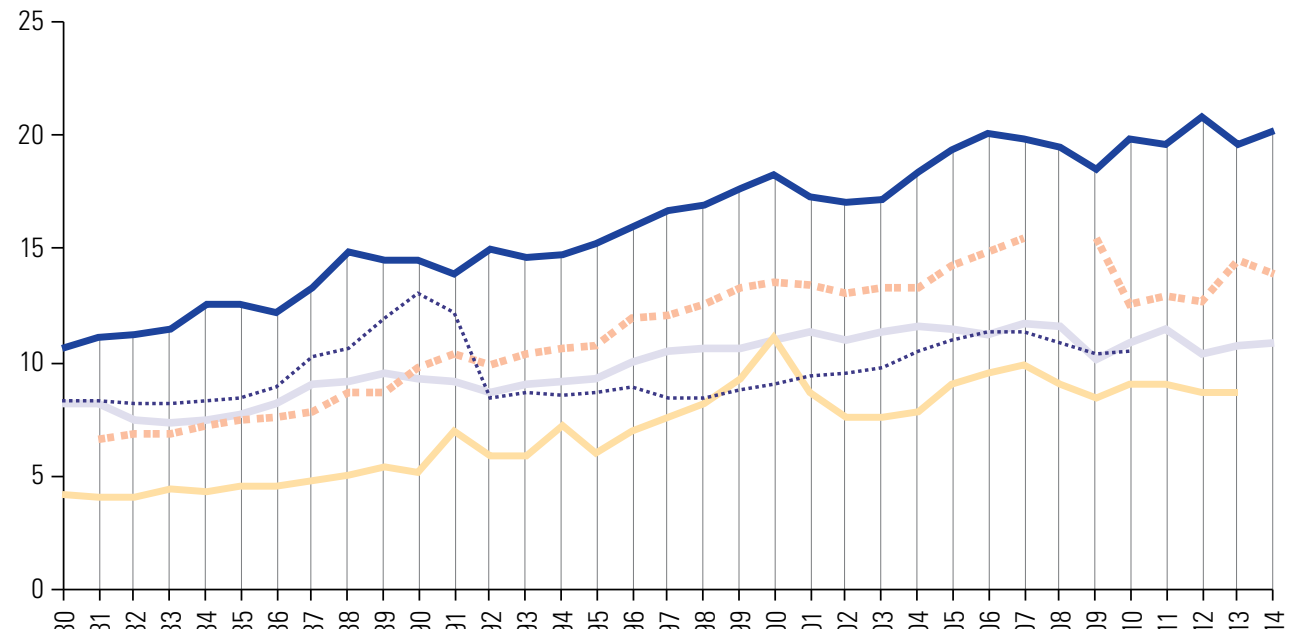

- United States

....... Japan

France

III I III United Kingdom

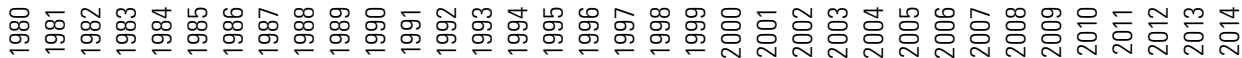

Sweden

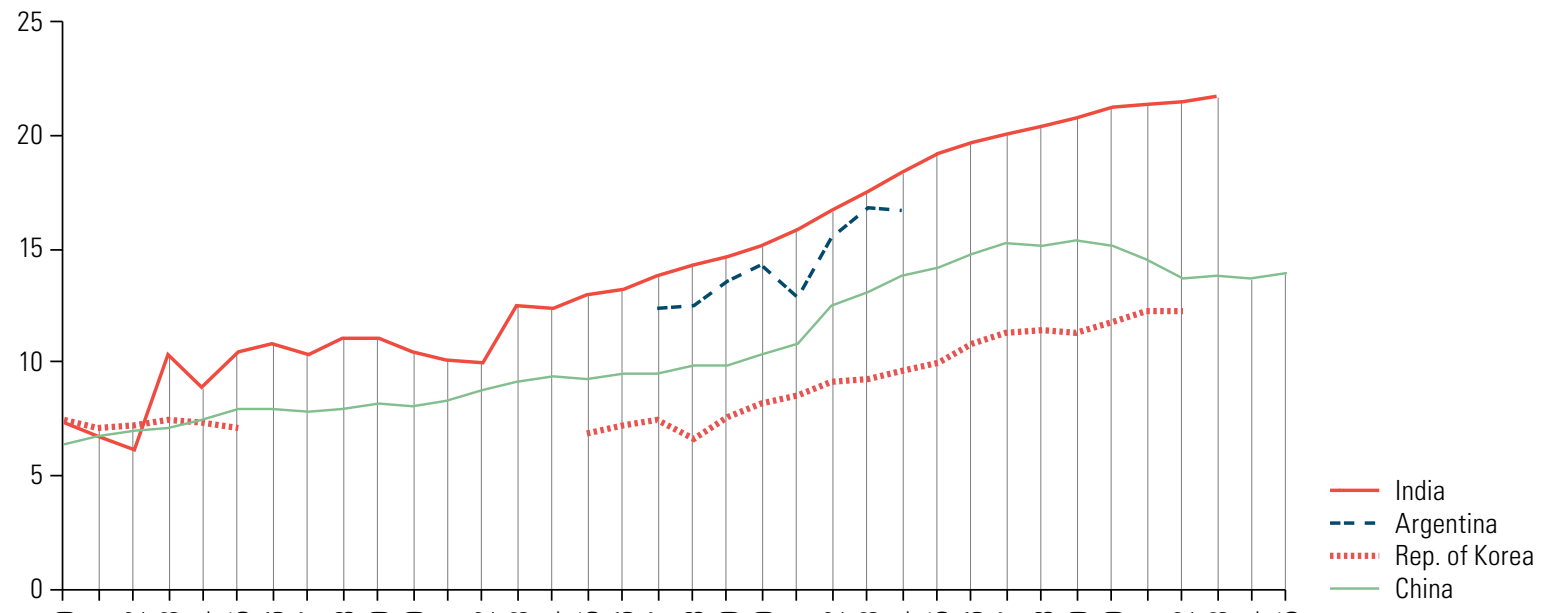

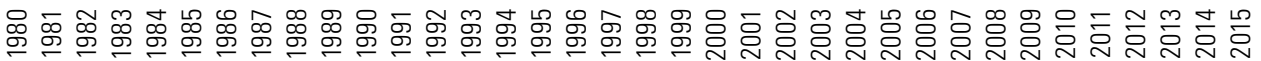

Source: World Health and Income Database (WID) [online database] http://wid.world/es/pagina-de-inicio/ 


\section{B. A more economically and technologically uncertain world}

\section{The trouble with the prevailing macroeconomic interpretation}

Despite the recent uptick in growth, the consolidation of the recovery remains uncertain. ${ }^{4}$ The major economies are reporting significant decelerations in per capita gross domestic product (GDP) growth compared to historical rates. At the same time, investment as a percentage of GDP is still below its pre-crisis levels in the major developed economies. Production capital continues to expand slowly and productivity growth has not returned to its past levels. Inflation rates are still too low, and while unemployment stands at all-time lows (particularly in the United States and Japan), nominal wages remain stagnant (see figure II.4).

The quantitative easing programmes adopted by the advanced economies in the wake of the crisis sought to stimulate growth by expanding the monetary base and accelerating inflation. ${ }^{5}$ The reduction in long-term interest rates was expected to drive up aggregate demand. However, despite those monetary stimulus policies, the recessionary bias of the global economy lasted longer than anticipated, which heightened social tensions and fuelled doubts about globalization and the traditional economic model (ECLAC, 2016a).

In addition to the risks and costs involved in a global financial sector detached from the real economy, highly concentrated in large, interconnected financial institutions (ECLAC, 2016a), the world economy periodically experiences the effects of bubbles that shift between sectors, countries and activities, such as those seen in the property sector, commodity investments or cryptocurrencies. This has led different bodies to warn that a new financial crisis could be triggered by the growth of speculative bubbles and risk factors, such as Chinese debt, current account imbalances and excess international liquidity.

Inflation's failure to react to low levels of unemployment and to economic growth, particularly in the United States and Japan, suggests that the relationship between these variables is weakening and calls into question the validity of some traditional economic models. The fact that certain key variables have not responded as those models suggest raises doubts about the assumption that the world economy has finally escaped the low growth trap. It is also clear that the relationship between economic growth, employment and inflation is not as stable as was once believed.

In the United States, the Federal Reserve has indicated its intention to begin reducing its balance sheet and to gradually adjust interest rates, with the prospect of a possible intervention in the event of change in the path of growth (Federal Reserve Bank of New York, 2017; Yellen, 2017a). The former Chair of the Federal Reserve had expressed optimism about the future response of inflation to economic growth and low unemployment, but admitted on a number of occasions that central banks had misjudged the strength of the labour market, the degree of consistency between long-term inflation expectations and inflation targets, and even the forces driving inflation (Yellen, 2017b). Meanwhile, the European Central Bank maintains that growth is solid and that inflation dynamics have ticked up (ECB, 2017). In Japan, the central bank has stated that economic conditions and inflation expectations do not warrant an interruption of its quantitative monetary easing policies (Central Bank of Japan, 2017).

\footnotetext{
Global GDP growth stood at 3.4\% in 2017, compared to 3\% in the previous year, and is expected to be $3.7 \%$ in 2018. Despite this acceleration, growth will remain below the average for the five years prior to the crisis. Industrial output, investment and private consumption are expanding, while international trade continues along the path of recovery begun in late 2016.

5 Quantitative easing is a non-conventional expansionary monetary policy adopted in response to the ineffectiveness of traditional monetary policy to stimulate economic growth. An increase in the monetary base - through purchases of public debt and other financial instruments - increases the amount of currency in circulation, thereby reducing its value and pushing up prices. Quantitative easing was adopted in Japan in the 1990s, in the United States in late 2008, in the United Kingdom in 2009, in the eurozone in 2011 and on successive occasions since then.
} 
Amid this uncertainty, policymakers face two scenarios. On the one hand, the weak relationship between inflation and unemployment suggests that expansionary fiscal policies could be implemented without pushing inflation to unsustainable levels. On the other hand, should the weakening of that relationship prove only temporary and expansionary fiscal policies fuelled inflation, a lengthy period of high unemployment might be needed to stabilize it. This makes it more important than ever to understand the forces that affect inflation and unemployment, and the relationship between the two.

Figure II.4

World, United States, eurozone, Japan and selected countries: different economic variables

\section{A. Changes in real world GDP, 2000-2017}

(percentages)

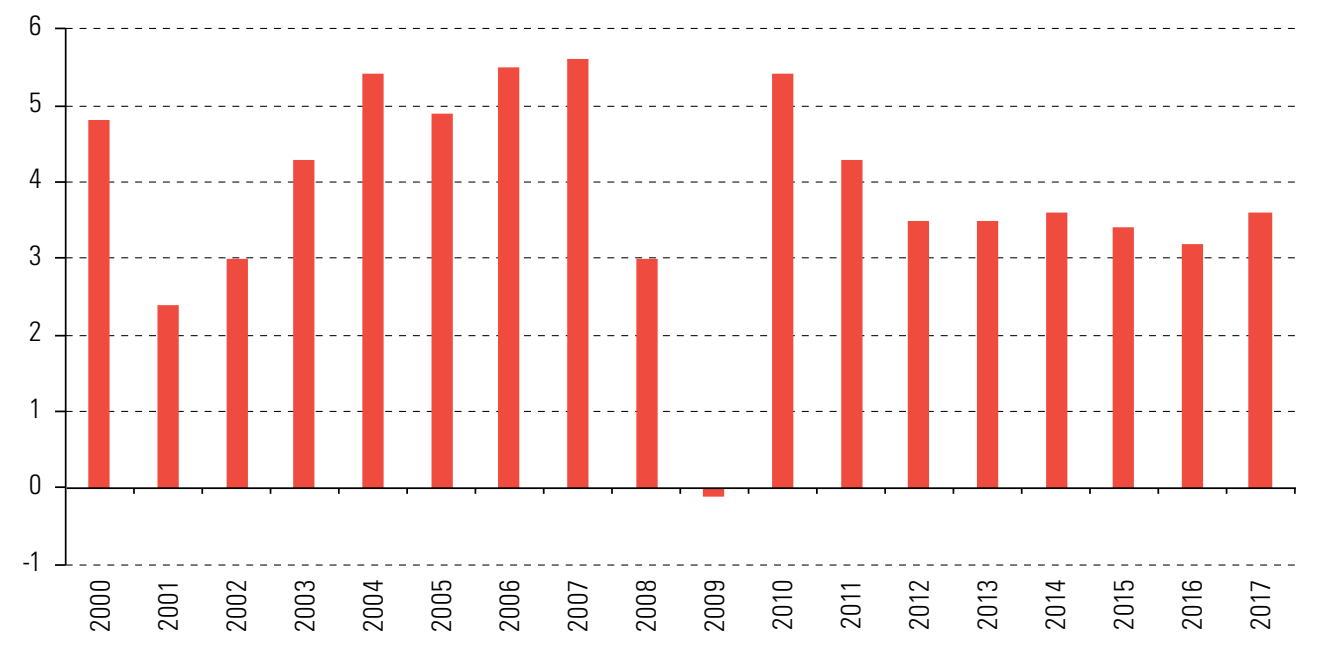

Source: Economic Commission for Latin America and the Caribbean (ECLAC), on the basis of data from the International Monetary Fund (IMF), World Economic Outlook, 2017 [online database] https://www.imf.org/external/pubs/ft/weo/2017/02/weodata/index.aspx

B. Selected countries: investment as a share of GDP, 1990-2018a (percentages)

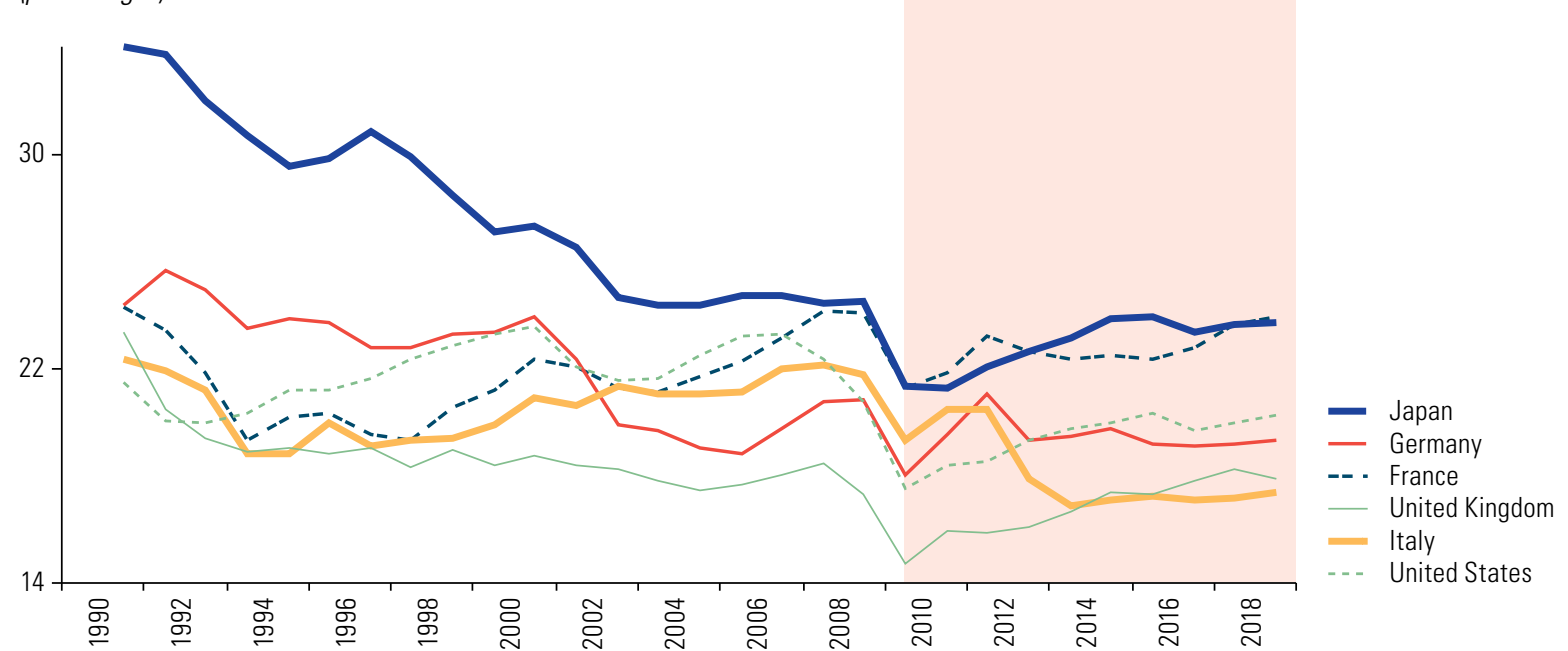

Source: Economic Commission for Latin America and the Caribbean (ECLAC), on the basis of information from the International Monetary Fund (IMF), World Economic Outlook: Gaining Momentum?, April 2017.

a Figures for 2017 and 2018 are projections. 
Figure II.4 (continued)

\section{United States, eurozone and Japan: unemployment rate} (percentages)

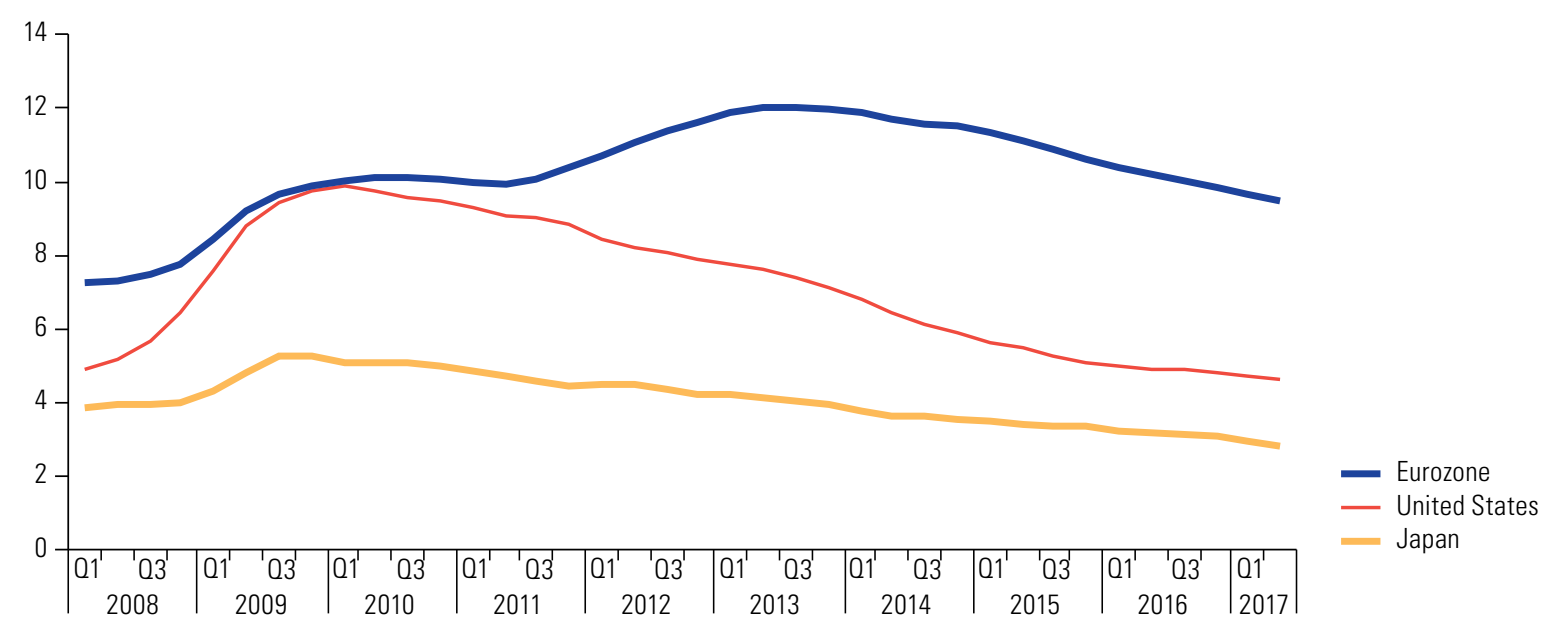

Source: Economic Commission for Latin America and the Caribbean (ECLAC), on the basis of figures from the Organization for Economic Cooperation and Development (OECD).

\section{United States and Japan: change in nominal wages} (percentages)

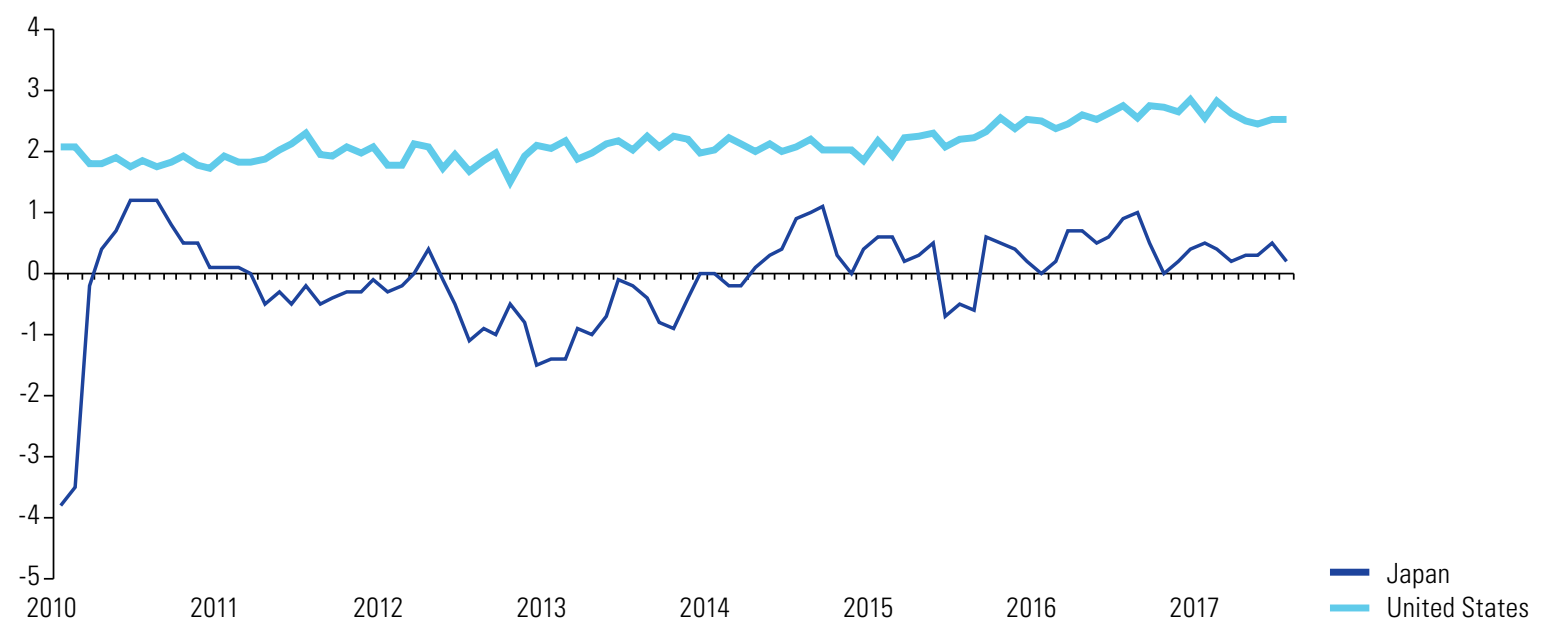

Source: Economic Commission for Latin America and the Caribbean (ECLAC), on the basis of data from the Bureau of Labor Statistics of the United States, "Current Employment Statistics" [online] https://www.bls.gov/ces/ and Ministry of Health, Labour and Welfare of Japan. 
Figure II.4 (concluded)

E. United States, eurozone and Japan: core inflation, 2010-2017 (change over previous period in percentages)

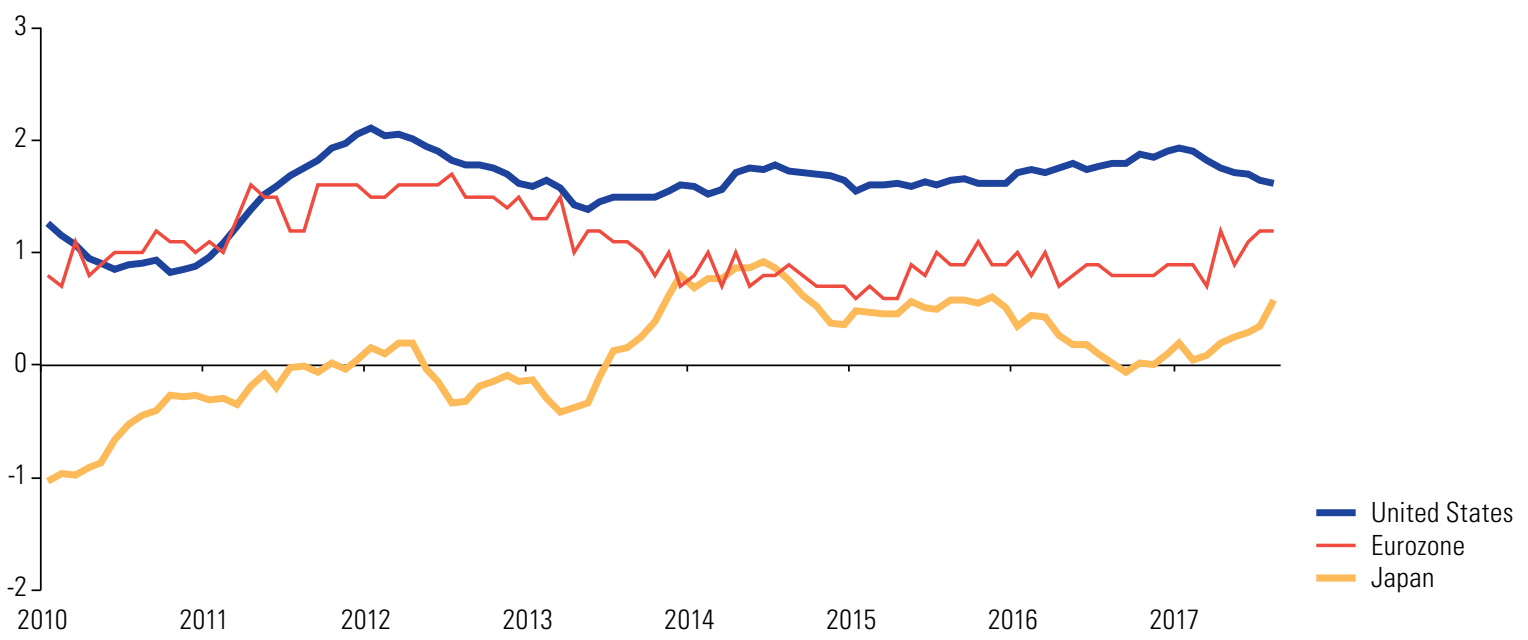

Source: Economic Commission for Latin America and the Caribbean (ECLAC), on the basis of information from the Federal Reserve Bank of St. Louis, Federal Reserve Economic Data (FRED) "Trimmed Mean PCE Inflation Rate" [online] https://fred.stlouisfed.org/series/PCETRIM1M158SFRBDAL; Eurostat, Harmonised Indices of Consumer Prices (HICP) [online] http://ec.europa.eu/eurostat/web/hicp/methodology/euro-area, and Japan Macro Advisors, "Trimmed Mean CPI Inflation Rate" [online] https://www.japanmacroadvisors.com/page/category/economic-indicators/inflation-and-prices/10per-trimmed-cpi.

Note: The calculation of core inflation does not include energy, food, alcohol or tobacco.

These developed countries' macroeconomic authorities interpret inflation's unresponsiveness to labour market dynamics and economic growth as a temporary phenomenon and expect a return to normality. They argue that temporary factors are now constraining inflationary pressures and will at some point dissipate, reviving growth in productive investment. The return to pre-crisis levels could take between 15 and 20 years. That is the time frame required to deleverage the central banks' balance sheets, especially given the uncertainty about their desirable structure and size. Accordingly, the two largest central banks, the Federal Reserve and the European Central Bank, have maintained a considerable degree of flexibility in their short- and medium-term policies.

Another view is that the forces involved are more structural and long-term, and that economic and monetary policy instruments must factor in those forces and their effects in order to restore predictability (Auer, Borio and Filardo, 2017). Age-old economic forces that are felt as positive supply shocks could have lasting effects on macroeconomic variables. From that point of view, it would be naive to expect wages and prices to remain unaffected by globalization and the technological revolution. Globalization constrains inflationary pressures, keeping the prices of goods and services imported from China and other emerging markets low. Furthermore, the entry of a growing number of workers into the world market and the weakening of trade unions have reduced workers' bargaining power. So, although structural unemployment is low, wage compression remains in place. The technological revolution and the possibility of job automation reinforce those processes. The expansion of the Internet and e-commerce has helped compress inflationary pressures by lowering the prices of consumer goods, enabling consumers to compare prices more easily, and reducing intermediation costs.

Moreover, in a high-debt context expansionary monetary policy loses its effectiveness and can even be harmful. ${ }^{6}$ To counter these effects of monetary policy actions, public balance sheet vulnerabilities must be taken into account before interest rates are modified. Meanwhile, in a climate of uncertainty, keeping the cost of public sector borrowing low could facilitate the implementation of expansionary fiscal policies and stimulate private investment and consumption.

6 Total debt in the global economy increased from 180\% of GDP in 2007 to 220\% of GDP in March 2017 (BIS, 2017). 
The global economy's slow recovery means that there must be certainty that growth will be sufficiently stable and will stop relying on the monetary stimulus provided by quantitative easing policies. The causes of inflation's weak response to economic growth, of slow productivity growth and of wage stagnation must be identified to prevent a shift in central bank policies from slowing growth or generating new recessionary forces.

\section{The digital revolution compounds uncertainty}

The world of technology also causes a high degree of uncertainty, with regard to both its performance and its impact on related activities. However, in contrast to macroeconomic reality, where uncertainty is the result of a decade of slow growth and doubts about the validity of the interpretative model that underpins policies, the uncertainty in the digital sphere is the result of its success. The development of new technologies has accelerated and their effects are being felt across the economy and society.

Data flows, measured in terms of installed cross-border bandwidth capacity, show clearly that the rate of technological change has accelerated. That capacity has grown exponentially since 2007, while international flows of goods and services, foreign direct investment (FDI) and finance have fluctuated wildly, particularly in the wake of the global financial crisis (Manyika and others, 2016). Digital expansion, in the shape of increased data processing, transmission and storage capacities, was not affected by the problems that beset capital formation, growth and employment at the aggregate level.

The speed of change is also revealed by numerous other indicators, including those related to Internet access and the use of mobile technologies. These technologies have continued to spread around the world in 2017, with more than 5 billion unique mobile subscribers, 3.58 billion Internet users (48\% of the global population) and more than 5.1 billion fixed and mobile broadband subscriptions, which generate IP traffic of more than 100 exabytes per month and has led to some 180 billion application downloads, which is about 26 for every person on the planet. The use of applications has gained momentum and the most popular apps can reach 50 million users in as little as one month, instead of years as before. As a result, it is increasingly difficult to predict what type of apps will be used in the medium term (for example, five years hence) and, accordingly, to foresee what hardware and skills will be needed to develop them efficiently (ITU 2017).

The most advanced technologies have also seen remarkable levels of growth. In less than a decade, technology bundles linked to cloud computing and big data analysis have been launched and quickly taken up by consumers and businesses, especially medium-sized and large companies. Moreover, in less than two years, new fields of action have opened up in the areas of robotics and artificial intelligence which, although they have been in development for decades, have now become commonplace in policy discussions on account of their potential impact. The uncertainty caused by these new technological developments is compounded by a radical reconfiguration of business structures. Global digital platforms, which dominate the online universe and have an increasing impact on the analogue economy, are being consolidated. These platforms, which were developed in the last 15 years, have a strong presence throughout the world but belong mostly to companies from the United States (Apple, Google, Facebook, Amazon, Microsoft) and China (Baidu, Alibaba, Tencent). It is still too early to predict how successful this new business structure will be and how governments will respond to regulatory (safety, privacy) and fiscal matters. This also increases global uncertainty, as these platforms are the biggest investors in and providers of digital goods and services, and their activities might be incompatible with national regulations.

The development of the digital economy and society has many consequences, but three are of particular interest for policymaking. First, the expansion of digital technologies has blurred the boundaries between sectors that produce goods and those that provide services. The proliferation of "smart, connected products" makes it increasingly difficult to separate the costs and benefits of physical production and use from those arising from digital features. Traditional cost-based competitive advantages have become more difficult to identify and build on as the use of physical goods increasingly depends on their connection to the "product cloud". A similar 
phenomenon can be seen in the growing number of businesses using online-to-offline (o20) strategies to manage, for example, idle service capacity. Second, it has rekindled the debate surrounding Solow's paradox ("you can see the computer age everywhere but in the productivity statistics"). Discussions about the impact of the platform economy on productivity have intensified and are far from reaching a conclusion. In particular, attention has been drawn to problems arising from measurement errors and from delays in implementing and creating the necessary complementarities (McAfee and Brynjolfsson, 2017).

The third consequence is by far the most relevant for policy decisions and is possibly the most uncertain. The impact of new technologies — particularly robotics and artificial intelligence- on employment levels and quality can be seen in areas ranging from compensatory mechanisms for affected sectors to the design of new education plans. Estimates from 2013 onwards suggest very different outcomes; but the effects are significant regardless, particularly against a backdrop of slow employment growth or a rapidly expanding working-age population, as discussed in chapter IV.

\section{From goods to bits}

\section{The great disruption: exponential technologies}

Digitization is transforming economic flows by reducing transaction costs and marginal production and distribution costs as a result of creating digital goods and services, adding value by incorporating digital features into non-digital goods and services, and developing production, exchange and consumption platforms (ECLAC, 2016b).

The integration of digital technologies into the economy is not recent; it dates from the 1960s with the advances in electronics and the automation of production processes. It picked up pace between the 1980s and 1990s with spread of personal computers and data communications, and such technology became increasingly commonplace with the development of the Internet, mobile telephony and information systems that facilitated the creation of global value chains. By adopting these technologies, companies sought to generate productivity gains through reduced transaction and labour costs, which led them to relocate their production plants to places with lower labour costs. These developments promoted globalization and strengthened links among the more developed countries by facilitating trade and financial flows, and streamlining management, production and marketing processes.

The world is on the verge of even greater disruption, as it moves from an analogue age to a digital one, giving rise to the so-called fourth industrial revolution, which is defined not by a range of emerging technologies, but by the transition to new systems built on the infrastructure of the digital revolution. There are three reasons why these changes indicate the arrival of a new revolution: (i) velocity, owing to the exponential nature of technological developments; (ii) scope, insofar as they affect all sectors and industries; (iii) and impact, as they completely transform production, management and governance systems (Schwab, 2016; ECLAC, 2017).

The convergence of data transmission, capture and storage capacities, the exponential increase in those capacities, their steadily falling costs and the penetration of digital technologies in the economy are giving rise to a disruptive period based on smart machines and objects and data analytics, and are driven by worldwide digital platforms that support sectoral activities (see diagram II.1). 
Diagram II.1

Digital disruption
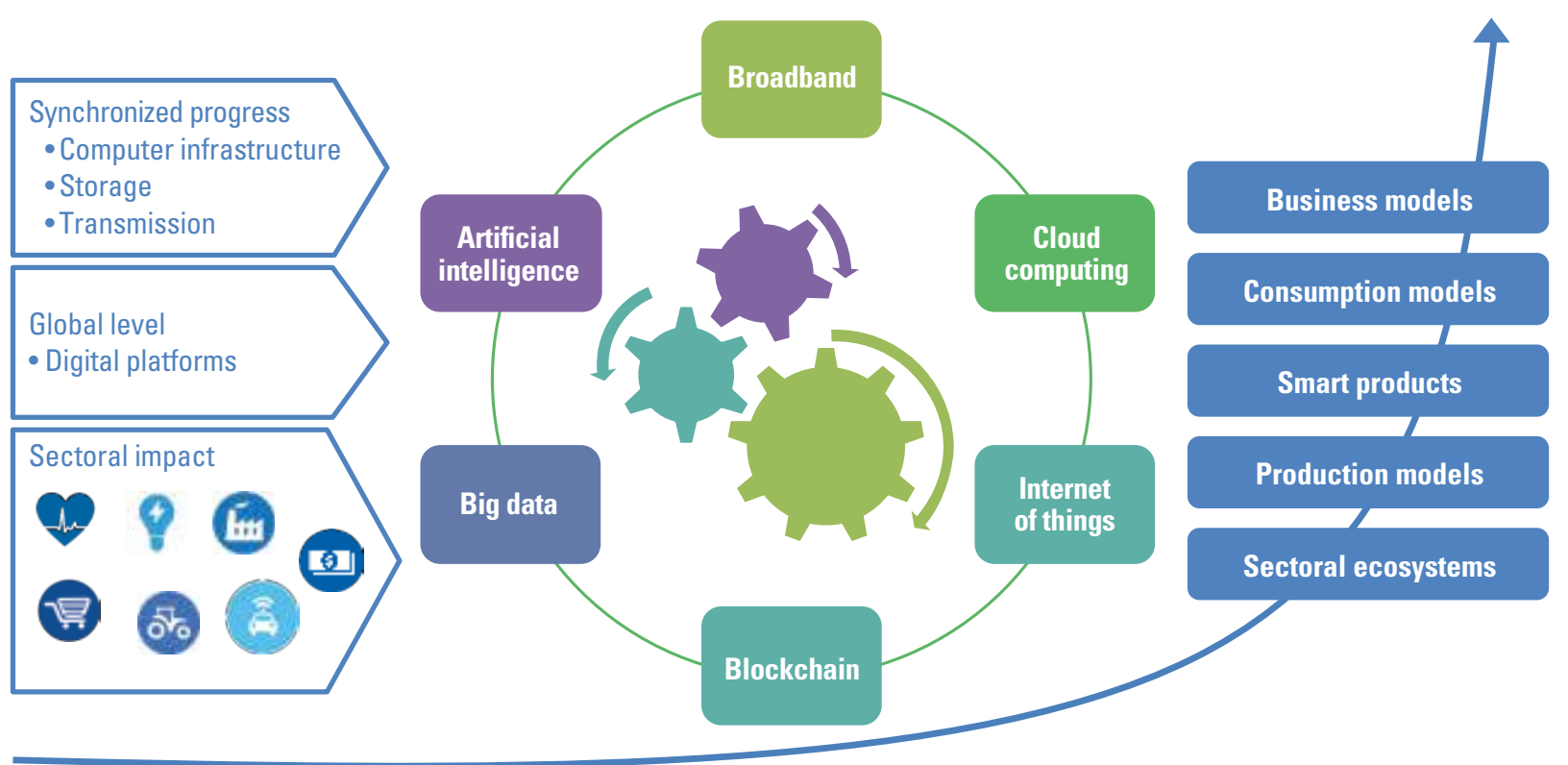

Source: Economic Commission for Latin America and the Caribbean (ECLAC).

Considered in isolation, high-speed broadband Internet networks, the ubiquity of access with multiple devices, cloud computing, the Internet of things, big data analytics and advances in artificial intelligence create opportunities for innovation in service delivery and new business models. However, adopting all of them leads to disruptive changes that take the form of smart products connected through digital manufacturing ecosystems and new consumption and business models. More recently, blockchain technology is shaping new industries and modifying production systems for goods and services. ${ }^{7}$ This is the case in the financial system, where blockchains have made it possible to reduce the number of intermediaries, lower transaction costs and democratize the validation of operations, by reducing systemic risk (Casey and Wong, 2017). ${ }^{8}$ Over the last couple of years, digital technologies that support or enable banking and financial services (financial technologies or fintech) ${ }^{9}$ have been central to the development of the sector and have attracted the attention of the monetary authorities. Thus, the rapid growth of digital platforms, networks and data business models represent the latest shift in the forces of globalization. ${ }^{10}$

Just as the digital revolution transforms consumers' lifestyles and business models, smart and connected cities will improve the delivery of public services, such as education, health care, transport, and electricity generation and distribution, and thereby support sustainable urbanization. The lower costs arising from better city management should improve efficiency, which in turn could boost economic growth and create new employment and revenue opportunities. This suggests that the world can move towards a new development and industrialization model that manages social, economic and environmental resources sustainably, i.e. an environmental big push.

\footnotetext{
A blockchain is a cryptographic protocol that allows different users (computers) to validate and update transactions of digital objects. Blockchain technology is a set of algorithms that allow so-called cryptochannels -including bitcoin — to be marketed and electronically verified by a computer network without a central ledger.

8 Six large banking groups are looking into the possibility of developing a cryptocurrency to allow them to process transactions more quickly and securely than traditional currencies (Arnold, 2017).

9 The term "fintech" refers to activities and companies that use digital technologies to provide financial services that are cheaper, faster and more accessible, both to individuals and financial entities. It covers national and international electronic payments, collective financing loans, financial advice and investments using cryptocurrencies.

10 See the Initiative on the Digital Economy of the Massachusetts Institute of Technology (MIT) [online] http://ide.mit.edu/.
} 


\section{Digital platforms in the vanguard}

The forces of global disruption are digital platforms such as Apple, Google, Microsoft, Amazon, Facebook, Tencent and Alibaba, and more recently, Uber, Airbnb and Netflix. The digitally-enabled business model of these companies creates value by facilitating exchanges between two or more interdependent groups of users, thereby creating multilateral markets with powerful network effects by using the data that are produced and shared on the platform as business assets. Platforms' development can be accelerated by application programming interfaces (API) provided by third parties that allow participants to share data to create new services.

Platform companies are disruptive because they alter business, consumption and production models, not only in the industry in which they emerge, but in other sectors of the economy when they are combined with other innovations, altering the industry's organization. Towards the end of the 1990s and the beginning of 2000, the photography, music and print industries were the first to see the effects of digitization and the subsequent emergence of new business models. Within 15 years there have been successive waves of digital disruption, such as Skype in voice communications, Amazon and Alibaba in retail, iTunes and Spotify in music, Netflix and YouTube in audio and video content, Expedia and Airbnb in travel and accommodation, and Uber and Cabify in taxi services. Today, the most transformative activities are taking place in the automotive industry, with increasingly digitized products and more automated production processes (autotech), and in the financial sector, with the development of fintech. By 2020, the health, manufacturing, agriculture, transport and energy sectors (smart cities) are expected to be most affected by the next phases of digitization. These disruptive waves challenge traditional stakeholders and pose a major challenge to regulatory and governance models, with profound implications for the organization of industries and the labour market.

The downturn in the fortunes of Kodak is not only an example of how quickly a market leader can lose its leading position, ${ }^{11}$ but also reflects a shift toward a much less labour-intensive business model and a business strategy based on mergers and acquisitions in search of economies of scale and innovations that add value to the existing network. ${ }^{12}$ Although initially limited to the digital technology sector, these transactions have spread to others, creating hybrid industries that represent the growing convergence of traditional activities with technological subsectors, such as the Internet of things, artificial intelligence and blockchains (Baker McKenzie, 2017b). This diversification creates vertical digital ecosystems and turns platforms into complex innovation systems that blur the boundaries between industries, as in the automotive industry, or transform production chains and management in traditional sectors, such as agriculture. Moreover, the platforms' business model is being adopted in other sectors because it offers an effective approach to blending the physical and digital worlds.

Thanks to their business model based on digital technologies and economies of scale, platform companies can expand rapidly because they do not rely on physical capacity such as retail outlets or the development of production chains. The major technological platforms are the largest global companies in terms of market value, superseding companies from traditionally dominant sectors, such as energy, manufacturing and finance (see figure II.5).

11 Founded in 1888, Kodak was the photography market leader with a market capitalization of US\$ 28 billion and employed 140,000 people by 1996. Following the launch of digital cameras, the impact was first felt in the sales and processing of photographic film. This worsened with the development and spread of smartphones, which have replaced traditional cameras and allow images to be shared through social media such as Facebook or Instagram. So, while Kodak was declared bankrupt in 2012, Instagram, a small company of 13 employees, created in 2010, was bought by Facebook for approximately US\$ 1 billion (Leslie, 2014)

12 According to Statista, between 2013 and 2017, Google completed some 98 mergers and acquisitions, followed by Microsoft, with 56, and Apple, with 50, while General Electric totalled 18. Meanwhile, the Chinese platforms Tencent, Alibaba and Baidu followed a similar trend with 75, 72 and 27 transactions since 2012, respectively. 
Figure II.5

Market value of the largest global companies, 2006-2017

(Billions of dollars)

\section{A. 2006}

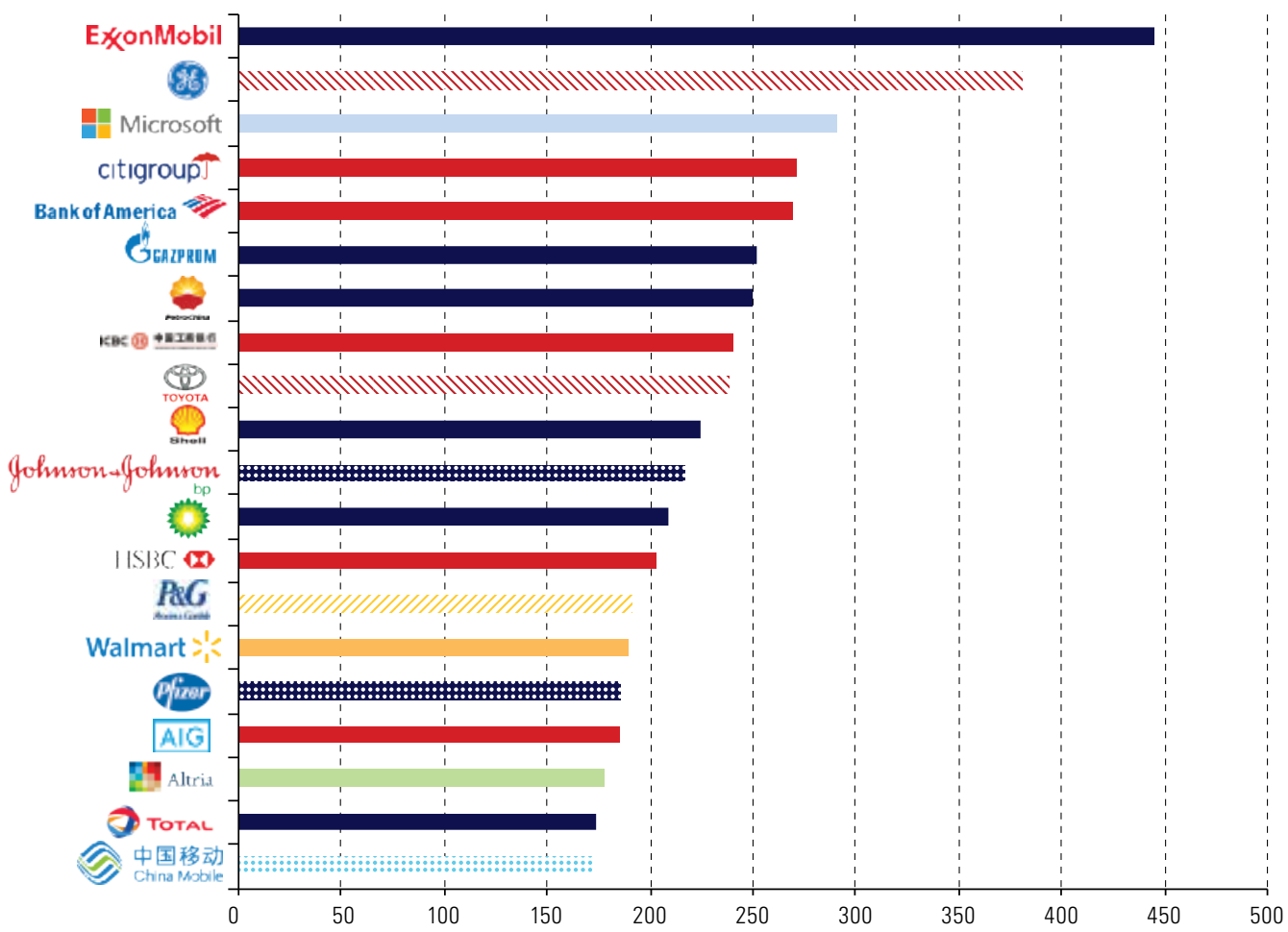

B. 2017

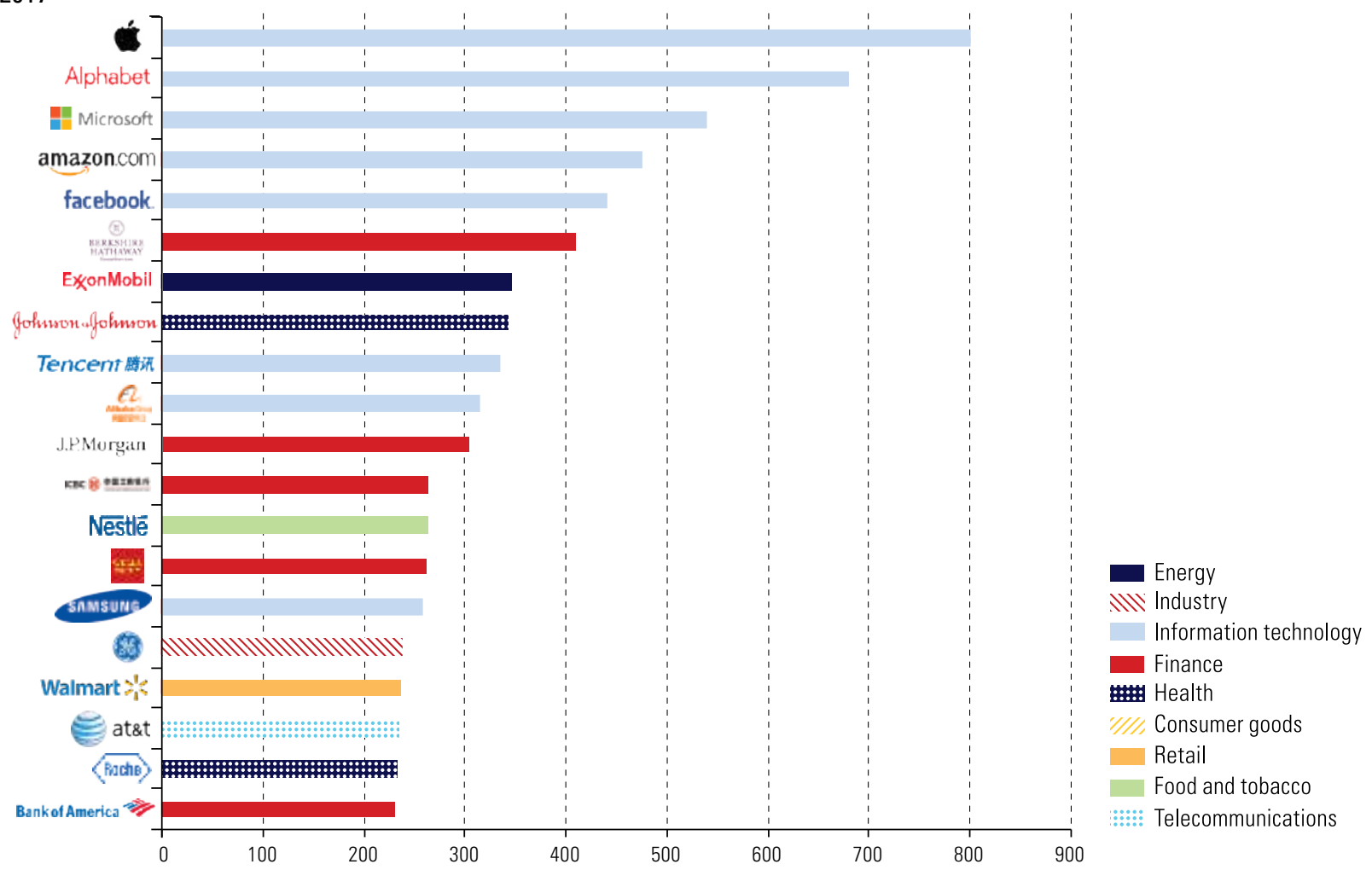

Source: Economic Commission for Latin America and the Caribbean (ECLAC), on the basis of data from Bloomberg (date of reference: March 2017). 
Meanwhile, technology firms feature prominently in terms of revenue and profitability among the world's 100 biggest public companies (Forbes, 2017). Most notably, their profits are similar to those of large financial firms and exceed those of the major energy and oil corporations, although these have been affected by lower commodity prices.

Digital platforms start out locally; however, as they expand and diversify, they move into the international market, meaning that national borders are irrelevant in terms of transactions and use. The United States has the largest number of digital platforms (led by Apple, Alphabet, Facebook, Amazon, Uber and Microsoft), with a total market capitalization of US\$3.2 trillion. Asia has the second-largest concentration, with platforms valued at US\$ 854.7 billion, including the Chinese firms Alibaba and Tencent. Europe has platforms valued at US\$ 128 billion, led by SAP, a German multinational that designs business management software. The other regions trail behind (see figure II.6). ${ }^{13}$ Nevertheless, the platform model offers Latin American companies greater opportunities for participation compared with the previous paradigms. In 2017, the region had more than 5,000 technology companies, coined tecnolatinas, ${ }^{14}$ of which the top 123 have a combined value of more than US\$ 37 billion. There are nine unicorns (new companies with a value exceeding US $\$ 1$ billion each), all of which started as small businesses around the time of the 2001 dot.com crash.

Figure II.6

Market capitalization of digital platforms, by region, 2016

(Dollars)

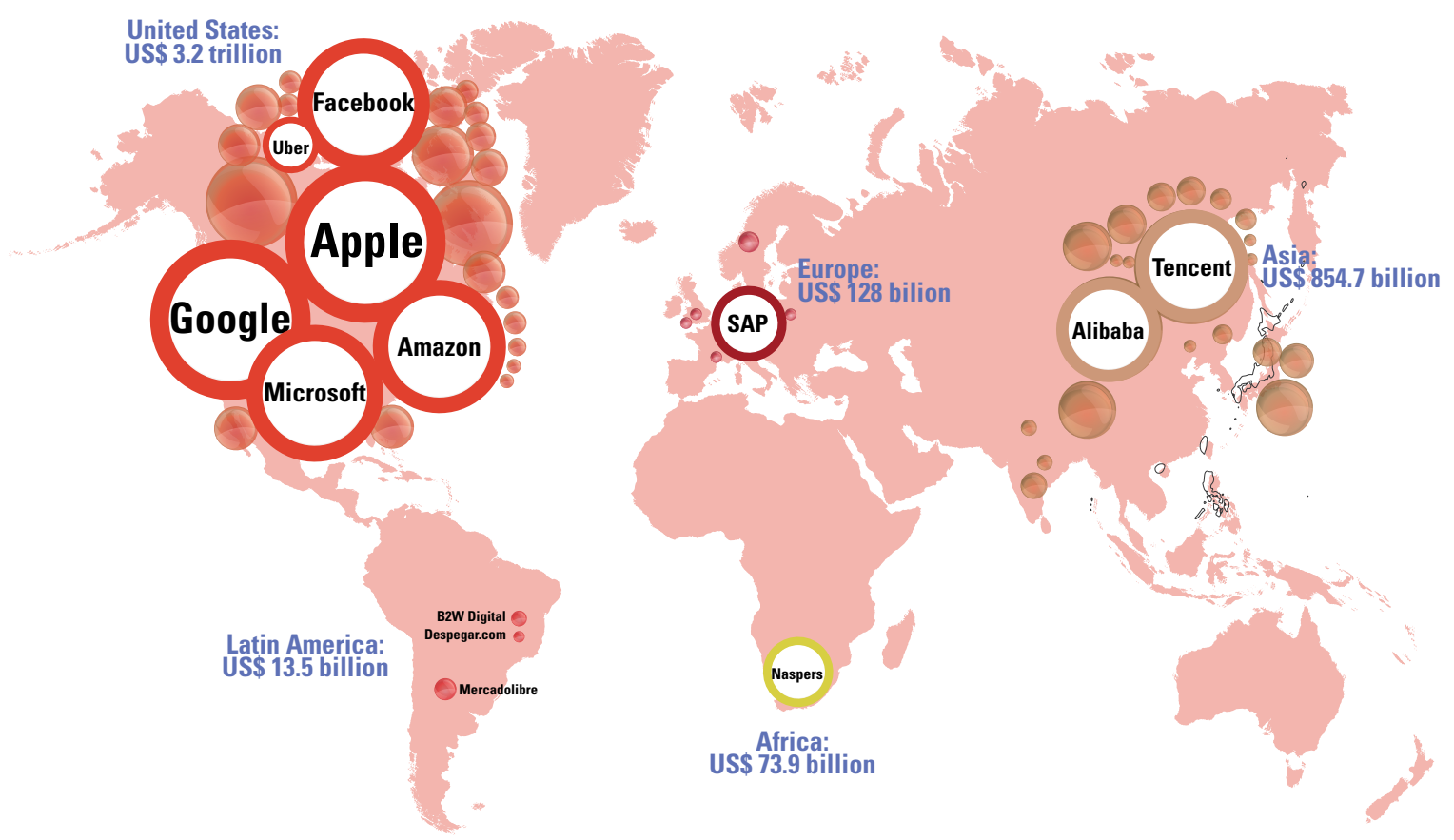

Source: Economic Commission for Latin America and the Caribbean (ECLAC), on the basis of specialized non-official sources.

13 In Africa, the leader is Nasper, a South African company providing entertainment and Internet services, which are valued at almost US $\$ 74$ billion on that continent. Lastly, platforms based in Latin America are valued at US\$ 13.5 billion, the most prominent being Mercado Libre (an Argentine online marketplace), B2W Digital (a Brazilian online retail firm) and Despegar.com (an online travel agency founded in Argentina).

14 Tecnolatinas are defined as technology-based, privately-owned start-ups that are born and based in the region. Of the 123 companies mentioned, only those valued at more than US\$ 25 million are considered to be tecnolatinas. (Arrieta and others, 2017). 
The primary revenue drivers of the five technology giants with the highest market value (Apple, Alphabet, Microsoft, Amazon and Facebook) are hardware, e-commerce and online advertising (the basis for free online services), which made up $76 \%$ of their total revenues in 2016 , and to which software and cloud computing services have been added (Visual Capitalist, 2017). Global digital platforms are the biggest players in the markets in which they operate. ${ }^{15}$ Beyond that market power, in the future the most important developments in the field will be innovations linked to cloud computing, the use of big data and artificial intelligence, which will affect data services in multiple industries.

The new economy is changing the rules and limits of the market, affecting competition and challenging regulatory models. The value of data is not clearly understood by consumers, who willingly hand over information in exchange for a free online service, or by many companies, which are unaware of the specific importance of data and still less how to manage them. Meanwhile, there are companies that specialize in managing data, in extracting information and more particularly in creating artificial intelligence. In these areas, the use of data does not have diminishing returns, as more information is needed to improve the accuracy of predictive algorithms and learning ability of that technology. This poses policy challenges not only with regard to competition but also privacy, security and equity when accessing these key resources of the new economy.

Concerns have been voiced in the United States about how power is being concentrated in the hands of the technology giants. The criteria for authorizing acquisitions and mergers are also being reviewed, moving beyond company size and market share towards an assessment of the type of assets held by the companies involved and transaction impact analysis. In addition, mechanisms to give consumers greater control over their data, by promoting data location systems and restricting data flows by type, are being examined.

In Europe, regulators have already taken some measures. During his State of the Union address, the President of the European Commission announced that a proposal will be presented to establish common tax rules for the digital industry by the end of 2018 (European Commission, 2017). At the same time, the finance ministers of several European Union economies have called for the introduction of a turnover tax to reform the tax rules throughout the bloc, so that online companies pay taxes where they generate their revenues and not where they are domiciled (Europost, 2017). ${ }^{16}$

These steps show that there is a growing debate about regulations covering areas ranging from competition laws to taxation, including privacy and security issues, as well as technological standards. This already complex topic also requires international coordination to ensure a minimum level of consistency on matters that transcend geographical boundaries.

\section{World trade is still below its pre-crisis levels}

Global trade in goods - which since 1990 has accounted for an average of $80 \%$ of the world's gross trade in goods and services - suffered a dramatic drop in performance following the global economic crisis of 2008-2009. While its volume grew by an annual average of $6.3 \%$ between 2000 and 2007 , this figure was only $2.2 \%$ per annum for 2012-2016 and a sluggish $1.3 \%$ over the past year. ${ }^{17}$ Similarly, on average, trade expanded 1.7 times faster than global GDP during the pre-crisis period, but between 2012 and 2015 the two variables grew at the same pace and, in 2016, trade underperformed GDP (see figure II.7).

15 With regard to global online trade in 2016, Alibaba (27\% market share) and Amazon (13\%) stood out, with both dominating the market in their countries of origin. Facebook and Google raised about $60 \%$ of their total global revenues from digital advertising. Amazon was the world leader in cloud computing with more than $30 \%$ of the global market, followed by Microsoft, IBM and Google. With regard to operational systems, in February 2017, Windows had a market share of 38.6\%, followed by Google's Android with 37.4\%. Lastly, Google continues to dominate the search engine market in the United States and Europe, with a market share of more than $85 \%$, while Baidu leads in China.

16 Antitrust regulators fined Google US\$2.7 billion in June 2017 for abusing its dominant position as a search engine.

17 The analysis excludes 2008 and 2009 (the crisis years) and 2010 and 2011 (short-term recovery). 
Figure II.7

Annual variation in the volume of global trade in goods and in world GDP, and the ratio between them, 1981-2018 (Percentages and ratio)

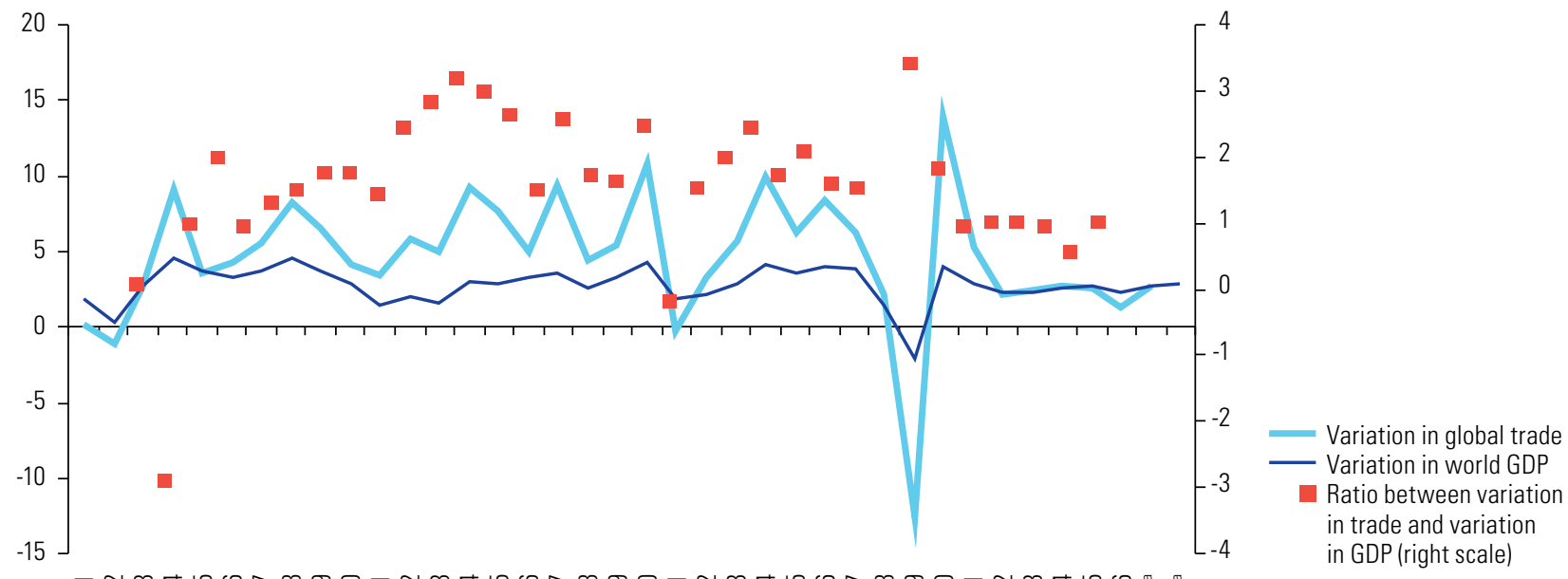

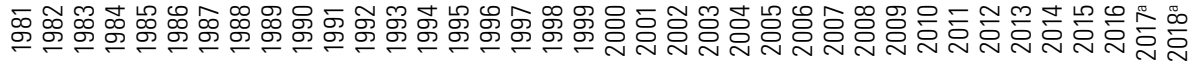

Source:World Trade Organization (WTO), World Trade Statistical Review 2017 [online] https://www.wto.org/english/res_e/statis_e/wts2017_e/wts17_toc_e.htm; and "WTO upgrades forecast for 2017 as trade rebounds strongly", Press Release, September 21, 2017 [online] https://www.wto.org/english/news_e/pres17_e/ pr800_e.htm.

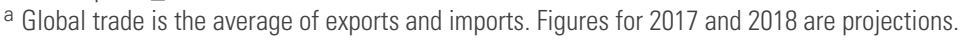

The most recent forecasts hint that the recovery in global trade will be more robust than was anticipated at the beginning of 2017. Trade was expected to expand by 3.6\%, after rising by $4.2 \%$ over the first half of 2017 , driven by increased growth in output —and, as a result, in the demand for imports - in the United States, the eurozone and China. Slightly slower growth (3.2\%) is forecast for 2018, owing to a higher baseline than in 2017 and the tighter monetary policy expected in the United States, the eurozone and China, exacerbated in the case of China by a less expansionary fiscal policy. In the medium term, China's demand for imports is also expected to cool, as the weight of services in the Chinese economy rises (from $43 \%$ in 2008 to $54 \%$ in 2017) at the expense of manufacturing, given the services sector's lesser demand for imports (WTO, 2017).

Notwithstanding this incipient recovery, world trade has still not returned to the levels seen between the late 1980s and the first half of the 2000s, a period that Auboin and Borino (2017) have called "the long 1990s". The factors most frequently offered as an explanation for the decline in world trade during the post-crisis period are weak global demand, a change in the composition of output, a slowdown in the expansion of global value chains and less trade liberalization, if not an outright increase in protectionism (ECB, 2016; World Bank, 2016; Constantinescu, Matto and Ruta, 2015; IMF, 2016; OECD, 2016).

In general, the literature agrees that the persistent weakness of the global economy is the main factor behind the slowdown in trade. This effect has been amplified by the fact that import-intensive components of aggregate demand - specifically investment- have performed poorly during the post-crisis period. It has therefore been argued that about $75 \%$ of the reduction in global goods import growth over the periods 2003-2007 and 2012-2015 was due to weak economic activity (IMF, 2016). In a similar vein, Auboin and Borino (2017) conclude that $80 \%$ of the slowdown seen in global trade between 2012 and 2015 can be explained by weak aggregate demand, adjusted for the import intensity of its components. These phenomena feed off each other, as weak trade exacerbates sluggish aggregate demand in each country, reducing opportunities to access larger markets and reduce costs, with negative consequences for investment decisions and consumption.

Most authors also agree that lower global trade growth in the aftermath of the crisis was partly attributable to a slowdown in the expansion of global and regional value chains (for example, Auboin and Borino, 2017; 
ECB, 2016; Constantinescu, Mattoo and Ruta, 2015; OECD, 2016). ${ }^{18}$ That phenomenon has several possible causes. One is that those chains have matured, as most of the efficiency gains associated with the geographical fragmentation of production processes that began in the 1990s have been exhausted. A second factor is that global supply chains have got shorter in some key economies, especially China, which now produces many inputs that it previously had to import, as can be seen in the 9-percentage-point drop (from $57 \%$ to $48 \%$ ) in the share of parts and components in Chinese non-oil imports since 2000 (see figure II.8) The third factor is the slower momentum of trade liberalization. For example, a number of countries, developed and developing alike, have introduced local content requirements in recent years, in an effort to encourage firms to produce and source locally rather than through imports (ECB, 2016).

In contrast to the pre-crisis period, when trade liberalization and expanding global value chains were strong drivers of world trade, in recent years those factors have been a drag on its growth. The "long 1990s" was a period of intensive trade liberalization and substantial FDI around the world. Milestones include the establishment of the European Single Market in 1993, the entry into force of the North American Free Trade Agreement (NAFTA) in 1994 and the World Trade Organization (WTO) agreements in 1995, and China's accession to WTO in 2001. The successive expansions of the European Union (especially the accession of 10 Central and Eastern European countries in 2004) and the liberalization processes undertaken since the 1990s by many developing countries, including several from Latin America and the Caribbean, were also important. All those factors contributed to the expansion of international production networks and, in general, to the strong growth in global trade seen over the two decades prior to the crisis.

Figure II.8

China: share of parts and components in total imports (excluding oil) from the rest of the world and selected partners, 2000-2016

(Percentages)

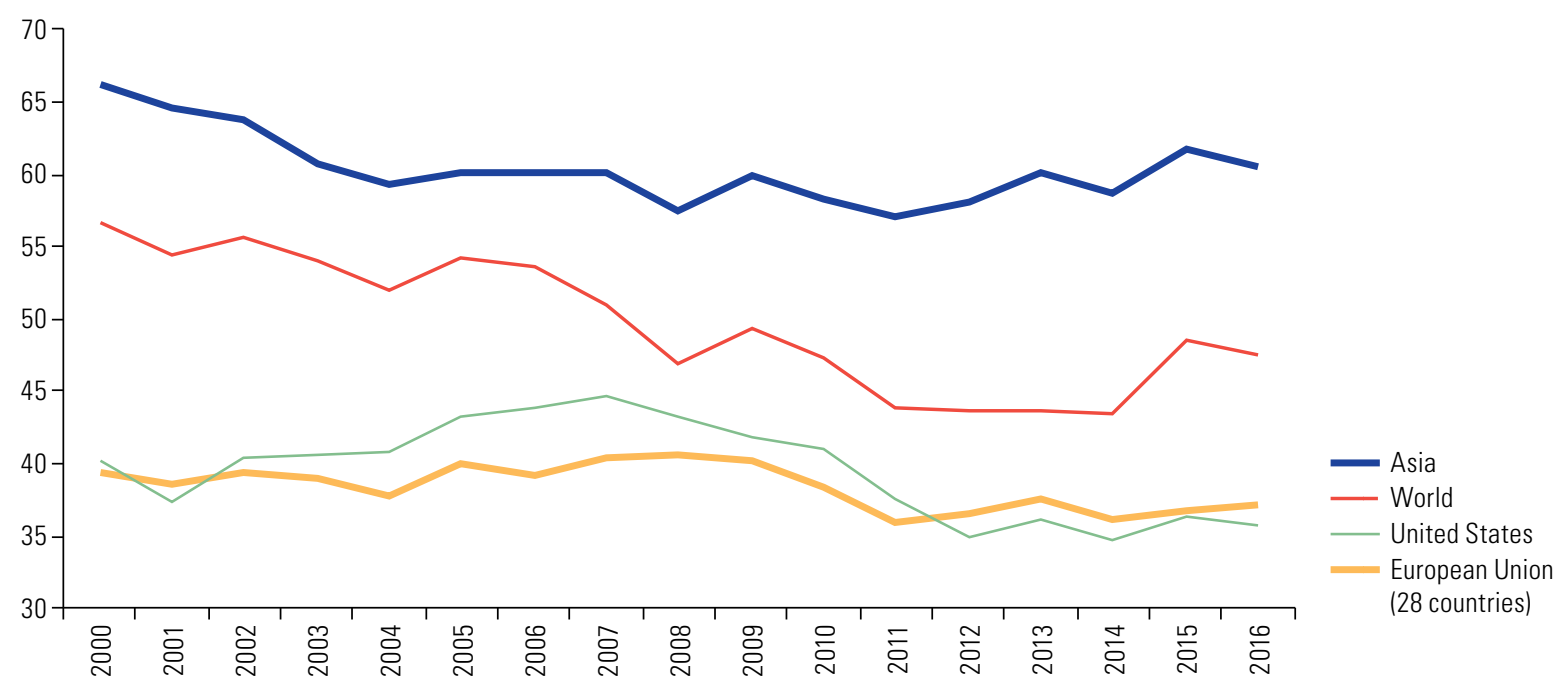

Source: Economic Commission for Latin America and the Caribbean (ECLAC), on the basis of information from the United Nations International Trade Statistics Database (COMTRADE).

Trade liberalization has slowed since the outbreak of the crisis. Two of the main trade initiatives launched during the current decade - the Trans-Pacific Partnership (TPP) and the Transatlantic Trade and Investment Partnership (TTIP) - were damaged by the drastic shift in United States trade policy under the current Administration. On the one hand, TTIP negotiations have been suspended since October 2016. On the other, after the withdrawal of the United States from TPP in January 2017, the agreement's other 11 signatories continued to negotiate a

18 The retraction of global value chains — proxied by the ratio of intermediate goods imports to final domestic demand at constant prices — is evidenced by the fact that they have contracted by an average of $1.7 \%$ a year since 2011, after expanding by an average of $4 \%$ per year between 1991 and 2011 (OECD, 2016). 
slightly modified version of the agreement, which led to the signature of the Comprehensive and Progressive Agreement for Trans-Pacific Partnership (CPTPP) ${ }^{19}$ in Santiago in March 2018. This was no small achievement, given the complex conditions facing global trade today. However, the absence of the United States means that the partnership will lack the economic and geopolitical weight of that the original TPP would have had. Therefore, its potential for setting new global standards would also be more limited. This is compounded by the difficulties facing WTO and the uncertainty caused by Brexit and the renegotiation of NAFTA. However, there is no consensus regarding the impact of reduced trade liberalization (or the rise of protectionism) on the performance of global trade in recent years, which is largely due to the difficulty of establishing precise and quantifiable metrics. In this regard, the OECD study (2016) concludes that the waning pace of trade liberalization could explain about 25\% of the reduction in trade growth over the period 2011-2015 compared to 1991-2007, while Auboin and Borino (2017) find that the effect of a potential increase in protectionism is small and statistically insignificant.

With regard to technology, continuous developments in automation, particularly in advanced economies, could undermine global trade growth over the coming years. Given that automation dilutes the labour-costreduction incentives to transfer production to developing countries, it puts a brake on the expansion of global value chains and, hence, on the associated trade.

Lastly, the statistics available today for measuring trade suffer from obvious limitations in an increasingly digital world economy. The emergence of digital platforms allows trade —including cross-border trade- in a growing range of services previously deemed to be non-tradable, as well as in digital goods such as e-books, video games and downloads of music and films. In some categories, digital goods have practically displaced their physical counterparts from the market. In those cases, the fall in "observable" trade (i.e. trade that physically crosses borders) could, at least partly, reflect an increase in digital trade, which available statistics are unable to capture accurately. Clearly, then, new methodologies are needed for measuring the digital trade in goods and services.

\section{E. Transnational corporations in search of high-quality assets}

Changes in globalization are also reflected in higher FDI flows. During the financial crisis, cross-border capital flows decreased substantially. After peaking in 2007, global cross-border capital flows —FDI, international purchases of shares and debt securities, loans and other investments - fell by $65 \%$ to US $\$ 4.3$ trillion, dropping from $23 \%$ to $7 \%$ of global GDP, in relative terms. This collapse reflected the steep reduction in short-term bank loans, which led to a restructuring of these flows' components. As a result, FDI and share purchases became the main component, increasing from 36\% to 69\% of global flows between 2000-2007 and 2008-2016 (McKinsey Global Institute, 2017).

Despite this decrease, financial globalization continues apace: banking systems remain highly interconnected and transnational corporations continue to conduct transactions. Thus, the stock of cross-border capital relative to global GDP has changed little since the peak of transnational capital expansion in the pre-crisis period, with the ratio between the two barely down from 185 to 183 between 2007 and 2016.

In this new scenario, the shift in FDI flows was due to two factors: (i) the increase in mergers and acquisitions by firms seeking to build in technological capabilities and combine traditional activities with technological subsectors; and (ii) the surge in transnational investments by Chinese companies in their current expansion phase. Both factors reduced FDI flows to developing economies and boosted investment in advanced economies.

19 The main difference between TPP and CPTPP is the suspension of 22 provisions that originally reflected United States demands in relation to intellectual property and investment, which the other parties had resisted. 


\section{The return of capital to advanced economies}

Compared to other transnational flows, FDI tends to be less volatile, since it reflects long-term business investment decisions seeking natural resources, access to markets, greater operational efficiency or strategic assets (Dunning, 1998).

Natural-resource-seeking investment is widespread in developing economies and its evolution is linked to the commodity price cycle. Market- and efficiency-seeking investments surged in the wake of the common markets created by regional integration agreements and lower transport and transaction costs resulting from technological advances. The relocation of production to markets with lower costs, which began in the 1970s and picked up pace in the 1990s, accelerated further during the 2000s as a result of digital technologies and a global financing and marketing system that allowed major transnational companies to build complex global value chains, in which locations were chosen on the basis of not only cost advantages, but also the availability of strategic assets. Thus, value chains were created not only in the sectors such as textiles and electronics, which traditionally located their assembly operations in places with competitively advantageous labour costs, but also in more complex industries.

In recent years, as the technological revolution has gathered speed, the pressure to innovate and access strategic assets has intensified, leading to greater flows of FDI in search of high-quality assets, such as patents and highly skilled human resources, which are more widely available in developed economies, particularly the United States, Western Europe and East Asia. Latin America and the Caribbean as a region lags far behind (ECLAC, 2017).

These shifts are reflected in the changes in global FDI flows seen in the past 25 years. The first big increase occurred during the 1990s, with the majority of investments going to developed economies (68\% of the total). Flows grew substantially again in the 2000s, and although developed economies took a somewhat smaller percentage, they continued to receive the lion's share (64\%). Income growth in developing countries and the upturn in the commodity price cycle encouraged transnational companies to invest in emerging markets. The international financial crisis of 2008 also had a major effect on FDI flows to developed economies, allowing developing countries to increase their share as recipient markets and even, in 2014, to overtake the developed economies in this regard for the first time, which at the time was interpreted as a paradigm shift. However, over the last two years, the advanced economies have regained the lead, receiving $59 \%$ of total global FDI flows in 2016, while 37\% went to developing economies (see figure II.9).

Global FDI flows amounted to US\$ 1.75 trillion in 2016 . While this figure reflects a $2 \%$ drop compared with 2015, it is still higher than previous years and is only $8 \%$ lower than the peak attained in 2007. Thus, it is evident that transnational corporations' transactions are still crucial to financial globalization.

FDI to developed economies grew by $5 \%$ in 2016, while inflows to developing economies fell by $14 \%$. Asia saw the sharpest drop (15\%), followed by Latin America and the Caribbean (down $8 \%$ ), while Africa saw the smallest fall (3\%). The main reasons for these decreases were the sluggish performance of the world economy (with some Latin American countries even sliding into recession), the slow recovery in commodity prices, increasing technological sophistication and the expansion of the digital economy. Against that backdrop, transnational corporations in search of strategic assets are more likely to invest in developed countries. Thus, the European Union and the United States were the top recipients of FDI; inflows to the United States, the world's largest recipient and investor, increased by $12 \%$ in 2016 , an all-time high, while flows into European Union countries jumped by $17 \%$, largely as a result of major mergers and acquisitions that took place in the United Kingdom and greater inflows to the Netherlands, Belgium and Italy.

The shifts in FDI over the last two years may be interpreted as a change in investors' strategies and a reflection of the march of digital globalization. Capital flows are no longer moving to countries with lower costs in search of greater efficiency, but instead are driven by companies with high liquidity seeking strategic assets, which are key in a period of profound technological change. Mergers and acquisitions of high-tech targets have increased substantially. In 2015 and 2016, high-tech companies accounted for $20 \%$ of the total value of transactions, in 2013-2014 they accounted for 14\%. Furthermore, between 2012 and 2016, the percentage of all high-tech deals involving non-technological companies increased from $61 \%$ to $70 \%$, as companies in 
traditional sectors responded to the need to incorporate digital economy capacities (BCG, 2017). Convergence, digital platforms' high liquidity and their diversification into other sectors, and the recruitment of talent have driven cross-border mergers and acquisitions in high-tech sectors. The sectors most targeted are artificial intelligence, cloud computing, cybersecurity and big data, while the finance and health sectors are perhaps the areas with greatest potential for convergence today, as the automotive industry and consumer sector have already moved into the mainstream (Baker McKenzie, 2017a).

Figure II.9

Global FDI flows and share by economy groupings, 1990-2016

(Trillions of dollars and percentages of total flows)

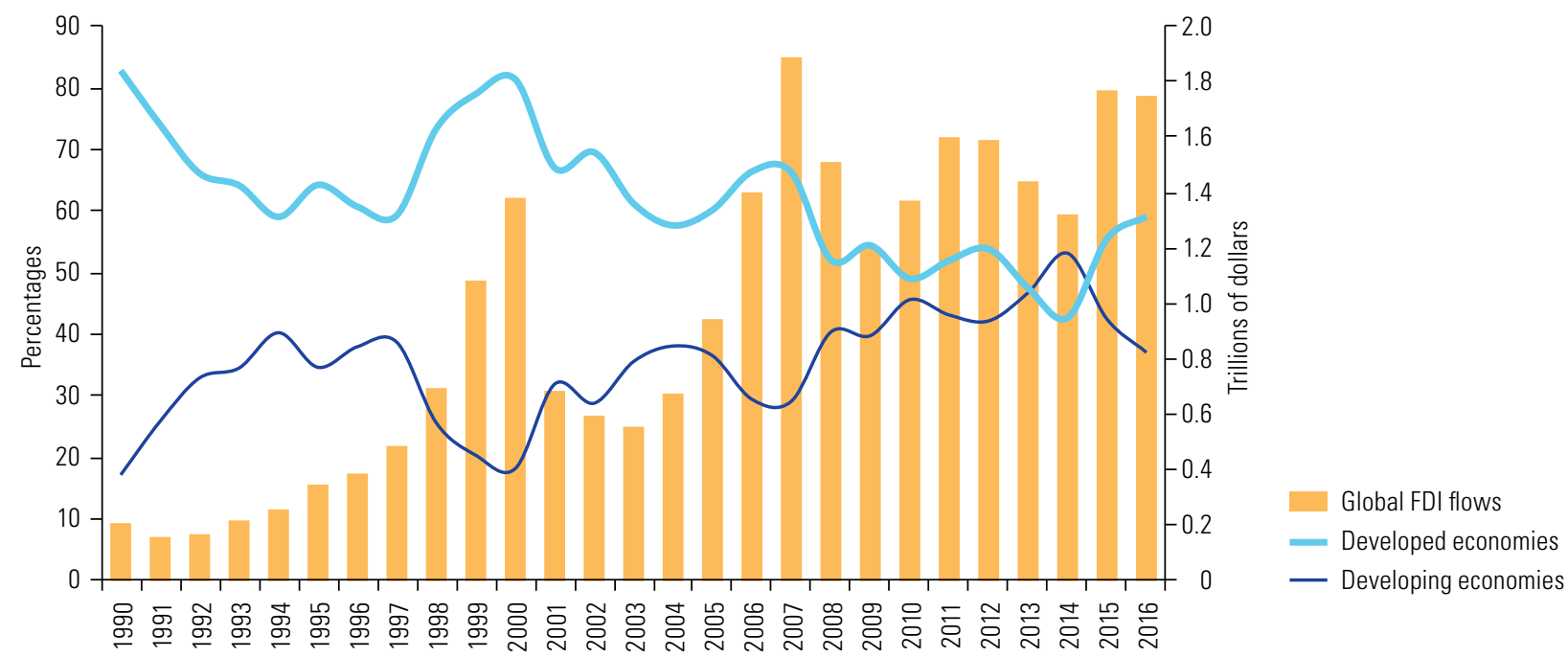

Source: Economic Commission for Latin America and the Caribbean (ECLAC), on the basis of United Nations Conference on Trade and Development (UNCTAD), World Investment Report 2017: Investment and the Digital Economy (UNCTAD/WIR/2017), Geneva, 2017.

\section{China is consolidating its position as an investor}

There are three types of FDI. The first type is greenfield investment to develop new projects that are expected to create production capacity. Second are funds for acquisitions or mergers with established companies, which are more likely to be associated with changes in firms' capacities, business models and technologies. A third type of FDI is investment that enters a country before being reinvested in a third market, associated mainly with financial centres that offer tax advantages. ${ }^{20}$ As these investment funds later enter other economies, it is difficult to analyse cross-border flows by real countries of origin in this case.

Mergers and acquisitions allow purchasing companies to quickly acquire knowledge, technological capacity, brands, a client base and market access. This means that the target companies of such transactions are primarily in advanced economies, where owning part of an existing company offers greater opportunities for proximity to the technological frontier. Thus, while Latin America and the Caribbean, Africa and China each receive around $10 \%$ of total global investment, cross-border mergers and acquisitions accounted for smaller percentages, ranging from $3.7 \%$ in China to $1.8 \%$ in Africa (UNCTAD, 2017). Global flows associated with cross-border mergers and acquisitions have grown steadily in recent years (see figure II.10). Their value increased by $18 \%$ in 2016 , mainly due to transactions in developed economies, which accounted for $91 \%$ of asset sales.

While most mergers and acquisitions originate in advanced economies ( $81 \%$ of the total in 2016), in recent years, Chinese companies have emerged as major global buyers, accounting for $11 \%$ of the total value of purchases, doubling their 2010 share (6\%) (see figure II.11).

20 In 2016, FDI stock reached 8,231\% of GDP in Luxembourg, 576\% in the Netherlands, 574\% in Hong Kong SAR and 447\% in Ireland (McKinsey, 2017). 


\title{
Figure II.10
}

Net value of global cross-border mergers and acquisitions, 2005-2016

(Trillions of dollars)

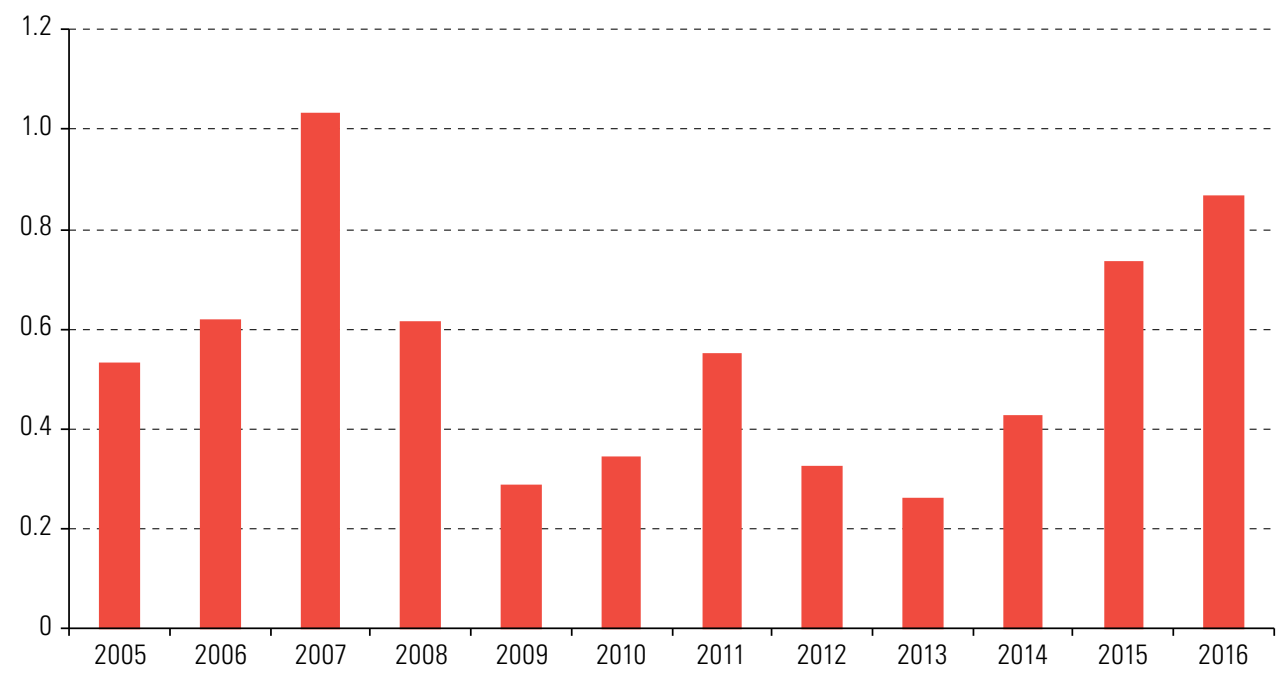

Source: Economic Commission for Latin America and the Caribbean (ECLAC), on the basis of information from United Nations Conference on Trade and Development (UNCTAD), World Investment Report 2017: Investment and the Digital Economy (UNCTAD/WIR/2017), Geneva, 2017.

Figure II.11

Share of net cross-border mergers and acquisitions, by value, by country or region, 2016 (Percentages)

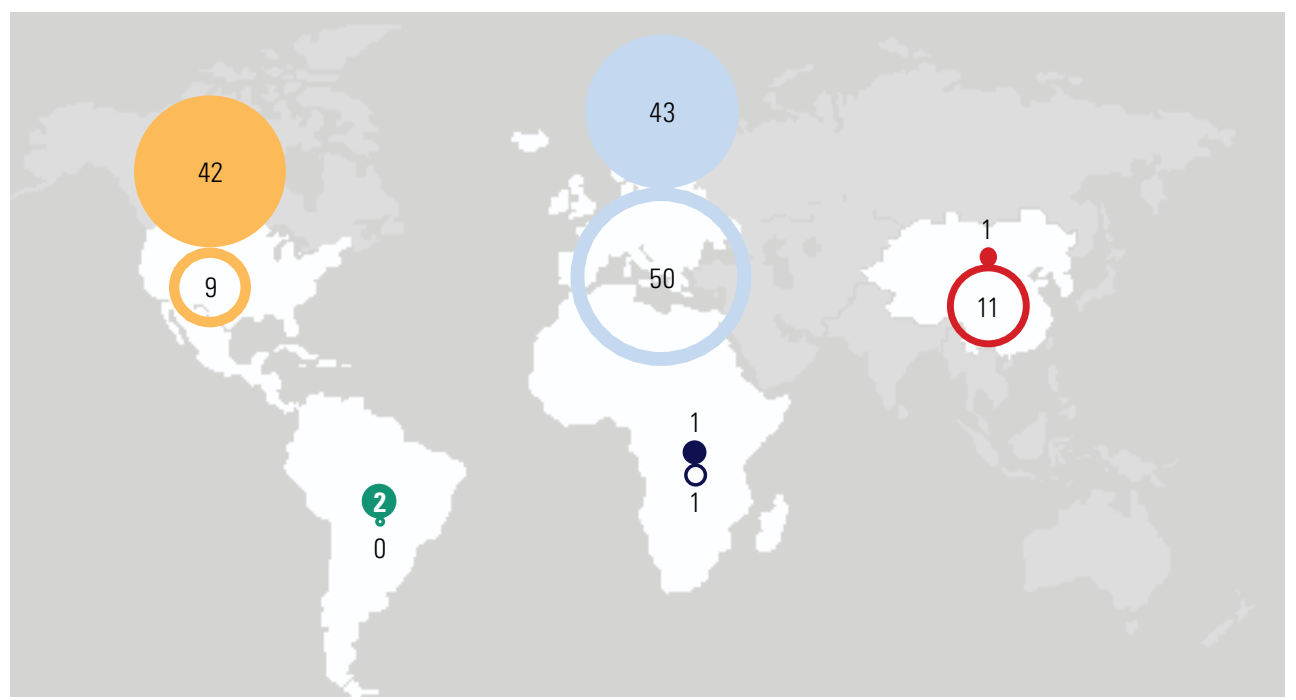

\author{
- United States purchases \\ - United States sales \\ - Europe purchases \\ - Europe sales \\ - Latin America and \\ the Caribbean purchases \\ o Latin America and \\ the Caribbean sales \\ - Africa purchases \\ - Africa sales \\ - China purchases \\ o China sales
}

Source: Economic Commission for Latin America and the Caribbean (ECLAC), on the basis of information from United Nations Conference on Trade and Development (UNCTAD), World Investment Report 2017: Investment and the Digital Economy (UNCTAD/WIR/2017), Geneva, 2017.

Recent developments in outward investment by multinational Chinese corporations have also helped to position China among the global geopolitical and economic leaders. Its share of FDI outflows has grown steadily since the mid-2000s, up from $1.3 \%$ of global outflows in 2006 to $12.6 \%$ in 2016 . This is equivalent to a record US\$183.1 billion, propelling China to the position of second largest home country for FDI, after the United States (see figure II.12). 
Figure II.12

United States and China: share of global FDI inflows and outflows, 2006-2016

(Percentages)

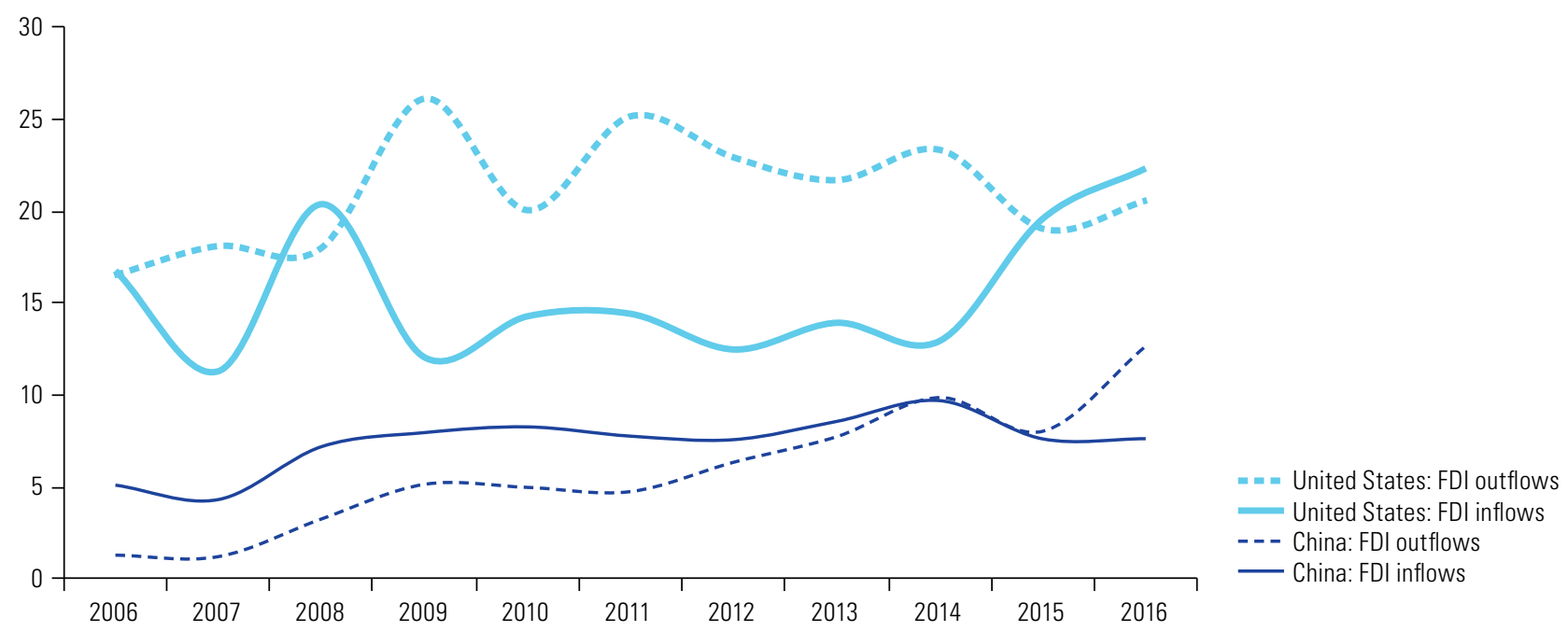

Source: Economic Commission for Latin America and the Caribbean (ECLAC), on the basis of information from United Nations Conference on Trade and Development (UNCTAD), World Investment Report 2017: Investment and the Digital Economy (UNCTAD/WIR/2017), Geneva, 2017.

There are three factors behind this expansion. First, a large trade surplus that supports low-interest lending, mainly by public banks. Second, companies find it difficult to maintain high profits in their domestic market, pushing them to undertake cross-border transactions. Third, China is looking to take on a leading role in the new industrial and technology-based economy.

The majority of China's FDI outflows were spent on mergers and acquisitions, with target companies in the United States and Europe and, although transactions are sectorally diverse, higher-tech industries account for the largest share. Chinese transnationals have made major acquisitions in the hardware and consumer electronics, real estate and entertainment sectors in the United States. Meanwhile, Chinese investments in Europe have focused on information and communications technologies (ICTs), transport, energy and infrastructure and industrial equipment. Through these acquisitions, China has consolidated its position in the world economy by integrating itself successfully into the workings of increasingly sophisticated sectors, thereby joining the vanguard of the digital revolution.

This rate of expansion may not be sustainable in the near future. On the one hand, the Chinese monetary authorities have tightened controls on capital outflows to prevent negative impacts on the balance of payments, ease pressure on the national currency and slow the rising debt levels of some Chinese multinational companies. On the other hand, but in the same vein, acquisitions by Chinese companies, many of which have been supported by State banks or enterprises, have aroused concerns in Europe and the United States. In September 2017, the European Commission proposed a screening framework to examine FDI inflows to its member States to defend their strategic interests should they be threatened; ${ }^{21}$ meanwhile, many of the investigations undertaken by the Committee on Foreign Investment in the United States (CFIUS) have focused on transactions by Chinese companies. 
Analysis shows that foreign capital is increasingly being invested in the triad of advanced economies (the United States, Western Europe and East Asia). FDI flows still exceed those of the pre-crisis period and in the last two years inflows to developed countries have increased, mainly reflecting strategic-asset-seeking mergers and acquisitions as companies strive to join the rapid technological change that is driving the growth of the digital economy. Among the emerging economies, China is strengthening its position and following a strategy of mergers and acquisitions in high-tech sectors in countries such as the United States and Germany, in order to attain the front line of the capacities needed to drive the digital economy.

\section{F. Ineffective global governance}

In the last decade, the driving stakeholders, governments and institutions of globalization have come under pressure from a combination of factors, in particular those relating to international migration, global macroeconomic dynamics, the technological revolution, international trade, FDI and the environmental crisis. International governance cannot be strengthened through isolated national actions but calls instead for global agreements capable of strengthening the implementation of the 2030 Agenda through a renewed multilateralism engaging all stakeholders.

\section{Major international migratory flows}

International migrants made up 3.3\% of the global population in 2015, some 244 million people. ${ }^{22}$ One third of them lived in Europe, another third in Asia and the remaining third were scattered across North America, Africa, Latin America and the Caribbean (9 million) and Oceania. International migrants constituted a larger share of the population in relative terms in Oceania, North America and Europe than in Asia, Africa and Latin America and the Caribbean (1.5\%). Between 1990 and 2015, the number of international migrants worldwide rose by $60 \%$. After particularly strong growth between 2000 and 2010, when some 4.9 million migrants were added annually (compared to 2 million per year between 1990 and 2000), migration flows slowed slightly, down to 4.4 million per year between 2010 and 2015 (United Nations, 2016).

After 2000, Asia received more migrants than any other region. In 2015, Asia-to-Asia was the largest regional migration corridor in the world (59 million international migrants). Europe-to-Europe was the second largest regional corridor (40 million international migrants). The corridor from Latin America and the Caribbean to North America was the third largest, with nearly 25 million international migrants. However, the average number of migrants arriving annually through this corridor declined steadily, from 0.8 million between 1990 and 2000 to 0.3 million between 2010 and 2015 .

In 2015, over $51 \%$ of all international migrants in the world were living in just a few countries: the United States, Germany, the Russian Federation, Saudi Arabia, the United Kingdom, the United Arab Emirates, Canada, France, Australia and Spain. Between 1990 and 2015, the largest increases in migrant stock occurred in the United States, the United Arab Emirates, Germany, Saudi Arabia and Spain. Five of the 10 main bilateral migration corridors had a developed country as destination, with the Mexico-to-United States corridor seeing the largest gains, on average around 240,000 additional migrants per year. Other major corridors were between Southern Asian countries and oil-producing countries of Western Asia. Between 2010 and 2015, migration patterns changed significantly: only one of the world's largest migration corridors terminated in a country in the developed regions, namely Mexico-United States. The other nine ended in a developing country. Several of the destinations recording the largest increases in international migrant numbers were oil-producing countries in Western Asia. In addition, the conflict in the Syrian Arab Republic has led to a large increase in the number of refugees living in neighbouring countries, in particular Jordan, Lebanon and Turkey, as well as in European countries, notably Germany and Serbia.

22 International migrants are persons living in a country other than where they were born or who identify themselves as foreign nationals. 
During the 1990s, net migration overtook natural increase as the primary driver of population growth in the developed regions, and is expected to be the sole engine of growth by the 2020s. By the 2040s, population growth in those regions is projected to be negative, with positive net migration no longer able to compensate for the higher number of deaths than births. In the developing regions, population growth is expected to decelerate between 2000 and 2050, mainly as a result of a slowdown in natural increase caused by the falling fertility rate. While, in general, the impact of migration on the size of the population in these regions will be relatively small, it is expected to be quite significant in some countries, especially those with smaller populations.

Because international migrant flows tend to comprise principally working-age persons, positive net migration can reduce the old-age dependency ratio (persons aged 65 or older for every 100 persons aged between 15 and 64), which is commonly used to assess the potential social and economic costs associated with population ageing. According to United Nations projections, that ratio will increase by $71 \%$ in the developed regions between 2015 and 2050. Assuming zero net migration, the ratio would rise $87 \%$. While international migration is expected to have a noticeable impact on dependency ratios in certain situations and periods, it is unlikely to reverse the long-term trend towards population ageing.

The international normative framework on international migration includes instruments pertaining to the human rights of all migrants, the rights of migrant workers and the protection of refugees, as well as instruments designed to combat migrant smuggling and human trafficking. Overall, ratification rates for instruments relating to migrant rights are lower than those for other migration-related instruments in all regions. Latin America and the Caribbean had the highest percentage of countries that had ratified at least one migrant rights instrument, while the North American countries have not ratified any (United Nations, 2016).

\section{The need for a new financial architecture}

The 2030 Agenda for Sustainable Development, the Addis Ababa Action Agenda on financing for development, the Sendai Framework for Disaster Reduction and the Paris Agreement on climate change will all require an profound shift in the pattern of development, which in turn will need a vast mobilization of resources, together with changes in the way those resources are financed, organized and allocated.

To achieve this, further efforts are needed to pursue the global governance reform launched by the international finance institutions to increase the proportion of members and voting rights of developing economies. In September 2016, IMF added the yuan to the special drawing right (SDR) currency basket. In addition, the Government of the United States approved the reform of the IMF quota system proposed in 2010, which took the unprecedented step of doubling quotas for the 188 member countries and reallocated $6 \%$ of quotas from developed countries to emerging and developing economies. This reform gives greater decision-making power to and more weight to the vote of some of the largest emerging and developing economies - Brazil, China, India and the Russian Federation - which have now entered the list of the Fund's 10 largest members. IMF also preserved the quota and voting share of the poorest member countries (those with per capita GDP below US\$1,135 in 2008). Lastly, the reform proposed increasing the quotas for emerging and developing countries.

In 2008, the World Bank launched a reform process to increase developing countries' representation, recognizing that "the distribution of shareholding is important for the legitimacy of the institution". In 2010, developing countries' share increased to $47.19 \%$ from $44.06 \%$ in 2009. In September 2015, the Bank's shareholding review acknowledged the growing share of developing and transition countries in the world economy and, in line with this, the voting share of developing countries is expected to increase to $52.76 \%$.

These developments are important, but insufficient. It is becoming increasingly clear that the international financial system must be made compatible with efforts to mobilize the resources needed for the 2030 Agenda. In that connection, ECLAC (2016a) noted that greater representation and decision-making power for the 
developing countries in international financial institutions (given their greater weight in the global economy) amounted to a global public good. This would also need to be complemented by other public goods, such as coordinated fiscal, exchange rate and financial policies and, in particular, international action to reduce tax evasion and avoidance, issues that are discussed in chapter III.

\section{The weakening of multilateralism in international trade}

The digital revolution poses unprecedented challenges for the regulation of global trade. The trade agreements of the 1990s are not up to the task of governing today's exponentially expanding cross-border digital flows. The digital platforms, infrastructure, innovation systems and institutions of the new paradigm will determine competitive advantages in this new industrial era and, consequently, global hegemony in coming years.

While the traditional industrial policy space has been much reduced by WTO agreements and North-South trade and investment arrangements, the digital economy remains largely unregulated. This means that governments have room to implement measures such as blocking specific Internet sites, imposing network location server requirements or compelling foreign providers to reveal the source code of their software. Actors such as China, the United States and the European Union are competing to influence the regulation of global digital trade, with widely divergent visions and models.

Partly in response to the emergence of the digital economy and e-commerce, several megaregional (so called because of their magnitude) trade negotiations were opened in the first half of the present decade. These were the Trans-Pacific Partnership (TPP) and the Transatlantic Trade and Investment Partnership (TTIP) and the Regional Comprehensive Economic Partnership (RCEP). Although different in several ways, these three agreements were all multilateral in nature, their signatories accounted for a significant share of the world economy and population, and they covered a broad thematic agenda (ECLAC, 2016a). These were the first generation of trade agreements that, in addition to liberalizing traditional trade and investment flows, sought (to varying degrees) to liberalize and regulate digital flows. Given their scale, and the involvement of the major players in the digital economy, the megaregional negotiations offered the opportunity to establish de facto global standards for e-commerce, particularly in the light of the deadlock in the Doha Round of trade negotiations. In fact, one of the most notable features of TPP was its emphasis on regulating the digital economy, and this continues to be the case with the successor of TPP, the Comprehensive and Progressive Agreement for Trans-Pacific Partnership (CPTPP). This was originally in response to the United States' interest in maintaining its advantage over emerging competitors, particularly China, given that country's aggressive digital industrial policy (Azmeh and Foster, 2016) and achievement of a leading role in the hierarchy of the global digital economy that challenged the United States' pre-eminence.

The entry into office of a new Administration in the United States in January 2017 seriously disrupted ongoing efforts to redefine global trade governance. The United States' new trade policy, known as America First, is characterized by an openly protectionist discourse; a shift from multilateralism to bilateralism or even unilateralism; an approach that prioritizes the reduction of trade deficits over any other objective; and various efforts to reshore industries and jobs by renegotiating trade agreements, repealing environmental regulations and adopting a tax reform that came into force in December 2017 (see box II.1).

Another important change concerned Internet neutrality. In December 2017, the Federal Communications Commission agreed to repeal net neutrality regulations adopted in 2015 that, in principle, prohibited Internet providers from blocking legitimate traffic, throttling Internet speeds and prioritizing paid services, and reclassified Internet services as public utilities. The Administration justified the change on the basis that such regulations have a negative effect on investment, innovation and the emergence of new business models. However, given the structure of this market, the changes could also adversely affect consumers, on whom operators may now impose additional charges based on the quality and speed of online services. Smaller online service providers (such as e-commerce retailers) could also be affected as, unlike larger companies, they may not be able to afford preferential treatment for their content, exacerbating Internet asymmetry. 


\section{Box II.1}

The United States' new tax reform

On 1 January 2018, the Tax Cuts and Jobs Act -the largest and most comprehensive federal tax reform since 1986- came into effect. This new fiscal framework fundamentally changes the corporate tax structure by reducing the corporate tax rate from $35 \%$ to $21 \%$. It also includes provisions for a one-time repatriation tax $(15.5 \%$ on liquid assets and $8 \%$ on illiquid assets) to encourage companies to bring back nearly US\$ 3 trillion of corporate assets currently held overseas, mainly in Europe, and for making the United States a territorial tax system. The Tax Cuts and Jobs Act is expected to provide a powerful stimulus for the technology, manufacturing, pharmaceutical, automotive, financial and telecommunications sectors. The overarching objectives of the new tax regime are to reshore firms, jobs and intellectual property, to encourage foreign and domestic investment, and to raise fiscal revenue. The Act also adjusts individual income tax rates.

The macroeconomic impacts of the new fiscal framework are still unclear, given that the tax stimulus may add more than US\$ 1 trillion to the national deficit over the next 10 years, a cost that could be offset by projected GDP growth of anywhere between $0.7 \%$ and $5 \%$ (Joint Committee on Taxation, 2017; CEA, 2017b). This potential increase in the national debt -already close to US\$20 trillion-to the highest levels since World War II (Appelbaum, 2017) also raises concerns about its sustainability. The Tax Cuts and Jobs Act is the first of many legislative reforms expected in the near future, which include a broad infrastructure plan, an overhaul of social safety net programmes and deregulation across many sectors.

Source:Economic Commission for Latin America and the Caribbean (ECLAC), on the basis of Joint Committee on Taxation, Macroeconomic Analysis of the Conference Agreement for H.R. 1, the Tax Cuts and Jobs Act, Washington, D.C., 22 December 2017 [online] https://www.jct.gov/publications. html?func=startdown\&id=5055; Council of Economic Advisers, The Growth Effects of Corporate Tax Reform and Implications for Wages, Washington, D.C., October 2017 [online] https://www.whitehouse.gov/sites/whitehouse.gov/files/images/Corporate\%20Tax\%20Reform\%20and\%20 Growth\%20Final.pdf; and B. Appelbaum, "Debt concerns, once a core Republican tenet, take a back seat to tax cuts", New York Times, 1 December 2017 [online] https://www.nytimes.com/2017/12/01/us/politics/tax-cuts-deficit-debt.html.

The main megaregional negotiation to have survived the dramatic shift in the United States' trade policy is the Regional Comprehensive Economic Partnership (RCEP), which covers the 10 member countries of the Association of Southeast Asian Nations (ASEAN), Australia, China, India, Japan, New Zealand and the Republic of Korea. If concluded successfully, this process will create a free trade area with a membership covering half of the world's population, 38\% of its GDP (measured in purchasing power parity), $31 \%$ of global goods exports and $26 \%$ of imports. However, there are a significant number of hurdles to overcome first. Most of these stem from the marked differences in the parties' levels of development and, thus, in their negotiating positions (Cook and Basu Das, 2017).

The uncertainty surrounding the megaregional agreements has implications for the regulation and structure of the global economy. First, it highlights the lack of consensus among the major global actors on how to regulate trade in goods and services and the emerging sectors of the twenty-first century. This hinders regulatory convergence and the modernization of the WTO framework. Second, it has sapped the momentum of the wide-ranging economic integration projects between the United States, Latin America and the Caribbean and the Asia-Pacific region (TPP), and between the United States and the European Union (TTIP). The greatest degree of economic integration that could be achieved in the medium term is in the Asia-Pacific region, under RCEP, if the parties can overcome their difficulties.

The absence of multilateral regulatory frameworks has led countries to adopt piecemeal standards based on national priorities, particularly with regard to trade, investment and technology. After being the leading advocate of trade liberalization for seven decades, the United States has set out in the opposite direction, the consequences of which are still difficult to foresee. That shift does not yet appear to mark a turning point in the process of trade liberalization that the world has undergone over the past three decades. In fact, the other major global economies, particularly the European Union, China and Japan, have publicly reiterated their commitment to openness and multilateralism. However, there is no doubt that there is considerable uncertainty surrounding global governance, which can only be remedied by a stronger and more equitable multilateralism framework that responds to the most pressing needs of the twenty-first century. 


\section{Settling investor-State disputes}

Foreign investment is another fundamental aspect of globalization in which current controls are seriously flawed. In recent years dissatisfaction has been growing with the existing international investment agreements regime, which are argued to favour the rights of foreign investors over host countries' right to regulate in the public interest and in pursuit of sustainable development (UNCTAD, 2015). This discussion has gained currency as a result of events such as the global financial crisis, which led many governments to take more interventionist stances on economic matters.

The compression of States' regulatory space is exacerbated by the inclusion in many investment agreements of investor-State dispute settlement (ISDS) mechanisms that allow foreign investors to sue host countries directly in international tribunals if they believe that their rights under the agreement have been breached. Since the mid-1990s, foreign investors have made increasing use of these mechanisms, with over $80 \%$ of cases in this period initiated by transnational corporations from developed countries.

The main criticisms of dispute settlement mechanisms are: (i) that the host country might refrain from enacting regulation in the public interest for fear of being sued (regulatory chill); (ii) inconsistency between rulings on similar issues; (iii) the lack of right of appeal, meaning that it is impossible to correct any erroneous awards made by the tribunals; (iv) that the tribunals system discriminates against domestic investors who cannot go to international arbitration; ( $v$ ) the arbitrators' potential conflicts of interest; (vi) the opacity of the procedures; (vii) the high defence costs for host countries; and (viii) the excessive sums awarded as compensation to foreign investors (Herreros and García-Millán, 2017).

Many countries have responded to the concerns about ISDS mechanisms by amending their investment agreements. Some have made minor adjustments to the mechanism, while maintaining its basic structure (this was the approach followed in the negotiations relating to TPP and the Comprehensive and Progressive Agreement for Trans-Pacific Partnership). Others, such as India, have made prior recourse to domestic courts a precondition for international arbitration. More ambitious is the European Union's proposal to move away from the current ad hoc arbitration system, without right of appeal, to a system with a permanent Appeal Tribunal. ${ }^{23}$ Lastly, other countries, such as Brazil, chose to eliminate ISDS mechanisms from their new investment agreements, adopting alternative dispute resolution mechanisms instead.

Current trade and investment controls are increasingly inadequate in the face of new developments, such as the digital economy, the public's demands that States' regulatory space be preserved and the need to ensure that trade and investment support the 2030 Agenda for Sustainable Development. Recent signs that multilateralism is weakening make it even more difficult to overcome these shortfalls.

\section{The difficulties of practising environmental governance}

In recent decades, environmental pressures have been accumulating on a global scale in areas such as biodiversity loss, chemical pollution of soil and water, ozone depletion and global warming. In the light of the increasing degradation of global natural heritage, the concept of development was redefined, reflecting a shift towards sustainable development. ${ }^{24}$ This concept was central to the development of the modern environmental governance structure, which was formally set out in the agreements reached at the Earth Summit in 1992, including the Rio Declaration on Environment and Development with 27 principles for environmental governance and the Programme of Action for Sustainable Development (Agenda 21), as well as in the Vienna Convention for the Protection of the Ozone Layer, the United Nations Framework Convention on Climate Change, the

23 Its recent trade agreements with Canada and Singapore include such a mechanism, as well as the parties' commitment to create a multilateral investment court. The European Commission (2015) also notes that those agreements include provisions to guarantee the right of the host States to enact regulations in the public interest.

24 This was defined in 1987, in the Report of the World Commission on Environment and Development: Our Common Future, known as the Brundtland Report, as "development that meets the needs of the present without compromising the ability of future generations to meet their own needs". 
United Nations Convention to Combat Desertification and the Convention on Biological Diversity. These were later supplemented by the Minamata Convention on Mercury, the Stockholm Convention and the Convention on Biological Diversity. Global environmental governance efforts have sought to protect the foundations that underpin society and the economy. That is why the Sustainable Development Goals and the 2030 Agenda have adopted an integrated and universal approach, based on the concept of sustainable development, to the different areas of development.

Progress on this road has been slow and limited. A notable exception are the signs that the ozone layer is recovering. Other issues have seen little progress or have actually worsened, as is the case with the collapse of fisheries, ocean pollution, the mass extinction of species, soil degradation and the relentless march of global warming.

Climate change is proof of the urgent need for a change in production patterns towards more sustainable development. The United Nations Framework Convention on Climate Change illustrates the problem of global environmental governance. Creating a virtuous circle depends, to a large extent, on implementing the Paris Agreement adopted in 2015 —which recognizes that for climate security the rise in the global average temperature must not exceed $2^{\circ} \mathrm{C}$ above pre-industrial levels - and on pursuing efforts to limit the temperature increase even further to $1.5^{\circ} \mathrm{C}$ above pre-industrial levels. However, average global temperatures have risen more than $1.0^{\circ} \mathrm{C}$ since 2015 and the available global carbon budget to limit the temperature increase to $1.5^{\circ} \mathrm{C}$ has already been exceeded. Moreover, at the current emission rate, ${ }^{25}$ the barrier of $2^{\circ} \mathrm{C}$ will be broken in around 20 years. ${ }^{26}$ The gap remains alarming even if all the nationally determined contributions (NDCs) are implemented, as these cover only one third of the reductions needed to achieve the $2^{\circ} \mathrm{C}$ target (see figure II. 13 and UNEP, 2017). ${ }^{27}$

\section{Figure Il.13}

Depletion of the carbon budget

(Cumulative $\mathrm{CO}_{2}$ emissions in gigatons)

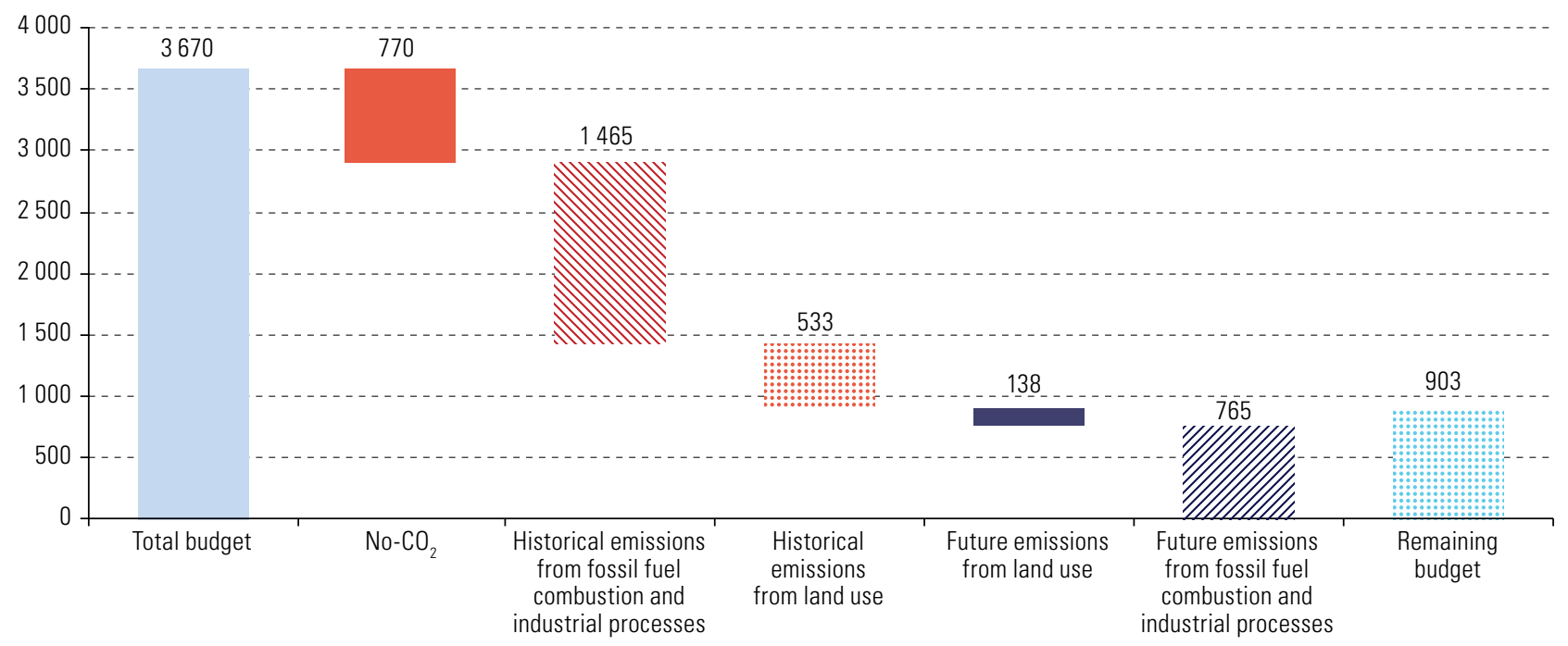

Source: United Nations Environment Programme (UNEP), The Emissions Gap Report 2017, Nairobi, November 2017

25 Fossil fuel emissions, cement production and other industrial processes currently account for $70 \%$ of total greenhouse gas emissions (35.8 GtCO2e for 2016 and $40 \mathrm{GtCO2e}$ today) (UNEP, 2017). Total global greenhouse gas emissions, including those from land use and land-use change, were estimated at $51.9 \mathrm{GtC02 \textrm {e }}$ in 2016. There is $66 \%$ probability of attaining the $2^{\circ} \mathrm{C}$ target, if total emissions do not exceed $42 \mathrm{GtCO2e} \mathrm{by} 2030$. In the region, land-use change accounts for $49 \%$ of greenhouse gas emissions (ECLAC, 2015). Therefore, most of the NDC actions aim to reduce such emissions.

26 See Global Carbon Project [online] http://www.globalcarbonproject.org/.

27 The emissions gap in 2030 related to the $2^{\circ} \mathrm{C}$ target is between $11 \mathrm{GtCO}_{2}$ e and $13.5 \mathrm{GtCO}_{2} \mathrm{e}$, depending on whether it is calculated on the basis of only unconditional NDCs or the more ambitious conditional NDCs that require resource transfers and other international support. For the $1.5^{\circ} \mathrm{C}$ target, the gap is between $16 \mathrm{GtCO}$ e and $19 \mathrm{GtCO}_{2}$ e. Six categories have the potential to reduce emissions by as much as $22 \mathrm{GtCO}_{2} \mathrm{e}$ per year. These categories are solar energy, wind energy, energy efficiency, efficient transport, afforestation and stopping deforestation. Under the Paris Agreement, nationally determined contributions will be stepped up every five years. 
The objective of the United Nations Framework Convention on Climate Change is to stabilize greenhouse gas concentrations in the global atmosphere and to cut waste emissions from industrial activities. The relationship between the global powers and their misgivings about accepting limits on and shifts in development styles have paralysed efforts to effect change and called into question the effectiveness and efficiency of a governance structure that lacks instruments to ensure compliance. Efforts to bring about a change in environmental governance and adopt an assessment framework have been undermined by the technology lag, the fact that time is running out and the vested interests of the status quo. To bring about change, States must move from an ineffective multilateral approach to one capable of meeting the mounting challenges that are arising as the planet approaches the critical limits of its capacity to absorb waste created by existing production patterns. Given that even full implementation of the current NDCs would mean a temperature increase of $3.2^{\circ} \mathrm{C}$ by 2100, which could be very harmful for humankind, comprehensive climate policies must be adopted in conjunction with industrial policies that seek progressive structural change. In this context, the proposal made by ECLAC (2016a) to treat climate security and the implementation of the 2015 Paris Agreement as a core aspect of governance for creating global public goods is all the more essential.

The 2030 Agenda underlines the link between human well-being, environmental quality, human rights and peace. Its guiding tenet that no one be left behind clearly establishes a rights-based perspective that requires active public policymaking to reduce inequality in all its forms. The effective application of Principle 10 of the Rio Declaration on Environment and Development is thus a pillar of the 2030 Agenda in terms of ensuring that environmental governance consider the needs of vulnerable people and groups, such that they can exercise their rights under conditions of equality and non-discrimination. Accordingly, the Regional Agreement on Access to Information, Participation and Justice in Environmental Matters in Latin America and the Caribbean, a binding agreement resulting from a successful regional negotiation process inspired by Principle 10, is an example at the global level.

In short, the high levels of uncertainty seen in the economic, technological, environmental and geopolitical spheres further complicate assessments of whether current growth will be sustained in the medium term. In any case, the uncertainty itself is detrimental to policies aimed at promoting investment and production diversification. It hampers economic calculations and, if all other factors remain constant, it reduces expected rates of return, with negative repercussions for investment. It is increasingly difficult to design sector-wide policies as technological change fuels greater doubts about patterns of specialization and employment generation, even in the medium term. Lastly, the growing contradictions between patterns of increasing use and consumption of digital goods and the analogue world raise questions about the production structure that can be resolved only over time. As discussed in chapter VII, all this makes it increasingly necessary to move towards a new pattern of development based on an environmental big push. 


\section{Bibliography}

Alvaredo, F. and others (coords.) (2018), World Inequality Report 2018, World Inequality Lab [online] http://wir2018.wid. world/files/download/wir2018-full-report-english.pdf.

Arnold, M. (2017), "Six global banks join forces to create digital currency", Financial Times, August [online] https://www. ft.com/content/20c10d58-8d9c-11e7-a352-e46f43c5825d.

Arrieta, A. and others (2017), Tecnolatinas: Latin America Riding the Technology Tsunami, Inter-American Development Bank (IDB), May [online] https://publications.iadb.org/bitstream/handle/11319/8722/Tecnolatinas-Latin-America-Ridingthe-Technology-Tsunami.pdf? sequence $=1$ \&isAllowed $=y$.

Auboin, M. and F. Borino (2017), "The falling elasticity of global trade to economic activity: testing the demand channel", Working Paper, No. ERSD-2017-09, World Trade Organization (WTO), Geneva, April [online] https://www.wto.org/english/ res_e/reser_e/ersd201709_e.pdf.

Auer, R., C. Borio and A. Filardo (2017), "The globalisation of inflation: the growing importance of global value chains", Working Paper, No. 602, Bank of International Settlements (BIS), January [online] https://www.bis.org/publ/work602.pdf.

Autor, D. (2014), "Skills, education and the rise of earnings inequality among the "other 99 percent"," Science, vol. 344, No. 6186, May [online] http://seii.mit.edu/wp-content/uploads/2014/05/Science-2014-Autor-843-51.pdf.

Azmeh, S. and C. Foster (2016), "The TPP and the digital trade agenda: digital industrial policy and Silicon Valley's influence on new trade agreements", Working Paper Series, No. 175, London, January [online] http://www.lse.ac.uk/internationaldevelopment/Assets/Documents/PDFs/Working-Papers/WP175.pdf.

Baker McKenzie (2017a), "Convergence, cash, acqui-hires and super sectors drive record tech deals" [online] http:// crossbordermaindex.bakermckenzie.com/technology-q2-2017.

(2017b), "Blockchain and Financial Institutions: The Information Governance Challenge Ahead", June [online] http://www. bakerinform.com/home/2017/6/21/blockchain-and-financial-institutions-the-information-governance-challenge-ahead.

Casey, M. and P. Wong (2017), "Global chains are about to get better, thanks to blockchain," Harvard Business Review, March [online] https://hbr.org/2017/03/global-supply-chains-are-about-to-get-better-thanks-to-blockchain.

CEA (Council of Economic Advisers) (2017a), Corporate Tax Reform and Wages: Theory and Evidence, Washington, D.C., October, [online] https://www.whitehouse.gov/sites/whitehouse.gov/files/documents/Tax\%20Reform $\% 20$ and $\% 20$ Wages.pdf.

(2017b), The Growth Effects of Corporate Tax Reform and Implications for Wages, Washington, D.C., October [online] https://www.whitehouse.gov/sites/whitehouse.gov/files/images/Corporate\%20Tax\%20Reform\%20and\%20Growth \%20Final.pdf.

Central Bank of Japan (2017), "Statement on Monetary Policy", September [online] https://www.boj.or.jp/en/announcements/ release_2017/k170921a.pdf.

Constantinescu, C., A. Matto and M. Ruta (2015), "The global trade slowdown: cyclical or structural?", IMF Working Paper, No. WP/15/6, Washington, D.C., International Monetary Fund (IMF).

Cook, M. and S. Basu Das (2017), "RCEP's strategic opportunity", Perspective, No. 76, Singapore, ISEAS-Yusof Ishak Institute, October [online] https://www.iseas.edu.sg/images/pdf/ISEAS_Perspective_2017_76.pdf.

Dunning, J. (1998), "Location and the multinational enterprise: a neglected factor?", Journal of International Business Studies, vol. 1, $N^{\circ} 29$, March.

ECB (European Central Bank) (2017), "Monetary policy decisions", Press Release, September [online] https://www.ecb. europa.eu/press/pr/date/2017/html/ecb.mp170907.en.html.

(2016), Economic Bulletin, No. 6 [online] https://www.ecb.europa.eu/pub/pdf/ecbu/eb201606.en.pdf?736d49e 8295d82ec1762c76d09812ef8.

ECLAC (Economic Commission for Latin America and the Caribbean) (2017), Foreign Direct Investment in Latin America and the Caribbean 2017 (LC/PUB.2017/18-P), Santiago.

(2016a), Horizons 2030: Equality at the Centre of Sustainable Development (LC/G.2661/Rev.1), Santiago, July.

(2016b), The New Digital Revolution: From the Consumer Internet to the Industrial Internet (LC/L.4029(CMSI.5/4)/Rev.1), Santiago, August.

(2015), The economics of climate change in Latin America and the Caribbean: Paradoxes and challenges of sustainable development (LC/G.2624), Santiago, February.

European Commission (2017), Communication from the Commission to the European Parliament, the European Council, the Council, the European Economic and Social Committee and the Committee of the Regions (COM/2017/494), Brussels, September.

(2015), Trade for All: Towards a More Responsible Trade and Investment Policy, Luxembourg, October [online] http:// trade.ec.europa.eu/doclib/docs/2016/january/tradoc_154134.pdf. 
Europost (2017), "Turnover tax for digital giants sought", 16 September [online] http://www.europost.bg/article?id=20616.

Federal Reserve Bank of New York (2017), "Statement regarding reinvestment in treasury securities and agency mortgage-backed securities," Press Release, September [online] https://www.newyorkfed.org/markets/opolicy/operating_policy_170920.

Forbes (2017), "The Global 2000" [online] https://www.forbes.com/global2000/\#2296fea2335d.

Herreros, S. and T. García-Millán (2017), "Opciones para la convergencia entre la Alianza del Pacífico y el Mercado Común del Sur (MERCOSUR): la regulación de la inversión extranjera directa", International Trade series, No. 135 (LC/TS.2017/81), Santiago, Economic Commission for Latin America and the Caribbean (ECLAC), September.

IMF (International Monetary Fund) (2016), World Economic Outlook: Subdued Demand: Symptoms and remedies, Washington, D.C., October [online] http://www.imf.org/external/pubs/ft/weo/2016/02/pdf/text.pdf.

ITU (International Telecommunication Union) (2017), The State of Broadband: Broadband catalyzing sustainable development [online] https://www.itu.int/dms_pub/itu-s/opb/pol/S-POL-BROADBAND.18-2017-PDF-E.pdf.

Kengelbach, J. and others (2017), "The 2017 M\&A Report: the technology takeover," The Boston Consulting Group, September [online] https://www.bcg.com/en-cl/publications/2017/corporate-development-finance-technologydigital-2017-m-and-a-report-technology-takeover.aspx.

Leslie, I. (2014), "Kodak vs Instagram: this is why it's only going to get harder to make a good living", New Statesman, January [online] https://www.newstatesman.com/politics/2014/01/kodak-vs-instagram-why-its-only-going-get-hardermake-good-living.

Manyika, J. and others (2016), Digital Globalization: The New Era of Global Flows [online] http://www.mckinsey.com/ business-functions/digital-mckinsey/our-insights/digital-globalization-the-new-era-of-global-flows.

McAfee, A. and E. Brynjolfsson (2017), Machine, Platform, Crowd: Harnessing our Digital Future, New York, W.W. Norton \& Company, June.

McKinsey Global Institute (2017), The New Dynamics of Financial Globalization, McKinsey and Company, August [online] https://www.mckinsey.com/ /media/McKinsey/Industries/Financial\%20Services/Our\%20Insights/The\%20new\%20 dynamics\%20of\%20financial\%20globalization/Financial\%20globalization_Full\%20Report_August_29_2017\%20(1).ashx.

Milanovic, B. (2016), Global Inequality: A New Approach for the Age of Globalization, Cambridge, Massachusetts, Harvard University Press, April.

New York Times (2017), "Debt concerns, once a core republican tenet, take a back seat to tax cuts", New York, 1 December [online] https://www.nytimes.com/2017/12/01/us/politics/tax-cuts-deficit-debt.html.

OECD (Organization for Economic Cooperation and Development) (2016), "Cardiac arrest or dizzy spell: why is world trade so weak and what policy do about it?", OECD Economic Policy Paper, No. 18, Paris, September [online] http://www. oecd-ilibrary.org/economics/cardiac-arrest-or-dizzy-spell_5jlr2h45q532-en.

Oxfam International (2017), An Economy for the 99\%: It's Time to Build a Human Economy that Benefits Everyone, not Just the Privileged Few, January [online] https://d1 tn3vj7xz9fdh.cloudfront.net/s3fs-public/file_attachments/bpeconomy-for-99-percent-160117-es.pdf.

Schwab, K. (2016), "The Fourth Industrial Revolution: what it means, how to respond,"World Economic Forum (WEF), January [online] https://www.weforum.org/agenda/2016/01/the-fourth-industrial-revolution-what-it-means-and-how-to-respond/.

Setterfield, M. (2013), "Wages, demand and us macroeconomic travails: Diagnosis and prognosis", After the Great Recession: The Struggle for Economic Recovery and Growth, B. Z. Cynamon, S. Fazzari and M. Setterfield (eds.), New York, Cambridge University Press.

United Nations (2016), International Migration Report 2015 (ST/ESA/SER.A/384), New York. (1987), Report of the World Commission on Environment and Development: Our Common Future (A/42/427), New York, August.

UNCTAD (United Nations Conference on Trade and Development) (2017), World Investment Report 2017: Investment and the Digital Economy (UNCTAD/VIR/2017), Geneva.

(2015), World Investment Report 2015: Reforming International Investment Governance, Geneva.

UNEP (United Nations Environment Programme) (2017), The Emissions Gap Report 2017, Nairobi, November.

Visual Capitalist (2017), "Chart: here's how 5 tech giants make their billions," May [online] http://www.visualcapitalist.com/ chart-5-tech-giants-make-billions/.

World Bank (2016), Global Economic Prospects: Divergences and Risks, Washington, D.C, June [online] http://pubdocs. worldbank.org/en/842861463605615468/Global-EconomicProspects-June-2016-Divergences-and-risks.pdf.

WTO (World Trade Organization) (2017), World Trade Statistical Review 2017, Geneva [online] https://www.wto.org/english/ res_e/statis_e/wts2017_e/wts17_toc_e.htm.

Yellen, J. (2017a), Press Conference at the meeting of the Federal Open Market Committee (FOMC), 20 September [online] https://www.federalreserve.gov/mediacenter/files/FOMCpresconf20170920.pdf.

(2017b), "Inflation, uncertainty, and monetary policy", document presented at the fifty-ninth Meeting of the National Association of Business Economics (NABE), Cleveland, September [online] https://www.federalreserve.gov/newsevents/ speech/files/yellen20170926a.pdf. 


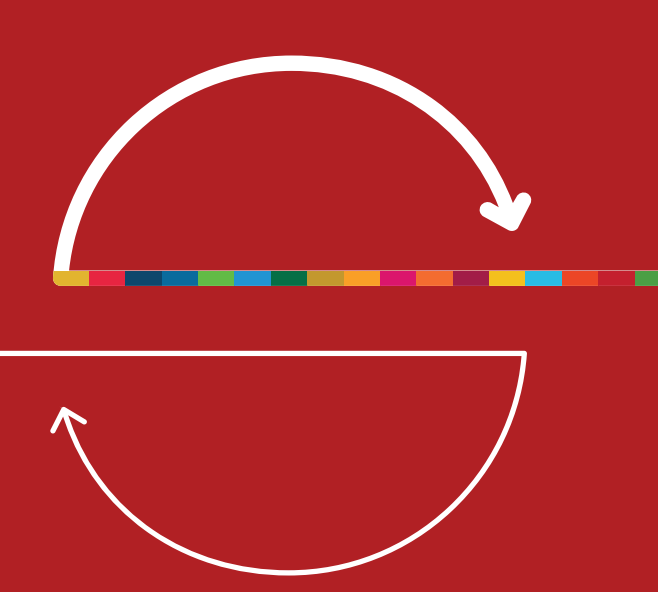

\section{CHAPTER}

III

\section{External vulnerability hinders development and increases inequality}

Introduction

A. The structural factors that limit growth, investment and employment

B. Negative labour and social effects

1. Fewer quality jobs are being created

2. Income equality is no longer falling

3. Poverty rates have risen

C. Fiscal policy fails to reduce inequality in the region

1. Tax revenues are biased against equality

2. Weak redistributive capacity of fiscal policy

3. Tax evasion: a manifestation of the culture of privilege

D. Positive and negative interactions between distribution, growth and investment

1. The role of institutional and structural variables

2. The virtuous circle between growth and investment

E. Financialization heightens external vulnerability

I. Peripheral financialization and indebtedness

2. Increased real and financial external vulnerability

3. Obstacles to growth, investment and production diversification in the long term

Bibliography 



\section{Introduction}

Chapter II discussed the slow growth of international trade and the persistence of a global recessionary bias, which are affecting the region's economic performance through both trade and financial channels. The trade channel produces the most direct effect, seen in export growth figures, while the financial channel transmits the portfolio decisions that determine inward and outward volumes of cross-border capital flows. The financial channel became more important in recent decades as the countries of Latin America and the Caribbean were integrated into global credit markets, local financial systems were deregulated and the preponderance of transnational corporations in the region's economies -including trans-Latin companies- steadily increased.

Amid weak international trade and heightened exposure to global liquidity cycles, the growth of the region's economies slowed or turned negative after the initial rebound that followed the 2009 global financial crisis. The slowdown, which began in 2012 and bottomed out in 2016, was of historic magnitude compared to the region's past performance and that of other developing regions.

Although economic slowdown was largely due to external factors, the intensity with which these affected the region's internal dynamics was also shaped by domestic considerations, some of which augmented the exogenous impact while others attenuated it. The domestic considerations are determined by individual national structures and institutional frameworks, including such elements as a country's production pattern, tax structure, environmental regulations, governance of natural resources, labour institutions, education and health policies, care system, level of openness, financial deregulation and economic policy goals. This chapter discusses how domestic conditions mediate the impact of external factors and hamper the adoption of measures to accelerate economic growth.

\section{A. The structural factors that limit growth, investment and employment}

Growth in the region's economies tailed off following the rebound from the international financial crisis in 2010 and 2011. The average growth rate of 2.3\% recorded between 2012 and $2017^{1}$ was lower than the 3.8\% the region posted between 2000 and 2008 (see figure III.1), and well below that achieved in other parts of the world such as South-East Asia (5.3\%), North Africa (3.1\%) and the largest European emerging economies $(2.8 \%)$ during the same period. ${ }^{2}$

By subregion, the slowdown was sharper in South America, largely on account of developments in the economies of Argentina, Brazil and the Bolivarian Republic of Venezuela, which in 2016 shrank by 2.2\%, 3.6\% and $16.5 \%$, respectively. Even if those countries are excluded from the calculation, overall growth in the rest of South America slumped by almost two thirds from $6.0 \%$ in 2011 to $2.3 \%$ in 2016. The slowdown was gentler in the Caribbean, Central America and Mexico, where economic activity is more closely linked to trends in the United States. Those countries as a group grew by 3.8\% between 2012 and 2016, with a slight upward trend, at a time when the United States, in contrast to the European Union and Japan, was posting average annual growth rates of $2.2 \%$. The downturn was reverted to a certain degree in 2017 , primarily by the performance of South America and, most particularly, a return to growth in Argentina and Brazil. However, excluding those two countries (and the Bolivarian Republic of Venezuela, where GDP again fell in 2017), the growth slowdown in the rest of the region was reverted only marginally between 2016 and 2017, with an uptick from $2.3 \%$ to $2.5 \%$.

The 2017 figure for the countries of Latin America and the Caribbean is a forecast by ECLAC (2018).

The 2017 figures for the countries of South-East Asia, North Africa and the largest European emerging economies are forecasts by the International Monetary Fund (IMF). 
Briefly stated, as Raúl Prebisch said in referring to the link between peripheral countries and the "universal cyclical movement," the region's recent dynamics are closely tied to the global context. ${ }^{3}$ In South America, there is a strong correlation between growth rates and the dynamics of commodity prices, while the growth rate in Central America, Mexico and the Caribbean is tied in with the performance of the United States (see figure III.2).

\section{Figure III.1}

Latin America and the Caribbean: economic growth, 1965-2017

(Percentages, moving 5-year average)

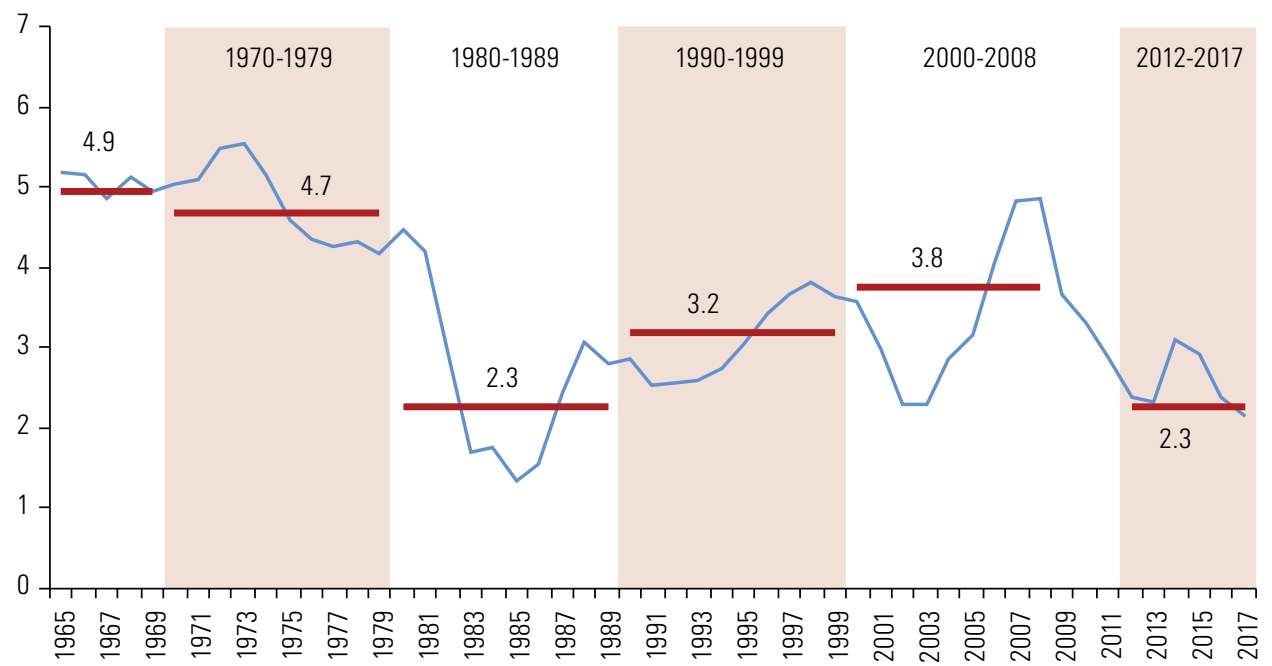

Source: Economic Commission for Latin America and the Caribbean (ECLAC), CEPALSTAT [online database] http://estadisticas.cepal.org/cepalstat/portada. html?idioma=english; ECLAC, Preliminary Overview of the Economies of Latin America and the Caribbean, 2017 (LC/PUB.2017/28-P), Santiago, 2018 (for 2017 figures); World Bank, Data Bank [online database] http://databank.worldbank.org/data/home.aspx; and International Monetary Fund (IMF), World Economic Outlook. Seeking Sustainable Growth: Short-Term Recovery, Long-Term Challenges, 2017 [online] https://www.imf.org/en/Publications/WE0/ Issues/2017/09/19/world-economic-outlook-october-2017.

a Figures for 2017 are projections.

\section{Figure III.2}

Latin America and the Caribbean: subregional growth rates and external determinants, 2004-2017

(Percentages)

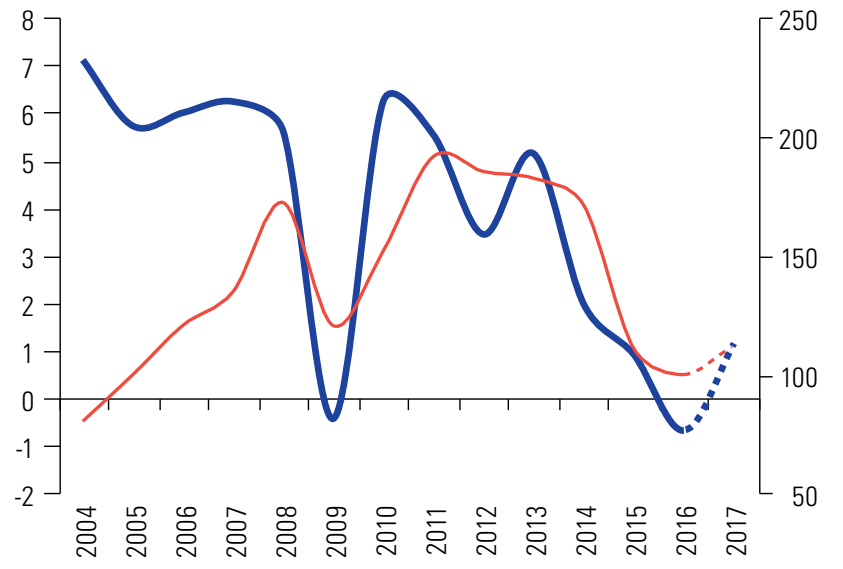

GDP of South America

— Commodity price index (right scale)

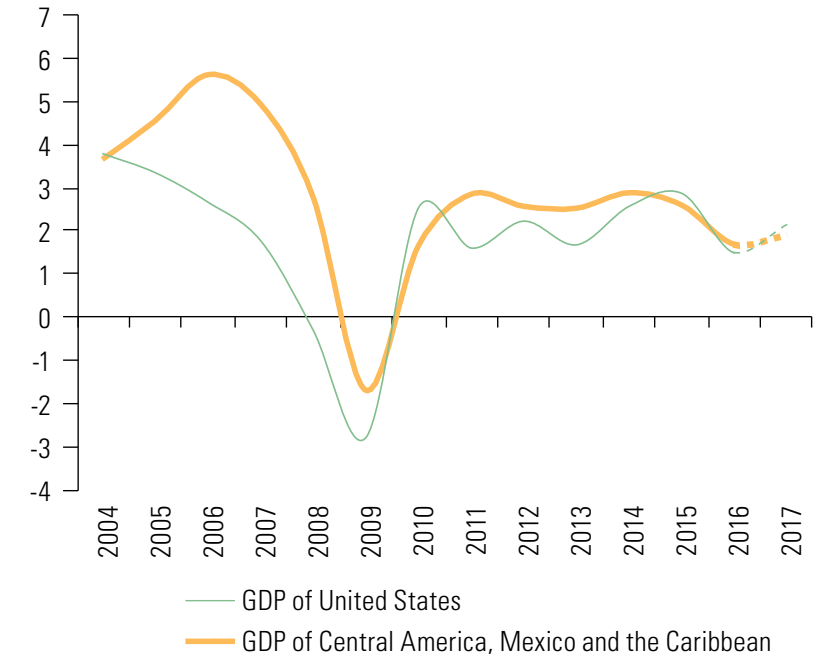

Source: Economic Commission for Latin America and the Caribbean (ECLAC), on the basis of CEPALSTAT [online] http://estadisticas.cepal.org/cepalstat/portada. html?idioma=english, and International Monetary Fund (IMF), World Economic Outlook. Seeking Sustainable Growth: Short-Term Recovery, Long-Term Challenges, 2017 [online] https://www.imf.org/en/Publications/WEO/Issues/2017/09/19/world-economic-outlook-october-2017. 
Falling export growth cannot be explained solely by external factors acting through the trade channel, such as worsening terms of trade or slackening export demand on the part of major trading partners; it is also the result of domestic factors related to the evolution of each country's production and commercial profile. As indicated in table III.1, which shows the downward trend in the global income elasticity of exports for many of the region's countries, their ability to capitalize on the impetus provided by growth elsewhere in the world is decreasing.

Table III.1

Latin America (selected countries): foreign trade elasticity ratios, 1999-2008 and 2007-2016

\begin{tabular}{|c|c|c|c|c|c|c|}
\hline & \multicolumn{2}{|c|}{ Income elasticity of exports $(\varepsilon)$} & \multicolumn{2}{|c|}{ Income elasticity of imports ( $\pi$ ) } & \multicolumn{2}{|c|}{ Elasticity ratio $(\varepsilon / \pi)$} \\
\hline & 1999-2008 & $2007-2016$ & 1999-2008 & $2007-2016$ & 1999-2008 & $2007-2016$ \\
\hline Argentina & 1.5 & 0.4 & 2.5 & 2.9 & 0.6 & 0.2 \\
\hline Bolivia (Plurinational State of) & 2.8 & 1.5 & 1.7 & 1.2 & 1.7 & 1.3 \\
\hline Brazil & 2.6 & 0.6 & 1.4 & 2.2 & 1.8 & 0.3 \\
\hline Chile & 0.9 & 0.4 & 2.2 & 1.1 & 0.4 & 0.3 \\
\hline Colombia & 1.7 & 1.5 & 2.2 & 1.6 & 0.8 & 0.9 \\
\hline Costa Rica & 1.7 & 0.8 & 1.2 & 0.7 & 1.4 & 1.1 \\
\hline Ecuador & 2.5 & 1.6 & 1.8 & 0.9 & 1.4 & 1.9 \\
\hline Guatemala & 1.0 & 1.3 & 0.6 & 1.1 & 1.5 & 1.1 \\
\hline Honduras & 1.9 & 2.2 & 1.5 & 1.1 & 1.3 & 2.1 \\
\hline Mexico & 1.6 & 2.9 & 2.1 & 2.2 & 0.7 & 1.3 \\
\hline Nicaragua & 3.4 & 4.8 & 1.5 & 1.6 & 2.2 & 3.0 \\
\hline Paraguay & 2.1 & 2.3 & 2.2 & 0.8 & 1.0 & 2.8 \\
\hline Peru & 3.4 & 0.6 & 1.7 & 1.2 & 2.0 & 0.5 \\
\hline Dominican Republic & 0.6 & 1.5 & 0.6 & 0.6 & 1.0 & 2.3 \\
\hline
\end{tabular}

Source: Economic Commission for Latin America and the Caribbean (ECLAC), on the basis of CEPALSTAT [online database] http://estadisticas.cepal.org/cepalstat/ portada.html?idioma=english.

Comprehensive analyses of the external sustainability of growth generally use the global income elasticity of exports and the domestic income elasticity of imports. Thirlwall's Law (1979) states that given the pace of growth of trade partners, economic growth consistent with long-term external equilibrium depends on the ratio between a country's export and import elasticities. An analysis of the subregions reveals that in South America, the ratio between those elasticities - Thirlwall's condition- deteriorated significantly in recent years, largely as a result of decreases in the income elasticity of exports. ${ }^{4}$ South America's export volume rose by a mere 0.6\% between 2012 and 2016, compared with a growth of 5.7\% between 2000 and 2008 . The fall in export dynamism was therefore caused not only by the slowdown in international trade, but also by structural decline.

By contrast, in Central America and Mexico, Thirlwall's condition mostly improved, thanks to the increased income elasticity of exports (see table III.1). Those countries' exports grew at an annual rate of $4.3 \%$ between 2012 and 2016, slightly better than the 4\% recorded between 2000 and 2008 and above the average rate of GDP growth.

The dynamics of foreign trade elasticities reveal the persistence of structural problems: technology gaps, specialization patterns and other variables that affect the systemic competitiveness of the region's countries (ECLAC, 2007 and 2010). Economies specializing in products with more dynamic global demand (Keynesian efficiency) and with greater capacity for disseminating technological progress (Schumpeterian efficiency) can be expected to contribute more to growth in global output and to have higher levels of domestic growth consistent with current account equilibrium. Deteriorating ratios between export and import elasticities — that is, drops in the growth that is consistent with long-term external equilibrium - reveals the existence or expansion of productivity gaps in the region compared to advanced countries. ${ }^{5}$

4 The exception was Paraguay, which posted a slight improvement thanks to the adoption of new soybean production technologies, which Argentina, Brazil and Uruguay had taken up and deployed earlier.

5 They are also the result of the relatively low technology content of the region's exports, which can be seen in variables such as its declining share - down from $8 \%$ in 2000 to 5\% in 2015 - in global exports of high-technology manufactures (ECLAC, 2016e). 
This scenario describes the South American countries, which deepened their specialization in commodities as these rose in relation to total exports. In Central America and Mexico, by contrast, the share of mediumtechnology exports increased and the trend was towards more diversified export baskets. The Caribbean countries, in turn, remained heavily dependent on raw and processed commodities but diversified their export mix somewhat. ${ }^{6}$

Given the prevailing economic sluggishness, investment also decelerated, which fed back into the low rates of growth over recent years. In line with the level of economic activity, after a rebound in 2010 and 2011, investment growth slowed to 4\% in 2012 and 2\% in 2013, and turned negative (averaging -3.6\%) over the following three years. Machinery and equipment — which is the most dynamic, highest-tech and most economically volatile component of investment— was the most severely affected investment item, especially in the South American countries.

Investment levels have been mediocre in recent years in relation to historic patterns. Figure III.3 compares recent investment levels to those of the 1960s and 1970s (when, on average, they exceeded 24\% of GDP) and illustrates the relationship between growth and investment (a topic that will be dealt with below).

Figure III.3

Latin America and the Caribbean: growth and investment rates, 1960-2017

(Percentages)

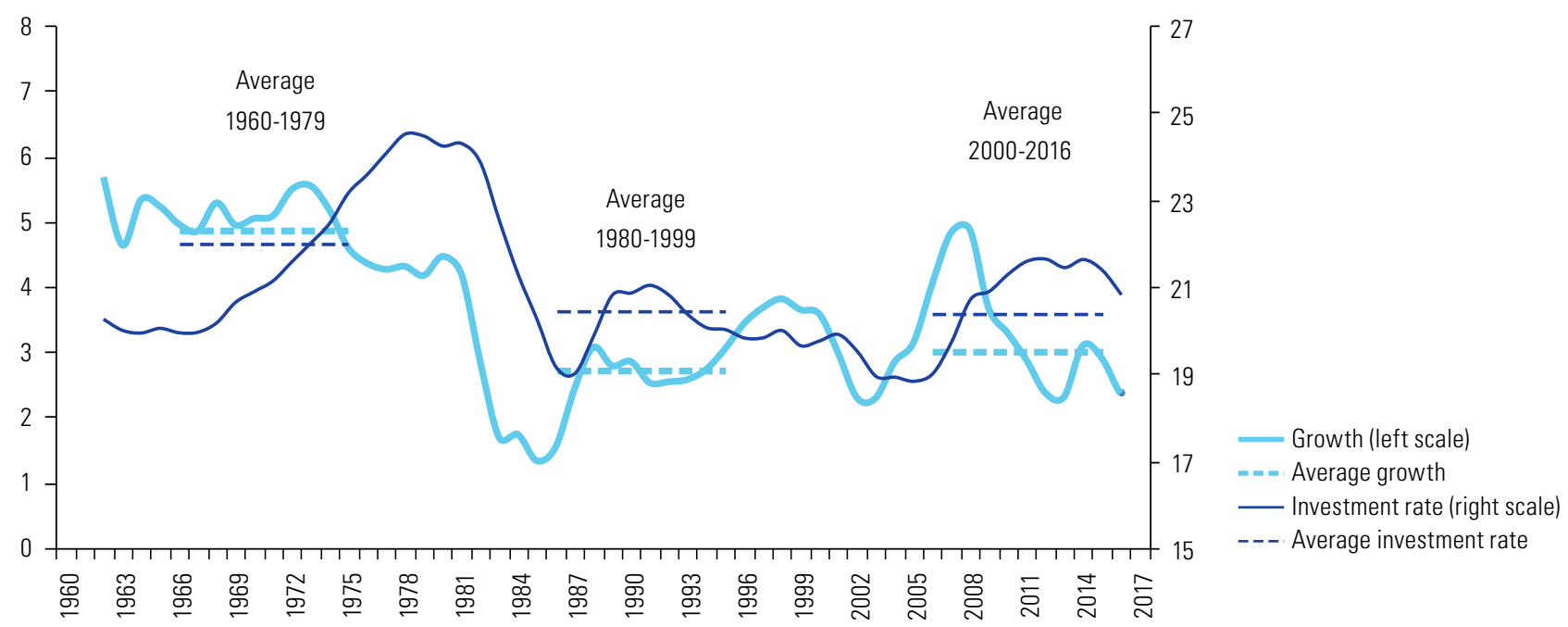

Source: Economic Commission for Latin America and the Caribbean (ECLAC), on the basis of World Bank, Data Bank [online database] http://databank.worldbank. org/data/home.aspx; International Monetary Fund (IMF), World Economic Outlook. Seeking Sustainable Growth: Short-Term Recovery, Long-Term Challenges, 2017 [online] https://www.imf.org/en/Publications/WEO/Issues/2017/09/19/world-economic-outlook-october-2017; and ECLAC, Preliminary Overview of the Economies of Latin America and the Caribbean, 2017 (LC/PUB.2017/28-P), Santiago, 2018 (for 2017 figures).

a Five-year moving average. The 2017 figure is the ECLAC forecast included in Preliminary Overview of the Economies of Latin America and the Caribbean, 2017.

The slowdown in growth also impacted the job market. Job creation ${ }^{7}$ was particularly strong during the years in which the economy was most buoyant (before 2009), partly owing to the pace of growth but also because of an unusually high employment-output elasticity (ECLAC, 2017a). During that period, economic growth broke through the threshold needed to absorb population growth, which explains the significant drop in unemployment. ${ }^{8}$ That threshold stands at around $2.5 \%$ for the region as a whole, and between $2.4 \%$ and

6 According to estimates of the Herfindahl-Hirschman index of world goods exports by product calculated by the Economic Commission for Latin America and the Caribbean (ECLAC), the export concentrations of the Caribbean, Central America and Mexico declined between 2000 and 2016.

7 Includes the total number of employed persons in the various categories that make up the labour market: employers, employees, self-employed and unpaid family workers.

8 The growth threshold is calculated as the ratio between population growth and employment-output elasticity. It allows estimates of the economic growth needed for the total number of jobs to increase at the same rate as population growth and thus for a stable employment rate to be maintained. 
$2.7 \%$ in its individual subregions (see figure 111.4 ). ${ }^{9}$ The region's growth remained above the threshold until 2014 , but at a rate that was barely sufficient to absorb population growth and maintain the employment rate. After that point, the region's average growth fell below the threshold.

\section{Figure III.4}

Latin America and the Caribbean (as a whole and by subregions): effective growth rate and rate of growth consistent with employment rate equilibrium, 2000-2016

(Percentages)

\section{A. Latin America and the Caribbean}

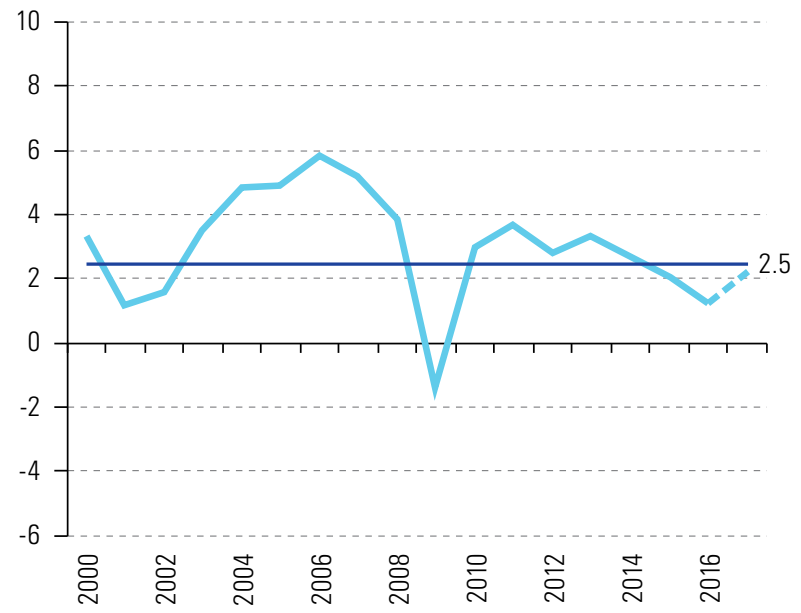

C. Central America and Mexico

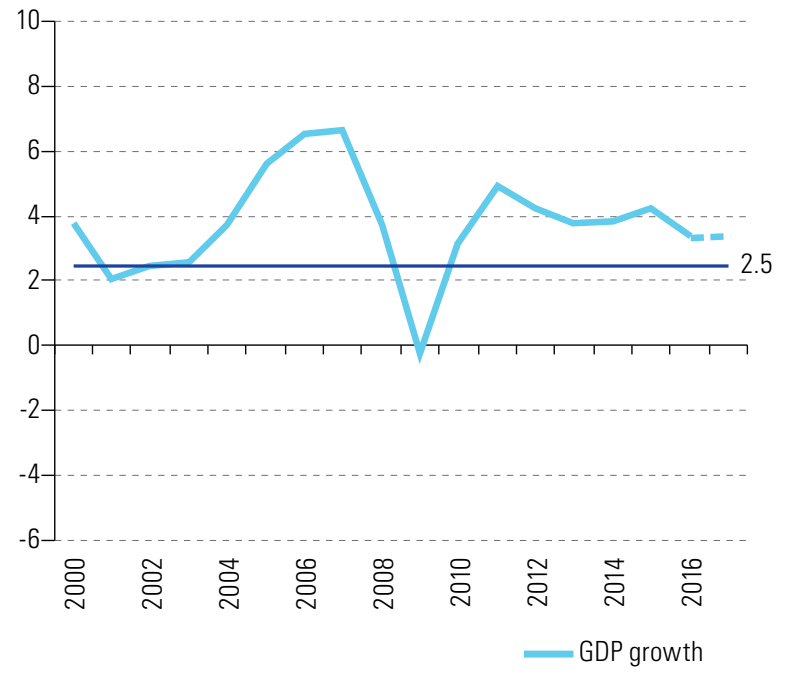

B. South America

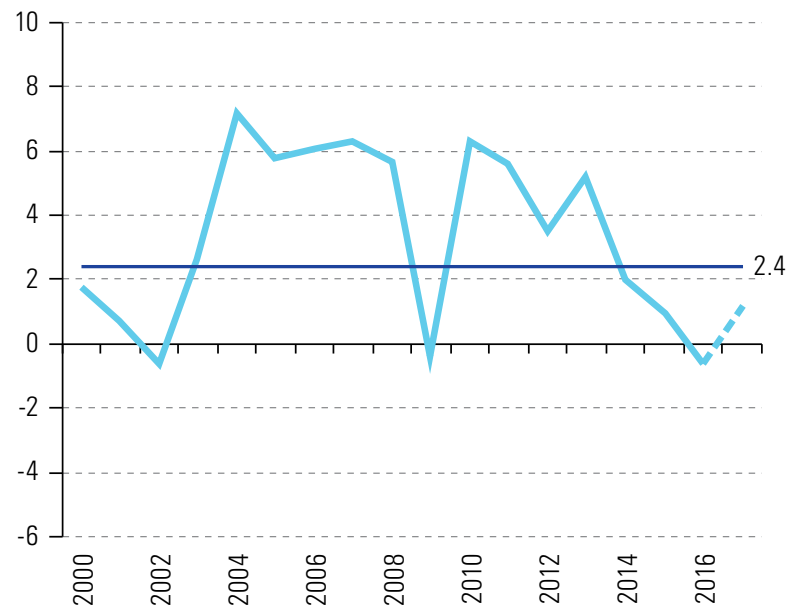

D. The Caribbean

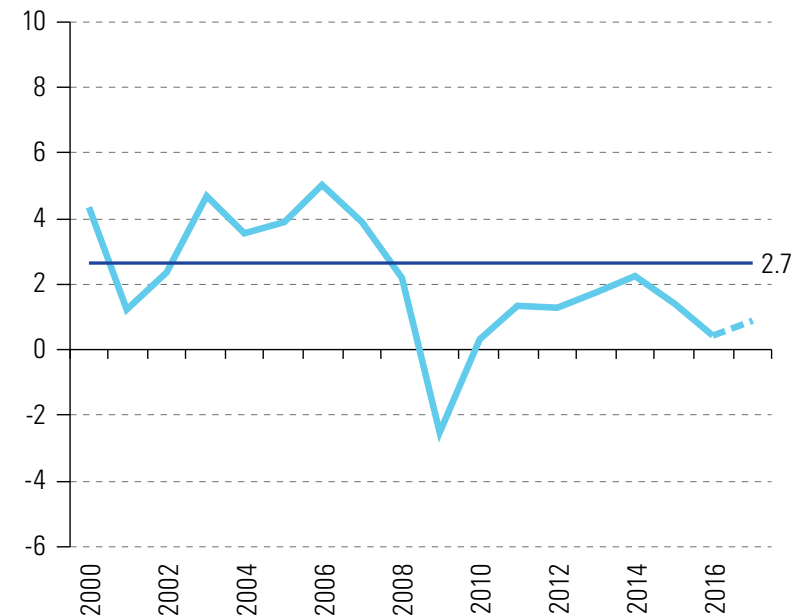

Growth threshold

Source: Economic Commission for Latin America and the Caribbean (ECLAC), on the basis of CEPALSTAT [online database] http://estadisticas.cepal.org/cepalstat/portada. html?idioma=english, World Bank, Data Bank [online database] http://databank.worldbank.org/data/home.aspx, and International Labour Organization (ILO).

Note: Employment-income elasticity rates were estimated at 0.53 for South America, 0.57 for Central America and Mexico and 0.33 for the Caribbean. The equivalent average annual population growth is $1.3 \%$ for South America, $1.4 \%$ for Central America and Mexico and $0.9 \%$ for the Caribbean.

That dynamic began to be reflected in the unemployment rate, which rose by 1.6 percentage points between 2015 and 2016 for an accrued increase of 2 percentage points since $2014 .{ }^{10}$ There were also differences between countries and subregions, with the indicators in South America worsening more severely. ${ }^{11}$ As discussed in the following section, the deteriorating labour indicators were mirrored in inequality and poverty trends.

The threshold assumes average natural population growth of around $1.2 \%$ and an employment-output elasticity of 0.48 over the past 16 years.

10 The 2014 unemployment rate was the lowest in the past 20 years.

11 South America accounted for 9 of the 13 countries that recorded increased unemployment in 2016. 
The proximity between the minimum threshold of growth needed to absorb the population increase and the ceiling for growth consistent with long-term external equilibrium indicates that the structuralist approach remains valid, given that job generation is ultimately limited by the external constraints on growth and, consequently, by the production specialization pattern. As shown by figure III.5, in many of the region's countries (those located below the $45^{\circ}$ line), the minimum growth threshold needed to absorb population growth (horizontal axis) is above the ceiling that long-term external sustainability imposes on growth (vertical axis).

Figure III.5

Latin America (14 countries): ratio between growth consistent with external equilibrium and growth consistent with stable employment, 2000-2016

(Percentages)

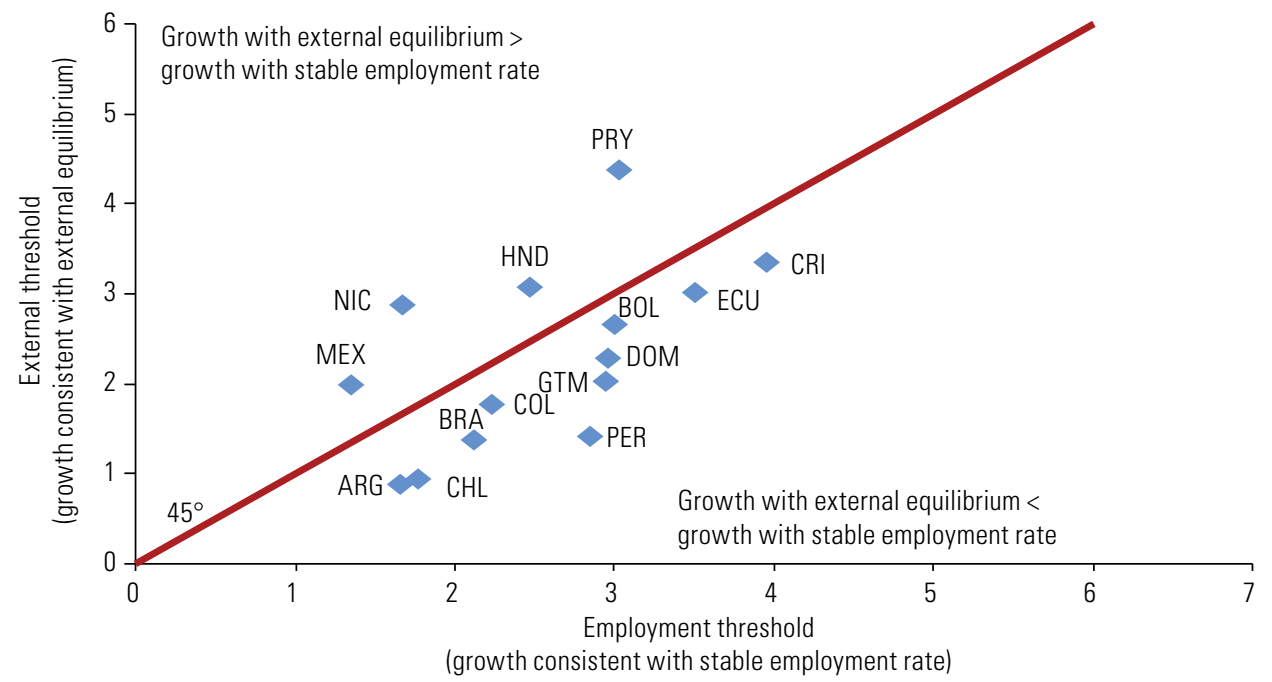

Source: Economic Commission for Latin America and the Caribbean (ECLAC).

Note: Thirlwall's condition is defined as $y^{*}=\frac{\phi_{1} \varepsilon . z}{\pi}$ where $\varepsilon$ is the income elasticity of exports, $\pi$ is the income elasticity of imports, $z$ is the growth of trading partners, $\phi_{1}$ is the ratio of exports to imports, and $y^{*}$ is the growth of the domestic economy consistent long-term equilibrium in the current account. A rate of $2 \%$ is assumed for the growth of trading partners.

\section{B. Negative labour and social effects}

\section{Fewer quality jobs are being created}

In addition to affecting unemployment, the slower economic growth of recent years also had an impact on the creation of good quality jobs, which is one of the key factors for progressive structural change. To analyse the dynamics of quality employment, the adjusted employment rate was calculated. That metric is used to correct the employment rate by using the wage-earner rate, ${ }^{12}$ given that the rate of wage employment is closely correlated to the level of economic development. ${ }^{13}$

12 The correction consists of calculating the total number of wage workers in the working-age population. Its chief advantage is that it allows comparisons between countries, provided that information on the employment rate (standardized by the population aged 15 years and over) and on the wage-earner rate is available. One limitation is that not all wage-earning jobs are of good quality, for which other indicators — such as rates of labour informality and non-registered employmentwould be more useful. As those indicators are not widely available or strictly comparable from one country to the next, this chapter analyses trends across the region in terms of the adjusted employment rate. Chapter IV explores the prevailing situation in certain individual countries by means of more specific indicators.

13 The adjusted employment rate provides a good approximation of individual countries' levels of development; the most advanced nations have high wage-earner rates. For example, the United States, Sweden, Germany, Japan, France, Austria, Switzerland, New Zealand and the United Kingdom are among those with rates in excess of $85 \%$. Despite technological change and the emergence of new forms of employment in recent decades, the rate has remained constant and, in some cases, has even increased since 1990. A few countries —including Germany, Switzerland and the United Kingdom— recorded drops, but in no instance was the decline more than 1.2 percentage points. 
Growth in the adjusted employment rate began to accelerate in 2002 and it remained high until 2008 (see figure III.6). It then took a hit from the economic slowdown in and after 2012, when its annual average rate of growth fell from $0.8 \%$ (2000-2008) to $0.05 \%$ (2012-2016) as unwaged own-account work began to account for a larger share of employment. This plateauing in adjusted employment rates was most apparent in South America and, to a lesser extent, in the Caribbean. In Central America and Mexico, the adjusted employment rate continued to rise, albeit more slowly.

Figure III.6

Latin America and the Caribbean (overall and by subregion): adjusted employment rate, 1991-2000

(Percentages)

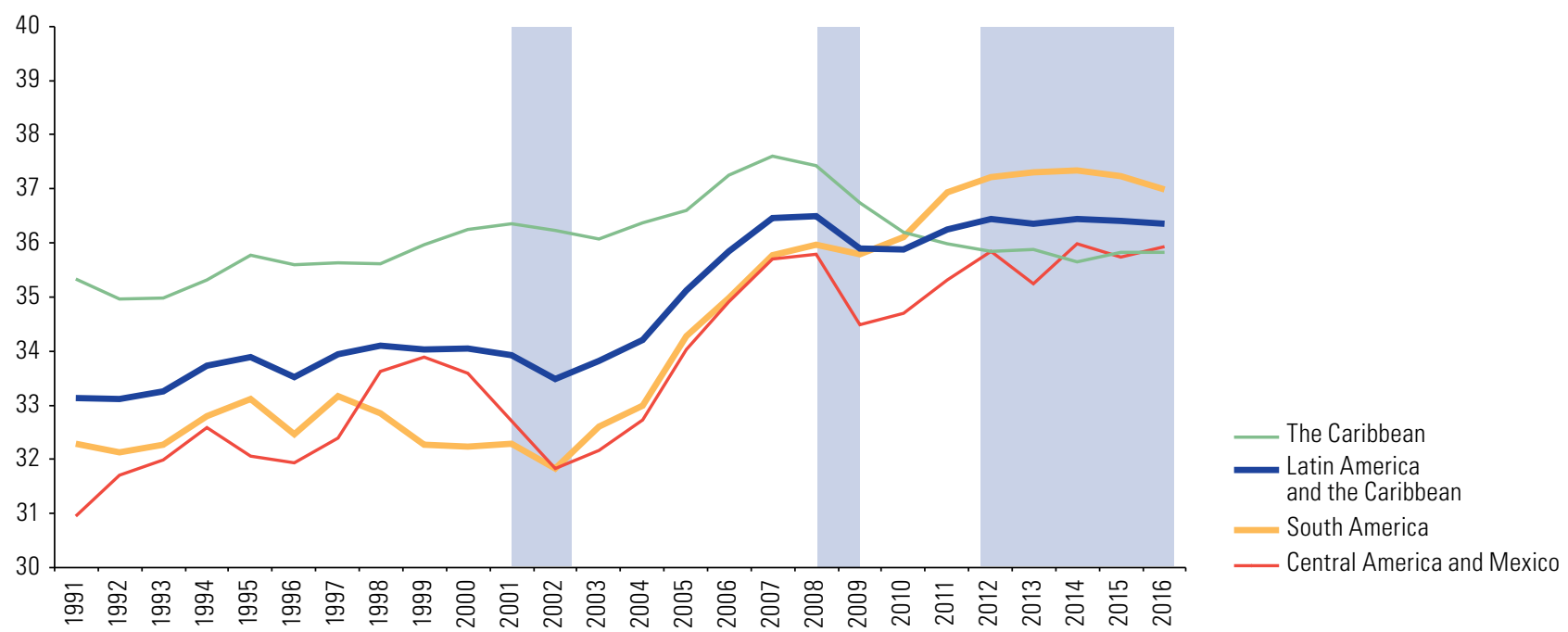

Source: Economic Commission for Latin America and the Caribbean (ECLAC), on the basis of International Labour Organization (ILO), ILOSTAT database [online] http:// www.ilo.org/ilostat/faces/ilostat-home?locale=en.

As shown in figure III.7, improvements in the adjusted employment rate depend on the evolution of its two components: the total employment rate and the wage-earner rate. During the period of highest growth (up to 2008), a significant portion (about 25\%) of the average annual increase in the adjusted employment rate reflected improvements in the wage-earner rate. Between 2012 and 2016, however, the wage-earner rate's contribution was negative. This implies a qualitative difference between the most dynamic years and the economic slowdown period. During the slowdown, the uptick in own-account work was generally driven by highly precarious employment as workers sought to make up for the inadequate creation of quality employment (Weller, 2014; ECLAC, 2017a).

A breakdown by sex reveals differing trends in how the adjusted employment rate has evolved for women and for men. First, their starting points are very different: in 2000, the rate was $42 \%$ for men and $26 \%$ for women. Then, in the years leading up to the international financial crisis, women's adjusted employment rates grew more than those of men. As shown in figure III.8C, this narrowed the gap between the sexes, although it still remained wide. The dynamics during the plateau phase favoured women: the adjusted employment rate for men showed negative growth (the annual rate of growth fell from $3 \%$ to $-0.2 \%$ between the two periods) while the women's growth rate merely slowed, from $1.4 \%$ to $0.4 \%$ (see figure III.9). This pattern was seen across the subregions as well and allowed the gap to continue narrowing over time. 


\section{Figure III.7}

Latin America and the Caribbean (overall and by subregion): contribution of components to average annual change in the adjusted employment rate, 2000-2008 and 2012-2016

(Percentages)

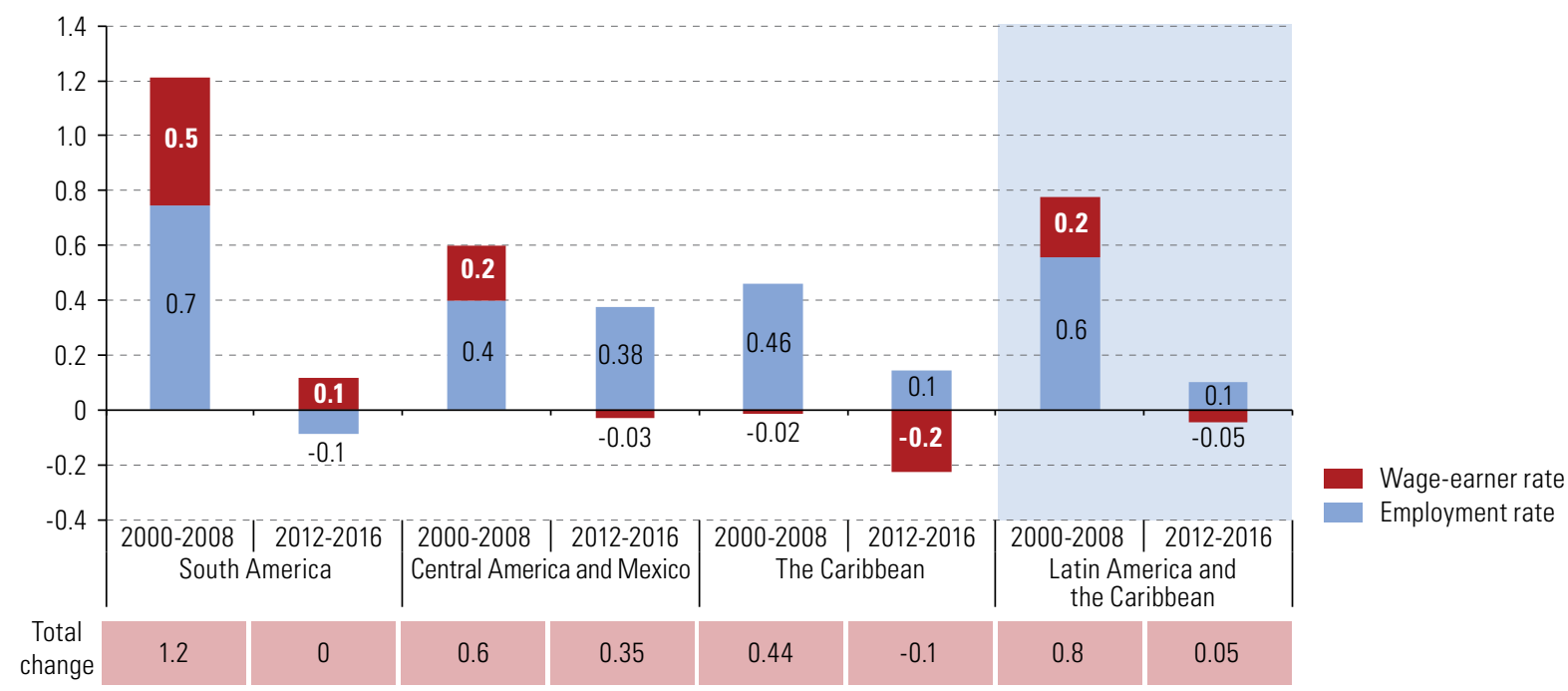

Source: Economic Commission for Latin America and the Caribbean (ECLAC), on the basis of International Labour Organization (ILO).

Figure III.8

Latin America and the Caribbean: rates and gaps in selected indicators by sex, 2000-2016

(Percentage points)

\section{A. Activity rate}

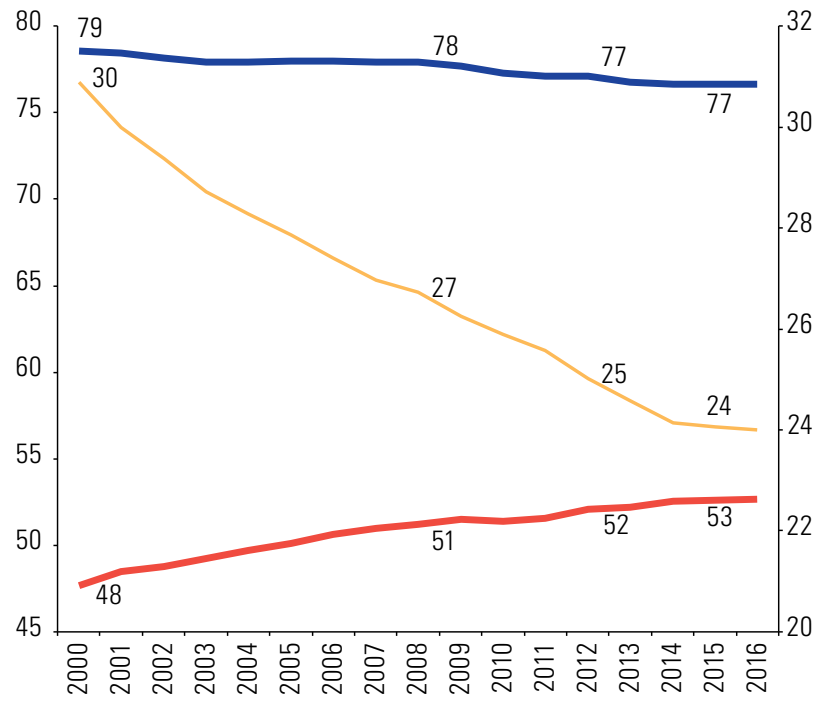

\section{B. Unemployment rate}

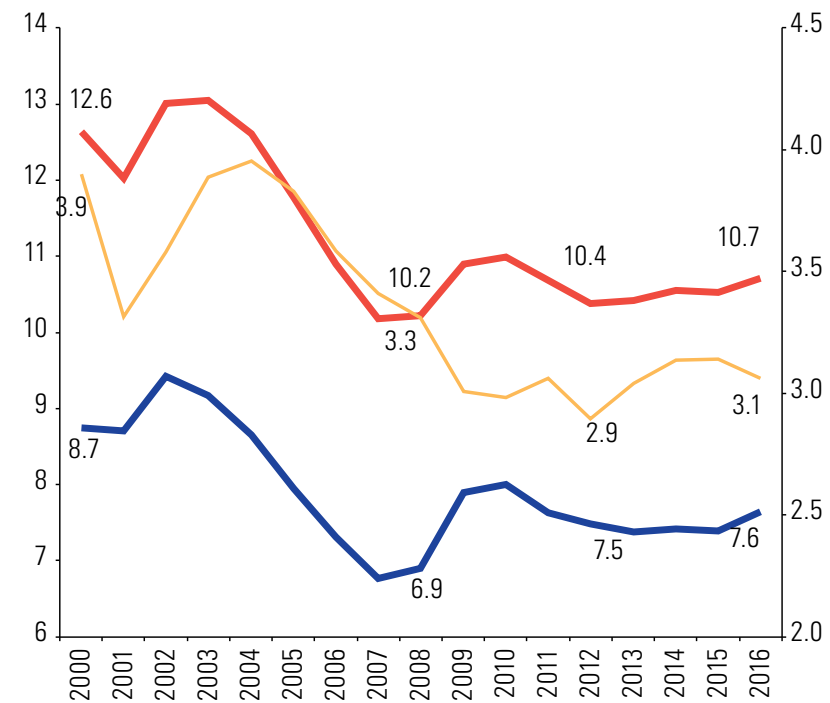

-Men -Gap (right scale) -Women 
Figure III.8 (concluded)

\section{Adjusted employment rate}

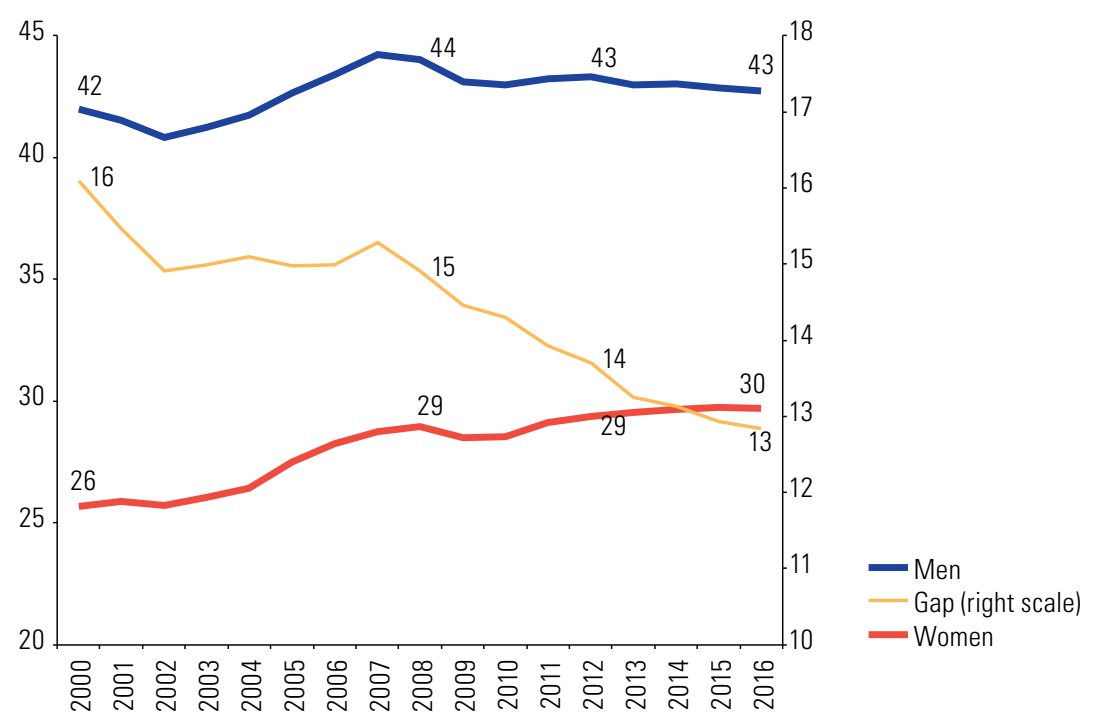

Source: Economic Commission for Latin America and the Caribbean (ECLAC), on the basis of data from the International Labour Organization (ILO).

Figure III.9

Latin America and the Caribbean: average annual change in the adjusted employment rate by component, by sex, selected periods

(Percentages)

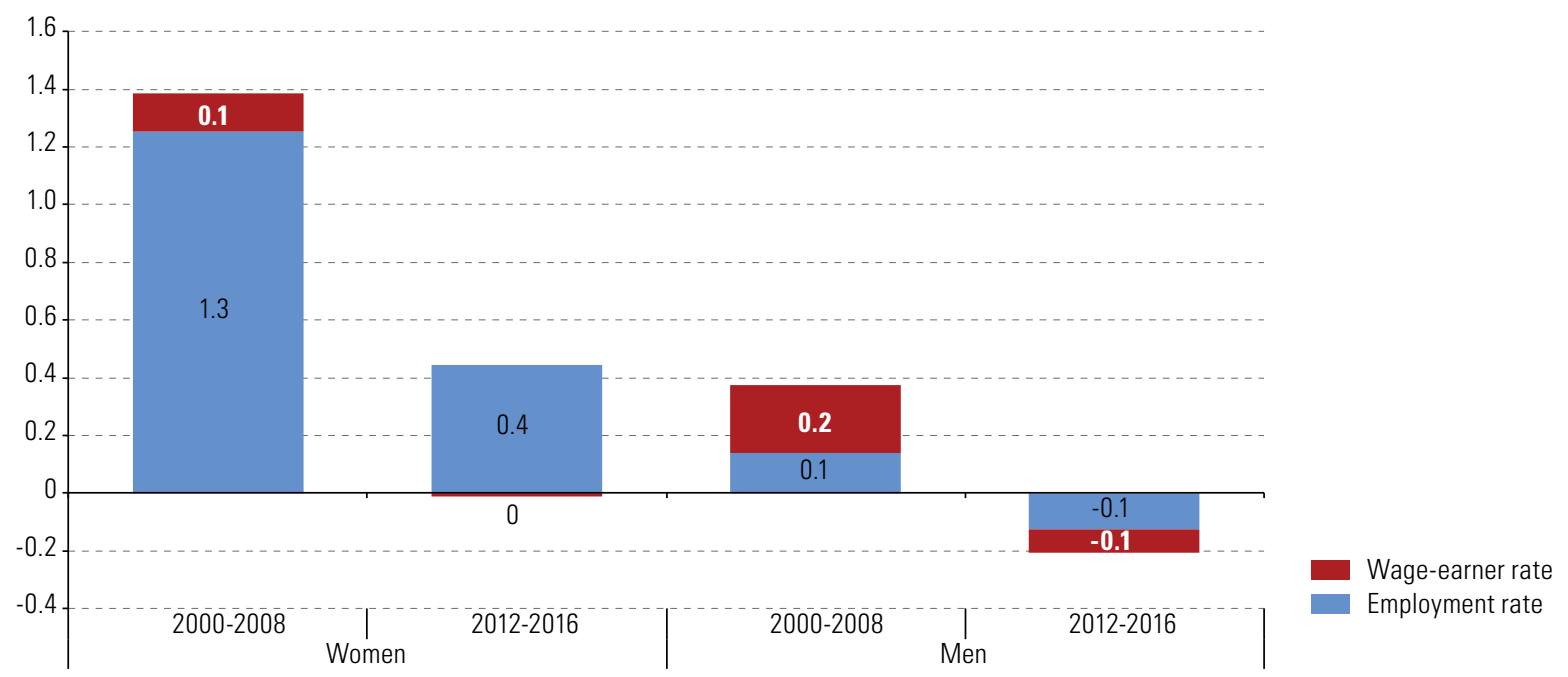

Source: Economic Commission for Latin America and the Caribbean (ECLAC), on the basis of data from the International Labour Organization (ILO).

The different patterns between the sexes were caused by different, but interconnected, employment dynamics, reflecting inequalities and stereotypes present in the labour market as well as the unequal gender division of household work. Women's demands for greater economic autonomy to reverse this inequality are beginning to be reflected in the narrowing of the gap between male and female participation rates (see figure III.8A), although, as in the case of employment rates, there is still a significant differential in the men's favour (20 percentage points according to the latest available data). The gap in unemployment rates is also narrowing, but it remains highly significant (see figure III.8B). 
The combined effect of increased female participation in the labour market and the slowdown in the expansion of female employment has led to a sharper increase in unemployment among women than among men since 2012. ${ }^{14}$ Thus, paradoxically, while the gaps in participation, activity and employment narrowed, the gaps linked to unemployment widened.

Another manifestation of gender inequality can be seen in the types of jobs were women and men find employment. The higher quality (in terms of rights) of men's employment compared to women's employment can be seen by analysing the changes in their sources over time. Figure III.9 illustrates how the increases in the adjusted rate for women can be explained almost exclusively by the effect of the employment rate; by contrast, for men - and regardless of whether the employment rate is rising or falling - it is the result of the wage-earner rate. In other words, not only is the adjusted employment rate of men higher than that of women, but its movements are also generally determined by changes in the wage-earner rate.

The overall picture shows that some progress has been made towards greater economic autonomy for women (Vásconez, 2012; ECLAC, 2016a), albeit with the constraints visible in the continued existence of gaps in job quality and in differentiated unemployment dynamics. There have been no major advances in the division of care work between the sexes, however. Time-use surveys indicate that women spend more than three times as many hours on unpaid work than men, and that women's total work time (paid and unpaid) is also greater than men's (ECLAC, 2016a). Those differences are, in general, sharper among poorer women who cannot purchase care services on the market. ${ }^{15}$

At a time of slower economic growth and job creation, increases in women's participation rate and in the unemployment rate raise questions about whether some of the recent improvements in women's employment situation and economic autonomy can be expected to continue. The historical evidence shows that during slow growth periods, a weaker employment rate affects women and men differently, with relative growth in favour of women. As men's working conditions worsen and household incomes decline, women in the intermediate age group increase their participation in the labour market, which narrows the participation gap; however, discrimination in the labour market leads them into jobs that are precarious, unstable and low paid (Rodríguez Enríquez, 2012). The question is whether the region is at the start of another cycle of greater female economic participation in order to compensate for the decline in household income caused by lower employment among men, or whether this is instead a different cycle in which the improvements of recent years will be consolidated further.

\section{Income equality is no longer falling}

During the most recent period of economic growth, Latin America and the Caribbean saw unprecedented drops in different aspects of income inequality; even after those improvements, however, it remained one of the world's most unequal regions. The progress was primarily a reflection of labour market dynamics complemented by the impact of social protection policies. The recent growth slowdown and its impact on employment could interrupt those ongoing improvements or even send them into reverse.

Income inequalities generated in the production process, which can be seen in the low wage share in national incomes, have long been a hallmark of Latin American and Caribbean economies. ${ }^{16}$ In recent years, significant efforts have been made to collect and analyse data on the functional distribution of income in the region. These have shown that the wage share in income has been declining steadily since the mid-1970s,

14 The exception to this is 2016, when the trend was partially reverted.

15 Women who can afford to pay for care services make larger transfers of time from reproductive activities to the job market. The remainder face a double working day (paid and unpaid) and, generally, worse working conditions: their families are larger, they are further from the public services provided in cities and they have more limited transport facilities for performing tasks related to household management and caregiving.

16 The notion of equality used by ECLAC is not limited to economic equality or equality of means. As explained in chapter IV, it also entails equality in the exercise of rights, capacity-building, mutual acknowledgement among the social actors involved in it and relational equality by gender, ethnicity and race. In economic terms, in addition to inequalities in the monetary incomes available to individuals and households for attaining well-being (personal distribution of income), it also includes the primary distribution determined by the capacity of the factors of production or social classes to appropriate the revenues generated in economic processes (functional distribution of income). Likewise, the distribution of asset ownership — both financial and non-financial alike — is an increasingly important factor. Measuring these latter two dimensions of inequality continues to be a major challenge for the region. This chapter includes some data on the topic. See ECLAC (2016b); Alarco Tosoni (2014); Abeles, Amarante and Vega (2014); and Abeles, Arakaki and Villafañe (2017). 
with the exception of the early 1990s. That trend reverted at some point between 2004 and 2006, when the share of workers' wages in total income increased (see figure III.10), albeit not uniformly across the different subregions and countries. Between 2004 and 2014, of the 16 countries with information available, the participation of wage-earners in total income rose in eight (most notably, Argentina, Uruguay, the Bolivarian Republic of Venezuela, Brazil and Costa Rica), remained virtually unchanged in three and fell in the remaining five.

Figure III.10

Latin America and the Caribbean (overall and by subregion): share of waged employment in GDP, 1950-2014

(Percentages)

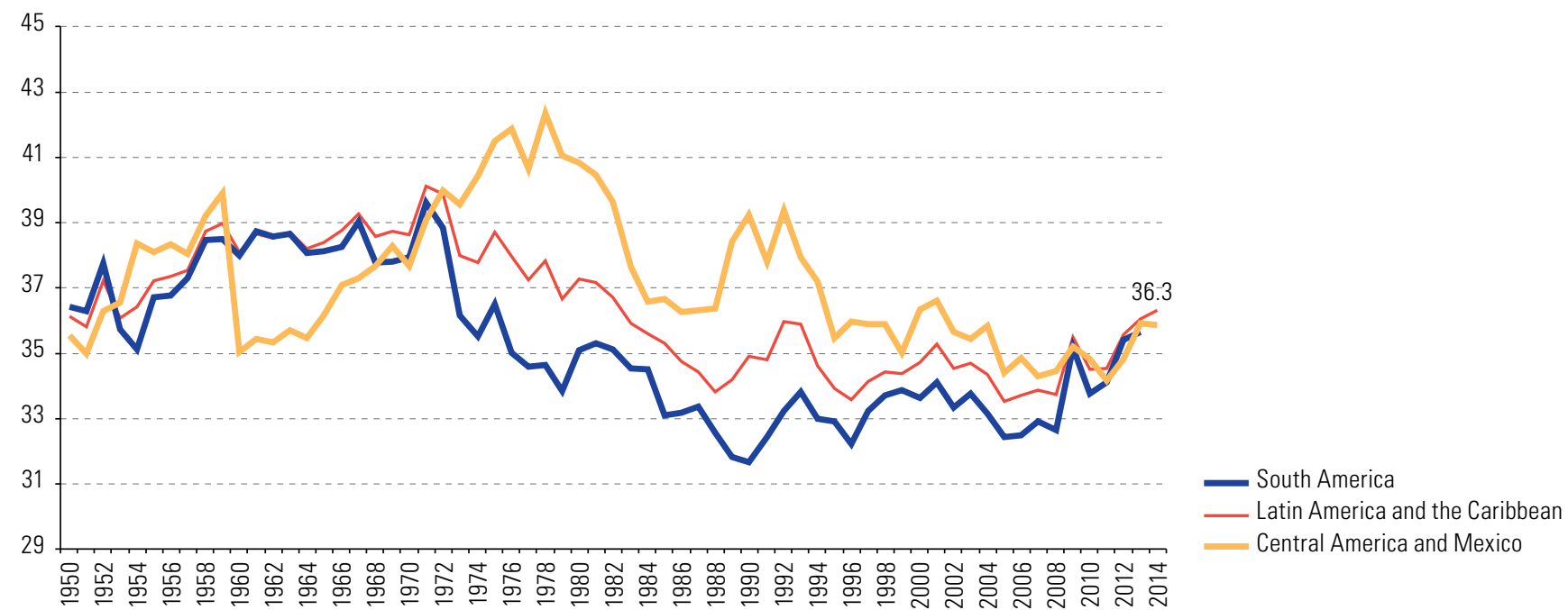

Source: Economic Commission for Latin America and the Caribbean (ECLAC), on the basis of CEPALSTAT [online database] http://estadisticas.cepal.org/cepalstat/ portada.html?idioma=english; United Nations, UNdata database [online] http://data.un.org/; G. Alarco Tosoni, "Wage share and economic growth in Latin America, 1950-2011", CEPAL Review, No. 113 (LC/G.2614-P), Santiago, Economic Commission for Latin America and the Caribbean (ECLAC), 2014; and statistical institutes and central banks of the countries.

Note: Unweighted average of countries with available information: Argentina, Bolivarian Republic of Venezuela, Brazil, Chile, Colombia, Costa Rica, Ecuador, El Salvador, Honduras, Mexico, Nicaragua, Panama, Paraguay, Peru, Plurinational State of Bolivia and Uruguay.

These improvements notwithstanding, in most cases the wage share in income remains below the historic highs of the 1960s and 1970s and much lower than the rates found in developed countries. Even with the caveats that apply to comparisons of workers' shares in national incomes from one country to the next, ${ }^{17}$ figure III.11 shows the region's weak relative position, with the highest share of any Latin American country still below the lowest posted by the extraregional members of the Organization for Economic Cooperation and Development (OECD) and far below the lowest positioned member of the Group of Eight (G8).

Another important factor is the highly unequal distribution among households of the remuneration on factors of production. The distribution of income - mainly payments for labour and transfers from the State- as revealed by household surveys is discussed below. First, however, it must be recalled that the evidence available (albeit scare and fragmented) shows that the distribution of wealth from financial or non-financial assets - which in turn generate the capital revenues and property revenues recorded in the functional distribution of income series - is considerably more unequal than the distribution of disposable income. A study of 26 countries conducted by ECLAC (Amarante and Jiménez, 2015) shows that the average Gini coefficient for wealth inequality stands at 0.68 , whereas the corresponding figure for income inequality is only 0.36. In the few Latin American countries where information is available (Argentina, Brazil and Mexico), the Gini coefficient of wealth is among the highest (i.e. the most uneven) in the sample. Thus, the region's countries also appear to be among the most unequal in the world in terms of the distribution of wealth.

17 See Abeles, Arakaki and Villafañe (2017) for a discussion on the problems inherent to comparison of this indicator between countries, not only because of differences in the share of workers' earnings in income per se but also because of differences in sectoral composition. 


\section{Figure III.11}

Latin America and other regions: wage earners' participation in total income, around $2008^{a}$ (Percentages)

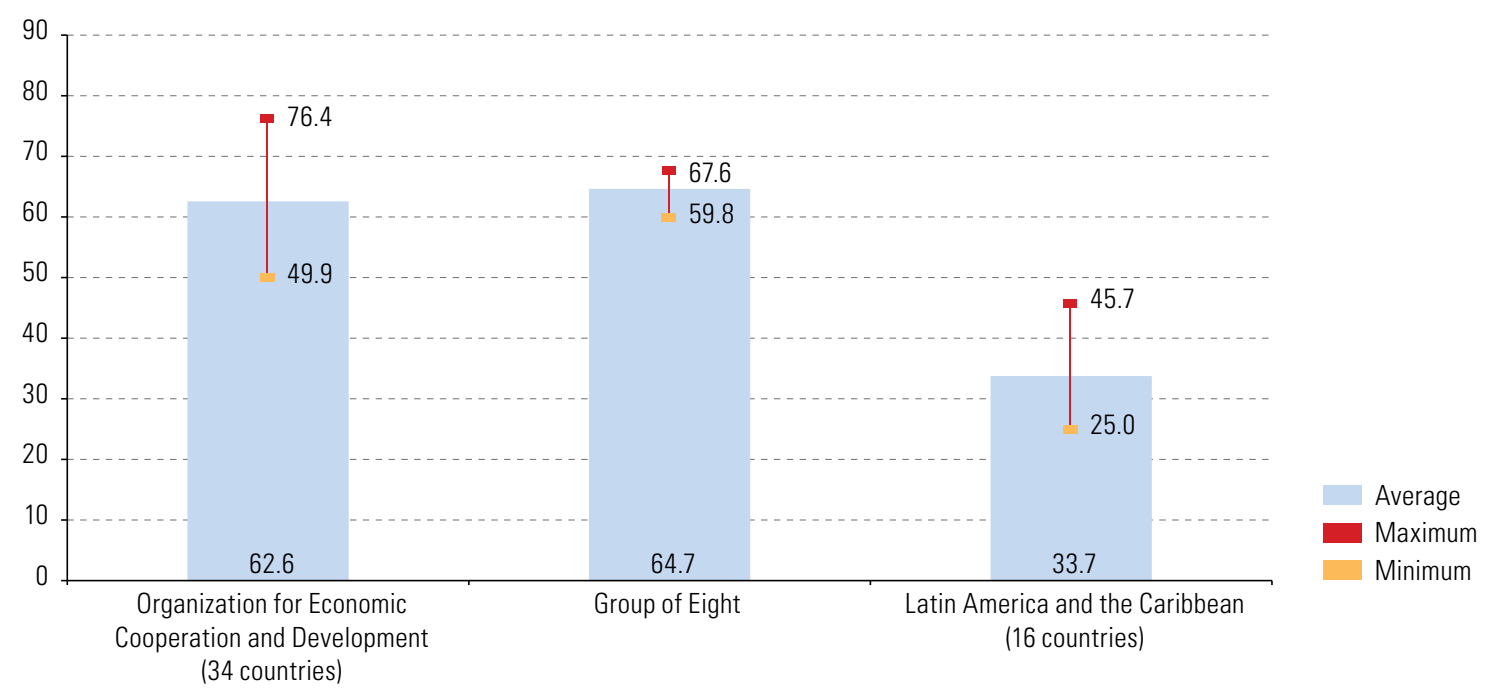

Source: Economic Commission for Latin America and the Caribbean (ECLAC), on the basis of CEPALSTAT [online database] http://estadisticas.cepal.org/cepalstat/ portada.html?idioma=english; Organization for Economic Cooperation and Development (OECD), OECDSTAT database [online] http://stats.oecd.org/; United Nations, UNdata database [online] http://data.un.org/; G. Alarco Tosoni, "Wage share and economic growth in Latin America, 1950-2011", CEPAL Review, No. 113 (LC/G.2614-P), Santiago, Economic Commission for Latin America and the Caribbean (ECLAC), 2014; and statistical institutes and central banks of the countries.

Note: OECD Statistics exclude both Mexico and Chile.

a Regional data are simple averages.

One increasingly important alternative for measuring inequality and the concentration of income and wealth is to include tax records in the analysis. ${ }^{18}$ This serves to assess not only the impact of the tax system on distribution, but also the appropriation of income by elites, which estimates derived from household surveys have historically underestimated. Although this line of work is still embryonic, the data confirm the region's high income concentration. For example, the richest $1 \%$ of the population in Brazil, Chile, Colombia and Mexico capture more than $20 \%$ of total income. As a comparison, in most developed countries (excluding the United States) the incomes of the richest $1 \%$ do not exceed $15 \%$ of total income (see figure III.12).

High inequality in personal income distribution is another hallmark of Latin American societies, where the Gini coefficient for income as revealed by household surveys is substantially higher than in other regions. The least unequal country in the region is more unequal than any OECD member country (excluding Chile and Mexico, its two Latin American members). With the exception of Uruguay, the countries of Latin America have higher Gini coefficients than the average results for all the other world regions except sub-Saharan Africa (see figure III.13).

18 The literature on top incomes (with Piketty, Atkinson, Sanz and Alvaredo among its main exponents) has revived the debate on inequality, concentration and public policies in the region. 
Figure III.12

Selected countries: share in income of the richest $1 \%$ of the population, around 2014

(Percentages)

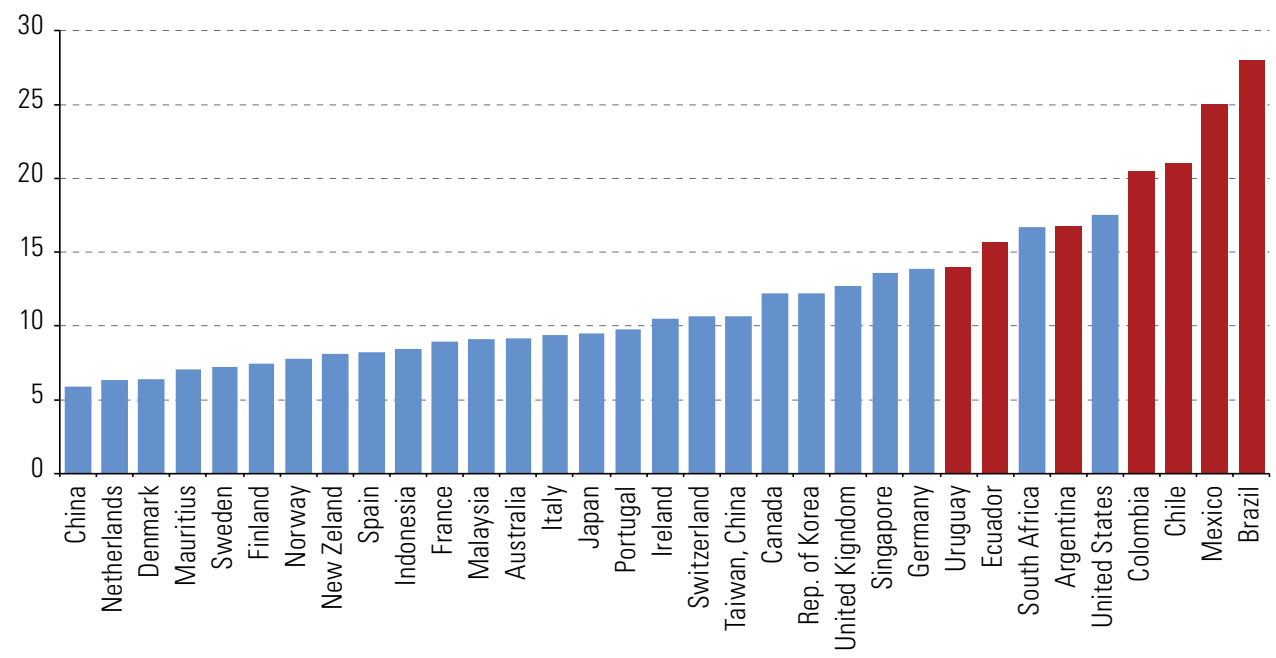

Source: Economic Commission for Latin America and the Caribbean (ECLAC), on the basis of World Wealth and Income Database (WID.world), T. Fairfield and M. Jorratt, "Top income shares, business profits, and effective tax rates in contemporary Chile", The Review of Income and Wealth, vol. 62, No. S1, Hoboken, Wiley, 2016; D. Rossignolo, N. Oliva and N. Villacreses, "Cálculo de la concentración de los altos ingresos sobre la base de los datos impositivos: un análisis para el Ecuador", Macroeconomics of Development series, No. 184 (LC/L.4278), Santiago, Economic Commission for Latin America and the Caribbean (ECLAC), 2016; R. Campos, E. Chávez and G. Esquivel, "Los ingresos altos, la tributación óptima y la recaudación posible", document prepared for the National Public Finance Award, Mexico City, Centro de Estudios de las Finanzas Públicas (CEFP), 2014; M. Morgan, "Extreme and persistent inequality: new evidence for Brazil combining national accounts, surveys and fiscal data, 2001-2015", WID. world Working Paper, No. 2017/12, World Wealth and Income Database (WID.world), 2017.

Figure III.13

Gini coefficient, around $2012^{a}$

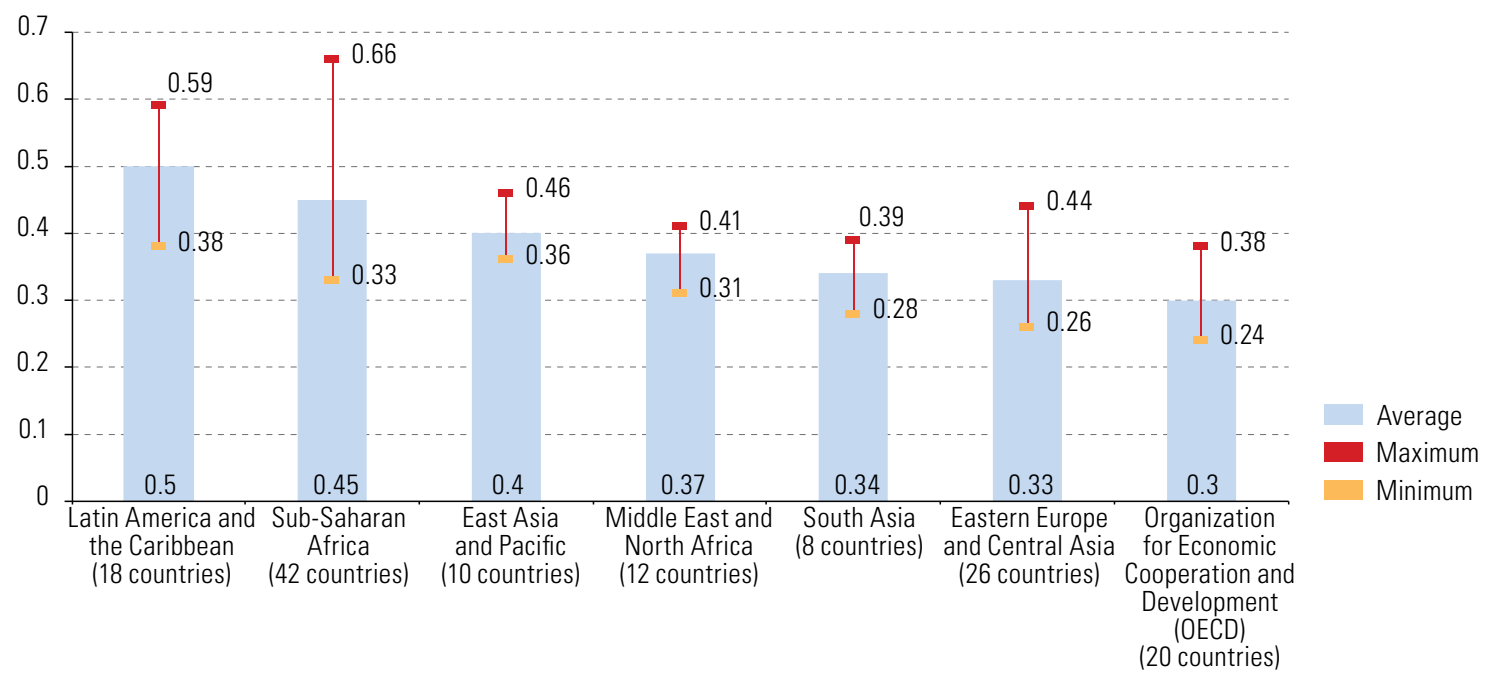

Source: Economic Commission for Latin America and the Caribbean (ECLAC), on the basis of CEPALSTAT [online database] http://estadisticas.cepal.org/cepalstat/ portada.html?idioma=english; Organization for Economic Cooperation and Development (OECD), OECDSTAT database [online] http://stats.oecd.org/; World Bank, World Development Indicators [online database] http://databank.worldbank.org/data/reports.aspx?source=world-development-indicators.

${ }^{a}$ Regional data are simple averages. The calculation uses the last measurement available in each country over the 2002-2012 period.

Although the region's levels of inequality remain among the highest in the world, in the first decade of the new millennium Latin America and the Caribbean - in contrast to other regions - saw the start of a sustained reduction in household income inequality. Between 2002 and 2013, the average Gini coefficient fell from 0.527 to 0.467 . Since 2012, the slowdown in growth has brought some decline in the average rate 
of reduction in income concentration and the pattern has become more uneven from one country to another. Figure III.14 shows that between 2000 and 2008, inequality declined —albeit unevenly-in all the subregions and in almost all the countries for which information is available. The trends began to diverge in 2012, with some countries losing the gains they had made, others seeing the improvements come to a halt and a third group where the coefficient continued to drop at the same rate.

Figure III.14

Latin America and the Caribbean (15 countries): inequality measured by the Gini coefficient of per capita family income, 2002-2016

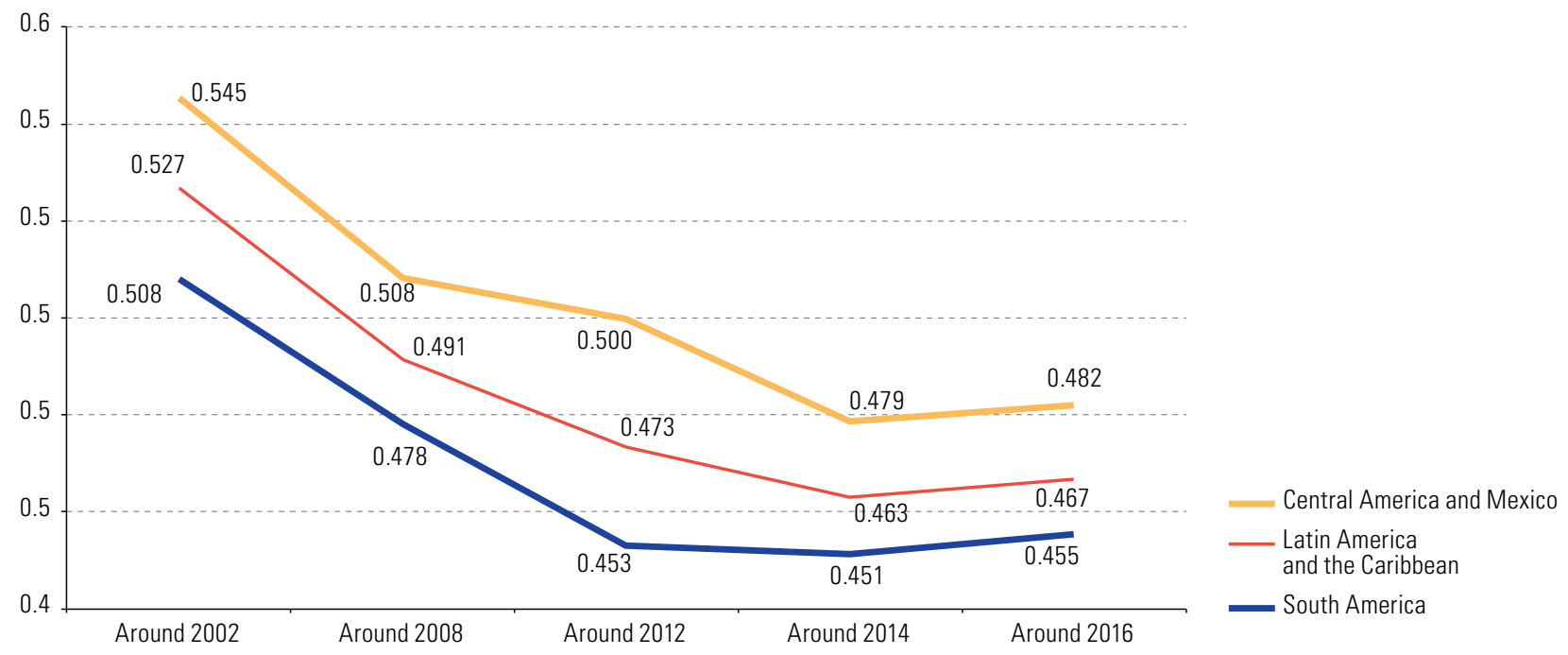

Source: Economic Commission for Latin America and the Caribbean (ECLAC).

Note: Data for Argentina, Bolivarian Republic of Venezuela, Brazil, Chile, Colombia, Costa Rica, Dominican Republic, Ecuador, Guatemala, Honduras, Mexico, Panama, Peru, Paraguay and Uruguay.

a Unweighted averages.

Since the turn of the century, the region has made significant progress in social and labour fronts, strengthening its institutions or introducing new tools that, to different extents, explain the improvements in distributive dynamics. Notable in the labour sphere was the rapid rate of job creation and of improvements in employment quality (in terms of formality and rights), thanks to economic buoyancy and the re-emergence of key labour institutions such as minimum wages, collective bargaining and vocational training policies. Social policy, which will be discussed in chapter IV, saw improvements in social protection systems, especially income transfers targeting the most disadvantaged sectors of the population (Martínez, 2017).

Notwithstanding the progress made in social protection, improvements in the labour market were the strongest driver of the reduction in inequality seen during the years of strongest economic growth. ${ }^{19}$ The reason for this is, primarily, the weight of labour earnings in households' disposable incomes compared to social protection funds. Another factor is the weakness of the region's tax systems, which reproduce the regressive distribution of income caused by the market. The preponderance of labour dynamics in the evolution of inequality can be seen in studies ${ }^{20}$ that show that more than $60 \%$ of the reduction in inequality reported during the phase of fastest economic growth was associated with improvements in wage earnings. In Argentina, Brazil and Uruguay, the falling inequality was mainly the result of the income generated by the wages of registered workers (Bertranou and Maurizio, 2011; Amarante and Arim, 2015). As shown by Amarante

19 Consistent with findings in developed countries, measurements based on household surveys underestimate the scope of non-contributory transfers and understate their impact on reducing poverty and income inequality. In particular, with respect to the conditional transfer programmes in place in 13 of the region's countries between 2011 and 2015, the surveys underestimated the number of recipients by 13\%. In the case of social pensions, surveys underestimated total income by 21.1\% compared to administrative records (Villatoro and Cecchini, 2018).

20 Countries and periods examined: Argentina (2003-2010), Brazil (2001-2009) and Mexico (2000-2008). 
and Jiménez (2015), the evolution of inequality in the region can be explained primarily by the improvements in the distribution of labour income, which was partly the result of decreasing pay gaps between workers with different skills levels. However, those authors also emphasize the strengthening of labour institutions and redistributive policies.

To summarize, the region has seen significant improvements in distribution since the early 2000s. However, it remains the world's most unequal region in terms of the relationship between capital and labour (functional distribution), the distribution of assets (wealth) and the distribution of income among households and individuals, largely because of the disproportionate capture of income by the elites. Given that the improvements largely reflected labour dynamics, they could be affected by the weakening of the region's economies in recent years. A similar concern, albeit supported by less clear-cut evidence, exists regarding the dynamics of poverty.

\section{Poverty rates have risen}

The reduction in poverty and extreme poverty rates achieved by the region before the global crisis came to a standstill between 2012 and 2014, then went into reverse (see figure III.15). For the region overall, the incidence of poverty — which had fallen at an average annual rate of 4.8\% between 2002 and 2008- rose by an average of 1.8\% per annum between 2012 and 2016, with a sharper spike between 2014 and 2016. In Central America and Mexico, where the pre-crisis reduction had not been as significant as in South America, the trend stagnated after that point.

Figure III.15

Latin America and subregions (15 countries): incidence of poverty in households, 2002-2017

(Percentages)

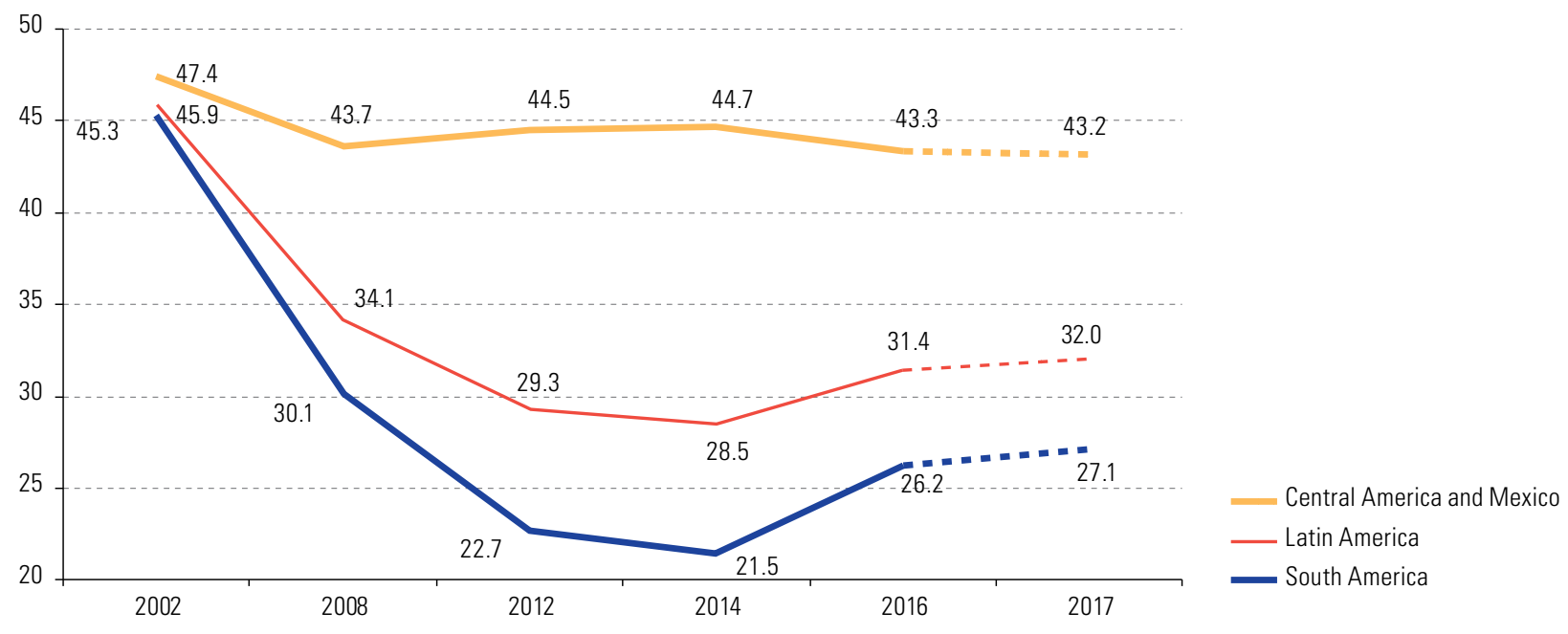

Source: Economic Commission for Latin America and the Caribbean (ECLAC).

Note: Data for Argentina, Bolivarian Republic of Venezuela, Brazil, Chile, Colombia, Costa Rica, Dominican Republic, Ecuador, Guatemala, Honduras, Mexico, Panama, Paraguay, Peru and Uruguay.

a Weighted average.

As with income distribution, changes in poverty were also closely linked to labour dynamics. In several of the region's countries, improvements in employment were the main factor behind the fall in poverty during the pre-crisis period (Beccaria and others, 2013). ${ }^{21}$ Although the results vary from one country to the next, between $30 \%$ and $70 \%$ of those who escaped poverty did so on the back of employment-

21 Countries and periods examined: Argentina (2003-2006), Brazil (2003-2006), Costa Rica (2006-2008), Ecuador (2004-2008) and Peru (2002-2006). Methodology: household-level analysis with household survey panels. 
related developments alone (new jobs or wage increases). The second reason was the combination of employment-related developments and non-work events (in the domain of social protection), which together accounted for between $60 \%$ and $80 \%$ of the total number who escaped poverty.

The reduction in poverty and extreme poverty during the economic buoyancy years affected women and men differently. ECLAC (2016a) has drawn attention to the overrepresentation of women among the poor. Even in countries that saw significant reductions in overall levels of poverty and extreme poverty, the figures for women, while improving in absolute terms, worsened in comparison to those of men. One additional problem underlying this dynamic is the proportion of women without income of their own. While significant improvements were seen in this indicator (10 percentage points), in 2014 it was still the case that one out of every three women aged over 15 years and not in full-time education had no independent income. Among men, the ratio was one in 10.

Even with the progress made regarding women's economic autonomy, the labour market is still marked by strong discrimination (ECLAC, 2016a). This can be seen in women's relatively disproportionate engagement in self-employment and family microenterprises: activities that demand fewer skills, receive lower pay and lack the protection of social security (Vásconez, 2012).

\section{Fiscal policy fails to reduce inequality in the region}

\section{Tax revenues are biased against equality}

The ability of fiscal policy to reduce distributive inequality depends on the volume and composition of tax revenues. The region's tax burden is much lower than in the developed world, and the share of direct taxes on income and property (especially personal income tax) within the total is also lower.

The levels and composition of tax revenues available to each country are fairly uneven. In some countries, $90 \%$ of public revenue or more comes from taxation, while in others, non-tax income from activities such as hydrocarbons or mining also play an important part (see figure III.16). Revenue from such sources is more volatile, which makes the fiscal arena subject to swings in international commodity prices.

Figure III.16

Latin America (18 countries): tax burden by income type and country, 2016

(Percentages of GDP)

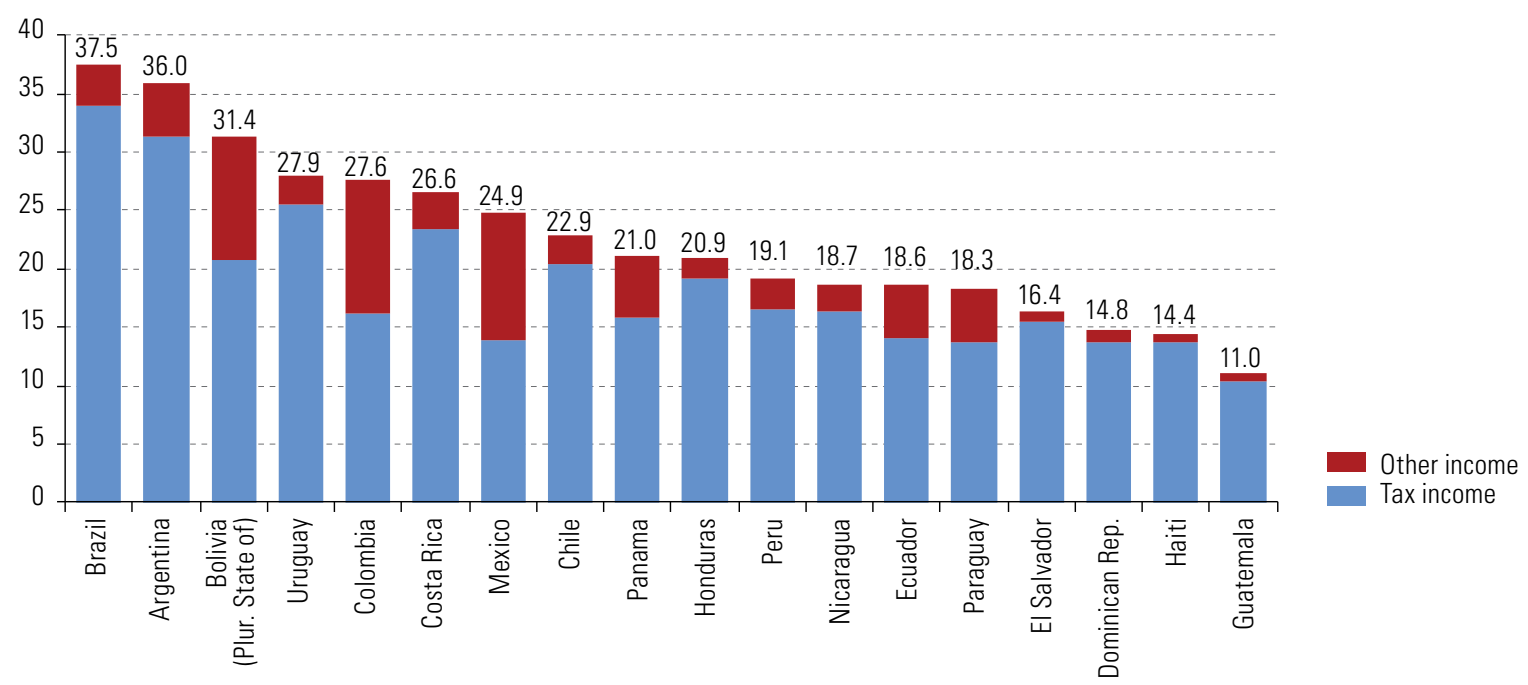

Source: Economic Commission for Latin America and the Caribbean (ECLAC), on the basis of official figures.

Note: Figures refer to central covernment; exceptions are non-financial public sector for Argentina, Colombia, Mexico and Panama, and general government for Brazil, Chile, Costa Rica and the Plurinational State of Bolivia. Tax income includes social security contributions. 
Many countries have increased their tax burden in recent years, as a result of a series of reforms aimed at strengthening tax collection, among other objectives. Nevertheless, this burden remains relatively low in relation to the respective countries' levels of development. Figure III.17 identifies three groups of countries: one group with higher tax burdens than are typical among countries with similar levels of per capita GDP (notably, Argentina, Brazil and the Plurinational State of Bolivia and, to a lesser extent, Nicaragua and Uruguay), a second group with tax burdens that are similar to those of other economies with similar levels of development (Costa Rica, Haiti and Honduras) and a third group (11 countries) with lower tax burdens that those of countries with similar per capita GDP.

Figure III.17

Latin America (19 countries): tax burden and per capita GDP, around 2013

(Percentages of GDP and logarithms)

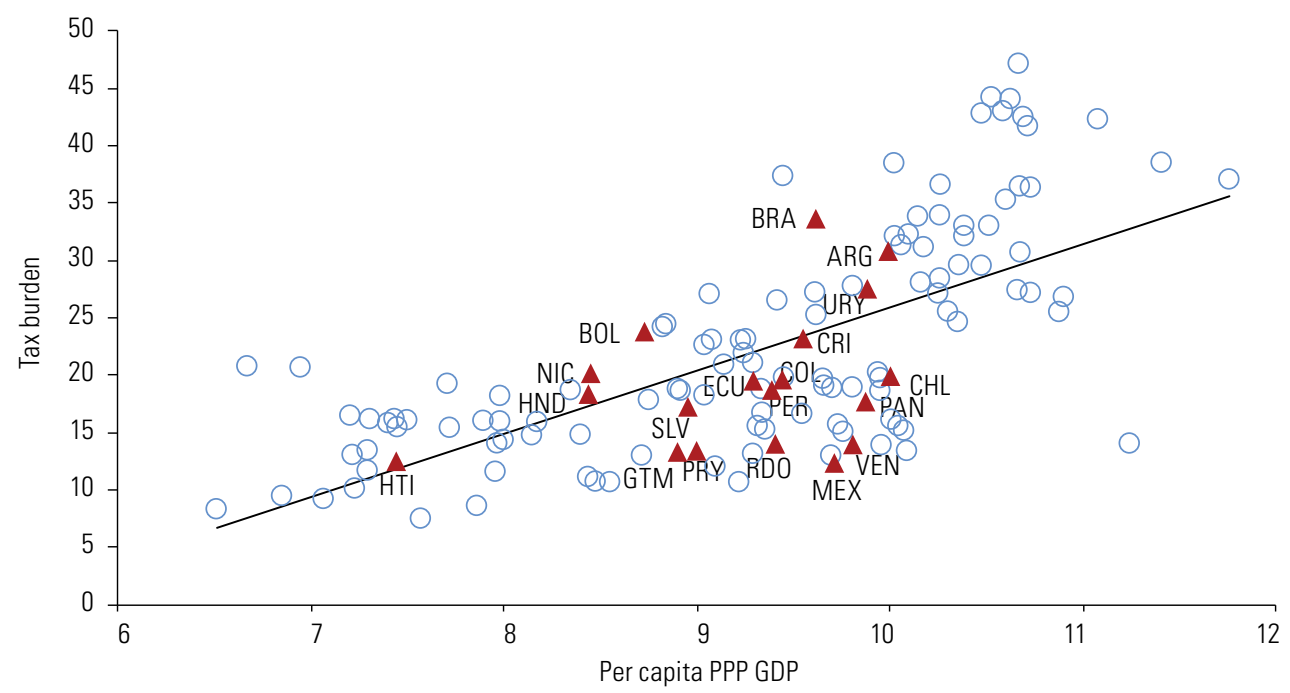

Source: Economic Commission for Latin America and the Caribbean (ECLAC), on the basis of CEPALSTAT [online database] http://estadisticas.cepal.org/cepalstat/ portada.html?idioma=english; Organization for Economic Cooperation and Development (OECD), OECDSTAT database [online] http://stats.oecd.org/; World Bank, World Development Indicators [online database] http://databank.worldbank.org/data/reports.aspx?source=world-development-indicators.

Note: Most recent data available from the 2011-2013 period. For Latin American countries, figures refer to central government; exceptions are general government for Argentina, Brazil, Chile, Colombia, Costa Rica, Mexico and the Plurinational State of Bolivia.

${ }^{a}$ In purchasing power parity (PPP).

The region's average tax burden is half the average reported in 15 countries of the European Union and 13.5 percentage points of GDP below the OECD average (see figure III.18). This difference is largely due to the different composition of tax revenues, in particular the lower relative revenues from direct (progressive) taxes on incomes and property. Most especially, the difference is because of the low collection of personal income tax in the region's countries, where fewer than one third of fiscal revenues comes from direct taxes and the bulk of the burden falls on consumption taxes and other indirect taxes, which are heavily regressive. Between 2010 and 2015, the region collected an average of 9.5\% of GDP in indirect taxes (compared to 10.8\% of GDP in the OECD countries). At the same time, it raised $6.0 \%$ of GDP in direct taxation, well below the $13.4 \%$ reported in the OECD countries. 
Figure III.18

Latin America (18 countries), OECD (34 countries) and European Union (15 countries): composition of tax revenue, 1990-2015

(Percentages of GDP)

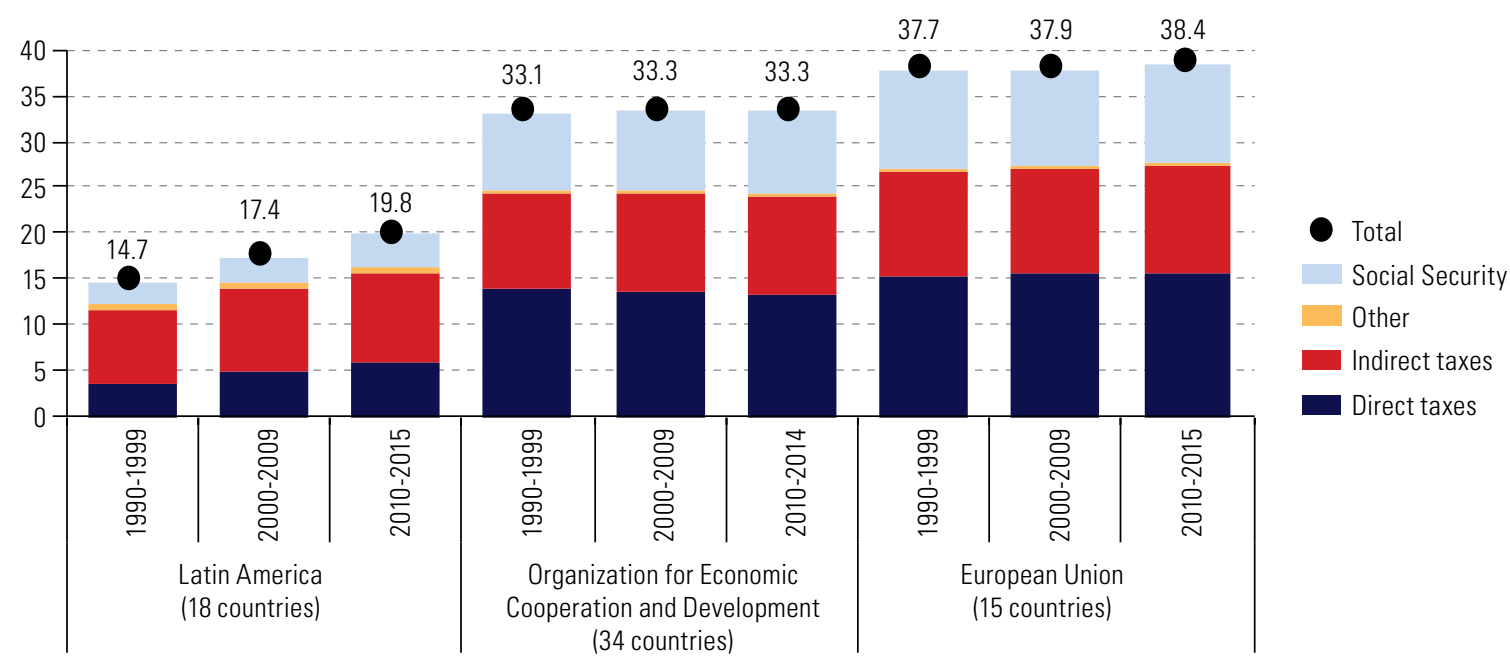

Source: Economic Commission for Latin America and the Caribbean (ECLAC), on the basis of data from Organization for Economic Cooperation and Development (OECD). Note: Figures for OECD member countries' averages cover up to 2014.

The low tax burden in the region and the regressive bias of its composition limit the ability of fiscal policy to improve income distribution. A study of 16 countries shows that before considering public revenues and expenditures, income inequality is only slightly higher in Latin America than in OECD in the average figures, and is in fact lower in some countries of the region. The difference between the two groups of countries emerges after taxation and social spending, an area where the region is much less effective than the developed world in improving the distribution of disposable income. Hanni, Martner and Podestá (2017, p. 130) estimated Gini coefficients before and after direct taxes and cash and in-kind transfers and concluded that fiscal policy produces a smaller reduction in the Gini index in Latin America (9 percentage points) than in the OECD countries (23 percentage points) or the European Union (26 percentage points).

\section{Weak redistributive capacity of fiscal policy}

The main difference in the redistributive capacity of fiscal policy between the region and the developed world arises from cash transfers and direct taxes, since the fall in the Gini coefficient produced by the distribution of expenditure on education and health is similar in the two groups. On average, the region's Gini coefficient falls by just three percentage points as a result of direct fiscal measures, while it drops a further six through the public provision of education and health services. ${ }^{22}$ In European and other OECD economies, however, the combined redistributive impact of cash transfers and personal income tax averages around 17 and 19 percentage points respectively, while redistribution through public expenditure accounts for between 6 and 7 percentage points. Figure III.19 shows that the region's fiscal policy tools for reducing inequality vary widely in their effectiveness.

22 This outcome, where public social spending has a greater redistributive effect than direct taxes in the Latin American and Caribbean countries, is consistent with other studies conducted in both Latin America and the other OECD countries (Goñi, López and Servén, 2011; Lustig, Pessino and Scott, 2013; Joumard, Pisu and Bloch, 2012; Barreix, Bes and Roca, 2009). 
Figure III.19

Latin America and the Caribbean (16 countries): inequality reduction by fiscal policy instruments, measured by the Gini coefficient, around 2011

(Percentage points)

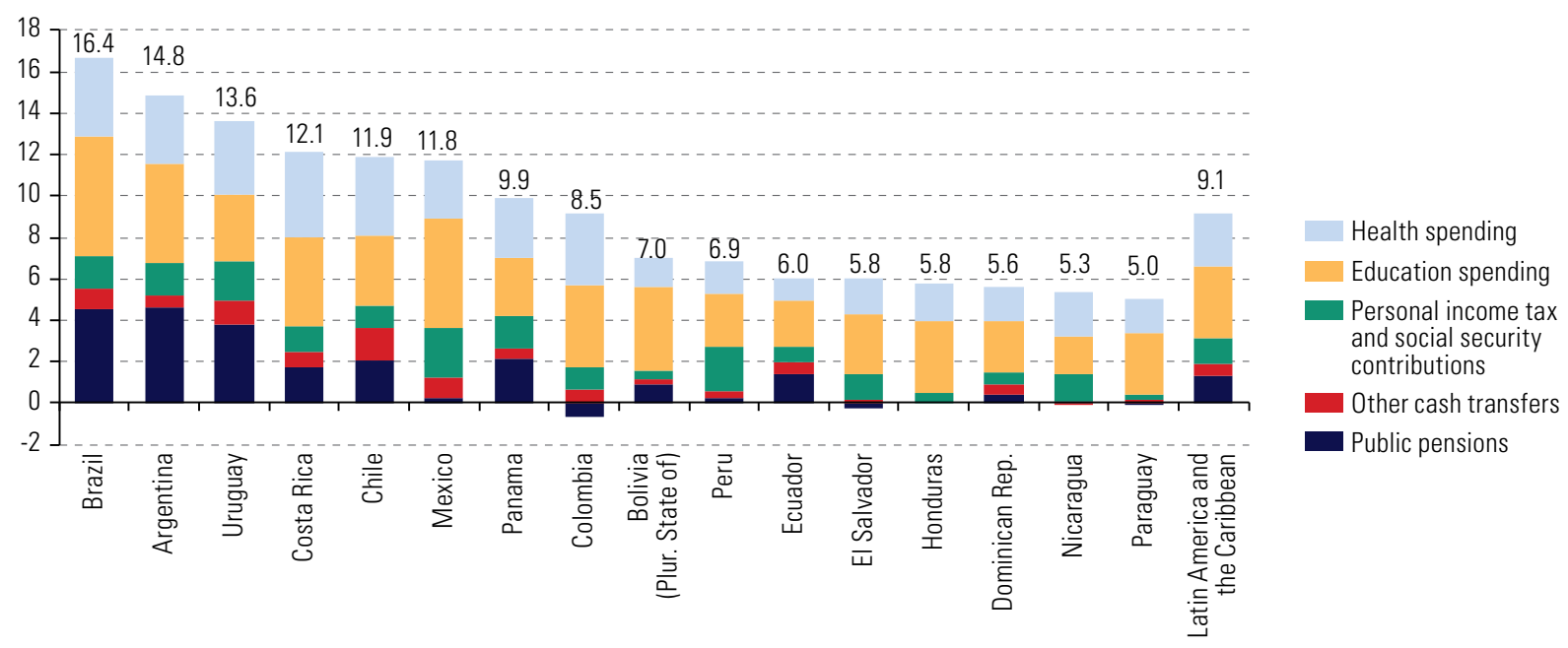

Source: M. Hanni, R. Martner and A. Podestá, "El impacto redistributivo de la acción fiscal en América Latina: los efectos de impuestos y transferencias públicas", Los efectos de la política fiscal sobre la redistribución en América Latina y la Unión Europea, Colección Estudios, No. 8, Madrid, EUROsociAL Programme, 2014.

Note: The information available from household surveys does not allow estimation of the redistributive impact of public cash transfers in Honduras.

\section{(a) Direct income taxes}

The low levels of direct income tax collection are primarily a reflection of low rates of personal income tax. Measured as a proportion of GDP, corporate income tax collections do not differ greatly between the countries of Latin America (3.4\%) and the developed countries $2.9 \%$ in OECD and $2.7 \%$ in the European Union). The tax burden on household incomes, by contrast, accounts for a significantly smaller proportion of GDP in Latin America (1.4\%) than in either the OECD countries (8.4\%) or the European Union (10\%). Thus, as table III.2 shows, the region's countries collect the equivalent of $4.7 \%$ of GDP through income tax, with businesses accounting for $72 \%$ of that total and individuals contributing $28 \%$. In the OECD countries, and in the European Union countries included in the table, those proportions are inverted. This differential in personal income tax collections is the most significant gap between the tax structures of these groups of countries.

Table III.2

Latin America (18 countries): collection and relative share of corporate and personal income tax, around 2011 (Percentages of GDP and percentages)

\begin{tabular}{|c|c|c|c|c|c|}
\hline & & $\begin{array}{l}\text { Collection } \\
\text { rcentage of }\end{array}$ & & & \\
\hline & Personal & Corporate & Total & Personal & Corporate \\
\hline Argentina & 1.7 & 3.7 & 5.3 & 31.1 & 68.9 \\
\hline Bolivia (Plurinational State of) & 0.2 & 3.4 & 3.6 & 4.6 & 95.4 \\
\hline Brazil & 2.4 & 3.7 & 6.1 & 39.6 & 60.4 \\
\hline Chile & 1.4 & 6.3 & 7.7 & 18.6 & 81.4 \\
\hline Colombia & 0.2 & 4.6 & 4.8 & 4.4 & 95.6 \\
\hline Costa Rica & 1.3 & 2.7 & 4.0 & 32.9 & 67.1 \\
\hline Dominican Republic & 0.9 & 2.1 & 2.9 & 30.5 & 69.5 \\
\hline Ecuador & 0.6 & 3.5 & 4.1 & 14.8 & 85.2 \\
\hline El Salvador & 2.2 & 2.4 & 4.5 & 48.1 & 51.9 \\
\hline Guatemala & 0.2 & 2.9 & 3.1 & 7.7 & 92.3 \\
\hline Honduras & 1.2 & 3.5 & 4.7 & 26.1 & 73.9 \\
\hline
\end{tabular}


Table III.2 (concluded)

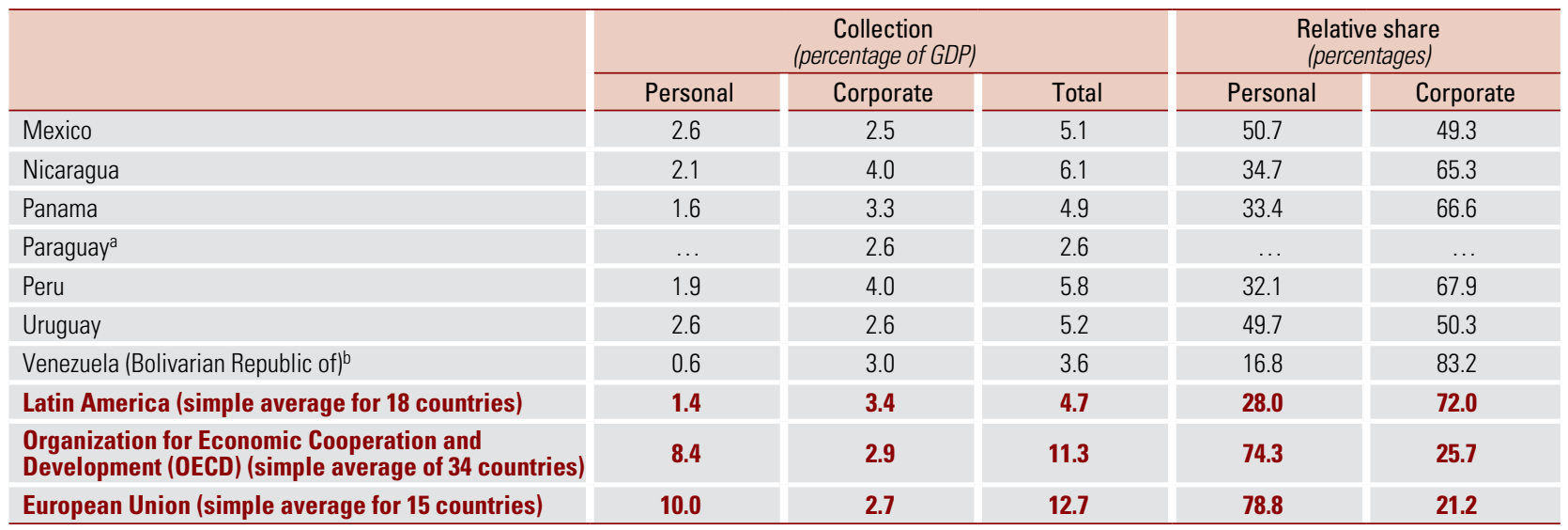

Source: Economic Commission for Latin America and the Caribbean (ECLAC), on the basis of CEPALSTAT [online database] http://estadisticas.cepal.org/cepalstat/ portada.html?idioma=english; Inter-American Development Bank (IDB), Inter-American Center of Tax Administrations (CIAT) and Organization for Economic Cooperation and Development (OECD).

a Personal income tax was introduced in Paraguay on 1 August 2012.

${ }^{\mathrm{b}}$ Estimates for the shares of personal and corporate income tax in the Bolivarian Republic of Venezuela according to their relative shares in budget information.

The limited redistributive capacity of personal income tax is essentially a product of the low tax burden borne by richer taxpayers, and it represents one of the clearest manifestations of the culture of privilege discussed in chapter VI.

\section{(b) Direct property taxes}

The limited magnitude of taxes on wealth is another endemic weakness in the region's tax systems; it erodes their tax bases and limits their redistributive capacity. Collections of such taxes have historically been low and, as a result, have been virtually absent from discussions about the fiscal tools available to improve income distribution. Direct taxation on property, which covers a wide range of instruments, has great potential for taxing the most affluent households. In addition to taxes levied on the ownership or possession of real estate, the region also uses taxes on inter vivos real estate transfers (gifts) and taxes on automobile ownership, while some countries also have a tax on net worth. ${ }^{23}$ In 15 Latin American countries, revenues from property taxes for the 1990 to 2014 period amounted to an average of $0.8 \%$ of GDP, which was less than half the OECD average for the same period (1.9\% of GDP).

\section{Tax evasion: a manifestation of the culture of privilege}

High tax evasion is another reason for the region's relative paucity of tax revenue and high levels of inequality. According to the latest information available, the average rate of VAT evasion stands at $27.8 \%$, although the figure varies from one country to the next (ECLAC, 2016d). On the one hand stands Uruguay, with the region's lowest rate of evasion; then comes a group of countries with rates close to or higher than $20 \%$ but below $30 \%$ (several South American countries and Mexico); and, finally, there is a group with evasion rates in excess of $30 \%$ (the Central American countries, Ecuador and Paraguay). Estimates of income tax evasion are much higher: the average for the region is calculated at almost $50 \%$ (47.5\%). At one extreme are Costa Rica, the Dominican Republic, Ecuador and Guatemala, with rates of about $65 \%$, and, at the other, Brazil, Chile and Mexico, with substantially lower values ranging from $28 \%$ to $31 \%$.

23 One particular case, largely distinct from other wealth taxes, is taxes on financial and capital transactions and movements. These have adopted by a limited number of countries over the past decade and have yielded acceptable levels of revenue (Gómez Sabaini and Morán, 2013). 
ECLAC estimates that tax non-compliance equates to 2.4 percentage points of GDP in the case of VAT and 4.3 percentage points of GDP in the case of income tax (assuming an effective collection of that tax equal to 68 GDP points). Taken together, these amounts exceed the average share of GDP that Latin American governments allocate to public investment —which stood at $6.7 \%$ of GDP in 2015 (ECLAC, 2017b)—and are equal, for example, to more than 13 times the total public investment on research and development (R\&D) that year.

Figure III.20

Latin America (15 countries): tax collection and estimated tax evasion, $2015^{\mathrm{a}}$

(Percentages of GDP and billions of dollars)

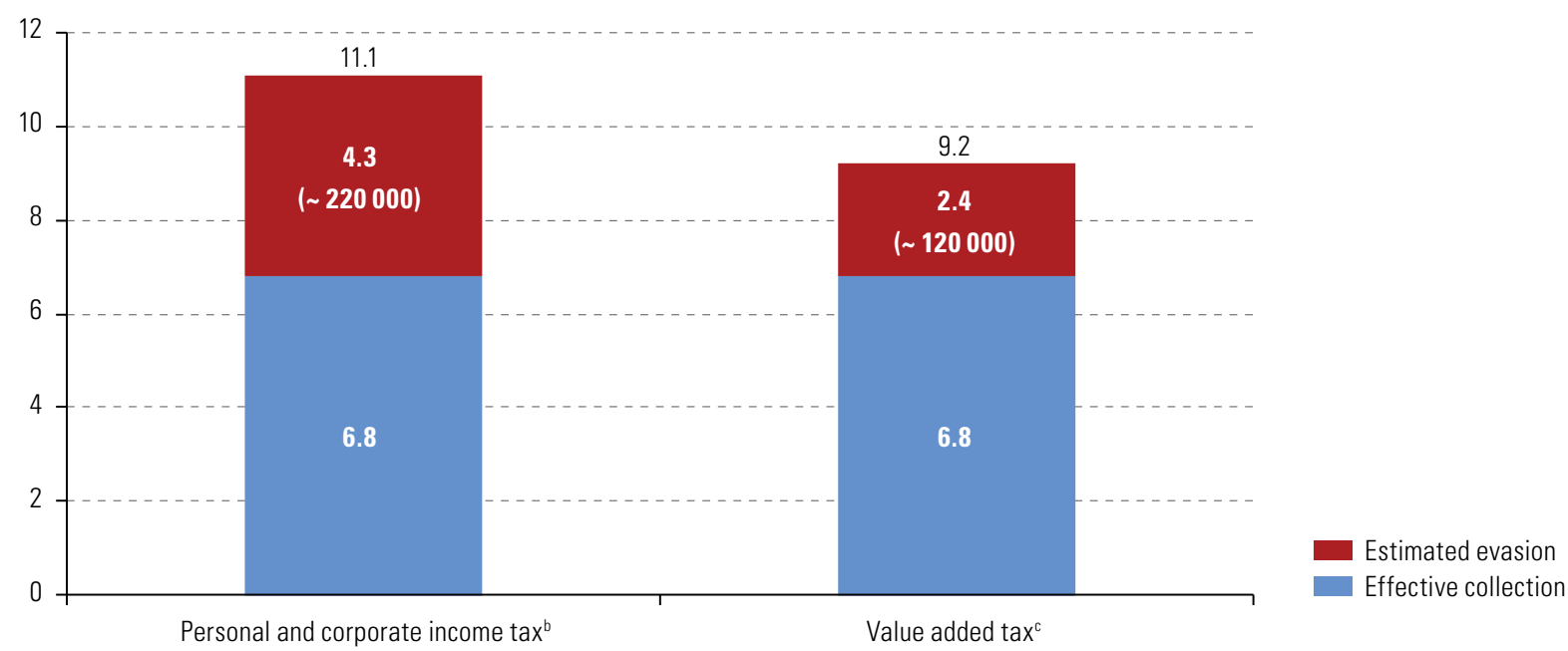

Source: Economic Commission for Latin America and the Caribbean (ECLAC).

a Effective collection and estimated evasion are calculated on the basis of the take for the two taxes expressed in dollars; the sum of this value is presented as a percentage of the GDP of the reporting countries (weighted average). Finally, the percentages are applied to the GDP of Latin America to estimate the regional values in dollars.

${ }^{b}$ Estimate on the basis of data from Argentina, Brazil, Chile, Costa Rica, Ecuador, El Salvador, Guatemala, Mexico and Peru.

${ }^{c}$ Estimate on the basis of data from Argentina, Brazil, Chile, Colombia, Costa Rica, the Dominican Republic, Ecuador, El Salvador, Guatemala, Mexico, Nicaragua, Panama, Peru, the Plurinational State of Bolivia and Uruguay.

Particularly noteworthy in this regard is evasion by transnational companies in their international operations - through international tax arbitrage — and by extremely wealthy individuals. UNCTAD (2015) estimated that the total tax revenue lost between 2009 and 2012 amounted to US\$ 90 billion annually in developing countries (US\$ 200 billion globally). Furthermore, OECD (2015) found that the tax revenues lost through base erosion and profit shifting (BEPS) mechanisms amounted to between US\$ 100 billion and US\$ 240 billion in 2014, and the relative impact on developing countries is estimated to be heavier because of their higher dependence on corporate income tax.

ECLAC (2016d) has estimated the illicit financial outflows from trade misinvoicing at over US\$ 92 billion in 2015 , or about $1.5 \%$ of regional GDP (see figure III.21). The funds denied to treasuries as a result of that practice are estimated at some $0.5 \%$ of GDP.

The erosion of the tax base takes a particular shape in developing countries, especially among extractive sectors that play a leading role in the economy; for example, Hanni and Podestá (2016) show that illicit financial flows from mining in the Andean countries arise from problems in the inspection of the industry's exports. 
Figure III.21

Latin America and the Caribbean: estimated value of trade misinvoicing, 2004-2015

(Billions of dollars)

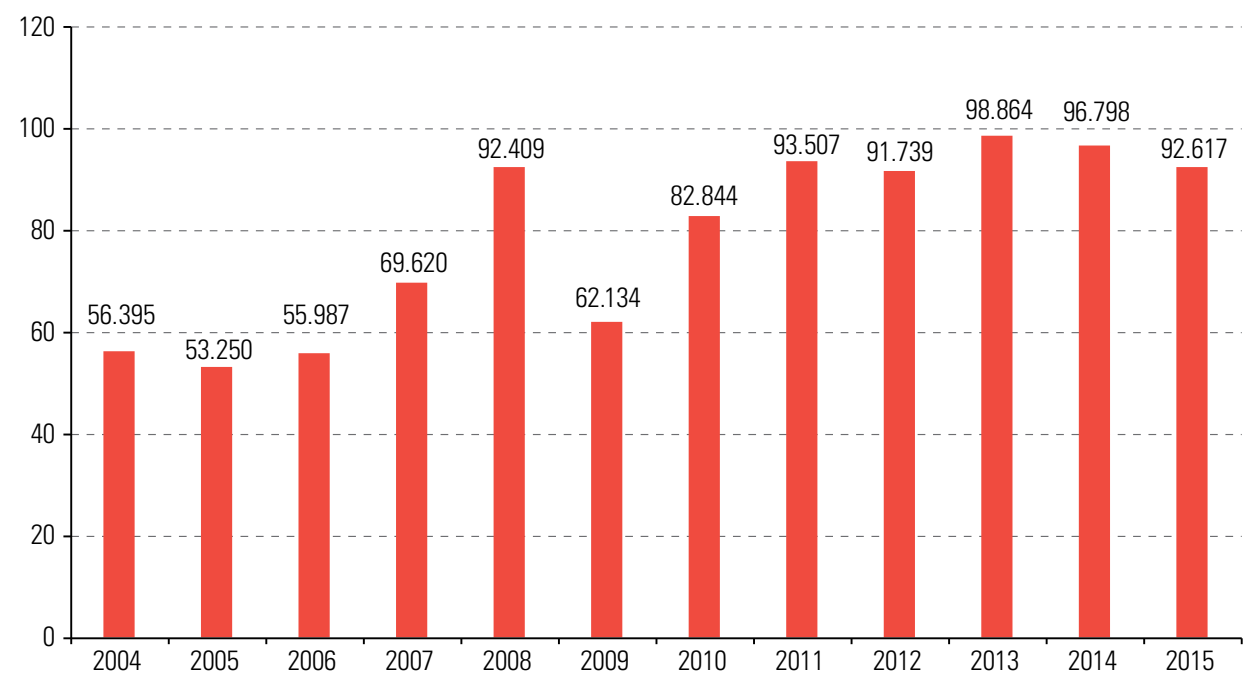

Source: Economic Commission for Latin America and the Caribbean (ECLAC).

Evasion and avoidance are not found solely among companies, however: such practices are also common among high net worth individuals. Calculations indicate that $8 \%$ of the world's wealth, equivalent to US\$ 7.6 trillion, is held in tax havens (see table III.3). It is estimated that some US\$ 700 billion of this belongs to Latin Americans, representing $22 \%$ of the region's financial wealth, and that the bulk of this amount (around $80 \%$ ) has not been declared to the relevant tax authorities. Recent programmes for regularizing unreported assets have provided evidence of the rampant levels of evasion among high-income sectors. ${ }^{24}$

Table III.3

National financial wealth in tax havens, 2013

(Trillions of dollars and percentages)

\begin{tabular}{l|c|c}
\hline \multicolumn{1}{c}{ Country or region } & Offshore financial wealth & \multicolumn{2}{c}{$\begin{array}{c}\text { Percentage of total financial wealth } \\
\text { of country or region held offshore }\end{array}$} \\
\hline Europe & 2.6 & 10 \\
\hline United States & 1.2 & 4 \\
\hline Asia & 1.3 & 4 \\
\hline Latin America & 0.7 & 22 \\
\hline Africa & 0.5 & 30 \\
\hline Canada & 0.3 & 9 \\
\hline Russian Federation & 0.2 & 52 \\
\hline Gulf States & 0.8 & 57 \\
\hline World & 7.6 & 8 \\
\hline
\end{tabular}

Source: G. Zucman (2015), The Hidden Wealth of Nations: The Scourge of Tax Havens, Chicago, University of Chicago Press, 2015.

The predominance of regressive tax systems that are highly dependent on indirect taxes and collect relatively less revenue from direct taxes on income and property, especially from personal income tax, explains the reduced fiscal space available in most of the region's countries and the weak redistributive impact of State action in general.

24 Assets equal to $1.8 \%, 0.8 \%$ and $0.6 \%$ of GDP were regularized in Argentina, Brazil and Chile, respectively. 
A low tax burden, with a clear regressive bias, hampers not only the State's redistributive functions but also the impact of public policies. In most of the region's countries, the increase in tax revenues that began in 1990 allowed public spending to rise by an average of some 6 percentage points of GDP over the past 25 years. That increase, together with the drop in public debt service payments in recent years, expanded the availability of public funding. Countries were thus able to significantly expand their spending on education and social protection, as well as their capital expenditure, which grew from a meagre $2.6 \%$ of GDP in 1990 to $4.6 \%$ of GDP in $2014 .{ }^{25}$ That progress notwithstanding, the fiscal space for promoting progressive structural change remains limited. Thus, the economic slowdown has led to a widespread decline in capital spending in recent years, by 0.3 percentage points of GDP between 2010-2014 and 2015-2016. ${ }^{26}$

\section{Positive and negative interactions between distribution, growth and investment}

\section{The role of institutional and structural variables}

Enquiry into the relationship between inequality and growth is characteristic of heterodox thinking (the orthodox approach normally posits a positive relationship between those two variables). This is true of the structuralist trend, for example, but also of the post-Keynesian and neo-Kaleckian traditions, which generally analyse how changes in the functional distribution of income, through their impact on aggregate demand, affect the evolution of output and employment. In the terminology of Bhaduri and Marglin (1990), a growth regime is wage-led if an improvement in real wages has an expansionary effect on consumption -and, through the accelerator principle, on investment - that more than offsets the contractionary effect of the fall in the rate of return on investment. The alternative scenario is a profit-led growth regime.

There is no evidence of the widespread existence of profit-led growth regimes, at least when only the influence of distribution on the domestic components of demand is considered (Stockhammer, Onaran and Ederer, 2009; Onaran, Stockhammer and Grafl, 2011; Onaran and Galanis, 2012). In Latin America, there are fewer empirical studies of the topic; ${ }^{27}$ the most comprehensive is that of Alarco Tosoni (2016), who conducted a study of 16 of the region's economies and showed that most of them had wage-led growth regimes.

The relationship between distribution and growth depends in practice on structural (productive, geographical) factors and institutional factors (capital account openness, type of labour market regulation) that vary from year to year (Stockhammer, 2011). Smaller, more open economies (in trade or financial terms) can be expected to show a weaker link between equality and growth than larger, more closed economies, or even a negative correlation when they are profit-led (Blecker, 1989).

One way to assess the extent to which structural characteristics shape the relationship between distribution and growth is to analyse how the positive impact of the wage share on private consumption changes under different institutional scenarios, such as an economy's degree of financialization and financial openness or the complexity of its production system. Increased financialization is associated with scenarios of greater financial volatility, where consumption and production decisions can be conditioned by the greater uncertainty and subject to the short-term decision-making rationales. A more complex production structure, by contrast, is associated with the economy's capacity to spread the momentum of stronger effective demand through the broader economy via sectoral linkages, without encountering premature foreign-exchange constraints.

Capital expenditure rose the most in Panama, Ecuador and Peru, and climbed significantly in the Plurinational State of Bolivia.

26 The procyclical trend in fiscal policy seen, for example, in decreased capital spending, and how this relates to the processes of financialization under way in the region are discussed below.

27 In other studies, profit-led regimes dominate, such as in Argentina and Mexico (Onaran and Galanis, 2012) and in Brazil (Araújo and Gala, 2012). As with the developed countries, the estimates in those studies are based on short-term dynamics. Analyses using a longer time frame have found, for example, wage-led growth regimes in Mexico (Caballero and López, 2012) and in Argentina, Brazil, Chile and Mexico (Reyes, 2018). 
Evidence collected from 25 OECD countries between 1970 and 2015 indicates that the wage share's positive effect on private consumption falls as an economy's financial openness rises and its diversification increases (compared to its own historical levels). ${ }^{28}$ This suggests that the relationship between distribution and growth is not independent of an economy's institutions or structures.

The issue becomes more complex when dealing with economies in which the balance of payments constraint predominates, such as those of Latin America and the Caribbean (Ocampo, 2011): in other words, those with short-term dynamics that are more exposed to international trade and capital flows. In such circumstances, as the real exchange rate rises and the economy's become more externally competitive, falling wages may induce a rise in exports and a process of export-led growth that offsets the drop in domestic consumption (Blecker, 1989). Dynamically, the rising exports would open up the space for domestic demand to expand without pushing the current account deficit into unsustainable territory, although the effect of the real exchange rate would depend on the price elasticities of demand for exports and imports. ${ }^{29}$

Studies on the relationship between distribution and growth in open economies often aim to identify the wage effect that does most to shape private demand. Those analyses assume that an increased wage share in income has a positive impact on consumption (because wage-earners have a greater propensity to consume than those who receive their incomes from property) but a negative impact on investment (assuming that it responds more to profit margins than to domestic demand) and on net exports (because of its impact on external competitiveness). A growth regime is defined as wage-led or, alternatively, as profit- or export-led depending on the total effect that the wage share has on private demand, which arises from the sum of the individual impacts on each component (consumption, investment and exports).

A similar analysis was conducted for the region over two periods (1950-1984 and 1985-2014) in order to assess how the effects of functional income distribution on growth changed according to the economic institutions in place at each time. ${ }^{30}$ The first period was characterized by steeper regulations on trade and financial flows, as well as by stronger labour institutions, indicating a more active role of the State in the economy. The results show that the overall impact of the wage share on private demand waned between 1950-1984 and 1985-2014, possibly owing to institutional changes. ${ }^{31}$

The results suggest that this historic change had more to do with a weaker positive effect of wage rises on private consumption than a stronger negative impact on investment or exports. They indicate, first, that the foreign trade of the region's economies is not especially sensitive to changes in relative prices. This is because the main constraint on exports is not distributive but structural, arising from the large productivity gaps that -with some specific exceptions, such as commodities in South America or certain manufacturing activities in Central America and Mexico- characterize much of the region's tradable output. ${ }^{32}$ The smaller positive impact of wages on private consumption is, moreover, in line with the evidence from the OECD countries, where a strong association was found between the institutional configuration and the relationship between distribution and consumption. At times of greater trade and financial openness, such as the years from 1985 to 2014, wages may be expected to have a smaller impact on private consumption, because of the deindustrialization that took place in several of the region's countries during that period and the resulting lower density of production chains. ${ }^{33}$

28 This conclusion was reached through an econometric estimation of the effect of changes in the wage bill on consumption, mediated by variables reflecting each economy's degree of financial openness and level of productive diversification, for a panel of OECD countries. The results reveal a negative coefficient between the wage bill and the degree of financial openness, and a positive coefficient between the wage bill and the level of productive diversification

29 Studies that support the maintenance of a competitive real exchange rate as a buttress of industrial policy (Frenkel and Ros, 2006; Razmi, Rapetti and Skott, 2012; Bresser Pereira, 2012 and 2016; Ros, 2016) assume, in practice, the prevalence of profit-led regimes.

30 The elasticities of the three components of private demand with respect to the wage share in income were estimated for a panel of 16 Latin American countries over the two periods. The overall effect on output was then calculated, following Alarco Tosoni (2016). The results suggest that the positive effect of wages on private demand declined during the latter period (1985-2014), primarily owing to the smaller positive impact on consumption.

31 Alarco Tosoni (2017) calculated empirical estimates for the 1950-1979 and 1980-2014 periods, through which he found that the wage share had a positive effect on growth in the first period and a negative impact in the second.

32 See Bernat (2015) for an empirical analysis of the small impact of currency devaluations on the export performance of developing countries in an exercise based on the experiences of South America.

33 With regard to what has been termed Latin America's premature deindustrialization, see Palma (2014) and Castillo and Martins (2016). 
As noted above, notwithstanding the slowdown towards the end of the period, the region's economic growth between 2004 and 2014 occurred alongside increases in the wage share. That dynamic, reflecting a positive relationship between functional income distribution and (wage-led) growth, had more to do with a favourable external context -allowing currency restrictions to be circumvented - than with a change in the macroeconomic regime. Figure III.22 depicts this shift in the trend in the most recent period. It illustrates the evolution of the wage share in GDP and average economic growth in Latin America between 1950 and 2014. However, even after the improvement between 2004 and 2014, the wage share in total income was low both in historical terms and by comparison with other countries. That is consistent with the empirical analysis, which found a stronger positive relationship between the wage share and economic growth in the period between the 1950s and the mid-1980s.

Figure III.22

Latin America and the Caribbean: average distribution and growth by period, 1950-2014

(Percentages)

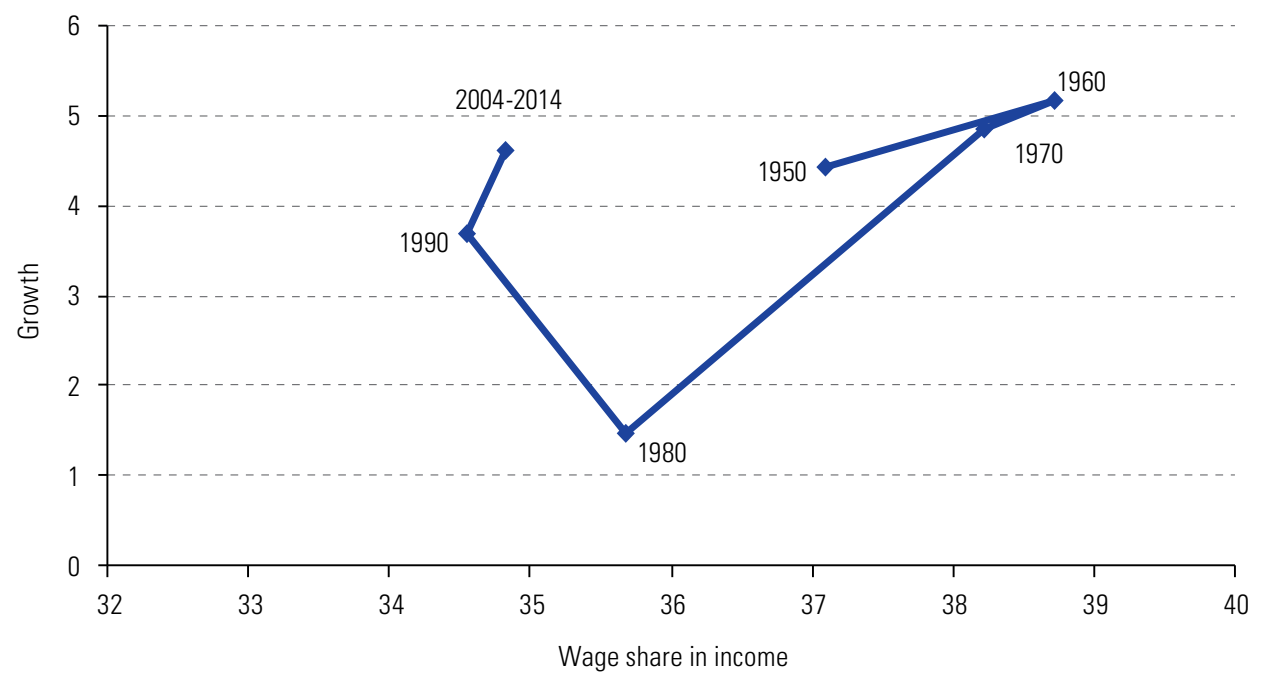

Source: Economic Commission for Latin America and the Caribbean (ECLAC), on the basis of World Bank and G. Alarco Tosoni, "Distribución factorial del ingreso y regímenes de crecimiento en América Latina, 1950-2012", Revista Internacional del Trabajo, vol. 135, No. 1, Hoboken, Wiley, 2016.

Note: A Hodrick-Prescott filter was applied to smoothen the average wage share series.

\section{The virtuous circle between growth and investment}

Reference has already been made to the negative impact of the investment slowdown on the region's growth over the past five years. This section analyses how declining growth can, in turn, hurt investment. As shown in table III.4, there is a strong correlation between high investment rates and periods of rapid growth.

Evidence shows a high level of correspondence between the rates of change in gross fixed capital formation and in GDP. The moving correlation coefficient (for a 10-year window) for the 1980-2015 period is, on average, statistically significant ( 0.87 for the period overall). As shown in figure III.23, the correlation between the two variables began to increase in the late 1990s, rising from an average of 0.74 in 1990-2000 to 0.94 in 2001-2010 and 0.98 in 2011-2015. 
Table III.4

Latin America: annual rate of change in investment and GDP, 1990-2015 (Percentages)

\begin{tabular}{|c|c|c|c|c|c|c|c|c|}
\hline \multirow{2}{*}{ Period } & \multicolumn{4}{|c|}{ South America } & \multicolumn{4}{|c|}{ Central America and Mexico } \\
\hline & Total & Machinery & Construction & GDP & Total & Machinery & Construction & GDP \\
\hline 1990-2000 & 5.2 & 6.5 & 3.9 & 3.2 & 9.5 & 11.9 & 7.2 & 3.5 \\
\hline 2001-2008 & 8.7 & 12.2 & 5.2 & 4.2 & 4.9 & 5.3 & 4.4 & 4.0 \\
\hline 2009 & -8.3 & -16.5 & -0.1 & -0.4 & -13.7 & -19.3 & -8.2 & -0.7 \\
\hline 2010 & 16.9 & 22.1 & 11.7 & 6.3 & 4.8 & 10.1 & -0.6 & 3.3 \\
\hline 2011-2015 & 4.2 & 3.7 & 4.7 & 3.5 & 7.1 & 8.2 & 6.0 & 4.1 \\
\hline
\end{tabular}

Source: Economic Commission for Latin America and the Caribbean (ECLAC), on the basis of data from International Monetary Fund (IMF).

Figure III.23

Latin America: moving correlation coefficient between the rates of change in gross fixed capital formation and in GDP, 1991-2016

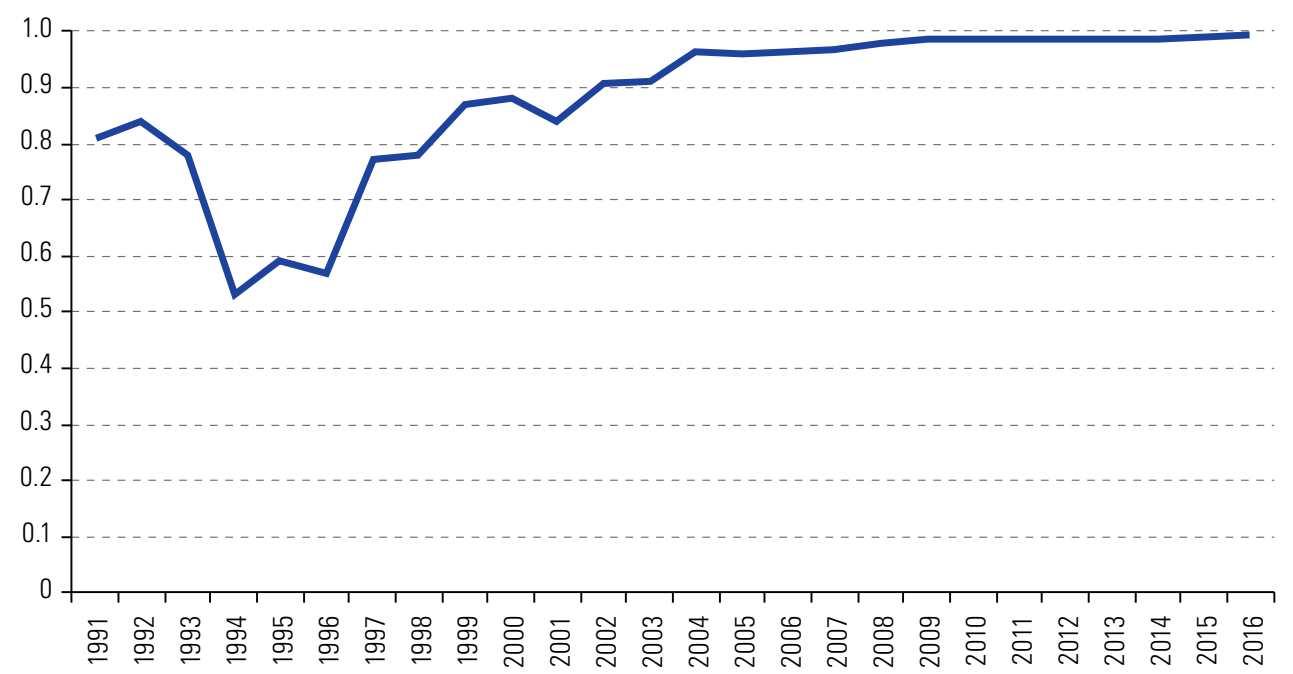

Source: Economic Commission for Latin America and the Caribbean (ECLAC), on the basis of data from the World Bank.

This rising correlation between growth in GDP and in capital formation indicates a two-way causal relationship between the two variables. First, investment is one of the components that catalyse short-term economic growth and boost the potential for long-term growth. Second, growth and expectations of higher growth are central to embarking on and maintaining an investment programme.

The two-way relationship between investment and growth stems from the dual nature of the effects of investment. Investment utilizes installed production capacity not only through direct spending but also through the effect it induces on the other components of aggregate demand. A higher multiplier effect of investment spending generates increased demand for inputs and finished products, which can lead to increased utilization of production capacity. At the same time, higher investment, particularly in machinery and equipment, expands installed capacity and adds to the capital stock.

An empirical analysis of the relationship between growth and investment reinforces the hypothesis of this two-way relationship, which was evaluated using a Granger causality test based on World Bank data (which has information on both variables - fixed capital and GDP- covering 1960 to 2016). It can be seen that the more that a country grows, the more it invests in fixed capital during the next period and, in some cases, in the period after that; similarly, the more a country invests in fixed capital, the more growth increases. The 
results indicate a causal relationship between growth and investment in 12 of the 18 sample countries. In Chile, the Plurinational State of Bolivia, Brazil, Colombia, Peru, the Bolivarian Republic of Venezuela, Costa Rica and Panama, the causality is bidirectional: not only does growth fuel investment, but investment also fuels growth. In Uruguay, Honduras, Nicaragua and the Dominican Republic, only GDP has a significant impact on investment in fixed capital. Lastly, no causality was observed between GDP and fixed capital for Argentina, Mexico, Paraguay, Ecuador, Guatemala and El Salvador. ${ }^{34}$

The intensity of the virtuous relationship between distribution, investment and growth may vary depending on the institutional context, as well as on the characteristics of the production system. The fact that less financially open economies report a strong positive correlation between distribution and growth is not only important for the design of national public policies; it also has implications for the multilateral agenda. Considered as a whole, the global economy may be seen as a closed economy; this means that an increase in the global income wage share should have the same positive effect on aggregate demand and global growth that an increase in the wage share in national income has in a closed economy. The difficulty of attaining that dynamic in a joint and coordinated manner at the international level is what led Raúl Prebisch to suggest the need for the principle of global "reciprocity" (Prebisch, 1959). This echoes the suggestion by Keynes (1980) that multilateral cooperation mechanisms be created to force those countries running surpluses (creditors) to shoulder, through increased spending, part of the responsibility for adjusting payment imbalances. This would prevent the full weight of external imbalances from falling on the countries running deficits (debtors).

The (downward) co-evolution of the wage share and investment in developed countries (see figure III.24) reflects the shortcomings of multilateralism for collectively addressing the problem of secular stagnation. ${ }^{35}$ The recessionary bias described in chapter II is directly linked to this dynamic, which originates in the central economies, intensifies inequality in income distribution and severely constrains global prospects for growth.

Figure III.24

Selected developed countries: wage share of income and investment rate, 1970-2010a

(Percentages)

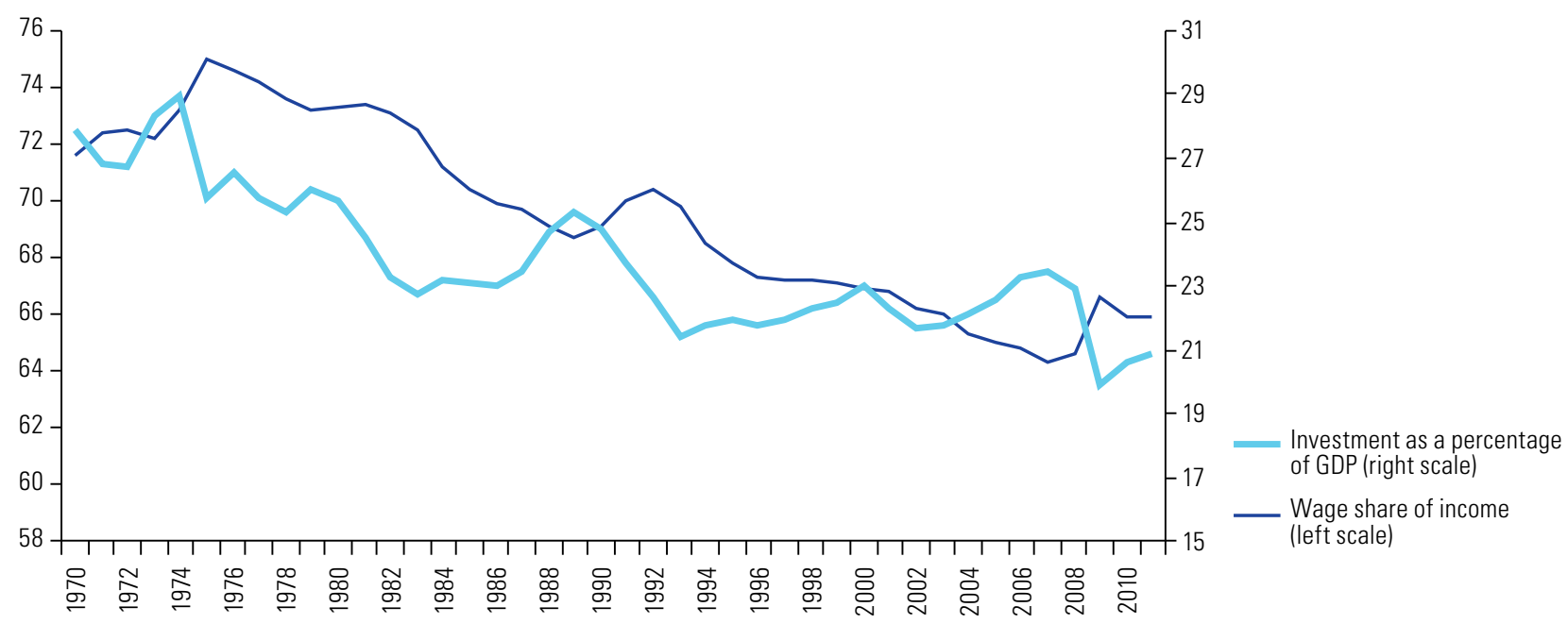

Source: Economic Commission for Latin America and the Caribbean (ECLAC), on the basis of data from the Organization for Economic Cooperation and Development (OECD) and the World Bank.

a Canada, France, Germany, Italy, Japan, Spain, United Kingdom and United States.

34 This inference uses a 5\% margin of error; using a 10\% margin, however, GDP shows an impact on fixed capital investment in Mexico and Ecuador.

35 Eggertsson, Mehrotra and Summers (2016) described secular stagnation as the coexistence of low interest rates, inflation rates below the targets set by the monetary authorities and relatively slow rates of growth. 


\section{E. Financialization heightens external vulnerability}

At a time of growing financial globalization (or financialization), greater reliance by the region's countries on external borrowing increases their exposure to international liquidity cycles. The definition of the term "financialization" depends on the analytical framework used. In general terms, it entails the rising importance of financial markets, financial institutions and financial elites in the workings of economies and their institutions of governance, both nationally and internationally (Epstein, 2006). Its manifestations include a global financial sector with transaction volumes far larger than those of the real economy, led by large, complex financial institutions that tend to be highly interconnected and concentrated and have a liability structure skewed towards procyclical leverage.

Based on that general concept, some authors focus on the increasing weight of the financial sector (including the banking sector, the insurance industry and real estate) in output, with the consequent growth in the power of financial players in areas other than finance (Epstein and Montecino, 2015; Lapavitsas, 2014). Other commentators emphasize the impact of financialization on the non-financial sector, particularly businesses and households. Within businesses, financialization leads to an increase in financial operations, such as credit or carry trade activities (the downside of which, in both cases, is a drop in production investment). ${ }^{36}$ For households, it is associated with growing indebtedness among waged employees who, at times of falling real incomes, tend to supplement their wages by borrowing (Hein, 2012; Stockhammer, 2012). Financialization is also associated with a style of corporate governance where shareholders' interests outweigh those of management (Froud and others, 2006; Aglietta and Bretton, 2001; Epstein and Jorratt, 2016), which in turn leads to a shortening of the time frames over which an investment is expected to yield profit (short-termism). ${ }^{37}$

In developing economies, the trend towards financialization adopts forms that reflect their subordinate position in the global monetary hierarchy (Fischer, 2015; Kaltenbrunner and Painceira, 2016), which assigns a central role to financial account openness. Subordinate financialization (Lapavitsas, 2014) or peripheral financialization (Becker and others, 2010; Rodrigues, Santos and Teles, 2016) refers to relations of dependence that emerge most strongly when the global financial cycle becomes the determining factor in the dynamics of developing economies and gives rise to a regime of accumulation that is dominated by international finance, but with specific features. Those features relate, in the main, to the impact of the financial system's operation in the domestic economy, and to the changes it induces in the behaviour of actors (central banks, commercial banks, companies and households, and even the political system) brought on by cross-border movements of capital.

The concept of peripheral financialization is to contemporary capitalism what the notion of peripheral capitalism (Prebisch, 1981) was to late 1970s global capitalism. Peripheral financialization involves a set of economic practices characterized by subordination to the global financial cycle -and to those internal and external actors who determine its dynamics. Those relations induce behavioural changes in local economic and political actors that reinforce existing patterns of specialization and increase external vulnerabilities, a pattern that has been facilitated by the greater liberalization of the financial account in the region compared with other regions of the planet (ECLAC, 2012).

\section{Peripheral financialization and indebtedness}

In a context of peripheral financialization, unrestricted financial account opening means that international liquidity conditions (derived largely from the monetary policy and risk aversion prevailing in central countries) are transmitted, practically without mediation, to the periphery, where they become a basic determinant of

36 See Orhangazi (2008) and De Souza and Epstein (2014).

37 For a discussion on the relationship between short-termism and the decline of transformative investments in Latin America and the Caribbean, see ECLAC (2010, chapter II). 
short-term economic dynamics. ${ }^{38}$ Prebisch (1946) gave an early warning of the risks of that interdependence when he spoke of the subordination of Latin American economic dynamics to the universal cyclical movement. That interdependence has increased in recent decades as a result of the region's greater financial openness. At times of particularly buoyancy, for example, peripheral central banks accumulate large international reserves to neutralize the negative effects of massive capital inflows (such as currency appreciation). As a counterpart to that, they tend to engage in financial transactions with local banks that, because the temporal structure of their assets has been altered, encourage the extension of short-term credit (generally to finance household consumption) to the detriment of longer-term loans (Kaltenbrunner and Painceira, 2016).

Massive influxes of capital from abroad produce a pattern of growth that does not necessarily translate into increased export potential. The non-financial private sector, local and international alike, also tends to tap into liquidity conditions on global markets for funding and investments in local assets, thereby benefiting from the differentials in the rates of return and, again, without a counterpart in the production sphere (Caballero, Panizza and Powell, 2015; Bruno and Shin, 2015; Serena and Moreno, 2016). Thus, the distorting and destabilizing effects of short-term capital flows prevail, which facilitate the formation of financial bubbles and lead to currency appreciations that have a negative impact on output (Rajan and Subramanian, 2011; Botta, Godin and Missaglia, 2015). It was in reaction to such effects that certain international agencies, including IMF, revised their position in recent years to affirm that regulating the capital account can be a necessary and legitimate policy tool (IMF, 2015). ${ }^{39}$

The aftermath of the 2008 crisis saw considerable growth in the global bond market. Emerging economies were actively involved in this process and increased their total stock of international bonds from approximately US $\$ 500$ billion in 2000 to around US\$ 7 trillion in 2016. That stands in contrast to the behaviour of the developed economies, most of which reduced their levels of indebtedness over the same period.

One novel feature of this borrowing was the role played by the private sector, which gained importance as an issuer of international securities compared to the public sector throughout the developing world. The region's countries were no exception to this new phase in the global liquidity cycle: international debt issues, which stood at US\$ 310 billion in the 2000-2007 period, rose to US\$ 761 billion in 2017, with Argentina, the Bolivarian Republic of Venezuela, Brazil, Chile, Colombia, Mexico and Peru accounting for $89 \%$ of that amount. While governments remain the largest issuers of international debt, their relative importance has declined. ${ }^{40}$

Greater indebtedness on the part of the non-financial corporate sector has three macroeconomic consequences for the region. First, beyond certain borrowing thresholds, funds obtained by companies are not used to finance investments in production. Second, a change takes place in the composition of the balance-ofpayments financial account, in particular as regards portfolio flows. Since the global financial crisis, the annual cumulative amounts of flows associated with bond investments, which are more sensitive to changes in the external context, have outstripped those associated with borrowing operations (see figure III.25).

The third effect is increased financial fragility. According to the framework defined by Minsky, which distinguishes hedged, speculative and Ponzi financing structures, the latter two, which involve greater financial fragility, showing evidence of having increased, particularly among the companies most active in issuing international bonds. Of the companies issuing international bond debt, the percentage doing so in Ponzi conditions rose from $13.2 \%$ to $21.1 \%$ between 2009 and 2015, while those in speculative conditions increased from $48.6 \%$ to $57.1 \%$ (see figure III.26).

38 Recent studies indicate that the intensity and orientation of international financial flows are determined more by global liquidity conditions (push factors) and less by the quality of institutions or sound macroeconomic results in each country (pull factors) (Aizenmann, Binici and Hutchinson, 2014; Eichengreen and Gupta, 2014; Cerutti, Claessens and Puy, 2014). See a review of the literature in Koepke (2015).

39 See a review of recent literature on this topic in Bastourre and Zeolla (2017).

40 In South and Central America, between 2000-2007 and 2017, the share of public debt as a percentage of total debt fell from $71.5 \%$ to $44.7 \%$ and from $89.0 \%$ to $57.2 \%$, respectively. Meanwhile, the share of the non-financial corporate sector's indebtedness in total debt rose from $2.0 \%$ to $6.8 \%$ in Central America and from $12.2 \%$ to $25.0 \%$ in South America. 


\section{Figure III.25}

Latin America (selected countries): debt flows (bonds) and bank lending (total and non-financial corporate sector), 2001-2015

(Billions of dollars)

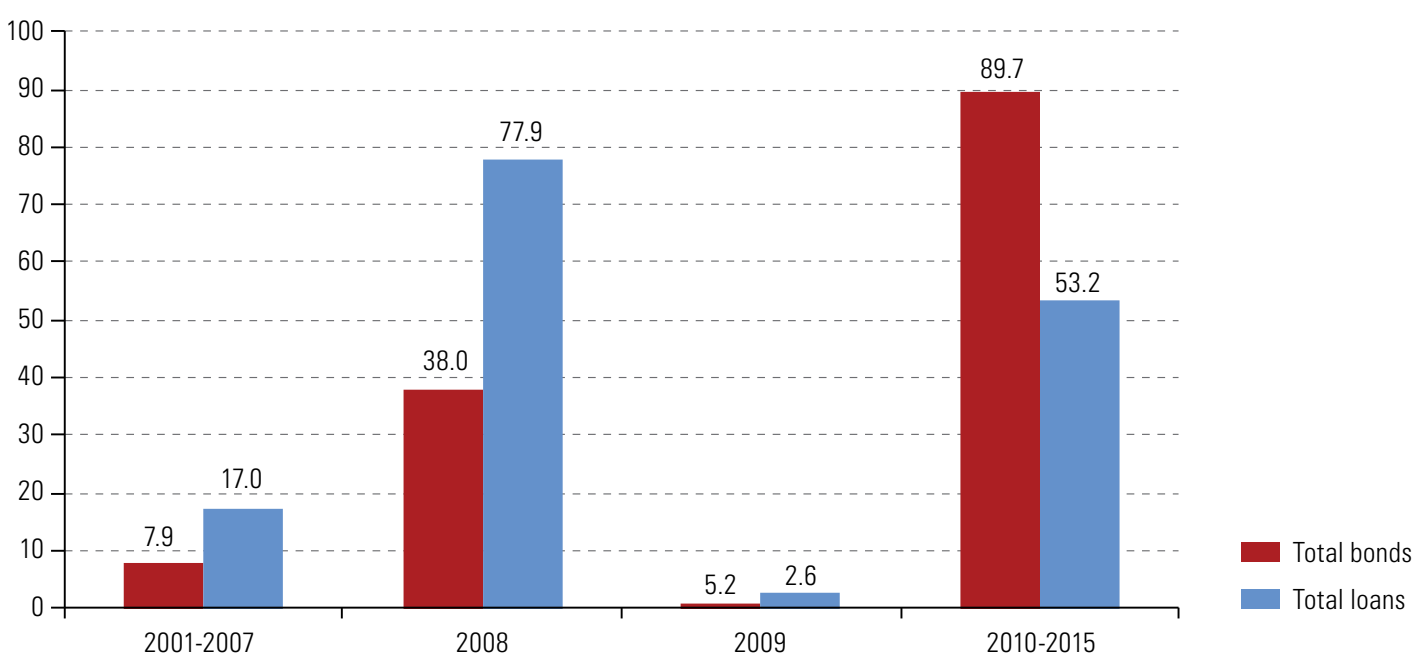

Source: Economic Commission for Latin America and the Caribbean (ECLAC), on the basis of data from the International Monetary Fund (IMF).

a Argentina, Brazil, Colombia, Chile, Mexico and Peru.

${ }^{b}$ On the basis of quarterly data.

\section{Figure III.26}

Proportion of companies in Ponzi, speculative and hedged situations in international bond markets, 2009-2015 (Percentages)

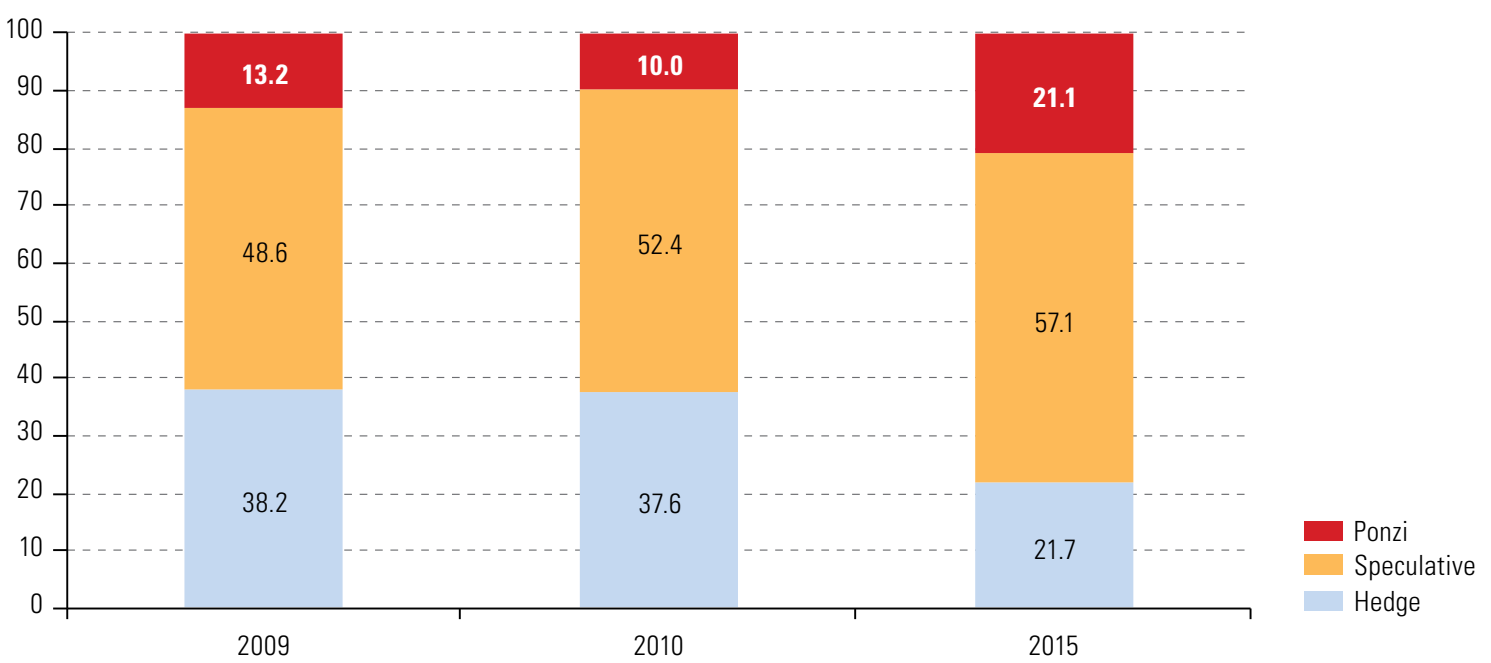

Source: Economic Commission for Latin America and the Caribbean (ECLAC), on the basis of R. Mulligan, "A sectoral analysis of the financial instability hypothesis", The Quarterly Review of Economics and Finance, vol. 53, No. 4, Amsterdam, Elsevier, 2013; E. Torres Filho, N. Martins and C. Miaguti, "Minsky's financial fragility: an empirical analysis of electricity distribution companies in Brazil (2007-15)", Working Paper, No. 896, Annandale-on-Hudson, Levy Economics Institute, 2017.

Another identifying feature of financialization, especially in developed countries, is the level of household debt, as families begin to use loans to fund part of their consumption at times of stagnated or falling real wages (Boyer, 2000). This phenomenon, in which consumption is no longer so dependent on income, can also be seen in the countries of Latin America. The financial system and the possibility of borrowing have turned consumption into a partially autonomous component of demand and thus a driver of economic growth (ECLAC, 2017a, chapter III). 
This type of strategy has an important limitation as, above certain levels, indebtedness can impose a financial burden on households that is disproportionate to their income and generate conditions that are unsustainable over time. Figures from Brazil, Chile and Colombia show an increase in the financial burden between 2006 and 2016 and a clear increase in the credit extended to households as a proportion of GDP between 2011 and 2016 (see figure III.27). ${ }^{41}$

Figure III.27

Latin America (selected countries): household debt, 2011-2016

(Percentages of GDP)

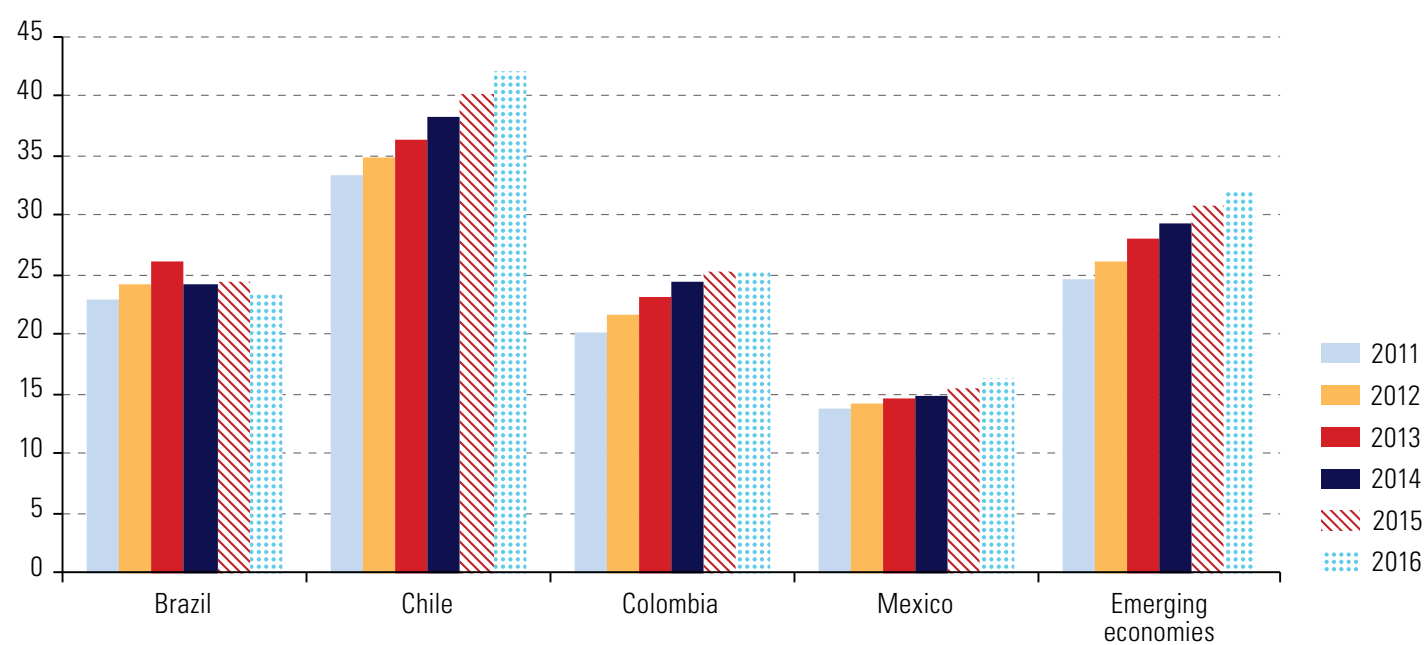

Source: Economic Commission for Latin America and the Caribbean (ECLAC), on the basis of Bank for International Settlements (BIS), Global Liquidity Indicators database [online] http://www.bis.org/statistics/gli.htm.

\section{Increased real and financial external vulnerability}

The region's external vulnerability increased as a result of its external indebtedness. Figure III.28 breaks down external vulnerability by its real and financial components. ${ }^{42}$ Increases in the level of real external vulnerability were detected in 21 of the 32 sample countries, with no apparent differences between subregions. At the same time, greater external financial fragility was seen in 27 of the 32 countries, albeit with significant geographical differences: most of the Caribbean is far more vulnerable than the countries of Central and South America.

The real and financial dimensions of external vulnerability are mutually reinforcing, which heightens external constraints on growth. That reinforcement can be analysed by expanding Thirlwall's Law to include other components of the balance of payments, such as income and transfer flows. ${ }^{43}$ This exercise is particularly useful at times of rising financialization, when financial flows tend to be increasingly important compared to real flows.

41 Between 2006 and 2016, the financial burden on households rose from 17.4\% to 21.3\% of GDP in Brazil and from 12.9\% to 15.4\% in Chile; in Colombia, it increased from 21.2\% in 2010 to $22.0 \%$ in 2014; and, in Mexico, from 7.5\% in 2006 to $8.0 \%$ in 2014. Between 2011 and 2014, loans to households as a percentage of GDP grew at an even sharper rate: from $22.8 \%$ to $23.4 \%$ in Brazil, from $33.3 \%$ to $40.2 \%$ in Chile, from $20.1 \%$ to $25.2 \%$ in Colombia and from $13.7 \%$ to $15.5 \%$ in Mexico.

42 Real vulnerability is calculated as the weight of primary exports among total credits to the current account or the weight of manufactured exports, tourism and remittances in current account credits (the larger of the two ratios is chosen for each country, following the methodology of Abeles and Valdecantos, 2016). Financial external vulnerability, in turn, is calculated as external liabilities — including foreign direct investment (FDI) stock — minus international reserves, as a proportion of purchasing power parity GDP.

43 For an analysis of external constraints expanded to include financing problems, see Moreno-Brid (1998) and Barbosa-Filho (2001). 
Figure III.28

Latin America and the Caribbean: real and financial external vulnerability, 2005-2007 and 2012-2014

(Percentages)

A. Real vulnerability

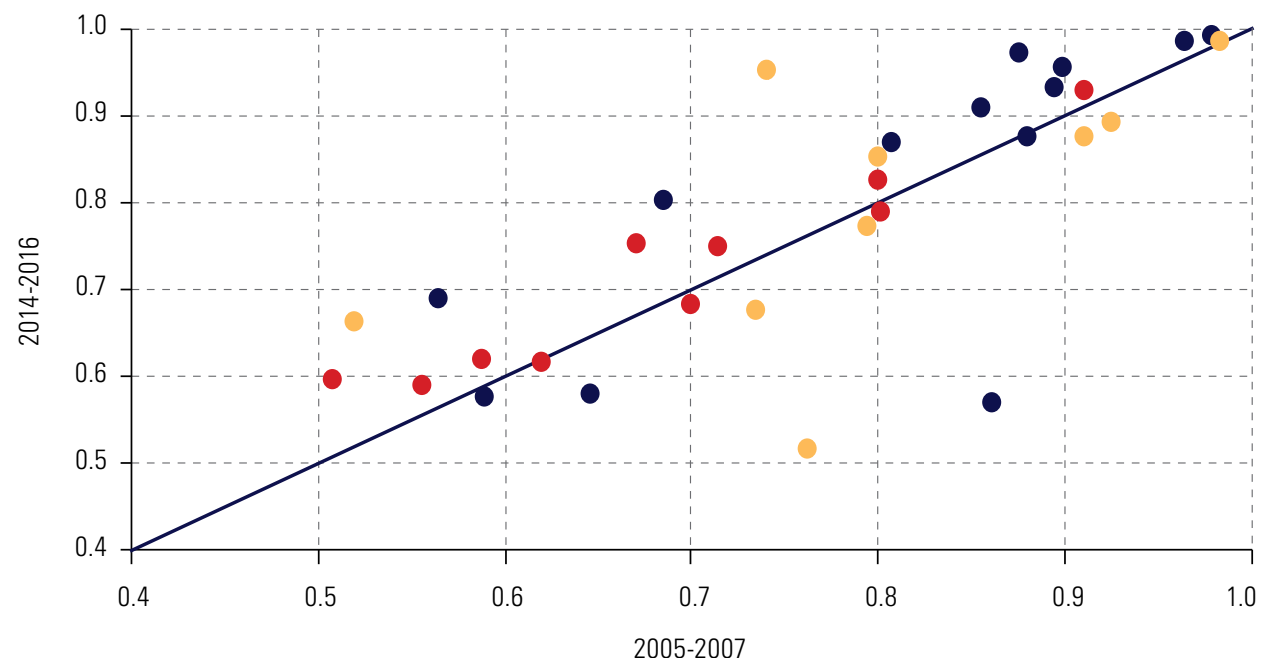

B. Financial vulnerability

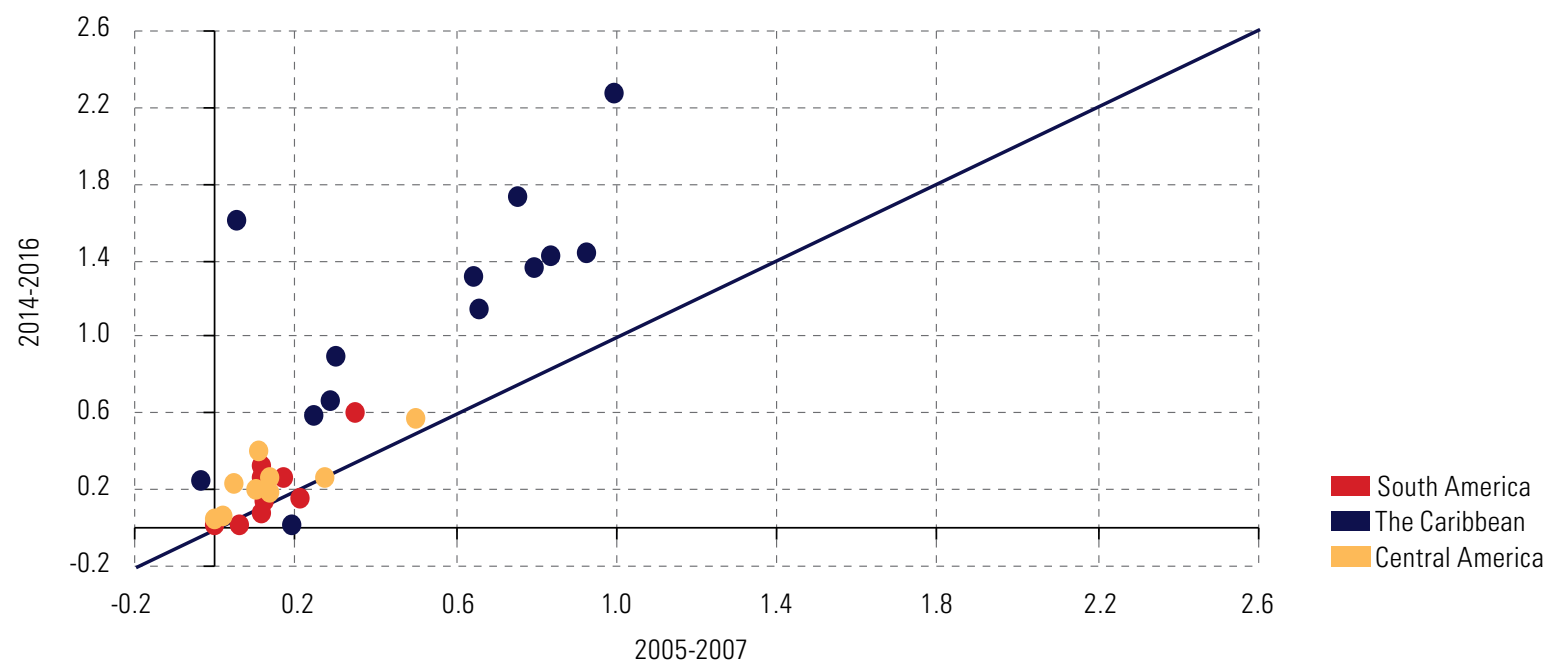

Source: Economic Commission for Latin America and the Caribbean (ECLAC), on the basis of CEPALSTAT [online database] http://estadisticas.cepal.org/cepalstat/ portada.html?idioma=english; United Nations Conference on Trade and Development (UNCTAD); International Monetary Fund (IMF), International Financial Statistics (IFS) database [online] http://data.imf.org/?sk=4C514D48-B6BA-49ED-8AB9-52B0C1A0179B; World Economic Outlook (WE0) database [online] http://www.imf.org/external/ns/cs.aspx?id=28.

The modifications to Thirlwall's condition ${ }^{44}$ for South America show that, in general, including income and transfer flows lowers the rate of growth consistent with long-term external equilibrium compared to calculations that only take trade flows into account (see figure III.29). In Central America and Mexico, by contrast, remittance transfers can offset the income deficit and even expand the limits on growth compatible with external equilibrium. Be this as it may, the fact that all the region's countries are structural debtors leaves them -and particularly those of South America and the Caribbean-more vulnerable to potential changes in the global financial cycle.

44 Thirlwall's expanded condition is defined as $y a^{*}=\frac{\phi_{1} \varepsilon \cdot z+\phi_{2} r+\phi_{3} t}{\pi}$, where $\phi_{2}$ y $\phi_{3}$ are the shares of income and transfers in total imports, respectively, and $r$ and $t$ are the rate of growth of income and transfer flows, respectively. It assumes that global growth and growth in transfer flows are both $2 \%$ and that the growth in income flows is $5 \%$. 
Figure III.29

Latin America (14 countries): growth conditions compatible with external equilibrium,

for the 2000-2016 period

(Percentages)

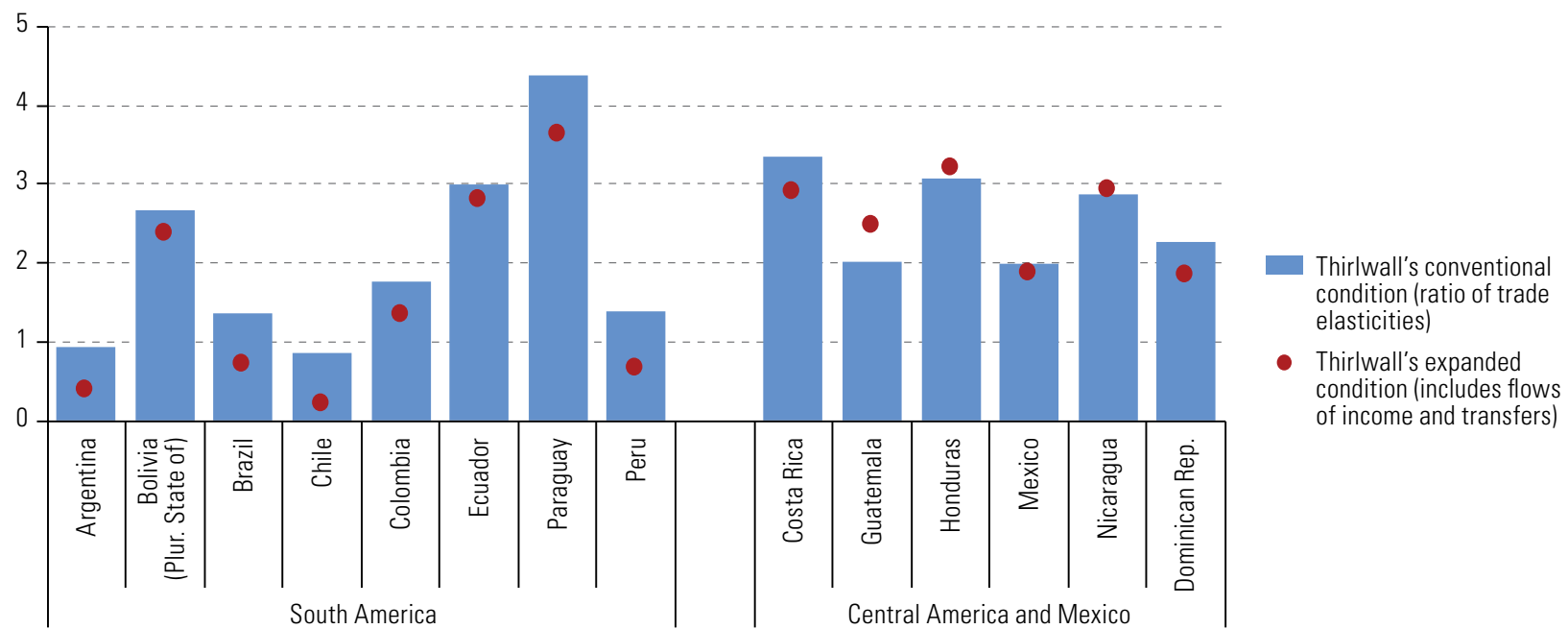

Source: Economic Commission for Latin America and the Caribbean (ECLAC), CEPALSTAT database [online database] http://estadisticas.cepal.org/cepalstat/portada. html?idioma=english.

\section{Obstacles to growth, investment and production diversification in the long term}

The effects of financialization are not limited to the short-term impact associated with greater external vulnerability; they also trigger processes that could deepen the region's structural problems, such as inequality, low levels of investment and reduced macroeconomic space.

The relationship between rising financialization and deteriorating income distribution in the developed countries is one of the stylized facts in the literature (see figure III.30). Three basic methods through which financialization leads to greater inequality have been identified: changes in the sectoral composition of the economy, higher salaries for top management and increased profits for rentiers, and the weakening of trade unions (Hein, 2012). The negative relationship between financialization and distribution seems to be at play in the region as well: the wage share of income fell between the 1990s and the 2006-2015 period in 7 countries from a sample of $12 .{ }^{45}$

Another prominent stylized fact in relation to developed countries in recent decades is that financialization has a negative impact on both production investment and spending on R\&D (see figure III.31). Several ways in which financialization affects the investment rate have been identified. First, higher levels of investment in financial assets, which provide shorter-term profits, tend to displace real-sector investments, whose returns tend to materialize over the longer term. Resources used to pay dividends at a practically constant rate (imposed by shareholder dominance) also displace real investment by reducing the availability of internal funds for acquiring production assets. From a dynamic perspective, funds used to pay interest on financial services also reduce the capital available for investment (Orhangazi, 2008). This rationale seems to have a particular impact on R\&D spending, which is the basis for achieving the productivity gains necessary for creating jobs and sustainable growth rates but whose fruits take much longer to emerge.

45 Average values for the periods 1990-1999 and 2006-2015 were used for this comparison. 
Figure III.30

Latin America and the Caribbean: relationship between financialization and wage share of income, 1970-2014 (Percentages)

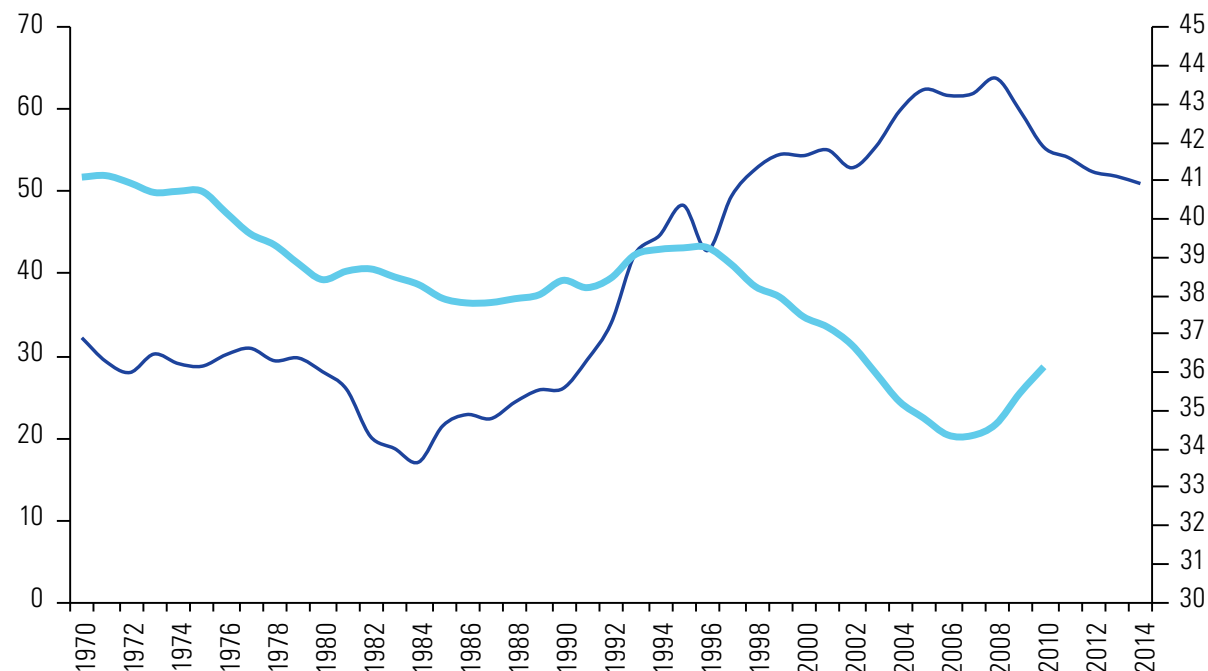

Functional distribution of income (five-year moving average, right scale)

- Index of capital account

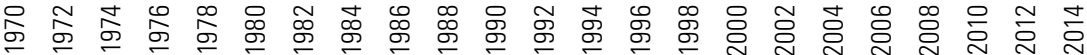

Source: M. D. Chinn and H. Ito, "What matters for financial development? Capital controls, institutions, and interactions", Journal of Development Economics, vol. 81, No. 1, Amsterdam, Elsevier, 2006; G. Alarco Tosoni, "Wage share and economic growth in Latin America, 1950-2011", CEPAL Review, No. 113 (LC/G.2614-P), Santiago, Economic Commission for Latin America and the Caribbean (ECLAC), 2014.

Figure III.31

Latin America and the Caribbean: relationship between financialization and investment, 1970-2014

(Percentages and index number)

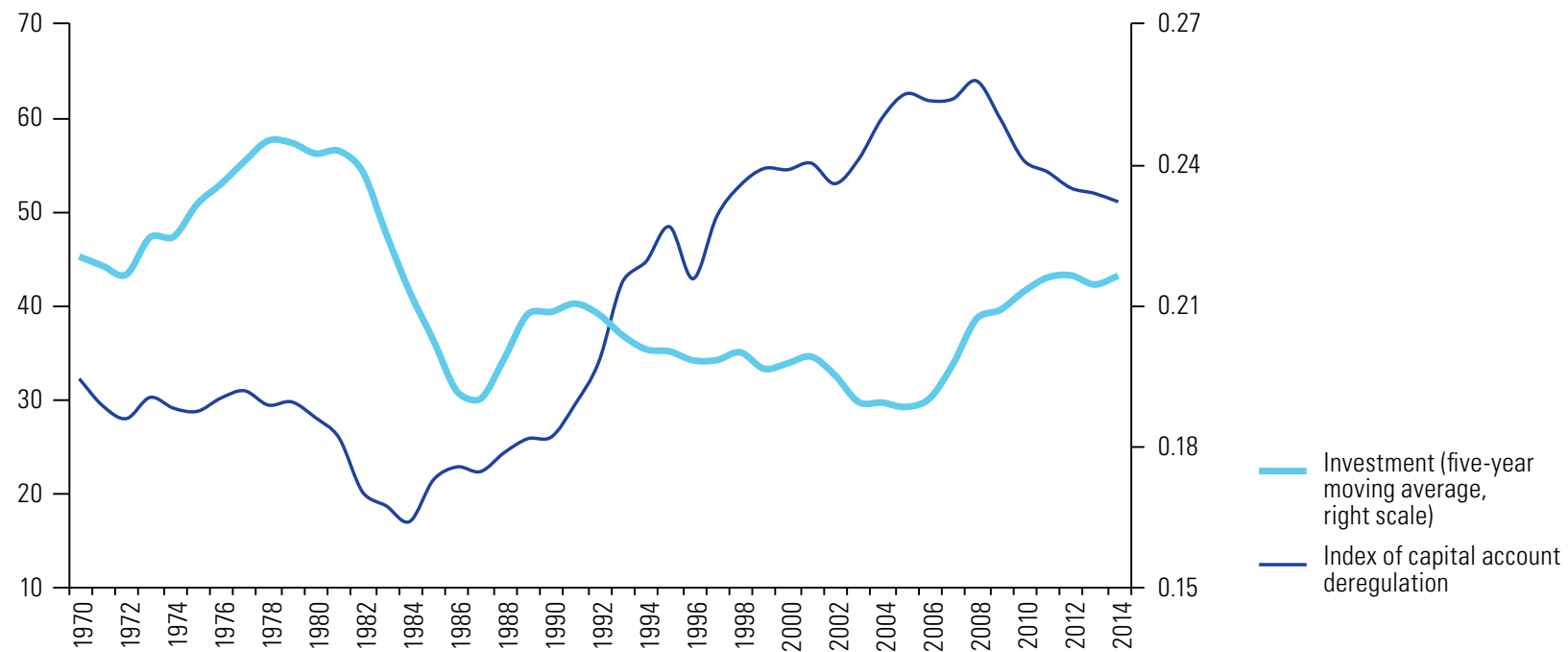

Source: M. D. Chinn and H. Ito, "What matters for financial development? Capital controls, institutions, and interactions", Journal of Development Economics, vol. 81, No. 1, Amsterdam, Elsevier, 2006; University of Groningen, Penn World Table database [online] https://www.rug.nl/ggdc/productivity/pwt/.

Given the slow growth prevailing in the region, the deployment of countercyclical macroeconomic policies is essential. One of the features of (peripheral) financialization is that developing countries face severe constraints in pursuing independent economic policies (Akyüz, 2007). Given that global liquidity conditions (push factors) tend to have the upper hand in shaping the country's macroeconomic performance (pull factors), governments are forced to adopt prudential principles to ensure short-term macrofinancial stability, which frequently introduces a procyclical bias into macroeconomic policy. 
That bias can be seen in figure III.32, constructed from a panel of annual data from 2010 onwards. In periods of little or no growth, governments implemented expansionary fiscal and monetary policies only half the time and, in most of those cases, only weakly. ${ }^{46}$ This reveals the limitations on the ability of the region's economies to respond countercyclically or to do so in a powerful enough way to support a more stable and vigorous rate of growth.

Figure III.32

Latin America and the Caribbean (selected countries): macroeconomic policy responses to recessions and slowdowns, 2010-2016

(Percentages and annual change in interest rates)

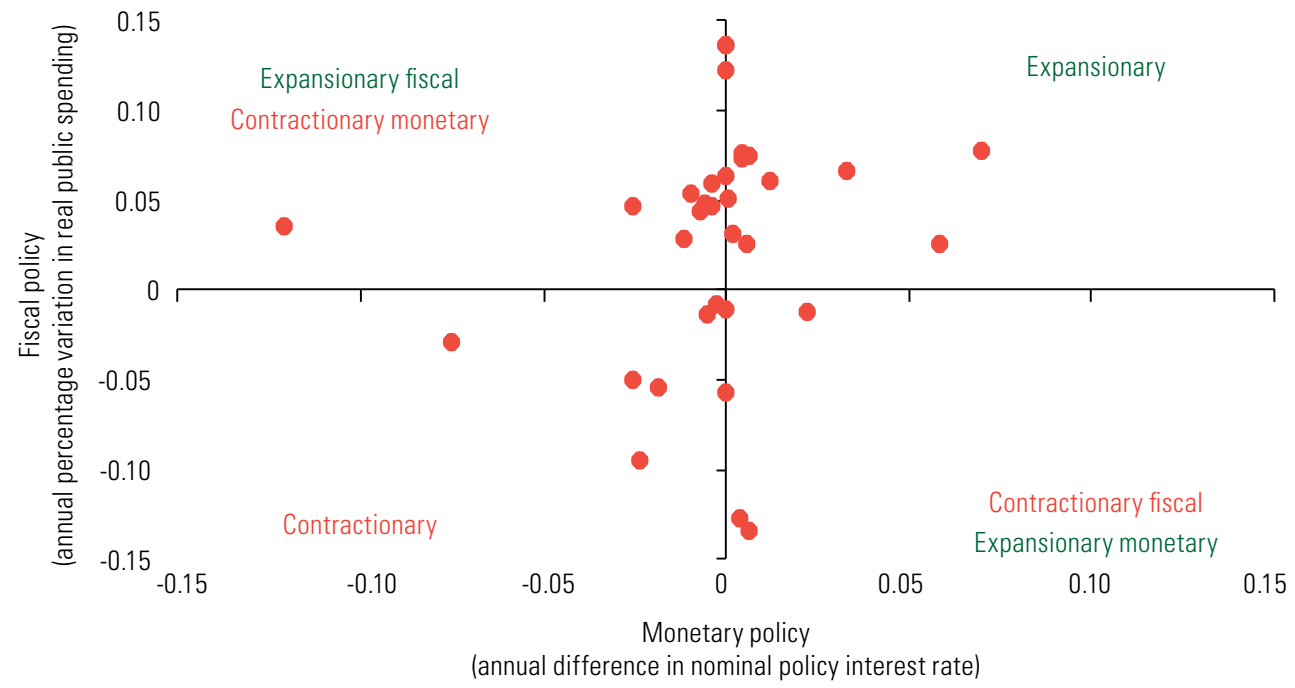

Source: Inter-American Development Bank (IDB), Economic Commission for Latin America and the Caribbean (ECLAC), CEPALSTAT database [online] http://estadisticas. cepal.org/cepalstat/portada.html?idioma=english.

a Argentina, Bahamas, Barbados, Belize, Brazil, Chile, Colombia, Costa Rica, Dominican Republic, El Salvador, Guatemala, Haiti, Jamaica, Mexico, Paraguay and Peru.

Understanding financialization is essential for understanding the workings of the global economy. Evidence of a negative link between financialization, external vulnerability and several of the key vectors of progressive structural change casts a new light on the magnitude of the challenges facing the region. By accentuating inequality, delaying investment and reducing the margin for countercyclical manoeuvres, the trend towards financialization seen in recent decades helps consolidate the dynamics of low growth and the resulting shortfall in investment; this stands in sharp contrast to the claims made by the proponents of market reforms that it attracts capital for stimulating development. Consequently, in addition to working for closer coordination between industrial, social and environmental policies (see chapter VII), it is at least as important that the agenda for progressive structural discuss and possibly revise the actions taken over the past decades that facilitated the growing importance of financial elites in the functioning of the region's economies.

46 Most of the cases in which both fiscal and monetary countercyclical measures were adopted are Caribbean economies. With few exceptions, such as Chile in 2014 or Mexico in 2013, the region's largest economies have not implemented significant countercyclical measures at times of slowdown or recession. 


\section{Bibliography}

Abeles, M., V. Amarante and D. Vega (2014), "The earnings share of total income in Latin America, 1990-2010", CEPAL Review, No. 114 (LC/G.2629-P), Santiago, Economic Commission for Latin America and the Caribbean (ECLAC), December.

Abeles, M., A. Arakaki and S. Villafañe (2017), “Distribución funcional del ingreso en América Latina desde una perspectiva sectorial", Studies and Perspectives series-ECLAC Office in Buenos Aires, No. 53 (LC/TS.2017/39; LC/BUE/TS.2017/2), Santiago, Economic Commission for Latin America and the Caribbean (ECLAC), May.

Abeles, M. and S. Valdecantos (2016), "Vulnerabilidad externa en América Latina y el Caribe: un análisis structural”, Studies and Perspectives series-ECLAC Office in Buenos Aires, No. 49 (LC/L.4220; LC/BUE/L.228), Santiago, Economic Commission for Latin America and the Caribbean (ECLAC), August.

Aglietta, M. and R. Bretton (2001), "Financial systems, corporate control and capital accumulation", Economy and Society, vol. 30, No. 4, Routledge, Taylor \& Francis.

Aguilar, P. (2011), "La feminización de la pobreza: conceptualizaciones actuales y potencialidades analíticas", Katálysis, vol. 14, No. 1, Santa Catarina, Federal University of Santa Catarina.

Aizenman, J., M. Binici and M. M. Hutchison (2014), "The transmission of Federal Reserve tapering news to emerging financial markets", NBER Working Paper, No. 19980, Cambridge, National Bureau of Economic Research (NBER).

Akyüz, Y. (2014), "Internationalization of finance and changing vulnerabilities in emerging and developing economies", UNCTAD Discussion Paper, No. 217, Geneva, United Nations Conference on Trade and Development (UNCTAD), November. 2007), "Global rules and markets: constraints over policy autonomy in developing countries", Discussion Paper, No. 2007/5, Ankara, Turkish Economic Association, July.

Alarco Tosoni, G. (2017), "Ciclos distributivos y crecimiento económico en América Latina", Cuadernos de Economía, vol. 36, No. 72, Bogota, National University of Colombia.

(2016), "Distribución factorial del ingreso y regímenes de crecimiento en América Latina, 1950-2012", Revista Internacional del Trabajo, vol. 135, No. 1, Hoboken, Wiley, March.

(2014), "Wage share and economic growth in Latin America, 1950-2011", CEPAL Review, No. 113 (LC/G.2614-P), Santiago, Economic Commission for Latin America and the Caribbean (ECLAC), August.

Amarante, V. and J. P. Jiménez (2015), "Desigualdad, concentración y rentas altas en América Latina", Desigualdad, concentración del ingreso y tributación sobre las altas rentas en América Latina, J. P. Jiménez (ed.), ECLAC Books, No. 134 (LC/G.2638-P), Santiago, Economic Commission for Latin America and the Caribbean (ECLAC), April.

Amarante, V. and R. Arim (eds.), Desigualdad e informalidad: un análisis de cinco experiencias latinoamericanas, ECLAC Books, No. 133 (LC/G.2637-P), Santiago, Economic Commission for Latin America and the Caribbean (ECLAC), May.

Araújo, E., M. Bruno and D. Pimentel (2012), "Financialization against industrialization: a regulationnist approach of the Brazilian paradox", Revue de la Régulation, No. 11, Grenoble, Pierre Mendès France University.

Araújo, E. and P. Gala (2012), "Regimes de crescimento econômico no Brasil: evidências empíricas e implicações de política", Estudos Avançados, vol. 26, No. 75, São Paulo, University of São Paulo, May-August.

Bairoch, P. and R. Kozul-Wright (1998), "Globalization myths: some historical reflections on integration, industrialization and growth in the world economy", Transnational Corporations and the Global Economy, R. Kozul-Wright and R. Rowthorn (eds.), Berlin, Springer.

Barbosa-Filho, N. (2001), "The balance of payments constraint: from balanced trade to sustainable debt", BNL Quarterly Review, No. 219, Rome, Banca Nazionale del Lavoro, December.

Barbosa-Filho, N. and L. Taylor (2006), "Distributive and demand cycles in the US economy: a structuralist Goodwin model", Metroeconomica, vol. 57, No. 3, Hoboken, Wiley.

Barreix, A., M. Bes and J. Roca (2009), Equidad fiscal en Centroamérica, Panamá y República Dominicana, Washington, D.C., Inter-American Development Bank (IDB)/Eurosocial.

Bastourre, D. and N. Zeolla (2017), "Regulación de la cuenta capital en un mundo financieramente complejo: evolución reciente y perspectivas en América Latina", Studies and Perspectives series-ECLAC Office in Buenos Aires, No. 52 (LC/L.4289), Santiago, Economic Commission for Latin America and the Caribbean (ECLAC), January.

Beccaria, L. and others (2013), "Urban poverty and labor market dynamics in five Latin American countries: 2003-2008", The Journal of Economic Inequality, vol. 11, No. 4, Berlin, Springer, December.

Becker, J. and others (2010), "Peripheral financialization and vulnerability to crisis: a regulationist perspective", Competition \& Change, vol. 14, No. 3-4, Thousand Oaks, SAGE Publications.

Bernat, G. (2015), "Tipo de cambio real y diversificación productiva en América del Sur", Studies and Perspectives series-ECLAC Office in Buenos Aires, No. 43 (LC/L.4031), Santiago, Economic Commission for Latin America and the Caribbean (ECLAC), June.

Bertranou, F. and R. Maurizio (2010), "The role of labour market and social protection in reducing inequality and eradicating poverty in Latin America", MPRA Paper, No. 39843, Munich, Ludwig-Maximilian University of Munich, August. 
Bhaduri, A. and S. Marglin (1990), "Unemployment and the real wage: the economic basis for contesting political ideologies", Cambridge Journal of Economics, vol. 14, No. 4, Oxford, Oxford University Press, December.

Blecker, R. (2016), "Wage-led versus profit-led demand regimes: the long and the short of it", Review of Keynesian Economics, vol. 4, No. 4, Cheltenham, Edward Elgar Publishing.

(1989), "International competition, income distribution and economic growth", Cambridge Journal of Economics, vol. 13, No. 3, Oxford, Oxford University Press, September.

Bonizzi, B. (2013), "Financialization in developing and emerging countries: a survey", International Journal of Political Economy, vol. 42, No. 4, Routledge, Taylor \& Francis.

Botta, A., A. Godin and M. Missaglia (2015), "Finance, foreign direct investment, and Dutch disease: the case of Colombia", Working Paper, No. 853, Annandale-on-Hudson, Levy Economics Institute, November.

Boyer, R. (2000), "Is a finance-led growth regime a viable alternative to Fordism? A preliminary analysis", Economy and Society, vol. 29, No. 1, Abingdon, Routledge.

Breen, R. and C. García-Peñalosa (2005), "Income inequality and macroeconomic volatility: an empirical investigation", Review of Development Economics, vol. 9, No. 3, Hoboken, Wiley, August.

Bresser Pereira, L. (2016), "Reflecting on new developmentalism and classical developmentalism", Review of Keynesian Economics, vol. 4, No. 3, Cheltenham, Edward Elgar Publishing.

(2012), "Summing up structuralist development macroeconomics and new developmentalism", Challenge, vol. 55, No. 5, Routledge, Taylor \& Francis.

Bruno, V. and H. S. Shin (2015), "Global dollar credit and carry trades: a firm-level analysis", BIS Working Papers, No. 510, Basel, Bank for International Settlements (BIS), August.

Caballero, E. and J. López (2012), "Gasto público, impuesto sobre la renta e inversión privada en México," Investigación Económica, vol. 71, No. 280, Mexico City, National Autonomous University of Mexico (UNAM), April-June.

Caballero, J., U. Panizza and A. Powell (2015), "The second wave of global liquidity: why are firms acting like financial intermediaries?", Working Paper, No. HEIDWP21-2015, Geneva, Graduate Institute of International and Development Studies, October.

Campos, R., E. Chávez and G. Esquivel (2014), "Los ingresos altos, la tributación óptima y la recaudación posible,, document prepared for the National Public Finance Award, Mexico City, Centro de Estudios de las Finanzas Públicas (CEFP), August.

Castillo, M. and A. Martins (2016), "Premature deindustrialization in Latin America", Production Development series, No. 205 (LC/L.4183), Santiago, Economic Commission for Latin America and the Caribbean (ECLAC), June.

Cerutti, E., S. Claessens and D. Puy (2015), "Push factors and capital flows to emerging markets: why knowing your lender matters more than fundamentals", IMF Working Paper, No. 15-127, Washington, D.C., International Monetary Fund (IMF), June.

Chinn, M. D., and H. Ito (2008), "A new measure of financial openness", Journal of Comparative Policy Analysis: Research and Practice, vol. 10, No. 3, Routledge, Taylor \& Francis, September. (2006), "What matters for financial development? Capital controls, institutions, and interactions", Journal of Development Economics, vol. 81, No. 1, Amsterdam, Elsevier, October.

Davis, L. (2013), "Financialization and the nonfinancial corporation: an investigation of firm-level investment behavior in the U.S., 1971-2011", Economics Department Working Paper series, No. 2013-08, Amherst, University of Massachusetts Amherst, August.

Demir, F. (2009), “Financial liberalization, private investment and portfolio choice: financialization of real sectors in emerging markets", Journal of Development Economics, vol. 88, No. 2, Amsterdam, Elsevier, March.

De Souza, J. P. and G. Epstein (2014), "Sectoral net lending in six financial centers", PERI Working Paper series, No. 346, Amherst, University of Massachusetts Amherst, March.

Dünhaupt, P. (2013), "The effect of financialization on labor's share of income", Working Paper, No. 17/2013, Berlin, Berlin Institute for International Political Economy (IPE).

Eatwell, J. and L. Taylor (2001), Global Finance at Risk: The Case for International Regulation, New York, The New Press.

ECLAC (Economic Commission for Latin America and the Caribbean) (2018), Preliminary Overview of the Economies of Latin America and the Caribbean, 2017 (LC/PUB.2017/28-P), Santiago, February.

(2017a), Economic Survey of Latin America and the Caribbean 2017 (LC/PUB.2017/17-P), Santiago, September.

(2017b), Fiscal Panorama of Latin America and the Caribbean, 2017 (LC/PUB.2017/6-P), Santiago, March.

(2016a), Equality and Women's Autonomy in the Sustainable Development Agenda (LC/G.2686/Rev.1), Santiago, December.

(2016b), Social Panorama of Latin America, 2016 (LC/PUB.2017/12-P), Santiago, August.

(2016c), The Social Inequality Matrix in Latin America (LC/G.2690.MDS.1/2), Santiago, October.

(2016d), Fiscal Panorama of Latin America and the Caribbean, 2016 (LC/L.4140), Santiago, March.

(2016e), Science, Technology and Innovation in the Digital Economy: The State of the Art in Latin America and the Caribbean (LC/G.2685(CCITIC.2/3)), Santiago, September. 
(2016f), Horizons 2030: Equality at the Centre of Sustainable Development (LC/G.2660/Rev.1), Santiago, July. (2012), Structural Change for Equality: An Integrated Approach to Development (LC/G.2524(SES.34/3)), Santiago, July. (2010), Time for Equality: Closing Gaps, Opening Trails (LC/G.2432(SES.33/3)), Santiago, May.

(2007), "Progreso técnico y cambio estructural en América Latina", Project Documents (LCM.136), Santiago, October. (2004), "Entender la pobreza desde la perspectiva de género", Mujer y Desarrollo series, No. 52 (LC/L.2063-P), Santiago, January.

Eggertsson, G., N. Mehrotra and L. Summers (2016), "Secular stagnation in the open economy", American Economic Review, vol. 106, No. 5, Pittsburgh, American Economic Association (AEA), May.

Eichengreen, B. (2001), "Capital account liberalization: what do cross-country studies tell us?", The World Bank Economic Review, vol. 15, No. 3, Washington, D.C., World Bank, September.

Eichengreen, B. and P. Gupta (2014), "Tapering talk: the impact of expectations of reduced federal reserve security purchases on emerging markets", Emerging Markets Review, vol. 25, Amsterdam, Elsevier, December.

Epstein, G. (ed.) (2006), Financialization and the World Economy, Northampton, Edward Elgar.

Epstein, G. and J. A. Montecino, (2015), "Banking from financial crisis to Dodd-Frank: five years on, how much has changed?", PERI Working Paper series, Amherst, University of Massachusetts Amherst, July.

Fairfield, T. and M. Jorratt (2016), "Top income shares, business profits, and effective tax rates in contemporary Chile", The Review of Income and Wealth, vol. 62, No. S1, Hoboken, Wiley, August.

Feenstra, R., R. Inklaar and M. Timmer (2015), "The next generation of the Penn World Table", American Economic Review, vol. 105, No. 10, Pittsburgh, American Economic Association (AEA) [online] https://www.rug.nl/ggdc/docs/the_next_ generation_of_the_penn_world_table.pdf.

Fischer, A. (2015), "The end of peripheries? On the enduring relevance of structuralism for understanding contemporary global development", Development and Change, vol. 46, Hoboken, Wiley.

Fischer, S. (1998), "Capital account liberalization and the role of the IMF", Should the IMF pursue capital account convertibility?, S. Fischer and others, Essays in International Finance, No. 207, Princeton, Princeton University, May.

Fraser, N. (2016), "Contradictions of capital and care", New Left Review, No. 100, London, July-August.

Frenkel, R. and J. Ros (2006), "Unemployment and the real exchange rate in Latin America", World Development, vol. 34, No. 4, Amsterdam, Elsevier, April

Froud, J. and others (2006), Financialization and Strategy: Narrative and Numbers, New York, Routledge.

Furceri, D. and P. Loungani (2015), "Capital account liberalization and inequality", IMFWorking Paper, No. 15/243, Washington, D.C., International Monetary Fund (IMF), November.

Gómez Sabaini, J., J. Jiménez and D. Rossignolo (2012), "Imposición a la renta personal y equidad en América Latina: nuevos desafíos", Macroeconomics of Development series, No. 119 (LC/L.3477-P), Santiago, Economic Commission for Latin America and the Caribbean (ECLAC), July.

Gómez Sabaini, J. and D. Morán (2013), "Tax policy in Latin America: assessment and guidelines for a second generation of reforms", Macroeconomics of Development series, No. 133 (LC/G.3632), Santiago, Economic Commission for Latin America and the Caribbean (ECLAC), June.

Goñi, E., J. López and L. Servén (2011), "Fiscal redistribution and income inequality in Latin America", World Development, vol. 39, No. 9, Amsterdam, Elsevier, September.

Hall, R. (1988), "Intertemporal substitution in consumption", Journal of Political Economy, vol. 96, No. 2, Chicago, University of Chicago Press, April.

Hanni, M., R. Martner and A. Podestá (2017), "La incidencia distributiva de la fiscalidad en América Latina," Consensos y conflictos en la política tributaria de América Latina, J. Gómez Sabaini, J. Jiménez and R. Martner (eds.), ECLAC Books, No. 142 (LC/PUB.2017/5-P), Santiago, Economic Commission for Latin America and the Caribbean (ECLAC), March. (2014), "El impacto redistributivo de la acción fiscal en América Latina: los efectos de impuestos y transferencias públicas", Los efectos de la política fiscal sobre la redistribución en América Latina y la Unión Europea, Colección Estudios, No. 8, Madrid, EUROsociAL Programme, September.

Hanni, M. and A. Podestá (2016), "Flujos financieros ilícitos en los países andinos: una mirada al sector minero", Project Documents (LCM.724), Santiago, Economic Commission for Latin America and the Caribbean (ECLAC), December.

Hansen, B. (1999), "Threshold effects in non-dynamic panels: estimation, testing and inference," Journal of Econometrics, vol. 93, No. 2, Amsterdam, Elsevier, December.

Hein, E. (2015), "Finance-dominated capitalism and re-distribution of income: a Kaleckian perspective", Cambridge Journal of Economics, vol. 39, No. 3, Oxford, Oxford University Press, May.

(2012), "Finance-dominated capitalism, re-distribution, household debt and financial fragility in a Kaleckian distribution and growth model", PSL Quarterly Review, vol. 65, No. 260, Rome.

IMF (International Monetary Fund) (2015), "Managing capital outflows: further operational considerations", IMF Policy Paper, Washington, D.C., December. 
Joumard, I., M. Pisu and D. Bloch (2012), “Less income inequality and more growth: are they compatible? Part 3. Income redistribution via taxes and transfers across OECD countries", OECD Economics Department Working Papers, No. 926, Paris, Organization for Economic Cooperation and Development (OECD), January.

Kaltenbrunner, A. and J. Painceira (2016), "International and domestic financialisation in middle income countries: the Brazilian experience", Working Paper series, No. 146, Financialisation, Economy, Society and Sustainable Development (FESSUD).

Kapsos, S. (2005), "The employment intensity of growth: trends and macroeconomic determinants", Employment Strategy Paper, No. 2005/12, Geneva, International Labour Organization (ILO).

Keynes, J. (1980), "Activities 1940-1944. Shaping the post-war world: the clearing union", The Collected Writings of John Maynard Keynes, vol. 25, London, Macmillan.

Kiefer, D. and C. Rada (2015), "Profit maximising goes global: the race to the bottom", Cambridge Journal of Economics, vol. 39, No. 5, Oxford, Oxford University Press, September.

Koepke, R. (2015), "What drives capital flows to emerging markets? A survey of the empirical literature", MPRA Paper, No. 62770, Munich, Ludwig-Maximilian University of Munich, April.

Kose, M. and others (2006), “Financial globalization: a reappraisal," NBER Working Paper, No. 12484, Cambridge, National Bureau of Economic Research (NBER), August.

Kose, M., E. Prasad and M. Terrones (2008), “Does openness to international financial flows raise productivity growth?”, NBER Working Paper, No. 14558, Cambridge, National Bureau of Economic Research (NBER), December.

Lapavitsas, C. (2014), Profiting without producing: how finance exploits us all, New York, Verso Books.

Lustig, N., C. Pessino and J. Scott (2013), "The impact of taxes and social spending on inequality and poverty in Argentina, Bolivia, Brazil, Mexico, Peru and Uruguay: an overview", CEQ Working Paper, No. 13, New Orleans, Tulane University, April.

Martínez, R. (2017), Institucionalidad social en América Latina y el Caribe, ECLAC Books, No. 146 (LC/PUB.2017/14-P), Santiago, Economic Commission for Latin America and the Caribbean (ECLAC), October.

McKinnon, R. (1973), Money and Capital in Economic Development, Washington, D.C., Brookings Institution Press.

Medeiros, M. and J. Costa (2008), "Is there a feminization of poverty in Latin America?", World Development, vol. 36, No. 1, Amsterdam, Elsevier, January.

Medeiros, C. and N. Trebat (2018), "Finance, trade, and income distribution in global value chains: implications for developing economies and Latin America", Estudios sobre financierización en América Latina, M. Abeles (ed.), Santiago, Economic Commission for Latin America and the Caribbean (ECLAC), forthcoming.

Milberg, W. and D. Winkler (2013), Outsourcing Economics: Global Value Chains in Capitalist Development, Cambridge, Cambridge University Press.

Moreno-Brid, J. (1998), “On capital flows and the balance of payments constrained growth model”, Journal of Post Keynesian Economics, vol. 21, No. 2, Routledge, Taylor \& Francis.

Morgan, M. (2017), “Extreme and persistent inequality: new evidence for Brazil combining national accounts, surveys and fiscal data, 2001-2015", WID.world Working Paper, No. 2017/12, World Wealth and Income Database (WID.world).

Mulligan, R. (2013), "A sectoral analysis of the financial instability hypothesis", The Quarterly Review of Economics and Finance, vol. 53, No. 4, Amsterdam, Elsevier, November.

Ocampo, J. A. (2013), "Macroeconomía para el desarrollo: políticas anticíclicas y transformación productiva", Reflexiones sobre el desarrollo en América Latina y el Caribe: conferencias magistrales 2011-2012 (LC/G. 2563), Santiago, Economic Commission for Latin America and the Caribbean (ECLAC), January.

(2011), “¿Cómo fue el desempeño de América Latina durante la crisis financiera global?”, Ensayos Económicos, No. 61-62, Buenos Aires, Central Bank of Argentina, January-June.

OECD (Organization for Economic Cooperation and Development) (2015), Measuring and Monitoring BEPS. ACTION 11: 2015 Final Report, Paris.

Onaran, Ö., E. Stockhammer and L. Grafl (2011), "Financialisation, income distribution and aggregate demand in the USA", Cambridge Journal of Economics, vol. 35, No. 4, Oxford, Oxford University Press, July.

Onaran, Ö. and G. Galanis (2012), "Is aggregate demand wage-led or profit-led? National and global effects", Conditions of Work and Employment series, No. 40, Geneva, International Labour Organization (ILO), October.

Orhangazi, Ö. (2008), "Financialisation and capital accumulation in the non-financial corporate sector. A theoretical and empirical investigation on the US economy: 1973-2003", Cambridge Journal of Economics, vol. 32, No. 6, Oxford, Oxford University Press, November.

Palma, J. (2014), “De-industrialisation, 'premature' de-industrialisation and the Dutch-disease”, Revista NECAT, vol. 3, No. 5, Santa Catarina, Federal University of Santa Catarina, January-June.

Pérez Caldentey, E., N. Favreau Negront and L. Mendez (2017), “Deuda del sector corporativo no financiero en América Latina y sus posibles implicaciones macroeconómicas", document presented at the workshop "¿Cómo dinamizar el crecimiento económico de América Latina y el Caribe?", Santiago, Economic Commission for Latin America and the Caribbean (ECLAC), 3-4 October. 
Prasad, E., R. Rajan and A. Subramanian (2007), "Foreign capital and economic growth", NBER Working Paper, No. 13619, Cambridge, National Bureau of Economic Research (NBER), Noviembre.

Prebisch, R. (1981), Capitalismo periférico: Crisis y transformación, Mexico City, Economic Commission for Latin America and the Caribbean (ECLAC)/Fondo de Cultura Económica.

(1959), The Latin American Common Market (E/CN.12/531), Santiago, Economic Commission for Latin America and the Caribbean (ECLAC), July.

(1946), "Panorama general de los problemas de regulación monetaria y crediticia en el continente americano: América Latina", Memoria: Primera Reunión de Técnicos sobre Problemas de Banca Central del Continente Americano, Mexico City, Bank of Mexico.

Rajan, R. and A. Subramanian (2011), "Aid, Dutch disease and manufacturing growth", Journal of Development Economics, vol. 94, No. 1, Amsterdam, Elsevier, January.

Razmi, A., M. Rapetti and P. Skott (2012), "The real exchange rate and economic development", Structural Change and Economic Dynamics, vol. 23, No. 2, Amsterdam, Elsevier, June.

Reyes, L. (2018), "¿Wage-led, profit-led o export-led? Un análisis empírico sobre los regímenes de crecimiento en América Latina", Studies and Perspectives series-ECLAC Office in Buenos Aires, Santiago, Economic Commission for Latin America and the Caribbean (ECLAC), forthcoming.

Rodrigues, J., A. Santos and N. Teles (2016), "Semi-peripheral financialisation: the case of Portugal", Review of International Political Economy, vol. 23, No. 3, Routledge, Taylor \& Francis.

Rodríguez Enríquez, C. (2012), "Care: the missing link in economic analysis?", CEPAL Review, No. 106 (LC/G.2518-P), Santiago, Economic Commission for Latin America and the Caribbean (ECLAC), April.

Rodrik, D. (1998), "Who needs capital-account convertibility?", Should the IMF Pursue Capital-Account Convertibility?, S. Fischer and others, Essays in International Finance, No. 207, Princeton, Princeton University, May.

Ros, J. (2016), "The real exchange rate, the real wage, and growth: a formal analysis of the 'development channel'," Macroeconomics and Development: Roberto Frenkel and the Economics of Latin America, M. Damil, M. Rapetti and G. Rozenwurcel (eds.), New York, Columbia University Press.

Rossignolo, D., N. Oliva and N. Villacreses (2016), "Cálculo de la concentración de los altos ingresos sobre la base de los datos impositivos: un análisis para el Ecuador", Macroeconomics of Development series, No. 184 (LC/L.4278), Santiago, Economic Commission for Latin America and the Caribbean (ECLAC), December.

Schumpeter, J. (1954), "The crisis of the tax state", International Economic Papers, No. 4, A. Peacock and others (eds.), London, Macmillan.

Sepúlveda, C. and J. Martinez-Vazquez (2012), "Explaining property tax collections in developing countries: the case of Latin America", Decentralization and Reform in Latin America: Improving Intergovernmental Relations, G. Brosio and J. Jiménez (eds.), Cheltenham, Edward Elgar.

Serena, J. and R. Moreno (2016), "Domestic financial markets and offshore bond financing", BIS Quarterly Review, Basel, Bank for International Settlements (BIS), September.

Shaw, E. (1973), Financial Deepening in Economic Development, New York, Oxford University Press.

Shin, H. Y. (2012), "Essays on the causes and consequences of the Asian financial crisis: financialization, stagnant corporate investment, and alternative measures of the Asian labor markets", doctoral thesis on philosophy, New York, New School University, February.

Steiner, A. and T. Saadma (2016), "Measuring de facto financial openness: a new index", Munich, University of Munich [online] https://editorialexpress.com/cgi-bin/conference/download.cgi?db_name=EEAESEM2016\&paper_id=2412.

Stockhammer, E. (2012), "Financialization, income distribution and the crisis", Investigación Económica, vol. 71, No. 279, Mexico City, National Autonomous University of Mexico (UNAM), January-March.

(2011), "Neoliberalism, income distribution and the causes of the crisis", The Financial Crisis: Origins and Implications, P. Arestis, R. Sobreira and J. L. Oreiro (eds.), Berlin, Springer.

(2009), "The finance-dominated accumulation regime, income distribution and the present crisis", Papeles de Europa, vol. 19, Madrid, Complutense University of Madrid.

(2004), "Financialisation and the slowdown of accumulation," Cambridge Journal of Economics, vol. 28, No. 5, Oxford, Oxford University Press, September.

Stockhammer, E., Ö. Onaran and S. Ederer (2009), "Functional income distribution and aggregate demand in the Euro area", Cambridge Journal of Economics, vol. 33, No. 1, Oxford, Oxford University Press, January.

Summers, L. (2000), "International financial crises: causes, prevention, and cures", American Economic Review, vol. 90, No. 2, Pittsburgh, American Economic Association, May.

Tan, J. (2014), "Running out of steam? Manufacturing in Malaysia," Cambridge Journal of Economics, vol. 38, No. 1, Oxford, Oxford University Press, January.

Thirlwall, A. (1979), "The balance of payments constraint as an explanation of the international growth rate differences", PSL Quarterly Review, vol. 32, No. 128, Rome. 
Tori, D. and Ö. Onaran (2015), "The effects of financialization on investment: evidence from firm-level data for the UK", Working Paper, No. 1601, Leeds, Post Keynesian Economics Study Group (PKSG), January.

Torres, E., N. Montani and C. Yukari (2017), "Minsky's financial fragility: an empirical analysis of electricity distribution companies in Brazil (2007-15)", Working Paper, No. 896, Annandale-on-Hudson, Levy Economics Institute, September.

UNCTAD (United Nations Conference on Trade and Development) (2015), "An FDI-driven approach to measuring the scale and economic impact of BEPS", Working Paper, Geneva, March.

Vásconez, A. (2012), "Mujeres, hombres, y las economías latinoamericanas: un análisis de dimensiones y políticas", La economía feminista desde América Latina: una hoja de ruta sobre los debates actuales en la región, V. Esquivel and others (eds.), Santo Domingo, United Nations Entity for Gender Equality and the Empowerment of Women (UN-Women), June.

Villatoro, P. and S. Cecchini (2018), “Discrepancias entre encuestas y registros: ¿cuál es el alcance de las transferencias no contributivas en América Latina?", Statistical Studies series, Santiago, Economic Commission for Latin America and the Caribbean (ECLAC), forthcoming.

Weller, J. (2014), "Aspects of recent developments in the Latin American and Caribbean labour markets", CEPAL Review, No. 114 (LC/G.2629-P), Santiago, Economic Commission for Latin America and the Caribbean (ECLAC), December.

Wichterich, C. (2012), "The other financial crisis: growth and crash of the microfinance sector in India," Development, vol. 55, No. 3, Berlin, Springer, September.

Zucman, G. (2015), The Hidden Wealth of Nations: The Scourge of Tax Havens, Chicago, University of Chicago Press. 


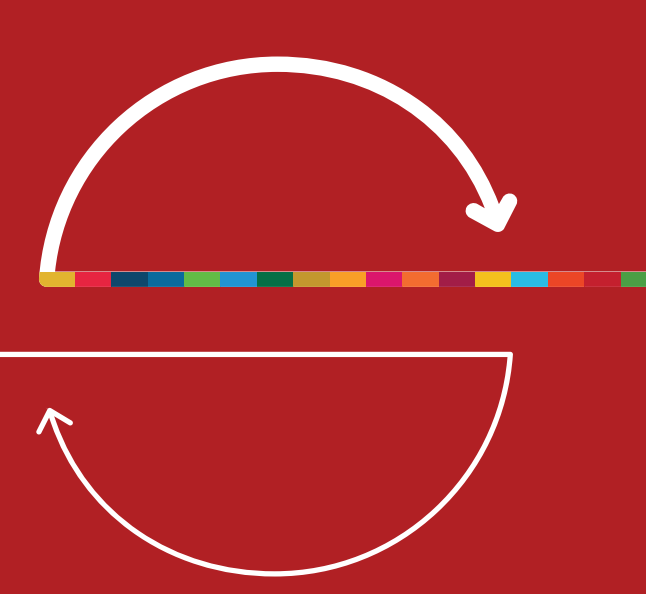

\section{CHAPTER}

IV

\section{Inequality is inefficient and unsustainable}

Introduction

A. Inequality as a development obstacle
1. The cost of education and health divides
2. Income inequality trammels intergenerational mobility
3. An inefficient labour market: persistent informality
4. Labour market discrimination and opportunities: gender inequality
5. The positive effects of social protection and care on growth and employment

B. Future challenges: demographic changes and the technological revolution

1. The effects of ageing, female labour force participation and education

2. Technological disruption in the labour market

Bibliography 



\section{Introduction}

One of the guiding principles in the thinking of the Economic Commission for Latin America and the Caribbean (ECLAC), and likewise a feature of the 2030 Agenda for Sustainable Development, is the positioning of equality as a core development value. ECLAC studies have shown how inequality "spreads and strengthens in the labour and social spheres and becomes intertwined in various ways with inequalities based on gender, ethnicity, race, life cycle and territory" (ECLAC, 2017a). Rather than addressing the normative aspects dealt with by earlier documents, ${ }^{1}$ the present chapter analyses inequality by reviewing its economic and social costs and consequences, adopting a strictly instrumental and economic perspective in order to explore the question: why reduce inequality?

The interest in equality as a tool to foster development is nothing new. ${ }^{2}$ ECLAC has stressed the need for a development style that links greater equality with increased productivity and capabilities and more sustainable growth, arguing that there is complementarity between social equality and transformation of the production structure. The challenge is to identify and bring out the synergies between the two variables.

What has come out of debates about distribution and growth is that inequality not only constrains poverty reduction (see box IV.1) but entails a loss of productivity that generates substantial costs for societies. This chapter describes the links between the region's high levels of inequality (with earlier declines having tailed off in recent years) and low productivity, both because capabilities (in education or health) are forfeited and because of segmentation and discrimination in the labour market, which are fed by and feed back into inequalities in the domestic sphere. Also brought into the discussion are two factors that are critical to the evolution of productivity in the region's economies and will pose major challenges in the near future: demographic change and the technological revolution.

Box IV.1

Income inequality constrains poverty reduction

Economic growth, understood as average household income growth, is arithmetically linked to poverty and income inequality (Bourguignon, 2003). Any reduction in monetary poverty in a country at a given point in time is wholly determined by the rate of growth in average income and changes in its distribution. If distribution does not change, the poverty rate can only fall if average income rises. Again, poverty could increase in a country even with a rise in average income, if inequality grew at the same time. Poverty and inequality have fallen in most Latin American countries over the last 15 years, while average income has risen. The decline in inequality has driven poverty reduction. One way of visualizing this outcome is to calculate what the poverty rates in each country would be had mean income risen as it did without any change in income distribution, applying the methodology of Datt and Ravallion (1992).

In countries where the improvement in distribution has not been substantial, such as Mexico, poverty levels in 2016 were quite close to what they would have been without any change in distribution. In other countries such as Argentina, Brazil, Chile and Uruguay, where income inequality has fallen considerably, the simulated poverty levels are significantly higher than those actually observed. The only country where poverty would have been lower had there had been no change in distribution is Costa Rica, where income inequality rose, driving up poverty (see table). In sum, maintaining high levels of inequality means accepting higher rates of poverty.

The main theses are laid out in institutional documents published over almost a decade. See ECLAC (2010, 2012, 2014, 2017a and 2017b).

See, for example, Atkinson's (2015) reflections on Stiglitz (2012) or Pickett and Wilkinson (2009). 
Box IV.1 (concluded)

Latin America (17 countries): actual poverty rates and simulated poverty rates assuming unchanged distribution, 2002-2016

(Percentages)

\section{A. Poverty rates}

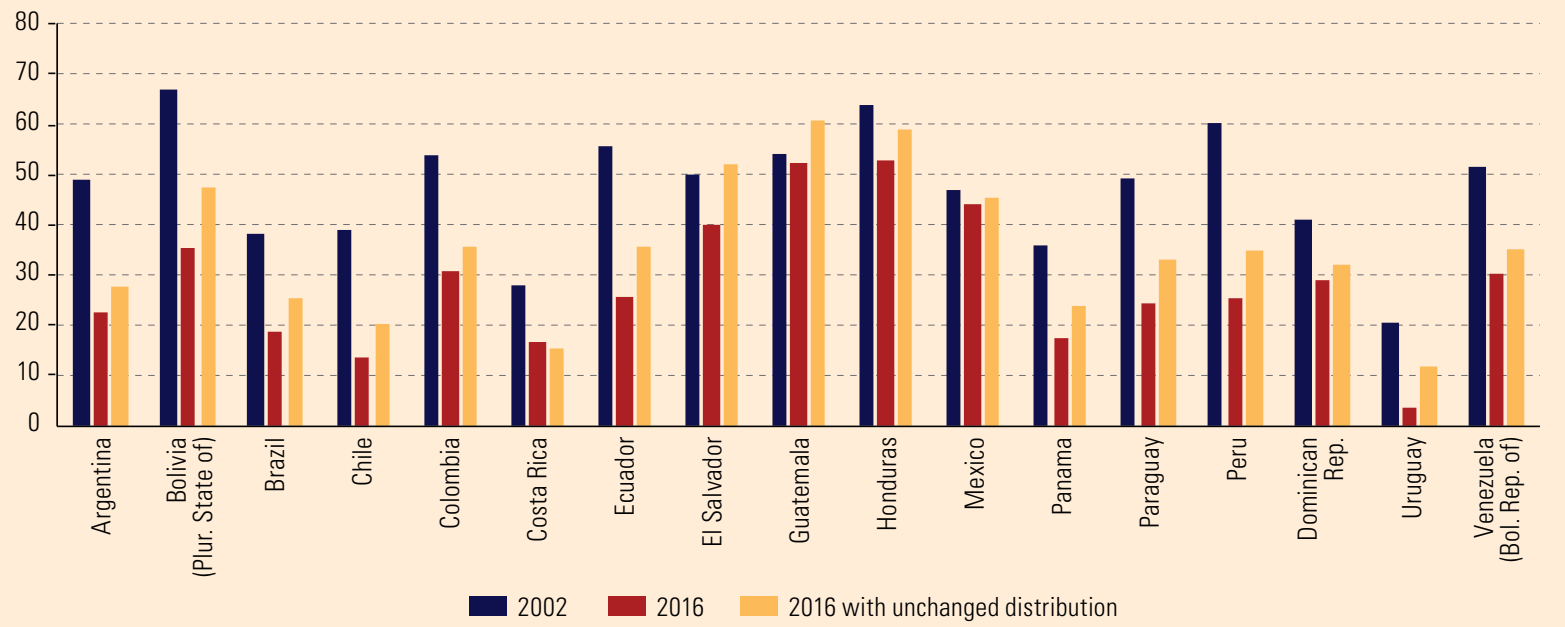

\section{B. Changes in poverty rates}

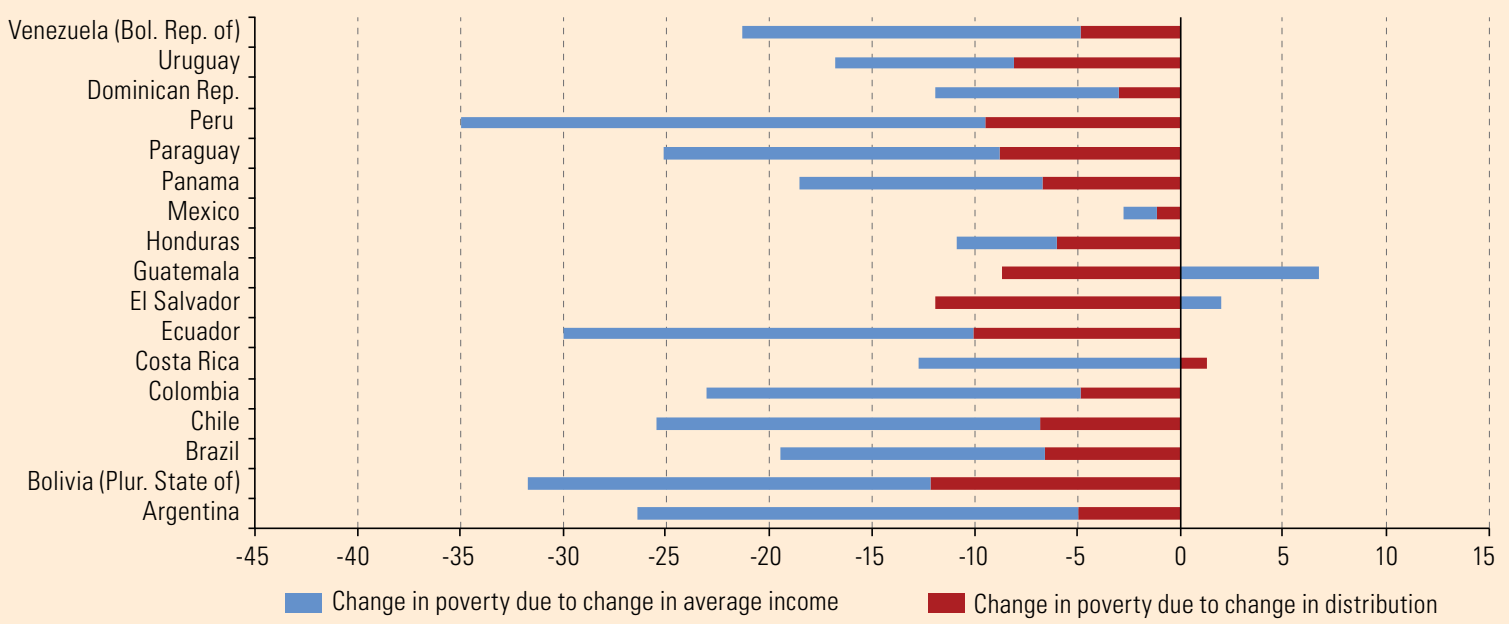

Source: Economic Commission for Latin America and the Caribbean (ECLAC), on the basis of household surveys from the respective countries.

Source: Economic Commission for Latin America and the Caribbean (ECLAC), on the basis of F. Bourguignon, "The growth elasticity of poverty reduction: explaining heterogeneity across countries and time periods", Working Paper, No. 28104, Washington, D.C., World Bank, 2003; G. Datt and M. Ravallion, "Growth and redistribution components of changes in poverty measures: a decomposition with applications to Brazil and India in the 1980s", Journal of Development Economics, vol. 38, No. 2, Amsterdam, Elsevier, 1992. 


\section{A. Inequality as a development obstacle}

Few links have been more studied in modern economics than the one between equality and economic growth. Chapter III analysed this link from the macroeconomic perspective, highlighting the importance of investment and the labour market, among other factors. The present chapter supplements this perspective by analysing the links between growth and equality at the sectoral and microeconomic level and discussing the potential adverse effects of inequality on growth, ${ }^{3}$ even though the empirical evidence is inconclusive given the vital part played in this linkage by institutional factors.

\section{The cost of education and health divides}

Of all the channels connecting inequality and growth, there is a particularly widespread view that high levels of inequality in access to education are a barrier to the spread of capabilities. ${ }^{4}$ Rates of return on years of education in the region show that the largest jumps in earnings come, first, for those completing secondary education and then, more markedly, for those embarking upon tertiary and postgraduate education. Additionally, returns on years of education vary considerably with certain important factors of social inequality (see figure IV.1). Given similar education levels, rates of return as measured by earnings favour men over women, formal over informal workers, non-indigenous over indigenous people and non-Afrodescendants over Afrodescendants. The most striking differences emerge from the analysis of formal-informal segmentation in labour markets, owing to the problems of structural heterogeneity in the region.

Lack of access to a high-quality education can impair a person's ability to make a contribution to the production process commensurate with their potential over their lifespan. In Latin America, a very substantial proportion of the population aged over 18 is still not attaining a level of education equivalent to the first full secondary cycle, and this is compounded by large differences between the top and bottom income quintiles (figure IV.2). The situation varies greatly by country. At one extreme is Guatemala, where just $50 \%$ of the population aged over 18 has a level of education equivalent to completing the first cycle of secondary school, and at the other is Chile, where the share is over $80 \%$.

Different studies have pointed to the importance of completing secondary education as a means of escaping from poverty and securing high-quality formal employment. Inadequate educational attainments among the active population are a major constraint on capabilities, with consequences for productivity. As a way of gauging the loss of productivity in the economy, the importance of non-completion of the first cycle of secondary education can be measured by the loss of household income. ${ }^{5}$

The income simulated for a situation in which all working people aged between 25 and 55 have completed the first cycle of secondary education is greater than current household income in all the countries (see figure IV.3). In the countries with the largest gaps (Guatemala and Honduras), the simulation yields a rise in household income of some $25 \%$, while at the other extreme (the Bolivarian Republic of Venezuela and Chile) the change is less than $5 \%$.

See Rajan (2010), Stiglitz (2012) and Ostry, Berg and Tsangarides (2014), among others.

This idea is formalized in Galor and Zeira (1993), who analyse the costs of investing in education and flaws in financial markets.

The estimation consists in calculating the difference between households' actual income and what they would be earning if individuals who have not attained this level of education had in fact done so. The incomes of individuals who have attained that minimum are left unchanged. A Mincer equation is used for a set of covariables in each country to explain the logarithm of the incomes of people in work (excluding those in the education system) aged between 25 and 55 . 


\section{Figure IV.1}

Latin America (17 countries): wages of employees aged 20 and over working for 20 or more hours a week, by years of education, around $2015^{a}$

(Wages of employees with zero years of education in the lowest-income comparison category=100)

\section{A. Male and female wages}

\section{B. Formal and informal sector wages ${ }^{b}$}
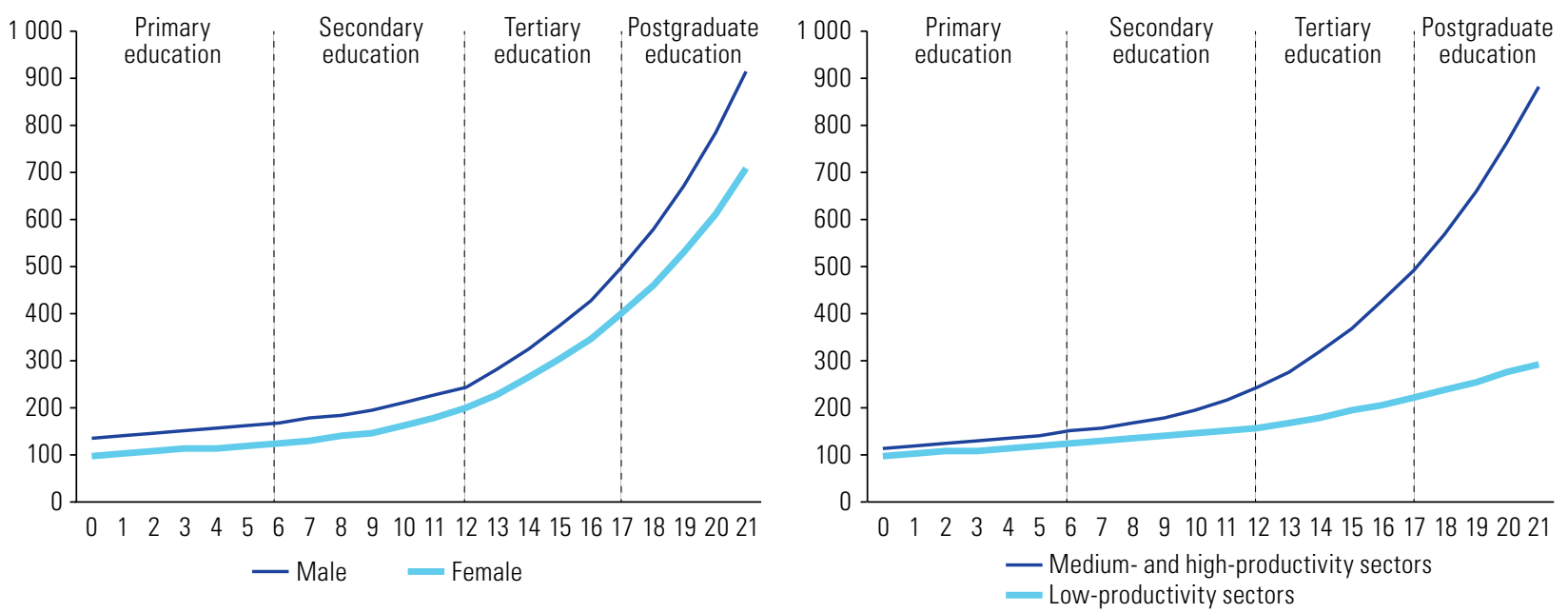

\section{Wages by ethnic origin ${ }^{\mathrm{d}}$}

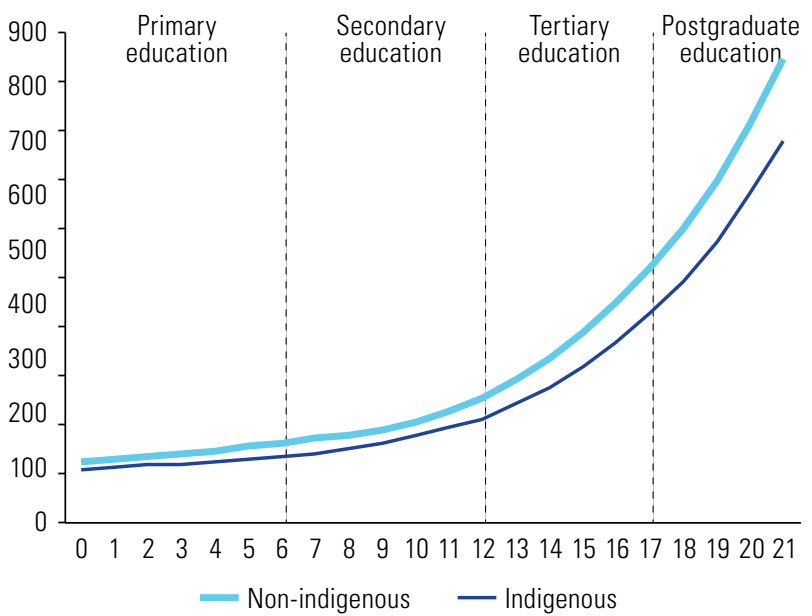

\section{Wages by racial origine ${ }^{f}$}

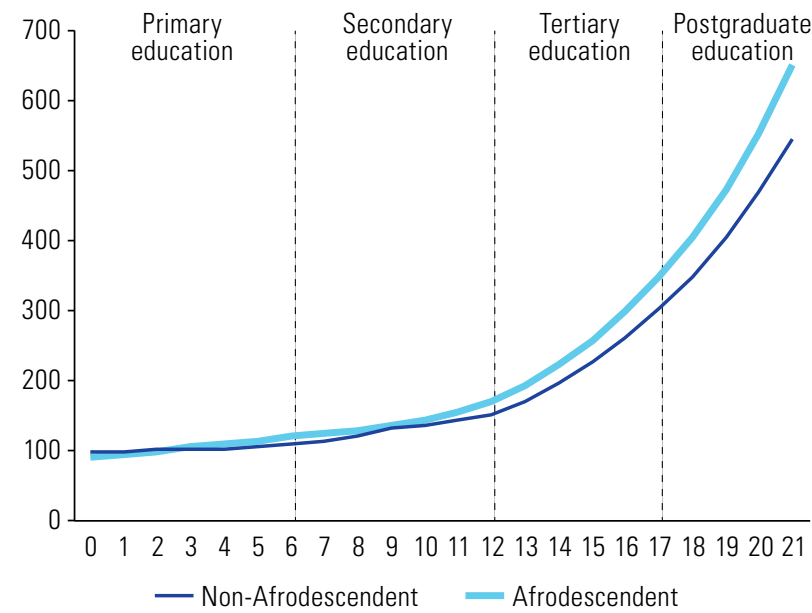

Source: Economic Commission for Latin America and the Caribbean (ECLAC), on the basis of household surveys from the respective countries.

Note: The countries analysed are Argentina, the Bolivarian Republic of Venezuela, Brazil, Chile, Colombia, Costa Rica, the Dominican Republic, Ecuador, El Salvador, Guatemala, Honduras, Mexico, Panama, Paraguay, Peru, the Plurinational State of Bolivia and Uruguay.

a Simple averages of wages for each labour market segment by country. A separate model was used to calculate pay within each segment.

b "Formal" refers to medium- and high-productivity jobs and "informal" to low-productivity jobs.

c The analyses for this category include eight countries of Latin America (Brazil, Chile, Ecuador, Guatemala, Mexico, Peru, the Plurinational State of Bolivia and Uruguay).

d The "non-indigenous" category does not include Afrodescendants.

e The analyses for this category include four countries of Latin America (Brazil, Ecuador, the Plurinational State of Bolivia and Uruguay).

f The "non-Afrodescendent" category does not include indigenous people. 
Figure IV.2

Latin America (17 countries): people aged over 18 who have completed the first cycle of secondary education, by income quintile, around 2016

(Percentages)

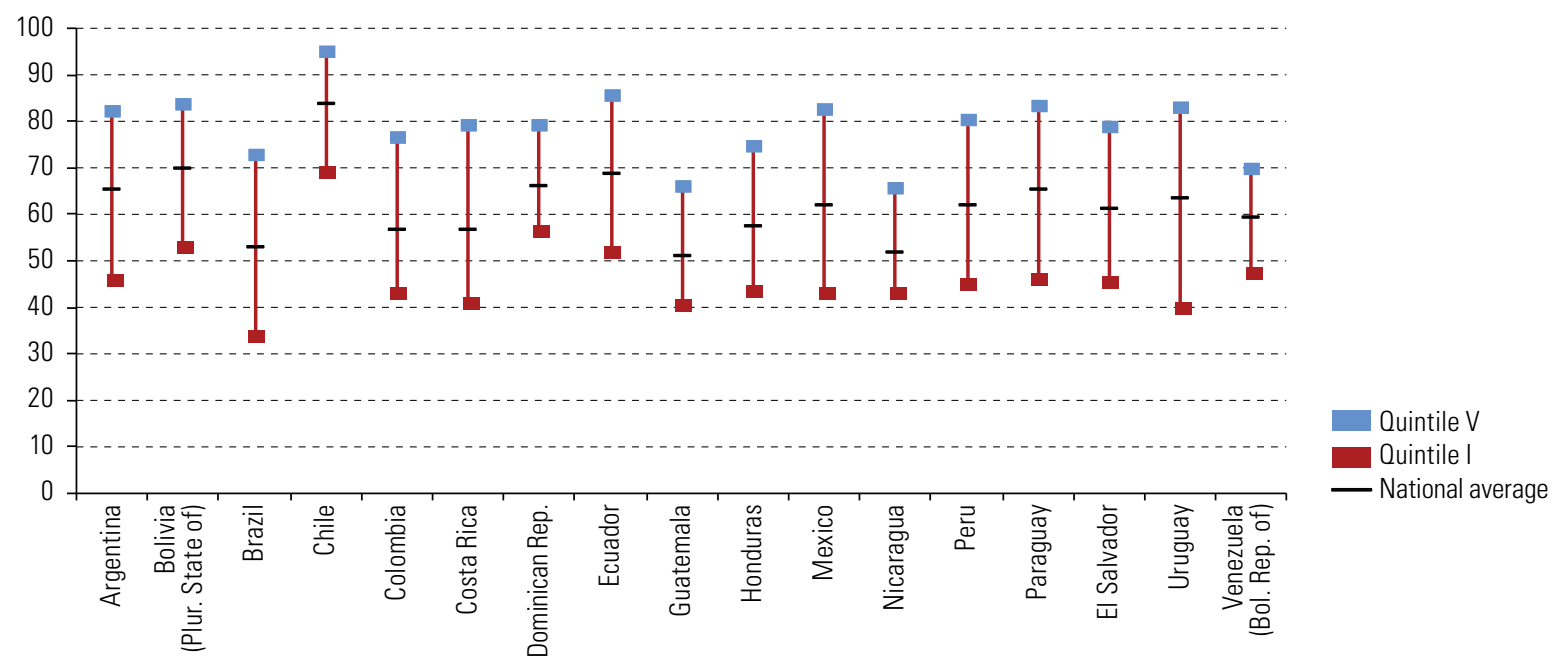

Source: Economic Commission for Latin America and the Caribbean (ECLAC), on the basis of household surveys from the respective countries.

Figure IV.3

Latin America (17 countries): increase in household income if completion of the first cycle of secondary education were universal, around 2016

(Percentages)

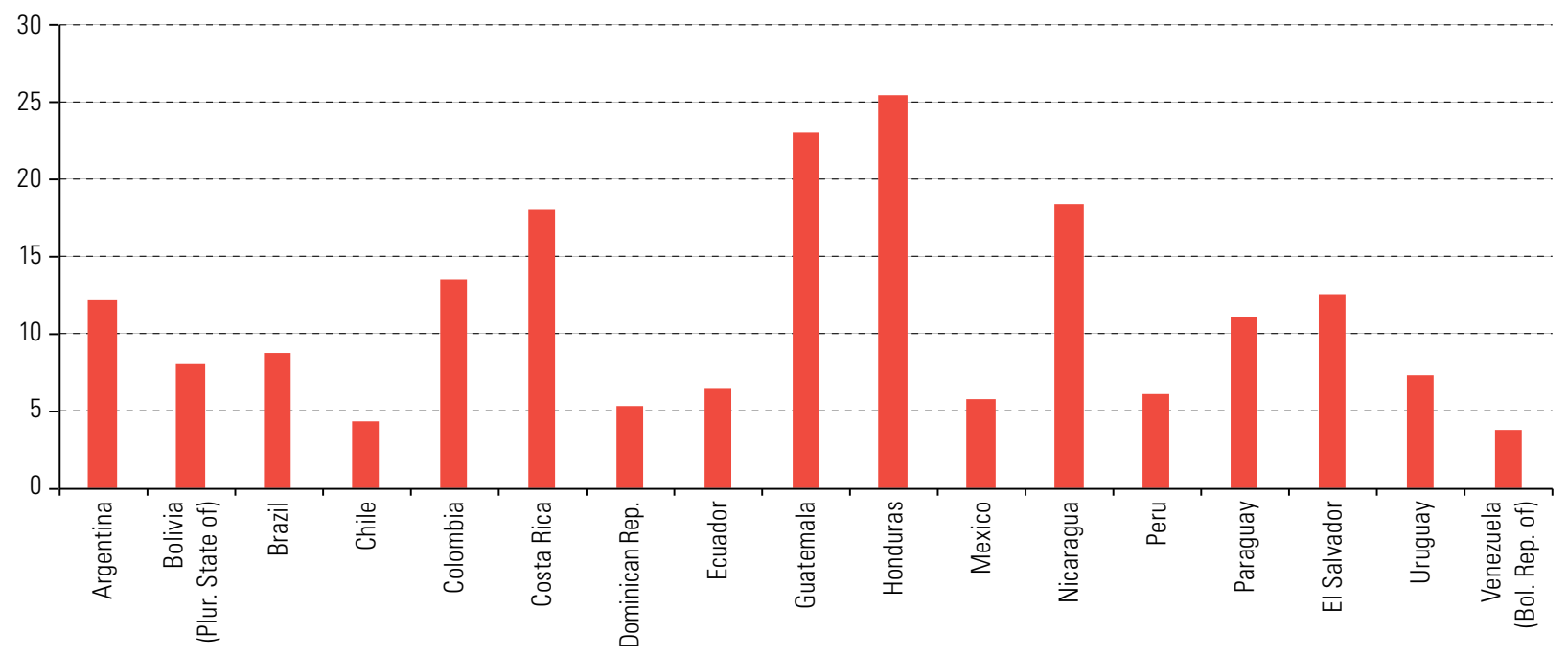

Source: Economic Commission for Latin America and the Caribbean (ECLAC), on the basis of household surveys from the respective countries. 
Both this exercise and those presented in the following sections assume that the extra supply of workers will be employed at current wages. This is a simplification that takes no account of the ability of the labour market to absorb higher-skilled labour, of general equilibrium effects, or of ongoing technological change. In economic contexts like those analysed in chapters II and III, then, the assumption is an unlikely one. The value of the exercises presented lies not in their predictive power but in the way they can illustrate the costs of inequality.

Besides the loss of productivity associated with non-attainment of what can be regarded as minimum levels of education, major problems remain with education quality, an aspect crucial to capacity-building. Figure IV.4 shows that, with the exception of Chile, the Latin American countries participating in the Programme for International Student Assessment (PISA) tests in 2015 had the world's highest percentages of fifteen-year-old students below the minimum standards of competence expected in mathematics, reading and science. In fact, $62 \%$ of students from the region who participated in the tests did not meet the required standard in mathematics, while the figures were $45 \%$ for reading and $50 \%$ for science. This reflects the quality shortcomings of secondary education in the region.

\section{Figure IV.4}

Student performance in PISA tests by region and competence (mathematics, reading and science), 2015 (Percentages)

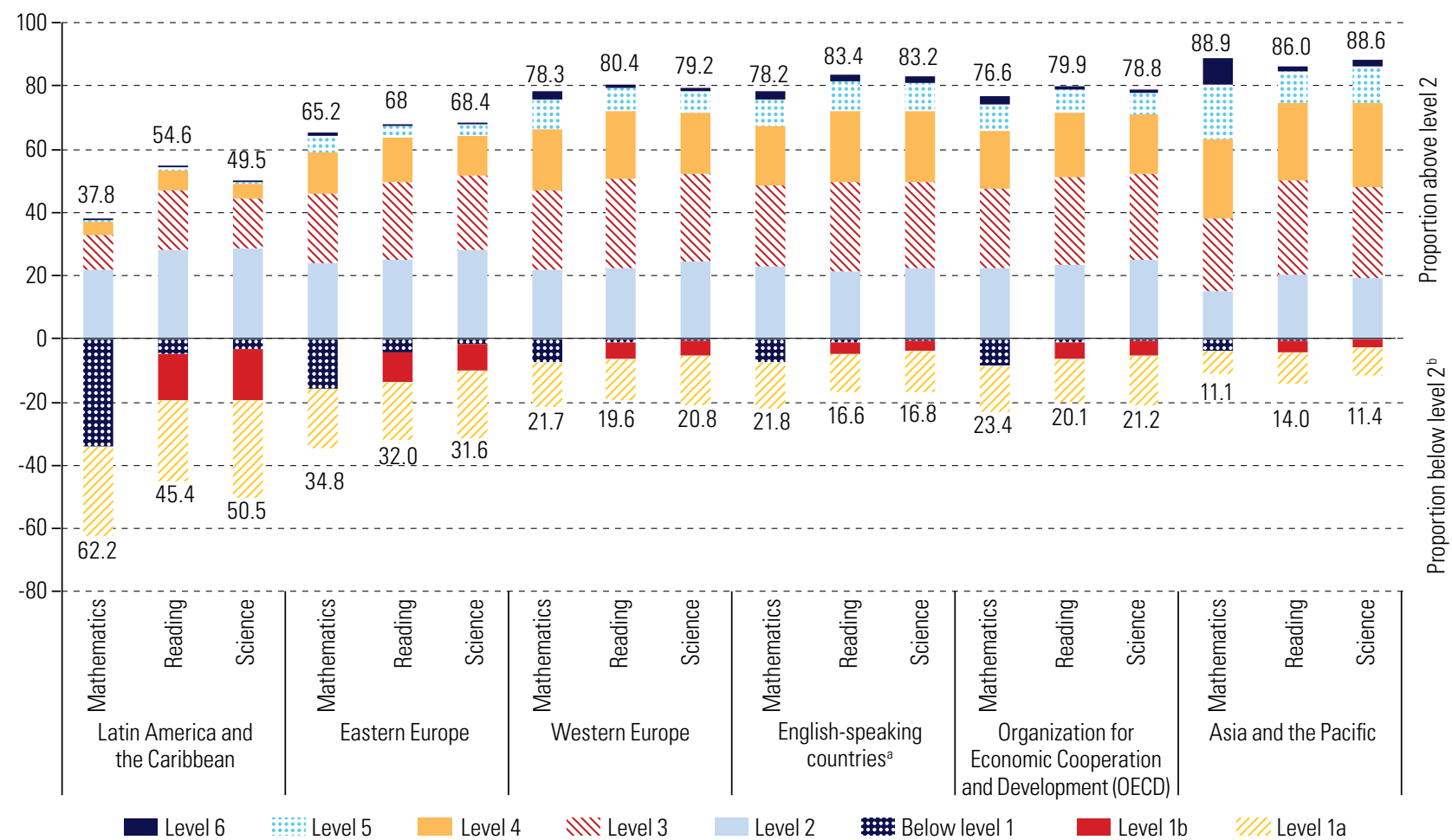

Source: Economic Commission for Latin America and the Caribbean (ECLAC), on the basis of Organization for Economic Cooperation and Development (OECD), Programme for International Student Assessment (PISA) 2015

a The "English-speaking countries" category includes Australia, Canada, New Zealand, the United Kingdom and the United States.

b Students at levels below 2 (level 1a, level $1 \mathrm{~b}$ and below level 1) have not attained the basic level of competence expected.

Another dimension crucial to higher productivity is health, and a major contribution can also be made by closing gaps in this area. Healthy, well-nourished people have greater physical and mental capacity for work and lower rates of absenteeism. Health also indirectly affects productivity by aiding cognitive development, 
learning capacity and school performance, as well as the ability to learn and acquire new skills (Fogel, 2004). Health spending yields especially large returns when it goes on children, adolescents and young adults, as action of this type can forestall future health problems and enhance the development of cognitive faculties and capabilities, generating economic returns via savings on future healthcare costs and higher productivity (UNICEF, 2012). ${ }^{6}$

However, the relationship between health and income, whether at the individual level or in society as a whole, is not one-way: good health can be a result of high earnings, as well as a cause. ${ }^{7}$ In Latin America and the Caribbean, it is estimated that annual changes in life expectancy contributed some $1.5 \%$ a year to overall income growth between 1990 and 2000 and $1.1 \%$ a year between 2000 and 2011, which is consistent with the tendency observed in high-income countries for increases in life expectancy to tail off (see figure IV.5).

\section{Figure IV.5}

Contribution of annual changes in life expectancy to total income, by region, 1990-2000 and 2000-2011 (Percentages)

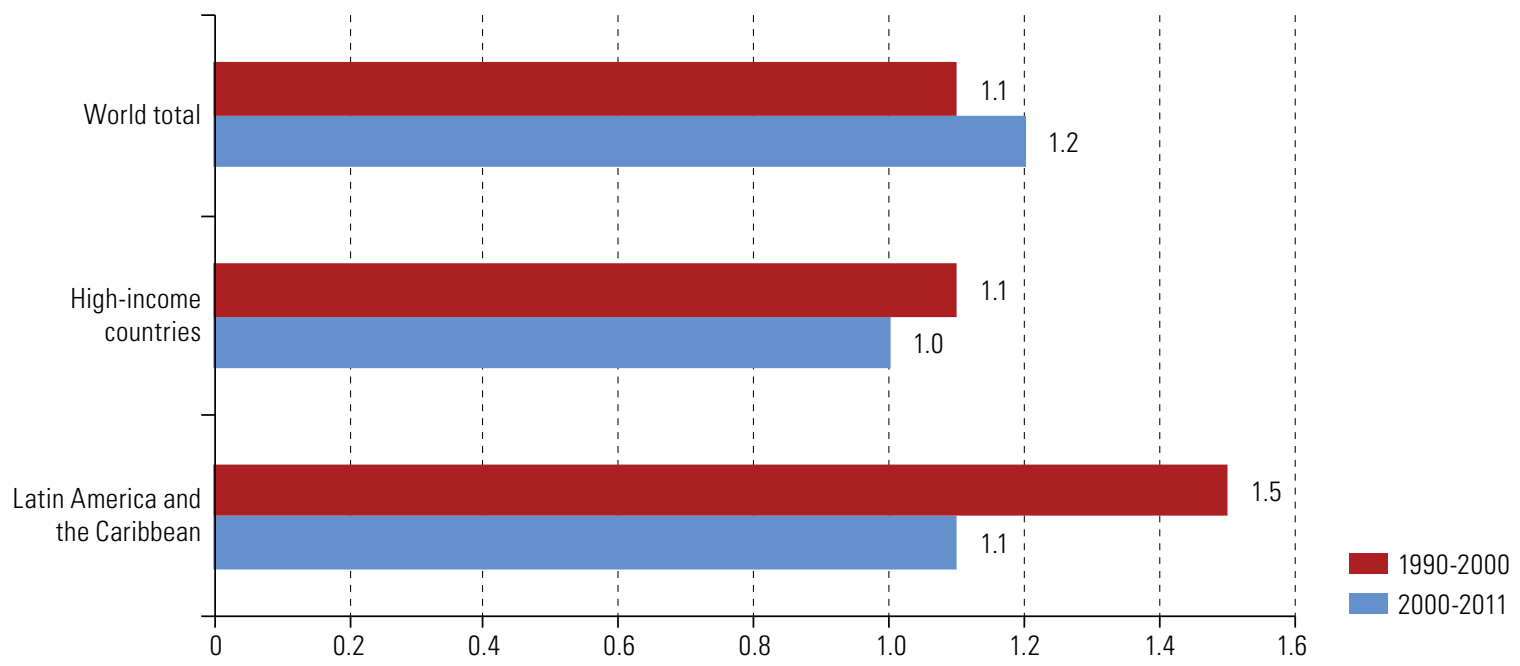

Source: Economic Commission for Latin America and the Caribbean (ECLAC), on the basis of D. Jamison and others, "Global health 2035: a world converging within a generation", The Lancet, vol. 382, No. 9908, Amsterdam, Elsevier, 2013

Note: Total income includes income growth as measured in the national accounts plus the monetary value of the extra years of life gained in the period.

Positive productivity effects are also identified from the decline in teenage motherhood. Although fertility has fallen dramatically in Latin America and the Caribbean over recent decades, it remains high among adolescents, particularly those from low economic strata, those belonging to indigenous peoples and those living in rural areas (ECLAC, 2017a). This is a cause for concern and has been identified as a key factor in the intergenerational transmission of poverty because of the marked negative consequences of motherhood in adolescence, particularly early adolescence (ECLAC, 2016b). Besides being unequally distributed in the population, adolescent motherhood perpetuates social inequalities by affecting the level of education young women attain and their present and future prospects of obtaining work and social protection

6 There are studies in the region confirming the cost-effectiveness of interventions to promote infant health in areas such as nutrition (Llanos and others, 2007), malaria (Bleakley, 2010) and vaccination against pneumococcus and rotavirus (Constenla and others, 2008; De Soárez and others, 2008). The cost-benefit ratio is 5.6 for interventions to prevent traffic accidents among the adolescent population (the benefits are 5.6 times as great as the costs) and 17.0 for vaccination against human papillomavirus (HPV) (Sheehan and others, 2017).

7 Even so, different studies have sought to quantify the effects of health on productivity, employment and growth. See, for example, WHO (2011), Bloom, Canning and Sevilla (2004) and Alsan and others (2008). 
(ECLAC, 2016a). On average, women aged from 25 to 35 in the region who became mothers in adolescence have studied for 3.2 years fewer than women in the same age group who were not adolescent mothers (see figure IV.6).

Figure IV.6

Latin America (7 countries): average years' education of women aged 25 to 35 who did and did not become mothers in adolescence, 2008-2015

(Years)

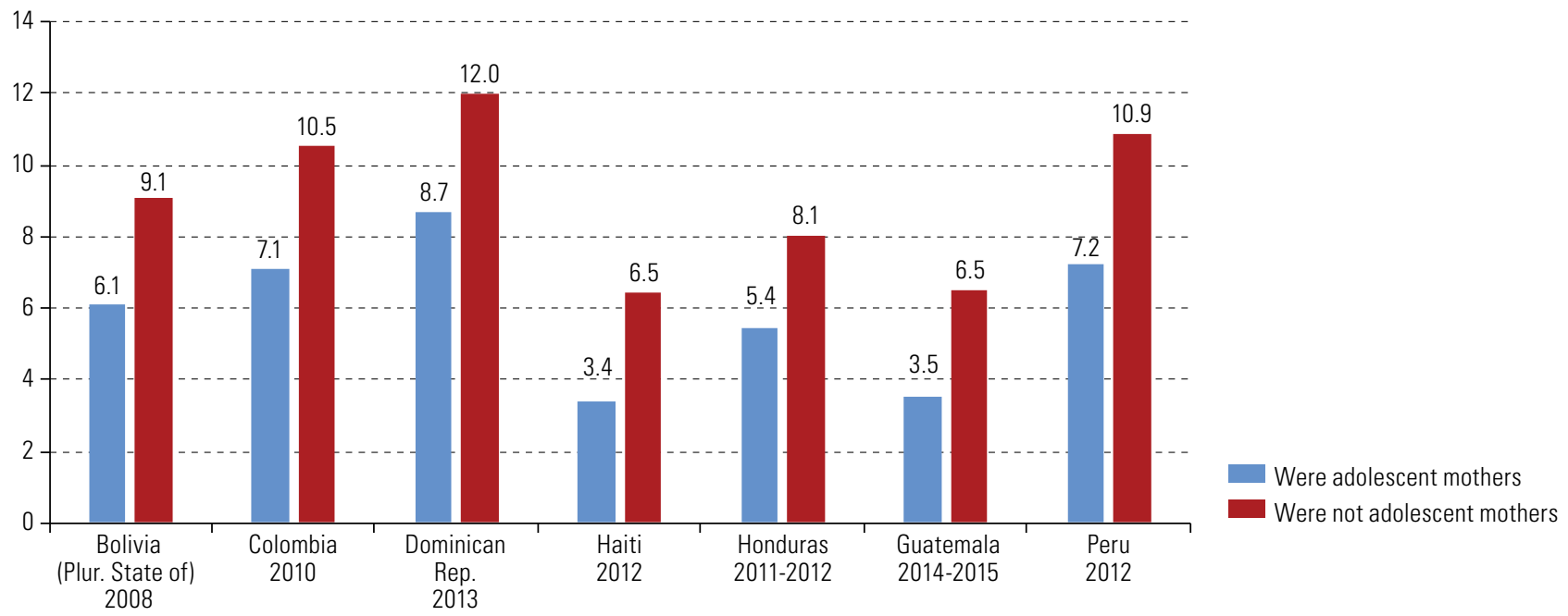

Source: Economic Commission for Latin America and the Caribbean (ECLAC), on the basis of demographic and health surveys from the countries and years shown.

The adverse effects of premature motherhood also extend to the children born to adolescent mothers, creating another source of future economic costs (ECLAC, 2016a).

If the mother's education level is controlled for, children born to women who were mothers in adolescence present a greater prevalence of chronic malnutrition, which has costs for productivity and health systems (Fernández and others, 2017). Thus, health spending in adolescence has a threefold positive effect, paying dividends in adolescence itself, in adulthood and for the next generation.

\section{Income inequality trammels intergenerational mobility}

There is a strong association between greater income inequality and reduced mobility between generations (Corak, 2013). This association can be seen in both developed and developing countries. Latin America and the Caribbean (see figure IV.7 and box IV.2) display some of the highest correlations (as measured by intergenerational income elasticity) between parents' and children's incomes. ${ }^{8}$ The countries are not offsetting higher levels of inequality with greater income mobility; in those where the differences between rich and poor are greater, there is a smaller probability of moving from poverty to wealth. Although causalities cannot be identified, this positive association is important for understanding the dynamic implications of the region's high inequality levels, as was pointed out in chapter I.

8 The empirical association between high inequality and low mobility, known as the Great Gatsby curve, has been a matter of controversy among economists. 
Figure IV.7

Intergenerational mobility and income inequality

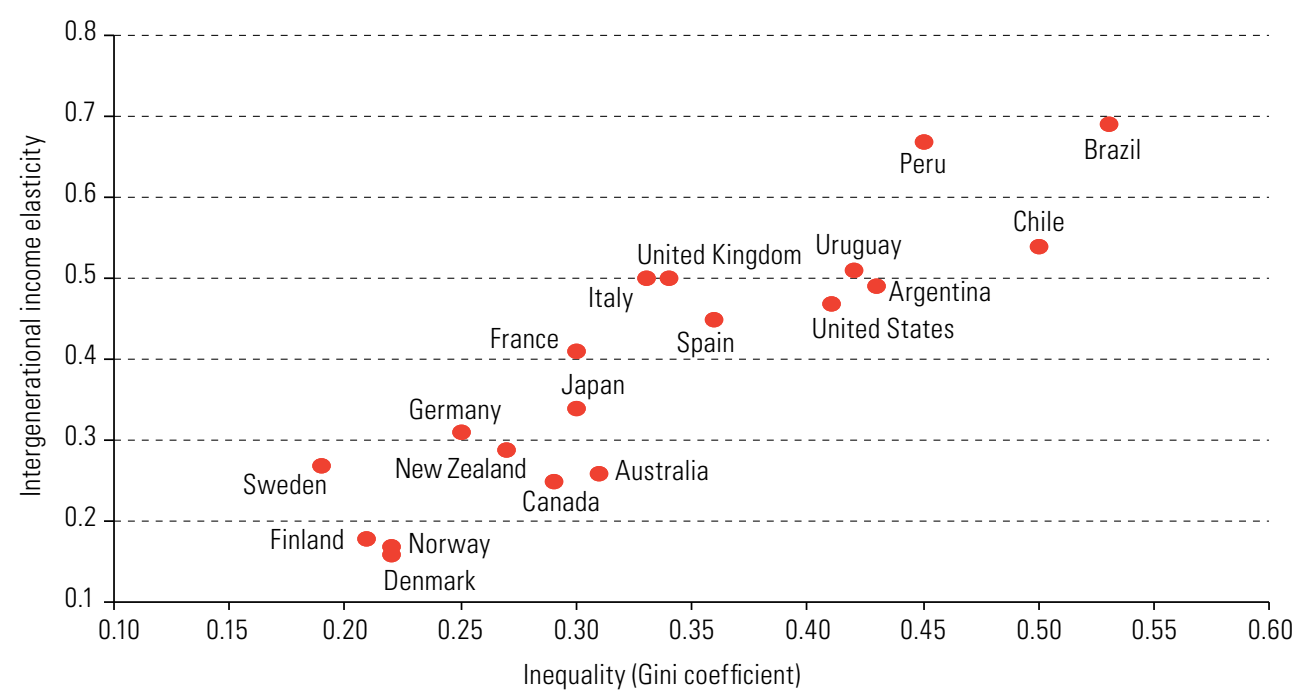

Source: F. Araya, "Una aproximación a la movilidad intergeneracional de los ingresos laborales en Uruguay", master's thesis, Montevideo, University of the Republic, 2017; M. Corak, "Income inequality, equality of opportunity, and intergenerational mobility", Journal of Economic Perspectives, vol. 27, No. 3, Pittsburgh, American Economic Association, 2013; C. Dunn, "The intergenerational transmission of lifetime earnings: evidence from Brazil", The B.E. Journal of Economic Analysis \& Policy, vol. 7, No. 2, Berlin, De Gruyter, 2007; N. Grawe, "Intergenerational mobility for whom? The experience of high- and low-earning sons in international perspective", Generational Income Mobility in North America and Europe, M. Corak (ed.), Cambridge, Cambridge University Press, 2004; J. Núñez and L. Miranda, "Recent findings on intergenerational income and educational mobility in Chile", Documento de Trabajo, No. 244, Santiago, University of Chile, 2007; and M. Jiménez and M. Jiménez, "La movilidad intergeneracional del ingreso: evidencia para Argentina", Documento de Trabajo, No. 84, La Plata, National University of La Plata, 2009.

\section{Box IV.2}

Measuring intergenerational mobility

Studies on intergenerational income mobility usually analyse the link between the permanent incomes of parents and their children. This can be done using the coefficient of correlation between the two variables or by means of a coefficient obtained by estimating the regression of the children's level of education relative to their parents', which reflects the intergenerational elasticity of income. When the coefficient approaches 1 , this means that an increase of a certain size in the parents' income is associated with a virtually equal increase in the children's; i.e. the higher intergenerational income elasticity values are, the less intergenerational mobility there is. The relationship between the two indicators is as follows: the coefficient is equal to the coefficient of correlation between the parents' and children's education, weighted by the ratio between the parents' and children's standard deviations. The divergences between the two are the result of changes in the standard deviation ratio (Daude and Robano, 2015).

Source:Economic Commission for Latin America and the Caribbean (ECLAC), on the basis of C. Daude and V. Robano, "On intergenerational (im)mobility in Latin America", Latin American Economic Review, vol. 24, No. 9, Berlin, Springer, 2015.

A review of the information available on Latin America (of which there is little, owing to a lack of appropriate databases) prompts the conclusion that levels of intergenerational mobility are low in the region, even when compared with the United Kingdom or the United States, countries that have low levels of mobility by international standards (Azevedo and Bouillon, 2010). Other studies (Hertz and others, 2007; Torche, 2014; Daude and Robano, 2015) concur in highlighting low levels of intergenerational mobility, with a focus on education. The influence of family background on educational outcomes emerges as a distinctively Latin American characteristic. Torche (2014) notes that the high returns to education in Latin America can become an inherited meritocracy trap, given the inequalities of access and the barriers faced by individuals from less affluent households in terms of education quantity and quality. 
Daude and Robano (2015) evaluate children's educational attainments relative to their parents' across 18 countries of the region using information from the Latinobarómetro Corporation. Comparing the results of their estimates for Latin America with others available for the world, they find the coefficient of correlation between parents' and children's education to be significantly higher in Latin America (see figure IV.8A). Estimates for the different countries of the region are very heterogeneous: whereas in Costa Rica an increase of 4 years' education for the parents entails 1.6 years' more education for the children, in Guatemala the figure is 3.4 years' more (see figure IV.8B).

\section{Figure IV.8}

Educational mobility between generations

\section{A. Coefficient of correlation between parents' and children's education, by region, around 2008}

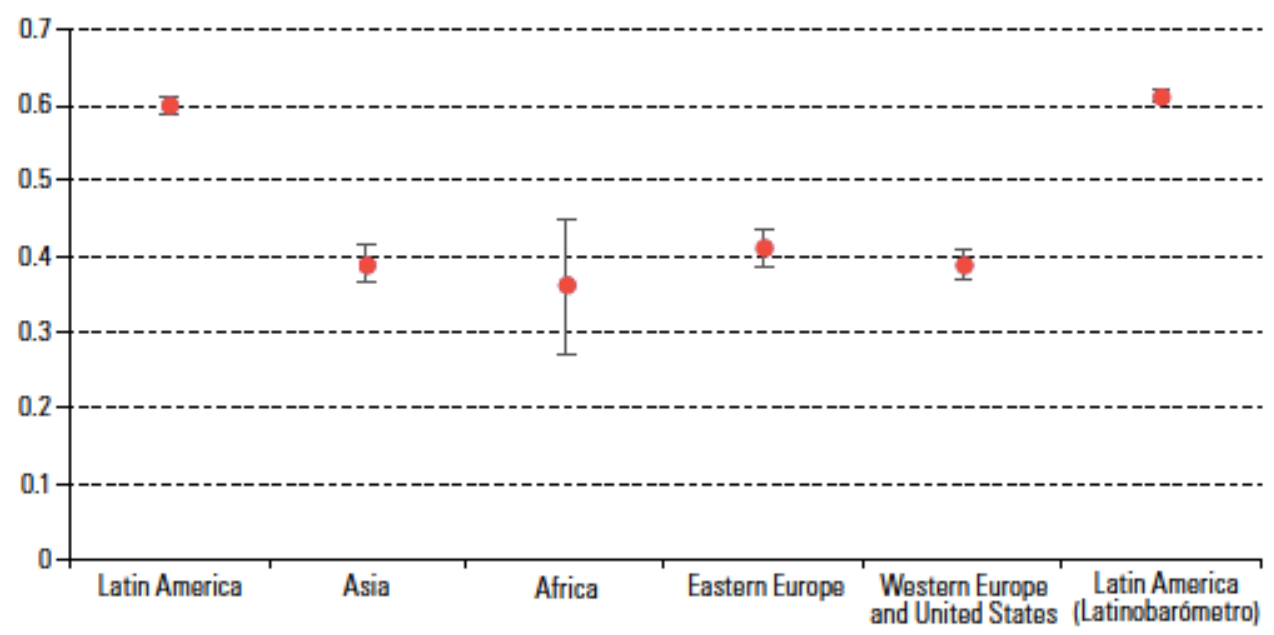

B. Latin America (18 countries): $\beta$ coefficient between parents' and children's education, by country, around 2008

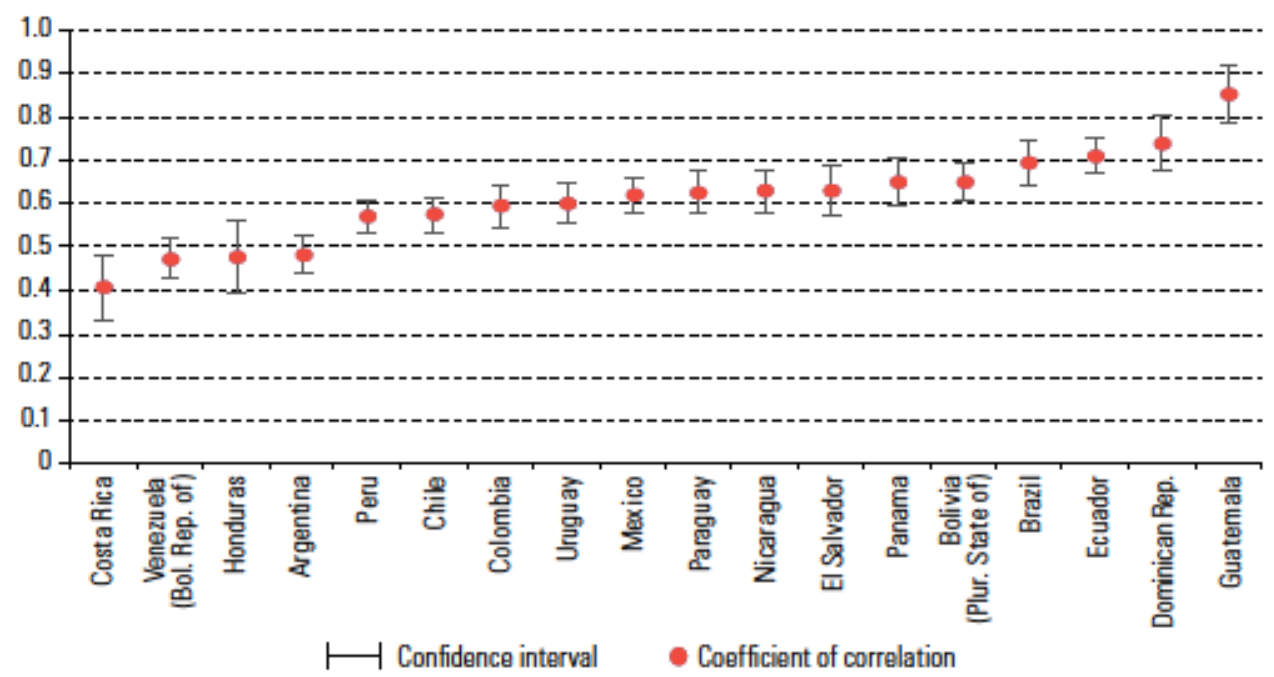

Source: Latinobarómetro Corporation; C. Daude and V. Robano, "On intergenerational (im)mobility in Latin America", Latin American Economic Review, vol. 24, No. 9, Berlin, Springer, 2015; T. Hertz and others, "The inheritance of educational inequality: international comparisons and fifty-year trends", The B.E. Journal of Econamic Analysis \& Policy, vol. 7. No. 2, Berlin, De Gruyter, 2007.

Another recent study also finds very strong educational persistence at the upper end of the distribution (Neidhöfer, Serrano and Gasparini, 2017). However, the authors add that mobility has increased at the bottom 
of the distribution owing to the expansion of education, which has benefited children from more disadvantaged homes. ${ }^{9}$ Figure IV.9 shows the proportion of children attaining given levels of education relative to the educational categories of their parents. The region presents low intergenerational mobility, as almost $60 \%$ of children with a high or low level of education had parents with that same level of education. Just $14 \%$ of children with a high level of education came from homes with a low level of education.

Figure IV.9

Latin America (18 countries): transition matrix ${ }^{a}$

(Percentages)

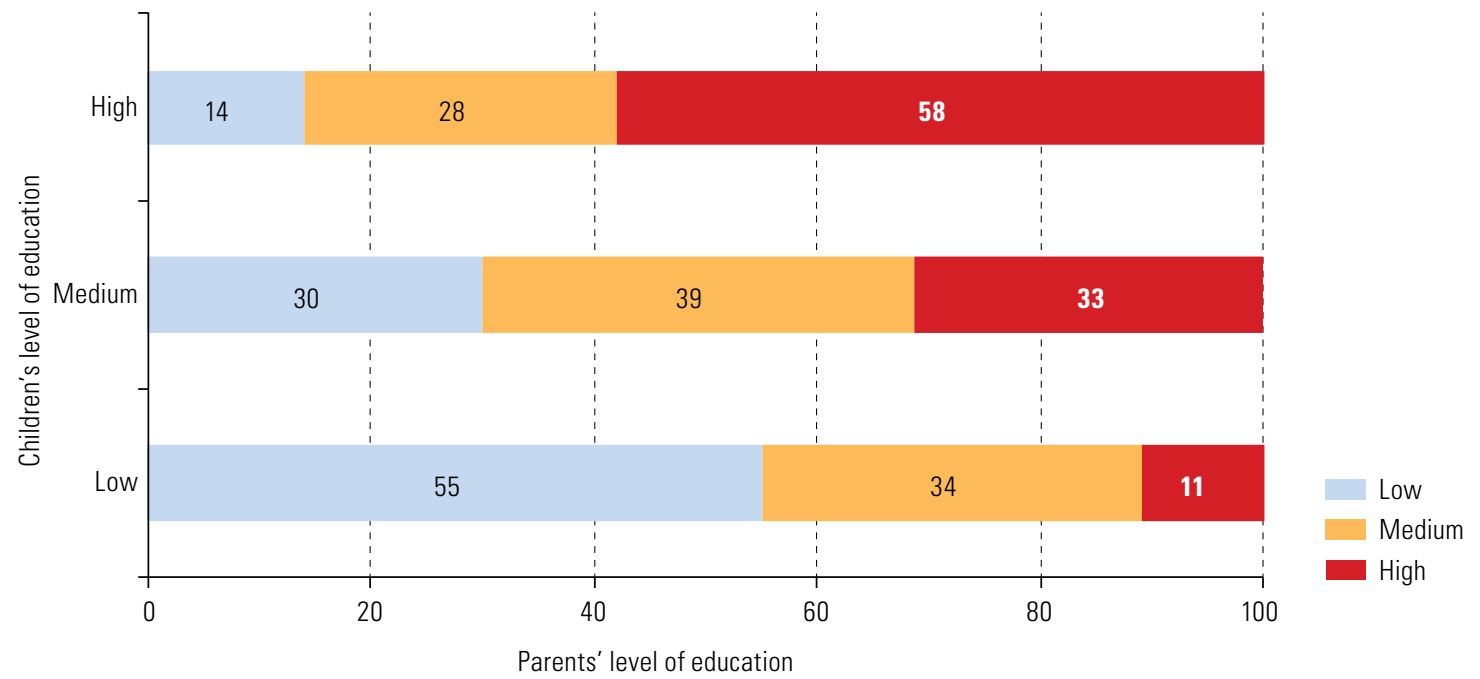

Source: G. Neidhöfer, J. Serrano and L. Gasparini, "Educational inequality and intergenerational mobility in Latin America: a new database", Documentos de Trabajo, No. 215, La Plata, National University of La Plata, 2017 [online] http://www.cedlas.econo.unlp.edu.ar/wp/wp-content/uploads/doc_cedlas215.pdf.

a Data for Argentina, the Bolivarian Republic of Venezuela, Brazil, Chile, Colombia, Costa Rica, the Dominican Republic, Ecuador, El Salvador, Guatemala, Honduras, Mexico, Nicaragua, Panama, Paraguay, Peru, the Plurinational State of Bolivia and Uruguay. Surveys conducted between 1998 and 2015.

In summary, the initial distribution of resources determines the scope for educational attainment, even when a supply of public services exists. Consequently, people's likelihood of becoming skilled or unskilled workers, i.e. individuals' productive potential, is strongly correlated with their origin. This is a clear reflection of the culture of privilege that has traditionally prevailed in the region, where it is considered acceptable for parents' socioeconomic position to be a determinant of subsequent generations' potential to develop their capabilities. Prospects for intergenerational mobility are particularly limited, and this should prompt reflection about public policies and the fundamental role to be played, in the form of affirmative action aimed at evening out opportunities and access to education and training, by a universalism sensitive to differences. Breaking the vicious circle between high levels of inequality and low mobility requires public policies to operate from the earliest stages of individuals' lives.

\section{An inefficient labour market: persistent informality}

Most developing economies have large informal sectors (Schneider, 2012; Tornarolli and others, 2014; La Porta and Shleifer, 2014) and high levels of income inequality. Different studies have documented the positive association between income inequality and informality in Latin America (Attanasio and Binelli, 2010; Binelli, 2016; Amarante, Arim and Yapor, 2016). It is difficult to reach theoretical conclusions about the causality of the relationship, though, so what is argued here is not that inequality necessarily leads to informality, but that they tend to be found together.

9 The authors additionally find that economic growth and progressive public spending are positively associated with intergenerational mobility. 
Arguments can be made for causality in both directions. For example, Chong and Gradstein (2007) present a model in which rising income inequality leads to rising informality, as it entails a relative reduction in the benefits of formality for poorer individuals. It has also been argued that rising income inequality generates greater demand for informal goods, spurring growth in the informal sector (Mishra and Ray, 2013). Other authors have stressed the impact of informality on inequality, arguing that rising informality results in a reduced tax take and affects the direct and indirect redistributive capacity of the State, impacting income distribution (Loayza, 1997; Johnson, Kaufmann and Zoido, 1998; Schneider and Enste, 2000).

Informality is not straightforward to approach empirically. Two ways of addressing the issue can be distinguished. One conceptualizes informality as low productivity, while the other uses the yardstick of noncompliance with legal requirements to characterize and identify the informal sector. In the first case, and in employment-based approaches, the traditional definition of the International Labour Organization (ILO) for the low-productivity or informal sector is usually taken. This treats as informal domestic service workers, unpaid family members, workers in private sector establishments with fewer than five employees and own-account workers with and without premises, other than administrative, professional and technical workers. ${ }^{10}$ In the second case, the criterion used to classify a worker as formal or informal is usually whether or not he or she pays social security contributions. Table IV.1 shows the overlap between the two approaches in the region's countries: on average, $83 \%$ of workers classified as low-productivity do not pay into social security systems (with a range from 56\% in Uruguay to $98 \%$ in Honduras, depending on the type of employment and the legislation in force). Similarly, $89 \%$ of workers who do pay social security contributions are classified as medium- and high-productivity workers.

Table IV.1

Latin America (9 countries): productivity and social security contributions, around 2016 (Percentages)

\begin{tabular}{|l|c|c|}
\hline & $\begin{array}{c}\text { Proportion of low-productivity workers } \\
\text { not paying into social security }\end{array}$ & $\begin{array}{c}\text { Proportion of workers paying into social security } \\
\text { whose productivity is medium or high }\end{array}$ \\
\hline Argentina & 87.5 & 92.6 \\
\hline Brazil & 63.6 & 78.7 \\
\hline Chile & 67.7 & 87.3 \\
\hline Colombia & 89.7 & 84.0 \\
\hline Honduras & 98.0 & 93.9 \\
\hline Mexico & 95.1 & 93.1 \\
\hline Peru & 99.0 & 97.4 \\
\hline Uruguay & 55.8 & 79.3 \\
\hline Venezuela (Bolivarian Republic of) & 93.8 & 93.1 \\
\hline Average & 83.4 & 88.8 \\
\hline
\end{tabular}

Source: Economic Commission for Latin America and the Caribbean (ECLAC), on the basis of household surveys from the respective countries.

Note: $\quad$ Data relate to 2016 for Argentina, Colombia, Honduras and Peru, 2015 for the Bolivarian Republic of Venezuela, Brazil, Chile and Uruguay and 2014 for Mexico.

If workers' relative incomes are observed, the ranking by monthly and hourly earnings is as follows: low-productivity workers who are not contributors have the lowest incomes, followed by non-contributing high-productivity workers (a category that in practice includes both medium- and high-productivity workers). Third placed are contributing low-productivity workers, and at the top with the highest earnings are contributing high-productivity workers.

0 This was the definition used at the fifteenth International Conference of Labour Statisticians (ICLS). However, the seventeenth ICLS distinguished between the informal sector and informal employment. Combining the two units, all informal employment in both formal sector firms and informal sector firms and households is treated as informal. This definition includes: (i) own-account workers in their own informal sector businesses, (ii) employers in their own informal sector businesses, (iii) contributing family workers, (iv) members of informal producers' cooperatives, (v) employees who have informal jobs as defined by the employment relationship (not subject to the country's employment laws, taxes, social protection or benefits) and (vi) own-account workers producing goods exclusively for their households' own final use. 
This can be seen from the coefficients of the binary variables distinguishing each of these groups in wage equations for the different countries, omitting the category of non-contributing low-productivity workers (table IV.2). Each of these coefficients is interpreted as the wage differential relative to the omitted category. By way of example, non-contributing high-productivity workers in Argentina earn $10 \%$ more a month than non-contributing low-productivity workers. In turn, the earnings differential is 55\% for contributing low-productivity workers and $76 \%$ for contributing high-productivity workers. In other words, the fact of contributing or not to social security is critical to workers' ranking by earnings. Although it may be simplistic to associate the presence of social security contributions with employment quality and the limitations of this approach cannot be disregarded, the data suggest that it is a fairly accurate proxy.

Table IV.2

Latin America (9 countries): wage differential relative to low-productivity workers who do not contribute to social security, around 2016

(Percentages)

\begin{tabular}{|l|c|c|c|}
\hline & $\begin{array}{c}\text { Non-contributing medium- and } \\
\text { high-productivity workers }\end{array}$ & $\begin{array}{c}\text { Contributing low- } \\
\text { productivity workers }\end{array}$ & $\begin{array}{c}\text { Contributing medium- and } \\
\text { high-productivity workers }\end{array}$ \\
\cline { 2 - 4 } \cline { 3 - 4 } Argentina & 10.1 & 55.3 & 75.8 \\
\hline Brazil & 23.8 & 52.0 & 63.8 \\
\hline Chile & 33.1 & 44.0 & 65.4 \\
\hline Colombia & 41.9 & 69.4 & 92.1 \\
\hline Honduras & 64.7 & 97.1 & 111.3 \\
\hline Mexico & 48.0 & 73.4 & 107.8 \\
\hline Peru & 36.0 & 79.4 & 82.2 \\
\hline Uruguay & 32.3 & 81.5 & 103.8 \\
\hline Venezuela (Bolivarian Republic of) & 5.4 & 7.2 & 12.5 \\
\hline Average & 32.8 & 62.1 & 79.4 \\
\hline
\end{tabular}

Source: Economic Commission for Latin America and the Caribbean (ECLAC), on the basis of household surveys from the respective countries.

Note: Data relate to 2016 for Argentina, Colombia, Honduras and Peru, 2015 for the Bolivarian Republic of Venezuela, Brazil, Chile and Uruguay and 2014 for Mexico.

The positive correlation between income inequality and informality (defined as non-contribution to social security) is found in the region, whether the data are considered in the aggregate or by country. The large earnings penalty associated with informality that can be observed in figure IV.10 may be interpreted as a loss of income or productivity in the present. Accordingly, it is possible to arrive at an estimate based on the wage-earning population of the costs associated with informality, understood as the earnings thus forfeited and expressed as a percentage of GDP (see figure IV.11). ${ }^{11}$ In the 11 countries analysed, earnings would be between 1 and 10 percentage points above their current values if there were no informal employment.

Lastly, informality generates substantial medium- and long-term costs because it means that a large proportion of workers will not have access to contributory retirement benefits when they leave the labour market. Mitigating this lack of income for older persons requires fiscal efforts by the countries to expand their non-contributory social protection systems, created in part to make up for the shortfall in saving (whether individual or collective) over the course of people's working lives. It is yet another cost generated by the high levels of inequality and informality in the region, since fewer resources would need to be spent on noncontributory benefits if this informality did not exist. Non-contributory pension coverage varies considerably between countries, from $5 \%$ of the population aged 60 and over in El Salvador to full coverage of the population aged 60 and over in the Plurinational State of Bolivia. Although this spending still represents a fairly small share of GDP (it is highest in the Plurinational State of Bolivia, where the Renta Dignidad non-contributory pension costs $1.2 \%$ of GDP), population ageing could require greater fiscal efforts in future (see figure IV.12).

11 The calculations do not consider the dynamics that could develop if informality divides in the labour market were closed, providing rather a static picture of possible increases in the wage total that would be obtained if informal workers' earnings were similar to those of formal wage workers. 
Figure IV.10

Latin America (15 countries): wage inequality (Gini coefficient) and informality, 1990-2014

A. All countries

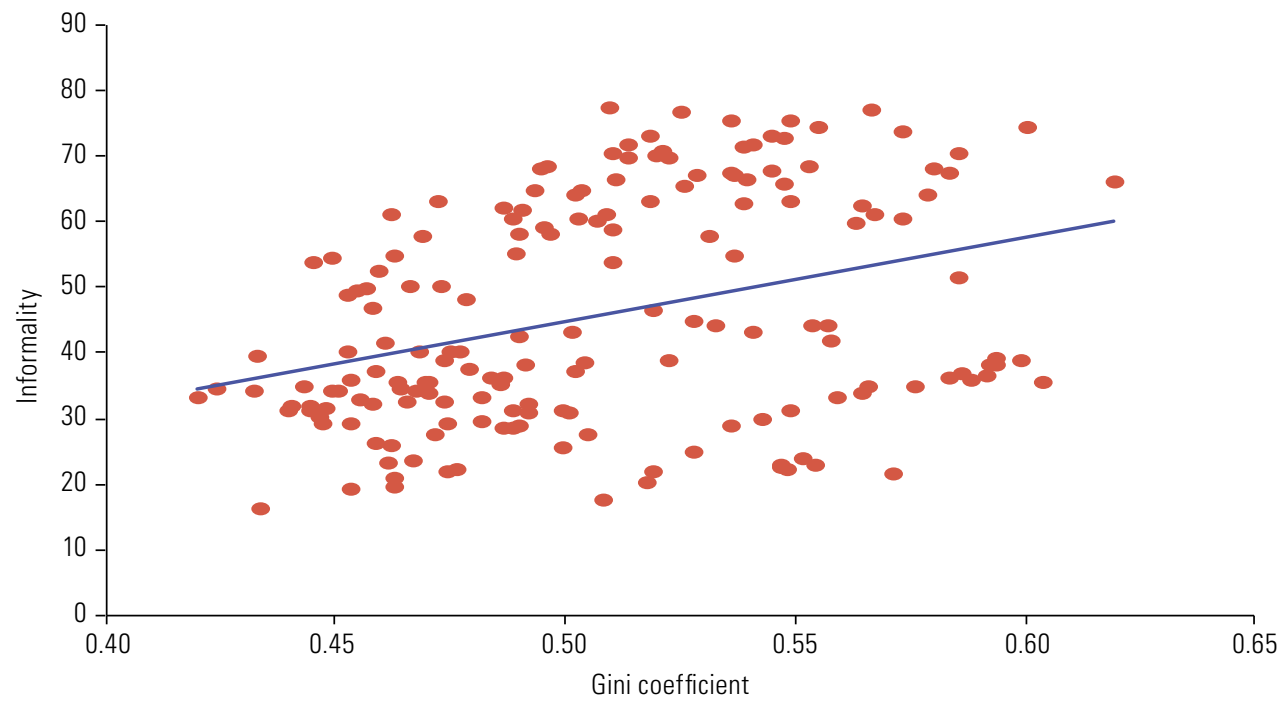

\section{B. By country}

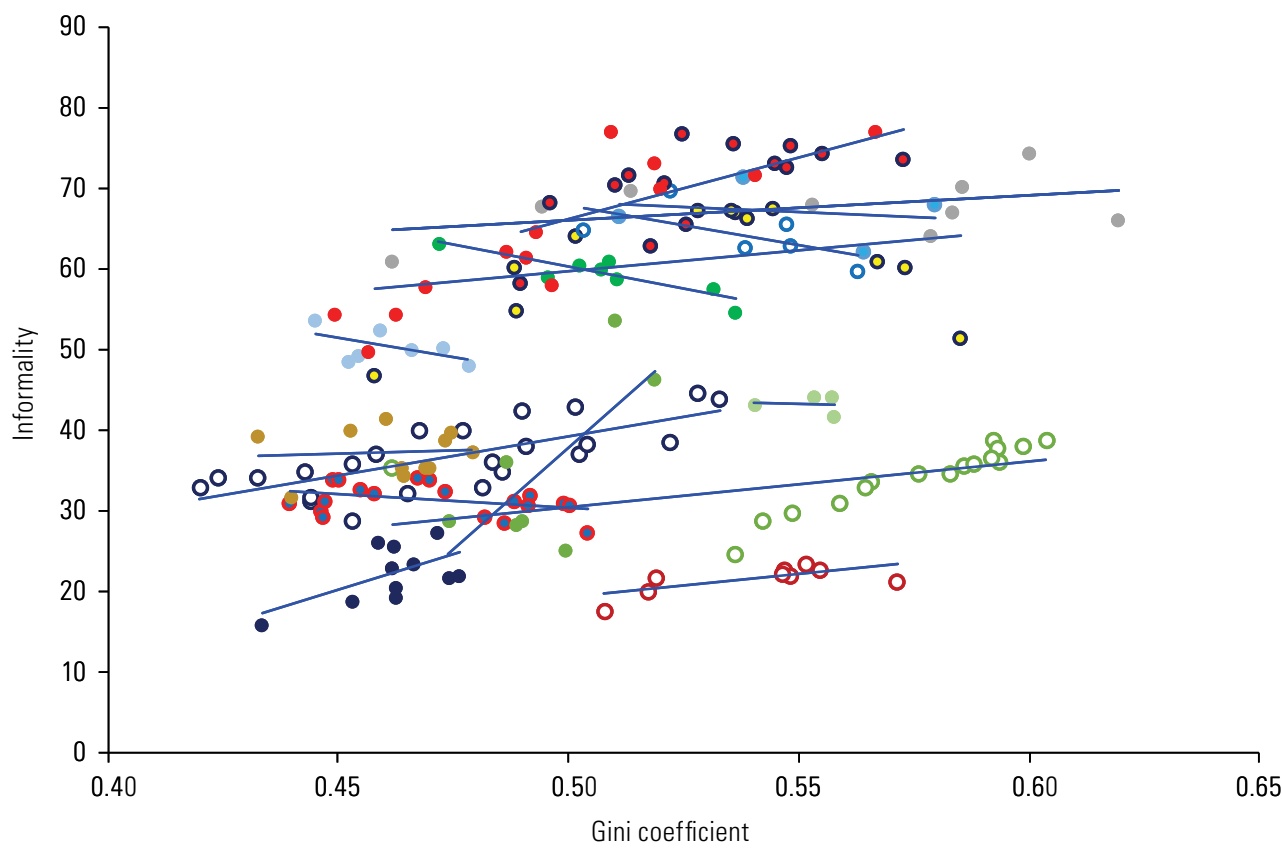

- Argentina

- Bolivia (Plur. State of)

- Brazil

- Chile

- Colombia

- Costa Rica

- Dominican Rep.

- Ecuador

- El Salvador

- Guatemala

- Mexico

- Nicaragua

- Paraguay

- Peru

- Uruguay

- Venezuela (Bol. Rep. of)

Gini coefficient

Source: Economic Commission for Latin America and the Caribbean (ECLAC), on the basis of National University of la Plata/World Bank, Socio-Economic Database for Latin America and the Caribbean (SEDLAC) [online] http://www.cedlas.econo.unlp.edu.ar/wp/en/estadisticas/sedlac/.

Note: Informal workers are defined as those not paying social security contributions. 
Figure IV.11

Latin America (11 countries): wages forfeited because of informality, around 2008 and 2016

(Percentages of GDP)

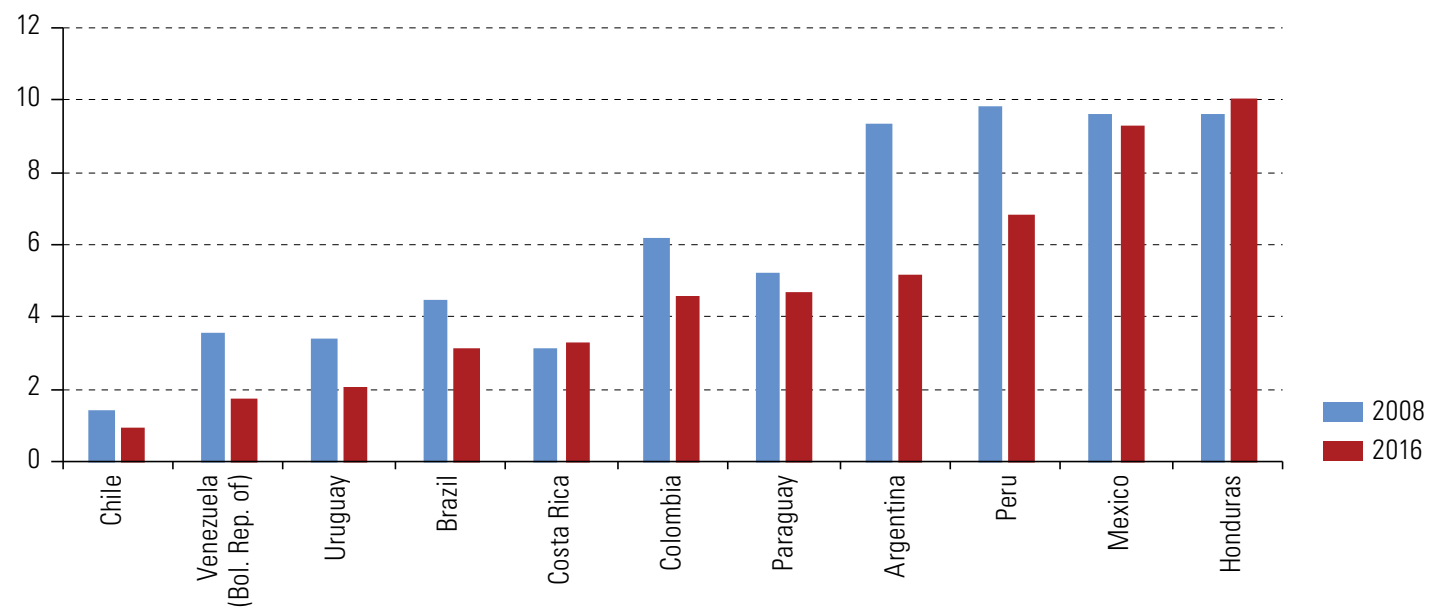

Source: Economic Commission for Latin America and the Caribbean (ECLAC), on the basis of household surveys from the respective countries.

Note: A lack of up-to-date information meant that the same overall wage share as a percentage of GDP was taken for both years in the case of Argentina and the same informality rate in the case of the Bolivarian Republic of Venezuela. For Honduras, the proportion of workers without an employment contract is used as the informality rate.

Figure IV.12

Latin America and the Caribbean (15 countries): non-contributory pension coverage and spending, 2015

(Percentages)

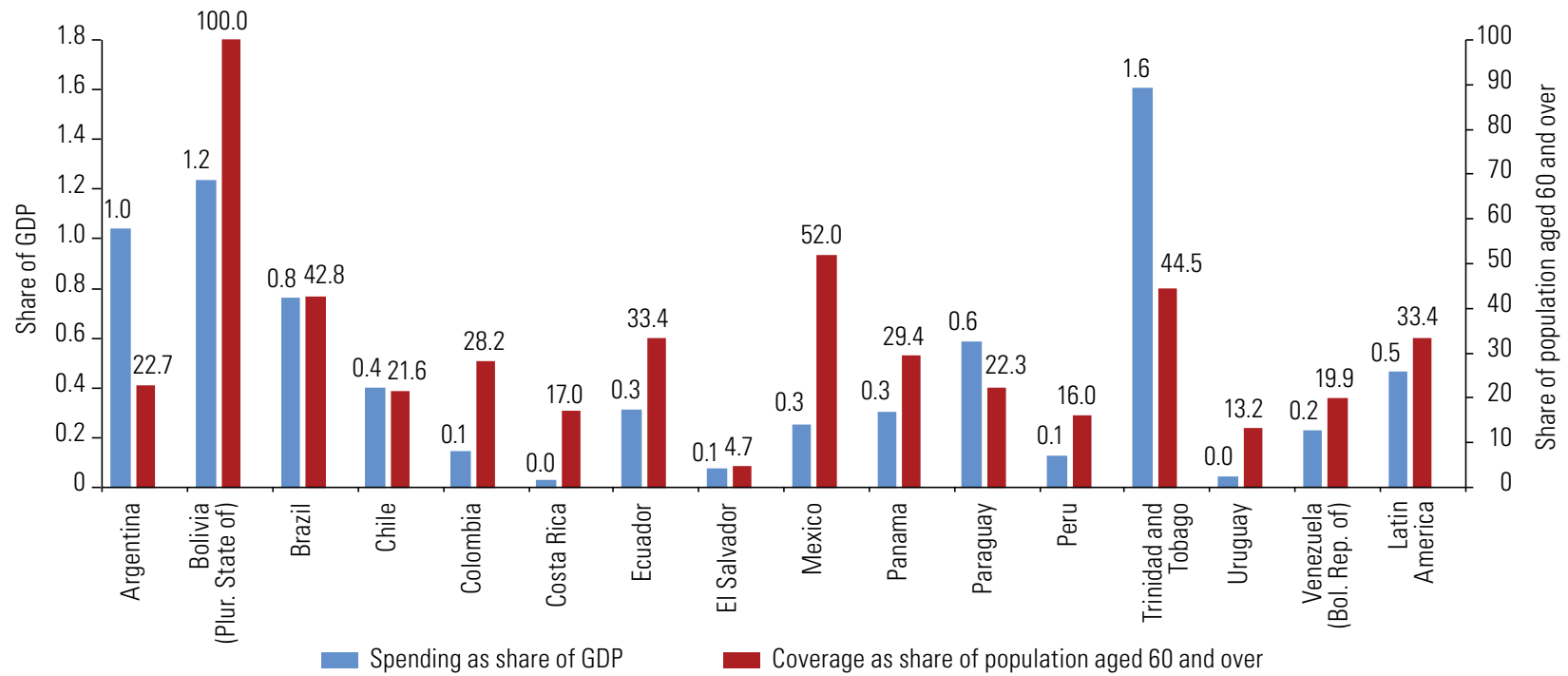

Source: Economic Commission for Latin America and the Caribbean (ECLAC), Non-contributory social protection programmes in Latin America and the Caribbean database [online] http://dds.cepal.org/bpsnc/index-en.php.

Note: Argentina: non-contributory pension programme; Bolivarian Republic of Venezuela: Gran Misión en Amor Mayor; Brazil: Continuous Cash Benefit (BPC) programme and Rural Welfare programme; Chile: Basic Solidarity Pension; Colombia: Colombia Mayor programme; Costa Rica: Non-contributory Scheme for Basic Pensions; Ecuador: Older Adults Pension of the Human Development Bond; El Salvador: Nuestros Mayores Derechos; Mexico: Pension Programme for Older Persons and Maintenance for Older Persons Aged 68 and Living in Mexico City; Panama: 120 a los 65; Paraguay: Maintenance for Older Persons in Poverty; Peru: Pensión 65; Plurinational State of Bolivia: Renta Dignidad; Trinidad and Tobago: Senior Citizens' Pension; Uruguay: non-contributory old-age and disability pensions. 


\section{Labour market discrimination and opportunities: gender inequality}

The debate about inequality usually focuses on the vertical dimension, i.e. the differences between rich and poor. However, horizontal inequalities are also significant, as they reflect differences depending on sex or membership of certain population groups, such as indigenous or Afrodescendent populations. These two dimensions of inequality (vertical and horizontal) are not unconnected but closely related. As ECLAC (2017b) argues, class differences and inequalities based on gender, ethnicity, race, life cycle and territory are the cruxes of the social inequality matrix in Latin America. The existence of these inequalities means that people's potential will not be developed fully. There will be less of an incentive for people who are discriminated against to educate themselves, as they will not see education translating into better employment opportunities, and there will be a loss of productivity and growth in society as a whole.

An exercise in comparative statics carried out by ECLAC (2014) provides an estimate of the gains that would come from doing away with gender inequalities in the labour market. Two scenarios were constructed to model the disappearance of the gender participation gap and the gender wage gap, respectively, in that market. ${ }^{12}$ First, the study analysed what would happen if women at central ages (between 14 and 65) presented activity rates similar to men's, i.e. if the participation gap between men and women were closed. The second question is what would happen if earnings inequalities between men and women disappeared. The approach taken was to do away with the monthly earnings gap between men and women, implying no difference in hours worked. ${ }^{13}$ Lastly, the study looked at what would happen if both gaps were eliminated, with no difference in participation and with female labour market participants being paid the same as men. It is from this scenario that the best results are expected, considering that the most successful processes of female labour market inclusion, like that in the Nordic countries, have involved progressive narrowing of both gaps simultaneously.

Household incomes increase substantially in all three scenarios, with the consequent reductions in poverty and inequality. The scale of these changes depends on where each country starts from and where the greatest gender inequalities in the labour market are. If the gender gap in the activity rate were closed, average household income would rise by between 3\% and $4 \%$ in Argentina, Brazil, Colombia, Mexico and Uruguay and by more than $10 \%$ in El Salvador, Honduras, Nicaragua and Peru. The countries where the female activity rate differs most from the male rate are the ones that would show the greatest gains in average household income if participation gaps disappeared (ECLAC, 2014b).

Eliminating the income gap between men and women also yields increases in the great majority of countries, but these are smaller than in the participation scenario. The change would be negative in Honduras, zero in Mexico and very small in the Dominican Republic, at just 1\%. This is explained by the strong selection bias in female employment in those countries, where the greatest participation is by the most highly educated women, who can accordingly expect larger returns in the labour market. The result is that women's average earnings are higher than men's and that closing the gap entails a reduction in female incomes.

In all the countries, closing both gaps simultaneously enhances the increases in average household income obtained by closing them separately (see figure IV.13). Not only do more women enter the labour market, but both these women and those already participating in the market are paid as much as men with the same characteristics. In this scenario, household income in Latin America would be considerably higher, with increases ranging from $10 \%$ in Peru to over $30 \%$ in Nicaragua.

12 Both exercises controlled for personal characteristics influencing women's and men's labour market outcomes, especially age and education.

13 This means assuming that the differential returns to education and experience currently favouring men in the market disappear and that men and women of the same age and education level are paid alike. 
Figure IV.13

Latin America (18 countries): changes in average household income under three gender gap removal scenarios (participation, income and both), around 2012

(Percentages)

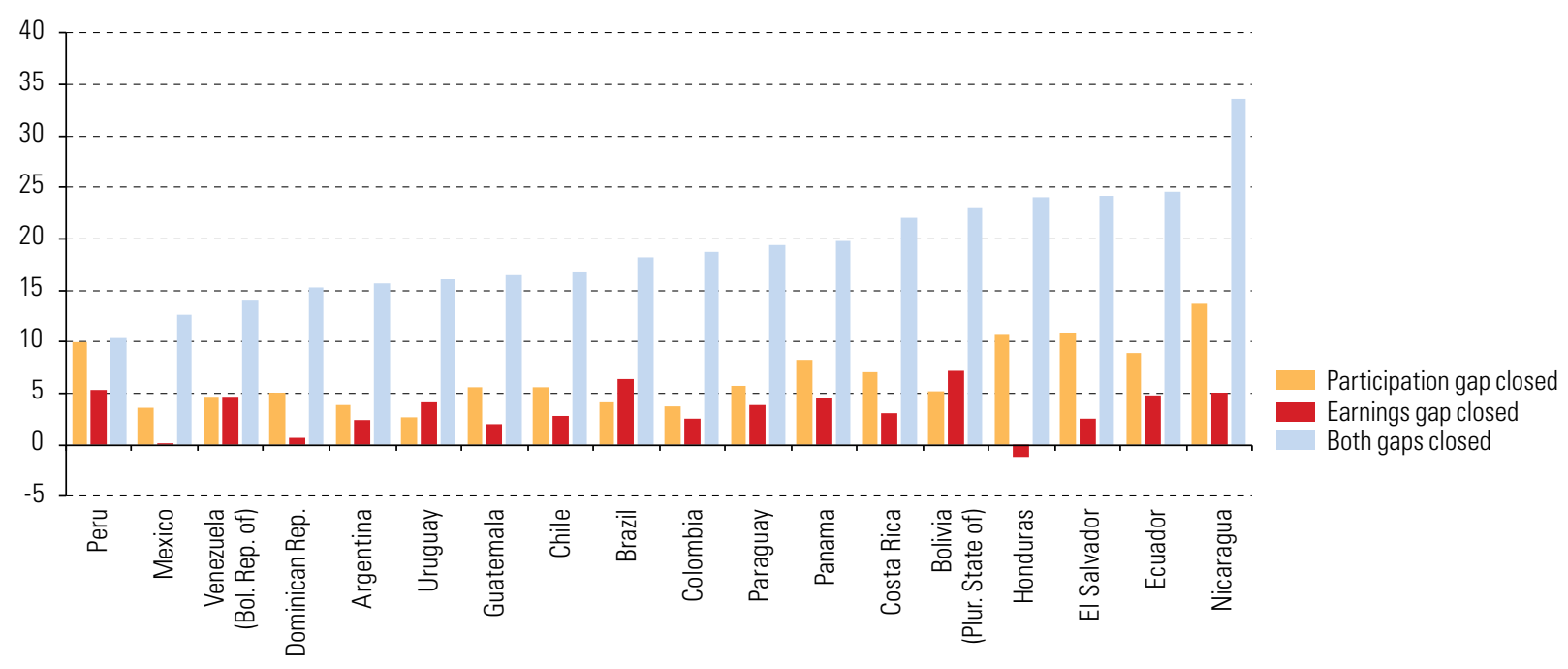

Source: Economic Commission for Latin America and the Caribbean (ECLAC), on the basis of household surveys from the respective countries.

Besides the consequences that would arise from incorporating women into the labour market in terms of the full exercise of their autonomy, socialization outside the home, fulfilment of capabilities and potential and access to contributory social protection, the exercise illustrates the effects of higher household incomes, one of them being poverty reduction. At the same time, the gains generated by increasing women's labour market participation would potentially be greater if women joining the labour market were paid as much as equally qualified men.

This analysis does not consider general equilibrium effects, which could alter the results substantially. For example, men's earnings can be expected to react to the rise in employment opportunities for women. Likewise, many women not currently in the labour market carry out a large share of the unpaid tasks that sustain the reproduction of the workforce (cooking, cleaning, looking after children or the sick and elderly, etc.). If women worked to the same extent as men, they would be unable to carry out these activities sustainably, and they would have to be redistributed between the sexes and between the State and families. Accordingly, the hours worked by men would also react to an increase in the hours worked by women. By way of example, in the Nordic countries, where the greatest progress has been made in terms of gender equality in the labour market, the male activity rate is lower than in the Latin American countries (Amarante and Colacce, 2016). This shows that more equitable participation by women and men in the labour market requires simultaneous adjustments for both sexes.

The inequalities between men and women in the time spent on unpaid work is well documented in Latin America. Female labour market participation has increased substantially in the last 25 years, with activity rates rising from $41 \%$ in 1990 to some $53 \%$ in 2015 . However, this remains considerably lower than the male rate, besides which women who do work for pay put in fewer hours than men. At the same time, patterns of distribution of unpaid work within households seem to be more rigid than those of paid work. The consequence is that the total burden of work in households is greater for women than for men in many countries (ECLAC, 2017a).

Given this divide, the question is whether the choices made by couples within households regarding the share-out of the paid and unpaid workload are economically rational -i.e. whether labour markets present gender asymmetries that discourage an equitable distribution of labour or whether, conversely, other 
aspects of current norms are what explain the persistence of the sexual division of labour. To address this question, a microsimulation exercise was carried out on the basis of time-use surveys. In the simulation, first the share-out of paid and unpaid work between men and women was equalized and then pay gaps were closed, after which household earnings in the different scenarios were compared. The sample selected was of households in which a couple comprising a man and a woman lived, at least one of them employed, and both aged between 25 and $64 .^{14}$

Setting out from the actual situation of households, with the burden of paid and unpaid work declared by men and women in surveys, two scenarios were constructed. In the first, the total hours of paid and unpaid work done by households remained as they were but were shared out equally between the two members of the couple. This implied average household income being reduced in accordance with the decline in hours of paid work done by men and augmented in accordance with the increase in hours of paid work done by women. Women joining the labour market would earn the market rate for women of their age, region and education level, controlling for the presence of children in the household. In the second scenario, there was also assumed to be no wage gap between men and women, i.e. women were assumed to earn as much as men of the same age and level of education (again controlling for the presence of children in the household).

Figure IV.14 shows the observed average distribution of paid and unpaid work within couples. The distribution is similar in the five countries analysed: while women account for about $80 \%$ of the time spent on unpaid work in the home, men account for about $70 \%$ of time spent on paid work. In the simulation exercises, the two members of a couple divide up the paid and unpaid workload equitably (as represented by the grey line in the chart). There are earnings gaps between men and women in all the countries, but these gaps are substantially smaller when considered on an hourly than on a monthly basis, given the difference in the time spent on paid work by men and women.

Figure IV.14

Latin America (5 countries): distribution of paid and unpaid work in households containing a couple,

by sex, 2007-2015

(Percentages)

A. Paid work

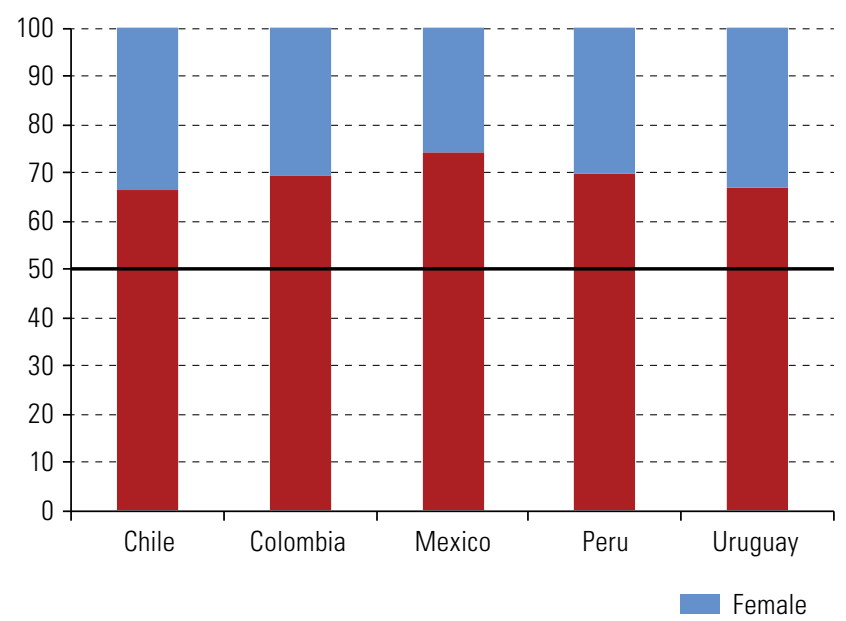

B. Unpaid work

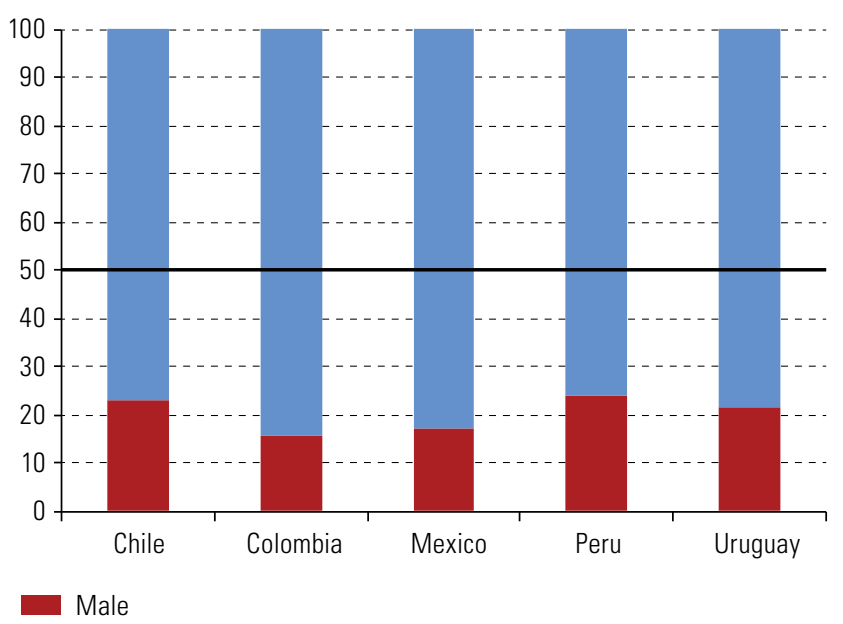

Source: Economic Commission for Latin America and the Caribbean (ECLAC), on the basis of time-use surveys from the selected countries.

Note: Data relate to 2015 for Chile, 2010 for Colombia, Peru and Mexico and 2007 for Uruguay.

While the importance of other household compositions is appreciated, the aim is to confine the analysis to just one type. The households selected represent $21 \%$ of the total in Chile, $39 \%$ in Mexico and Uruguay, $40 \%$ in Colombia and $47 \%$ in Peru. 
If hours of paid and unpaid work were shared out equitably between men and women but current earnings inequalities still obtained, average household income would be practically unchanged, as can be seen by comparing the baseline scenario and scenario 1. In Uruguay, indeed, there would be a fairly substantial drop (figure IV.15). In this scenario, an equitable share-out of the paid and unpaid workloads would not significantly alter household income. In scenario 2, where earnings differences between men and women additionally disappear, there is a substantial rise in average household incomes.

Figure IV.15

Latin America (5 countries): income of households containing a couple, scenarios 1 and 2

(Household income in baseline scenario=1)

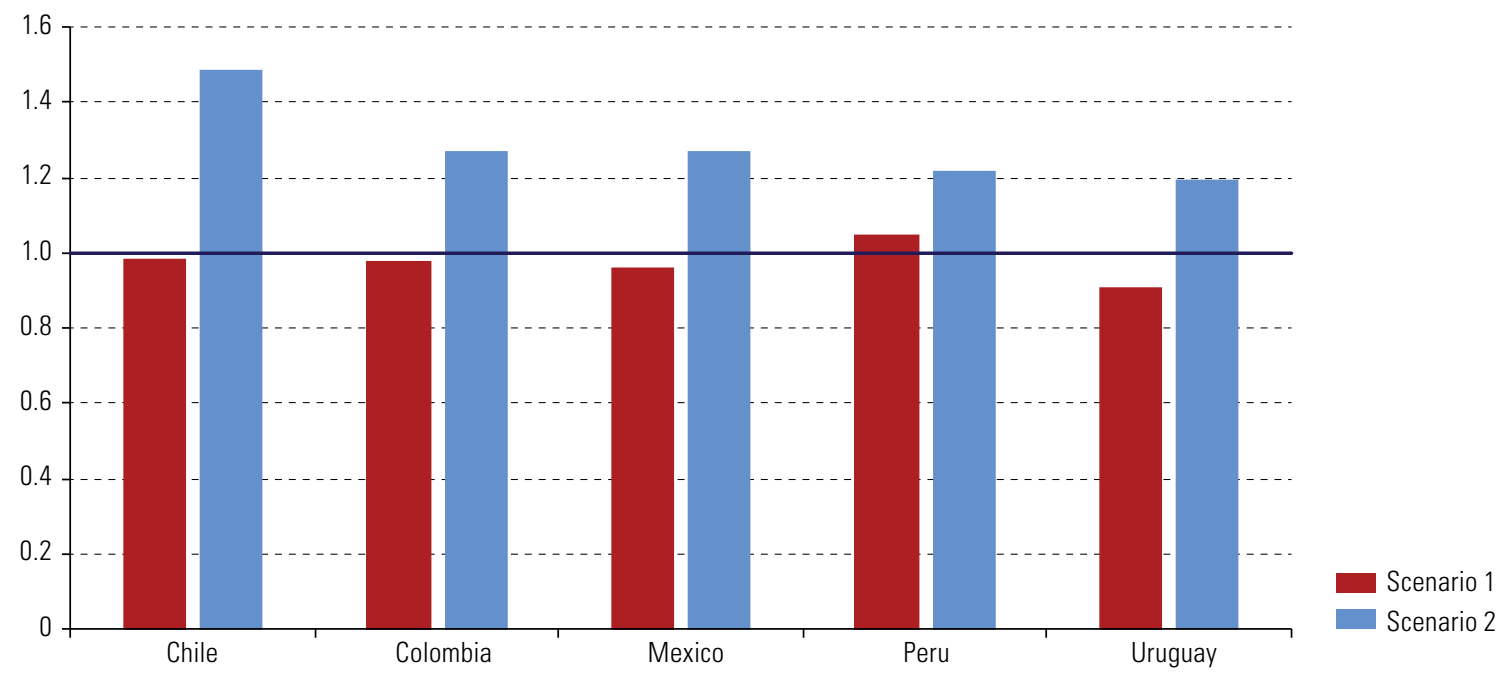

Source: Economic Commission for Latin America and the Caribbean (ECLAC), on the basis of time-use surveys from the selected countries.

Note: Data relate to 2015 for Chile, 2010 for Colombia, Peru and Mexico and 2007 for Uruguay.

In scenario 1, although household incomes in at least three of the five countries analysed would not be reduced by an equitable distribution of work, their inhabitants opt for an unequal distribution, probably because women have greater difficulty participating in the labour market and because prevailing norms associated with a hegemonic gender system still impose a traditional notion of the role of women. In this case, earnings discrimination and occupational segregation could be playing a large role in discouraging female labour force participation. If the two sexes were paid the same (assuming the same individual characteristics), households could attain a higher level of economic well-being than at present.

The benefits of a more equitable share-out of unpaid work would be especially great in lower-income households, where female participation in the labour force is more limited. However, earnings inequalities between men and women in labour markets conspire against a fairer division of the burden of paid and unpaid work. Public policies, especially those relating to the labour market and its institutions, should help create conditions that encourage this.

\section{The positive effects of social protection and care on growth and employment}

Social protection seeks to ensure a basic level of income, access to services (including care services), development of human capacities and opportunities for decent work over the whole life cycle (Cecchini and Martínez, 2011). It helps to give effect to economic, social and cultural rights and reduce poverty and inequality, and it can also yield growth-boosting productivity gains (Arim, 2017; ECLAC, 2006). 
The evidence for the impact of social protection policies largely comes from analysis of non-contributory cash transfer programmes designed for poverty relief. This evidence provides a different perspective on social protection policies, which are often treated as though they were potentially inefficient compensation mechanisms liable to create dependency on public policies and jeopardize the sustainability of the public finances.

The reality shows that these transfers have had large effects on school enrolment, attendance, progress and retention (ECLAC, 2014a) and have helped to improve access to health services, especially check-ups and immunization coverage (Cecchini and Veras Soares, 2015). However, impact assessments indicate that learning outcomes, anthropometric and nutrition outcomes and health effects are heterogeneous and largely depend on the quantity and quality of universal public services (see box IV.3).

\section{Box IV.3}

The effects of non-contributory social protection on final indicators of human capabilities

There is a huge amount of evidence for the positive effects of conditional transfer programmes in the region. Báez and Camacho (2011) find that pupils participating in Colombia's Families in Action programme are between 4 and 8 percentage points more likely to complete secondary school than the control group. Garcia and others (2012) state that participating in this programme increases standardized mathematics test scores by 1.07 standard deviations. Barham, Macours and Maluccio (2013) and Barham and others (2016) estimate the effects of Nicaragua's Social Protection Network, 10 years from its inception, on those who participated in the programme for three years, focusing mainly on the educational attainments of minors who had participated between the ages of 9 and 12. Their findings show an accumulated 0.5 extra grades at school and better learning outcomes. In Mexico, the Prospera programme (formerly Oportunidades) has helped to reduce and almost eliminate gender gaps in secondary school enrolment, especially in rural areas (Parker, 2003), and has increased enrolment and promotion rates among indigenous students (Escobar and González, 2002 and 2009). Lastly, Rasella and others (2013) indicate that Brazil's Bolsa Familia programme contributed to a $17 \%$ drop in mortality among infants aged under 5 between 2004 and 2009 by acting on poverty-related causes of death such as malnutrition and dysentery.

Source:Economic Commission for Latin America and the Caribbean (ECLAC), on the basis of J. Baez and A. Camacho, "Assessing the long-term effects of conditional cash transfers on human capital: evidence from Colombia", IZA Discussion Paper, No. 5751, Bonn, Institute for the Study of Labor (IZA), 2011; A. García and others, "Impactos de largo plazo del programa Familias en Acción en municipios de menos de 100.000 habitantes en los aspectos claves del desarrollo del capital humano. Informe final", Bogotá, Unión Temporal Econometría/National Planning Department, 2012 [online] https://colaboracion. dnp.gov.co/CDT/Sinergia/Documentos/393_Impactos_de_Largo_Plazo_en_el_Programa_Familias_en_Accion_DOC.pdf; T. Barham, K. Macours and J. Maluccio, "More schooling and more learning? Effects of a three-year conditional cash transfer program in Nicaragua after 10 years", IDB Working Paper series, No. 432, Washington, D.C., Inter-American Development Bank (IDB), 2013; T. Barham and others, "Long-term impacts of conditional cash transfers in Latin America: review of the evidence", IDB Working Paper series, No. 732, Washington, D.C., Inter-American Development Bank (IDB), 2016; S. Parker, "Evaluación del impacto de Oportunidades sobre la inscripción escolar: primaria, secundaria y media superior", Documentos de Investigación, No. 6, Mexico City, National Institute of Public Health/Economic Research and Teaching Centre (CIDE), 2003; D. Rasella and others, "Effect of a conditional cash transfer programme on childhood mortality: a nationwide analysis of Brazilian municipalities", The Lancet, vol. 382, No. 9886, Amsterdam, Elsevier, 2013; A. Escobar and M. González, "Girls, mothers and poverty reduction in Mexico: evaluating Progresa-Oportunidades", The Gendered Impacts of Liberalization: Towards "Embedded Liberalism", S. Razavi (ed.) New York, Routledge, 2009; "Documento final de diagnóstico cualitativo de hogares semiurbanos: localidades de 2500 a 50000 habitantes, 2001", Guadalajara, Centre for Research and Higher Learning in Social Anthropology (CIESAS), 2002 [online] http://lanic.utexas.edu/project/etext/oportunidades/2002/escobar1.pdf.

As regards employment, cash transfer programmes designed to overcome poverty do not discourage participation in the workforce at the household level, and may even encourage it. Evidence of this can be found both in randomized controlled trials in countries of Latin America (Honduras, Mexico and Nicaragua), Asia (Indonesia and the Philippines) and Africa (Morocco) (Banerjee, Chassang and Snowberg, 2016) and in impact assessments carried out in Latin America (ECLAC, 2017a; ECLAC/ILO, 2014). In the case of Brazil's Bolsa Familia programme, for example, the proportion of people looking for work is significantly higher in households using the programme (De Oliveira and others, 2007), and labour force participation rates in the bottom three deciles of the income distribution are higher among programme beneficiaries than among non-beneficiaries (Medeiros, Britto and Soares, 2008).

In Colombia, an assessment of Families in Action shows that this programme has been having a significant positive impact on the employment rate in urban households, contributing to declines of 3.2 percentage points and 0.7 percentage points, respectively, in inactivity and unemployment rates. It has also boosted per capita 
household income by an average of 25\% (Núñez, 2011). Findings for the entry of women into the workforce are mixed (Holmes and others, 2010). The effects on men and women differ because of factors that may operate to a greater or lesser degree depending, for example, on the design of conditionalities, the characteristics of local labour markets and the availability of care-related services or benefits. One such factor is the time that has to put into meeting programme conditions and the burden of responsibility this represents, which falls primarily on women (ECLAC, 2014 and 2017b; Martínez and Voorend, 2008). Another is that becoming regular recipients of transfers, even if small, means that women (who are worse placed than men in the labour market) do not have to submit to excessively poor working conditions, such as low incomes, long days, long travel times between home and work or exposure to abuses (ECLAC, 2017a).

Social protection can affect productivity through a number of interconnected channels and can operate on the micro (individual or household), meso (local community and economy) and macro levels (Alderman and Yemtsov, 2012). Through the interaction of these three levels, and by linking to production development and decent work strategies with a gender approach and an emphasis on ethnic and racial equality, social protection can help to create a virtuous circle of independent income generation, with large multiplier effects (ECLAC, 2017a; Hanlon, Barrientos and Hulme, 2010; Samson, 2009). ${ }^{15}$

At the individual level, social protection improves education and health care along with employment indicators and the ability to generate income in families (Hanlon, Barrientos and Hulme, 2010; Samson, 2009). Cash transfers also have multiplier effects on local economies by increasing consumption and demand. Non-contributory social protection programme participants spend a large part of the cash transfers they receive from programmes within their local areas, especially on food (Cecchini, 2014; Ibarrarán and others, 2017), which creates positive externalities for households that are not users of the programmes and for business owners. ${ }^{16}$ At the community level, the multiplier effect arises as a result of greater public investment in infrastructure.

With regard to rural pensions in Brazil, Schwarzer (2000) describes the dynamizing effect of increased purchasing power among those receiving cash transfers on the economies of municipalities in the state of Paraná. Payment day is when "the wheel of the economy turns" in small rural localities, and many firms, including commercial banks, are profitable because of these transfers. Similar results have been seen in the case of Bolsa Familia: Luiz Pereira and others (2008) find that, in the five municipalities with the lowest human development index scores in Brazil as of 2006, the programme's cash transfers substantially boosted the earnings of food shops, and commerce would lose $40 \%$ of its revenues if the programme did not exist. Similarly, Landim (2009) shows for 5,500 Brazilian municipalities that a $10 \%$ annual per capita increase in transfers from the Bolsa Família programme increases municipal GDP by $0.6 \%$, largely thanks to increased commerce. ${ }^{17}$

At the aggregate level, the impact of social protection, both contributory and non-contributory, may arise from aggregate demand shifts, changes in overall labour force participation and the activation of capital markets, for example by way of pension funds (Mathers and Slater, 2014; Alderman and Yemtsov, 2012), and indeed by efforts to promote social cohesion and reduce violence, all actions that help create a more favourable growth environment. Social protection can also act as an economic stabilizer during crises, bolstering domestic demand (Videt, 2014).

The multiplier effect of social protection does not act just at the local level, but throughout the economy. In the United States, when Barack Obama's government implemented a fiscal stimulus package to deal with the 2008 financial crisis, an increase of one dollar in food stamps had a multiplier effect of 1.73 dollars of GDP, while the extension of unemployment insurance benefits generated a rise of 1.63 dollars of GDP for each

15 The extent of the impact of social protection on economic growth is influenced by the scale and distribution of social protection spending. Although social protection may affect production capacity at the individual or community level, its direct effect on aggregate growth is unlikely to be substantial in countries with low social spending and high levels of inequality (Mathers and Slater, 2014).

16 Davis, Di Giuseppe and Zezza (2017) use general equilibrium models based on household survey microdata to calculate multipliers for cash transfers made under seven programmes in sub-Saharan Africa and find that they all generate positive effects for the local economy. Real income multipliers range from 1.08 (Kenya) to 1.81 (Ethiopia).

17 Additionally, money invested in these programmes flows back into the municipal coffers. Thus, a $10 \%$ rise in the beneficiary population increases municipal tax receipts by an average of $1.05 \%$, while a rise of $10 \%$ in the value of transfers increases receipts by $1.36 \%$. 
dollar spent (Zandi, 2009). Chimerine, Black and Coffey (1999) estimate that unemployment insurance in the United States played a substantial countercyclical role in real GDP changes over three decades, as a result of which an average of 131,000 jobs were preserved each year, and that each dollar added to the economy by unemployment insurance increased GDP by 2.15 dollars. ${ }^{18}$ In the case of Brazil, Mostafa, Monteiro and Ferreira (2010) and Côrtes, Monteiro and Guimarães (2013) estimated short-run multipliers for government cash transfers. Their findings showed that Bolsa Familia had had a greater effect than other benefits, with each real invested in the programme in 2009, for example, adding 1.78 reais to the country's GDP. ${ }^{19}$

Childcare policies likewise set out to increase equality and can have substantial effects on productivity. Social protection systems in developed countries have made major efforts to extend childcare provision, with a variety of rationales. For one thing, there is abundant evidence that the returns to early childhood education are high, particularly in the case of households suffering from high levels of deprivation, and this has begun to be used as one of the main arguments for investment in public policies aimed at this age group. The most recent education studies maintain not only that skills acquired early in life yield cumulative benefits for the acquisition of capabilities at later stages, but that, in addition, certain skills are harder to attain after a certain age (Cunha and others, 2006; Cunha and Heckman, 2010). Another consideration is that childcare services are a way of stimulating the labour market and moving towards gender equality by increasing the rate of female labour market participation.

In developing countries, policy experiences of this type are more recent, as is the analysis of their effects. ${ }^{20}$ Where the effects on childhood development are concerned, most of the data concern childcare or child development programmes targeted at the most vulnerable children, and the results are generally positive. This is probably due to the situation these children would be in if they did not attend a care centre, i.e. what they would be doing if these services were unavailable. The effects depend on the quality of services and care and on how much stimulation they would receive at home. In the case of children from more disadvantaged environments whose carers (mothers, fathers or grandparents, among others) have low levels of education, even poor-quality services can positively affect their cognitive and non-cognitive development (Cascio and Whitmore, 2013).

The situation with universal childcare services is unclear. Positive effects on cognitive and non-cognitive outcomes can be found in the literature review presented by Cascio (2015). Likewise, high-quality services can increase adults' attendance at education centres and their employability. Almost all studies show the best results for children from more vulnerable homes, although the benefits diminish or disappear as they grow up. Where quality is low, the effects of care policies can actually be negative.

In Latin America, researchers have documented positive effects on child development, even though service quality differs substantially between the countries and territories of the region. ${ }^{21}$ For Ecuador and in one of the studies available on Chile, the conclusion is that poor-quality care services have negative effects. In general, these effects depend on age (they are greater for older children), the vulnerability of households and the time spent in the programme (longer exposure enhances the effects). Studies evaluating the effects on children in Argentina, Colombia and Uruguay years after they have attended care services found them to be persistent. Regarding women's participation in the workforce, Del Boca (2015) concentrates on studies carried out in Europe and the United States and finds that the effects depend on each country's starting point in relation to this variable. In countries where participation was relatively low, childcare programmes generally

18 Unemployment insurance covered an average of 5 million people in the troughs of the five recessions between 1969 and the early 1990s, cushioning the loss of real GDP by about $15 \%$ each quarter.

19 The other benefits analysed were the Continuous Cash Benefit (BPC) programme, unemployment insurance, the wage top-up programme, the General Social Security Regime (RGPS), the Public Sector Social Security Regime (RPPS) and the Length of Service Indemnity Fund (FGTS).

20 The main problem for assessments is to identify the causal effect of policies, as families opting to use care services usually have special characteristics that may affect the workforce participation of women and the development of children, even if they did not take up these services. The review centres on studies that take this endogeneity into account, concentrating on ex post impact assessments of childcare programmes.

21 The targeted programme studies referred to are Behrman, Cheng and Todd (2004) on the Plurinational State of Bolivia, Attanasio, Meghir and Vera-Hernández (2007) and Bernal and others (2009) on Colombia, Rosero and Oosterbeek (2011) on Ecuador, Ángeles and others (2011) on Mexico and Urzúa and Veramendi (2011) and Noboa-Hidalgo and Urzúa (2012) on Chile. Four studies analyse universal programmes: Berlinski, Galiani and Gertler (2009) in Argentina and Berlinski, Galiani and Manacorda (2008), Borraz and Cid (2013) and Mullin and Vairo (2015) in Uruguay. 
have positive effects. If participation was high, these programmes do not improve employment opportunities for women and essentially bring about displacement between informal and formal care. The effects generally differ between groups, with less educated women benefiting most.

In Latin America, studies analysing the effects of childcare services on mothers' labour market participation have shown the importance of programme operating hours spanning the working day and the significant effect of the number of children people have and their ages, including those not directly affected by the policy being assessed. ${ }^{22}$ In Chile, where care services for children aged under 6 are part-time and therefore mothers do not have time to work full-time, there are no effects on female labour force participation. When school hours extension programmes are analysed, however, positive and significant effects are found.

In Argentina, an effect on women's labour force participation is seen exclusively in cases where the child accessing the preschool service is the youngest, while in Uruguay full-time schooling is found to have a positive effect on the labour force participation of mothers who do not live with children under 6 . The findings of the studies carried out in Rio de Janeiro, Colombia, Ecuador and Mexico, which relate to programmes more targeted on situations of vulnerability, are invariably positive, with the effects being greatest for mothers who were not working before their children entered the programme.

\section{B. Future challenges: demographic changes and the technological revolution}

The production structure, income distribution, gender and racial or ethnic relationships, territory and the environment are critical factors when it comes to attaining the goals of the 2030 Agenda, since they create linkages that widen gaps. To close these gaps and give effect to the injunction that no-one should be left behind, it is indispensable for the interactions between them to be recognized. The analysis carried out in the earlier sections of this chapter highlights the strong effects of inequality on productivity and the challenges faced by the region's countries. Now these challenges need to be projected into the future.

Two elements need to be incorporated into the analysis, owing to the scale of their likely impact on productivity. First, the demographic changes that the region's countries are going through at different speeds will have very diverse implications for their productivity. Second, the dynamics of technological change are giving rise to concerns about its possible effects on the labour market. Using advanced technologies to attain higher productivity may bring significant short-term disruption by making some workers' skills obsolete and potentially forcing them out of the labour market. There is nothing inexorable about either process, but it is imperative to make preparations by means of social dialogue and country-specific public policy responses.

\section{The effects of ageing, female labour force participation and education}

The demographic transition entails progressive population ageing, i.e. a decline in the number of children and an increase in the number of older persons, and a general tendency for the population structure to stabilize. This process is the outcome of declining fertility and mortality rates, a consequence of development. Its speed has varied in the region, however. In many countries, the period during which the percentage of the population that is of working age and able to save is greatest, known as the demographic dividend, will last for a number of years yet. In others, it is closer to its end. In both cases, it is relevant to analyse the challenges that will be involved in maintaining growth.

22 The studies referred to are Berlinski and Galiani (2007) and Berlinski, Galiani and McEwan (2011) on Argentina, Nollenberger and Perazzo (2016) and Vairo (2014) on Uruguay, Barros and others (2011) on Rio de Janeiro, Attanasio, Meghir and Vera-Hernández (2007) on Colombia, Rosero and Oosterbeek (2011) on Ecuador and Ángeles and others (2011) on Mexico. There is a particularly large number of studies for Chile: Encina and Martínez (2009), Medrano (2009), Aguirre (2011), Bentancor (2013), Manley and Vázquez (2013), Contreras, Sepúlveda and Cabrera (2010) and Martínez and Perticará (2017). 
For this, three scenarios were developed to reflect what would happen to labour and productivity in the countries by 2050: (i) if only demographic changes occurred, with each country's current levels of activity by age group and sex remaining unchanged; (ii) if in addition to the demographic changes the female activity rate rose to the levels of what are currently the best-performing countries; and (iii) if the population's level of education increased. ${ }^{23}$ These scenarios are not projections of what will happen to activity and productivity levels in the region's countries, but have been developed as the basis for analysis of possible trajectories. ${ }^{24}$ Although migration flows may alter the supply and productivity of labour, they are not considered in this exercise because of the difficulty of modelling them. ${ }^{25}$

Figure IV.16 presents the results for five countries (each representative of a group of countries with similar characteristics) of the evolution of the activity rate, reflecting the labour supply. ${ }^{26}$ There are major differences between the countries and between the scenarios for each country as regards both levels and evolution. In the demographic scenario, the activity rate declines in three of the five groups of countries. This means that the expected evolution of the age and sex composition of the population will force down the activity rate in most of the region's countries, as there will be a rise in the proportion of older persons, who participate less in the labour market. Indeed, when this rate is observed at the central ages (between 20 and 59), the declines are much more moderate, indicating that the observed reduction is explained by the rise in the relative size of the older age groups.

The effects are most pronounced in the countries where the demographic transition is most advanced, represented by the results for Brazil and Chile, which come out with significantly lower activity rates over the time horizon analysed. At the other extreme, the countries represented by Guatemala (Guatemala, Honduras and Nicaragua) and Peru (Paraguay, Peru and the Plurinational State of Bolivia) are at no risk of their active populations diminishing because of demographic factors, as their demographic transition is still in the early stages. ${ }^{27}$

Given the pressure exerted by the age and sex structure of the population, the other two scenarios consider factors exogenous to demography that can directly influence the population's activity levels and account for much of the evolution of the activity rate in the past: the large-scale incorporation of women into the labour force and rising levels of education. ${ }^{28}$

When female activity rates are assumed to increase, overall activity rates improve in all countries. Activity levels in Guatemala and Mexico would be higher than the observed levels, a finding explained by the low level of female activity in these countries and their less aged population structure. In Chile and Peru, the large-scale incorporation of women into the labour market would mitigate the negative effects of demographic developments. ${ }^{29}$ Indeed, the activity rate would increase in the medium run before the effect was offset by the weight of demographic factors. Conversely, rising female participation in the workforce in Brazil (and Uruguay) would not be enough to maintain current levels, and the overall activity rate would drop by about $5 \%$.

23 Details of the construction of these scenarios can be found in Colacce and Manzi (2017). The base projections of scenarios i and ii differ from those of scenario iii in that this last takes account of the effects of education and its evolution on fertility and mortality levels. Scenario iii follows the proposal of Lutz, Butz and Samir (2014)

24 ECLAC (2017b), among others, has prepared projections for the economically active population (EAP) and thence the activity rate. This study finds that the demographic effect alone would lead to an increase of 203 million people in the EAP between 1980 and 2050 . Meanwhile, the participation effect, obtained by maintaining the 1980 age structures but allowing participation to change, would increase the EAP by 185 million people in the same period.

25 Modelling migration is very difficult because of the unpredictability of the combination of conditions operating as endogenous causes in the countries of origin and the conditions in destination countries. Both sets of population projections used assume constant migration flows to 2015.

26 The groups were constructed using the statistical technique of clusters and are: (i) Argentina, Chile, Costa Rica and the Dominican Republic; (ii) the Bolivarian Republic of Venezuela, Ecuador, El Salvador, Mexico and Panama; (iii) Brazil and Uruguay; (iv) Guatemala, Honduras and Nicaragua; and (v) Colombia, Paraguay, Peru and the Plurinational State of Bolivia. Colacce and Manzi (2017) detail the methodology used to construct the groups. Footnotes indicate where there are major differences between the country selected to represent the cluster and one or other of the countries composing this.

27 Even in these cases, large differences in overall activity rates remain in the region, with a gap of almost 10 percentage points between the countries with the highest rate (Peru) and the lowest rate (Chile).

28 This study does not consider a third trend: rising retirement ages. Part of this trend could be incorporated into the increase in the level of education, since the activity rate among people aged over 60 rises with education.

29 The behaviour of the Dominican Republic, Paraguay and the Plurinational State of Bolivia is different from that of the representative country in their respective groups. These countries behave much like Guatemala and Mexico in that activity rates there will go on rising up to 2050. 
Figure IV.16

Latin America (5 countries): evolution of the activity rate, by country and scenario, 2015-2050

(Percentages)

A. Demographic change

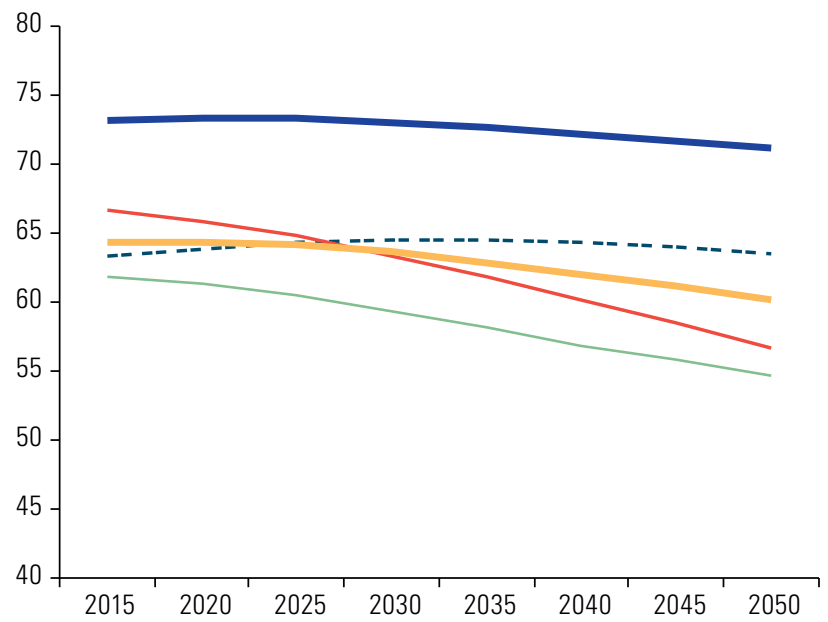

C. Increase in the level of education

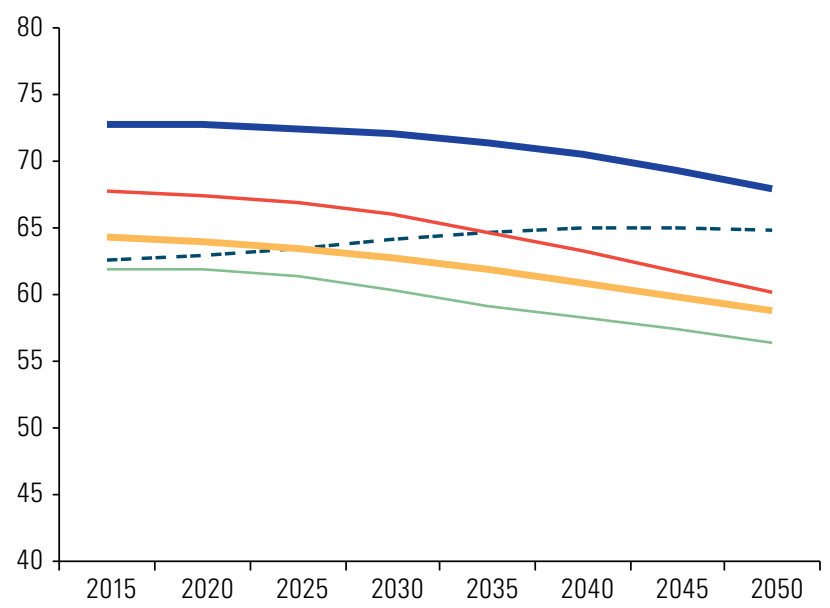

B. Increase in the female activity rate

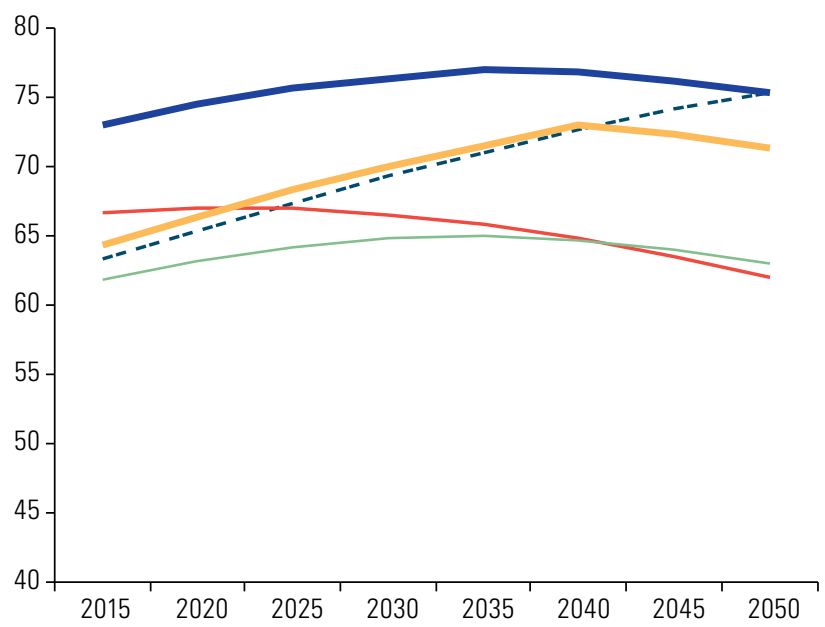

Source: Economic Commission for Latin America and the Caribbean (ECLAC), on the basis of United Nations, "World Population Prospects: The 2017 Revision", 2017 [online] https://esa.un.org/unpd/wpp/; and Wittgenstein Centre for Demography and Global Human Capital, "Wittgenstein Centre Data Explorer" [online] http://www.wittgensteincentre.org/dataexplorer.

Lastly, in the scenario of higher levels of education, the trend of the results is similar to that seen in the demographic scenario, with smaller changes. The assumptions underlying this scenario produce two effects. On the one hand, increasing the level of education would push up the activity rate, since more educated people have higher levels of participation, both by age and by sex. On the other, increasing the education rate has effects on fertility and mortality and strengthens the effects of the demographic shift, bearing down on the activity rate.

Since changes in the composition of workers in respect of sex, age and education affect what they can bring to the production process, it is worth considering the productivity changes implicit in each of the scenarios. The earnings of each group (by age, sex and education level, as appropriate) are used as a proxy for productivity, and the ratios between the groups are assumed to remain unaltered over time. The evolution of productivity per inhabitant can be explained by three components: (i) the number of workers (the more 
workers there are, the greater the productivity per inhabitant), (ii) the contribution of each worker, which can be summed up in productivity per worker, and (iii) the change in the number of inhabitants in the country (see figure IV.17).

\section{Figure IV.17}

Productivity per inhabitant, by country and scenario, 2015-2050

(Purchasing power parity (PPP) dollars)

\section{A. Demographic change}

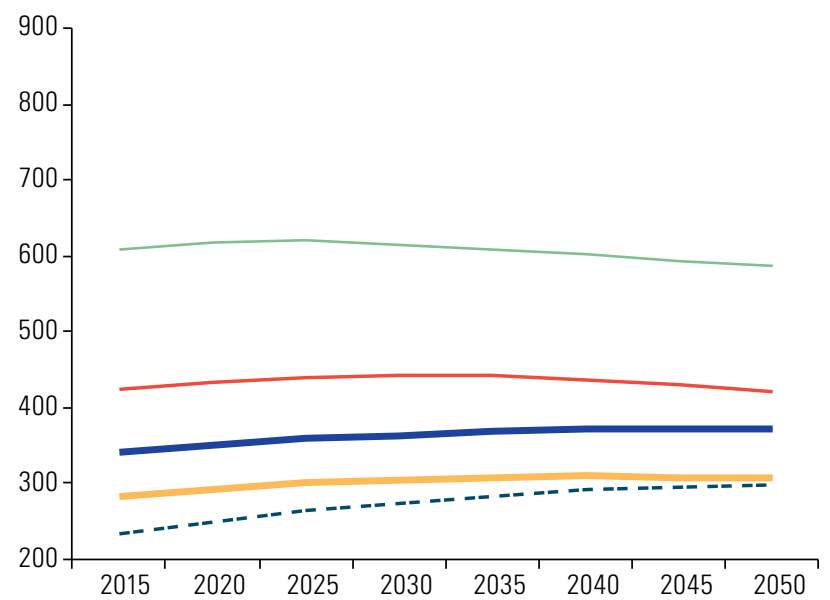

\section{Increase in the level of education}

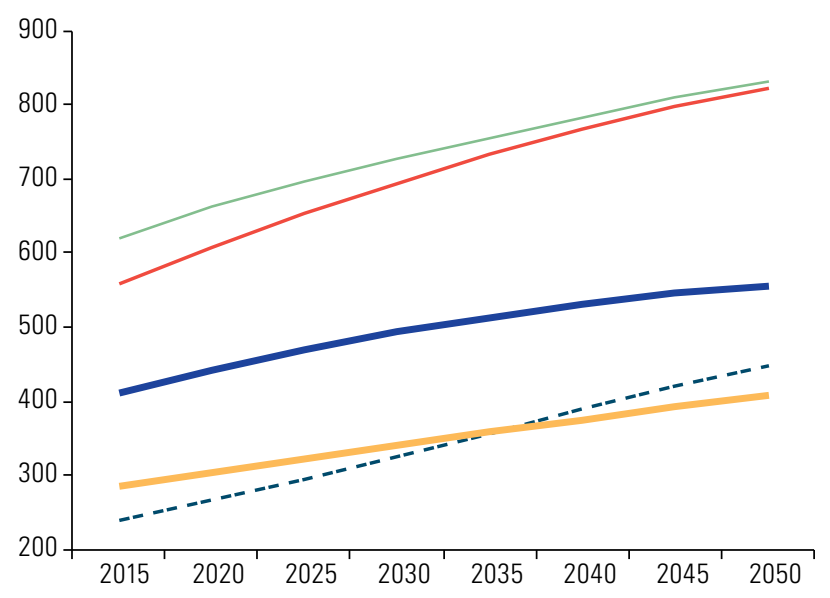

\section{B. Increase in the female activity rate}

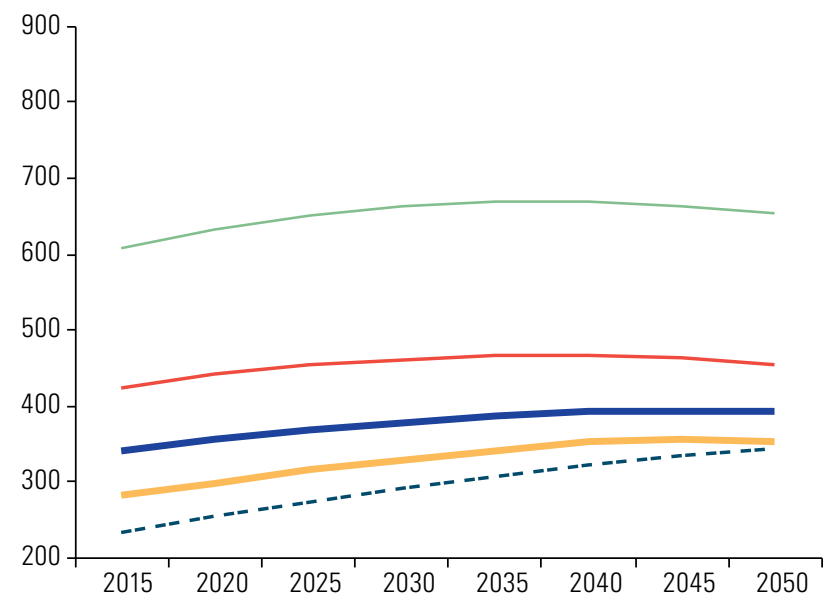

Source: Economic Commission for Latin America and the Caribbean (ECLAC), on the basis of United Nations, "World Population Prospects: The 2017 Revision", 2017 [online] https://esa.un.org/unpd/wpp/; and Wittgenstein Centre for Demography and Global Human Capital, "Wittgenstein Centre Data Explorer" [online] http://www.wittgensteincentre.org/dataexplorer.

In the purely demographic scenario, the differences observed in the productivity trend are explained by the stage in the demographic transition that countries have reached. While countries at early stages of the transition (Guatemala, Mexico and Peru) are expected to attain substantial increases in aggregate productivity over the 35-year period considered, ${ }^{30}$ the countries where the transition is most advanced (Brazil and Chile) present reductions in productivity, albeit not very large ones (less than 5\%). The main channel through which these changes are processed is the change in the number of people of working age: this group increases as

30 Two countries in the cluster represented by Chile (Argentina and the Dominican Republic) also present significant increases in productivity, while it rises slightly in Uruguay $(2 \%)$ and remains unchanged in Colombia. 
a share of the total in the first group and declines in the second. In all countries, though, the share of workers in the most productive age groups (between 30 and 50) increases, driving up productivity. Improvements notwithstanding, though, productivity is expected to remain low in all three countries of the first group.

When women are incorporated into the labour market, productivity improves in all the countries. This is because the number of people in the labour market increases, significantly raising overall output. However, Colacce and Manzi (2017) show productivity per worker improving by less than productivity per inhabitant. The reason is the assumption in the simulation that incorporating women into the labour market would not alter the gender gaps currently affecting earnings, which stand in for productivity differences in this exercise. The implication is that the new female workers entering the labour market would have below-average productivity, forcing down productivity per worker.

The exercise also shows that the only way to reverse the decline in overall productivity in the countries furthest advanced in the demographic transition is to increase education, as the higher productivity associated with this would offset the decline in the number of workers caused by demographic change.

These results indicate that the region's countries face different kinds of strain as regards their demographic evolution and the effects on productivity. In some countries (Brazil, Chile, Colombia, Costa Rica and Uruguay), major productivity increases can only be achieved by very substantial changes in the incorporation of women into the labour market and, especially, in the level of education. In most of the region's countries (the Bolivarian Republic of Venezuela, the Dominican Republic, Ecuador, El Salvador, Guatemala, Honduras, Mexico, Nicaragua, Paraguay, Peru and the Plurinational State of Bolivia) the demographic factor is still favourable and there is scope to exploit the demographic dividend. The problem they have is low productivity. Two countries (Argentina and Panama) are in an intermediate situation, with very small productivity gains in the demographic scenario ( $5 \%$ and $3 \%$, respectively). In all cases, there is a need to create the institutional and political conditions for higher productivity by incorporating new workers or increasing their level of education. Only this can secure the conditions for sustained growth once the ageing stage is reached.

\section{Technological disruption in the labour market}

The global digital platforms analysed in chapter II have introduced business models with high levels of returns and labour productivity. The different types of platforms present different patterns of labour demand, but usually require fewer employees to achieve a given level of turnover. ${ }^{31}$ The type of employees required is also changing: in some cases, the demand is mainly for highly skilled personnel, while in others it is for outsourced services provided by suppliers tied to the platform and operating with poorer employment conditions.

The digital revolution has taken the form of disruptive innovations giving rise to new models of production and consumption that can be grouped into three categories: the zero marginal cost economy, the industrial Internet and the on-demand economy. Each of these not only has implications for productivity, production patterns and organization and business models, but can also be expected to have significant effects on employment quantity and quality (see diagram IV.1). It is calculated that by 2020, on average, more than a third of the basic skills required for most occupations will be skills not currently considered vital for work and not imparted by education systems (ECLAC, 2016c).

31 In 1990, the top three carmakers in Detroit had nominal revenues of US\$ 250 billion, a market capitalization of US\$ 36 billion and 1.2 million employees. In 2014, the top three firms in Silicon Valley had revenues of US\$ 247 billion and a market capitalization of over US\$ 1 trillion, but just 137,000 employees (The Economist, 2016). 


\section{Diagram IV.1}

Technological disruption and the new employment environment

\section{Zero marginal cost economy}

- New models of digital goods and services production and distribution

- Very low marginal costs of distribution and duplication

- Production by firms and by consumers

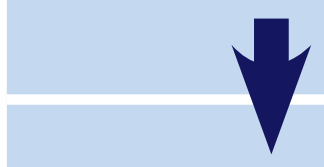

- Retraining and improvement of software development and data analysis capabilities

\section{Fewer jobs}

\section{Industrial Internet}

- New industrial models and production processes using:

- Internet-connected machines and sensors

Robots and machine learning

- Cyberphysical systems

- Complex cognitive capabilities, problemsolving and data analysis, social skills, critical thinking and active learning

\section{Fewer jobs and new capabilities}

\section{On-demand economy}

- Business models involving temporary jobs and organizations concluding short-term contracts with self-employed workers

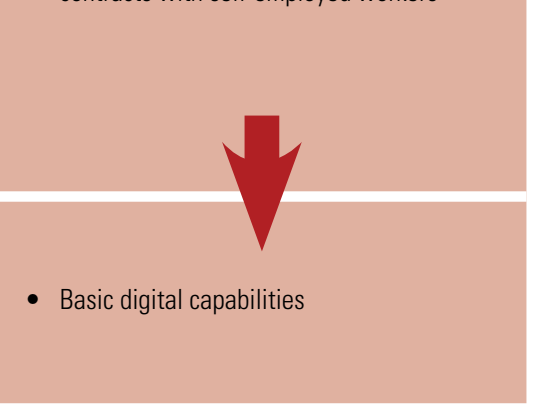

\section{Lower-quality jobs}

Source: Economic Commission for Latin America and the Caribbean (ECLAC).

As robots have swiftly become cheaper and more capable, they have been taken up more and more quickly in different industrial sectors and countries, irrespective of local labour costs. ${ }^{32}$ Technological progress means that manageably sized robots, ranging from industrial robots to stock management robots and those capable of providing services in call centres, can be produced and easily incorporated into the production structure. Combined with their falling cost, this will speed up the incorporation of robots into production processes. In 2015, a welding robot cost US\$ 8 per hour, much the same as human labour would cost for the same job in Brazil. It is estimated that costs will similarly equalize in the Mexican manufacturing sector in 2018 (see figure IV.18).

\section{Figure IV.18}

Brazil and Mexico: average cost of a welding robot and of manufacturing labour, 2015-2032

(Dollars per hour)

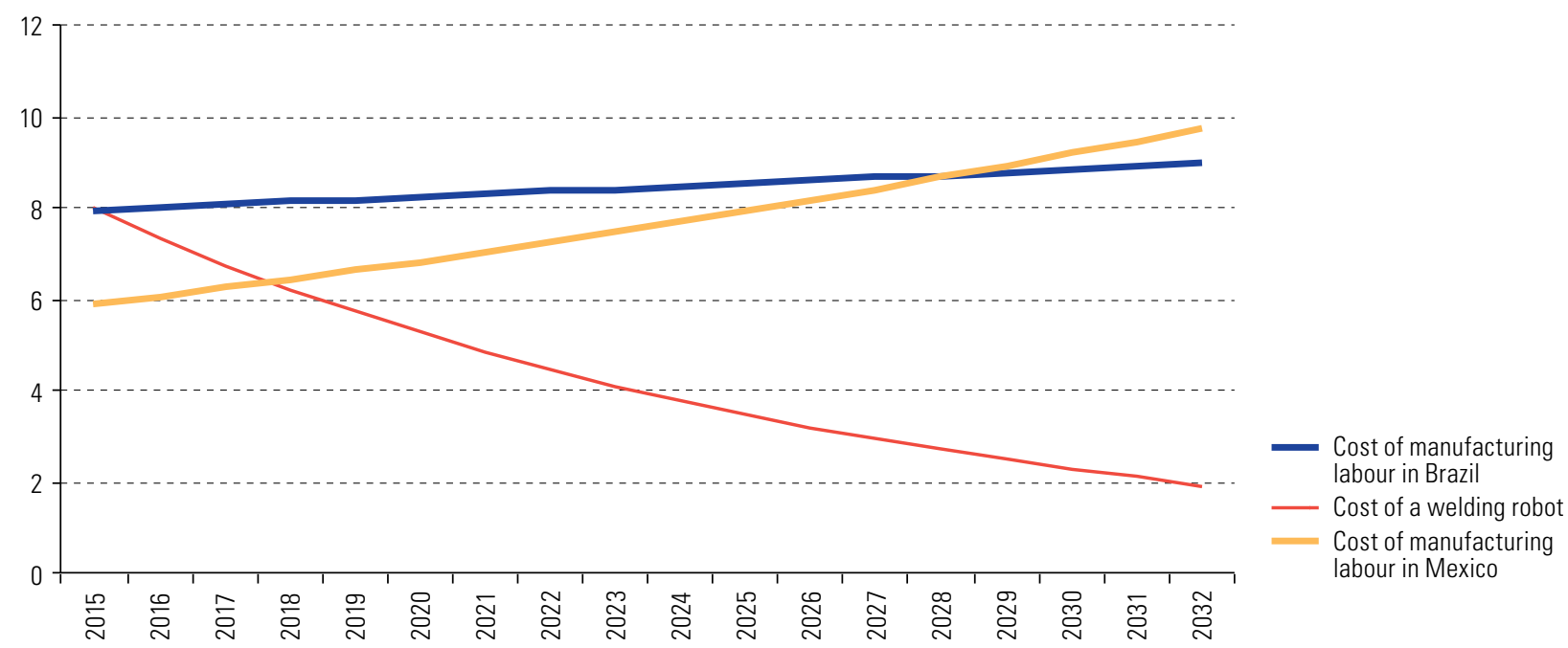

Source: Economic Commission for Latin America and the Caribbean (ECLAC).

32 In 2015, 253,748 robots were sold, with demand coming mainly from the electronics, metallurgical and chemical industries and above all the automotive industry, with this last accounting for about $40 \%$ of the total. The next strongest source of robot demand after industry was services, which marks a major development given the effects on the labour market. That same year, 41,060 professional services robots were sold, with $46 \%$ of them being installed in logistical systems, $27 \%$ in defence services, $16 \%$ in the agriculture and livestock sectors and 3\% in the medical area (International Federation of Robotics, 2016a, 2016b and 2016c). 
The effect of new technologies on the labour market, in terms of worker displacement, will depend on the occupational structure, which varies between countries (see box IV.4). It will also depend on the costs of introducing new technologies (including purchase, adjustment, installation, training, maintenance and updating costs) and on the infrastructure required in the places where they are to be installed, which could make moving from a technologically feasible replacement to an economically viable one more difficult in the countries of Latin America and the Caribbean than in developed countries (Weller, 2017).

\section{Box IV.4}

Technological change and the labour market in Argentina and Uruguay

The study by Apella and Zunino (2017) on Argentina and Uruguay analyses the possible impact of technological change on the demand for labour and draws attention to the substantial increase in the likelihood of technological unemployment, a development associated with falling demand for workers whose jobs are intensive in routine manual tasks. In addition, there could be a widening of the earnings gap between workers in non-routine cognitive task-intensive occupations and

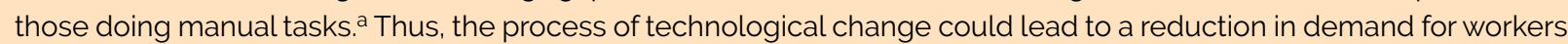
on medium incomes (usually employed on routine manual tasks) and increase the polarization of the labour market between two types of jobs: (i) lower-paid ones involving non-routine manual tasks and (ii) higher-paid ones involving non-routine cognitive tasks (see figure below).

\section{Argentina and Uruguay: likelihood of unemployment by type of work, 2015}

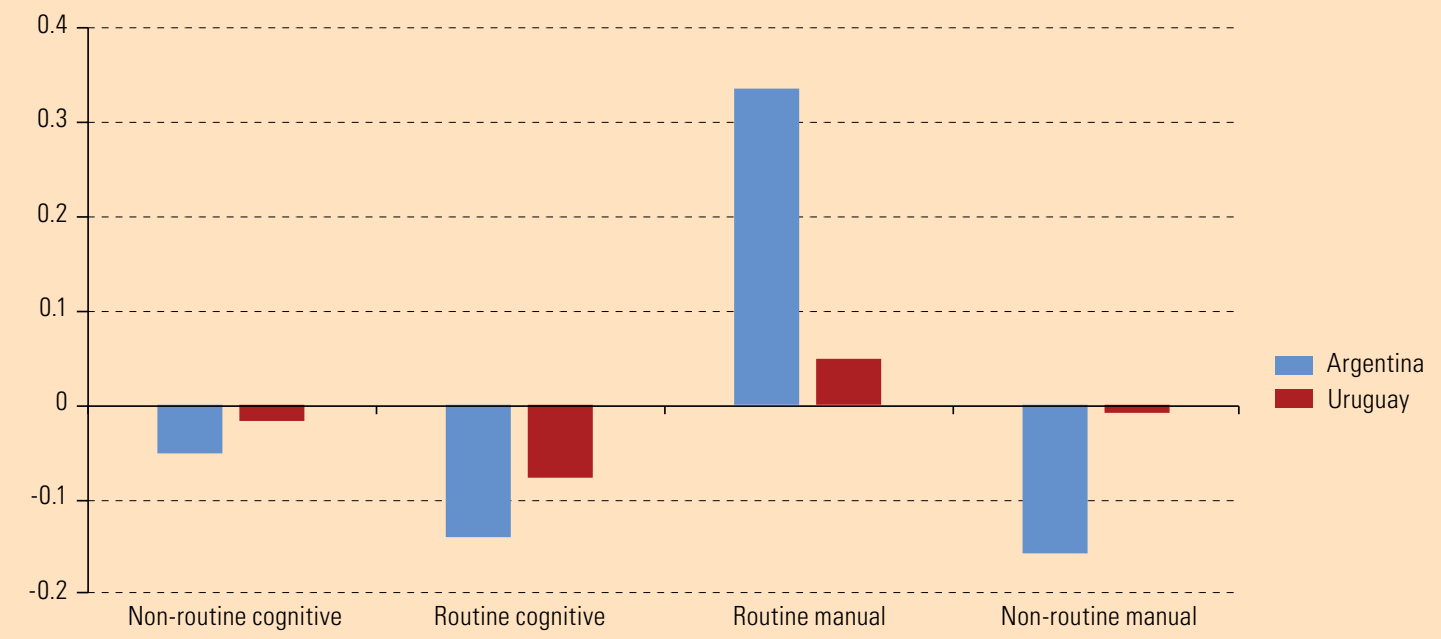

Source:Economic Commission for Latin America and the Caribbean (ECLAC), on the basis of I. Apella and G. Zunino, "Cambio tecnológico y el mercado de trabajo en Argentina y Uruguay: un análisis desde el enfoque de tareas", Serie de Informes Técnicos del Banco Mundial en Argentina, Paraguay y Uruguay, No. 11, Montevideo, World Bank, 2017.

Note: The non-routine manual task coefficient is not statistically significant for Uruguay. The other coefficients are significant at 1\%.

a The authors use a probit model to estimate the likelihood of a person being unemployed in relation to the technology intensity of the work they do and control variables such as age, years of education and a binary variable for sex.

The new production activities will create new skilled jobs and require new capabilities. However, it is possible that the fresh demand for labour will not be enough to offset job losses resulting from the automation of production and management processes, which will mainly affect more routine tasks (WEF, 2015). ${ }^{33}$ The greatest challenge in this revolution arises not only from increased automation of tasks of this type but also

33 In the most developed countries, current trends would lead to a net loss of over 5.1 million jobs in 2015-2020 if continued, with a total loss of 7.1 million jobs (two thirds of them in administrative and office activities) and the creation of 2 million jobs in other areas. The sectors in which employment would grow (finance and sales, management, information technology and mathematics) would create fewer jobs than would be lost in the areas negatively affected by technological change (office and administrative work, manufacturing and construction). These outcomes would be particularly negative for the intermediate strata of the population and for women, given their high level of participation in administrative work (ECLAC, 2016c). 
from the growing cognitive capabilities of robots and machines as artificial intelligence technologies are developed. This looks like having a significant impact on the labour market. MGI (2017a and 2017b) estimates that, although fewer than $5 \%$ of jobs are liable to be fully automated, $60 \%$ could have at least $30 \%$ of their activities automated by adapting current technologies. Important though these findings are, the enormous range of outcomes predicted for the effects of automation on employment, as shown in table IV.3, means that caution is required in quantifying the effects in the short run.

Table IV.3

Anticipated effects of automation on employment

- Frey and Osborne (2017)

47\% of occupations in the United States are at high risk of automation

- Citigroup (2016)

$57 \%$ of jobs in the countries of the Organization for Economic Cooperation and Development (OECD) are liable to be automated

- Arntz, Gregory and Zierahn (2016)

Just $9 \%$ of jobs in 21 OECD countries can be automated

- World Economic Forum (2016)

5.1 million jobs in 15 major economies can be expected to be lost between 2015 and 2020, with a gross 7.1 million job losses being partly

offset by the creation of 2 million new ones

- MGI (2017a and 2017b)

At least $30 \%$ of working activities can be automated in $60 \%$ of occupations.

Source: McKinsey Global Institute (MGI), A Future That Works: Automation, Employment, and Productivity, San Francisco, 2017; “Where will Latin America's growth come from?", Discussion Paper, San Francisco, 2017; C. Frey and M. Osborne, "The future of employment: how susceptible are jobs to computerization?", Technological Forecasting and Social Change, vol. 114, Amsterdam, Elsevier, 2017; Citigroup, Technology at Work v2.0: The Future Is Not What It Used to Be, Oxford, 2016; M. Arntz, T. Gregory and U. Zierahn, "The risk of automation for jobs in OECD countries: a comparative analysis", OECD Social, Employment and Migration Working Paper, No. 189, Paris, Organization for Economic Cooperation and Development (OECD), 2016; World Economic Forum (WEF), The Future of Jobs: Employment, Skills and Workforce Strategy for the Fourth Industrial Revolution, Geneva, 2016.

Following the approach of breaking down each occupation into its separate activities, Cadena and others (2017) and MGI (2017b) estimate that, in seven Latin American countries, half of all working time has the potential to be automated, which would have an effect equivalent to the loss of 76.4 million full-time equivalent jobs paying wages of the order of US\$ 970 billion. Meanwhile, Weller (2017) puts the loss at some 8 million jobs, while OECD/ECLAC/CAF (2016), going by data from the World Economic Forum and ILO, estimates a net loss of 3.4 million jobs by 2030 (between $1 \%$ and $2 \%$ of employment in Latin America), concentrated in manufacturing, administrative and support functions and construction. Notwithstanding these large differences, the estimates all indicate that the effects of the new technologies will be large. Furthermore, there is the risk that the least skilled workers will be the most affected and that there will be a deterioration in employment quality as more highly skilled jobs become more insecure.

Job losses because of new technologies are just part of the story. The experience of earlier technological revolutions is that long-run job creation easily outstrips losses. Two dynamics account for this. First, the incorporation of new technologies raises productivity, reduces the cost of goods and, in addition to improving consumers' well-being, frees up income to be spent on other goods. At the same time, the creation of innovative products generates new demand, as suggested by Veblen (1914), who argued that "invention is the mother of necessity". Consequently, although the net effect on employment may be negative in the short run, it is possible to obtain positive results in the long run if the incorporation of new technologies is combined with policies to promote high-quality employment. ${ }^{34}$

Robotics leads to situations in which the cost of labour ceases to be a determining factor in the location of production plants. Accordingly, plants are being relocated in the most technologically advanced locations, a trend opposite to the one experienced in the earlier phase of globalization. In sum, the impact of the new

34 Although political action and resistance by those affected could slow the transition at the microeconomic level in the short run, Luddite attempts at collective bargaining by riot were not able to prevent the triumph of industrial capitalism (Hobsbawm, 1952). 
business models on the economy and society is challenging current production structures, markets, standards and regulations, and governance mechanisms will need to be revised accordingly. The challenge is particularly great for a region like Latin America and the Caribbean, which will have to cope with strong pressure to cut labour costs as the new technologies increasingly spread in the production sector, further weakening collective actors such as unions. In a region with as much informal working as Latin America and the Caribbean, this is a particularly serious problem.

Another subject of concern to decision makers and society at large are the effects of digitalization on wealth and income distribution owing to the size and capital-intensity of global platforms. Rapid technological progress and global economic integration have been the greatest determinants of global prosperity even as they have wrought permanent changes in the economy and deeply affected its structure. Technological change and the development of global value chains have been the two factors doing most to drive down the share of national income going to labour.

In the developed countries, the labour share of national income has been trending downward since the 1980s. It bottomed out during the financial crisis and has failed to recover since. Half this decline can be attributed to the effects of technological change. The progress of digital technologies and the automation of routine activities have affected the proportions of capital and labour employed on production processes and their contribution to national income. Increasing global integration through global value chains has had a smaller impact (about 50\% less than technological change) and affected the least skilled workers most.

In emerging economies, integration and technical progress have helped sustain productivity and growth. At the same time, they have played an important role in reducing the share of national income going to labour. In these economies, global integration has been responsible for most of the change in the labour share, with technology playing only a secondary role because a smaller proportion of jobs were liable to automation and the production process was less technologically sophisticated. Technology has absorbed routine functions carried out by medium-skilled workers, and this effect has been reinforced by integration into the global market and access to cheaper labour.

Study of the impact of new technologies and new ways of organizing production in the world of work is nothing new. Since the late 1980s, the crisis of Fordism and the rapid penetration of microelectronic technologies have given rise to analyses that have treated as inevitable the reduction or progressive disappearance of formal, protected and regulated employment and the weakening of union action (Abramo, 2015). However, the evolution of the labour market in Latin America since the early twenty-first century indicates that the effects of these trends were not inevitable but have largely depended on countries' development strategies.

The impact of changes will depend on macroeconomic dynamics and on how work is organized, and likewise on political and institutional factors, including the action of the State and public institutions, employment regulations, union organization and the ability to create spaces for collective bargaining and social dialogue (ECLAC, 2017a). Far-reaching transformations of the world of work will require new labour institutions and new mechanisms for redistributing power that make up for the loss or weakening of union bargaining power that automation might bring, together with the relocation of production. From this perspective, the ability of institutions and public policies to respond to and anticipate changes is crucial. First, it is necessary to change the production structure and encourage the reallocation of low- and medium-skilled workers to tasks not liable to automation. Training systems have a vital role to play here by preparing the new generations and re-equipping current ones for tasks with a large non-routine content. Second, social protection systems need to adapt to these challenges, with progress in the design and implementation of appropriate and workable alternatives. 


\section{Bibliography}

Abramo, L. (2015), Uma década de promoção do trabalho decente no Brasil: uma estratégia de ação baseada no diálogo social, Geneva, International Labour Organization (ILO), December.

Acemoglu, D. and D. Autor (2011), "Skills, tasks and technologies: Implications for employment and earnings", Handbook of Labor Economics, vol. 4, D. Card and O. Ashenfelter (eds.), Berlin, Elsevier.

Aguirre, R. (2011), "El reparto del cuidado en América Latina", El trabajo del cuidado en América Latina y España, Documento de Trabajo, No. 54, M. Á. Durán (coord.), Madrid, Fundación Carolina.

Alderman, H. and R. Yemtsov (2012), "Productive role of safety nets: background paper for the World Bank 2012-2022 Social Protection and Labor Strategy", Discussion Paper, No. 1203, Washington, D.C., World Bank, March.

Alsan, M. and others (2008), "The consequences of population health for economic performance" Health, Economic Development and Household Poverty: From Understanding to Action, S. Bennett, L. Gilson and A. Mills (eds.), Abingdon, Routledge.

Amarante, V. and M. Colacce (2016), "Mercado laboral y productividad", Cambio demográfico y desafíos económicos y sociales en el Uruguay del siglo XXI (LC/L.4121), R. Rofman, V. Amarante and I. Apella (eds.), Santiago, Economic Commission for Latin America and the Caribbean (ECLAC)/World Bank, March.

Amarante, V., R. Arim and M. Yapor (2016), "Decomposing inequality changes in Uruguay: the role of formalization in the labor market", IZA Journal of Labor \& Development, vol. 5, No. 1, Berlin, Springer, December.

Ángeles, G. and others (2011), "Evaluación de impacto del programa Estancias Infantiles para apoyar a madres trabajadoras: informe final de la evaluación de impacto," Cuernavaca, National Institute of Public Health, July [online] http://www. normateca.sedesol.gob.mx/work/models/SEDESOL/EvaluacionProgramasSociales/Evaluacion_Impacto/EI_PEI_2011/ Inf_Final_PEl.pdf.

Apella, I. and G. Zunino (2017), "Cambio tecnológico y el mercado de trabajo en Argentina y Uruguay: un análisis desde el enfoque de tareas", Serie de Informes Técnicos del Banco Mundial en Argentina, Paraguay y Uruguay, No. 11, Montevideo, World Bank, May.

Araya, F. (2017), "Una aproximación a la movilidad intergeneracional de los ingresos laborales en Uruguay", master's thesis, Montevideo, University of the Republic, August.

Arim, R. (2017), "Cambio estructural y distribución del ingreso: disyuntivas para la coyuntura. Borrador", document prepared for the second session of the Regional Conference on Social Development in Latin America and the Caribbean and the Ninth Ministerial Forum for Development in Latin America and the Caribbean, Montevideo, Economic Commission for Latin America and the Caribbean (ECLAC), 25-27 October.

Arntz, M., T. Gregory and U. Zierahn (2017), "Revisiting the risk of automation," Economics Letters, vol. 159, Amsterdam, Elsevier, October.

(2016), "The risk of automation for jobs in OECD countries: a comparative analysis", OECD Social, Employment and Migration Working Papers, No. 189, Paris, Organization for Economic Cooperation and Development (OECD), May.

Atkinson, A. (2015), Inequality: What Can Be Done?, Cambridge, Harvard University Press, May.

Attanasio, O. and C. Binelli (2010), "Mexico in the 1990s: the main cross-sectional facts", Review of Economic Dynamics, vol. 13, No. 1, Amsterdam, Elsevier, January.

Attanasio, O., C. Meghir and M. Vera-Hernández (2007), "Investigating different benefits of workfare programs", London, University College London/Institute For Fiscal Studies [online] https://pdfs.semanticscholar.org/2290/1a929d234c3b4 f493813d85afb9386a30b5f.pdf.

Autor, D. (2015), "Why are there still so many jobs? The history and future of workplace automation", Journal of Economic Perspectives, vol. 29, No. 3, Pittsburgh, American Economic Association.

Azevedo, V. and C. Bouillon (2010), "Intergenerational social mobility in Latin America: a review of existing evidence", Economic Analysis Review, vol. 25, No. 2, Santiago, Alberto Hurtado University.

Baez, J. and A. Camacho (2011), "Assessing the long-term effects of conditional cash transfers on human capital: evidence from Colombia", IZA Discussion Paper, No. 5751, Bonn, Institute for the Study of Labor (IZA), May.

Banerjee, A., S. Chassang and E. Snowberg (2016), "Decision theoretic approaches to experiment design and external validity", NBER Working Paper, No. 22167, Cambridge, National Bureau of Economic Research (NBER), April.

Barham, T., K. Macours and J. Maluccio (2013), "More schooling and more learning? Effects of a three-year conditional cash transfer program in Nicaragua after 10 years", IDB Working Paper series, No. 432, Washington, D.C., Inter-American Development Bank (IDB), July.

Barham, T. and others (2016), "Long-term impacts of conditional cash transfers in Latin America: review of the evidence", IDB Working Paper series, No. 732, Washington, D.C., Inter-American Development Bank (IDB), October.

Barros, R. and others (2011), "Uma avaliação do impacto da qualidade da creche no desenvolvimento infantil," Pesquisa e Planejamento Econômico, vol. 41, No. 2, Brasilia, Institute of Applied Economic Research (IPEA), August. 
Behrman, J., Y. Cheng and P. Todd (2004), “Evaluating preschool programs when length of exposure to the program varies: a nonparametric approach", The Review of Economics and Statistics, vol. 86, No. 1, Cambridge, The MIT Press, February.

Bentancor, A. (2013), “Desigualdades territoriales en los mercados laborales en Chile", Documento de Trabajo, No. 6, Santiago, Latin American Centre for Rural Development (RIMISP), June.

Berlinski, S. and S. Galiani (2007), "The effect of a large expansion of pre-primary school facilities on preschool attendance and maternal employment", Labour Economics, vol. 14, No. 3, Amsterdam, Elsevier.

Berlinski, S., S. Galiani and P. Gertler (2009), "The effect of pre-primary education on primary school performance”, Journal of Public Economics, vol. 93, No. 1-2, Amsterdam, Elsevier, February.

Berlinski, S., S. Galiani and M. Manacorda (2008), “Giving children a better start: preschool attendance and school-age profiles", Journal of Public Economics, vol. 92, No. 5-6, Amsterdam, Elsevier.

Berlinski, S., S. Galiani and P. McEwan (2011), "Preschool and maternal labor market outcomes: evidence from a regression discontinuity design", Economic Development and Cultural Change, vol. 59, No. 2, Chicago, University of Chicago Press.

Bernal, R. and others (2009), "Evaluación de impacto del Programa Hogares Comunitarios de Bienestar del ICBF", serie Documentos CEDE, No. 16, Bogota, University of the Andes, July.

Binelli, C. (2016), “Wage inequality and informality: evidence from Mexico", IZA Journal of Labor \& Development, vol. 5, No. 1, Berlin, Springer, December.

Bleakley, H. (2010), "Malaria eradication in the Americas: a retrospective analysis of childhood exposure", American Economic Journal: Applied Economics, vol. 2, No. 2, Pittsburgh, American Economic Association, April.

Bloom, D., D. Canning and J. Sevilla (2004), "The effect of health on economic growth: a production function approach", World Development, vol. 32, No. 1, Amsterdam, Elsevier, January.

Borraz, F. and A. Cid (2013), "Preschool attendance and school-age profiles: a revision", Children and Youth Services Review, vol. 35, No. 5, Amsterdam, Elsevier, May.

Bourguignon, F. (2003), "The growth elasticity of poverty reduction: explaining heterogeneity across countries and time periods", Working Paper, No. 28104, Washington, D.C., World Bank.

Cadena, A. and others (2017), "The productivity leap", Robot/ution: The Future of Work in Latin American Integration 4.0, Integration and Trade Journal, vol. 21, No. 42, Washington, D.C., Inter-American Development Bank (IDB), August.

Cascio, E. (2015), "The promises and pitfalls of universal early education", IZA World of Labor 2015, No. 116, Bonn, Institute for the Study of Labor (IZA), January.

Cascio, E. and D. Whitmore (2013), “The impacts of expanding access to high-quality preschool education”, NBER Working Paper, No. 19735, Cambridge, National Bureau of Economic Research (NBER), December.

Cecchini, S. (2014), “Transferencias monetarias y empleo: ¿círculo vicioso o virtuoso?", Madrid, EUROsociAL Programme, 18 November [online] http://reciprocamente.eurosocial-ii.eu/transferencias-monetarias-y-empleo-circulovicioso-o-virtuoso-de-simone-cecchini-cepal/.

Cecchini, S. and R. Martínez (2012), Inclusive social protection in Latin America: a comprehensive, rights-based approach, ECLAC Books, No. 111 (LC/G.2488-P), Santiago, Economic Commission for Latin America and the Caribbean (ECLAC), January.

Cecchini, S. and F. Veras Soares (2015), "Conditional cash transfers and health in Latin America", The Lancet, vol. 385, No. 9975, Amsterdam, Elsevier, April.

Chimerine, L., T. Black and L. Coffey (1999), “Unemployment insurance as an automatic stabilizer: evidence of effectiveness over three decades", Unemployment Insurance Occasional Paper, No. 99-8, Washington D.C., United States Department of Labor, July.

Chong, A. and M. Gradstein (2007), "Inequality and informality", Journal of Public Economics, vol. 91, No. 1-2, Amsterdam, Elsevier, February.

Colacce, M. and P. Manzi (2017), “El cuidado de la población uruguaya y la creación del Sistema Nacional Integrado de Cuidados: una mirada de largo plazo", Studies and Perspectives series-ECLAC office in Montevideo, No. 27 (LC/TS.2017/43; LC/MVD/TS.2017/2), Santiago, Economic Commission for Latin America and the Caribbean (ECLAC), August.

Constenla D. and others (2008), "Cost-effectiveness of pneumococcal conjugate vaccination in Latin America and the Caribbean: a regional analysis", Pan American Journal of Public Health, vol. 24, No. 5, Washington, D.C., World Health Organization (WHO), November.

Contreras, D., P. Sepúlveda and S. Cabrera (2010), "The effects of lengthening the school day on female labor supply: evidence from a quasi-experiment in Chile", Documentos de Trabajo series, No. 323, Santiago, University of Chile, July.

Corak, M. (2013), "Income inequality, equality of opportunity, and intergenerational mobility", Journal of Economic Perspectives, vol. 27, No. 3, Pittsburgh, American Economic Association.

Côrtes, M., F. Monteiro and P. Guimarães (2013), “Efeitos macroeconômicos do Programa Bolsa Família: uma análise comparativa das transferências sociais", Programa Bolsa Família: Uma Década de Inclusão e Cidadania, T. Campello and M. Côrtes (coords.), Brasilia, Institute of Applied Economic Research (IPEA). 
Cunha, F. and J. Heckman (2010), "Investing in our young people", NBER Working Paper, No. 16201, Cambridge, National Bureau of Economic Research (NBER), July.

Cunha, F. and others (2006), "Interpreting the evidence on life cycle skill formation", Handbook of the Economics of Education, E. Hanushek and F. Welch (eds.), Amsterdam, Elsevier.

Datt, G. and M. Ravallion (1992), "Growth and redistribution components of changes in poverty measures: a decomposition with applications to Brazil and India in the 1980s", Journal of Development Economics, vol. 38, No. 2, Amsterdam, Elsevier, April.

Daude, C. and V. Robano (2015), "On intergenerational (im)mobility in Latin America", Latin American Economic Review, vol. 24, No. 9, Berlin, Springer, December.

Davis, B., S. Di Giuseppe and A. Zezza (2017), "Are African households (not) leaving agriculture? Patterns of households' income sources in rural Sub-Saharan Africa", Food Policy, vol. 67, Amsterdam, Elsevier, February.

De Oliveira, A. and others (2007), "Primeiros resultados da análise da linha de base da pesquisa de avaliação de impacto do Programa Bolsa Família", Avaliação de Políticas e Programas do MDS: Resultados, vol. 2, J. Vaitsman and R. PaesSousa (orgs.), Belo Horizonte, Federal University of Minas Gerais.

De Soárez, P. and others (2008), "Cost-effectiveness analysis of routine rotavirus vaccination in Brazil", Pan American Journal of Public Health, vol. 23, No. 4, Washington, D.C., World Health Organization (WHO), April.

Del Boca, D. (2015), "Child care arrangements and labor supply", IDB Working Paper series, No. 569, Washington, D.C., Inter-American Development Bank (IDB), February.

Dunn, C. (2007), "The intergenerational transmission of lifetime earnings: evidence from Brazil", The B.E. Journal of Economic Analysis \& Policy, vol. 7, No. 2, Berlin, De Gruyter.

ECLAC (Economic Commission for Latin America and the Caribbean) (2017a), Linkages between the social and production spheres: gaps, pillars and challenges (LC/CDS.2/3), Santiago.

(2017b), Demographic Observatory of Latin America. Population Projections (LC/PUB.2017/3-P), Santiago, March.

(2016a), The Social Inequality Matrix in Latin America (LC/G.2690(MDS.1/2)), Santiago.

(2016b), Inclusive social development: the next generation of policies for overcoming poverty and reducing inequality in Latin America and the Caribbean (LC.L/4056/Rev.1), Santiago, January.

(2014), Compacts for Equality: Towards a Sustainable Future (LC/G.2586(SES.35/3)), Santiago, April.

(2012), Structural Change for Equality: An Integrated Approach to Development (LC/G.2524(SES.34/3)), Santiago, July. (2010), Time for equality: closing gaps, opening trails (LC/G.2432(SES.33/3)), Santiago, May.

(2006), Shaping the future of social protection: access, financing and solidarity (LC/G.2294(SES.31/3)), Santiago, March.

ECLAC/ILO (Economic Commission for Latin America and the Caribbean/International Labour Organization) (2014), "Conditional transfer programmes and the labour market", The Employment Situation in Latin America and the Caribbean, No. 10 (LC/L.3815), Santiago, May.

Encina, J. and C. Martínez (2009), "Efecto de una mayor cobertura de salas cuna en la participación laboral femenina: evidencia de Chile", Documentos de Trabajo series, No. 303, Santiago, University of Chile, November.

Escobar, A. and M. González (2009), "Girls, mothers and poverty reduction in Mexico: evaluating Progresa-Oportunidades", The Gendered Impacts of Liberalization: Towards "Embedded Liberalism", S. Razavi (ed.) New York, Routledge.

(2002), "Documento final de diagnóstico cualitativo de hogares semiurbanos: localidades de 2500 a 50000 habitantes, 2001", Guadalajara, Centre for Research and Higher Learning in Social Anthropology (CIESAS), August [online] http:// lanic.utexas.edu/project/etext/oportunidades/2002/escobar1.pdf.

Fernández, A. and others (2017), "Impacto social y económico de la malnutrición: modelo de análisis y estudio piloto en Chile, el Ecuador y México", Project Documents (LC/TS.2017/32), Santiago, Economic Commission for Latin America and the Caribbean (ECLAC), April.

Fogel, R. (2004), "Health, nutrition and economic growth", Economic Development and Cultural Change, vol. 52, No. 3, Chicago, University of Chicago Press, April.

Frey, C. and M. Osborne (2017), "The future of employment: how susceptible are jobs to computerization?", Technological Forecasting and Social Change, vol. 114, Amsterdam, Elsevier, January.

Galor, O. and J. Zeira (1993), "Income distribution and macroeconomics", The Review of Economic Studies, vol. 60, No. 1, Oxford, Oxford University Press, January.

García, A. and others (2012), "Impactos de largo plazo del programa Familias en Acción en municipios de menos de 100.000 habitantes en los aspectos claves del desarrollo del capital humano. Informe final", Bogotá, Unión Temporal Econometría/ National Planning Department, May [online] https://colaboracion.dnp.gov.co/CDT/Sinergia/Documentos/393_Impactos_ de_Largo_Plazo_en_el_Programa_Familias_en_Accion_DOC.pdf.

Grawe, N. (2004), "Intergenerational mobility for whom? The experience of high- and low- earning sons in international perspective", Generational Income Mobility in North America and Europe, M. Corak (ed.), Cambridge, Cambridge University Press. 
Hanlon, J., A. Barrientos and D. Hulme (2010), "Pro-poor growth: turning a \$1 grant into \$2 income", Just Give Money to the Poor: The Development Revolution from the Global South, London, Kumarian Press.

Havnes, T. and M. Mogstad (2009), "No child left behind: universal child care and children's long-run outcomes", IZA Discussion Paper, No. 4561, Bonn, Institute for the Study of Labor (IZA), November.

Hertz, T. and others (2007), "The inheritance of educational inequality: international comparisons and fifty-year trends", The B.E. Journal of Economic Analysis \& Policy, vol. 7, No. 2, Berlin, De Gruyter.

Hobsbawm, E. (1952), "The machine breakers", Past \& Present, vol. 1, No. 1, Oxford, Oxford University Press, February. Holmes, R. and others (2010), "Cash transfers and gendered risks and vulnerabilities: lessons from Latin America", ODI Background Note, London, Overseas Development Institute (ODI), October.

Ibarrarán, P. and others (eds.) (2017), How Conditional Cash Transfers Work: Good Practices after 20 Years of Implementation, Washington, D.C., Inter-American Development Bank (IDB).

IFR (International Federation of Robotics) (2016a), World Robotics Report 2016, Frankfurt am Main.

(2016b), World Robotics 2016: Industrial Robots, Frankfurt am Main.

(2016c), World Robotics 2016: Service Robots, Frankfurt am Main.

Jamison, D. and others (2013), "Global health 2035: a world converging within a generation", The Lancet, vol. 382, No. 9908, Amsterdam, Elsevier, December.

Jiménez, M. and M. Jiménez (2009), "La movilidad intergeneracional del ingreso: evidencia para Argentina," Documento de Trabajo, No. 84, La Plata, National University of La Plata, March.

Johnson, S., D. Kaufmann and P. Zoido (1998), "Regulatory discretion and unofficial economy", American Economic Review, vol. 88, No. 2, Berlin, Springer, May.

Kuznets, S. (1955), "Economic growth and income inequality", The American Economic Review, vol. 45, No. 1, Pittsburgh, American Economic Association, March.

Landim, P. (2009), "Relatório final: os efeitos do Programa Bolsa Família sobre a economia dos municípios brasileiros", São Paulo, Insper, August [online] http://www.ipcig.org/publication/mds/33P.pdf.

La Porta, R. and A. Shleifer (2014), "Informality and development," Journal of Economic Perspectives, vol. 28, No. 3, Pittsburgh, American Economic Association.

Llanos, A. and others (2007), "Cost-effectiveness of a folic acid fortification program in Chile," Health Policy, vol. 83, No. 2-3, Amsterdam, Elsevier, March.

Loayza, N. (1997), "The economics of the informal sector: a simple model and some empirical evidence from Latin America", Policy Research Working Paper, No. 1727, Washington, D.C., World Bank, February.

Luiz Pereira, L. and others (2008), "Efeitos do Programa Bolsa Família nas condições de vida de beneficiários em municípios de muito baixo IDH", Brasilia, International Policy Centre for Inclusive Growth (IPC-IG) [online] http://www.ipcig.org/ publication/mds/33M.pdf.

Lutz, W., W. Butz and K. Samir (eds.) (2014), World Population and Human Capital in the Twenty-First Century, London, Oxford University Press, October.

Manley, J. and F. Vásquez (2013), “Childcare availability and female labor force participation: an empirical examination of the Chile Crece Contigo program", Working Paper series, No. 2013-03, Towson, Towson University, December.

Mathers, N. and R. Slater (2014), "Social protection and growth: research synthesis", Canberra, Overseas Development Institute (ODI) [online] http://www.social-protection.org/gimi/gess/RessourcePDF.action?ressource.ressourceld=54036.

Martínez, C. and M. Perticará (2017), "Childcare effects on maternal employment: evidence from Chile", Journal of Development Economics, vol. 126, Amsterdam, Elsevier, May.

Martínez, J. and K. Voorend (2008), "Transferencias condicionadas e igualdad de género: ¿blancos, negros o grises?", Revista de Ciencias Sociales (Cr), vol. 4, No. 122, San José, University of Costa Rica.

Medrano, P. (2009), "Public day care and female labor force participation: evidence from Chile," Documentos de Trabajo series, No. 306, Santiago, University of Chile, December.

Medeiros, M., T. Britto and F. Soares (2008), "Targeted cash transfer programmes in Brazil: BPC and the Bolsa Familia, Working Paper, No. 46, Brasilia, United Nations Development Programme (UNDP).

MGI (McKinsey Global Institute) (2017a), A Future That Works: Automation, Employment, and Productivity, San Francisco, January.

_ (2017b), "Where will Latin America's growth come from?", Discussion Paper, San Francisco, April.

Mincer, J. (1958), "Investment in human capital and personal income distribution", Journal of Political Economy, vol. 66, No. 4, Chicago, University of Chicago Press, August.

Mishra, A. and R. Ray (2013), "Informality, corruption and inequality", Bath Economics Working Paper, No. 13/10, Bath, University of Bath.

Mostafa, J., F. Monteiro and P. Ferreira (2010), "Efeitos econômicos do gasto social no Brasil", Perspectivas da Política Social no Brasil, vol. 8, J. Castro and others (orgs.), Brasilia, Institute of Applied Economic Research (IPEA). 
Mullin, G. and M. Vairo (2015), “El impacto de la expansión de la educación preescolar en Uruguay: un análisis en base al enfoque de igualdad de oportunidades", Documentos de Investigación Estudiantil series, No. 01/2015, Montevideo, University of the Republic, March.

Neidhöfer, G., J. Serrano and L. Gasparini (2017), “Educational inequality and intergenerational mobility in Latin America: a new database", Documentos de Trabajo, No. 215, La Plata, National University of La Plata, August [online] http:// www.cedlas.econo.unlp.edu.ar/wp/wp-content/uploads/doc_cedlas215.pdf.

Noboa-Hidalgo, G. and S. Urzúa (2012), "The effects of participation in public child care centers: evidence from Chile", Journal of Human Capital, vol. 6, No. 1, Chicago, University of Chicago Press.

Nollenberger, N. and I. Perazzo (2016), “Efectos de la provisión universal de educación preescolar sobre la asistencia y la participación laboral femenina: evidencia para el caso uruguayo", Documentos de Trabajo series, No. 04/2016, Montevideo, University of the Republic, August.

Núñez, J. (coord.) (2011), "Evaluación del programa Familias en Acción en grandes centros urbanos: informe final", Bogotá, Centro Nacional de Consultoría, December [online] https://issuu.com/carlosgutierrez30/docs/evaluaci_n_del_ programa_familias_e.

Nuñez, J. and L. Miranda (2007), "Recent findings on intergenerational income and educational mobility in Chile", Documento de Trabajo, No. 244, Santiago, Universidad de Chile, June.

OECD/ECLAC/CAF (Organization for Economic Cooperation and Development/Economic Commission for Latin America and the Caribbean/Development Bank of Latin America) (2016), Latin American Economic Outlook 2017: Youth, Skills and Entrepreneurship (LC/G.2689), Paris, October.

Ostry, J., A. Berg and C. Tsangarides (2014), "Redistribution, inequality, and growth", IMF Staff Discussion Note, No. SDN/14/02, Washington, D.C., International Monetary Fund (IMF), February.

Parker, S. (2003), “Evaluación del impacto de oportunidades sobre la inscripción escolar: primaria, secundaria y media superior", Documentos de Investigación, No. 6, Mexico City, National Institute of Public Health/Economic Research and Teaching Centre (CIDE), March.

Pickett, K. and R. Wilkinson (2009), The Spirit Level: Why More Equal Societies Almost Always Do Better, London, Allen Lane. Rajan, R. (2010), Fault Lines: How Hidden Fractures Still Threaten the World Economy, Princeton, Princeton University Press.

Rasella, D. and others (2013), "Effect of a conditional cash transfer programme on childhood mortality: a nationwide analysis of Brazilian municipalities", The Lancet, vol. 382, No. 9886, Amsterdam, Elsevier, July.

Rosero, J. and H. Oosterbeek (2011), "Trade-offs between different early childhood interventions: evidence from Ecuador", Tinbergen Institute Discussion Paper, No. 102/3, Amsterdam, Tinbergen Institute.

Samson, M. (2009), "Social cash transfers and employment: a note on empirical linkages in developing countries", Promoting Pro-Poor Growth: Employment, Paris, Organization for Economic Cooperation and Development (OECD).

Schneider, F. (2012), "The shadow economy and work in the shadow: what do we (not) know?", IZA Discussion Paper, No. 6423, Bonn, Institute for the Study of Labor (IZA), March.

Schneider, F. and D. Enste (2000), "Shadow economies: size, causes, and consequences", Journal of Economic Literature, vol. 38, No. 1, Pittsburgh, American Economic Association, March.

Schwarzer, H. (2000), "Impactos socioeconômicos do sistema de aposentadorias rurais no Brasil: evidências empíricas de um estudo de caso no estado do Pará", Texto para Discussão, No. 729, Rio de Janeiro, Institute of Applied Economic Research (IPEA), June.

Sheehan, P. and others (2017), "Building the foundations for sustainable development: a case for global investment in the capabilities of adolescents", The Lancet, vol. 390, No. 10104, Amsterdam, Elsevier, October.

Stiglitz, J. (2012), The Price of Inequality: How Today's Divided Society Endangers Our Future, New York, W.W. Norton.

The Economist (2016), "The superstar company: a giant problem. The rise of the corporate colossus threatens both competition and the legitimacy of business", London, 17 September.

Torche, F. (2014), “Movilidad intergeneracional y desigualdad: el caso latinoamericano", Annual Review of Sociology, vol. 40, Palo Alto, Annual Reviews, July.

Tornarolli, L. and others (2014), “Exploring trends in labor informality in Latin America, 1990-2010", Documento de Trabajo, No. 159, La Plata, National University of La Plata, May.

UNICEF (United Nations Children's Fund) (2012), A brief review of the social and economic returns to investing in children [online] https://www.unicef.org/socialpolicy/files/Investing_in_Children_19June2012_e-version_FINAL.pdf.

Urzúa, S. and G. Veramendi (2011), "The impact of out-of-home childcare centers on early childhood development", IDB Working Paper series, No. 240, Washington, D.C., Inter-American Development Bank (IDB), June.

Vairo, M. (2014), “Efectos de la extensión de la jornada escolar sobre la participación laboral femenina: evidencia del programa de Escuelas de Tiempo Completo", document presented at the Jornadas Académicas de la Facultad de Ciencias Económicas y de Administración, Montevideo, University of the Republic, 7-9 October. 
Van Lancker, W. and J. Ghysels (2011), "Who reaps the benefits? The social distribution of public childcare in Sweden and Flanders", Working Paper, No. 11/06, Antwerp, University of Antwerp, April.

Veblen, T. (1914), The Instinct of Workmanship and the State of the Industrial Arts, New York, Macmillan.

Videt, B. (2014), "Social protection for inclusive growth. How welfare schemes might contribute to economic growth", The Broker, Amsterdam, Foundation for International Development Publications (IDP), 16 January [online] http://www. thebrokeronline.eu/Articles/Social-protection-for-inclusive-growth.

WEF (World Economic Forum) (2015), "Bridging the skills and innovation gap to boost productivity in Latin America. The competitiveness lab: a World Economic Forum initiative", Insight Report, Geneva, January.

Weller, J. (2017), "Las transformaciones tecnológicas y su impacto en los mercados laborales", Macroeconomics of Development series, No. 190 (LC/TS.2017/76), Santiago, Economic Commission for Latin America and the Caribbean (ECLAC), September.

WHO (World Health Organization) (2011), Scaling Up Action Against Noncommunicable Diseases: How Much Will It Cost?, Geneva.

World Bank (2016), "World Development Report 2016: digital dividends overview”, World Development Report, No. 102724, Washington, D.C., January.

Zandi, M. (2009), "The economic impact of the American recovery and Reinvestment act," Moody's Investors Service, January [online] http://williambessette.com/Economic_Stimulus_House_Plan_012109.pdf. 



\section{$\bigcap$}

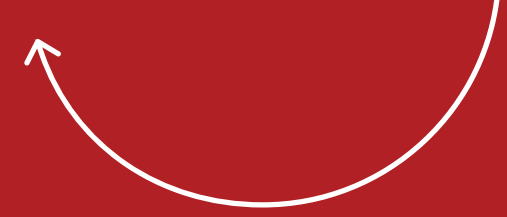

\section{CHAPTER}

\section{Inequalities that cause segregation and deterioration: territory and the environment}

Introduction

A. Territory as an expression of imbalances in the economic model
1. The inequality space
2. Infrastructure reinforces the model's inertia
3. The new rurality

B. Cities: dynamic centres that reproduce segmentation
1. Old gaps and new ones
2. Segregation is a denial of the right to the city
3. Urban mobility as an expression of inequality

C. The development pattern erodes its own environmental foundations
1. Territorial degradation destroys ecosystems and soils
2. Climate change: global pollution and localized impacts
3. The urgent need to increase the rate of decarbonization

D. Renewable energy sources: a new investment horizon
1. The need for a new energy matrix
2. The carbon content in the electric energy mix is declining slowly
3. Complementarity and integration between renewable energies

E. The foundations of a structure that is inefficient in terms of energy and production Bibliography 



\section{Introduction}

The foregoing chapters have analysed various dimensions of inequality and the adverse effects it has on productivity by restricting the development of capacities and limiting opportunities to make use of them. This chapter addresses other dimensions of inequality that are closely related to those already studied. One of these is territorial, since poverty or low levels of development are concentrated in certain areas and not in others. Cities are part of this territorial dynamic, in which development tends to be concentrated in certain spaces and to generate polarization, both within cities themselves and in relation to the rural world. Other inequalities relate to environmental degradation: the lower-income sectors suffer most from the negative consequences of pollution in urban areas, and poor subsistence farmers are forced to work in the most degraded rural ecosystems. Moreover, the infrastructure endowment and its existing investment patterns serve to consolidate and reproduce territorial and environmental inequalities.

These new expressions of inequality thus refer to territory, cities, infrastructure and the environment. Unequal territorial development, infrastructure disparities and the selective deterioration of the environment are interconnected dimensions of inequality. Analysing them jointly therefore helps to identify the limitations of the current model and to discuss the bases of a new one that is consistent with the 2030 Agenda for Sustainable Development. The new model is based on a recognition of the role of the environment and natural resources as the basis for the material, ecosystemic, environmental and energy underpinnings of economic processes (Sunkel, 1996). This analysis takes place in a scenario where climate change is an additional constraint that limits the scope for policy action and, at the same time, opens up investment horizons around innovation and structural change.

Each of these dimensions (territory, cities, environment and infrastructure) interacts with the others and can generate trade-offs - when, for example, an infrastructure work has a negative impact on the environment- or synergies — when, for example, a resilient piece of infrastructure decreases territorial inequalities. One of the key variables that define the interactions between these four dimensions is the intensity and direction of technical progress. Sustainable development requires reducing the technology gap and steering innovation and structural change towards greater energy efficiency and a change in the energy mix to reduce carbon dioxide $\left(\mathrm{CO}_{2}\right)$ emissions per unit of energy consumed. An effort in this direction is needed to break free from a pattern of low investment rates, lacklustre growth, poor productivity gains and stalled energy efficiency in the region; and to make stronger growth compatible with job creation and a smaller environmental impact. This chapter focuses on the interdependencies between those four dimensions and how they interact with inequality and technical progress, as key elements for proposing a new development pattern based on an environmental big push.

\section{A. Territory as an expression of imbalances in the economic model}

\section{The inequality space}

At the core of the modern theory of regional economics is a centre-periphery model, whose key variables (increasing returns, specialization patterns and localized technology spillovers) are those originally identified by the Economic Commission for Latin America and the Caribbean (ECLAC) and the pioneers of development theory. ${ }^{1}$ Indivisibilities, complementarities and external economies generate entrenched technological and productive path dependencies that are hard to reverse without diversification policies (Arthur, 1994).

The centre-periphery model is the core of regional economic theory (see Brakma, Garretsen and Marrewijk, 2011, chapter 3). On this model in the ECLAC tradition, see Prebisch (1976, 1981); Mattos (1988), Rodríguez (1980, 2006); Cimoli, Porcile and S. Rovira (2010); Bárcena and Prado (2016) and Infante (2016). 
This dynamic gives rise to sharp spatial disparities, both between countries and within them (ECLAC, 2016a, 2015b). The heavy concentration of production in a small group of sectors and large modern firms — structural heterogeneity- is manifested in the territory of the region's countries through a more pronounced concentration of population and production than occurs in the developed economies, which generates inequalities in living conditions (Cuervo 2004; ECLAC, 2015c). In some countries, this concentration reached extraordinary levels. In Panama, for example, $71 \%$ of GDP and $51 \%$ of the population are concentrated in just $16 \%$ of the country's area -in Panama province where the capital city is located. Other countries that have more than one major city, such as Ecuador and the Plurinational State of Bolivia, show concentration that is less severe, but nevertheless higher than elsewhere in the world. As discussed below, the trend towards concentration is being matched by a steady expansion of the main metropolitan areas.

Spatial disparities in production are associated with productivity differences: average productivity in the central metropolitan areas is systematically higher than elsewhere, although there is great heterogeneity in the region. ${ }^{2}$ Differences in productivity and income reflect not only increasing returns, but also proximity to political power, the transfer of wealth from commodity-producing territories towards those central zones, and their greater infrastructure endowment. They are the result of production patterns and political decisions on the allocation of public investment and the provision of infrastructure; in other words, of the non-inclusive rules of the game and the culture of privilege that have predominated throughout the region's economic history (see chapter VI).

Regional disparities are manifested in the dispersion of average productivity between territories, as measured by the standard deviation of the logarithm of per capita GDP between regions. It is found, first, that dispersion in the region is greater than in the two developed countries included in figure V.1. Although dispersion was high between 1995 and 2015, it declined slightly or convergence occurred between 2000 and 2010-2011. Thereafter, the process stalled, and dispersion actually increased. This could be associated with burgeoning demand for commodities (products that are usually produced in less developed territories or regions), which fuelled growth rates above the national average in several cases. Second, the social and economic policies implemented in some countries in favour of the poorest regions, such as the North-East of Brazil, boosted the production of goods and services for local consumption.

Figure V.1

Degree of income dispersion (trend in subnational disparities in per capita GDP), 1995-2015

(Standard deviation of logarithms of per capita GDP)

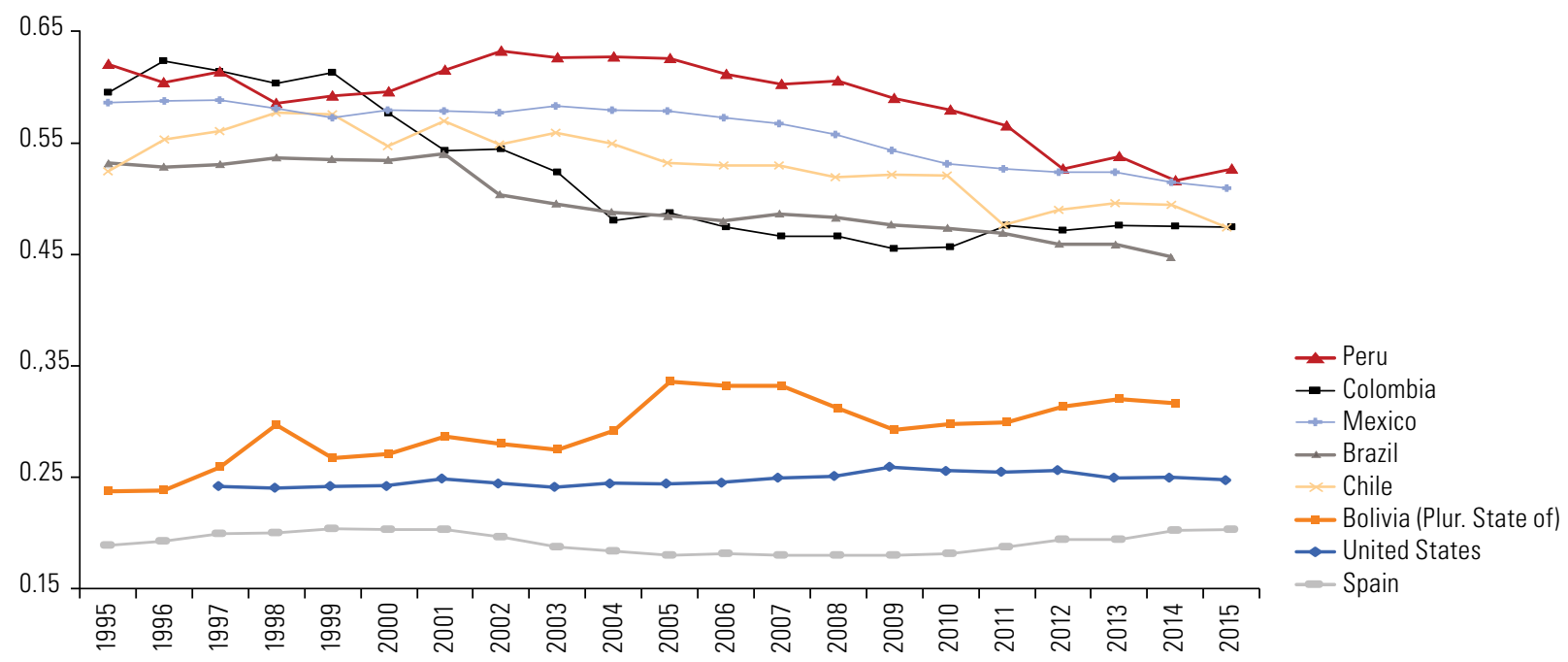

Source: Economic Commission for Latin America and the Caribbean (ECLAC), on the basis of the countries' official national accounts statistics. 
The Latin America and the Caribbean regional development index (RDI) for 2015, calculated by ECLAC, offers a broader perspective on territorial inequalities. Unlike traditional analyses of territorial disparities benchmarked on the averages of each country, RDI compares the relative development of 175 territorial entities in eight Latin American countries against the regional averages (see map V.1). ${ }^{3}$ This approach adds extra dimensions to per capita GDP, such as health, education and access to housing. The 2015 RDI enables identification of the macroregions with the largest relative lags in economic-social development, which include the North-East of Brazil, the south-western Mexico and the Andean and Amazonian areas of the Plurinational State of Bolivia, Colombia, Ecuador and Peru. By contrast, the territories with the best results are usually the national capitals or largest metropolitan areas.

Map V.1

Latin America (8 countries): regional development index (RDI) $2015^{\mathrm{a}}$
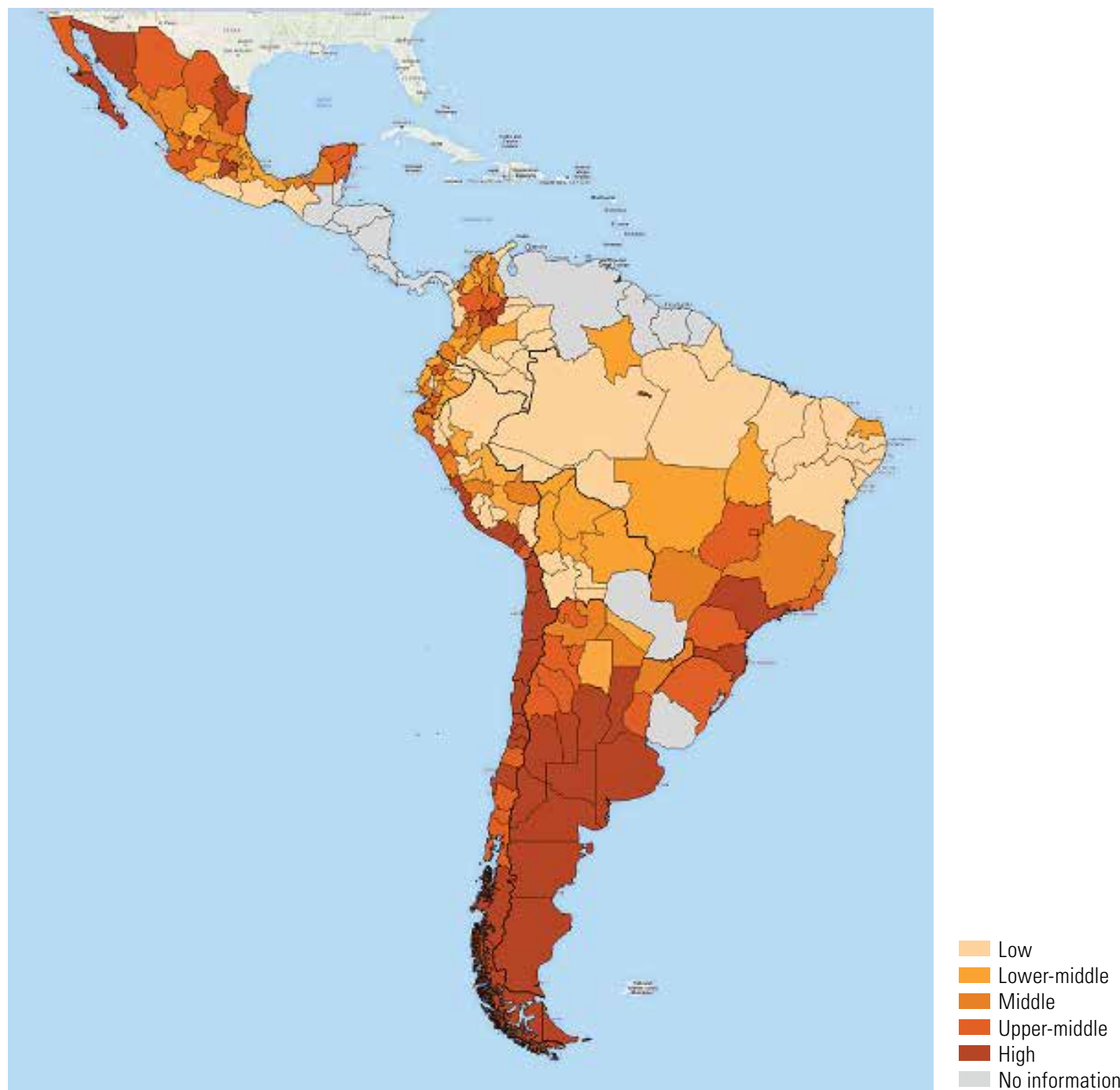

Source: Economic Commission for Latin America and the Caribbean (ECLAC), Panorama del Desarrollo Territorial en América Latina y el Caribe, 2015 (LC/W.671), Santiago, 2015.

Note: The boundaries and names shown on this map do not imply official endorsement or acceptance by the United Nations.

a The countries analysed are Argentina, Brazil, Chile, Colombia, Ecuador, Mexico, Peru and the Plurinational State of Bolivia.

$3 \mathrm{RDI}$ is a composite index based on 10 variables (percentage of rural population, employment rate, per capita GDP without extractive mining, illiteracy rate, population with higher education, infant mortality rate, life expectancy, homicide rate, housing without indoor water connection, homes/housing with a computer), for eight countries and 175 territorial entities of first tier political-administrative divisions (region, state, province and department), taking 2015, or around 2015, as the base year. The variables are standardized to generate a score, and grouped by quintiles of degrees of development classified as high, upper-middle, middle, lower-middle and low. The 175 entities are highly heterogeneous. For a description of the methodology, see ECLAC (2017b) annex 1. 
If the regions are divided into five development levels according to this indicator, it may be seen that territories with lower-middle and low levels of RDI have more than 87 million inhabitants, close to $18 \%$ of the total population of the countries analysed, whereas their GDP share is just $9 \%$. The population in the high-development bracket amounts to 158 million, representing $32 \%$ of the total population of the eight countries and generating $47 \%$ of their GDP. The differences between the strata are also very marked in terms of the social indicators of life expectancy, infant mortality, illiteracy and access to drinking water (see figure V.2). For example, infant mortality in territories that have a low RDI is double the rate in high-RDI territories.

Figure V.2

Latin America (8 countries): selected indicators of RDI 2015, by development levela

(Simple averages)

\section{A. Life expectancy} (years)

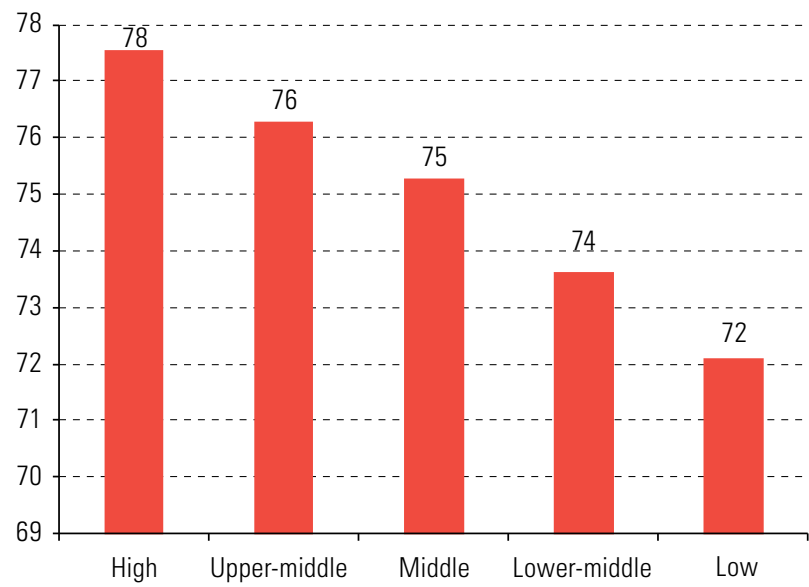

\section{Illiteracy rate} (percentages)

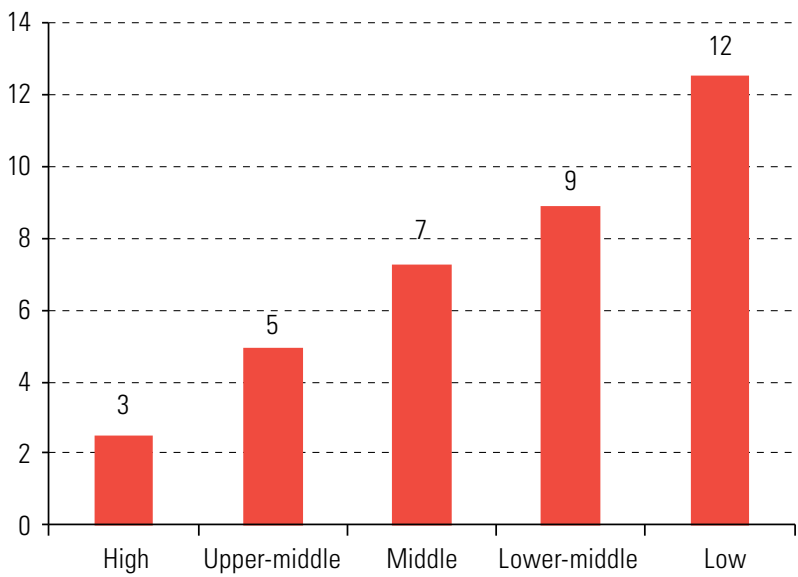

\section{B. Infant mortality (per 1000 live births)}

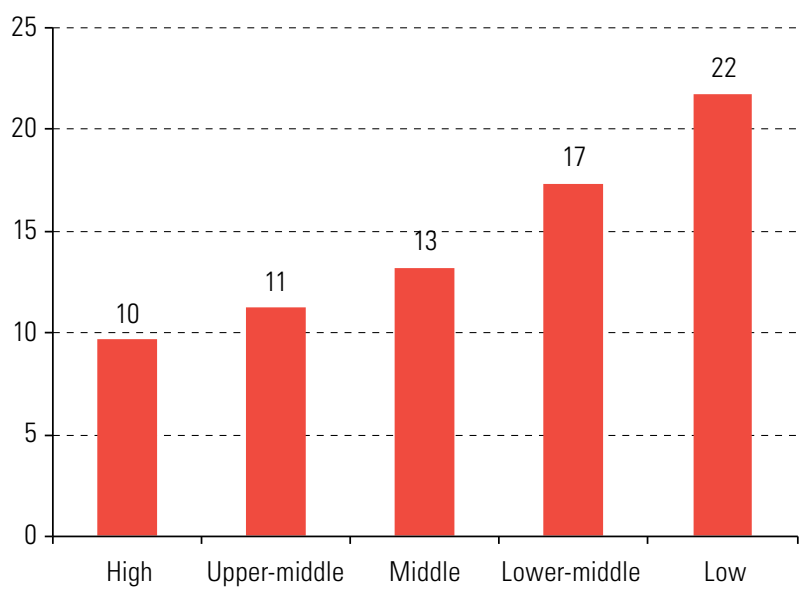

\section{Housing without indoor water connection} (percentages)

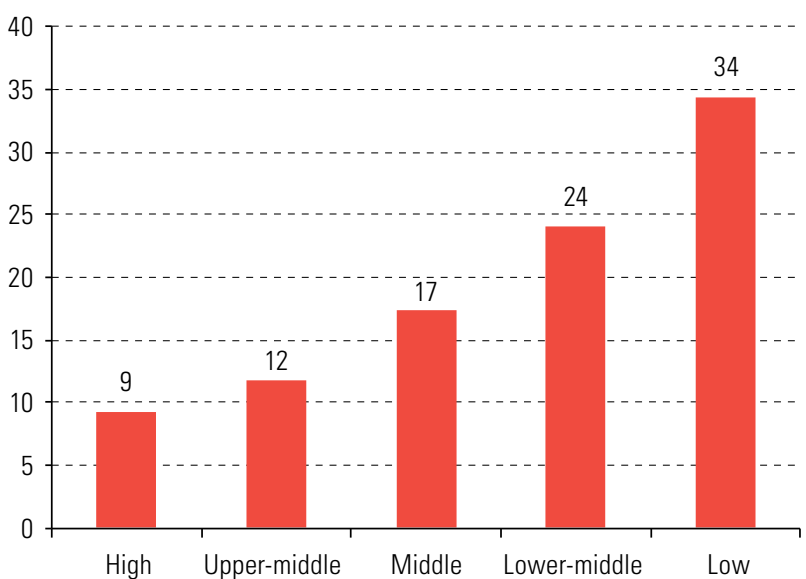

Source: Economic Commission for Latin America and the Caribbean (ECLAC), Panorama del Desarrollo Territorial en América Latina y el Caribe, 2015 (LC/W.671), Santiago, 2015.

a The countries analysed are Argentina, Brazil, Chile, Colombia, Ecuador, Mexico, Peru and the Plurinational State of Bolivia.

This territorially concentrated pattern is based on partially inherited infrastructure and is reproduced in the recent trends of investment in that infrastructure. 


\section{Infrastructure reinforces the model's inertia}

\section{(a) A model based on natural resources}

Originally, infrastructure development in the region was associated with the commodity export model and was built to convey natural resources to ports, without significantly improving domestic connections or links to other countries in the region. Natural resources remain extremely important as a basis for the region's international trade and investment, which entails a certain degree of external vulnerability. The problems associated with reliance on natural resources as the region's main source of competitiveness have been a traditional theme among development analysts, in addition to the urgent challenge of sustainability. The region has a wealth of renewable and non-renewable natural resources that have been exploited without observing social, environmental and economic sustainability criteria. ${ }^{4}$ In the energy sector, the region has great potential in the field of renewable energy sources (such as hydro, solar or wind), which also display remarkable geographical and seasonal complementarity. Nonetheless, the region depends mainly on hydrocarbons: three quarters of its energy supply comes from this source, as discussed below.

Another factor that needs to be considered is the region's extraordinary biodiversity — with a great variety of climates and types of ecosystem, and an enormous diversity of flora, more than half of which are endemic to Latin America and the Caribbean. The region's countries are the centres of origin and diversity of many plant and animal species. Many of them, such as the Bolivarian Republic of Venezuela, Brazil, Colombia, Ecuador, Mexico and Peru, are megadiverse because of their great wealth of species; especially birds, butterflies, reptiles and flowering plants. This is in addition to the biological and ecological assets of the region's rural areas, which contain four of the eight centres of origin of cultivated plants, according to Vavilov. ${ }^{5}$ Possession of a diversity of genetic resources is vital for adapting to the new conditions generated by climate change, such as drought stress, temperature change and extreme variation, diseases and pests and increased salinity. Biodiversity is a pillar for constructing a diversified bioeconomy. Much environmental damage is irreparable and represents irreplaceable losses of natural heritage that reduce development options for future generations.

In this context, the region exports its natural resources without internalizing the environmental costs of their exploitation in their prices, while paying the expensive technological rents built into imported goods. This unequal trade shifts environmental costs from the central countries to the peripheral countries (Martínez-Alier and Roca, 2016). Figure V.3 shows that South America is a net exporter of materials -mainly biomass, minerals and fossil fuels - and that the deficit in its physical trade (inflow of materials through imports minus outflow through exports) has increased in the new millennium. Failure to harness the technological and productive externalities associated with the exploitation of the region's natural resources has resulted in concentration of the associated benefits in just a few areas and in a poorly diversified production fabric (García Alonso, 2017).

4 Latin America and the Caribbean has 33\% of the world's water (ECLAC, 2014), 15\% of its agricultural area (FAOSTAT, 2017b) and a large proportion of its proven reserves of metallic ores. In the case of lithium, Argentina, Brazil and Chile own 68\% of the world's total proven reserves (USGS, 2017). Argentina, Chile and the Plurinational State of Bolivia also possess 19.3\%, 24.2\% and 21.9\%, respectively, of the potential global reserves of this metal (Perrotti and Coviello, 2015). In the case of copper, Chile, Mexico and Peru account for 47\% of the world's proven reserves. According to United States Geological Survey (USGS, 2014), roughly 2.1 billion tons of potential reserves of this metal have been identified, of which $21.4 \%$ could be located in South America and $2 \%$ in Central America and the Caribbean. In the case of bauxite, according to USGS (2017), South America and the Caribbean are thought to account for $21 \%$ of the world's potential reserves.

5 In the 1920s, the geneticist Nikolai Vavilov studied the origin and distribution of the main species of plants grown around the world and established eight centres of origin. The World Vegetable Centre has identified over 130 genes associated with the response to drought in wild relatives of tomatoes and has introduced the genes of tomatoes from Chile's deserts into commercial lines (National Commission for the Knowledge and Use of Biodiversity of Mexico, CONABIO, undated), http://www.biodiversidad.gob.mx/genes/centrosOrigen/centrosPlantas1a.html. 
Figure V.3

South America (9 countries): exports, imports and physical trade balance, 2002-2016a

(Millions of tons)

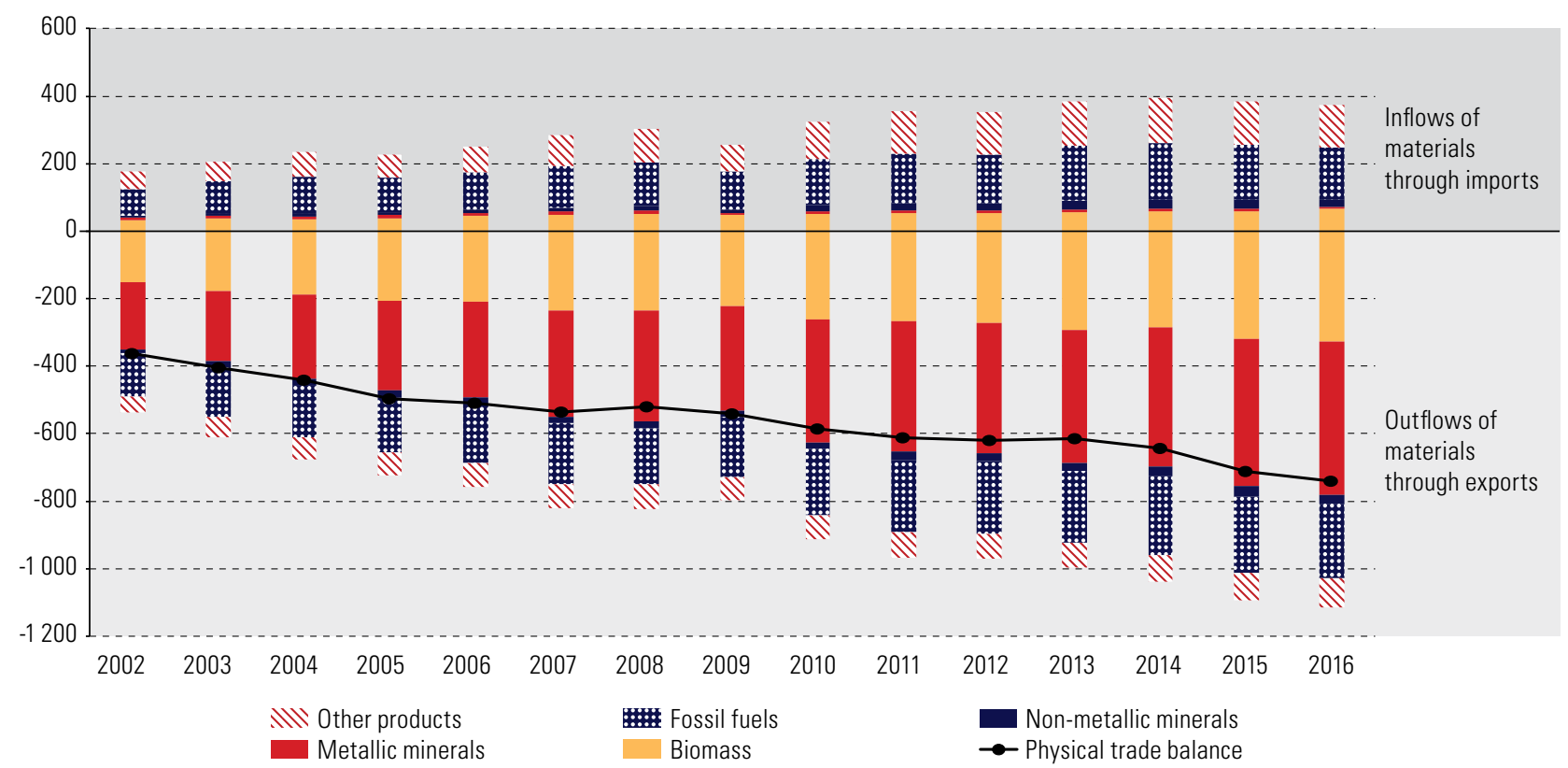

Source: Economic Commission for Latin America and the Caribbean (ECLAC), on the basis of the United Nations International Trade Statistics Database (UN Comtrade). a The countries analysed are Argentina, Brazil, Chile, Colombia, Ecuador, Paraguay, Peru, the Plurinational State of Bolivia and Uruguay.

In many cases, the expansion of the extractive model has resulted in social and environmental conflicts linked to the activities in question and to new infrastructure projects. These are rooted in structural factors, such as high levels of poverty, inequality, the absence of the State in vast areas, historical discrimination against indigenous peoples and other social groups, the lack of core services and resistance to changes in the status quo (Ramos, Muñoz and Pérez, 2017).

\section{(b) Insufficient and inefficient infrastructure development}

The region's infrastructure generally maintains the hallmark of an enclave model (Muñoz and Pérez, 2016), since it was originally built to take mining and agricultural output to the ports for export. Map V.2 shows how the region's infrastructure nodes are linked to the exploitation and exportation of extractive natural resources. Over time, the capacity and quality of the transport network have been upgraded; but territorial connectedness within each country or across the region remains insufficient.

Much of the region's settlements and production activities are associated with economic activity close to the coasts and with natural resources, mainly in South America. Possibilities for interconnection between transport modes remain precarious or suffer from technical complications. In some cases, this is because the network was designed to prevent regional interconnection for reasons of national security, economic concentration or political influence. As a result, high logistics costs act as a drag on integration and production linkages. 
Connections both within and between the region's countries are not only fragmented; they are also economically and environmentally inefficient. Most intraregional trade in South America is transported by sea $-63 \%$ of the total volume and $46.3 \%$ of the total value according to 2013 data. The rest travels predominantly by road, which accounts for $30.4 \%$ in volume terms and $39.5 \%$ by value. Within countries, $86 \%$ of the total volume is carried by road. National data suggest the same predominance of road transport in domestic freight even in countries that have rail or river networks, such as Argentina, Brazil, Colombia or Mexico (see figures V.4 and V.5).

\section{Map V.2}

Latin America and the Caribbean: extractive natural resources and transport infrastructure, 2017

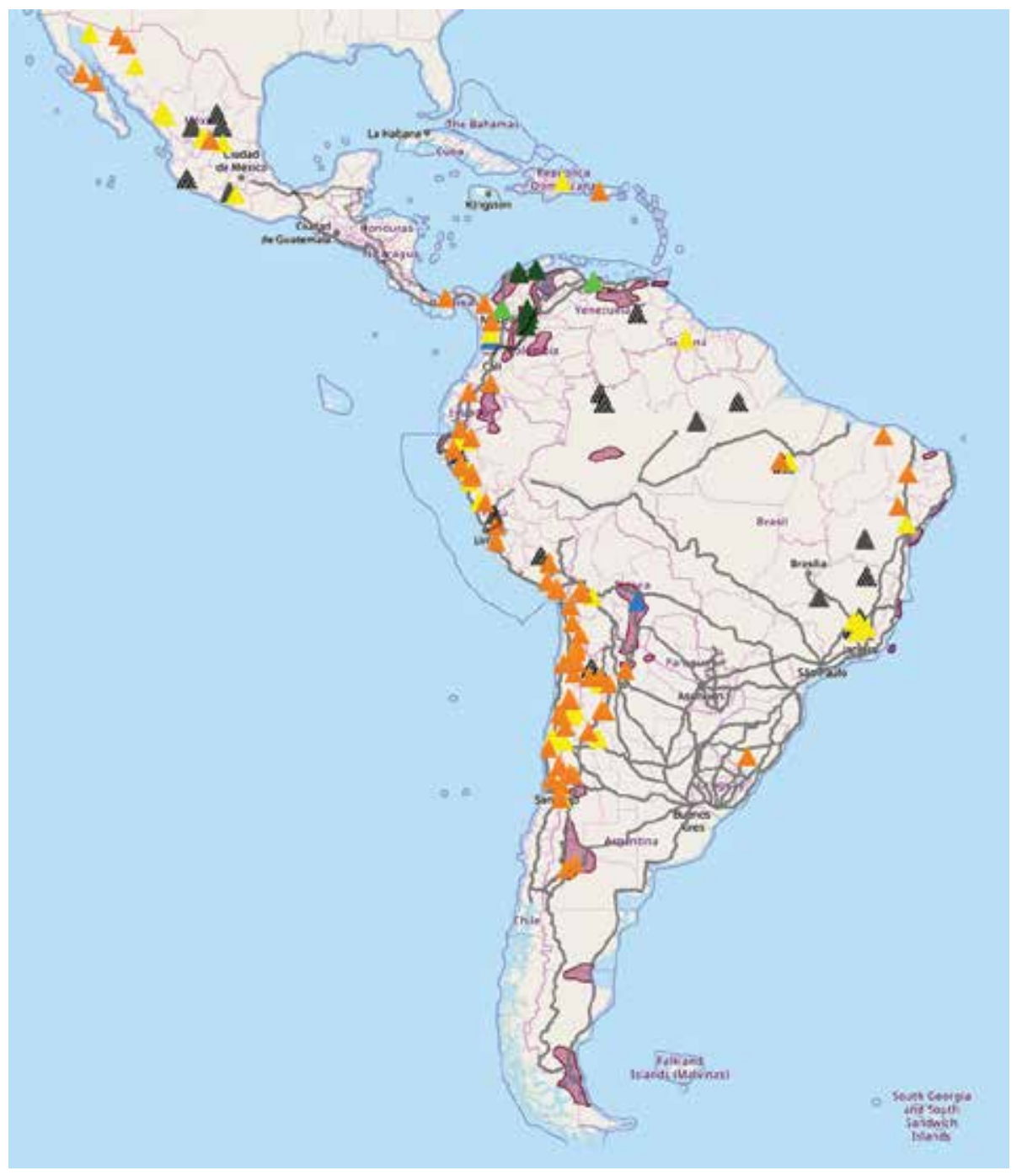

Aluminium

$\triangle$ Copper

4. Iron

$\triangle$ Nickel

$\triangle$ Gold

$\Delta$ Platinum

$\Delta$ Zinc

$\Delta$ Coal

Hydrocarbons

— Roads

Source: Economic Commission for Latin America and the Caribbean (ECLAC), on the basis of the United Nations International Trade Statistics Database (UN Comtrade). Note: The boundaries and names shown on this map do not imply official endorsement or acceptance by the United Nations. 


\section{Figure V.4}

South America: modal distribution of intraregional trade, 2013

(Percentages of volume and value)

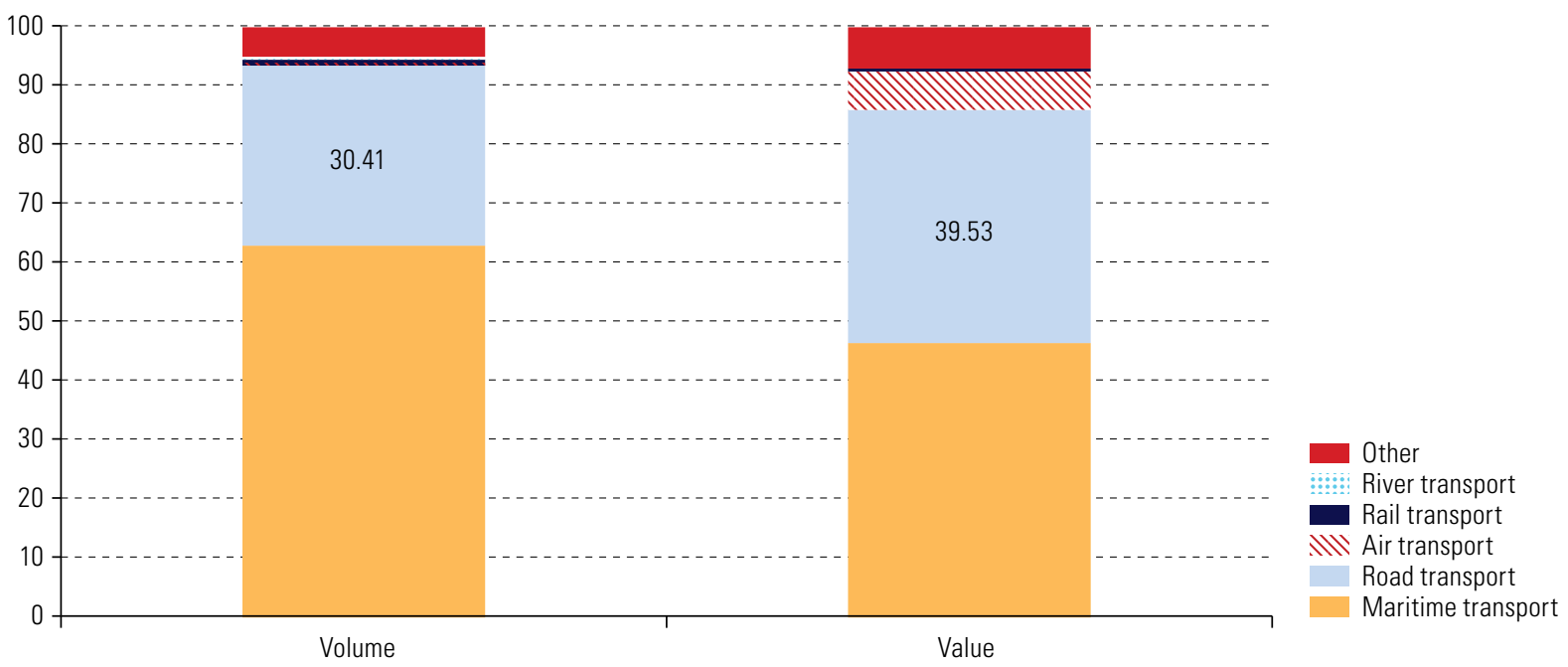

Source: Economic Commission for Latin America and the Caribbean (ECLAC), International Transport Database (BTI).

\section{Figure V.5}

Latin America (4 countries): domestic modal split, 2013

(Percentages of tons $/ \mathrm{km}$ transported)

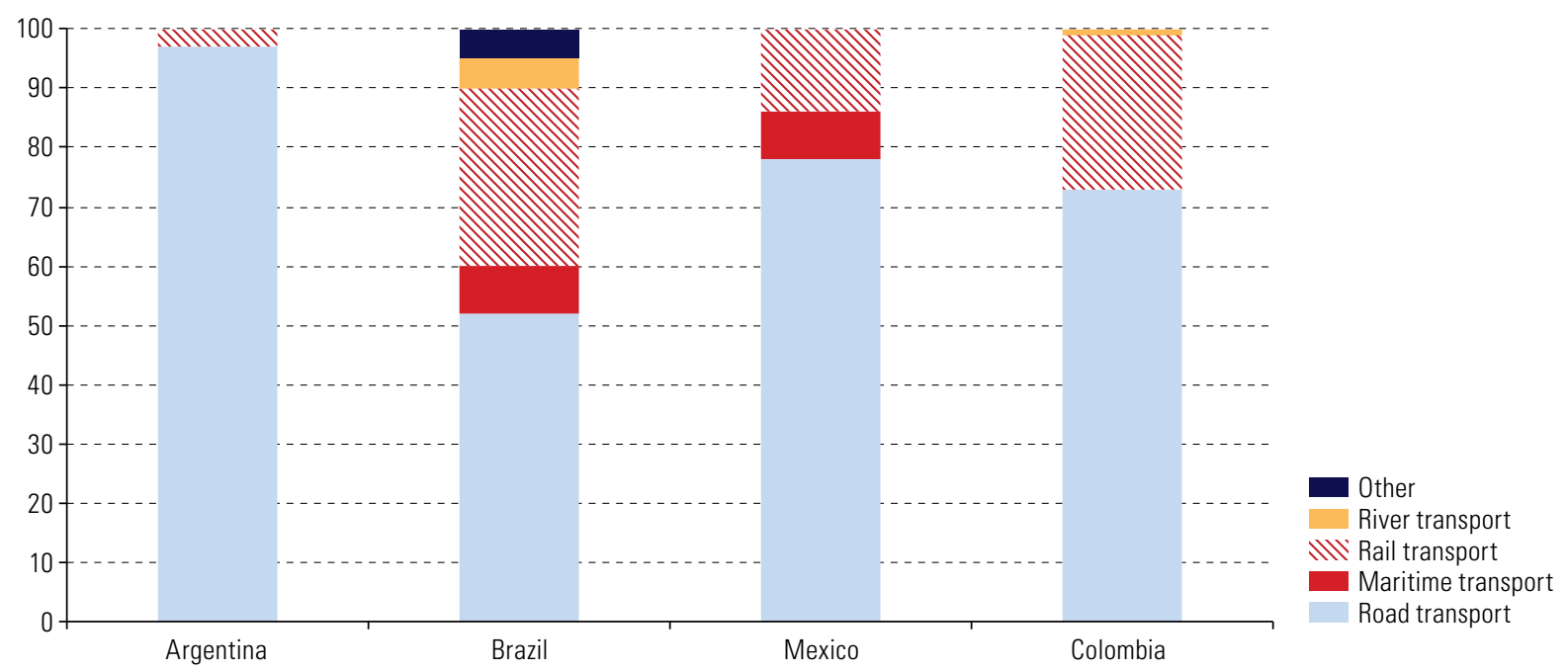

Source: Economic Commission for Latin America and the Caribbean (ECLAC), on the basis of national statistics.

Note: The data for Colombia are measured in tons.

The modal split entails large losses in terms of energy efficiency and heavy consumption of non-renewable energy with high carbon emissions. By contrast, the region's advantages in the river and rail modes of transport are underused in terms of capacity, complementarity and energy use. ${ }^{6}$

6 The 30,000 metric tons transported by 1,000 trucks could be transported on one barge or in 24 trains. With the same amount of diesel (1 t consumed by a truck with a 1-ton load in travelling $241 \mathrm{~km}$, a barge can travel over four times further ( $991 \mathrm{~km})$, and a train, more than three times (769 km) (Permanent Commission of Transportation of the River Plate Basin, 2015). 
That space for public investment policy has not been adequately exploited. Insufficient road connectivity, unequal access to basic and advanced infrastructure services and patterns of environmental unsustainability reveal the limitations of the traditional approach taken by public investment policies in the region. A key problem is the insufficiency of resources: the highest rate of investment in infrastructure occurred in the 1980s when it averaged $3.6 \%$ of GDP, peaking at $4.1 \%$ of GDP in 1987 (see figure V.6).

\section{Figure V.6}

Latin America (6 countries): infrastructure investment by sector (public and private), 1980-2015

(Percentages of GDP)

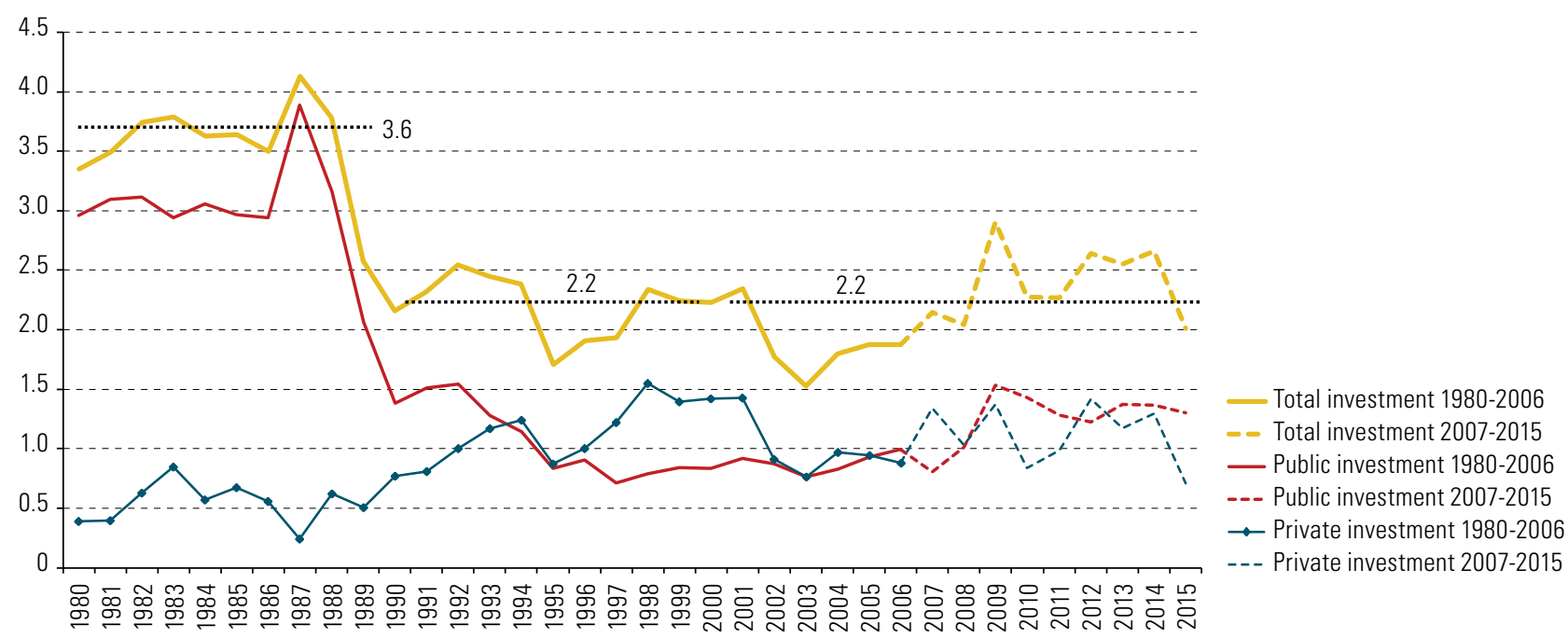

Source: Economic Commission for Latin America and the Caribbean (ECLAC), on the basis of C. Calderón and L. Servén, "Infrastructure in Latin America", World Bank Policy Research Working Paper, No. 5317, Washington, D.C., World Bank, 2010 for the period from 1980 to 2006 and Economic Infrastructure Investment Data (INFRALATAM) [online] http://infralatam.info/ for the period from 2007 to 2013.

Note: The figure analyses the transport, energy, telecommunications, water and sanitation sectors. Only roads and railways are included in the transport sector, except in the case of public investments in Argentina, which include total transport. The energy sector includes only electricity.

a The countries included are Argentina, Brazil, Chile, Colombia, Mexico and Peru. Chile is not included in the 2015 data.

The lack of harmonized data hampers comparison between regions of the world; but transport estimates reveal the weak position of Latin America and the Caribbean in relation to the amount of infrastructure investment and its quality compared to other countries or regions. The ratio between the infrastructure component of the logistics performance index (LPI) and per capita investment in infrastructure lags between 2008 and 2015. Although the region invests a percentage of GDP similar to that of other regions or even higher, its per capita investment is even lower than in China, where, between 2007 and 2016, infrastructure was not only expanded but also received a quality upgrade (see figure V.7).

In Latin America, road infrastructure absorbs over $70 \%$ of all transport investment, leaving scant funding for the waterway and rail modes, which are more environmentally efficient (see figure V.8). 


\section{Figure V.7}

Per capita investment in transport infrastructure: roads and railways, 2008-2015

(Per capita investment in dollars (left scale) and infrastructure quality component in the logistics performance index (right scale)

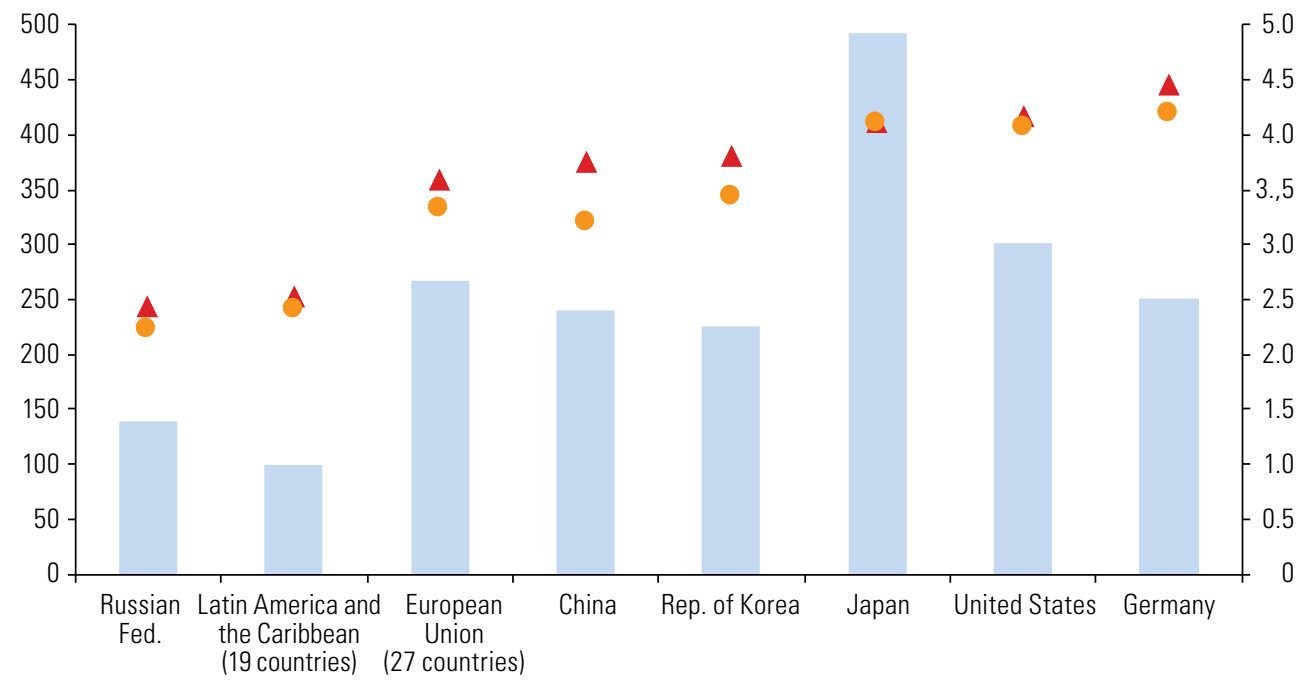

A Infrastructure quality, 2016

- Infrastructure quality, 2007

Per capita investment, 2008-2015

Source: Economic Commission for Latin America and the Caribbean (ECLAC), on the basis of Economic Infrastructure Investment Data (INFRALATAM) [online] http:// infralatam.info/; Organization for Economic Cooperation and Development (OECD) and World Bank.

\section{Figure V.8}

Latin America: infrastructure investment by mode of transport, 2008-2015

(Percentages of GDP)

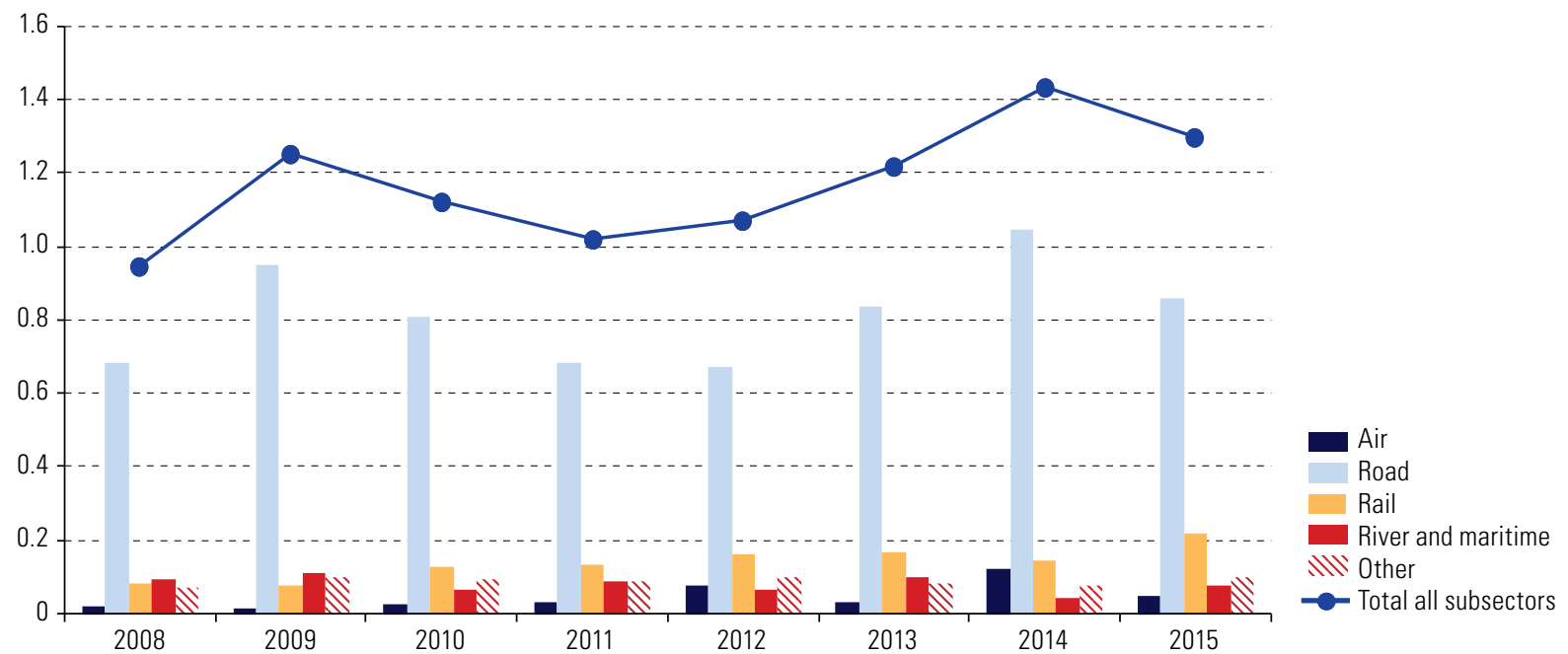

Source: Economic Commission for Latin America and the Caribbean (ECLAC), Natural Resources and Infrastructure Division, on the basis of Economic Infrastructure Investment Data (INFRALATAM) [online] http://infralatam.info/.

Investment in road infrastructure has been financed mainly with public funds, with the private investment contribution being made through public-private partnership (PPP) models. Roads account for a large proportion of infrastructure investment, unlike the situation in other countries, where the State promotes a better balance between the different modes of transport, especially through investment in railways (see figure V.9). 
Figure V.9

Infrastructure investment by mode of transport, 2008-2015

(Percentage shares of each subsector)

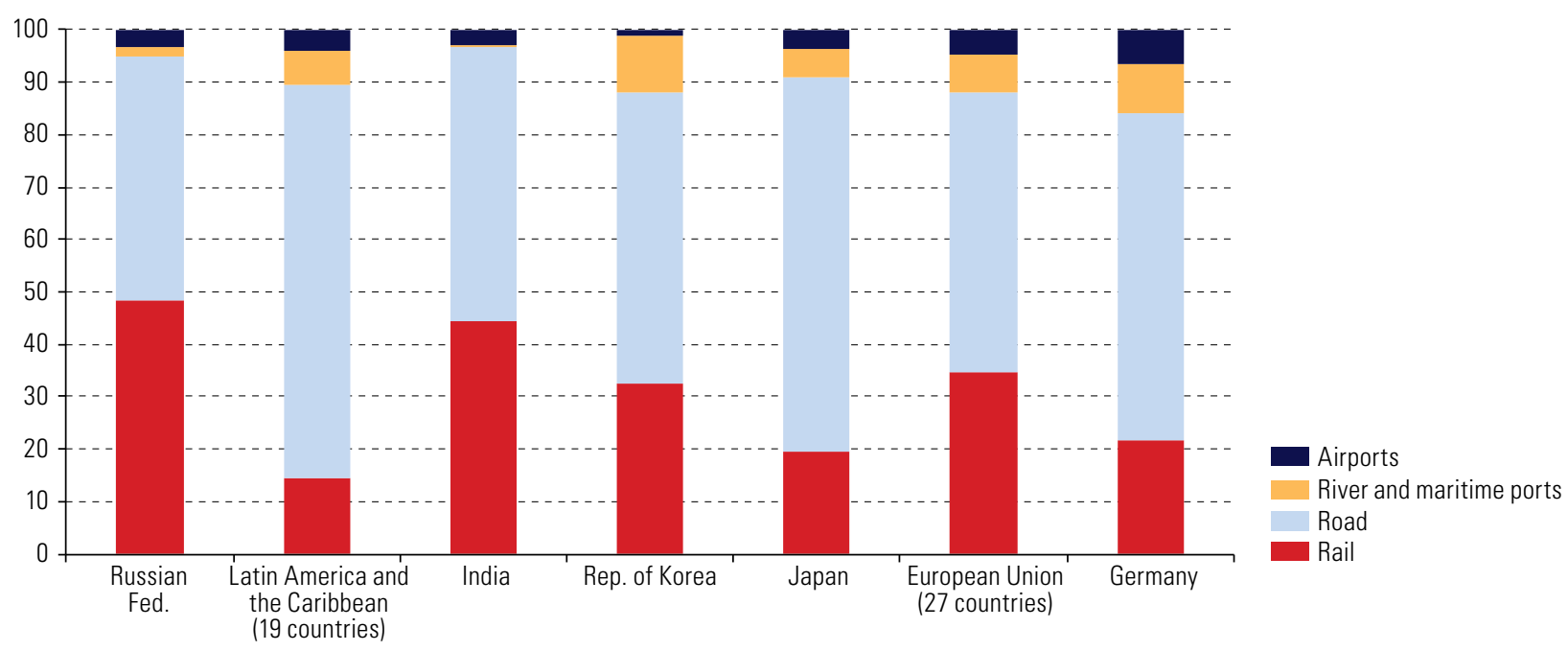

Source: Economic Commission for Latin America and the Caribbean (ECLAC), on the basis of data from the Organization for Economic Cooperation and Development (OECD) and World Bank.

According to the project information system of the South American Infrastructure and Planning Council (COSIPLAN), investment plans for the coming decade tend to maintain the bias towards roads and to reproduce the geography of economic infrastructure geared mainly towards commodity exports. New projects aim to expand capacity and upgrade infrastructure, but do little for network connectivity.

In short, the level and composition of infrastructure investment do not meet the needs of the twenty-first century but entrench patterns that generate problems of social, environmental and economic sustainability. In order for infrastructure to cease being a factor of inertia and reproducing inequalities and instead become an instrument capable of supporting new production patterns, greater territorial integration (both between and within the countries of the region) is needed to open up new opportunities for trade, together with investment in new, more energy-efficient transport modalities and efforts to close digital infrastructure gaps.

\section{The new rurality}

The rural world —conceptually broader than merely rural areas and defined as a territorial complex in interaction with the urban world and the different gradients that exist between the urban and the rural- has undergone major changes in recent decades. The new rurality in the region is not yet understood in all its economic, social, environmental and cultural complexity; and there is only partial awareness of its potential for building a development style that is compatible with the 2030 Agenda for Sustainable Development.

The relationship between the rural and the urban is often envisaged as a contrast, rather than an interaction in which possibilities exist for complementarity. The rural dimension is reduced to agricultural production; it is assumed that rurality is naturally trending towards extinction and that the migration of the rural population to other cities in the country or elsewhere is an inevitable fate. Accordingly, there is little appreciation of the new role of rural territories in combating climate change. Statistics underestimate the importance of the rural world and may overstate the real extent of urbanization in the region. A disaggregated analysis shows that many of the populations that are officially considered urban actually function around rural dynamics. 
The rural world and its territories comprise a highly diverse production fabric in which crop, livestock and forestry production are combined, sometimes more innovatively and sometime less, and these activities are increasingly integrated into value chains in which goods production is combined with the provision of environmental services. There are also different forms of occupation and employment: self-employment, wageearning work, rural residence with urban work or urban residence with rural work, and temporary and circular migration. In this tapestry of activities, traditional agricultural production coexists with small rural industries; subsistence and small farmers coexist with agribusiness complexes and even with large manufacturing firms; small infrastructure projects exist alongside development megaprojects; and producers that rely essentially on the land coexist with others that depend on lake resources and marine coasts. This shows that, in contrast to the image of the rural domain as static, it is actually in constant flux and interaction.

The distance separating the rural and urban worlds has diminished. In most countries of the region, investments in road infrastructure have reduced the distance and journey time between rural territories, urban capitals and large cities. The introduction and generalization of the use of digital technologies has narrowed the gap between the rural and urban worlds in terms of access to information, although significant connectivity gaps remain. Nonetheless, this reduction in distances has not been matched by a proportional reduction in territorial and welfare disparities. The rural world has a higher incidence, severity and intensity of poverty. It also displays the greatest lags in education, health, nutrition, social security and protection, access to drinking water and public services, quality of housing and life expectancy. The territorial inequalities discussed previously are partly an expression of those that exist between the rural and urban worlds. Addressing them thus requires an understanding of the specific features of the rural domain.

In addition to the foregoing, the rural world has undergone long-term sociocultural transformations, including the growing importance and the new roles of women, young people, indigenous peoples and Afrodescendent populations. Although significant gaps persist, rural women have been able to achieve higher education levels and engage more actively in production processes, including through the ownership or use of land. Rural youth is also better educated and has new expectations and aspirations; but young people often cannot find opportunities and life projects to match their new conditions and circumstances. Building an attractive rurality for young people is a major public policy challenge. Restoring the attractiveness of rural areas and achieving a new inclusive and equitable rurality is fundamental for rural territories to benefit from having more and better educated young people with a greater capacity for innovation.

In countries with large indigenous populations, such as Ecuador, Guatemala, Mexico or the Plurinational State of Bolivia, indigenous peoples are increasing in relation to the size of rural populations. Thus, the rural agenda increasingly overlaps with the indigenous agenda, which includes an integral vision of that world, as territory and habitat, and not only as a space and production resource. Nonetheless, public must also be formulated for rural Afrodescendent populations, which are significant in various countries and constitute one of the least visible social groups.

The construction of a new inclusive and sustainable rurality implies restoring the attractiveness of the rural world and involves two articulated, interdependent and complementary processes: first, a strategy to close rural-urban social gaps with policies to reduce inequalities, including improvement of the quality of public goods and services and a new generation of social security and protection that goes beyond conditional cash transfers; second, a strategy of progressive structural change that adds value to rural production and enhances job quality.

\section{B. Cities: dynamic centres that reproduce segmentation}

The increasing productivity and concentration of dynamic activities are occurring in the urban space. The centre-periphery dynamic is often reflected in an asymmetric rural-urban dynamic. It is also expressed in problems of poverty concentration in certain urban areas and, in many parts of the city, the absence of the public goods that the State should provide. The region's levels of urbanization are among the highest in the 
world —around $80 \%$, according to UN-Habitat (2016) — although the pattern is very uneven between countries and with respect to the population size of settlements that are classified as cities. ${ }^{7}$ Urbanization continues to increase, albeit less rapidly than in past decades (see figure V.10). Although urban concentration was consolidated in the twentieth century, its roots go back much further -in some cases as far as pre-Columbian times- depending on the patterns of political domination.

\section{Figure V.10}

Global urbanization trends: urban population as a percentage of the total, 1950-2050

(Percentages)

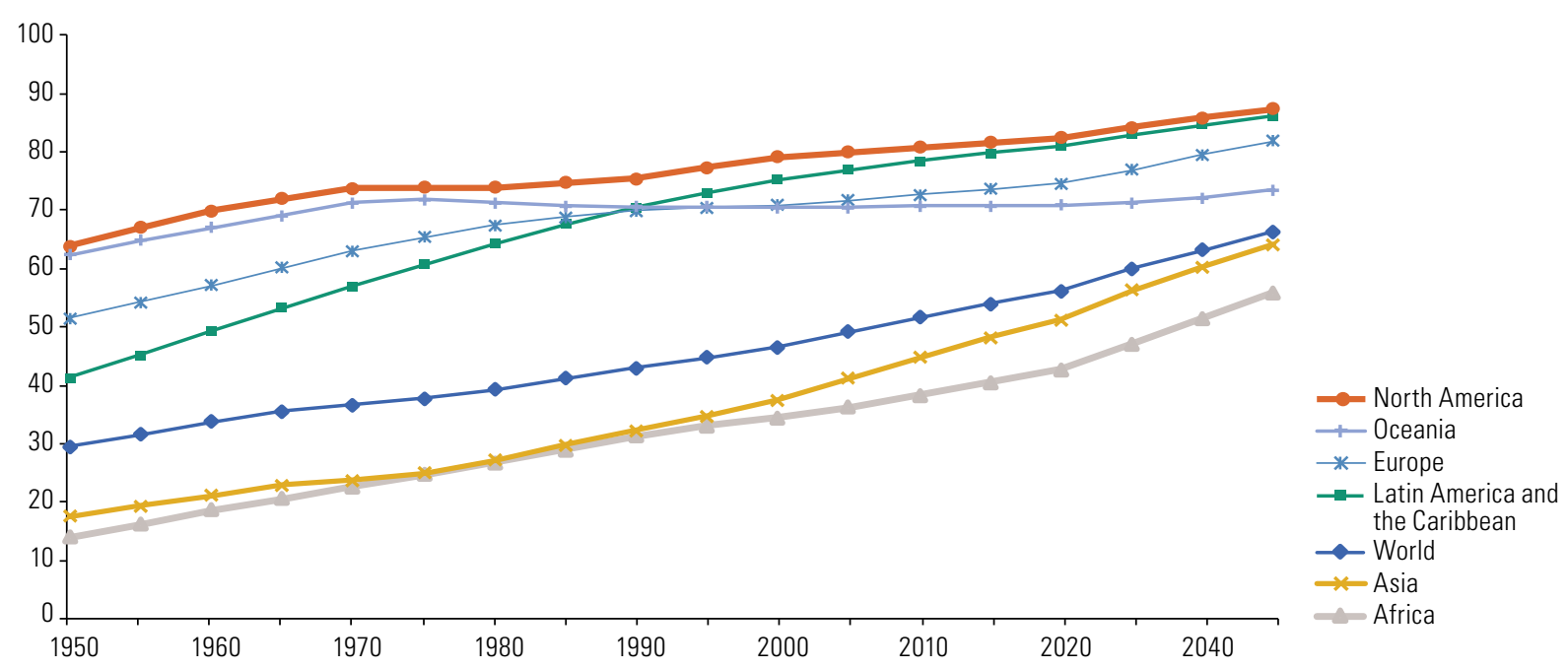

Source: United Nations, World Urbanization Prospects: The 2014 Revision(ST/ESA/SER.A/366), New York, 2015.

The region is home to four megacities which, together with their metropolitan areas, have more than 10 million inhabitants: two of them (São Paulo and Mexico City) were among the 10 largest in the world in 2015; and another two —Rio de Janeiro and Buenos Aires - were among the 20 largest. ${ }^{8}$ The relative share of cities with over 1 million inhabitants increased from 13\% in 1950 to $36.3 \%$ in 2010 (see figure V.11); in this context, the most dynamic group was that of cities of between 1 million and 5 million inhabitants, which grew from $16 \%$ in 1975 to $24.8 \%$ in 2015 , while the over-10 million segment, which grew vigorously until 1995, declined slightly thereafter.

Urbanization in the region has been accompanied by large and persistent socioeconomic disparities in income and other dimensions of inequality: high levels of residential segregation; insecurity, which affects the poorest disproportionately; inequality in urban mobility; possibilities for accessing public spaces and green areas; and the various consequences of environmental pollution. Income inequality affects cities acutely: the total income share of the wealthiest population quintile ranges from $40 \%$ in Montevideo, La Paz (Plurinational State of Bolivia) and Caracas, to close to $60 \%$ in Santiago, Brasilia and Santo Domingo. This inequality is a further reflection of the persistence of the culture of privilege and its new norms.

Inequality in the distribution of income, as measured by the Gini coefficient, varies across countries. While in 11 of the 18 countries included in figure V.12, the capital cities displayed less inequality than at the national level, in the other 7 the opposite was the case. The tendency towards declining inequality recorded in the region in the 2000 decade was also visible in the capital cities. In 10 cases, The Gini coefficient decreased by more than $1 \%$ per year in 10 cases, and by more than $2 \%$ in 5 (La Paz, Managua, Lima, Buenos Aires and Panama City), as reported in Jordan, Riffo and Prado (2017).

7 For example, the National Institute of Statistics and Geography of Mexico (INEGI) considers settlements of at least 2,500 people to be urban areas; while the National Geographical Institute of Argentina (IGN) uses a threshold of 2,000 people for this category.

8 Bogotá and Lima could grow to that size in the coming years. 


\section{Figure V.11}

Latin America and the Caribbean: proportion of the total urban population living in cities of over 1 million inhabitants, 1975-2015

(Percentages)

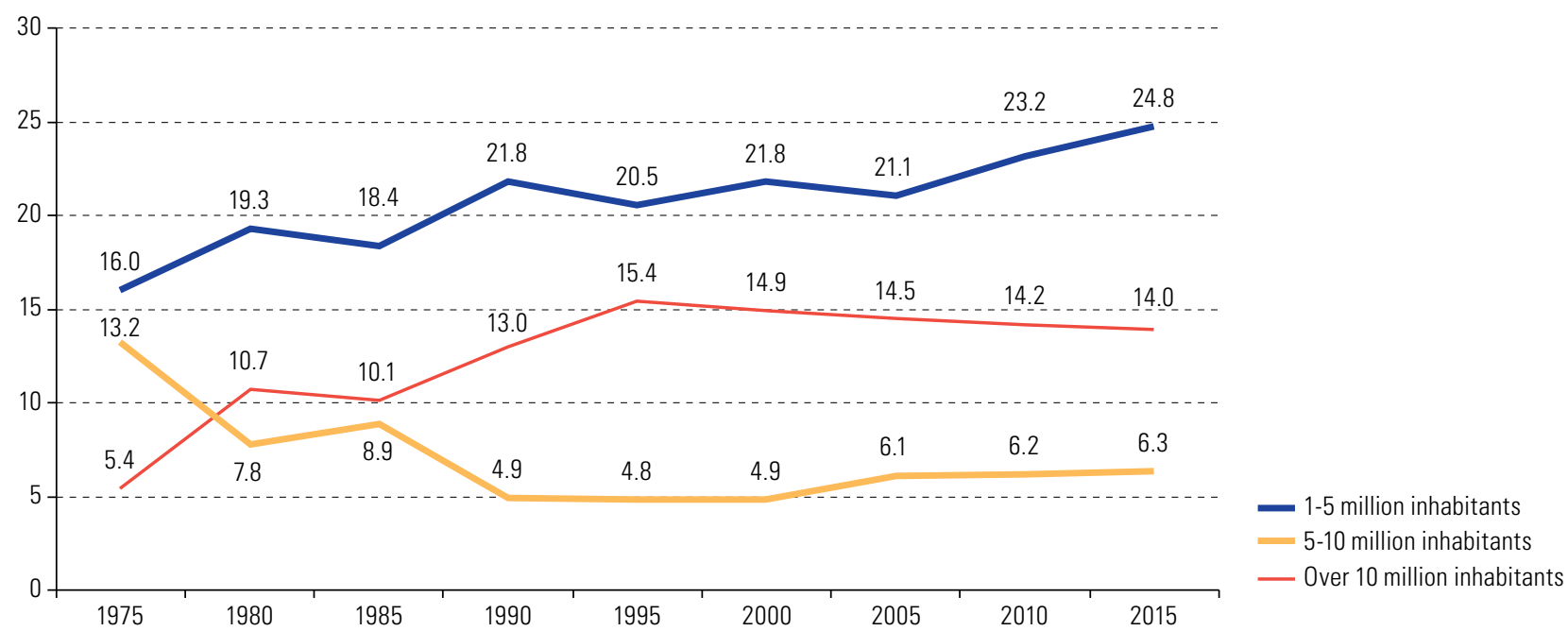

Source: Economic Commission for Latin America and the Caribbean (ECLAC), on the basis of data from the United Nations Population Division.

Figure V.12

Latin America and the Caribbean (18 countries): Gini coefficient by geographic area, 2013

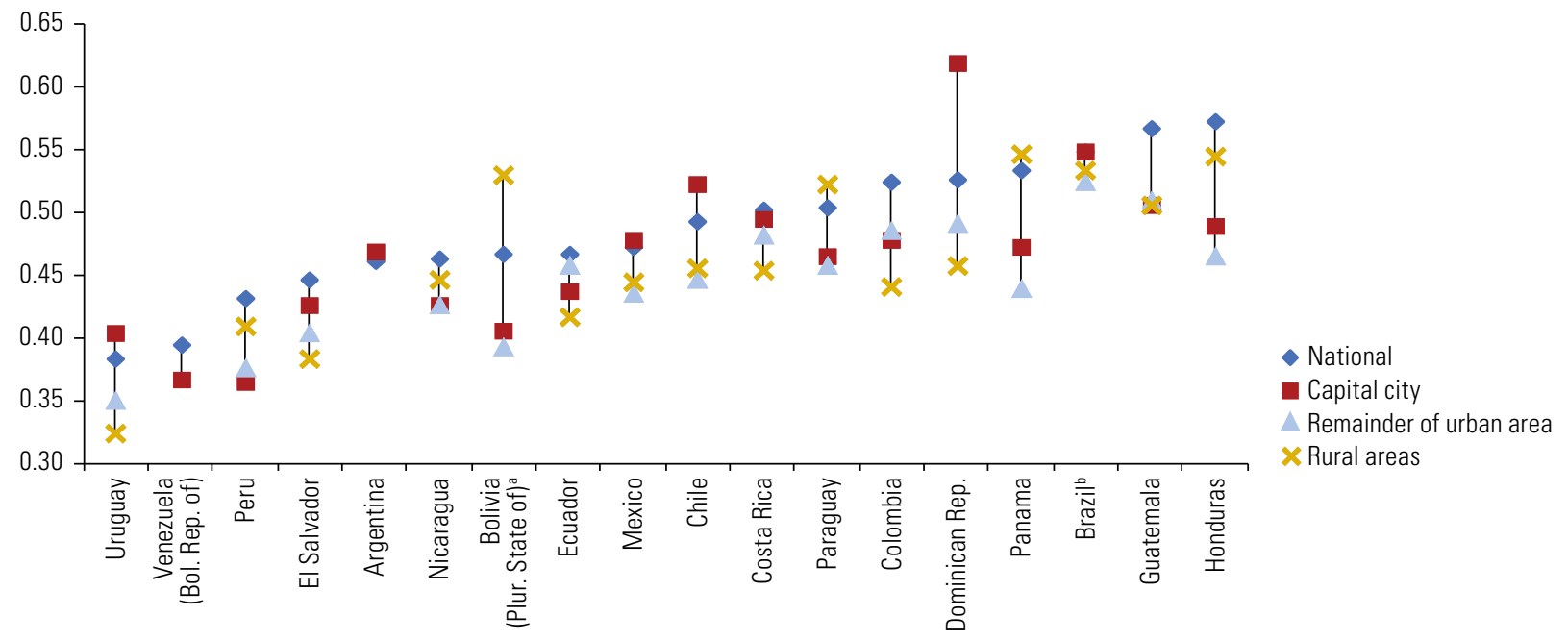

Source: R. Jordán, L. Riffo and A. Prado (coords.), “Desarrollo sostenible, urbanización y desigualdad en América Latina y el Caribe: dinámicas y desafíos para el cambio estructural", Project Documents (LC/PUB.2017/19), Santiago, Economic Commission for Latin America and the Caribbean (ECLAC), 2017.

a The data for the capital city refer to La Paz.

${ }^{b}$ The data for the capital cities refer to Brasilia, São Paulo and Rio de Janeiro.

Although the largest Latin American cities are dynamic centres in their own countries, they lag behind their peers in other parts of the world, with much lower average productivity than in cities of the developed world. Average productivity per employee in the metropolitan areas or regions of Mexico City, Buenos Aires, Santiago or São Paulo ranges between US\$ 30,000 and US\$ 40,000 per year; while in Oslo, San Francisco 
(United States), Paris or Washington D.C., it exceeds US\$160,000 per year (see figure V.13). In addition to the respective degrees of development, this disparity is explained by patterns of production specialization, policies and patterns of land use and inefficiency in the urban transport system -factors that are discussed below. This is another reflection of the technological and productivity gap that prevents the region from attaining the international frontier.

Figure V.13

Average labour productivity in selected cities, 2010

(Thousands of dollars)

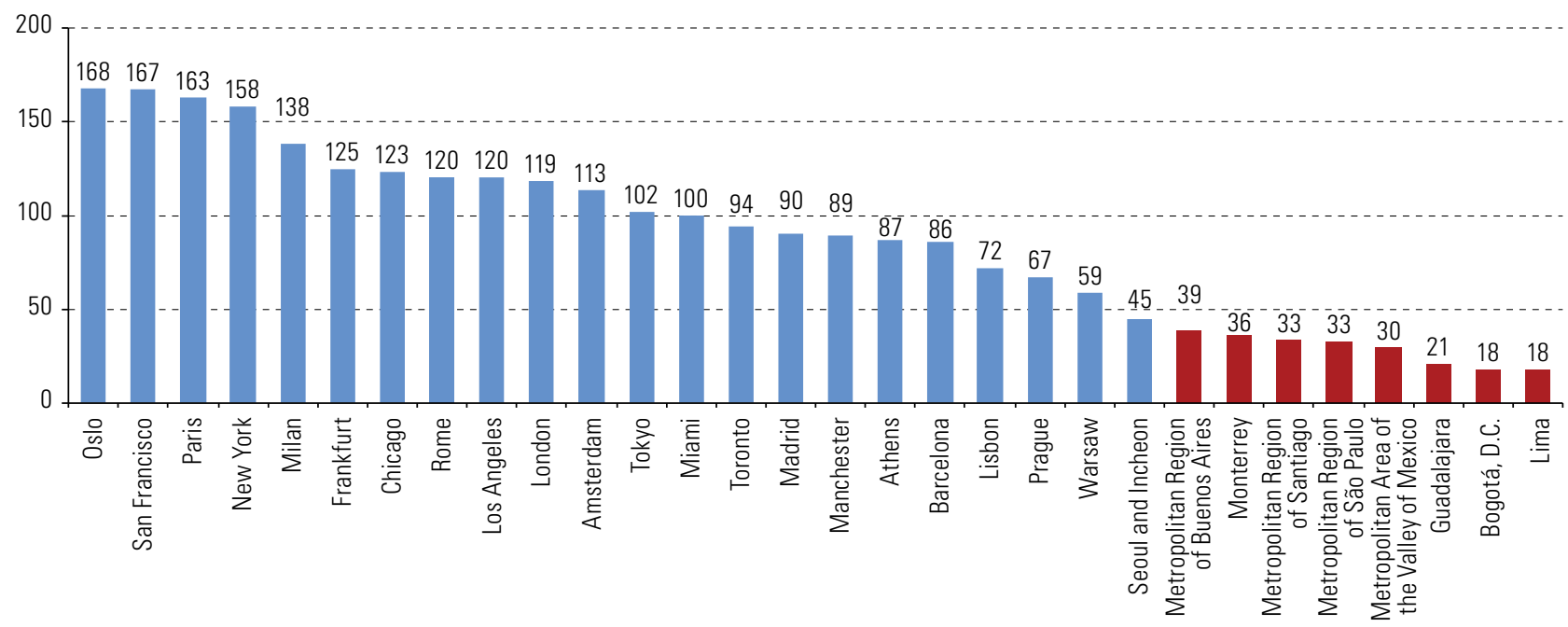

Source: Economic Commission for Latin America and the Caribbean (ECLAC), on the basis of official statistics from the countries and Organization for Economic Cooperation and Development (OECD), OECDStat.

\section{Old gaps and new ones}

Urban infrastructure shortcomings occur not only in road connectivity. There are internal disparities in access to basic drinking water and sanitation infrastructure, which are amplified in the comparison between rural and urban areas. No less important, given its productivity impact, is the lag in certain components of digital infrastructure, which is crucial for maintaining competitiveness in the context of the ongoing technological revolution.

\section{(a) Gaps in core services}

Sanitation coverage is broader among households in the highest income quintile than in the lowest quintile; and the gap is much wider in rural areas than in the cities. Disparities in access to electric power differ considerably between countries and they are notably high in El Salvador and Guatemala (see figures V.14 and V.15).

These gaps are also qualitative. The means by which water and sanitation are provided in the lowest-income households does not compare in technological quality to water provision in higher-income households (for example, a standpipe or public fountain some distance from the house, a well or delivery truck, compared to a household connection to the drinking water network; or a latrine or septic tank, instead of a household connection to the sewerage network). Moreover, access to water is often intermittent and vulnerable to interruptions caused by droughts or other factors. 


\section{Figure V.14}

Latin America and the Caribbean (17 countries): differences in sanitation coverage between urban households in the highest and lowest income quintiles

(Percentage points)

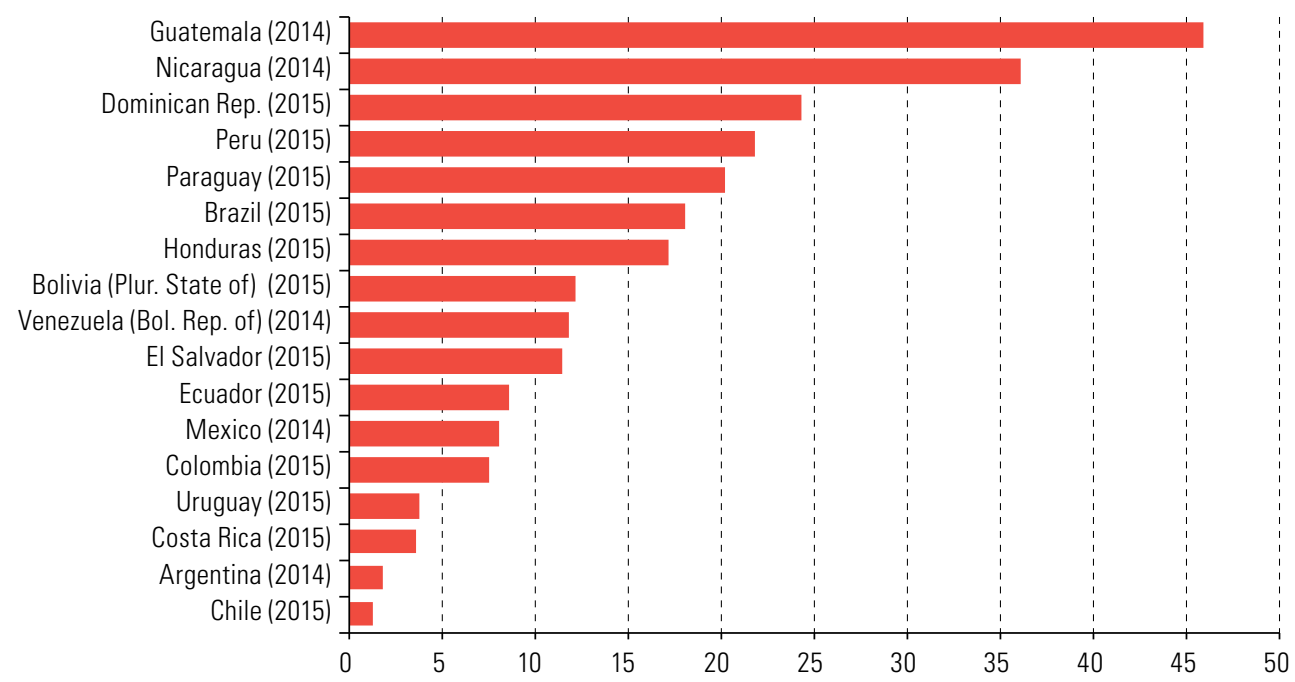

Source: Economic Commission for Latin America and the Caribbean (ECLAC), on the basis of Household Survey Data Bank (BADEHOG).

Figure V.15

Latin America and the Caribbean (15 countries): access to electric power among urban households in the highest and lowest income quintiles

(Percentages)

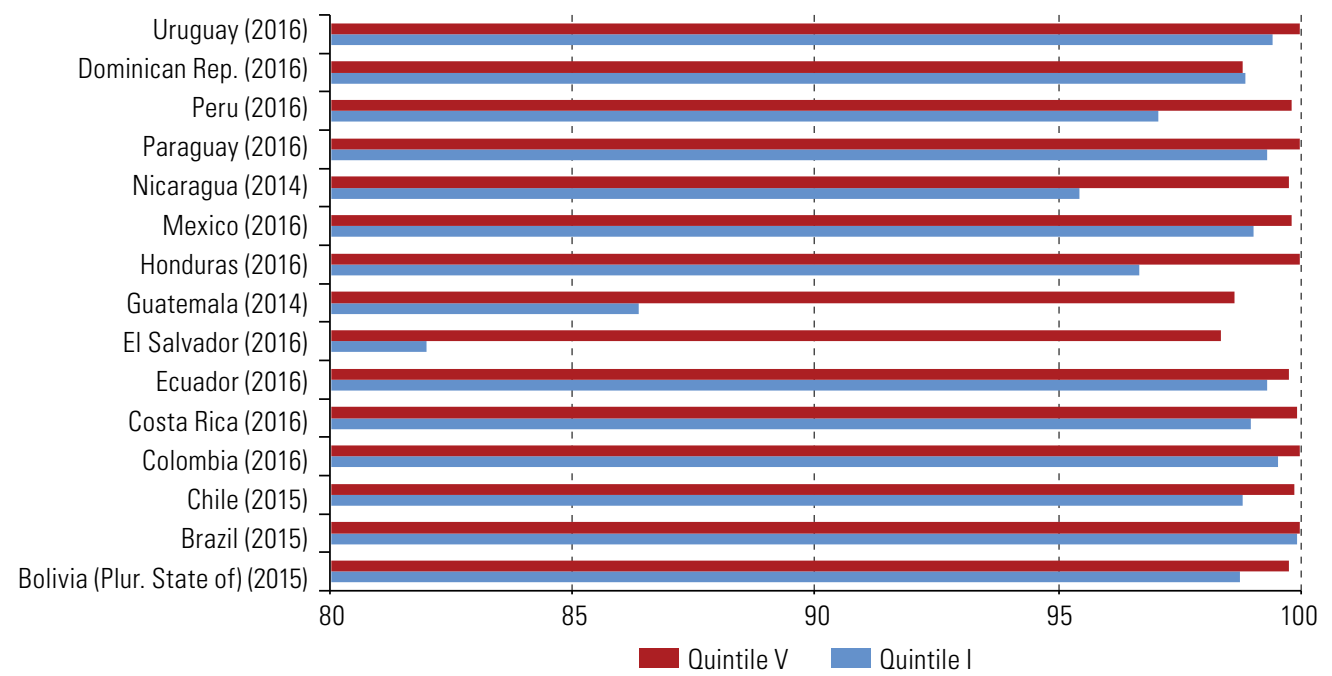

Source: Economic Commission for Latin America and the Caribbean (ECLAC), on the basis of Household Survey Data Bank (BADEHOG).

\section{(b) Shortcomings in digital infrastructure}

Major disparities by income level exist in the most advanced services as well (see figure V. 16). Although Internet access has increased in nearly all quintiles in recent years, the difference in the number of households with access to this technology between the highest (fifth) and lowest (first) income quintile remains egregious: nearly four times more in Chile and Costa Rica; between eight and nine times in Uruguay, Ecuador and Brazil; 
21 in the Plurinational State of Bolivia, and 45 times in Peru. This hinders online access to health, education and government services, and impairs e-commerce among Latin American countries, which could become a tool for regional integration, particularly in the area of digital goods and services. All these services and applications require quality infrastructure and generalized access to it.

Figure V.16

Latin America (9 countries): households with Internet access by income quintile, around 2011 and 2015

(Percentages)

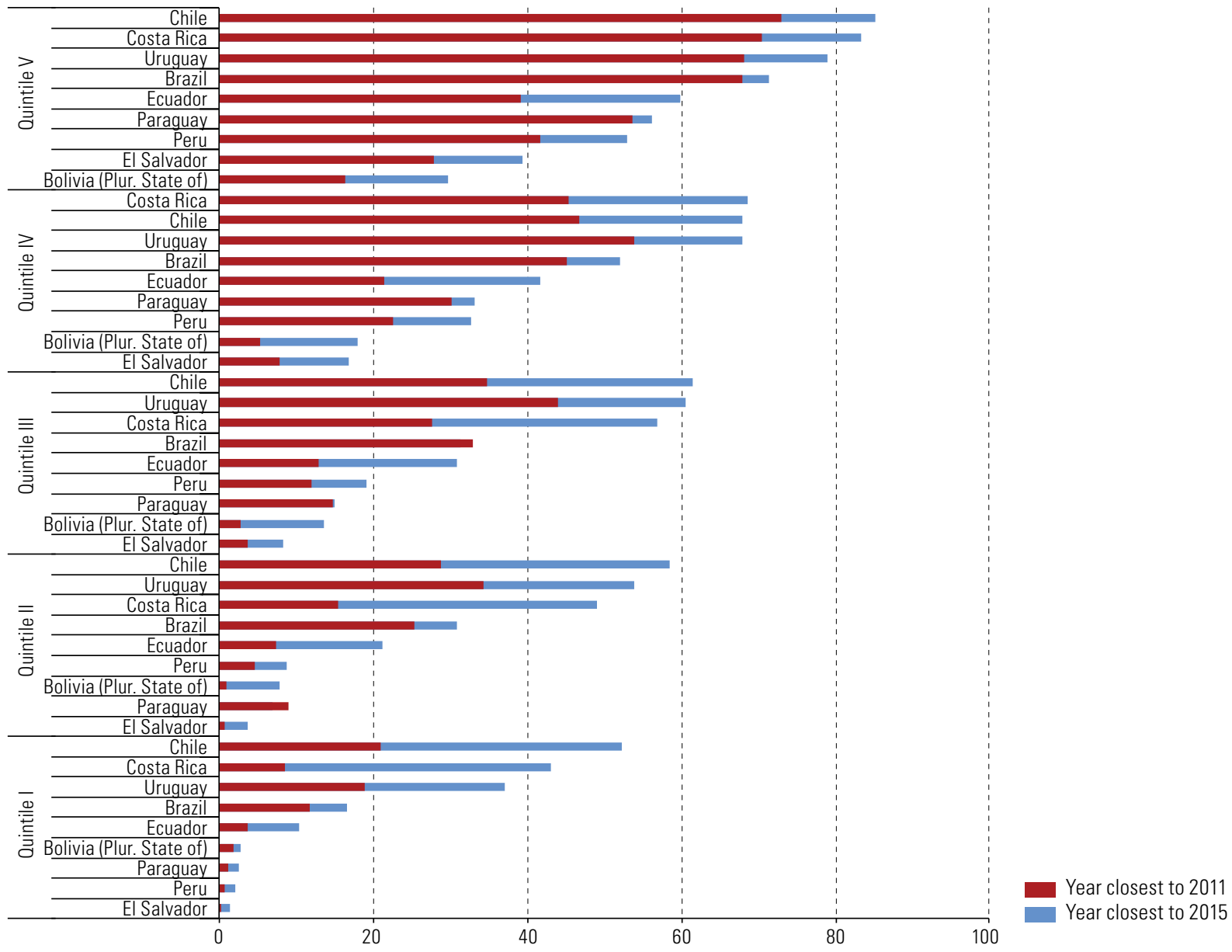

Source: Economic Commission for Latin America and the Caribbean (ECLAC), Regional Broadband Observatory (ORBA), on the basis of household surveys.

Note: The methodology used to calculate household per capita income was altered between the periods considered. The types of Internet connection that are included in the different countries are the following: in Paraguay, Internet by cable or wi-fi and Internet by USB modem; in Ecuador, dial-up, dedicated line, cable modem and mobile broadband (MBB); in Uruguay, fixed-line broadband (FLB), MBB and dedicated line; in Chile, fixed broadband (FBB) and MBB, either contracted or prepaid, in addition to mobile phone or another mobile device. In Costa Rica, the question is posed per housing unit, which could include more than one household.

In the first quarter of 2017, in a sample of 18 of the region's countries, network coverage was over $90 \%$ for $3 \mathrm{G}$, and around $70 \%$ for $4 \mathrm{G}$. Nonetheless, there is still a wide demand gap (coverage minus effective demand for the service), since the average number of subscribers is only $53 \%$ of the population covered.

The quality of broadband connections depends on their speed, which determines which services and applications may be accessed. ${ }^{9}$ The region displays significant differences, for example speeds almost

9 To measure quality more precisely, this parameter is combined with others, such as latency and the latency variability (jitter) rate. 
six times higher in Chile and Uruguay than in Paraguay, where speeds are slowest (see figure V.17). Nonetheless, speeds in even the most advanced countries in the region are only around half the average for the countries of the Organization for Economic Cooperation and Development (OECD). This indicates that the infrastructure gaps analysed above are also present in the infrastructure that is supposed to support the technological revolution.

\section{Figure V.17}

Latin America (12 countries): Internet connection speeds, fourth quarter of 2016

(Megabits per second (Mb/s))

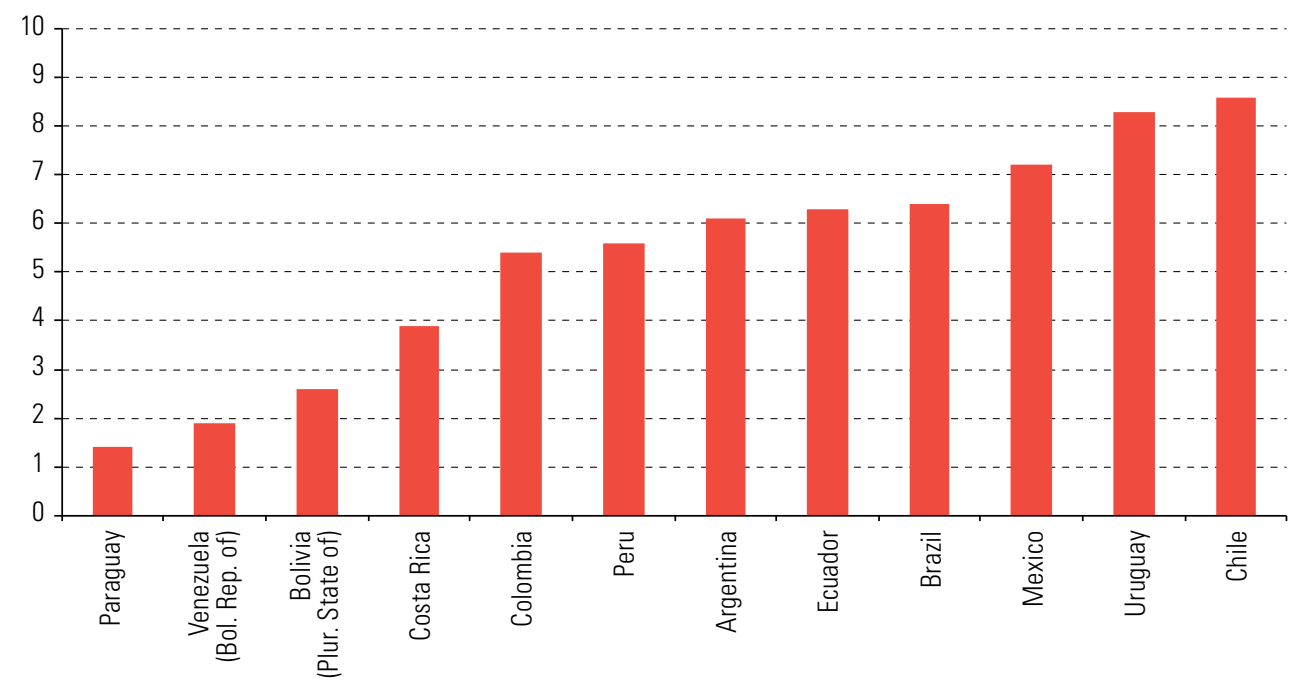

Source: Economic Commission for Latin America and the Caribbean (ECLAC), Regional Broadband Observatory (ORBA), on the basis of Akamai Technologies, Akamai's State of the Internet. 012016 Report, vol. 9, No.1, Cambridge, June 2016.

\section{Segregation is a denial of the right to the city}

\section{(a) Residential segregation}

Between 2000 and 2015, a process of rapid urbanization unfolded in the region, during which land consumption per capita increased and, with it, inefficiency in the use of the environment and space. Urban sprawl also increases the costs of water, electricity, transport, communication and road networks. As the urban area expands and population density decreases (see figure V.18), the social cost per inhabitant rises (ECLAC, 2017a), along with the rents appropriated by real estate activity. Inefficiency and inequality once again go hand in hand, since the expansion of the urban area is associated with urban segregation as the wealthiest segments self-isolate, and the poorest are driven out towards certain peripheral areas (ECLAC, 2014b).

Although middle- and high-income groups also migrate within urban or metropolitan areas to outlying urban areas, this does not produce a systematic reduction in residential segregation or an increase in social interaction between the socioeconomic groups living in these outlying areas (ECLAC, 2014b). Moreover, the tendency of middle- and high-income segments to use private services, and the privatization of public spaces (an example of this trend is the proliferation of gated condominiums and neighbourhoods) reinforce the pattern of segregated and fragmented cities (Caldeira, 2000) and prevent social mixing. 


\section{Figure V.18}

Latin America: urban density in selected cities, 1990-2014

(Persons per hectare)

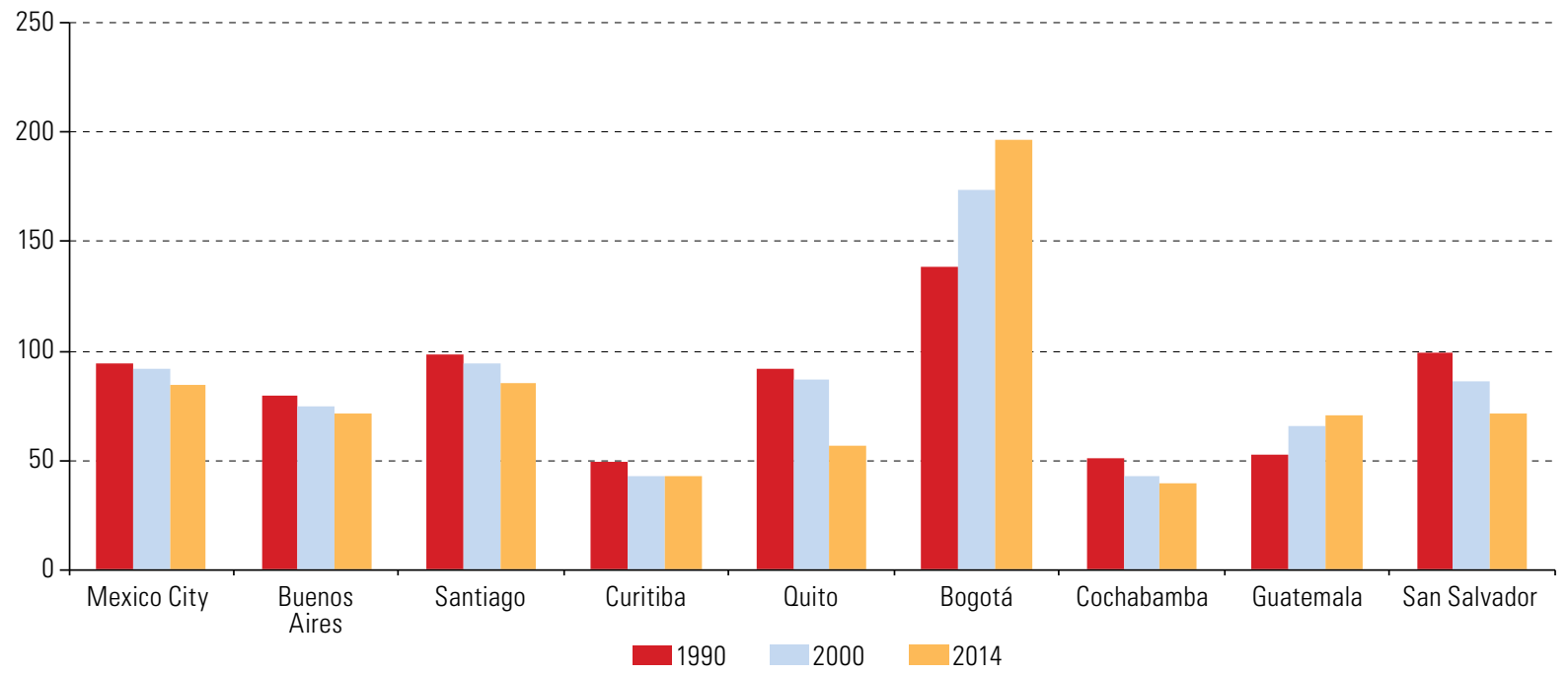

Source: Economic Commission for Latin America and the Caribbean (ECLAC), on the basis of S. Angel and others, Atlas of Urban Expansion, Cambridge, Massachusetts, Lincoln Institute of Land Policy, June 2012.

Note: The data for 2014 refer to the nearest year available.

Disparity in access to quality housing and urban land is another factor that increases urban inequality. Many countries have implemented demand-side subsidy schemes to reduce the housing deficit. Although these have indeed reduced the shortage, they have also had adverse effects in terms of peripheral expansion and socioeconomic residential segregation. The abandonment of housing is a clear symptom of the inefficiency of formulating housing policy separately from urban policy. For example, in 2010, there were 5 million abandoned dwellings in Mexico, representing 14\% of the country's total housing stock. The causes of abandonment included international migration, insecurity and local unemployment; but also the effects of subsidized public housing policies, since $80 \%$ of public mortgage loans granted between 2006 and 2010 were in municipalities with higher levels of uninhabited housing (Sánchez and Salazar, 2011). Among the causes of abandonment, $38 \%$ of respondents cited the lack of services, and $31 \%$ referred to distance to their place of work or study (UN-Habitat, 2011, p.51). ${ }^{10}$

In addition, inefficient urban land management, compounded by insufficient investment in water and sanitation services, contribute to the persistence of high-cost slums whose inhabitants frequently face higher risks of exposure to contagious or communicable diseases and natural disasters, which are in turn made more frequent by climate change. ${ }^{11}$ Moreover, the public policy costs are high, since regularizing informal urban land occupation is expensive. The proportion of the region's population living in slums fell from $34 \%$ in 1990 to $21 \%$ in 2014 (see figure V.19). In terms of absolute numbers however, although 2 million people left the slums, over 100 million still live in such settlements.

10 The Bolivarian Republic of Venezuela, Brazil and Chile also have significant rates of uninhabited housing $-9.02 \%, 9.6 \%$ and $7.7 \%$ of total housing units, respectively (López Moreno, 2014).

11 The term "slums" refers to dwellings known variously as "villas miseria", "pueblos jovenes", "encamentos", "cantegriles" or "favelas", among other terms. 
Figure V.19

Latin America and the Caribbean: urban population living in slums, 1990-2014

(Millions of persons and percentages)

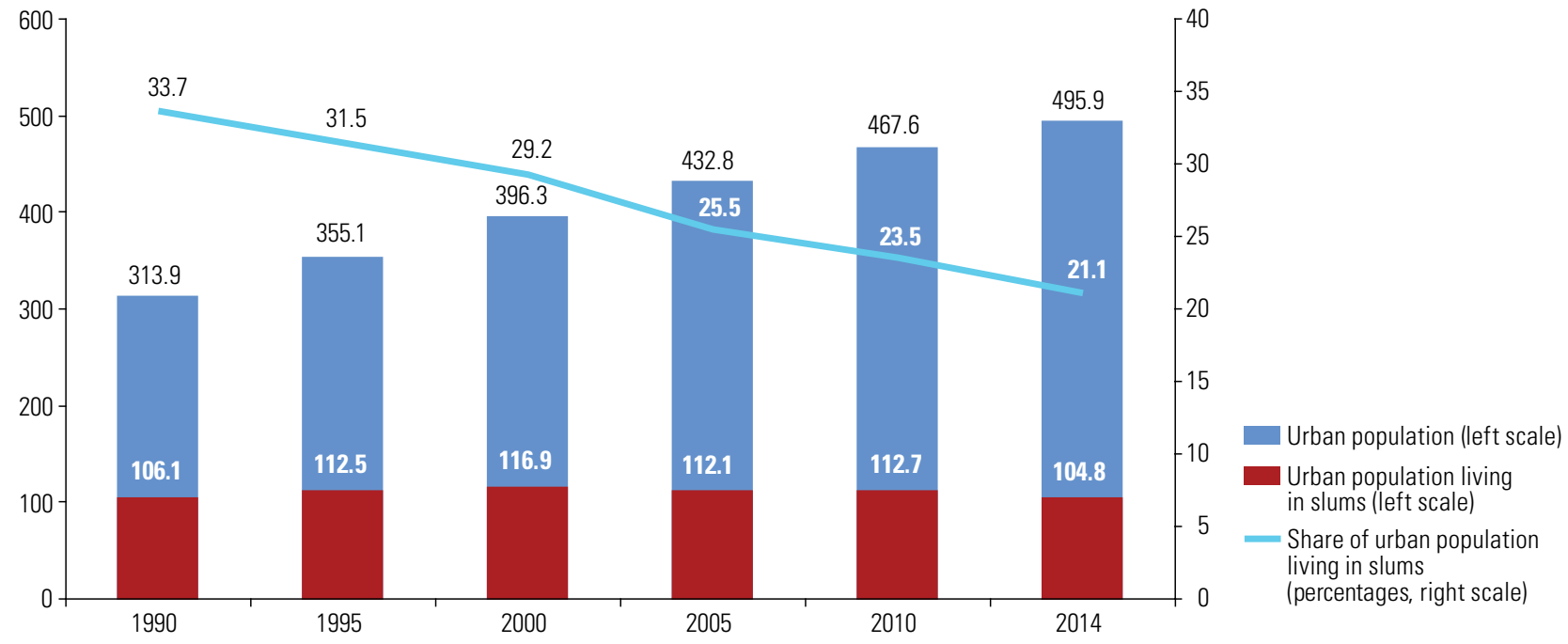

Source: United Nations Human Settlements Programme (UN-Habitat), "Global Urban Indicators Database", Nairobi [online database] https://unhabitat.org/books/ global-urban-indicators-database/.

\section{(b) Right to the city}

The unequal and excluding nature of cities has led to forceful vindication of the right to the city, thanks largely to the momentum of social movements, both in the countries of the region and internationally. This is exemplified by the negotiation of the New Urban Agenda, adopted at the United Nations Conference on Housing and Sustainable Urban Development (Habitat III), held in 2016.

The right to the city ${ }^{12}$ is a collective right founded on democratic control over the urban development process; in other words, it is a broader right than the individual freedom to access urban goods and services (Lefebvre, 1968 Harvey, 2008). In addition to emphasizing the public nature of the city, the right to the city offers a framework for addressing specific and serious problems in the region: unequal access to urban land, adequate housing and quality services and facilities, the lack of which produces adverse environmental impacts, in addition to social effects.

Policies approach the right to the city from two angles: first, citizen participation in urban management -the "right to participate" - which includes innovative experiences, such as the participatory budgets that have emerged in the region; second, the promotion of inclusive cities through urban regulations - the "right to inhabit" - (Fernandes, 2007). With respect to the latter, several of the region's countries (the most advanced being Brazil, Colombia and Ecuador) have developed urban legislation to support the application of land management and urban planning instruments aimed at offering well located social housing, investing in infrastructure with social inclusion objectives and urbanizing informal settlements. Moreover, thanks to the legal recognition of the social function of urban property, some cities, such as São Paulo, have been able to develop financing mechanisms based on the capital gains of urban land and instruments based on building rights that have become an important source of financing for urban infrastructure. ${ }^{13}$ In addition to national legislation, some city-level

12 The United Nations system does not have an official definition of the right to the city. Given the lack of consensus on the definition and acceptance of this right among Member States, the New Urban Agenda refers to this concept as "Cities for all." Resolution A/HRC/35/L.30/Rev. 1 of the Human Rights Council, adopted in June 2017, defines "Cities for all" by invoking concepts that also appear in the urban legislation of several of the region's countries and cities, such as the social function of the city. The resolution thus reaffirms "the vision of cities for all, referring to the equal use and enjoyment of cities and human settlements, seeking to promote inclusivity and ensure that all inhabitants, of present and future generations, without discrimination of any kind, are able to inhabit and produce just, safe, healthy, accessible, affordable, resilient and sustainable cities and human settlements to foster prosperity and quality of life for all, that envisages cities and human settlements that, inter alia, fulfil their social function."

13 This is also the case with the sale of certificates of additional construction potential (CEPAC) in São Paulo. 
regulations incorporate the concept of the right to the city. A prominent example is the 2017 Political Constitution of Mexico City, ${ }^{14}$ which emphasizes the right to the city among a broad spectrum of guaranteed rights. ${ }^{15}$

Despite these advances in regulatory frameworks and policies in several of the region's countries and cities, the experience of the past few decades shows that urban inclusion instruments and policies have not been applied uniformly or consistently across different cities, or even between successive administrations of the same city.

\section{Urban mobility as an expression of inequality}

\section{(a) Urban mobility patterns}

The urban mobility situation provides a further example of inequality, production and energy inefficiency, and environmental deterioration. Although $60 \%$ of the population in the region's metropolitan areas travel on foot, by bicycle or on public transport, societies overall spend three times more on private vehicles than on collective transport systems. ${ }^{16}$ The automobile occupies 30 times more space per person transported than a bus and five times more than a bicycle (ECLAC, 2017a). At the same time, a bus ride lasts between $50 \%$ and $220 \%$ longer than a car journey, as a result of spatial segregation and public mobility systems that favour higher-income sectors (CAF, 2016a).

There are gender differences in the modal split of urban mobility: public transport and walking represent larger shares of women's journeys than men's, while travel by car or motorcycle is more frequent among men than women (Jaimurzina, Muñoz and Pérez-Salas, 2015). In addition to its adverse environmental impact, encouraging private motorized transport prioritizes men's mobility patterns; whereas improving the quality of public transport by reducing journey times would contribute to gender equality in cities, among other benefits.

There is ample room to increase the share of cleaner modes of public transport. According to the Observatory of Urban Mobility ${ }^{17}$ of the Development Bank of Latin America (CAF) (2015), 56.4\% of daily journeys are made by public transport, and of these, electric trains and metros account for approximately $16 \%$. In the 29 cities included in the Observatory, Vasconcellos and Mendonça (2016) note that $49 \%$ of the spaces assigned to collective transport are used by buses, $7.5 \%$ by meters and $4.6 \%$ by urban trains. Thus, with $12.1 \%$ of the space, clean transport (metro and train) carries $16 \%$ of the public system's passengers. As proven sustainable mobility solutions, metro lines and trains offer important opportunities to invest in responding to urban mobility demand in a manner that is socially inclusive and environmentally efficient, which would make cities more competitive and dynamic.

Several major initiatives have recently been launched in the region to tackle urban congestion and pollution. In the early twenty-first century, systems with exclusive bus lanes were introduced. Although these experiences were successful, they have faltered due to the saturation of the services, and coverage and quality deficiencies have not been resolved. On the other hand, cable cars have been installed as a form of transport in cities such as Medellín (Colombia), La Paz (Plurinational State of Bolivia) and Ecatepec (Mexico); and the use of bicycles and their infrastructure has expanded (in Bogotá, Mexico City, Buenos Aires and Santiago, among others). Despite these advances, rising motorization rates suggest increasing pressures on public space and negative externalities (see figure V.20). The rise in the motorization rate in the region suggests a trend similar to that of the United States, where it is close to $80 \%$, or Norway, where it is close to $60 \%$.

14 Its main inspiration was the Mexico City Charter for the Right to the City. The Constitution refers to the guarantee of the right to the city and its objectives in sections devoted to development planning (article 15) and land regulation (article 16.c), which is thus made part of the processes that more directly govern the nature of urban development.

15 Article 12 states the following: (1) Mexico City guarantees the right to the city consisting of the use and full and equitable usufruct of the city, based on principles of social justice, democracy, participation, equality, sustainability, respect for cultural diversity, nature and the environment. (2) The right to the city is a collective right that guarantees the full exercise of human rights, the social function of the city and its democratic management, and ensures territorial justice, social inclusion and the equitable distribution of public goods with the participation of citizenship.

16 According to CAF (2009), "companies have invested very large sums to build roads and systems, and to purchase transport vehicles [...] the largest investments are made in private vehicles (63\%) and in urban roads (17\%). Investments in collective transport systems (rails and collective vehicles) account for $20 \%$ of the total."

17 The Observatory of Urban Mobility, which reports on 29 cities, began in 2009 with data from 15 metropolitan areas in nine of the region's countries: Belo Horizonte (Brazil), Bogotá, Buenos Aires, Caracas, Mexico City, Curitiba (Brazil), Guadalajara (Mexico), León (Nicaragua), Lima, Montevideo, Porto Alegre (Brazil), Rio de Janeiro (Brazil), San José, Santiago and São Paulo (Brazil). In 2016, another 14 cities were added: Barranquilla (Colombia), Brasilia, Cali (Colombia), Florianópolis (Brazil), Manaus (Brazil), Medellín (Colombia), Montería (Colombia), Panama City, Pereira (Colombia), Quito, Recife (Brazil), Rosario (Argentina), Salvador de Bahia (Brazil) and Santa Cruz de la Sierra (Plurinational State of Bolivia). The data for Montevideo were replaced by those of its metropolitan area. 


\section{Figure V.20}

Latin America (13 countries): motorization rate, per capita GDP and comparison with trends in the United States and Norway, 2005-2015

(Rate per 1,000 inhabitants and dollars in purchasing power parity at constant 2011 prices)

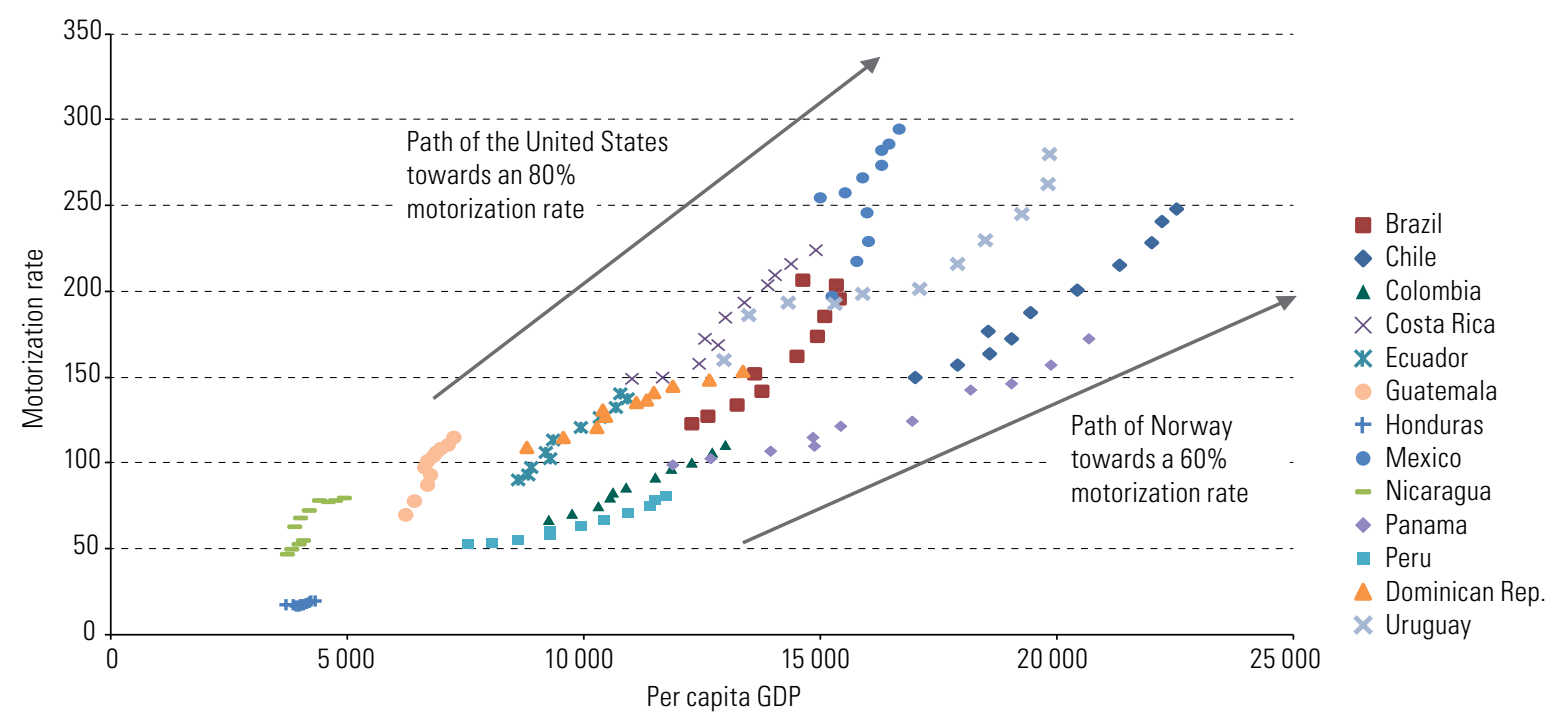

Source: Economic Commission for Latin America and the Caribbean (ECLAC), on the basis of information from International Organization of Motor Vehicle Manufacturers (OICA) and y World Bank, World Development Indicators.

Spatial segregation, congestion and lags in the implementation of adequate public systems lengthen travel times and cause users to shun these services (see figure V.21). ${ }^{18}$ This is driven by factors similar to those driving the flight from public to private services in education, health, safety and even drinking water.

\section{Figure V.21}

Latin America (12 metropolitan areas): travel time in private cars and buses, 2014

(Minutes per journey)

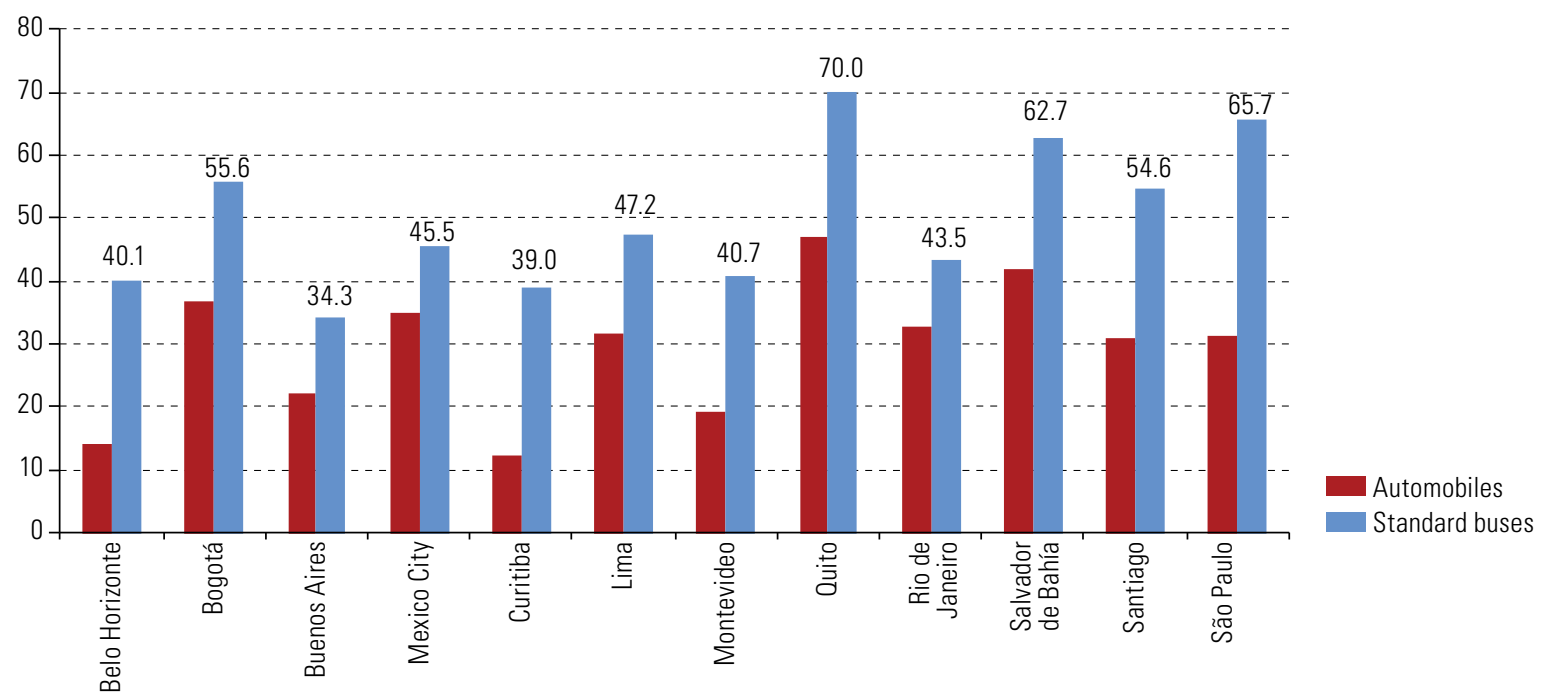

Source: Development Bank of Latin America(CAF), “Observatorio de Movilidad Urbana”, 2016 [online] https://www.caf.com/es/temas/o/observatorio-de-movilidad-urbana/.

18 The share of public transport in total transport has decreased in a sample of Latin American cities that include Montevideo, Quito, Santiago and São Paulo (Brazil) (CAF, 21016a). 


\section{(b) The environmental impact of the mobility model}

Beyond costs in terms of travel time, the inefficiency of the dominant modes of urban transport in the region affects the energy consumption pattern and, consequently, urban pollution and people's health. An individual automobile emits 2.5 times more $\mathrm{CO}_{2}$ per passenger than an equivalent trip by bus and five times more than by metro (ECLAC, 2017a).

In 2014, the use of individual motor vehicles (cars and motorcycles) in 29 large cities across the region consumed $66 \%$ of the energy used in the transport sector, while buses consumed $30 \%$ and rail vehicles $4 \%$. Roughly $94 \%$ of transport uses oil derivatives as an energy source (Enerdata, 2015), which slows the decarbonization of the energy mix. Although some countries, such as Chile, Costa Rica, Ecuador and Uruguay, have made progress in decarbonizing electricity production, significant effects have not yet fed through to the transport sector. ${ }^{19}$

Private transport is inefficient not only in terms of energy, but also in terms of pollution. Table V. 1 shows that individual transport is the leading cause of pollutant emissions, with the exception of nitrogen oxides $\left(\mathrm{NO}_{\mathrm{x}}\right)$. Urban transport as a whole is a major source of greenhouse gas $(\mathrm{GHG})$ emissions in the region, since it generates $38 \%$ of the $\mathrm{CO}_{2}$ emissions from the burning of fossil fuels, compared to $21 \%$ from electricity generation and $17 \%$ from industry (UN-Habitat, 2012). While transport produces $25 \%$ of fine particulates in suspension (PM2.5) in cities worldwide (Karagulian and others, 2015), the figure rises to 34\% in Brazil and $30 \%$ in the rest of the region. In the case of suspended particulates of up to 10 microns (PM10), transport is responsible for $38 \%$ of all emissions. Urban transport in Latin America and the Caribbean is more polluting than the world average.

Table V.1

Latin America and the Caribbean: pollutant emission by transport mode

(Percentages of the total per pollutant)

\begin{tabular}{|c|c|c|c|c|c|}
\hline Vehicle & Carbon monoxide (CO) & Hydrocarbons (HC) & Nitrogen oxides $\left(\mathrm{NO}_{\mathrm{x}}\right)$ & $\begin{array}{l}\text { Particulate matter up } \\
\text { to } 10 \text { microns (PM10) }\end{array}$ & Carbon dioxide $\left(\mathrm{CO}_{2}\right)$ \\
\hline Individual & 74.2 & 69.5 & 23.6 & 82.3 & 74.6 \\
\hline Public & 25.8 & 30.5 & 76.4 & 17.7 & 25.4 \\
\hline
\end{tabular}

Source: Development Bank of Latin America (CAF), 2014.

In 2014, in nearly all the cities included in figure V.22, concentrations of both particulates smaller than 2.5 microns (MP2.5) — which can enter the bloodstream — and those smaller than 10 microns (PM10) exceeded the recommended limits and the standard set established by the World Health Organization (WHO, 2016), and exceeded the concentrations recorded in a number of developed country capitals, such as Paris, Berlin or Madrid.

These emissions affect public health and have economic and social consequences. At the same time, they are an expression of inequality, since the social sectors that generate fewest emissions are those that suffer most from their consequences. ECLAC (2017a) estimates that the equivalent of around 560,000 life years are lost annually in the region for reasons stemming from environmental problems.

In short, although there have been improvements, the costs of pollution, energy and time used for transport services that expand with the urban sprawl, in addition to those associated with the shortcomings in waste treatment, embrace inequality, productivity loss and environmental unsustainability. The transport system is part of a vicious circle of inequality, irrational resource allocation, environmental deterioration and worsening quality of life. It is, therefore, another facet of the inefficiency of inequality; and, as such, it needs to become one of the fundamental concerns of public policies, particularly those aimed at decarbonization and the reduction of urban inequality.

19 The electrification of transport would reduce the carbon content of the energy matrix, but emissions of coarse particles (PM10), with the exception of black carbon from combustion, would not be significantly reduced, since they also come from wear and tear of the rolling stock. 
Figure V.22

Selected cities: PM10 and PM2.5 concentrations, 2014

$\left(\mu \mathrm{g} / \mathrm{m}^{3}\right)$

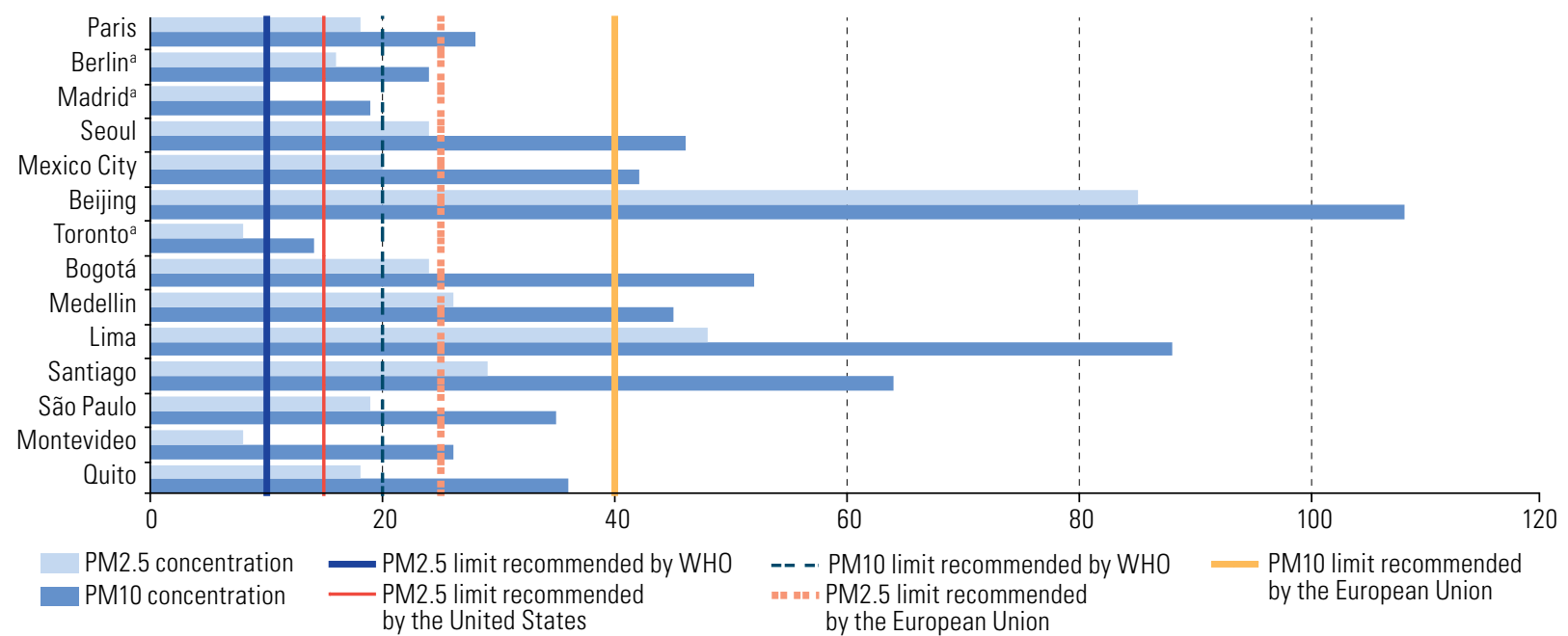

Source: Economic Commission for Latin America and the Caribbean (ECLAC), on the basis of World Health Organization (WHO), "Global Urban Ambient Air Pollution Database" 2016 [online database] http://www.who.int/phe/health_topics/outdoorair/databases/cities/en/.

${ }^{\text {a }}$ Mean annual concentration in 2013.

\section{The development pattern erodes its own environmental foundations}

The environmental problem intersects with problems of territory, infrastructure and cities; hence, the proposal by ECLAC of an "environmental big push" as a strategic pillar of industrial and technological policy that would tackle various problems in an articulated manner, exploring the complementarities between policies. The idea is to dismantle the undesirable constellation of low competitiveness, technological backwardness and high environmental inefficiency, and progress towards a model that is compatible with the 2030 Agenda and the Sustainable Development Goals.

\section{Territorial degradation destroys ecosystems and soils}

Changes in ecosystems have an impact on economic support systems often with negative consequences: productive lands become degraded and desertified to differing degrees; abundant water supply becomes drought, shortages and water deficits; a balanced climate morphs into climatic extremes with catastrophic effects; healthy ecosystems become contaminated and impoverished systems for providing environmental services; a productive ocean suffers acidification and loss of biomass productivity. In other words, increased vulnerability and economic disarticulation. In a region that is dependent on its natural heritage, the ability to develop sustainable production processes that generate jobs and income relies on the capacity of the environment to provide water, fertile soils, a balanced climate and other environmental services.

Land-use change is the source of $49 \%$ of GHG emissions in the region (ECLAC, 2015a), which has lost 9.4\% of its forest area since 1990 (UNEP, 2016). In South America, where major ecosystems such as the Amazon rainforest are located, forest cover shrank from 52.2\% in 1990 to 47.7\% in 2015 (ECLAC, 2016e). 
Lost hectares of forest cover are the result of the expansion of agricultural areas; it follows that, with more efficient and sustainable processes in agriculture, production could be increased without reducing forest cover. Nonetheless, most countries have yet to adopt these processes on a large scale. The loss of forests also has consequences for urban areas, since it alters the water balance: if the effect of evapotranspiration is largely lost, prolonged droughts will result.

The importance of agricultural activity in the countries' trade balances, especially in the Southern Cone, is a key determinant of deforestation. The region's share in world agricultural exports grew from $10 \%$ in 2000 to $13 \%$ in 2015 . South America is the origin of $80 \%$, on average, of the value of the region's agricultural exports, with Mexico accounting for $11 \%$, Central America $7 \%$ and the Caribbean just $1 \%$. Brazil, which rose from the world's eleventh largest agricultural exporter in 2000 to the fifth largest in 2015, with a 5\% share, followed by Argentina with $2 \%$ and Mexico with $1.7 \%$. Brazil is also the world's largest net agricultural exporter (ECLAC, 2017C).

There is a risk that expansion of the region's agro-export potential will continue to be at the expense of deforestation (see figure V.23). Between 2016 and 2025, Latin America is projected to be the world region with the largest increase in agro-export cultivation area (24\%) —driven by soybean cropping (29\% of the total), mainly in Brazil and Argentina (OECD/FAO, 2016).

\section{Figure V.23}

Latin America and the Caribbean: lost forest area and expansion of agricultural area, 1990-2014

(Millions of hectares)

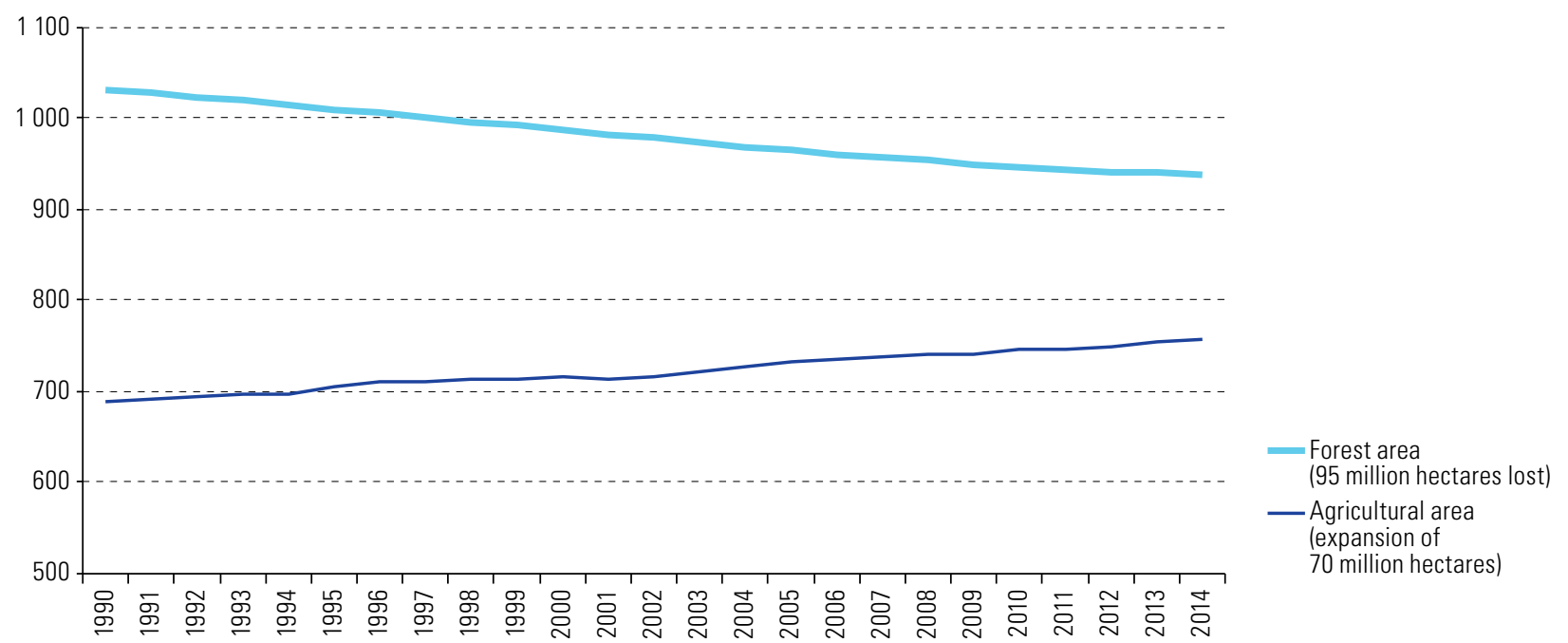

Source: Food and Agriculture Organization of the United Nations (FAO), Corporate Database for Substantive Statistical Data (FAOSTAT) [online] http://www.fao.org/ faostat/en/\#home.

Desertification is another consequence of unsustainable agricultural activity (see figure V.24). The desertification of agricultural land erodes the foundations of the economy, representing a loss of resources that undermines production and generates poverty. Figure V.24 shows the high levels of desertification in some countries, expressed in percentages of their territory. The United Nations Development Programme (UNDP, 2015) calculates that roughly $60 \%$ of the region is arid land; in addition, over 300 million hectares of its farmland are desertified, equivalent to about $20 \%$ of all usable land. The International Fund for Agricultural Development (IFAD, 2010) estimates that $50 \%$ of productive land will be desertified by 2050 . Soil degradation is also manifested through reduced fertility and in loss of organic carbon. 
Figure V.24

Latin America and the Caribbean (11 countries): territories desertified or in process of desertification ${ }^{a}$ (Percentage of the territory)

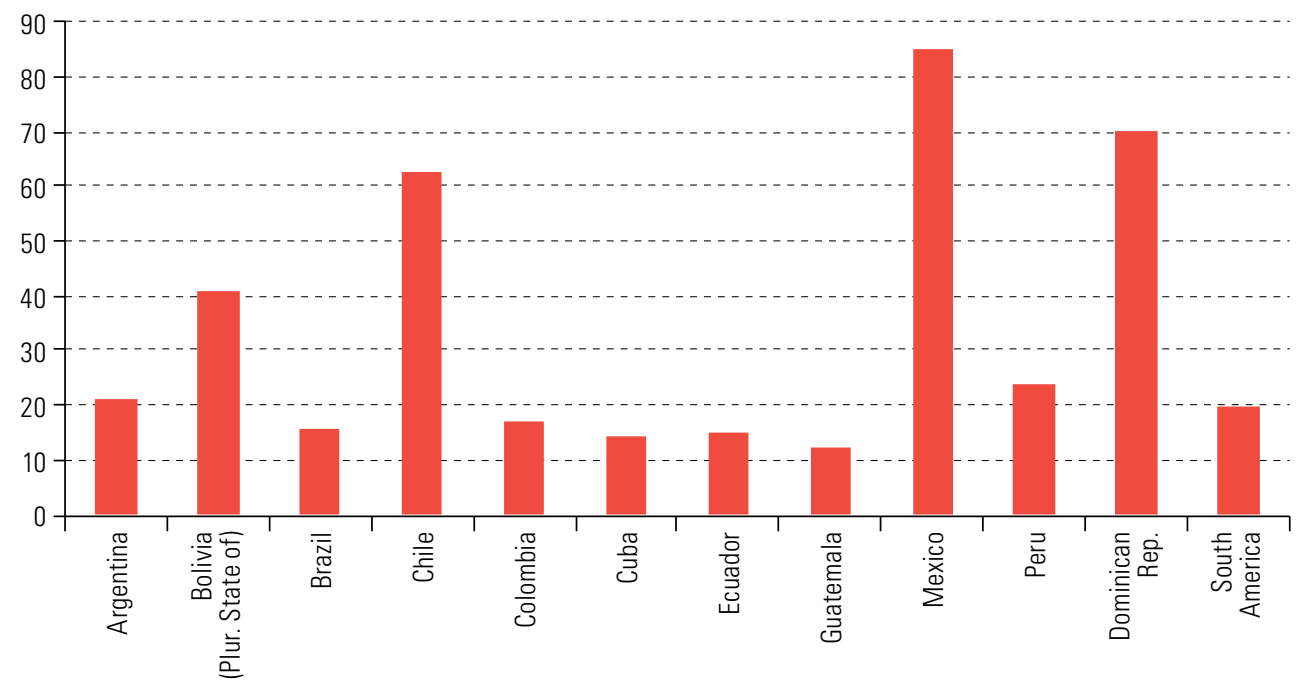

Source: Economic Commission for Latin America and the Caribbean (ECLAC), on the basis of European Union/Food and Agriculture Organization of the United Nations (FA0), Soil Atlas of Latin America and the Caribbean, Luxembourg, 2014, United Nations Convention to Combat Desertification in Those Countries Experiencing Serious Drought and/or Desertification (UNCDD), Country Profiles: Latin America and the Caribbean Region, Bonn, 2015. Data from the 5th Report and Review Cycle of the United Nations Convention to Combat Desertification (UNCCD, 2015)

a Latest year with data available: Argentina, 2011; Brazil, 2004; Colombia, 2010; Cuba, 2006; Ecuador, 2005; Guatemala, 2014; Dominican Republic, 2010; Plurinational State of Bolivia, Mexico and Peru (2012).

Alongside soil degradation, there has been a major increase in the use of fertilizers to compensate —not always successfully - for the loss of natural resources. At the same time, there is more intensive use of pesticides, such as fungicides, herbicides and insecticides that threaten people' health, the environment and the services it provides. These trends are captured by analysing land productivity dynamics. The Global Earth Outlook report (UNCCD, 2017) reveals signs of declining soil productivity in approximately $20 \%$ of the world's land surface with vegetation. The worst affected regions are South America and Africa, with $27 \%$ and $22 \%$ respectively.

The degradation of forests, soils and water forms part of a vicious circle that leads to loss of employment and income, and an increase in poverty and inequality in the medium and long terms, although it may boost the incomes of some sectors in the short run. The environmental costs of development are not a new concern for the international community, but only in recent years have global measures started to be taken to reduce them. These costs represent inefficiencies in a system that is unequal from the intertemporal standpoint (the ecosystems at the disposal of future generations would have less capacity to sustain growth than those available to past generations) and within each generation (the poor bear the highest costs of environmental degradation). The implementation of the 2030 Agenda for Sustainable Development is closely related to the investment pattern and, hence, to the trajectory of the use of energy and natural resources. Implementation of the Agenda requires investing in sectors that use clean production methods to decouple economic growth from material extraction and energy consumption, topics which are discussed below.

\section{Climate change: global pollution and localized impacts}

The effects of extreme weather events, which are becoming more frequent owing to climate change, are felt with increasing intensity in the region. Their greater frequency has also raised the economic cost of the consequent destruction (see figure V.25). This occurs because greater exposure to these events combines 
with the degradation of the ecosystems that help to mitigate them and facilitate adaptation. Climate change thus leads to a dual inequality: higher-income groups are the main emitters of greenhouse gases —-the largest consumers of fossil fuels - but the poorest are the most vulnerable to its effects because they have less capacity to adapt.

\section{Figure V.25}

Latin America and the Caribbean: cost of extreme weather events, 1961-2015

(Billions of dollars at current prices)

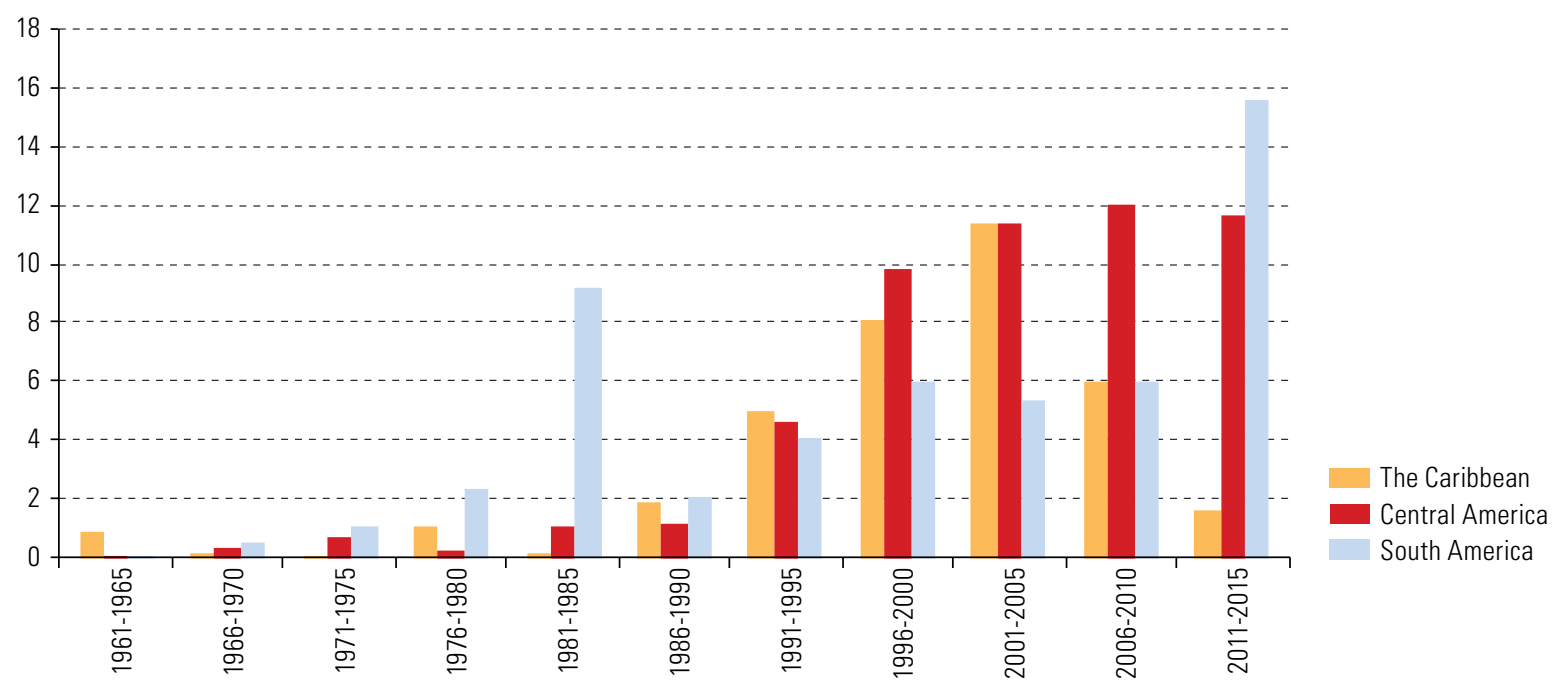

Source: Economic Commission for Latin America and the Caribbean (ECLAC), on the basis of International Disaster Database (EM-DAT), 2016 [online] http://www.emdat.be/.

Estimates of the economic costs of a $2.5^{\circ} \mathrm{C}$ rise in the planet's temperature (which is highly likely to occur around 2050) range between $1.5 \%$ and $5 \%$ of the region's current GDP, as shown in figure V.26 (ECLAC, 2015a). ${ }^{20}$

The impacts of climate change vary both between and within countries, as well as between different economic activities. Given the sensitivity of crop and livestock farming to climatic conditions, it is highly likely that the agriculture sector will be the most affected (Mendelsohn and Dinar, 2009), in terms of its net income and productivity, which is worrisome for the countries of the region where this sector has a strategic importance (ECLAC, 2017d).

Coastal areas are vulnerable to rising sea levels and the combined effects of floods, beach erosion and the destruction of coastal and port infrastructure; with the corresponding economic, social and environmental impacts (ECLAC, 2017a and 2014a). Adapting this infrastructure requires consideration of that vulnerability in environmental impact assessments, preferably in a regional framework to avoid a race to the bottom in regulatory competition.

Although these estimates are uncertain and conservative, limited to certain sectors and regions and have methodological shortcomings, they are useful for public policy. 


\section{Figure V.26}

Latin America and the Caribbean: economic impact of a $2.5^{\circ} \mathrm{C}$ rise in temperature according to different estimations, second half of the twenty-first century

(Percentages of regional GDP)

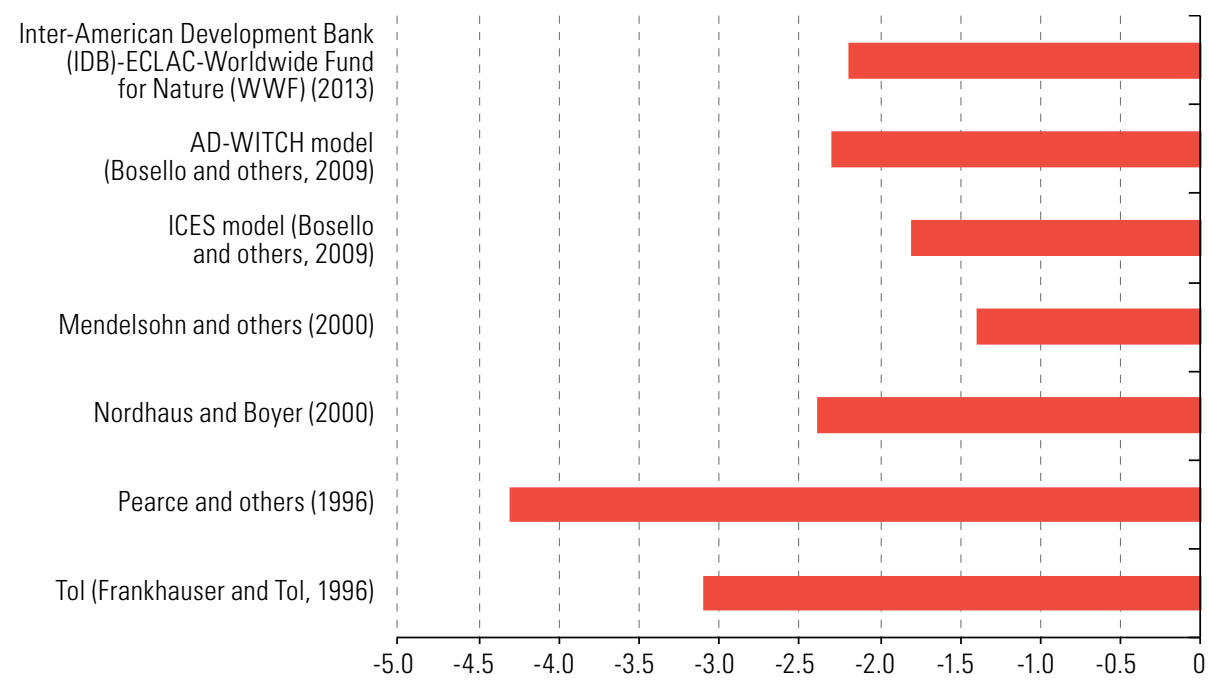

Source: Economic Commission for Latin America and the Caribbean (ECLAC), The economics of climate change in Latin America and the Caribbean: Paradoxes and challenges of sustainable development, Santiago, 2015, and F. Bosello and others, "Market- and policy-driven adaptation", Smart Solutions to Climate Change: Comparing Costs and Benefits, Cambridge, Cambridge University Press, 2010.

The Latin America and the Caribbean region has a high average availability of water resources, albeit distributed heterogeneously among the different countries (ECLAC, 2014c; Magrin and others, 2007). By modifying precipitation patterns, soil moisture and runoff, and by speeding up the melting of glaciers, climate change will affect the availability of water for human consumption and economic activities, such as agriculture and industry. In some areas, hydrological change will affect hydroelectric power generation. ${ }^{21}$ It is therefore necessary to scrutinize current water management practices in order to reduce the imbalance between supply and demand and reduce vulnerability in the future; together with regulatory and legal reforms that facilitate the efficient and effective management of water resources (Magrin and others, 2014; Magrin, 2015).

In Latin America and the Caribbean, climate change will also increase the spread and incidence of communicable diseases such as malaria, dengue and cholera (Magrin and others, 2007). Moreover, the rise in temperature in polluted localities will trigger chemical feedbacks and local emissions that increase the maximum concentrations of ozone and PM2.5 particulates (IPCC, 2013), when levels of air pollution in the region's cities are already high —in many cases above the recommended health standards (ECLAC, 2014c). All of this will impose an additional economic burden on health systems in the region's countries.

Natural disasters are another major source of costs for the region, amounting to US\$258 billion between 1970 and 2017, 42\% of which was incurred in Central America and Mexico, 39\% in South America and $19 \%$ in the Caribbean (ECLAC, 2017d). In addition to the economic losses that natural disasters entail, their consequences can increase poverty and accentuate inequality, thereby setting back the development of a country or a territory.

The impacts of climate change are not confined to sectors or economic activities, but are transmitted to the rest of society through changes in production and public finances. The slowdown in economic activity reduces tax revenues derived from agriculture, tourism and the port sector, among others. Moreover, the

21 For example, in Colombia, the availability of water and hydroelectric power generation would be affected; in Peru, the retreat of glaciers could affect water availability for population centres and the electricity sector, entailing an estimated annual additional cost of between US\$212 million and US\$1.5 billion for power generation (ECLAC, 2014c). 
impacts of climate change will demand additional spending and public investment to address the consequences of extreme events such as floods, droughts and hurricanes; and the implementation of measures to adapt to the new climatic conditions and reduce the population's vulnerability.

The adaptation costs for the region are estimated at approximately $0.4 \%$ of its current GDP (see figure V.27), although these estimates are subject to a high level of uncertainty and will most likely tend to rise 22 (World Bank, 2010b; Vergara and others, 2013). From the economic standpoint, it makes sense to invest in adaptation, since its costs are almost 10 times lower than the costs of inaction. In addition, investment in adaptation has a stimulating effect on the economy, especially if it drives technical change and production diversification.

Figure V.27

Latin America and the Caribbean: estimated annual costs of climate change adaptation, by sector to 2050 (Percentages of regional GDP)

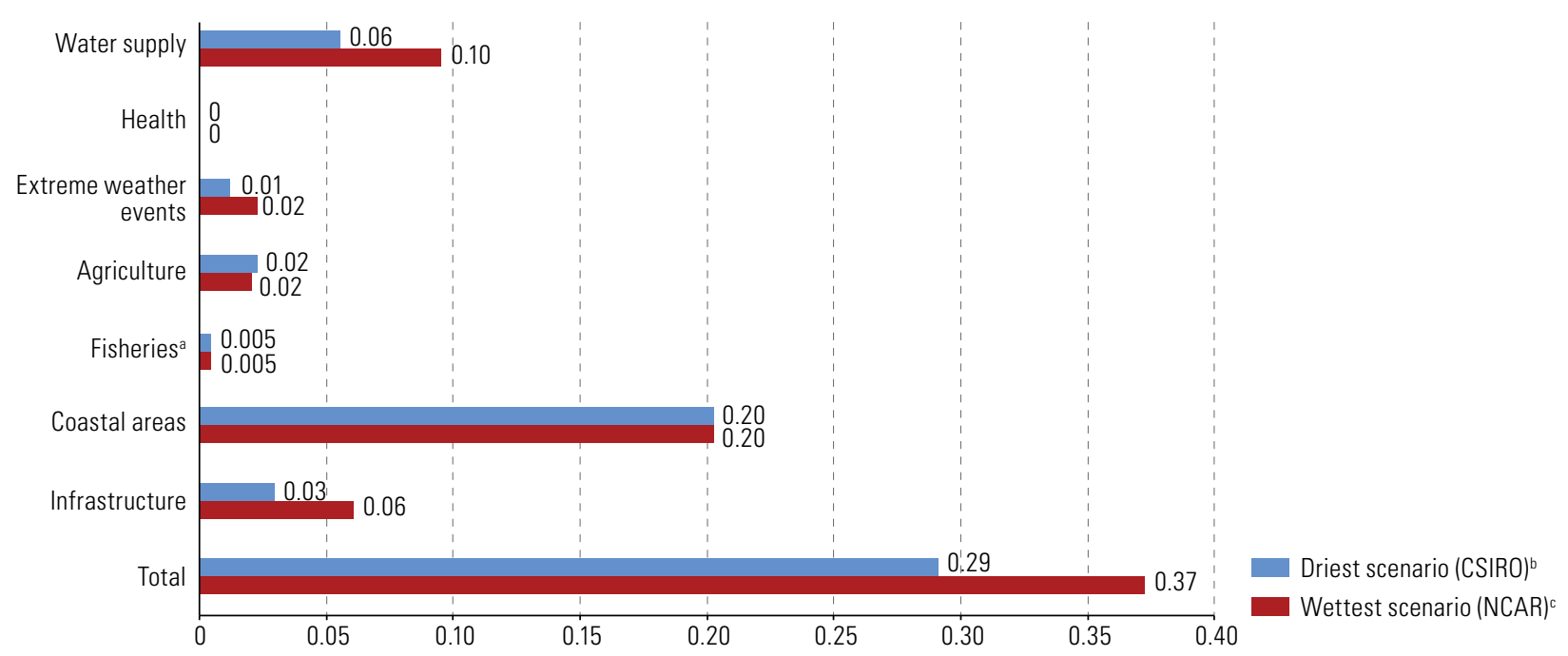

Source: Economic Commission for Latin America and the Caribbean (ECLAC), The economics of climate change in Latin America and the Caribbean: Paradoxes and challenges of sustainable development, Santiago, 2015, and World Bank, The Cost to Developing Countries of Adapting to Climate Change: New Methods and Estimates, Washington, D.C., 2010b.

a Fisheries sector: medium range (from 0.18 to 0.36 and from 0.18 to 0.35 for the NCAR and CSIRO models, respectively).

${ }^{\mathrm{b}}$ Commonwealth Scientific and Industrial Research Organisation (driest scenario).

${ }^{\mathrm{c}}$ National Center for Atmospheric Research of the United States (wettest scenario).

The reality of the Caribbean countries clearly illustrates the tension between global pollution and its widely differing effects across countries. Between 1990 and 2017, as many as 345 climate-related disasters were recorded in the Caribbean, an average of 12 per year. This type of occurrence seriously damages the economic infrastructure of small island developing States, diminishing their social achievements and deepening inequalities. The annual impact of these disasters on their capital stock is much greater, relatively, than those occurring in Europe or Central Asia, equivalent to $20 \%$ of their annual social expenditure (UNISDR, 2015). This leads to a significant deviation of the investment portfolio and budgetary resources that must be redirected towards rebuilding these economies and reducing the impact on the affected population. In the case of the disasters caused by the 2017 hurricane season, for example, the impacts exceeded $50 \%$ of GDP in some of the island States.

22 The World Bank (2010a) estimates that the adaptation costs in agriculture, water resources, infrastructure, coastal areas, health, extreme weather events and fishing will be less than $0.3 \%$ of the region's GDP; that is, they will oscillate between US\$16.8 billion and US\$21.5 billion a year until 2050 (World Bank, 2010 a). According to Agrawala and others (2010), adaptation costs in terms of irrigation, water infrastructure, coastal protection, early warning systems, investments in climate-resilient settlements, air conditioning, treatment of diseases and research and development for adaptation will be close to $0.24 \%$ of regional GDP. Given that adaptation requires public and private investments that can stimulate economic activity, this cost calculation is gross and does not consider the multiplier effects of these investments. 
Their nature as small island States (which prevents them from taking advantage of economies of scale), together with recurrent reconstruction efforts, has led these countries into chronic twin deficits (both the fiscal and current account) and, consequently, high levels of indebtedness. In 2016, the public debt of the central governments of Caribbean countries varied between $50 \%$ and $125 \%$ of GDP (in the case of Jamaica). High debt levels forces these countries to borrow at a higher risk premium and causes greater exchange-rate instability and major financial fragility, which compels them to apply austerity policies and cut back public investment. On average, in the Caribbean, interest payments on public debt absorb around $15 \%$ of tax revenues. In Jamaica and Barbados, one out of every three dollars of tax revenue is used to pay interest. Total debt service, including amortization, entails disbursements of $30 \%$ of central government revenues on average, and as much as $84 \%$ in Jamaica and $47 \%$ in Antigua and Barbuda. Paradoxically, five Caribbean countries are classified as high-income countries (Antigua and Barbuda, Bahamas, Barbados, Saint Kitts and Nevis and Trinidad and Tobago), and are therefore not eligible to receive concessional loans. The remaining eight (Belize, Grenada, Guyana, Jamaica, Saint Lucia, Saint Vincent and the Grenadines and Suriname) are classified as upper-middle-income countries. This state of affairs further weakens their financial situation.

Sustainable development is particularly difficult amid high disaster risk. This makes it urgent to build up the resilience of economic structures in the Caribbean and implement strategies to adapt to climate change. ECLAC has proposed a debt relief strategy for the subregion and the creation of a Caribbean Resilience Fund. This initiative targets Caribbean countries that have low growth rates despite reforms made to improve their economic performance, together with an unsustainable level of debt despite having adopted fiscal consolidation measures, debt service that has compressed their fiscal space and investment in infrastructure, and considerable difficulties in achieving the Sustainable Development Goals (including adaptation to climate change) because of budget constraints.

Debt reduction works in the following way: for countries with high levels of official debt, it involves using climate funds, such as the Global Climate Fund, to pay off multilateral and bilateral debts at a discount. In the case of high debt with private creditors, repurchase plans would be negotiated. The Caribbean Climate Resilience Fund has three components:

(i) In the case of natural disasters: funds for the recovery of economic activity and the reconstruction of infrastructure with elements of disaster risk reduction. These resources complement initiatives such as the Caribbean Catastrophe Risk Insurance Fund (CCRIF).

(ii) In the case of external shocks: financing for high-income Caribbean countries that do not have access to concessional financing to insure against these risks.

(iii) In the case of climate change: resources for infrastructure projects, particularly climate-change mitigation and adaptation.

In summary, the predominant development pattern generates inefficiencies and productivity losses in the most diverse areas. Estimates based on the global economic linkages model of the International Labour Organization (ILO) suggest that, if the situation does not change, global labour productivity will have fallen in relation to present levels by $2.4 \%$ in 2030, and by $7.2 \%$ in 2050 (ILO, 2012). These estimates coincide with the conclusions of various studies evaluating the economic damage caused by environmental degradation and the loss of basic ecosystem services. In the absence of climate change mitigation policies, per capita global consumption will drop by $14 \%$ by 2050 (Stern, 2006, OECD, 2012). These effects would accentuate inequality because they affect mainly groups with little capacity to protect themselves or lobby for prevention or reparation policies. 


\section{The urgent need to increase the rate of decarbonization}

\section{(a) The material and carbon footprints}

The total extraction of natural resources - the volume extracted from the natural environment, except air and water (IRP/UNEP, 2016) - produces a material footprint that serves as an indicator of the use intensity of these resources, relative to GDP. Between 1970 and 2010, total extraction in the region grew, and the intensity of resource use was not decoupled from economic growth (UNEP, undated; World Bank, 2015). An export profile with a high material impact implies high economic and environmental inefficiency (UNEP, 2011); and changing this requires the adoption of technologies that can sustain jobs and income without destroying natural capital.

Regional emissions from the energy sector grew from 2.2 tons per capita to roughly 3 tons per capita between 1990 and 2014 (see figure V.28), exceeding the level that was not expected to be attained before 2050. Between 2006 and 2011, total energy emissions grew by 14.2\% (World Bank, 2015), despite a reduction in emissions resulting from land-use change.

\section{Figure V.28}

Latin America and the Caribbean: per capita emissions of $\mathrm{CO}_{2}$ equivalent, 1990-2014

(Tons)

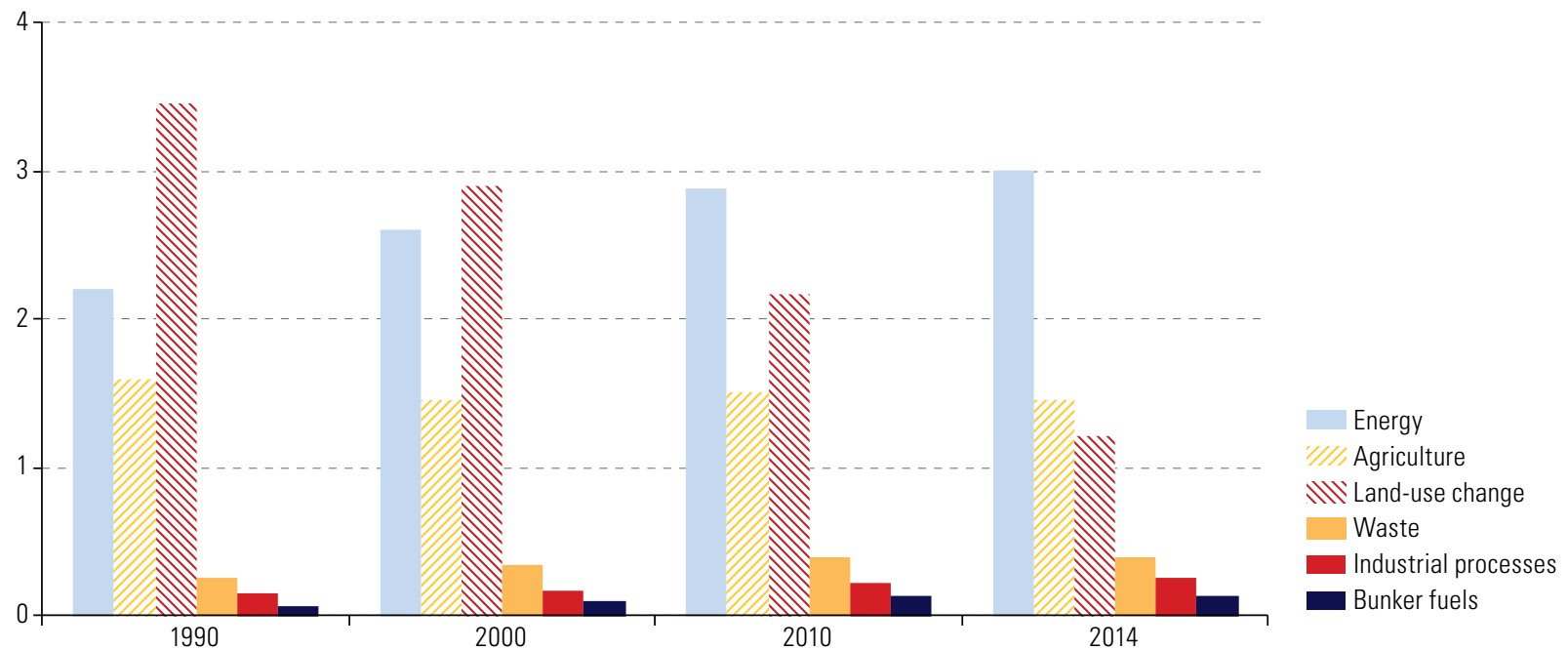

Source: Economic Commission for Latin America and the Caribbean (ECLAC), on the basis of European Commission, Trends in Global CO 2 Emissions: 2016 Report, 2016 [online] http://edgar.jrc.ec.europa.eu/news_docs/jrc-2016-trends-in-global-co2-emissions-2016-report-103425.pdf.

\section{(b) Path of the economy's energy and carbon intensity}

The specialist literature has suggested that environmental degradation (as measured by emissions of $\mathrm{CO}_{2}$ or other pollutants) behaves according to a Kuznets curve (an inverted $\mathrm{U}$ ): it is limited at low per capita income levels, increases as income levels rise, and then decreases after a certain critical income level has been attained. The environmental Kuznets curve is explained by the action of two forces: structural change associated with the transition from a (low pollution) agrarian economy to a (more polluting) industrial economy and then to a (less polluting) service-based economy; and technological change, especially the change in the energy mix, in response to a greater demand for clean technologies by consumers, who value the environment more highly once they reach high levels of income. 
In some European and North American economies, there was a significant drop in the ratio of $\mathrm{CO}_{2}$ emissions to per capita income, as predicted by the environmental Kuznets curve (see figure V.29), and the ratio rose in the Asian economies as they industrialized. Other economies, such as those in sub-Saharan Africa or in the Middle East and North Africa, have not followed the same pattern, however. In Latin America and the Caribbean, the ratio has flatlined. Thus, the hypothesis of the Kuznets curve is not confirmed in all cases, which suggests that the relationship between pollution and per capita income is less direct than originally thought. An explanation for this is that the two forces defining the curve (structural change and technical change) depend on policies and institutions, whose operation brings progress towards the least polluting stage to a premature halt.

Figure V.29

Trend in the ratio of carbon intensity to per capita GDP, 1971-2014

(Kilograms of $\mathrm{CO}_{2}$ per dollar of GDP and dollars at constant 2010 prices)

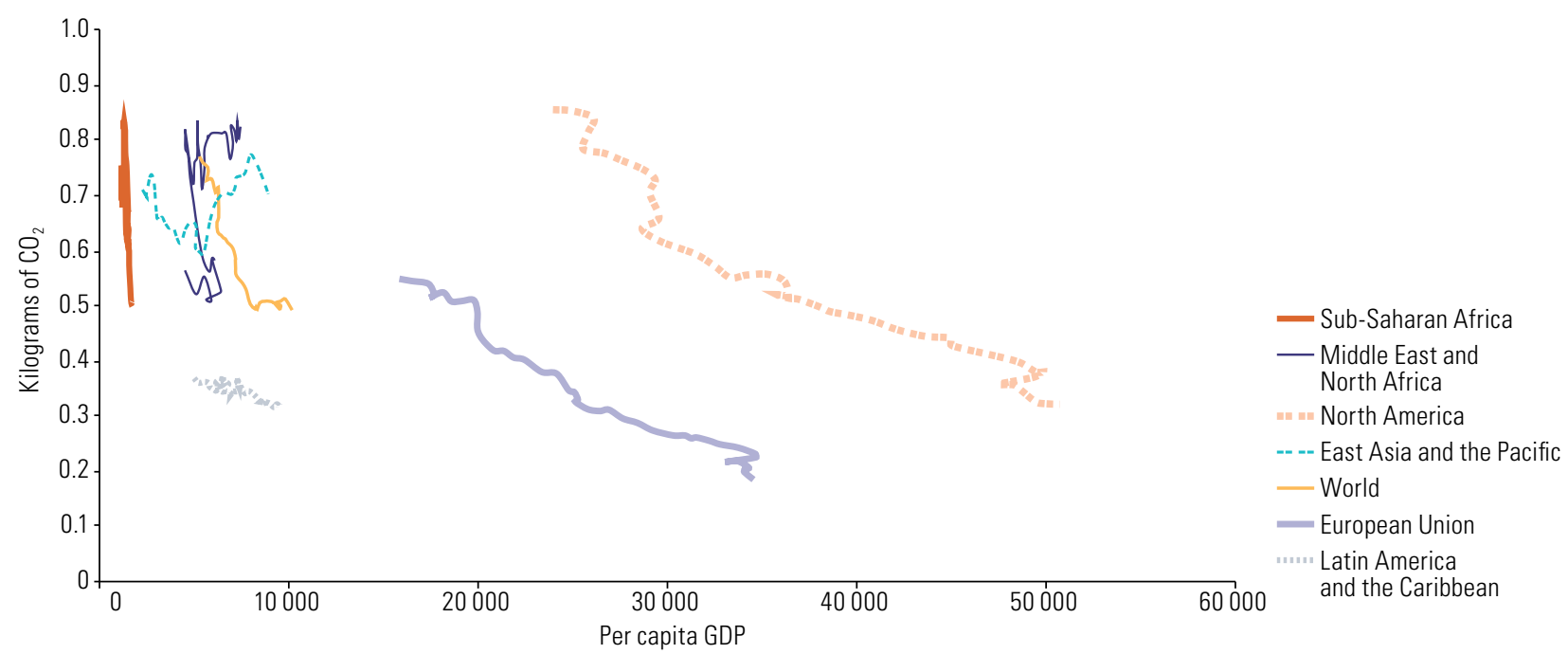

Source: European Commission for Latin America and the Caribbean (ECLAC), on the basis of World Bank, "World Development Indicators", 2017 [online] http://data. worldbank.org/data-catalog/world-development-indicators.

Reducing emissions requires a far-reaching technological change that has not yet been achieved in the region. Pollutant emissions per unit of energy consumed must be reduced, as must energy consumption per unit of per capita income. Figure V.30, which displays energy consumed per unit of income, shows insufficient progress in this area. Current levels of emissions and energy efficiency are both stagnating far short not only of desirable levels for sustainable development, but also of those attained in other parts of the world. Should it continue along this path, the region will not meet the climate targets of the Paris Agreement and the Sustainable Development Goals. This is an unsustainable path in the medium and long terms.

In 1971, the region's energy intensity was relatively low by global standards, but has changed little since then. This immobility may be attributed to a lock-in effect in the economic structure since, thus far, there has been no significant decoupling between economic growth and its energy requirements. This contrasts with the efforts of the European Union, which has reduced its energy intensity below that of Latin America and the Caribbean, and even the United States and Canada, which underscores the importance of policies for efficient energy use and energy diversification. 
Poor environmental efficiency can hold down the growth rate that is compatible with the maintenance of employment rates, as long as emissions and GDP growth are not decoupled (see box V.1). Similarly, very unequal cities, with areas that lack public goods such as transport, education, citizen security and a non-polluted environment, will suffer productivity losses caused by transportation time, poor health and loss of human lives, compounded by insufficient access to education. Lastly, inequality affects decisions on what types of infrastructure to invest, which affects energy and production efficiencies.

\section{Figure V.30}

Trend of the ratio of per capita GDP to energy intensity, 1971-2014

(Kilograms of $\mathrm{CO}_{2}$ per US\$1,000 of GDP at constant 2010 prices)

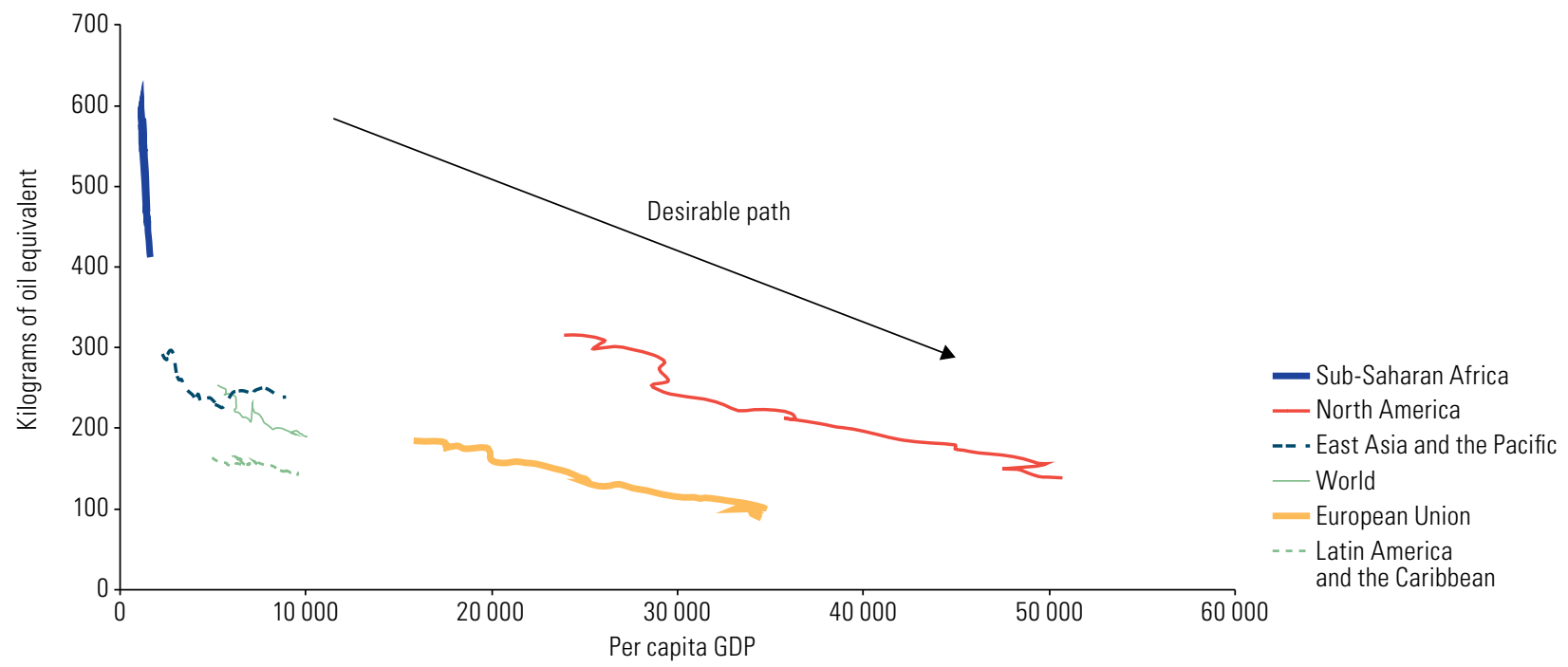

Source:World Bank, "World Development Indicators”, 2017 [online] http://data.worldbank.org/data-catalog/world-development-indicators.

\section{Box V.1}

The minimum necessary growth threshold and GHG emissions

Maintaining a pace of growth compatible with the necessary job creation requires energy policies to decouple economic growth from GHG emissions and meet climate targets. The regional growth needed to absorb the increase in population, or the minimum threshold necessary to create jobs, is around 2.2\% (see chapter III), whereas the average GDP growth rate has been about 3.2\% since 2000 .

GHG emission scenarios for 2030 a can be used to estimate the efforts needed to achieve a mitigation target based on these two growth rates. The "constant" scenario to 2030 considers the same GDP growth and the same decarbonization rate of the economyb from 2000 to the present. In the scenario "alternative I", the economy grows at the minimum necessary threshold rate, in other words $2.2 \%$, and the decarbonization rate is the same as in the constant scenario. Alternative scenario II uses the minimum threshold growth rate and the decarbonization rate of the economy needed to meet the emissions reduction target. Alternative scenario III uses the historical GDP growth rate; and the decarbonization rate is adjusted to achieve the regional mitigation target of $30 \%$ with respect to the constant scenario in which everything would remain unchanged.

Estimations of annual GDP growth and decarbonization to 2030

\begin{tabular}{l|c|c|c|c}
\hline Scenario & Constant & Alternative I & Alternative II & Alternative III \\
\hline GDP growth & 3.2 & 2.2 & 2.2 & 3.2 \\
\hline Decarbonization rate & -1.1 & -1.1 & -2.1 & -3.1 \\
\hline
\end{tabular}

Source: Galindo, L. and others, "Cambio climático, consumo, gasolinas, empleo y pobreza: Ios números de una ecuación no sostenible en América Latina", 2018, unpublished. 
Box V.1 (concluded)

Estimation of GHG emissions, 2030

(Gigatons of $\mathrm{CO}_{2}$ equivalent)

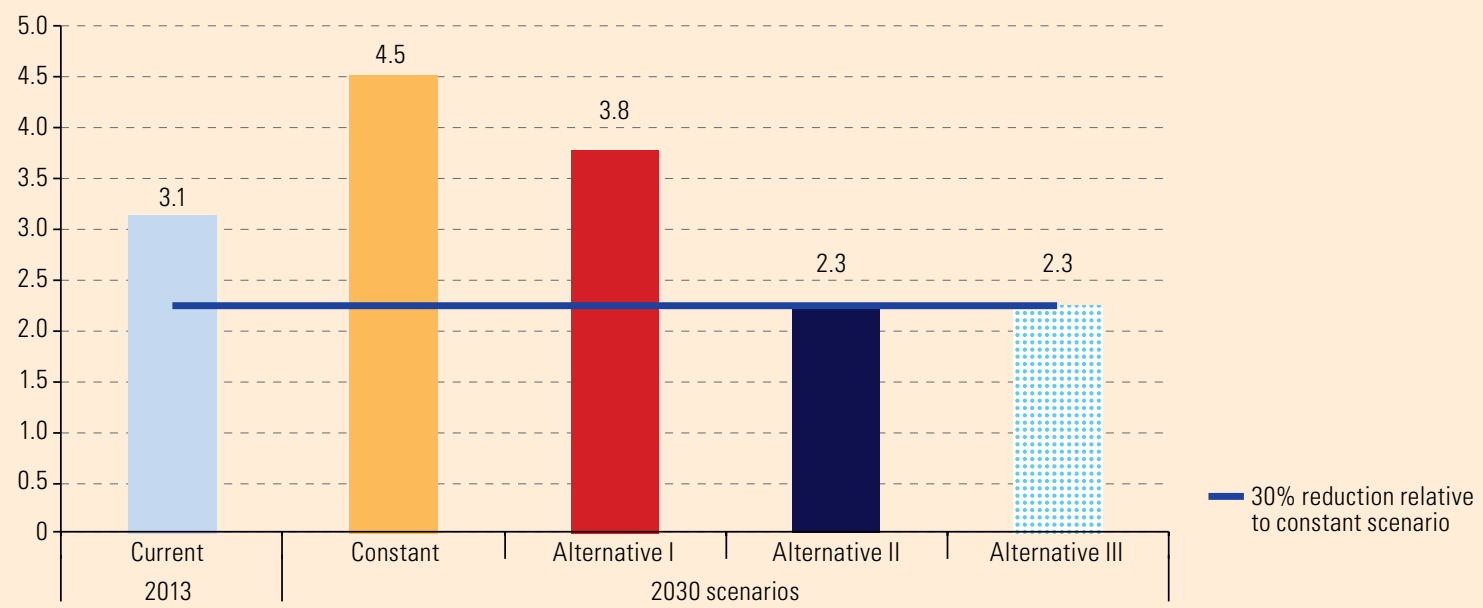

Source: Galindo, L. and others, “Cambio climático, consumo, gasolinas, empleo y pobreza: Ios números de una ecuación no sostenible en América Latina”, 2018, unpublished.

In this exercise, the target is $2.3 \mathrm{Gt}$ of $\mathrm{CO}_{2}$ equivalent. By 2030, regional emissions would exceed the target unless the decarbonization rate is doubled in a low-growth scenario (alternative II), or tripled in a growth scenario such as that experienced from 2000 to the present (alternative III), through improvements in energy efficiency, less use of chemical fertilizers, and an energy mix that is lighter on fossil fuels.

Source:Galindo, L. and others, "Cambio climático, consumo, gasolinas, empleo y pobreza: los números de una ecuación no sostenible en América Latina", 2018, unpublished.

${ }^{a}$ This exercise does not include emissions caused by land-use change and forestry; emissions from this sector are assumed reduced to zero.

${ }^{b}$ This is the rate at which economic growth is decoupled from the growth of emissions; a negative sign implies decoupling, while a positive sign implies stronger coupling.

\section{Renewable energy sources: a new investment horizon}

In the region, the generation of $\mathrm{CO}_{2}$ emissions depends on the share of fossil fuels in the energy matrix: $74 \%$ in total, $44 \%$ in electricity generation and over $90 \%$ in transport. Decarbonizing the economy requires electricity to be produced from renewable sources and a shift towards fossil-fuel-free electric mobility. The challenge is to reconcile economic growth with changes in the pattern of energy production and consumption in order to decouple emissions from GDP growth. This can be achieved by increasing the share of renewable energy sources in areas such as transport, and enhancing efficiency in the production structure and in the functioning of cities.

\section{The need for a new energy matrix}

Renewable energies are fundamental and must play a central role in changing the energy matrix. Nonetheless, over the last two decades the renewable energy supply has decreased in relative terms in the region, except in Central America (see box V.2). 


\section{Box V.2}

The energy transition in Central America

To reduce their vulnerability to oil shocks, the Central American countries embarked upon a cycle of renewable energy expansion starting in the first few years of this century. This included laws to promote renewable energies (which include tax benefits such as exemption from import tariffs for capital goods and exemption from income tax for the first few years of operation of the project) and technology tenders that facilitated the development of both conventional and non-conventional (solar and wind) renewable energies. At the subregional level, in 2007 these countries adopted the Central America 2020 Sustainable Energy Strategy with a common vision of energy development and integration, with targets to reduce hydrocarbon dependency, increase the share of renewable sources, reduce GHG emissions, increase electric power coverage and boost energy efficiency. Late 2014 saw the completion of the Central American Electrical Interconnection System (SIEPAC) - a multinational investment of around US\$ 500 million including a 1,800-km electric transport infrastructure stretching from Guatemala to Panama and linking up the six metropolitan areas of those countries.

These steps have steadily increased the share of renewables in the total energy supply, to $67 \%$ of electricity production in 2016. Solar and wind power sources have grown exponentially, recording installed capacity of 1,620 MW and production of $4.500 \mathrm{GWh}$ of energy ( $9 \%$ of total production) in that year. Costa Rica achieved over 300 consecutive days of energy produced entirely from renewable sources in 2016, which meant that renewables accounted for over $98 \%$ of its total electricity production for the year (see figures 1 and 2 ).

The following figures reflect the importance of each type of renewable technology in electricity production in 2016. In El Salvador, geothermal sources represented more than $26 \%$; in Nicaragua, $17 \%$ was produced from wind sources; in Guatemala, sugar mills contributed 16\%, and in Honduras, $10 \%$ was produced from solar power. The SIEPAC operation also increased the subregion's electricity trade; in 2016, the total volume of international transactions (imports plus exports) attained a record of nearly 4.6 terawatt-hours: $9 \%$ of the electricity produced was destined for the subregional market.

All countries have taken steps to boost energy efficiency; three (Costa Rica, Panama and Nicaragua) have passed specific laws on this issue. They have also supported changes in the patterns of energy consumption and diversification of sources, ranging from the opening of transmission and distribution networks to small-scale renewable energies (distributed generation), to the use of electric cars and biofuels.

Figure 1

Central America: energy generation mix, 2016

(Percentages)

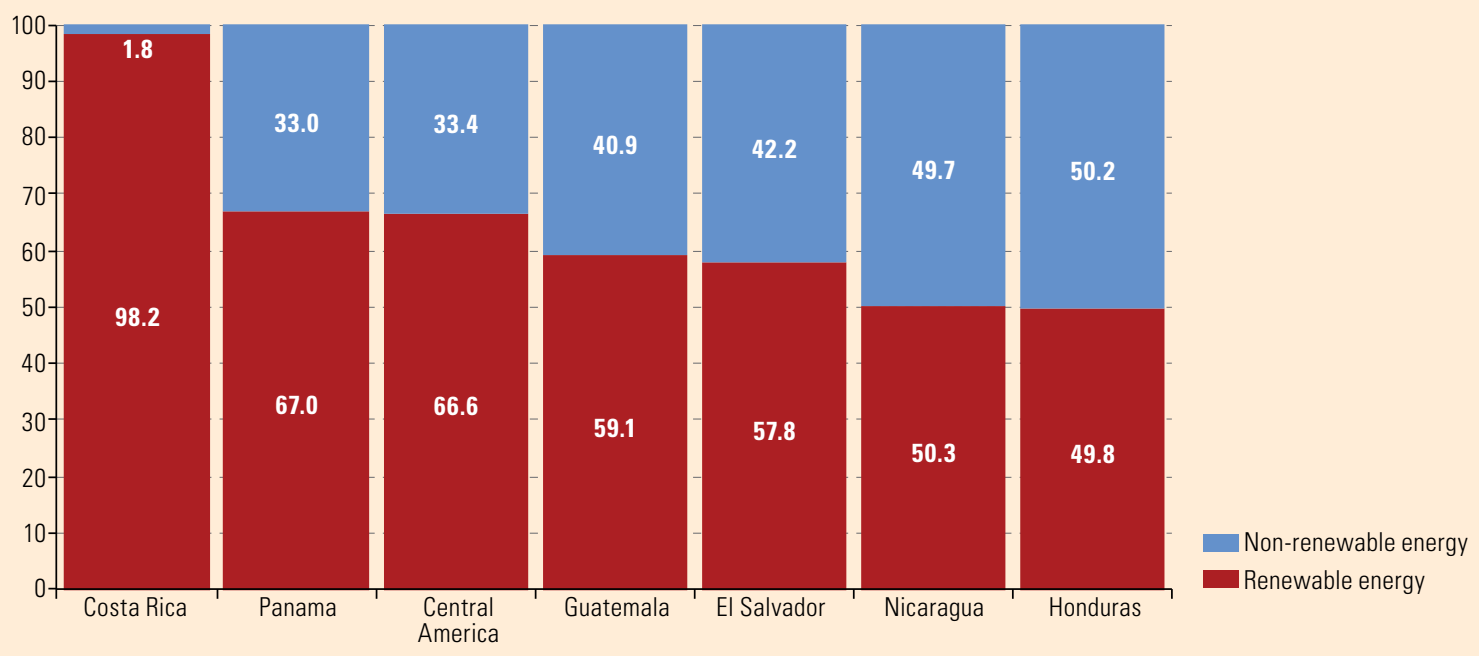

Source: Economic Commission for Latin America and the Caribbean (ECLAC), on the basis of official figures. 
Box V.2 (concluded)

Figure 2

Central America: solar and wind-based energy generation, 1995-2016

(GWh)

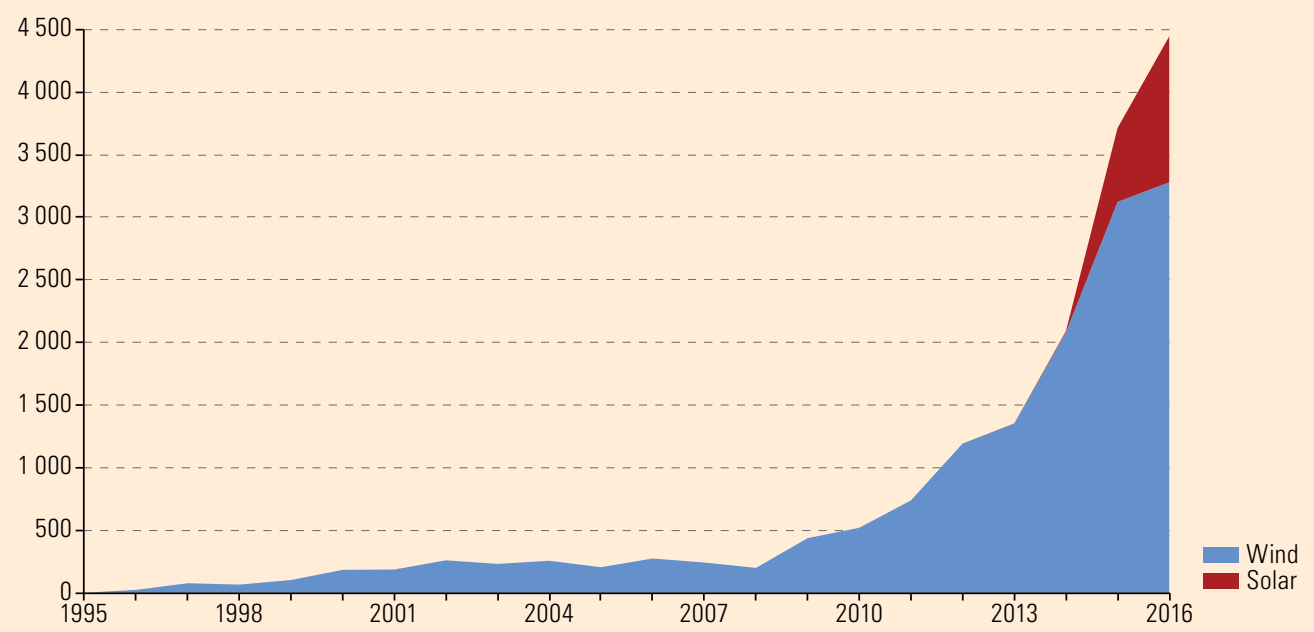

Source:Economic Commission for Latin America and the Caribbean (ECLAC), on the basis of official figures.

Source:Economic Commission for Latin America and the Caribbean (ECLAC), on the basis of M. Rojas Navarrete, Estadísticas del subsector eléctrico de los países del Sistema de la Integración Centroamericana (SICA), 2016 (LC/MEX/TS.2017/35), Mexico City, Economic Commission for Latin America and the Caribbean (ECLAC), ECLAC subregional headquarters in Mexico

Hydrocarbons still provide $74 \%$ of the region's total energy supply, despite the enormous potential of renewable sources and their geographical and seasonal complementarity. In absolute terms, renewable energy generation grew from 77 million tons of oil equivalent (Mtoe) in 1971 to 209 Mtoe in 2013, but its share of total primary energy dropped from $31 \%$ to about 24\% (IDB 2016; OLADE, 2016): the opposite of what needs to happen to reduce the environmental footprint of the energy supply. Between 1990 and 2015, the renewable share of the energy matrix shrank from $28.9 \%$ to $24.9 \%$, as shown in figure V. 31 .

\section{Figure V.31}

Latin America and the Caribbean: share of renewables in the total energy supply, 1990-2015

(Percentages)

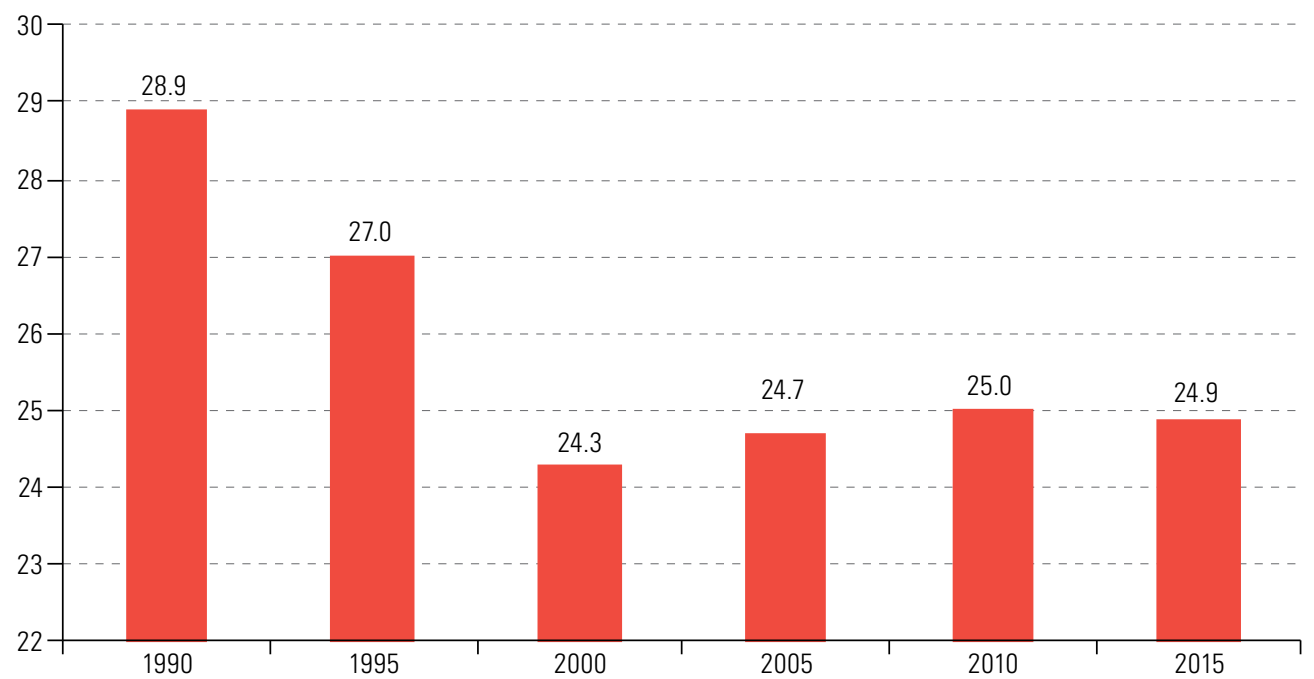

Source: Economic Commission for Latin America and the Caribbean (ECLAC), on the basis of Databases and Statistical Publications (CEPALSTAT) and Energy-Economic Information System SIEE) [online] http://estadisticas.cepal.org/cepalstat/portada.html?idioma=english; http://www.olade.org/producto/sie-regional/siee/?lang=en.

Note: Includes supply from the following energy sources: geothermal, hydropower, firewood whose use is considered sustainable, sugarcane products and other renewable sources (such as solar and wind). 
The challenge is very considerable, since more than 26 million people in the region (4\% of the population) still lack access to electricity. Moreover, at least 87 million people (15\%) still use non-sustainable biomass, firewood and charcoal for heating. The constant use of this biomass is closely related to lower income levels and has negative health consequences, particularly associated with indoor pollution, which affects women and children to a greater extent (IDB, 2016a). Emissions from the burning of fossil fuels and from cement production grew from 2.2 to approximately 3 tons per capita between 1990 and 2015, taking them already above the level forecast for 2050. Between 2006 and 2011, total emissions increased by 14.2\% (World Bank, 2015), in contrast to development and climate goals which require emissions to be first stabilized and then reduced.

The limited progress of renewable energies implies lost opportunities for income generation and jobs. ${ }^{23}$ Photovoltaic energy, for example, creates twice as many jobs per GWh as power generation using coal or natural gas: the most conservative estimate is $0.4 \mathrm{jobs} / \mathrm{GWh}$, while the best estimate for fossil fuels is $0.2 \mathrm{jobs} / \mathrm{GW}$ hour (UK Energy Research Centre, 2014). According to data from the International Renewable Energy Agency (IRENA, 2016b), 46\% of the total primary energy supply (TPES) in the region comes from oil. As oil represents only $31 \%$ of the total in the rest of the world, there is room to shift the energy matrix towards renewables and take advantage of the concomitant income and employment opportunities. The Agency also estimates that over 8.1 million jobs exist in the renewable energy sector across the world. According to ILO (2016a), in Brazil, 2.9 million people were employed in sectors with low carbon emissions, equivalent to $6.6 \%$ of the formal job market. In Mexico, 1.8 million jobs are related directly to low emissions, $4.4 \%$ of the employed population in 2011 (ILO, 2013). ${ }^{24}$ In Uruguay there were 44,108 green jobs in 2013 , representing $2.72 \%$ of the employed labour force (ILO, 2016b).

\section{The carbon content in the electric energy mix is declining slowly}

The 2030 Agenda for Sustainable Development and the Paris Agreement call for an ever-larger share of renewable sources in the energy matrix. According to IRENA (2016d), the world's annual investment in renewable energy generation grew from US $\$ 50$ billion in 2004 to US $\$ 360$ billion in 2015, with $85 \%$ of those investments made in Group of Twenty (G20) countries. In the projection of investments for 2020 (IRENA, 2015), the region's share is around 6\% (US\$21 billion). The small share of renewables in the region shows that there is plenty of scope for developing the necessary structural change.

For example, an increase in investments in non-conventional renewable energy (NCRE) is anticipated in the South American power generation matrix, mainly in wind and solar sources (CAF, 2016b), that would increase the NCRE share in total investment from 5.3\% in 2016 to over 37\% in 2030 (see figure V.32). However, this would achieve an installed power capacity (the energy capacity that a power plant can generate and deliver under ideal conditions) equivalent to only around $7.6 \%$ of the electricity matrix in 2030, compared to the current $3.9 \%$. In terms of effective power generation (the actual yield with which the generating plants operate), in 2030 this would represent $5.3 \%$ of the electricity matrix, up from $2.9 \%$ in 2015 (see figure V.33).

23 According to the International Renewable Energy Agency (IRENA, 2016b), doubling the supply of renewables in the Mexican and Brazilian energy matrices by 2030 would increase their GDP by over 1\%. More than 2 million people were working in the renewable energy sector in the region in 2015; in Brazil, wind power supported 41,000 jobs in 2015, corresponding to 64\% of such jobs in the region. In 2016 alone, more than 30,000 jobs were generated (ABEEÓLICA, 2017b). Projections by NRDC/ACERA (2013) suggest that supplying $20 \%$ of electricity from renewable sources in Chile could increase GDP by $0.6 \%$ and create 7,800 jobs. PwC (2015) estimates that generating $21 \mathrm{GW}$ from renewables in Mexico by 2029 could add a cumulative US\$ 27 billion to GDP, equivalent to $2 \%$ of GDP in 2013 , and also create 134,000 jobs. All renewables combined could generate 182,000 jobs in Mexico by 2029 (PwC, 2015). Brazil already has roughly 1 million workers in the liquid biofuels (ethanol) sector (IRENA, 2016a).

24 The sectors with the highest proportion of green jobs in Mexico are: waste recycling (12\%), sustainable construction (11\%), renewable electric power (9\%), forestry and reforestation $(8 \%)$, clean industry $(7 \%)$ and organic farming $(6 \%)$. 
Figure V.32

South America: distribution of investments in the electric energy matrix by generating sources, 2016 and 2030 (Percentages)

\section{A. Distribution of investments under way in 2016}

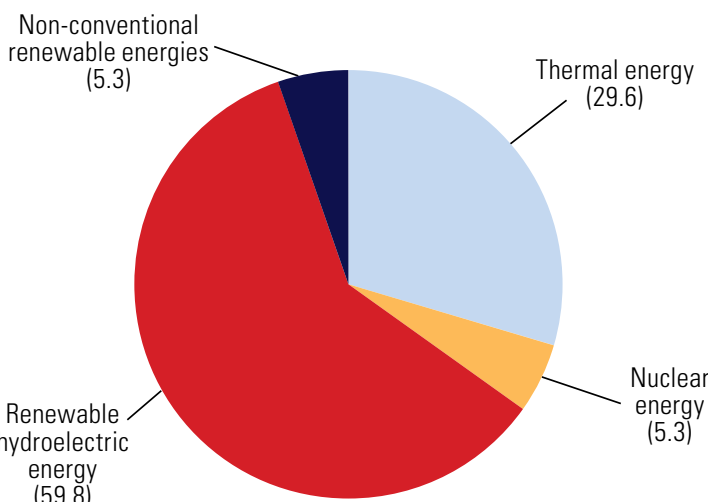

\section{B. Distribution of investments anticipated by 2030}

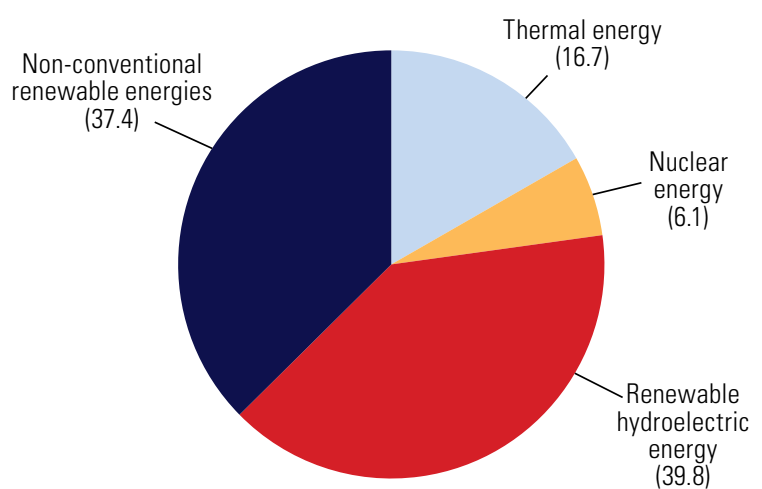

Source: Economic Commission for Latin America and the Caribbean (ECLAC), on the basis of Development Bank of Latin America (CAF), "Proyectos Estratégicos para Seguridad Energética Regional (PRESER)", Caracas, 2016.

\section{Figure V.33}

South America: installed power and effective generation of non-conventional renewable energies, 2015-2030 (Percentages)

\section{A. Installed power, 2015}

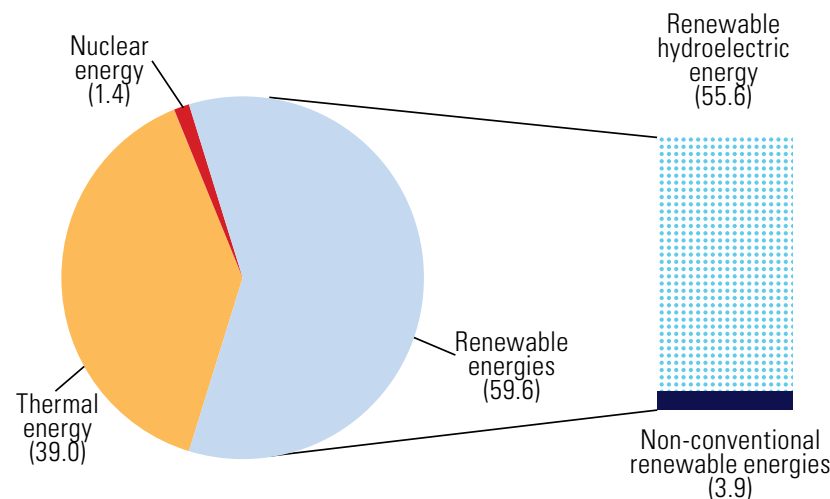

\section{Effective generation, 2015}

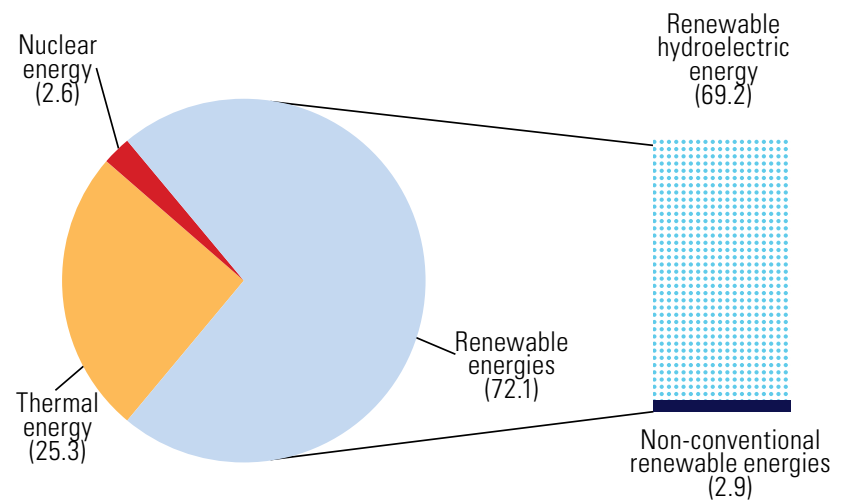

B. Installed power, 2030

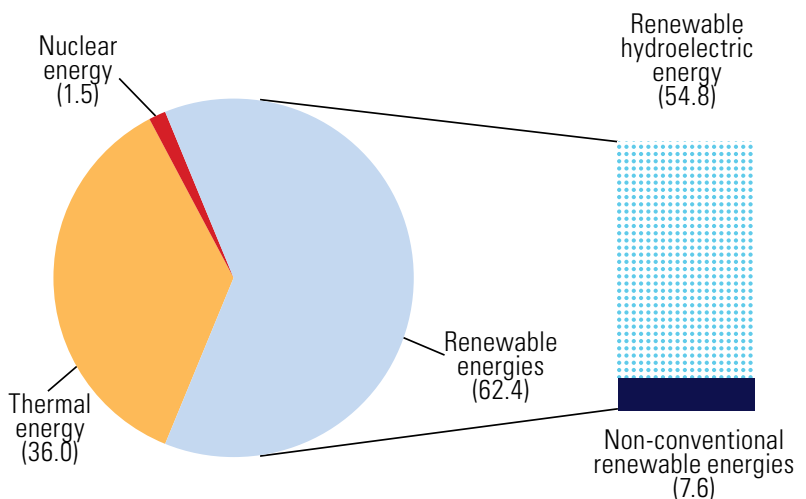

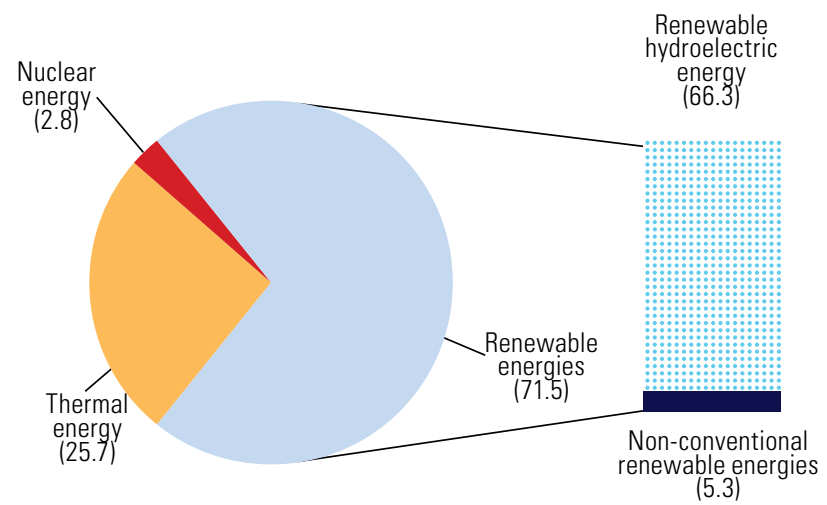

Source: Economic Commission for Latin America and the Caribbean (ECLAC), on the basis of Development Bank of Latin America (CAF), "Proyectos Estratégicos para Seguridad Energética Regional (PRESER)", Caracas, 2016b. 
The current and projected patterns of investment are insufficient to produce a profound change in the region's energy structure. In fact, between 2014 and 2016 there was a significant and worrying decline in renewable energy investments in the region (see figure V.34).

Figure V.34

Latin America and the Caribbean: investments in renewable energies, 2004-2016

(Billions of dollars)

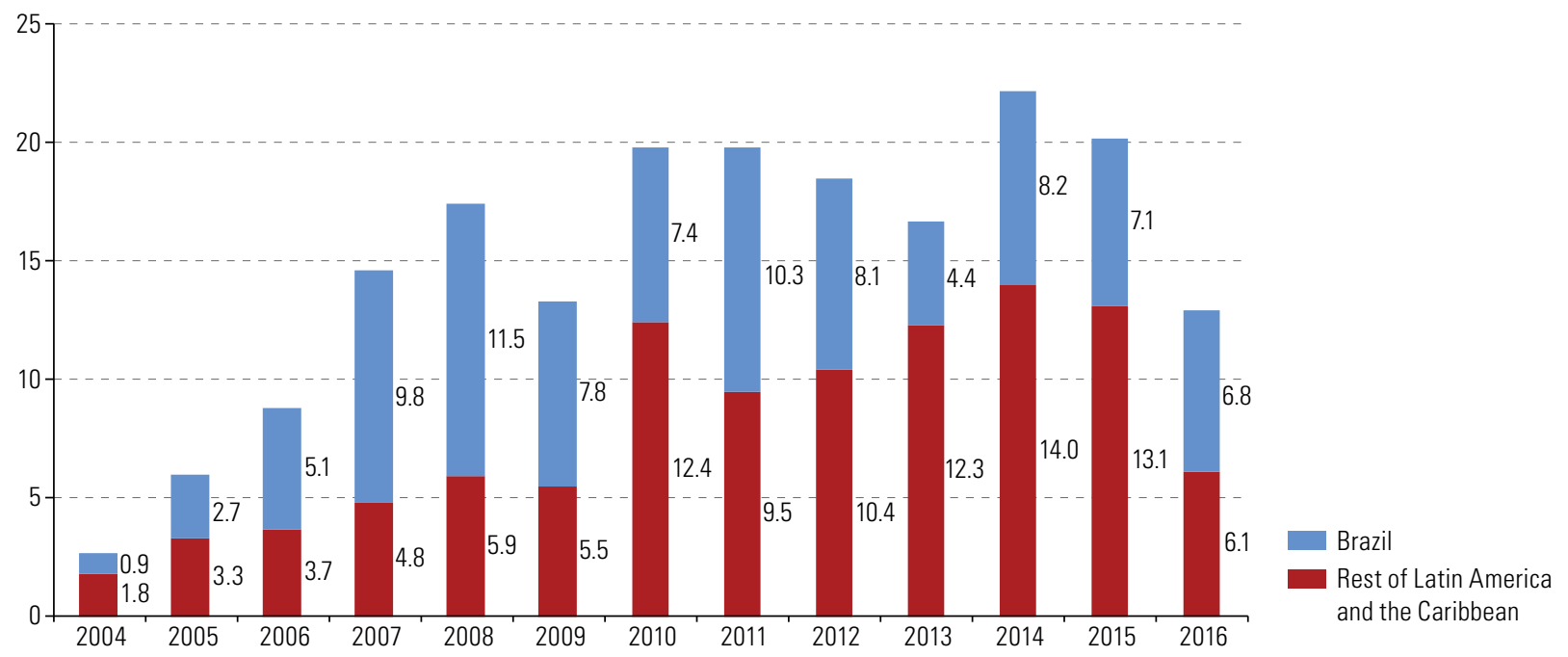

Source: International Renewable Energy Agency (IRENA), "Featured Dashboard" [online] http://resourceirena.irena.org/gateway/dashboard/?topic= 6\&subTopic=11, 2017

The limited penetration of renewables in the region may be attributed to several factors: the lack of formal commitments among the countries to reduce GHGs; the slowdown in the world economy; the significant volatility in the price of oil; and the inertia of regulatory and fiscal policies.

Making progress in these fields requires policies to promote new energy-efficiency projects, such as systems for storing large volumes of energy produced intermittently by renewables, taking advantage of the region's abundant natural resources (water and lithium) and forging production linkages associated with their production and technological applications. The current today is inconsistent with the enormous potential for renewable wind and solar energy existing in most countries and there is enormous room to increase the penetration of these sources.

\section{Complementarity and integration between renewable energies}

Hydroelectric power generation is vulnerable to climatic phenomena (such as El Niño, La Niña or drought). Given the growing opposition to the construction of reservoirs, which, like mining, is a source of major socioenvironmental conflict, licensing processes need to be more transparent and participatory. Conversely, projects that exploit renewable energies, such as wind and solar, are smaller, ${ }^{25}$ are geographically dispersed and have less environmental implications. As a result, they face fewer environmental permit barriers. Moreover, their construction period (18 to 24 months) is shorter than the 5-7 years required on average to complete a hydroelectric project; and they offer attractive solutions for providing electricity to isolated communities.

The region's abundant renewable energy resources (water, wind and solar) can complement each other, both geographically and seasonally (see maps V.3 and V.4). For example, the flow of the San Francisco River,

25 Compared to large hydroelectric projects, such as Belo Monte (11,233 MW) in Brazil or Ituango (2,400 MW) in Colombia, and in potential projects such as HidroAysén in Chile (2,000 MW) 
the main source of hydroelectric production in Brazil's North-East, diminishes during the summer, but the wind speed increases. ${ }^{26}$ Thus, complementarity in and between countries could produce virtuous technical and political processes for regional energy integration. This paradigm shift provides an opportunity for regulators to anticipate innovations in the electrical system.

Following an absence of almost a decade, energy complementation has returned to the discussion table, especially in South America, owing to the volatility of oil prices; the discovery of large resources of shale gas (particularly in Argentina, Brazil, Colombia and Mexico); the increase in the supply of renewable energies (mainly wind and solar) in Argentina, Brazil, Chile, Mexico and Uruguay and also Central America; the forecast growth in energy demand; obstacles to the approval of large and medium-scale hydroelectric projects; and the role of energy efficiency in combating climate change. The Paris Agreement emphasizes the role of these energies for the fulfilment of nationally determined contributions for decarbonizing the global economy. The energy and climate- change goals of the 2030 Agenda for Sustainable Development (SDGs 7 and 13, respectively) contain ambitious targets for renewable energies, energy efficiency, access to modern energy sources and international sector cooperation. As a strategic resource with geopolitical connotations, energy can be a major force for regional integration.

\section{Map V.3}

Latin America and the Caribbean: wind power potential, 2005

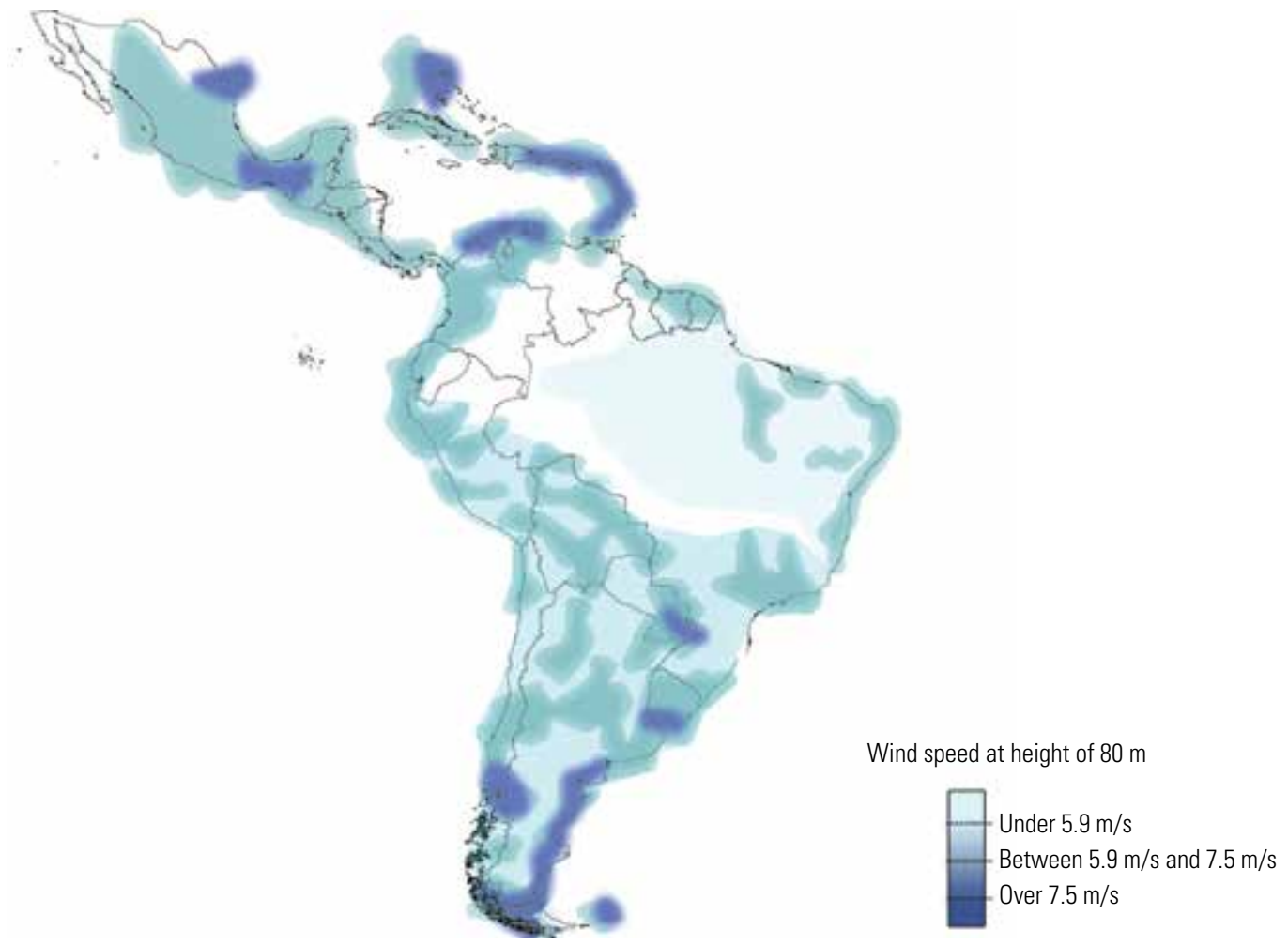

Source: Economic Commission for Latin America and the Caribbean (ECLAC), on the basis of Journal of Geophysical Research: Biogeosciences, vol. 110, 2005 and SolarGis [online database] https://solargis.com/.

Note: The boundaries and names shown on this map do not imply official endorsement or acceptance by the United Nations.

26 According to Vergara and others (2013), the World Bank analysed this complementarity in Colombia and found that wind energy is available in drought periods when its contribution to the system is most needed and demand is at its peak. 
Map V.4

Latin America and the Caribbean: solar power potential, 2009-2013

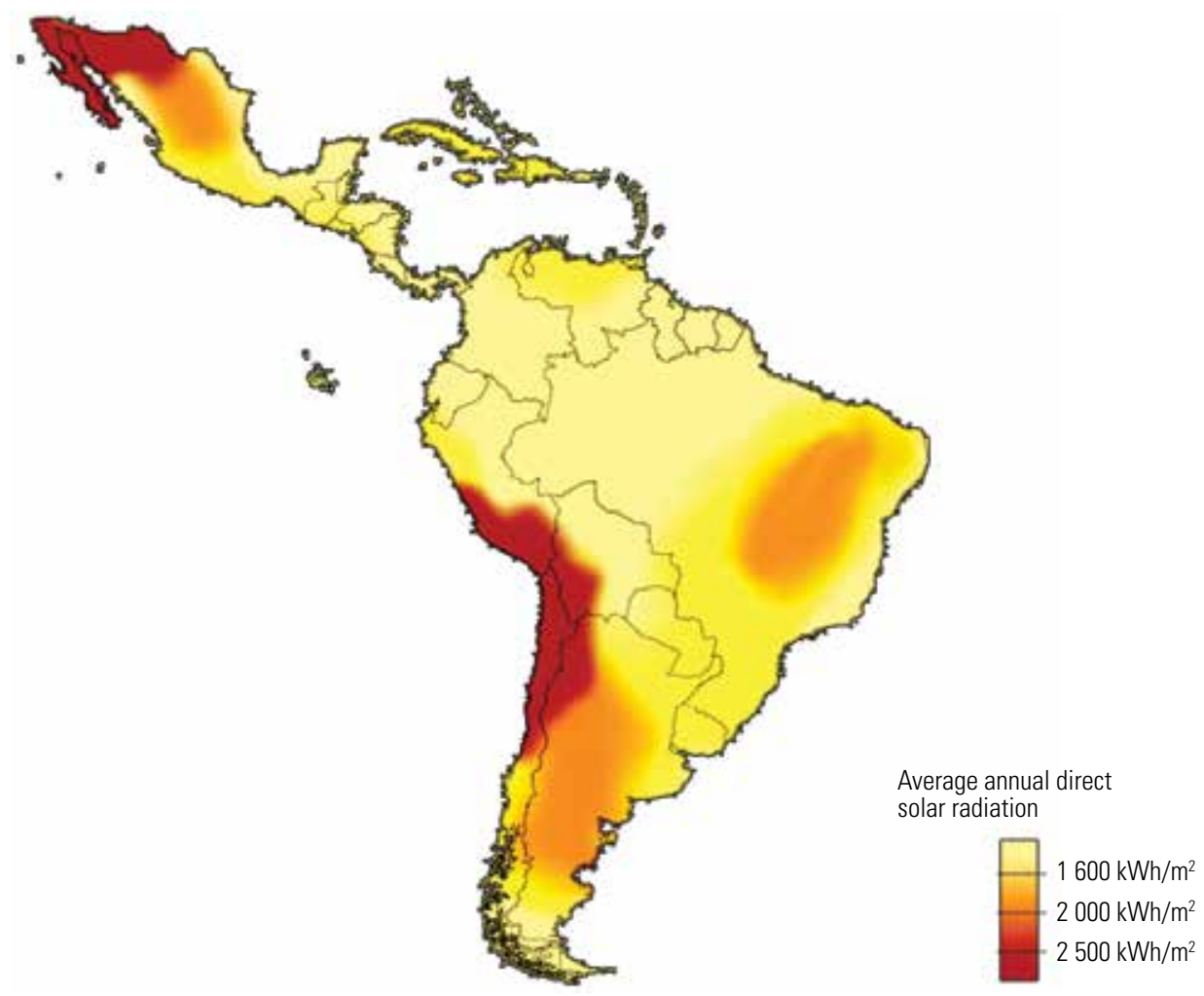

Source: Economic Commission for Latin America and the Caribbean (ECLAC), on the basis of Journal of Geophysical Research: Biogeosciences, vol. 110, 2005 and SolarGis [online database] https://solargis.com/.

Note: The boundaries and names shown on this map do not imply official endorsement or acceptance by the United Nations.

\section{E. The foundations of a structure that is inefficient in terms of energy and production}

Previous chapters analysed the impacts of inequality on productivity and capacity-building in the Latin American economies. This chapter has discussed its effects in terms of territory, infrastructure, cities and the environment. At these four levels, a pattern is reproduced in which the high concentration of income and skills hampers the diffusion of technology and produces high costs in terms of hours of work, health, energy consumption and destruction of natural resources.

If the current development style is maintained, an increase in global growth would mean breaching the planet's environmental limits. The negative externalities associated with this pattern impair the well-being of present generations, especially the poorest; and they challenge intergenerational equality, since the interests of future generations in preserving the environment are not represented in public policies. The 2030 Agenda for Sustainable Development therefore goes beyond the mere integration of social, economic, and environmental policies, and should be interpreted as a new style of development and growth with consequent new patterns of production and consumption.

A situation has grown up in the region in which inequality and low productive and environmental efficiency are combined, as characterized in diagram $\mathrm{V} .1 .{ }^{27}$ The blocks of the diagram have multiple interconnections, of which the two most important are detailed below. The first has inequality as its centre. A natural-resource-

27 The content of each chart in the diagram is discussed in depth in the respective chapters. 
reliant, poorly diversified production structure that is highly vulnerable to external shocks reinforces inequality by creating insufficient quality jobs, compounded by inequalities in education and opportunities which reduce capabilities and innovation.

The technological revolution also has a key role, but with effects in a single direction, as it is basically exogenous to the economies of the region. This revolution will have major impacts on specialization patterns and possibilities for moving onto a low-carbon path, which requires the countries of the region to internalize capacities to disseminate technical progress, innovate and reduce the gap with the developed world and thus break the technological, production and environmental lock-in.

\section{Diagram V.1}

Latin America and the Caribbean: nodes of lock-in reproduction in a low-dynamism equilibrium

\section{Production structure}

Technology lag, low share of R\&D-intensive activities.

Exports of natural resources and manufactures with little value added.

External vulnerability and unstable growth. Low intensity and duration of cyclical boom.

\section{Productive efficiency}

Low level and slow growth of productivity. Gaps in access and blocking of learning paths. Limits to investment and to increasing returns between investment, growth and productivity (per Kaldor-Schumpeter)

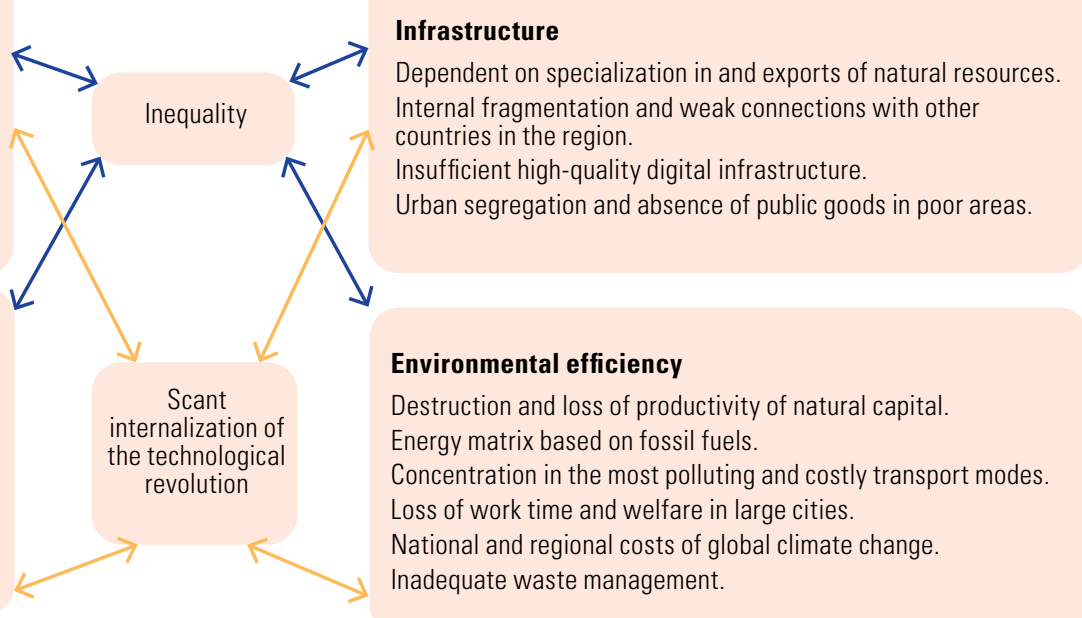

Source: Economic Commission for Latin America and the Caribbean (ECLAC).

In this framework, the four dimensions studied in this chapter make up a structure that is inefficient in terms of energy and productive activities. Inequality and technological dynamics have much to do with the model's inertia, while also reflecting political arrangements that make it hard to change the trajectory. Chapter $\mathrm{VI}$ discusses those arrangements and their expression at the institutional and cultural levels, one example being the way in which patterns of public and private investment in infrastructure reinforce historical distortions. Investment in energy and transport in large cities and more developed territories maintains inequalities and entrenches the model of inadequate connectivity between countries, as well as between the peripheral and more advanced regions in each country. This pattern is incompatible with sustainable development and it is both the result and the cause of persistent inequality. 


\section{Bibliography}

ABEEólica (Brazilian Wind Energy Association) (2017a), “Dados mensais. Fevereiro de 2017", São Paulo.

(2017b), "Brasil sobe no ranking mundial de capacidade instalada de energia eólica" [online] http://www.abeeolica.org. br/noticias/brasil-sobe-no-ranking-mundial-de-capacidade-instalada-de-energia-eolica/.

Agrawala, S. and others (2010), "Plan or react?: analysis of adaptation costs and benefits using integrated assessment models", OECD Environment Working Papers, vol. 23, No. 23.

Angel, S. and others (2012), Atlas of Urban Expansion, Cambridge, Massachusetts, Lincoln Institute of Land Policy, June. ANTP (Brazilian National Association of Public Transport) (2015), "Sistema de Mobilidade Urbana. Relatório 2014", São Paulo [online] http://www.antp.org.br/sistema-de-informacoes-da-mobilidade/apresentacao.html.

Aprosoja Brasil (2016), "Produtividade da soja é a mesma há 15 anos" [online] http://www.projetosojabrasil.com.br/ produtividade-da-soja-e-a-mesma-ha-15-anos/.

Arthur, B. (1994), Increasing Returns and Path-Dependency in Economics, Ann Arbor, Michigan University Press.

Bárcena, A. and A. Prado (2016), El imperativo de la igualdad: por un desarrollo sostenible en América Latina y el Caribe, Buenos Aires, Economic Commission for Latin America and the Caribbean (ECLAC)/Siglo XXI.

BCC Research (2015), Global Markets for Environmental Remediation Technologies, January.

Berger, R. (2014), Informe sobre el mercado de las tecnologías ambientales a nivel mundial [online] http://www. forumambiental.org/pdf/Greentech2014.pdf.

Biggs, R., M. Schlüter and M. Schoon (2015), Principles for Building Resilience: Sustaining Ecosystem Services in SocialEcological Systems, Cambridge, Cambridge University Press.

BNDES (Brazilian Development Bank) (2016), "O desenrolar da energia eólica no Brasil," Rio de Janeiro [online] http://www. bndes.gov.br/wps/portal/site/home/conhecimento/noticias/noticia/energia-eolica-brasil.

(2015), "Fundo Clima - energias renováveis", Rio de Janeiro [online] https://www.bndes.gov.br/wps/portal/site/home/ financiamento/produto/fundo-clima-energias-renovaveis.

Bogotá Chamber of Commerce (2016), "Taller sobre cosméticos e ingredientes naturales: mercado, tendencias y pasos para ser una empresa de biocomercio ético" [online] https://www.ccb.org.co/Clusters/Cluster-de-Cosmeticos/Noticias/2016/ Octubre/Pasos-para-ser-una-empresa-de-biocomercio-etico.

Brakman, S. H. Garretsen and C. van Marrewijk (2011), The New Introduction to Geographical Economics, Cambridge University Press.

Brazil (2017), "Percentual obrigatório de biodiesel no óleo diesel passa para 8\%," Brasilia [online] http://www.brasil.gov.br/ economia-e-emprego/2017/03/percentual-obrigatorio-de-biodiesel-no-oleo-diesel-passa-para-8.

CAF (Development Bank of Latin America) (2016a), "Observatorio de Movilidad Urbana" [online] http://www.caf.com/es/ temas/o/observatorio-de-movilidad-urbana/bases-de-datos.

(2016b), "Proyectos Estratégicos para Seguridad Energética Regional (PRESER)," Caracas.

(2009), Observatorio de Movilidad Urbana para América Latina: información para mejores políticas y mejores ciudades, Rio de Janeiro.

Caldeira, T. (2000), Cidade de muros: crime segregação e cidadania em São Paulo, São Paulo, University of São Paulo.

Calderón, C. and L. Servén (2010), "Infrastructure in Latin America," World Bank Policy Research Working Paper, No. 5317, Washington, D.C., World Bank.

CETESB (Environmental Sanitation Technologies Company) (2014), Plano de Controle de Poluição Veicular 2014-2016, São Paulo.

Cimoli, M., G. Porcile and S. Rovira (2010), "Structural change and the BOP-constraint: why did Latin America fail to converge?", Cambridge Journal of Economics, vol. 34, No. 2.

Comisión Permanente de Transporte de la Cuenca del Plata (2015), “Hidrovía Paraná Paraguay: camino clave para el desarrollo de la región" [online] http://www.agroindustria.gob.ar/sitio/areas/ss_mercados_agropecuarios/jornadas_ congresos/_archivos/000101_2017/000100_Infraestructura\%20y\%20Log\% C3\%ADstica/000104_Hidrov\%C3 \%ADa\%20Paran\%C3\%A1\%20Paraguay.pdf.

CONABIO (Mexico's National Commission for the Knowledge and Use of Biodiversity) (s/f), "Centros de plantas cultivadas" [online] http://www.biodiversidad.gob.mx/genes/centrosOrigen/centrosPlantas1a.html.

Crutzen, P. J. (2002), "Geology of mankind: the Anthropocene", Nature, vol. 415, No. 23.

Cuervo, L. M. (2004), "Desarrollo económico y primacía urbana en América Latina: una visión histórica comparativa", El rostro urbano de América Latina, A. Ribeiro (ed.), Buenos Aires, Latin American Social Sciences Council (CLACSO).

De Mattos, C. (1988), "Los procesos de concentración territorial del capital en la formación de los sistemas nacionales latinoamericanos. Versión preliminar", Santiago, Instituto Latinoamericano y del Caribe de Planificación Económica y Social (ILPES) [online] http://repositorio.cepal.org/bitstream/handle/11362/33304/S8800602_es.pdf. 
ECLAC (Economic Commission for Latin America and the Caribbean) (2017a), "Panorama multidimensional del desarrollo urbano en América Latina y el Caribe", Project Documents (LC/TS.2017/67), Santiago.

(2017b), "Panorama del desarrollo territorial de América Latina y el Caribe", Project Documents (LCM.671), Santiago. (2017c), International Trade Outlook for Latin America and the Caribbean, 2017 (LC/PUB.2017/22-P), Santiago.

(2017d), La economía del cambio climático en América Latina y el Caribe: una visión gráfica (LC/TS.2017/84/Rev.1), Santiago, December.

(2016a), Horizons 2030: equality at the centre of sustainable development (LC/G.2660/Rev.1), Santiago.

(2016b), The 2030 Agenda and the Sustainable Development Goals: an opportunity for Latin America and the Caribbean (LC/G.2681/Rev.2), Santiago, April.

(2016c), Statistical Yearbook for Latin America and the Caribbean, 2016 (LC/PUB.2017/2-P), Santiago.

(2016d), "Territorio e igualdad. Planificación del desarrollo con perspectiva de género", Handbooks series, No. 4 (LC/L.4237), Santiago, October.

(2016e), CEPALSTAT [online database] http://estadisticas.CEPAL.org/CEPALstat/web_CEPALstat/Portada.asp?idioma=i. (2015a), La economía del cambio climático en América Latina y el Caribe: paradojas y desafíos del desarrollo sostenible (LC/G.2624) Santiago, February.

(2015b), Statistical Yearbook for Latin America and the Caribbean, 2015 (LC/G.2656-P), Santiago.

(2015c), Social Panorama of Latin America, 2015 (LC/G.2691-P), Santiago, October.

(2014a), Compacts for Equality: Towards a Sustainable Future (LC/G.2586 (SES.35/3)), Santiago.

(2014b), Social Panorama of Latin America, 2014 (LC/G.2635-P), Santiago.

(2014c), The economics of climate change in Latin America and the Caribbean: paradoxes and challenges. Overview for 2014 (LC/L.3895), Santiago, November.

(2012), Structural Change for Equality: An Integrated Approach to Development (LC/G.2524(SES.34/3)), Santiago, July. (2010), Time for Equality: Closing Gaps, Opening Trails (LC/G.2432(SES.33/3)), Santiago.

ECLAC/FAO/IICA (Economic Commission for Latin America and the Caribbean/Food and Agriculture Organization of the United Nations/Inter-American Institute for Cooperation on Agriculture) (2017), "La bioeconomía: oportunidades y desafíos para el desarrollo rural, agrícola y agroindustrial en América Latina y el Caribe", Boletín CEPAL-FAO-IICA [online] http://repositorio.cepal.org/bitstream/handle/11362/42724/1/S1701068_es.pdf.

EIA (Energy Information Administration) (2017), Levelized Cost and Levelized Avoided Cost of New Generation Resources in the Annual Energy Outlook 2017 [online] https://www.eia.gov/outlooks/aeo/pdf/electricity_generation.pdf.

EIU/IDB (Economist Intelligence Unit/Inter-American Development Bank) (2017), Avances y desafíos para el reciclaje inclusivo: evaluación de 12 ciudades de América Latina y el Caribe, New York.

El Diario (2015), "El tren de alta velocidad Río-Sao Paulo dejó de ser una prioridad para Brasil", June [online] http://www. eldiario.es/economia/velocidad-Rio-Sao-Paulo-prioridad-Brasil_0_396861565.html.

ELD Initiative (2015), The Value of Land: Prosperous Lands and Positive Rewards through Sustainable Land Management, Bonn.

Eletrobras (2016), Relatório Anual 2016 [online] http://eletrobras.com/pt/SobreaEletrobras/Relatorio_Anual_Sustentabilidade /2016/Relatorio-Anual-Eletrobras-2016.pdf.

EMBRAPA (Brazilian Agricultural Research Enterprise) (2017), “Soja em números (safra 2016/2017)," Londrina [online] https://www.embrapa.br/web/portal/soja/cultivos/soja1/dados-economicos.

EM-DAT (The International Disaster Database) (2016) [online] http://www.emdat.be/.

Enerdata (2015), Research on Energy Efficiency, $\mathrm{CO}_{2}$ Emissions, Energy Consumption, Forecast.

EPE (Energy Research Office) (2016), Energia termelétrica: gás natural, biomassa, carvão, nuclear, M. T. Tolmasquim (coord.), Rio de Janeiro.

European Commission (2016), Trends in Global $\mathrm{CO}_{2}$ Emissions: 2016 Report [online] http://edgar.jrc.ec.europa.eu/news_docs/ jrc-2016-trends-in-global-co2-emissions-2016-report-103425.pdf.

(2015), World Atlas of Desertification (WAD) [online] http://wad.jrc.ec.europa.eu/.

(2014), Construir una infraestructura verde para Europa [online] http://ec.europa.eu/environment/nature/ecosystems/ docs/GI-Brochure-210x210-ES-web.pdf.

(2012), Innovating for Sustainable Growth: a Bioeconomy for Europe, Directorate-General for Research and Innovation.

European Union/FAO (Food and Agriculture Organization of the United Nations) (2014), Atlas de Suelos de América Latina y el Caribe, Luxemburg.

FAO (Food and Agriculture Organization of the United Nations) (2017a), "Sustainable food and agriculture" [online] http:// www.fao.org/sustainability/en/.

(2017b), Corporate Database for Substantive Statistical Data (FAOSTAT) [online] www.faostat.fao.org.

(2015), Global Forest Resources Assessment 2015: Desk reference [online] http://www.fao. org/3/a-i4808e.pdf.

Fernandes, E. (2007), "Constructing the 'right to the city' in Brazil", Social \& Legal Studies, vol. 16, No. 2. 
Ferrario, F. and others (2014), "The effectiveness of coral reefs for coastal hazard risk reduction and adaptation", Nature Communications, vol. 5, No. 3794.

Folk, C., C. R. Carpenter and B. H. Walker (2010), "Resilience thinking: integrating resilience, adaptability and transformability", Ecology and Society, vol. 15, No. 20.

Freeman, C. (2008), Systems of Innovation: Selected Essays in Evolutionary Economics, Cheltenham, Elgar.

García Alonso, L. (2017), "Aspectos metodológicos en el vínculo entre recursos naturales y logística regional”, Project Documents (LC/TS.2017/21), Santiago, Economic Commission for Latin America and the Caribbean (ECLAC).

Global Mechanism of the United Nations Convention to Combat Desertification in Those Countries Experiencing Serious Drought and/or Desertification, Particularly in Africa (2015), Land degradation neutrality fund: an innovative investment fund project, Paris, December.

Golden, J. S. and others (2015), An Economic Impact Analysis of the U.S. Biobased Products Industry: A Report to the Congress of the United States of America, Duke Center for Sustainability \& Commerce/Supply Chain Resource Cooperative, North Carolina State University.

Green, J. and S. Sánchez (2012), Air Quality in Latin America: An Overview, Washington, D.C., Clean Air Institute [online] http://www.cleanairinstitute.org/ calidaddelaireamericalatina/cai-report-english.pdf.

Harris, J. M. (2013), “Green Keynesianism: beyond standard growth paradigms", Working Paper, No. 13-02, Medford, Global Development and Environment Institute, Tufts University.

(2008), “Ecological macroeconomics: consumption, investment, and climate change", Working Paper, No. 08-02, Medford, Global Development and Environment Institute, Tufts University.

Harvey, D. (2008), "The right to the city", New Left Review, vol. 53, September-October.

Henry, G., E. Trigo and E. Hodson de Jaramillo (2014), “Bioeconomía en América Latina diferentes vías, resultados preliminares y buenas prácticas", Hacia una bioeconomía en América Latina y el Caribe en asociación con Europa, E. Hodson de Jaramillo (ed.), Bogotá, Editorial Pontificia Universidad Javeriana.

Herren, H. and others (2011), Green Jobs for a Revitalized Food and Agriculture Sector, Roma, Food and Agriculture Organization of the United Nations (FAO).

Heusser, N. (2017), "La deuda de Chile con los trenes", Diario La Hora, enero [online] http://www.lahora.cl/2017/01/ladeuda-chile-los-trenes/.

Holanda, A. (2004), “Biodiesel e inclusão social. Ariosto Holanda", Série Cadernos de Altos Estudos, No. 1, Brasilia, Chamber of Deputies.

Holling, C. S. (2001), "Understanding the complexity of economic, ecological and social systems", Ecosystems, vol. 4.

Hoornweg, D. and P. Bhada-Tata (2012), "What a waste: a global review of solid waste management", Urban Development Series Knowledge Papers, No. 15, Washington, D.C., Banco Mundial, March.

Hunter D. and V. Heywood (eds.) (2011), Crop wild relatives: a manual of in situ conservation, Roma, Bioversity International.

IDB (Inter-American Development Bank) (2016a), "Lights on?: Energy needs in Latin America and the Caribbean to 2040", IDB Monograph, No. 378, Washington, D.C. [online] https://publications.iadb.org/handle/11319/7361 ?locale-attribute=es\&. (2016b), "Natural capital \& roads: managing dependencies and impacts on ecosystem services for sustainable road investments", IDB Monograph, No. 476, Washington, D.C.

IEA (International Energy Agency) (2016), Key World Energy Statistics, Paris.

IFAD (International Fund for Agricultural Development) (2010), “Desertification", Roma.

ILO (International Labour Organization) (2016a), Green Jobs: Progress Report 2014-2015, Geneva.

(2016b), Empleos verdes para un desarrollo sostenible: el caso uruguayo, Montevideo, June.

(2013), Evaluation of the Potential of Green Jobs in Mexico, Geneva, September [online] http://www.ilo.org/wcmsp5/ groups/public/---ed_emp/---emp_ent/documents/publication/wcms_236143.pdf.

(2012), Working towards sustainable development: opportunities for decent work and social inclusion in a green economy, Geneva.

IMF (International Monetary Fund) (2015), “From ambition to execution: policies in support of sustainable development goals", IMF Staff Discussion Note, No. IMF/15/18.

Infante, R. (comp.) (2016), “Desarrollo inclusivo en América Latina: textos seleccionados 2009-2016", Páginas Selectas de la CEPAL (LC/M.35), Santiago, Economic Commission for Latin America and the Caribbean (ECLAC).

IPCC (Intergovernmental Panel on Climate Change) (2013), Climate Change 2013: The Physical Science Basis. Contribution of Working Group I to the Fifth Assessment Report of the Intergovernmental Panel on Climate Change. Summary for Policymakers, Cambridge/New York, Cambridge University Press [online] http://www.ipcc.ch/pdf/assessment-report/ ar5/wg1/WG1AR5_SPM_FINAL.pdf.

IRENA (International Renewable Energy Agency) (2017a), Rethinking Energy 2017, Abu Dhabi.

(2017b), Renewable Energy Auctions: Analysing 2016, Abu Dhabi

(2016a), Renewable Energy and Jobs: Annual Review 2016, Abu Dhabi. 
(2016b), Renewable Energy Market Analysis: Latin America, Abu Dhabi

(2016c), Renewable Energy Benefits: Measuring the Economics, Abu Dhabi [online] http://www.irena.org/ documentdownloads/publications/irena_measuring-the-economics_2016.pdf.

(2016d), G20 Toolkit for Renewable Energy Deployment: Country options for sustainable growth based on Remap, Abu Dhabi.

(2015), Rethinking Energy: Renewable Energy and Climate Change, Abu Dhabi.

IRP/PNUMA (International Resource Panel/United Nations Environment Programme) (2016), Global Material Flows and Resource Productivity: Assessment Report for the UNEP International Resource Panel, Paris.

ITD-UPM/IDB (Innovation and Technology for Development Centre/Inter-American Development Bank) (2014), Gestión integral de los residuos sólidos: el modelo de ciudad saludable en Perú, Madrid [online] http://nube.cesvima.upm.es/ public. php? service =files\&t=3b7beace51654ea674024eb7697d6aee\&download.

Jaimurzina, A., C. Muñoz and G. Pérez-Salas (2017), "Género y transporte: experiencias y visiones de política pública en América Latina", Natural Resources and Infrastructure series, No. 184 (LC/TS.2017/125), Santiago, Economic Commission for Latin America and the Caribbean (ECLAC).

Jaimurzina, A., G. Pérez-Salas and R. Sánchez (2015), “Políticas de logística y movilidad para el desarrollo sostenible y la integración regional", Natural Resources and Infrastructure series, No. 174 (LC/L.4107), Santiago, Economic Commission for Latin America and the Caribbean (ECLAC).

Jordán, R., L. Riffo and A. Prado (coords.) (2017), “Desarrollo sostenible, urbanización y desigualdad en América Latina y el Caribe: dinámicas y desafíos para el cambio estructural", Project Documents (LC/PUB.2017/19), Santiago, Economic Commission for Latin America and the Caribbean (ECLAC).

Karaguliana, F. and others (2015), "Contributions to cities' ambient particulate matter (PM): A systematic review of local source contributions at global level," Atmospheric Environment, vol. 120, Elsevier, November.

La Nación (2017), "Alstom busca su revancha en la Argentina", April [online] http://www.lanacion.com.ar/2009736-alstombusca-su-revancha-en-la-argentina.

(2012), "Brasil planea tener un tren de alta velocidad en 2018", August [online] http://www.lanacion.com.ar/1502161brasil-planea-tener-un-tren-de-alta-velocidad-en-2018.

La República (2012), "Primer tren de alta velocidad de América Latina operará en Brasil en el 2018", August [online] http:// larepublica.pe/tecnologia/654843-primer-tren-de-alta-velocidad-de-america-latina-operara-en-brasil-en-el-2018.

Lefebvre, H. (1968), Le droit à la ville, Paris, Anthropos.

López Moreno, E. (2014), "Ghost cities and empty houses: wasted prosperity", American International Journal of Social Science, vol. 3, No. 2, March.

Magrin, G. (2015), "Adaptación al cambio climático en América Latina y el Caribe," Project Documents, No. 692 (LCM.692), Santiago, Economic Commission for Latin America and the Caribbean (ECLAC), December.

Magrin, G. and others (2014), "Chapter 27. Central and South America", Climate Change 2014: Impacts, Adaptation, and Vulnerability. Part B: Regional Aspects. Contribution of Working Group II to the Fifth Assessment Report of the Intergovernmental Panel on Climate Change, V. R. Barros and others (eds.), Cambridge, Cambridge University Press. (2007), "Latin America", Climate Change 2007: Impacts, Adaptation and Vulnerability. Working Group II Contribution to the Fourth Assessment Report of the Intergovernmental Panel on Climate Change, M. L. Parry and others (eds.), Intergovernmental Panel on Climate Change (IPCC), Cambridge, Cambridge University Press.

Markets and Markets (2017), "Market reports" [online] http://www.marketsandmarkets.com/food-and-beverages-marketresearch-6.html.

(2016), Biostimulants Market by Active Ingredient (Humic Substances, Seaweed, Microbials, Trace Minerals, Vitamins \& Amino Acids), Crop Type (Row Crops, Fruits \& Vegetables, Turf \& Ornamentals), Formulation, Application Method, and Region - Global Forecast to 2022 [online] http://www.marketsandmarkets.com/Market-Reports/biostimulantmarket-1081.html.

Martínez-Alier, J. and J. Roca (2013), Economía ecológica y política ambiental, Mexico City, Fondo de Cultura Económica.

Mazzucato, M. (2013), "Finance, innovation and growth: creative destruction vs. destructive creation", Industrial and Corporate Change, vol. 22, No. 4, August.

Mazzucato, M. and C. Pérez (2014), "Innovation as growth policy: the challenge for Europe", SPRU Working Paper Series, No. SWPS 2014-13, July.

Mendelsohn, R. and A. Dinar (2009), Climate change and agriculture: an economic analysis of global impacts, adaptation and distributional effects, Edward Elgar, October.

Mendoza, M. A. (2014), "Panorama preliminar de los subsidios y los impuestos a las gasolinas y diésel en los países de América Latina", Project Documents (LCM.641), Santiago, Economic Commission for Latin America and the Caribbean/ German Agency for International Cooperation (ECLAC/GIZ). 
Metro de Bogotá (2017), "Resultados de la estructuración primera línea del metro de Bogotá", November [online] http://www.metrodebogota.gov.co/sites/default/files/Reuni\% C3\%B3n\%20de\%20Cierre\%20Estructuraci\% C3 \%B3n\%20Tecnica\%20-\%20Ciudadan\% C3\%ADa\%20Nov. \% 2014\%20a\% 2016\% 202017\%20PDF.pdf.

Ministry of the Environment of Brazil (2017), "PROCONVE: Programa de Controle de Poluição do Ar por Veículos Automotores" [online] http://www.mma.gov.br/estruturas/163/_arquivos/proconve_163.pdf.

Ministry of the Environment of Peru (2016), "El Modelo de Negocio de Biocomercio: innovación para el desarrollo sostenible”, documento presentado en el taller Identificación de Barreras al Comercio de Productos Peruanos de Biocomercio y otros Derivados de la Biodiversidad, Lima, United Nations Conference on Trade and Development (UNCTAD), August [online] http://unctad.org/meetings/en/Presentation/ditc-ted-16082016-peru-Sesion2-MINAM.pdf.

Muñoz, C. and G. Pérez (2017), "Reflections on the role of logistics in the sustainable exploitation of natural resources in Latin America and the Caribbean," FAL Bulletin, No. 357, Santiago, Economic Commission for Latin America and the Caribbean (ECLAC), May.

New York University/Lincoln Institute of Land Policy/UN-Habitat (2016), "Atlas of Urban Expansion" [online database] http:// www.atlasofurbanexpansion.org/.

NRDC/ACERA (Natural Resources Defense Council/Asociación Chilena de Energías Renovables) (2013), “Beneficios económicos de energías renovables no convencionales en Chile", September.

Observatório ABC (Agricultura de Baixo Carbono) (2017), Agricultura de baixa emissão de carbono: Observatório ABC avaliação do uso estratégico das áreas prioritárias do Programa ABC, São Paulo, Getúlio Vargas Foundation, April. (2015), Invertendo o sinal de carbono da agropecuária brasileira: Uma estimativa do potencial de mitigação de tecnologías do Plano ABC de 2012 a 2023, São Paulo, Getúlio Vargas Foundation, July.

OECD (Organization for Economic Cooperation and Development) (2012), OECD environmental outlook to 2050, Paris, OECD Publishing, March.

OECD/FAO (Organization for Economic Cooperation and Development/Food and Agriculture Organization of the United Nations) (2016), OECD-FAO Agricultural Outlook 2016-2025, Paris, OECD Publishing.

Otero, A. (2011), “Análisis de generación complementaria entre energía hidráulica y eólica. Caso: generación ISAGENProyectos eólicos en la Guajira Colombiana", master thesis, Medellín, National University of Colombia.

PAHO/AIDIS/IDB (Pan American Health Organization/Inter-American Association of Sanitary and Environmental Engineering/Inter-American Development Bank) (2010), Regional Evaluation on Urban Solid Waste Management in Latin America and the Caribbean-2010 Report [online] https://publications.iadb.org/bitstream/handle/11319/3286/2010 \% 20Regional \% 20Evaluation \% 20on \% 20Urban \% 20Solid\% 20Waste \% 20Management \% 20in \% 20 Latin \% 20 America \%20and\%20the\%20Caribbean.pdf?sequence=1\&isAllowed=y.

Perotti, R. and M. Coviello (2015), "Governance of strategic minerals in Latin America: the case of lithium", Project Documents (LCM.669), Santiago, Economic Commission for Latin America and the Caribbean (ECLAC), September.

Porcile, G. (2016) "Tecnología, medio ambiente y desarrollo: una nueva mirada al gran impulso ambiental", Santiago, Economic Commission for Latin America and the Caribbean (ECLAC), unpublished.

(2011), "La teoría estructuralista del desarrollo", El desarrollo inclusivo en América Latina y el Caribe: ensayos sobre políticas de convergencia productiva para la igualdad, ECLAC Books, No. 112 (LC/G.2500-P), Santiago, Economic Commission for Latin America and the Caribbean (ECLAC), September.

Porcile, G. and S. Rovira (2016), “ ¿Hacia un nuevo estilo de desarrollo? La Agenda 2030 y el big push ambiental”, Puentes, vol. 17, N 5, Geneva, International Centre for Trade and Sustainable Development (ICSTD).

Poschen, P. (2015), “Do we have to choose between creating jobs and protecting the climate?", International Labour Organization (ILO), June [online] http://www.ilo.org/global/about-the-ilo/newsroom/news/WCMS_373207/lang--en/ index.htm.

Prebisch, R. (1981), Capitalismo periférico: crisis y transformación, Mexico City, Fondo de Cultura Económica.

(1980), “Biosphere and development", CEPAL Review, No. 12 (E/ECLAC/G.1130), Santiago, Economic Commission for Latin America and the Caribbean (ECLAC), December.

_ (1976), "A critique of peripheral capitalism," CEPAL Review, No. 1, Santiago, Economic Commission for Latin America and the Caribbean (ECLAC).

PwC (PricewaterhouseCoopers) (2015), “Estudio sobre las inversiones necesarias para que México cumpla con sus metas de energías limpias", October [online] https://www.pwc.com/mx/es/industrias/energia/archivo/20151018-gp-cespedes.pdf.

QYResearch (2018), Global Biological Organic Fertilizer Market Professional Survey Report 2017, January.

Ramos, S., E. Muñoz and G. Pérez (2017), “La gobernanza de los recursos naturales y los conflictos en las industrias extractivas: el caso de Colombia", Natural Resources and Infrastructure series, No. 181 (LC/TS.2017/71), Santiago, Economic Commission for Latin America and the Caribbean (ECLAC), September.

REN21 (Renewable Energy Policy Network for the 21st Century) (2016), Renewables 2016 Global Status Report, Paris.

Robertson, J. (2010), Building a Green Economy, Citizens Climate Lobby, September [online] https://citizensclimatelobby. org/files/building-a-green-economy.pdf. 
Rodríguez, A., A. Mondaini and M. Hitschfeld (2017), "Bioeconomía en América Latina y el Caribe, contexto global, regional y perspectivas", Production Development series, No. 215 (LC/TS.2017/96), Santiago, Economic Commission for Latin America and the Caribbean (ECLAC), November.

Rodríguez, O. (2006), El estructuralismo latinoamericano, Mexico City, Siglo XXI.

- (1980), La teoría del subdesarrollo de la CEPAL, Mexico City, Siglo XXI.

Rosenstein-Rodan, P. (1961), "Notes on the theory of the 'big push'," Economic Development for Latin America, Palgrave MacMillan, London.

Samaniego, J. and H. Schneider (2017), "Financiamiento para el cambio climático en América Latina y el Caribe en 2015", Project Documents (LC/TS.2017/9), Santiago, Economic Commission for Latin America and the Caribbean (ECLAC), February.

Sánchez, L. and C. Salazar (2011), "Lo que dicen las viviendas deshabitadas sobre el censo de población 2010"', Coyuntura Demográfica, No. 1.

Secretariat of Communications and Transport of Mexico (2017a), "Tren suburbano del valle de México," November [online] http://www.sct.gob.mx/transporte-y-medicina-preventiva/transporte-ferroviario-y-multimodal/tren-suburbano/.

_ (2017b), "Tren eléctrico de Guadalajara", November [online] http://www.sct.gob.mx/transporte-y-medicina-preventiva/ transporte-ferroviario-y-multimodal/tren-electrico-de-guadalajara/.

Sharrock, S., S. Oldfield and O. Wilson (2014), "Plant conservation report 2014: A review of progress in implementation of the Global Strategy for Plant Conservation 2011-2020", CBD Technical Series, No. 81, Montreal, Secretariat for the Convention on Biological Diversity.

Steffen, W. and others (2015), "Planetary boundaries: guiding human development on a changing planet", Science, vol. 347, No. 6223, February.

Stern, N. (2006), The Economics of Climate Change, New York, Cambridge University Press.

Sunkel, O. (comp.) (1996), Sustentabilidad ambiental del crecimiento económico chileno, Santiago, Programme for Sustainable Development, Centre for Public Policy Analysis, University of Chile. (1970), "Desarrollo, subdesarrollo, dependencia, marginación y desigualdades espaciales: hacia un enfoque totalizante", Revista EURE, vol. 1, No. 1, Santiago, Catholic University of Chile (PUC).

Technavio (2016), “Global Cosmeceuticals Market 2017-2021" [online] https://www.technavio.com/report/global-cosmeticsand-toiletry-global-cosmeceuticals-market-2017-2021, November.

Transparency Market Research (2015), "Organic personal care products market - global industry analysis, size, share, growth, trends and forecast 2014-2020", March.

Trigo, E. and others (2015), "La bioeconomía argentina: alcances, situación actual y oportunidades, para el desarrollo sustentable", Buenos Aires, Buenos Aires Grain Exchange [online] http://www.bolsadecereales.com/ver-bioeconomia-580. (2014), "Hacia un desarrollo de la bioeconomía en América Latina y el Caribe", Hacia una bioeconomía en América Latina y el Caribe en asociación con Europa, Bogotá, Pontificia Universidad Javeriana, November.

UITP (International Union of Public Transport) (2016), Metro América Latina: perspectivas y tendencias, São Paulo, October [online] http://www.latinamerica.uitp.org/sites/default/files/Relat\% C3\%B3rio\%20Metr\%C3\%B4s _UITP\%20Am\%C3\%A9rica\%20Latina_ESP.pdf.

UKERC (UK Energy Research Centre) (2014), Low Carbon Jobs: The Evidence for Net Job Creation from Policy Support for Energy Efficiency and Renewable Energy, London, November.

UNASUR/ECLAC (Union of South American Nations/Economic Commission for Latin America and the Caribbean) (2016), South American Social and Economic Panorama, 2016 (LC/L.4274), Santiago, December.

UNCCD (United Nations Convention to Combat Desertification in Those Countries Experiencing Serious Drought and/or Desertification, Particularly in Africa) (2017), Global Land Outlook, Bonn.

(2015), Country Profiles: Latin America and the Caribbean Region, Bonn.

UN Comtrade (United Nations International Trade Statisics Database) (2017), [online database] https://comtrade.un.org/data/.

UNCTAD (United Nations Conference on Trade and Development) (2012), Trade and Biodiversity: The Biograde Experiences in Latin America, Geneva.

UNDP (United Nations Development Programme) (2015), Chile: instrumentos y estrategias para combatir la desertificación, Santiago, December.

UNEP (United Nations Environment Programme) (s/f), "Environment Live Database" [online database] uneplive.unep.org. (2017), The Emissions Gap Report 2017, Nairobi.

(2016), GEO-6: Regional Assessment for Latin America and the Caribbean, Nairobi.

(2011), Decoupling Natural Resource Use and Environmental Impacts from Economic Growth, Nairobi.

UNEP/Frankfurt School of Finance and Management (2016), Global Trends in Renewable Energy Investment 2016 [online] http://fs-unep-centre.org/sites/default/files/publications/globaltrendsinrenewableenergyinvestment2016lowres_0.pdf. 
UNFCCC (United Nations Framework Convention on Climate Change) (2015), Adoption of the Paris Agreement (FCCC/ CP/2015/L.9/Rev.1), Paris, December [online] https://unfccc.int/resource/docs/2015/cop21/eng/l09r01.pdf.

(2007), Vulnerability and adaptation to climate change in small island developing States [online] http://unfccc.int/files/ adaptation/adverse_effects_and_response_measures_art_48/application/pdf/200702_sids_adaptation_bg.pdf.

UNISDR (United Nations Office for Disaster Risk Reduction) (2016), The Sustainable Development Goals Report 2016, New York. (2015), Global Assessment Report on Disaster Risk Reduction. Making Development Sustainable: The Future of Disaster Risk Management, Geneva.

(2013), Annual Report 2013, Geneva.

(2011), Annual Report 2011, Geneva.

UN-Habitat (United Nations Human Settlements Programme) (s/f), "Global Urban Indicators Database," Nairobi [online database] https://unhabitat.org/books/global-urban-indicators-database/.

(2016), Urbanization and Development: Emerging Futures. World Cities Report 2016, Nairobi.

(2012), State of Latin America and Caribbean Cities 2012, Nairobi.

(2011), Estado de las Ciudades de México 2010/2011, Mexico City.

(2010), Solid Waste Management in the World's Cities: Water and Sanitation in the World's Cities 2010, London [online] http://mirror.unhabitat.org/pmss/listltemDetails.aspx?publicationID=2918.

United Nations (2015a), Transforming Our World: the 2030 Agenda for Sustainable Development (A/RES/70/1), October. (2015b), "Synthesis report on the aggregate effect of the intended nationally determined contributions. Note by the secretariat" (FCCC/CP/2015/7) [online] http://unfccc.int/resource/docs/2015/cop21/spa/07s.pdf.

USGS (United States Geological Survey) (2017), "Mineral Commodity Summaries 2017" [online] https://minerals.usgs. gov/minerals/pubs/mcs/2017/mcs2017.pdf.

(2014), Global Mineral Resource Assessment: Estimate of Undiscovered Copper Resources of the World, 2013, January.

Vanguardia (2017), "Cancelación del tren rápido México-Querétaro podría costarle a México ¡600 mdd!", November [online] https://www.vanguardia.com.mx/articulo/cancelacion-del-tren-rapido-mexico-queretaro-china-podria-costarlemexico-600-mdd-a-a.

Vasconcellos, E. and A. Mendonça (2016), Observatorio de Movilidad Urbana: Informe 2015-2016 (resumen ejecutivo), Caracas, Development Bank of Latin America (CAF).

Vergara, W. and others (2013), The Climate and Development Challenge for Latin America and the Caribbean: Options for Climate-Resilient, Low-carbon Development, Washington D.C., Inter-American Development Bank (IDB), April.

Weston, D. (2013), "State of the planet, Kyoto and technical fixes", The Political Economy of Global Warming: The Terminal Crisis, London, Routledge.

WHO (World Health Organization) (2016), "Global Urban Ambient Air Pollution Database" [online database] http://www. who.int/phe/health_topics/outdoorair/databases/cities/en/.

World Bank (2017), "World Development Indicators" [online database] http://data.worldbank.org/data-catalog/worlddevelopment-indicators.

(2015), "World Bank Open Data" [online database] http://data.worldbank.

(2010a), Natural Hazards, UnNatural Disasters: The Economics of Effective Prevention, Washington, D.C.

(2010b), "The cost to developing countries of adapting to climate change. New methods and estimates", Working Paper, No. 55726, Washington, D.C.

World Bank and others (2016), "Policy discussion briefs: regional integration in the current economic slowdown", document presented at the Eight Meeting of Ministers of Finance of the Americas and the Caribbean, Washington, D.C., 5 October. 


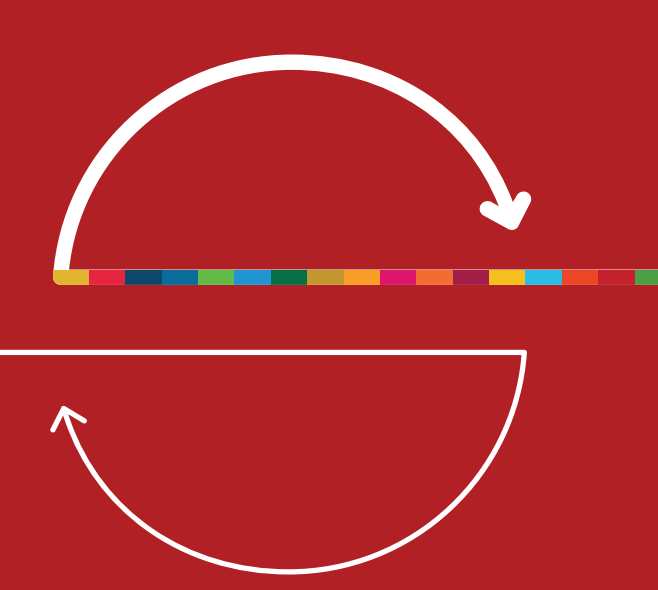

\section{CHAPTER}

\section{The political economy of inequality and the culture of privilege}

A. Egalitarian institutions and exclusionary institutions

B. The political economy of development

1. The roots of structural heterogeneity

2. The costs of financial liberalization

3. Structural change and production diversification

C. Inequality and fragmentation in social relations

1. A region without wars, but marked by violence

2. Insufficient support for democracy

D. Culture of privilege, rent-seeking and inequality

1. The domains of the culture of privilege

2. Strengthening the culture of equality erodes the culture of privilege

Bibliography 



\section{A. Egalitarian institutions and exclusionary institutions}

The role of institutions - the rules of the game and the formal and informal norms of conduct that delimit and structure actors' interactions - in the development process is an increasingly important topic because the institutional setting for stakeholder decision-making substantially alters the economy's growth and distribution trajectories. From the perspective of this document, the key questions are which rules of the game are most suited to supporting sustainable development and how they emerge and are maintained over time.

Institutions are not exogenous to the economic system. Rooted in history, they interact with structures that define who the key actors are, what economic power they wield and where their areas of cooperation and conflict lie. Economic and political powers are mutually reinforcing and can produce segregated societies in which a large part of the population, in practice, loses access to the capacities and opportunities enjoyed by the elite.

More specifically, within the interactions among political power, economic power and institutions, two opposite extremes may be identified. On the one hand, there are exclusionary institutions that prevent much of the population from accessing the capacities and opportunities associated with sustainable development, through a variety of segregation mechanisms. These institutions emerge and gain strength when political power and economic power are heavily concentrated within a small group. This is reflected in high wealth and income inequality and in authoritarian political systems that prevent less advantaged groups from having much real participation. Such economies produce few public goods and a low density of social and political organizations.

Conversely, egalitarian institutions promote capacity development for the population overall, broaden opportunities and prevent segregation or discrimination of any kind. Economic equality and political equality are reflected in a democratic system that ensures the full exercise of the civil rights of every citizen. Equality of access and opportunities means the elimination not only of explicit or implicit forms of discrimination — such as on the basis of religion, sex, ethnicity or caste- but also the discrimination arising from asymmetries in economic power. Egalitarian institutions emerge and gain strength in less unequal economies and political systems.

The subject of interaction between economic variables and institutions is by no means a new one. ${ }^{1}$ The contrast between egalitarian and exclusionary institutions has many points in common with the contrast between inclusive institutions and extractive institutions proposed by Acemoglu and Robinson (2006), and that of the "natural state" or limited access vis-à-vis the "open access order" of North, Wallis and Weingast (2009). Similarly, power asymmetries (external and internal), their impact on the rules of operation of the economy, and the constraints they impose on the actors' strategies are a key part of structuralist thinking. The historical structural model emphasizes that development paths are conditioned by the power configurations that emerged from the region's colonial past and the struggles between the dominant and subordinate classes in the Latin American and Caribbean nations (Sunkel and Paz, 1970; Cardoso and Faletto, 1977). ${ }^{2}$ The region's past left a legacy of sharp inequality as a result of land concentration and the extensive use of various forms of forced labour. Although the different countries followed widely varying trajectories in the twentieth century, problems of power concentration persisted, as witnessed by the long list of authoritarian regimes and democratic instability (O'Donnell, Schmitter and Whitehead, 1991).

Egalitarian institutions matter not only because of the classic concerns of political and economic inclusion but also because they are necessary for sustaining the three dimensions of sustainable development: (i) the social dimension, in terms of multidimensional equality; (ii) the dimension of learning or convergence with the development world, in terms of income and technological capacities; and (iii) the environmental dimension, in terms of making the process of convergence compatible with the preservation of natural resources and the environment for future generations (ECLAC, 2016).

Acknowledgement that institutions are a central part of the economic system is at the heart of the old institutionalism (Veblen) and has been addressed by economic historians in comparing the development trajectories of different countries (Moore, 1966), especially the development of what are termed newly settled countries (Álvarez and Bértola, 2007). It has also been a recurring theme in the tradition of the Economic Commission for Latin America and the Caribbean (ECLAC)

The importance of history in opening or closing development paths in historical structural analysis represented what came to be called "path dependency" (Arthur, 1994; Palley, 2017). 
In Latin America and the Caribbean, inequality has generated and continues to reproduce exclusionary institutions that limit the space for the structural change policies that are at the heart of sustainable development. These exclusionary institutions have also generated fragmented societies and cultures of privilege hostile to learning, innovation and productivity. ${ }^{3}$

\section{B. The political economy of development}

\section{The roots of structural heterogeneity}

Latin America and the Caribbean began the era of independence with highly concentrated distributions of both wealth and income. Although these initial conditions alone are unlikely to explain the situation of the region in the twenty-first century, a number of historical factors related to inequality and international specialization help account for the barriers that hold back the economic restructuring.

The crisis of 1930 marked a profound break with the growth pattern that had unfolded during the first globalization era, when (with sharp differences between countries) the region participated in the classic international division of labour (raw materials at the periphery, manufactures at the centre), under British hegemony (ECLAC, 2002). The crisis, which led to the collapse of the gold standard and the shrinking of world trade, triggered major political and economic changes, including the rise of new actors, the weakening of traditional oligarchies and advancing industrialization protected by tariff and non-tariff barriers and multiple exchange rates. In general, patterns of import-substitution-industrialization (ISI) emerged in response to the closing of traditional export markets and, later, during the Second World War, because industrial production in the central countries was absorbed by the war effort. These patterns were maintained and entrenched during the dollar shortage that lasted until the late 1950s, after which the European currencies regained convertibility.

The 1955-1980 import-substitution boom (or period of State-led industrialization, to use the term suggested by Bértola and Ocampo (2012)) generated important learning processes, especially in Argentina, Brazil and Mexico. These led to a larger share of manufactures in total exports and, in some cases, exports of turnkey technology. Brazil and Mexico came to be considered members of the group of newly industrializing economies, along with the Asian tigers. The capacities generated in those years helped to establish enclaves of excellence that either still survive or else formed the basis for the retooling of certain industries in the 1990s. This was a period of major social and economic advances and transformations, which Hirschman (1986) called Latin America's trente glorieuses.

Meanwhile, recurrent balance-of-payments crises, compounded by a reliance on exports of natural resources and goods of low technological intensity, as well as persistent inequality, showed that industrial policy had not created the conditions needed for international convergence. The technology gap did not narrow enough to enable industry to compete on the basis of its capabilities. A rent-seeking system based on natural resources was succeeded by one that placed increasing weight on the quasi-rents from privilege associated with what Fajnzylber (1983) called "frivolous protectionism" (of which Prebisch had warned as early as 1963). The redistribution of rents - which should have been a flexible instrument shifting to new sectors over time- became part of a political equilibrium that was constantly challenged by the external constraint. The instability of this equilibrium was reflected in stop-go growth cycles and mounting social and political conflict.

Fajnzylber (1983) emphasized that, to be successful, structural change policies needed an endogenous core of actors with interests articulated around technical change and catch-up. In the most dynamic countries of East Asia, this core consisted of a network of policymakers and executives from both public and private firms, whose interests and power expanded alongside the transformation of the economy and the growing

\footnotetext{
Exclusionary institutions are not incompatible with high growth rates in certain periods. Over longer periods of analysis, however, the negative relationship between the two becomes clearer. The negative effect of exclusionary institutions is more evident when the object of study extends beyond economic growth to include income distribution and environmental stewardship. On the relationship between institutions and inequality, see Chong y Gradstein (2007).
} 
competitiveness of their firms on international markets. While large national enterprises were key players in the Republic of Korea, the pattern in Taiwan Province of China left more space for the activities of medium-sized firms. In China itself, the endogenous core adopted the modality of partnership between foreign corporations (limited to some sectors) and both national public and private enterprises.

In these cases, technology transfer to build domestic capacities and reduce gaps was an overarching policy goal. The State maintained a link with the business sector that Evans and Heller (2015) dubbed "embedded autonomy": while information flows and monitoring between the public and private sectors was intense, it was kept at arm's length to prevent policymakers from being co-opted or captured by the private sector. This allowed the State to distribute rents in such a way that the sectors benefiting changed as the productive structure grew in complexity, and productivity and export goals were attained. Some actors grew without assistance, while those that failed to do so were effectively penalized. The export bias of the growth model was crucial in providing a clear benchmark in terms of the goals to be attained and their link with learning (Amsden, 1989; Wade, 1992; Poo, 2014).

In the international economy, industrialization processes in East Asia were supported by the United States (which provided one of the main export markets and sources of technology), owing to that region's importance in Cold War geopolitics. In the case of the Republic of Korea, the United States promoted an agrarian reform in the early post-war period, which had major implications for the political economy of development (Kim, 2016), in a strategy almost diametrically opposed to that adopted in Latin America.

Growth in Latin America and the Caribbean occurred in the form of the bubbles identified by Nochteff (1996), rather than by reducing gaps. Changes over time were driven by shifts mostly in non-technological quasi-rents and in the relative power of the different actors, without those quasi-rents becoming the Schumpeterian driver of economic expansion. In this context, heterogeneity and fracture between economic agents were constant features. ${ }^{4}$ The importance of these fractures can be seen in the dynamics of the alliances that were created and disbanded, both in the ISI phase and following the pro-market reforms of the late 1980s and early 1990s. Their impact on the political system and culture is discussed below.

During the ISI period, the implicit system of rent transfer to industry entailed a combination of inflation and currency overvaluation. Nonetheless, this policy generated its own antibodies. On the political front, inflation eroded workers' support for industry, and overvaluation attracted opposition from exporters, which intensified when the terms of trade deteriorated, or the pace of external demand slackened. Moreover, balance of payments deficits periodically strengthened the power of the traditional export sectors, by accentuating the need to promote their exports to avoid or mitigate a currency crisis. Shifting alliances were created between industrial workers, middle-class sectors, manufacturers producing for the domestic market and primary producers serving the international market. ${ }^{5}$ Economically, the established industrialists were suspicious of the backward linkages being forged by new industries, since this forced them to pay more for their inputs and thus undermined the effective protection they enjoyed. External crises made exchange-rate devaluation unavoidable and squeezed domestic demand, without stimulating external demand to the same extent owing to the low price-elasticity of exports. These acted as crucial political and economic constraints on the march of industrialization (Hirschmann, 1968).

The adoption of Washington Consensus policies (trade and financial liberalization, privatization and deregulation) from the mid-1980s onward generated expectations of a new era of expansion for the region (Stalling and Peres, 2000). These policies were rationalized in terms of reducing rent-seeking opportunities for protected sectors (decreasing privilege rents). The thinking was that this would suffice to dismantle the distortions of past interventionist policies in order to relaunch growth; but, as happened with the financial liberalization of the 1970s, that expectation was not realized. Trade liberalization did not generate learning in

4 According to Doner and Schneider (2016, p. 6), “(T)he main political obstacle to institution building is the fragmentation of social groups, especially business and labor, and the resulting absence of strong pro upgrading coalitions. Growth trajectories on the way to MI (medium income) status fractured the groups —especially business and labor - that are the core potential constituencies for a big leap coalition. In roughest terms, big business is split between foreign and domestic firms, labour is divided between formal and informal sectors, and societies overall are riven by high inequality. These cleavages splinter interests and make coalition building more difficult.

5 For an analysis of these alliances and their instability, see 0'Donnell (1978). 
a situation where there were no agents capable of learning, productive processes through which to learn, or the institutions to support them. Deregulation and privatization resulted in massive rent transfers to actors in privileged positions, without triggering increases in investment or productivity growth in most cases. The pro-market reforms and the Washington Consensus were processes that had very little to do with the impersonal nature of the open-access order described by North, Wallis and Weingast (2009).

Moreover, the degree of fracture or heterogeneity among actors increased. At the microeconomic level, intermediate inputs were increasingly imported; and many production chains started to disintegrate, which meant that the leading firms became more efficient while small and medium-sized enterprises (SMEs) disappeared. At the macroeconomic level, capital account liberalization ushered in a new cycle of exchange-rate appreciation which, in countries such as Argentina, Brazil and Uruguay, culminated in very severe external crises (especially in Argentina and Uruguay) in the late 1990s and early years of the new millennium. This pushed up unemployment, informality and, thus, inequality very considerably.

Last but not least, the region's economies have displayed high levels of employment informality and (with a few exceptions) low levels of unionization - a state of affairs that plays a significant role in shaping a pattern of fragmented interests. The impact occurs on several levels. Firstly, informality means that neither workers nor employers see their relationship as stable and lasting, which reduces the former's interest in the firm's results and the latter's incentives to provide training (since a higher-skilled worker can migrate to a competing firm). Secondly, the absence of institutionalized forms of representation and negotiation makes it more difficult to arbitrate disputes and set distributive and productivity goals. Technical change is viewed as a path to unemployment rather than to worker training and real wage growth. Thirdly, the fact that a large proportion of workers have no protection mechanisms increases the instability of the political system and paves the way for unsustainable policies, because it maximizes the redistribution drive by feeding inflationary processes or by fuelling an overvalued national currency.

This context gives rise to a development style of hierarchical capitalism (Doner and Schneider, 2016). Many of the economy's leading firms are subsidiaries of transnationals and, therefore, subject to planning and control by their parent companies. By contrast, many of the leading domestic firms are still family-owned, and relations between capital and labour lack the negotiation mechanisms observed in the corporate capitalisms of northern Europe. ${ }^{6}$ Highly hierarchical and fragmented societies make it harder to reach political agreements for the effective implementation of structural change policies.

\section{The costs of financial liberalization}

In the second half of the 1970s a new factor compounded the instability of regional growth. The emergence of an international financial market operating outside national regulations (the Eurodollar market) and the huge surpluses that were recycled by the major oil exporters following the first price shock in 1974 (petrodollars) dominated the dynamics of the external sector. From then on, actors linked to the financial sector assumed an increasingly important role. Business cycles started to be driven more by liquidity cycles on the international financial market than by international trade cycles. Capital account liberalization (initially in the Southern Cone countries in the mid-1970s, and later in all the countries of the region in the 1990s) accentuated the predominance of the balance of payments in the region's macroeconomic performance (Ocampo, 2013).

The first major manifestation of this type of rent-seeking and its negative consequences for productivity and growth occurred with the debt crisis of the early 1980s, which brought the previous industrialization phase to a halt. Its severity, however, was not a consequence of ISI policies. The crisis was equally intense in countries that had maintained this strategy (such as Brazil and Mexico) and in those that had liberalized trade and opened up their capital account in the 1970s (such as Argentina, Chile and Uruguay). The common denominator was the combination of abundant external capital, the willingness of countries to use this capital

6 This argument converges with a point that Medina Echavarría raises in his studies on the sociology of development in the region: the persistence of forms of traditional societal organization that resist the rules of Weberian rationality in the State and firms. "The traditional structure has been relatively permeable and (...) that porosity has enabled it to absorb the elements of modernity it needs without breaking its very structure" (Medina, cited by Rodríguez, 2007, p. 173). 
to sustain growth in conditions of low external competitiveness (with a consequent increase in external debt) and the steep rise in international interest rates since 1979. By contrast, the successful Asian countries, despite being hit by the international crisis, were able to recover quickly because they had kept their capital accounts closed and had implemented selective industrial policies to promote export diversification that enabled them to absorb the external shock more effectively.

It was international political economy factors - the unequal distribution of power between actors - that made the crisis so intense and its cost to the region so high. Countries had to negotiate individually with a cartel of creditor banks that had full backing from the large international financial institutions. The result of this unequal negotiation was a gigantic transfer of rents to foreign banks, with deleterious consequences for investment and growth that gave rise to the so-called "lost decade". Domestic rent-seeking was compounded by a shift in the operating conditions of the international economy in which the quasi-rents of the international financial sector oligopoly multiplied rapidly (for example, in the United States, the profits of the financial sector grew by 800\% in real terms between 1980 and 2005, while its share of GDP almost doubled between 1988 and 2007 in the same period) (Acemoglu and Robinson, 2013, p. 182).

Thus, instead of the economies of the region capturing a share of the technological quasi-rents (by reducing the technology gap) created by innovative firms in the global economy, there was a massive capture of privilege quasi-rents by creditors in the central countries, based on their capacity to solve their problems of collective action much more easily, with help from the international financial institutions (particularly the International Monetary Fund (IMF) and the World Bank). The debt crisis also redefined the domestic political economy. The State's capacity to formulate and implement policies was greatly weakened for three reasons, of which the first was the fiscal constraint. As private external debt was taken over by nation States, the debt crisis became a fiscal one, thus eroding the capacity to implement any policy that relied heavily on public investments or subsidies. Secondly, States were frequently having to negotiate debt repayment conditions. The conditionality attached to their loans meant accepting a growth strategy that was hostile to industrial policies. Lastly, countries focused their efforts on paying down the debt and containing the pace of inflation, which in some emblematic cases reached hyperinflation levels. The fiscal crisis and inflationary phenomena associated with the transfer of resources abroad aggravated poverty and indigence levels. In such circumstances, there was neither time nor resources to think long-term.

Financial liberalization, which was tried out early in the Southern Cone (in the 1970s), was supposed to enable economic actors to access credit more easily, eliminating the rent-seeking associated with privileged access to finance in a context of financial repression. What actually happened was an accentuation of rent-seeking, with a new and more dynamic role for financial sector players, based on their ability to arbitrage domestic and external interest-rate spreads, credit bubbles in the real-estate market and moral hazard stemming from their belief that they would be bailed out in the event of crisis (Palma, 2012). This regressive income transfer (within each country and between debtor and creditor economies) was associated not with productivity growth, but with its collapse. Instead of fuelling higher rates of investment, financial liberalization produced a drastic decline in investments under the impact of the debt crisis. The opening of the capital account that has been unfolding since the 1990s has coincided with very low rates of physical capital formation (in fact, no higher, on average, than those of the lost decade). Investment recovered only with the commodities boom after 2004, and even then it was unable to regain 1970s levels.

Capital account liberalization is a decisive factor in the political economy of the region and in limiting economic policy autonomy. Firstly, it increases the advantage of holding funds in more liquid and short-term financial assets, compared to specific physical assets that represent the materialization of structural change and are more vulnerable to cyclical effects. Financial assets can more easily avoid taxation and are more responsive to arbitrage opportunities, while the result of investment in physical assets (such as building a factory or buying a machine) is tied to what happens in the market for the end-product in question. The rational response of productive capital is to maintain a certain portion of its investment portfolio in financial assets, thereby widening the gap between the interests of large firms, which can diversify in this way, and smaller-scale entrepreneurs and labour. 
Secondly, capital account liberalization hangs like a sword of Damocles over economic policy, by giving veto power to more liquid agents, since capital flight intensifies if policy takes a direction that such agents perceive as less reliable. This veto power is significant because it can be manifested in a short period of time - weeks or days - while investors in physical assets, and especially workers, do not have equivalent defence mechanisms. Lastly, public debt in the hands of financial actors is not only a major source of quasi-oligopoly, but it also reinforces their veto power over monetary and fiscal policies. Public debt issuers are forced to permanently monitor the reaction of these agents (expressed through their demand for government securities) to any economic policy measure.

The economic history of the Republic of Korea offers a number of lessons on the role of capital account liberalization. It only opened up (gradually) in the 1990s, by which time it already had a diversified and competitive economy. China kept its exchange rate depreciated until 2010 as an instrument that complemented an industrial policy through which it accessed new markets and sectors. These economies have been classified as "currentaccount-based" in exchange-rate and monetary-policy management, whereas the Latin American economies are seen as dominated by the capital account (Dooley, Folkerts-Landau and Garber, 2003; Frieden, 2015). In the region, the external constraint has generally put a brake on economic growth before full employment has been reached, except in brief periods; and this barrier is compounded by the tendency towards exchange-rate appreciation, as discussed in chapter III.

A question that naturally arises is why episodes of real exchange rate appreciation, with the attendant instability and crisis, have been so persistent. There are political economy reasons explaining this phenomenon. Currency appreciation is a major source of rent for investors who enter when the exchange rate is rising and interest rates in the peripheral economies are higher than in the central countries, but who exit en masse when devaluation risks increase. This further intensifies the external crisis and turns it into a self-fulfilling prophecy. The bubbles that are generated in different markets, especially real estate, reinforce the appreciation and accentuate the decline, in a process involving large income transfers that weaken investment, growth and productivity-building. ${ }^{7}$

\section{Structural change and production diversification}

The political economy of inequality affects a diverse range of policies. This section focuses on those that relate to diversification of the production structure, which are broadly referred to as industrial and technology policies. These encompass what in other contexts have been called production development policies, sectoral policies and policies related to the national innovation system. The emphasis on these policies is justified because they are essential for changing the pattern of production and consumption in the region, as required by sustainable development and the environmental big push. ${ }^{8}$

The Economic Commission for Latin America and the Caribbean (ECLAC) argues that, in a world in which the predominant production and consumption patterns have become unsustainable, the region must adopt a style of development that is based on an environmental big push. Transforming these patterns - and, consequently, the energy matrix, the technological base, articulation between the different sectors and their relative weight in the economy - requires a qualitative leap in industrial and technological policies. This is particularly hard to achieve in a world in which the technology revolution systematically redefines the direction and intensity of technical progress and, hence, the parameters that agents rely on to make decisions.

International experience offers some important lessons on the role of structural change policies, as summarized below.

Adair Turner (2016) considers that the exponential growth of the financial system since the end of the 1980s represents a large negative externality that compromises the functioning of the economic system as a whole. Cecchetti and Kharroubi (2012) highlight a similar point and find a negative relationship (after a certain critical point) between the financial sector growth, economic growth and increased productivity. The evidence is clear: faster growth in the financial sector is bad for real aggregate growth. One interpretation of this is that financial booms are inherently bad for trend growth.

8 This concept, introduced in ECLAC (2016), is analysed in detail in chapter VII. 
- All countries have used and continue to use sectoral policy of some kind, and this is true of developing and developed countries alike (Stiglitz, 2014; Cimoli and Dosi, 2017). The reasons vary widely, including those related to the arms and space race, food security, prevention or mitigation of the effects of climate change, and the demands of health systems; and others associated with more traditional economic objectives, such as how to reduce unemployment, diversify the production mix and increase the share of high-tech sectors.

- There is great similarity between the instruments of structural change policy adopted by successful cases of international convergence in the post-war period (the Republic of Korea, Taiwan Province of China and, more recently, China itself) and those adopted by the (far more numerous) cases of divergence and failure of such policies. ${ }^{9}$ More than a difference in formulation and instruments, the key to the success or failure of a structural change policy lies in the implementation phase.

- The main difference that emerges when comparing successful and unsuccessful cases is the policy's capacity to define and monitor performance goals, effectively penalizing strategies based exclusively on protecting quasi-rents derived from natural resources, cheap labour or political privileges, and stimulating the generation of quasi-rents based on learning and innovation. This capacity is related to the building of coalitions that sustain the industrial and technological policies both politically and socially.

- The ability of agents and institutions to learn, evolve and adjust is paramount for industrial policy to achieve its objectives. In an uncertain world, where shocks in financial markets and technology are as unpredictable as they are far-reaching, the ability to adapt is even more important than in conditions of global stability. When this capacity exists, apparent failures in some sectors are subsequently transformed into enablers of progress. When such capacity is absent, failures are extremely costly, which reinforces the obstacles to development.

Coalitions are formed around a policy to create or defend rents or quasi-rents of different types. ${ }^{10}$ Some are associated with innovation (technological quasi-rents), others with access to cheap labour (Lewisian quasi-rents) or abundant natural resources (Ricardian quasi-rents); and still others are created by entry barriers to new competitors, based on economies of scale or political barriers (privilege quasi-rents). The role of industrial policy is to manage this process of rent creation and destruction in order to prioritize innovators and the quasi-rents that are obtained from knowledge. ${ }^{11}$

More specifically, industrial and technological policy must transfer part of the quasi-rents derived from privileged positions, low wages or natural resources to strengthen actors that create quasi-rents from learning and innovation. The quasi-rents that the latter create often come from reducing or diluting those obtained by firms on the technological frontier in advanced countries. The redistribution and creation of technology quasi-rents domestically is then aligned with their redistribution internationally (towards the peripheral country) where a process is under way narrowing the technology gap between the centre and the periphery.

The political problem inherent in a technological convergence strategy of this type is extremely hard to solve. The sectors that obtain high quasi-rents from natural resources or cheap labour are generally very powerful in peripheral countries and can block industrial policy. Moreover, those that receive protection and subsidies (granted on the basis of expected learning and increases in productivity over time) can capture privilege quasi-rents unless investment in technological learning is monitored and its absence is punished.

\footnotetext{
In this context, success or failure is measured solely in terms of narrowing the technology gap, since none of the examples mentioned fully satisfies the definition of sustainable development.

10 Quasi-rents are payments made to a factor of production over and above its opportunity cost; they may derive from a temporary rigidity in the supply of the factor, or from positions of oligopoly, monopoly or political power in organizations. Quasi-rents are distinguished from rents because the latter are associated with the fixed supply of a factor of production (usually land), while quasi-rents are temporary. For example, the monopoly granted by a patent may expire after a certain time, or new products and processes may reduce the initial advantage of the innovator, even where a patent exists. Similarly, the supply of the fixed factor (land par excellence) may expand as technical progress makes previously unproductive land usable. Privilege rents undermine the dynamism of the economic system and are unrelated to the contribution to productivity made by the different actors (Stiglitz, 2013, chapter 2).

11 This point is summarized by Nochteff (1996, p. 115): "In short, what is being postulated is that the economy is undergoing a process of development only if technological quasi-rents predominate over the other types of quasi-rents. If this is not so, periods of expansion are regarded as "bubbles" in relation to innovation-based development."
} 
The predominant political coalitions in a technologically backward economy will tend to block the diversification effort or else turn industrial policy into a new variety of privilege quasi-rents. This is because industrial policy imposes costs on these actors (to finance the public goods needed to participate in the technological revolution or to pay higher prices for some intermediate or capital goods during the transition). In contrast, the benefits are uncertain and can favour actors that are very different from traditional entrepreneurs (for example, new entrepreneurs with human capital and the willingness to assume the risks of entering more technology-intensive sectors). The incentive to protect and replicate existing quasi-rents increases with the technology gap relative to the developed world, since it reflects the difficulty faced by peripheral-country entrepreneurs in competing through innovation with actors in the central economies. ${ }^{12}$

The management of rents must be viewed from a dynamic perspective. Not all privilege, natural-resource or cheap-labour rents are inimical to innovation. The key is the extent to which quasi-rents of this type are used to generate (or become) innovation quasi-rents. A sector benefited by industrial policy (whether vertical or horizontal), which manages to compete initially based on the support provided by that policy, will, for a certain time, combine privilege quasi-rents with those that come from learning. A natural-resource-intensive sector that uses the advantage provided by these resources to add knowledge to production will combine Ricardian and Schumpeterian quasi-rents; and an economy that initially competes on the basis of very high real exchange rates and very low wage costs will combine Lewisian and privilege rents with Schumpeterian ones. What matters in a development process is that the share of the innovation quasi-rents increases over time and that they are transferred between sectors with that objective.

Full access by working people to health and education is a necessary condition for a sustainable development policy to be effective, owing to the positive externalities this produces. The redistributive effects of these policies must occur not only between economic sectors, but also between capital and labour, as part of the creation of public goods in a world based on competition in capacities.

An economy that is heavily dependent on natural resources or cheap labour generates a political dynamic that tends to hold back diversification. More economically powerful actors perceive a threat in the redistribution of rents, either towards lower-income sectors or in favour of other productive sectors that compete through innovation. These actors do not need workers with high levels of human capital (except to a very limited extent); they have greater incentives to invest in non-productive activities (such as repression or corruption), but fewer incentives to move into activities where competition in innovation is more intense (especially when the technology gap is wide); and they also have less incentive to invest in public goods (they will tend to produce goods either privately or as club assets, restricted to a small group of agents).

To sum up, industrial and technological policy for sustainable development — targeting progressive structural change with dimensions that include the absorption of technical progress, quality employment and environmental stewardship - will be successful if the firms benefited by the policies create quasi-rents based on knowledge; and if, after a certain time, these firms cease to be favoured, and support is retargeted to more dynamic sectors in terms of technology and effective demand, thus generating increasing capacities and presence in world markets.

\section{Inequality and fragmentation in social relations}

Inequality has not only economic consequences, but also political, social and cultural ones. It tends to reproduce fragmented societies, with low levels of social interaction, limited reciprocal trust, a weak sense of belonging, a limited perception of common projects and little propensity for collaboration and the valuation and protection

12 Kahn and Blackenburg (2009, p. 11) suggest that the success or failure of industrial policies is explained precisely by their degree of compatibility between political coalitions and the management of rents in favour of learning and innovation: "Our core argument is that managing rents for technology acquisition is not just constrained by state capacities, but also and often primarily by political constraints that prevent specific strategies of rent management from being implemented. (...) (T)he success or failure of rent-management strategies for industrialization is largely determined by the compatibility of technological and institutional strategies for late development with political constraints arising from inner-societal power constellations as well as from transnational —external—influences." 
of public goods. This manifests itself in various areas of social relations, of which this section analyses two: violence and support for democracy. These were chosen because they reflect the de-integrating power of the exclusive institutions that exist in the region's societies.

\section{A region without wars, but marked by violence}

Latin America and the Caribbean is not only the most unequal region in the world, but also the most violent —as measured by the homicide rate per 100,000 inhabitants - if areas in which there are wars or armed conflicts are excluded. Although it is a region at peace, insofar as there are no wars between countries and domestic armed conflicts are being brought to a conclusion through political negotiations, the frequency of intentional homicide is higher than expected, given the region's level of economic, political and social development.

In 2015, the global homicide rate was 8.3 per 100,000 inhabitants, down slightly from the 2010 level (see figure VI.1). All subregions of Latin America and the Caribbean experienced a rise in the homicide rate, albeit in highly varied degrees. The worst situation is in Central America and Mexico where the homicide rate is five times the global average, while Caribbean countries report rates of 25 per 100,000 inhabitants, making them third worst in the world in this regard. The South American average combines two very different situations: whereas Argentina, Chile and Uruguay display rates below the global average, rates in the Bolivarian Republic of Venezuela, Brazil and Colombia are between three and seven times the world average. In terms of dynamic change, however, the worst deterioration occurred in the Southern Cone, where the rate increased more than $60 \%$.

\section{Figure Vl.1}

Homicide rate per 100,000 inhabitants, by region and subregion, 2010 and 2015

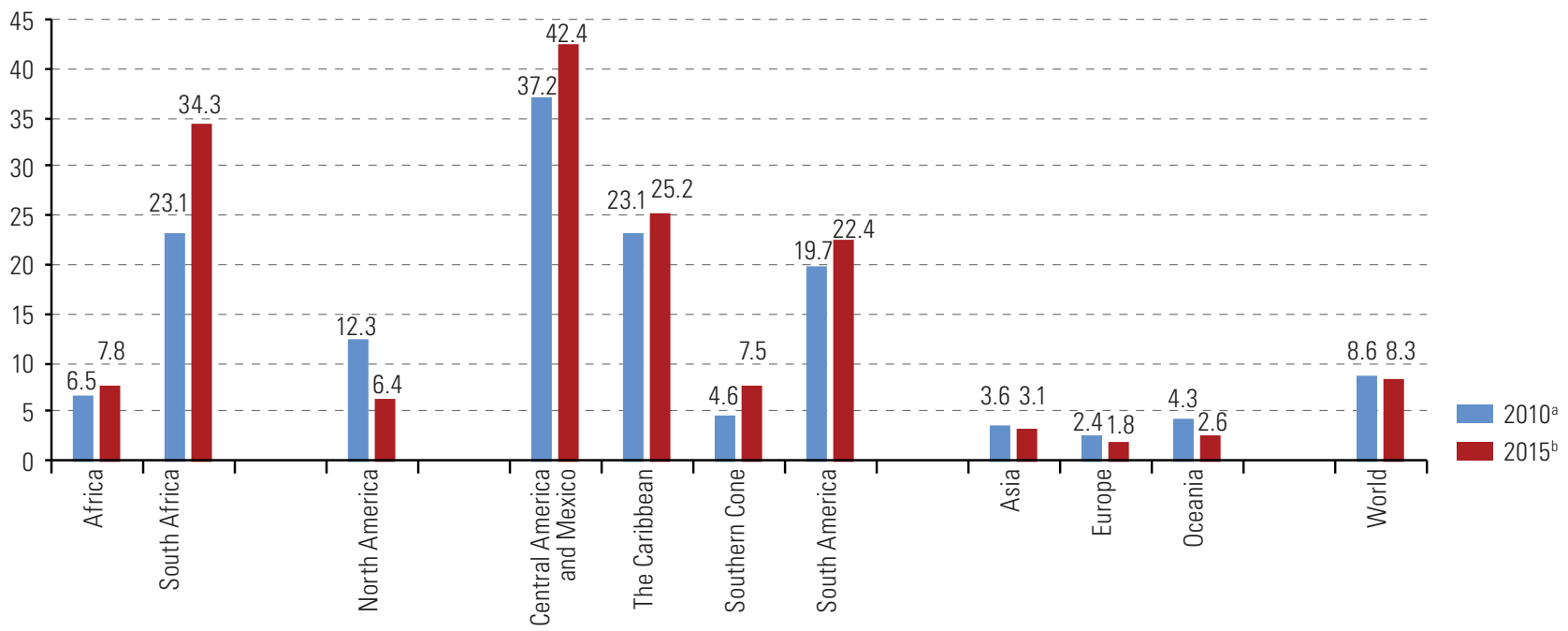

Source: Economic Commission for Latin America and the Caribbean (ECLAC), on the basis of United Nations Office on Drugs and Crime (UNODC), Statistics [online] https://www.unodc.org/unodc/en/data-and-analysis/statistics.html, 2017.

a For 2010, simple averages for each subregion are calculated as follows: Africa (47 countries), Southern Africa (5 countries), North America (4 countries), Central America and Mexico (8 countries), the Caribbean (16 countries), Southern Cone (3 countries: Argentina, Chile and Uruguay), South America (9 countries), Asia (49 countries), Europe (42 countries), Oceania (11 countries), World (110 countries).

b For 2015, simple averages for each subregion are calculated as follows: Africa (31 countries), Southern Africa (1 country), North America (4 countries), Central America and Mexico ( 5 countries), the Caribbean (4 countries), Southern Cone (3 countries: Argentina, Chile and Uruguay), South America (7 countries), Asia (22 countries), Europe (33 countries), Oceania (3 countries), World (110 countries).

Violence and high homicide rates are not new phenomena, either in the Americas generally or in Latin America and the Caribbean in particular. The high levels recorded at least since the 1950s started to fall at the end of the twentieth century; but, in the last two decades, the improvement has come to a halt and there has been a clear deterioration, particularly in Mexico, the northern triangle of Central America and some Caribbean countries. 
In the region as a whole, the origin of violence seems to be shifting from political motives to causes linked to common and organized crime. In this context, femicide has gained visibility and repudiation as an extreme expression of gender inequality and the distance yet to be travelled to guarantee women the right to a life free from violence. Its intensity, especially in the northern triangle of Central America and in the Dominican Republic, is an indicator of the persistence and severity of gender violence.

The relationship between inequality and violence is complex: the positive correlation between the two in the medium and long terms does not explain its short-term variation. A significant correlation between inequality and different forms of violent death is tending to be confirmed, such as intentional homicide in less developed countries and suicide in more developed ones (Wilkinson and Pickett, 2009).

Figure VI.2, which relates the Gini coefficient to the homicide rate in 18 countries in the region, shows that very few are below the world average homicide rate. There are exceptions, such as Chile, where high levels of inequality coexist with low homicide rates; and there are other countries, such the Bolivarian Republic of Venezuela or El Salvador, which have very high homicide rates and relatively low levels of inequality. Brazil and Mexico, on the other hand, seem to more closely reflect the pattern that associates high inequality with a high level of violence.

Figure VI.2

Latin America (18 countries): homicide rate per 100,000 inhabitants and Gini index (values between 0 and 1), 2014 ${ }^{a}$

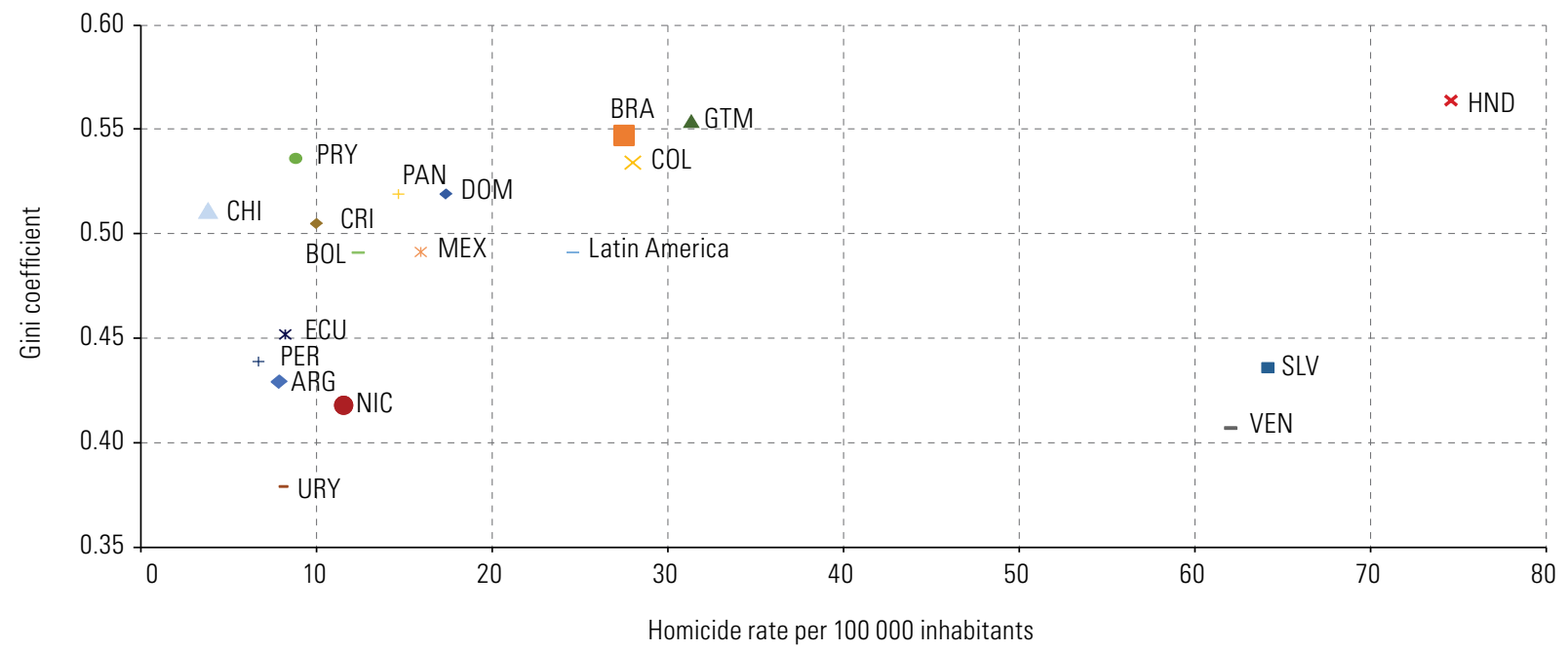

Source: Economic Commission for Latin America and the Caribbean (ECLAC), on the basis of United Nations Office on Drugs and Crime (UNODC), Statistics [online] https://www.unodc.org/unodc/en/data-and-analysis/statistics.html, 2017; CEPALSTAT database [online] http://estadisticas.cepal.org/cepalstat/WEB_ CEPALSTAT/estadisticasIndicadores.asp?idioma=e and World Bank, Gini index [online] https://datos.bancomundial.org/indicador/SI.POV.GINI?locations= AR-BR-GT-NI-UY, 2017.

a The Gini index refers to the latest year for which data are available (2014). In the cases of Argentina and Nicaragua, the data are from the World Bank. Data on homicide rates are available up to 2015. However, to compare with the latest data available from the Gini index, the 2014 figures were used, except in the Plurinational State of Bolivia and Nicaragua (2012). According to the International Classification of Crimes for Statistical Purposes (ICCS), intentional homicides include: murder, honour killing, serious assault leading to death, death as a result of terrorist activities, dowry-related killings, femicide, infanticide, voluntary manslaughter, extrajudicial killings, killings caused by the excessive use of force by law enforcement officers/State officials. Intentional homicides exclude: death due to legal intervention, justifiable homicide in self-defence, attempted intentional homicide, homicide without the element of intention (unintentional homicide); non-negligent (not culpable) or involuntary manslaughter, assisted suicide or instigating suicide, illegal abortion, euthanasia, death as a result of armed conflict.

Studies on violence make a distinction between effective rates and subjective perceptions, in other words between the number of crimes committed and citizens' perception of insecurity. Latinobarómetro data for 2016 show that $43 \%$ of people in the region believed they could be the victim of a crime always or nearly always, whereas just $13 \%$ feel completely safe (see table VI.1). This high perception of insecurity, which rises to nearly $87 \%$ including people who sometimes or occasionally consider themselves potential victims, has implications for social subjectivity; changing behavioural norms; the use of public spaces; higher State spending on security, businesses and families; an intensification of territorial segmentation; the acceptance of measures that restrict freedoms; indifference to abuses in security policies and even the discrediting of human rights discourse. 
Table VI.1

Latin America (18 countries): frequency with which people think they could become victims of a crime ${ }^{a}$ (Percentages)

\begin{tabular}{|c|c|c|c|c|c|c|c|}
\hline Frequency & 2007 & 2009 & 2010 & 2011 & 2013 & 2015 & 2016 \\
\hline Always or nearly always & 38 & 31 & 33 & 39 & 44 & 41 & 43 \\
\hline Sometimes & 35 & 39 & 35 & 37 & 28 & 28 & 29 \\
\hline Occasionally & 18 & 21 & 21 & 16 & 16 & 17 & 14 \\
\hline Never & 8 & 9 & 10 & 7 & 12 & 13 & 13 \\
\hline
\end{tabular}

Source: Economic Commission for Latin America and the Caribbean (ECLAC), on the basis of Latinobarómetro 2017 [online] http://www.latinobarometro.org /latOnline.jsp.

a The information refers to Argentina, the Bolivarian Republic of Venezuela, Brazil, Chile, Colombia, Costa Rica, the Dominican Republic, Ecuador, El Salvador, Guatemala, Honduras, Mexico, Nicaragua, Panama, Paraguay, Peru, the Plurinational State of Bolivia and Uruguay. No data for 2008.

Large-scale public funds that could otherwise be used to finance investment, science and technology policies or social protection are spent on security. In a context of growing concern about insecurity, these expenses are downside inelastic and display a tendency to rise, so reducing them would be very costly politically. Fiscal adjustment policies seldom touch security items; instead, they tend to reduce public investment and even social protection. Thus, between 2000 and 2015, the region increased spending on defence, security and public order from $1.7 \%$ to $2.6 \%$ of GDP (ECLAC, 2017).

The increase in security spending reflects what legal scholars call "crime demagoguery", which advocates more severe punishments, reduction of prison benefits, lowering of the age of criminal responsibility and reinstatement of the death penalty. In extreme cases, even extrajudicial killings are considered justified. This reflects the evolution of the security perception indicator. In 2015, in 18 countries in the region, 63\% of the population considered that their country had become a less safe place to live, while only $9 \%$ thought otherwise (see figure VI.3).

Figure $\mathrm{VI} .3$

Latin America (18 countries): perception of security in the country, 2007-2015

(Percentages)

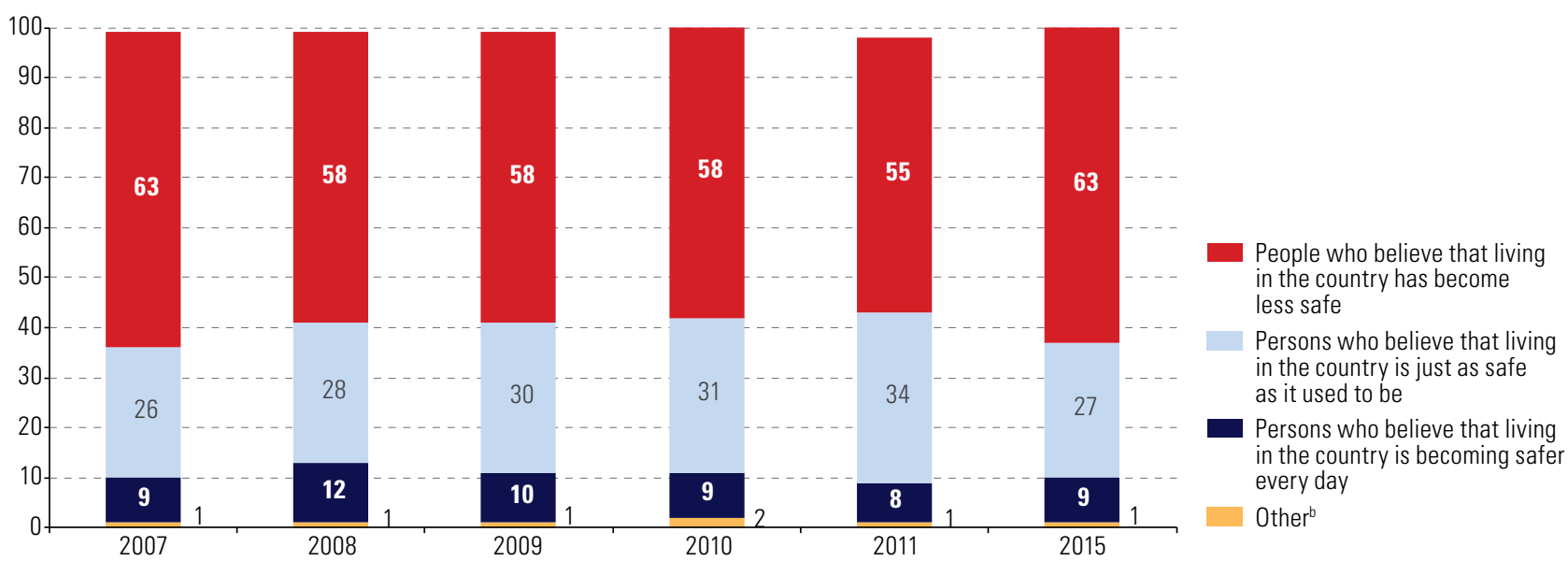

Source: Economic Commission for Latin America and the Caribbean (ECLAC), on the basis of Latinobarómetro 2017 [online] http://www.latinobarometro.org /latOnline.jsp.

Note: The percentages may not sum to $100 \%$ owing to rounding errors.

a The information refers to Argentina, the Bolivarian Republic of Venezuela, Brazil, Chile, Colombia, Costa Rica, the Dominican Republic, Ecuador, El Salvador, Guatemala, Honduras, Mexico, Nicaragua, Panama, Paraguay, Peru, the Plurinational State of Bolivia and Uruguay.

b The "other" category includes people who did not reply or did not know at the time of the survey. 


\section{Insufficient support for democracy}

One of the region's most significant achievements is to have ended the military regimes and dictatorships that were frequent in the last century and which perpetrated serious human rights violations. Elections are now being held regularly and political democracy has been consolidated, although in a context of great heterogeneity. These achievements are not free from risks and setbacks. Formal respect for legality can coexist with a weakening of democracy measured as a political order of fully functioning rights and effective separation of powers.

Despite its limitations, the return to democracy and its normalization has been a very important civilizing process. Nonetheless, it has not been accompanied by an equivalent spread of full equality in terms of economic and social rights. The redistributive effect of democratic regimes has been limited. There are still disparities in the enjoyment of political, economic and social rights; and the gap between political and social citizenships has not been sufficiently closed. There is a clear warning in the fact that, between 1995 and 2016, the proportion of the population that believes democracy is preferable to any other form of government has never exceeded $60 \%$. Moreover, $20 \%$ consider that an authoritarian government is preferable in some circumstances, and $20 \%$ have no preference between a democratic and an authoritarian regime (see figure VI.4).

Figure Vl.4

Latin America: support for democracy, 1995-2016 ${ }^{a}$

(Percentages)

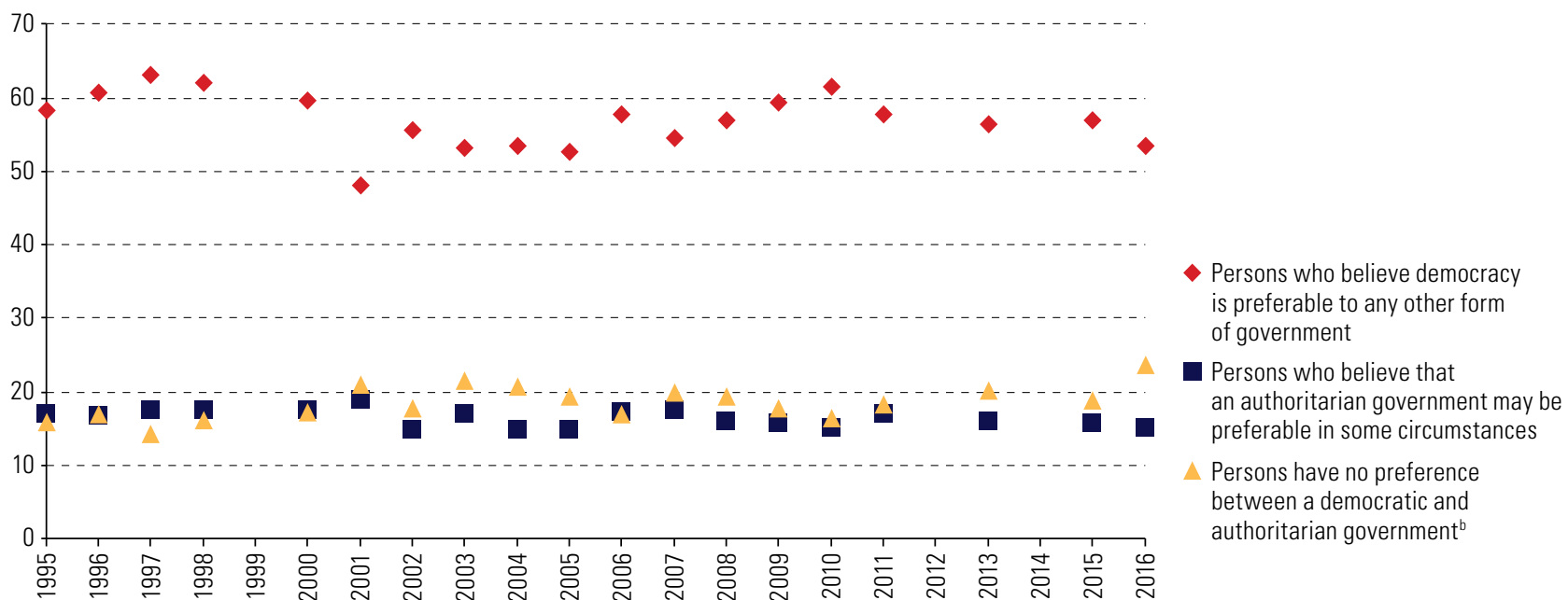

Source: Economic Commission for Latin America and the Caribbean (ECLAC), on the basis of Latinobarómetro 2017 [online] http://www.latinobarometro.org /latOnline.jsp.

a No information is available for 1999, 2012 and 2014. In 1995, the data refer to eight countries (Argentina, the Bolivarian Republic of Venezuela, Brazil, Chile, Mexico, Paraguay, Peru and Uruguay). In 1996-1998 the information comes from 17 countries (Argentina, the Bolivarian Republic of Venezuela, Brazil, Chile, Colombia, Costa Rica, Ecuador, El Salvador, Guatemala, Honduras, Mexico, Nicaragua, Panama, Paraguay, Peru, the Plurinational State of Bolivia and Uruguay). In 2000-2002 it covers 17 countries (Argentina, the Bolivarian Republic Venezuela, Brazil, Chile, Colombia, Costa Rica, Ecuador, El Salvador, Guatemala, Honduras, Mexico, Nicaragua, Panama, Paraguay, Peru, the Plurinational State of Bolivia and Uruguay). In 2003, 16 countries (Argentina, the Bolivarian Republic of Venezuela, Brazil, Chile, Colombia, Costa Rica, Ecuador, El Salvador, Guatemala, Honduras, Mexico, Panama, Paraguay, Peru, the Plurinational State of Bolivia and Uruguay). In 20042011, 18 countries (Argentina, the Bolivarian Republic of Venezuela, Brazil, Chile, Colombia, Costa Rica, the Dominican Republic, Ecuador, El Salvador, Guatemala, Honduras, Mexico, Nicaragua, Panama, Paraguay, Peru, the Plurinational State of Bolivia and Uruguay); and in 2013, 2015 and 2016 the data relate to 18 countries (Argentina, the Bolivarian Republic of Venezuela, Brazil, Chile, Colombia, Costa Rica, the Dominican Republic, Ecuador, El Salvador, Guatemala, Honduras, Mexico, Nicaragua, Panama, Paraguay, Peru, the Plurinational State of Bolivia and Uruguay).

${ }^{\mathrm{b}}$ The percentage of individuals who do not know or did not answer the question is not included.

The foregoing shows that large segments of the population are dissatisfied with the results of a democracy that has proven ineffective in reducing inequalities, deficient in terms of the performance of State agencies, unreliable in terms of the probity of public servants, and highly prone to the capture of public institutions 
by power and interest groups. Insufficient support for democracy as a regime and a public good cannot be attributed mechanically to the persistence of inequalities in the region, since there are also political, social and cultural factors in play. Nonetheless, the depth of inequalities, along with their persistence and their resistance to policies aimed at reducing them, probably play a role in the indifference, detachment and limited civic and political life in the region.

Another warning sign is the decline in citizens' perception of the degree of development of democracy. Although the proportion of those questioned who consider the region's regimes to be totally democratic rose from $6 \%$ to $11 \%$ between 1997 and 2016, the proportion who consider them undemocratic also increased, from $5 \%$ to $11 \%$ (see figure VI.5).

Figure VI.5

Latin America: citizens' perception of the degree of development of democracy, 1997 and $2016^{a}$

(Percentages)

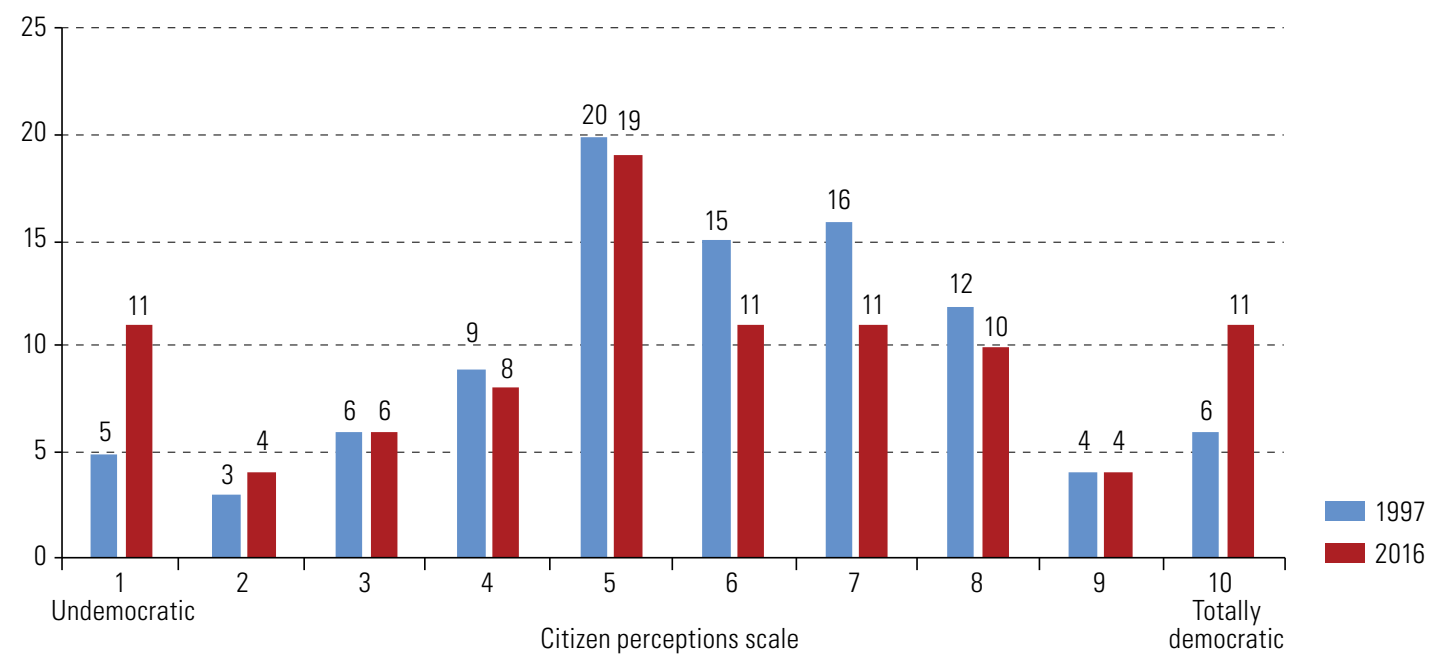

Source: Economic Commission for Latin America and the Caribbean (ECLAC), on the basis of Latinobarómetro 2017 [online] http://www.latinobarometro.org /latOnline.jsp.

The inequality and deprivations associated with poverty have implications for participation in public affairs by lower-income sectors and those who suffer the greatest lacks. In countries where voting is not mandatory, the electoral participation rate of low-income sectors is less -in some cases markedly so- than that of the middle- and high-income sectors, and this weakens their ability to influence public affairs. Moreover, it is common for clientele networks and illegitimate mechanisms for inducing voting to operate among the poorest segments. This reproduces a democracy of poor quality and redistributive capacity, which feeds on a citizenship with limited autonomy or effective capacity to influence public decisions.

\section{Culture of privilege, rent-seeking and inequality}

Analysing development challenges from a political economy standpoint highlights the importance of the actors, their interests and their power to influence politics and policies, together with the institutions that guide their behaviour. In this connection, nothing is more deeply rooted in institutions and actors than culture, understood as the world vision, values and norms that guide projects and actions and ways of relating to nature and to others. References are made, for example, to political culture, civic culture, environmental culture and even productive culture to emphasize dimensions of development that are less an object of policy than features of 
an intangible societal heritage, which can either favour or obstruct the deepening of democracy, transformation of the productive structure, sustainability of strategic resources and quality of life, or collective solidarity. Just as the institutional environment in which agents interact and make decisions is key to the trajectories of growth and distribution of its benefits, culture is also crucial as the bedrock on which institutions are built or as a set of values that form the basis for debating and formulating strategic decisions.

Although culture does not wholly determine development styles, the sustainability of growth and the distribution of its benefits, it does condition them in one direction or the other. It is therefore important to consider the cultural dimension of development, since cultural changes tend to unfold over longer time cycles than technological advances or policy changes. Conversely, culture can also be moulded and transformed as a result of the diffusion of technical change and by politics and policies.

There is a dialectic between culture and institutions that can have either virtuous or harmful effects on the dynamic of development. A culture that supports innovation, environmental stewardship and equal rights, for example, will tend to be embodied in institutions that promote a form of sustainable development that has equality as a meta-value. Political economy is a crucial link in this dialectic, since it relates internalized collective values and practices with management and planning efforts to steer development in a specific direction. Politics and policymaking can reproduce and consolidate relationships that have formed between culture and institutions (or between values, organizations and established practices); or, on the contrary, they can work to alter these relationships.

Culture and institutions are reciprocally determined; and institutions, insofar as they include norms, attitudes and behaviours, are based on culture -in other words on visions of the world and society. Conversely, some political-institutional changes have an impact on the culture of development —on the values that affect, in the deepest and most granular way, how society forges understandings to produce, distribute capacities and opportunities, and ensure sustainability for future generations.

The Latin American and Caribbean region is now at a crucial turning point in the tensions between two opposing matrices of the development culture: (i) the culture of privilege, which has historically predominated; and (ii) the culture of equality, which is emerging on the equal rights horizon as a meta-value of twenty-first century democracies, in the light of growing citizen demands in the social sphere and in terms of reciprocal recognition.

The culture of privilege is a system of values that organizes established practices, in which it is considered acceptable for a specific population group, hierarchically characterized by its ethnic or racial or gender ascription, by socioeconomic status, membership of political or cultural elites, class status or ancestry or inheritance, to have advantages over the rest of society. Such advantages relate to conditions for capacity-building and the formation of cultural capital; the use of relationship networks to win contracts and do business, and access to better jobs and higher salaries and financing facilities; power in deliberative or decision-making bodies; voice in the communicational circuits where ideas, ideologies and political agendas are imposed; access to public resources for private benefit; impunity or special legal facilities in respect of economic crimes, damage caused to third parties, illicit forms of power over others and discrimination; and capacity in respect of pressure, negotiation, manipulation of, and veto against, policies and government or State agencies.

As noted in chapter I, the culture of privilege shows that privilege is perceived as a natural condition in society, or at least in the collective imaginary of certain social groups. This means, firstly, that those who hold privileges take them as given and desirable. The culture of privilege then assumes the normalization of an asymmetry in the rights and duties of citizenship that consecrates and reproduces an unequal order in terms of effective ownership of rights, participation in political debate, distribution of capacities and benefits of economic and social progress.

This culture of privilege in the region has historical roots that stretch back to the characteristic features of colonization, involving the appropriation of natural resources by political and economic elites, forced labour, deprivation of full citizenship for a large part of society and concentration of power on ascriptive and class basis. 
The culture of privilege is also manifested in the racism and dehumanization that underlay the transatlantic trafficking of Africans and the practice of slavery, which, in some countries, survived as a form of subjugation and economic exploitation until the late nineteenth century. The legacy of slavery, the social relations produced by its practice and the multiple discriminations that persist to this day have a crucial impact on ethno-racial inequalities in the region. In 2013, the member countries of the Caribbean Community (CARICOM) formed a Caribbean Community Reparations Commission to establish the ethical and legal case for the payment of reparations to the CARICOM nations by the governments of the former colonial powers, for crimes of genocide against indigenous peoples, the transatlantic slave trade and the racist slavery system. In addition to highlighting aspects of historical and cultural identity, the CARICOM Ten-point Action Plan for Reparatory Justice links the legacy of the slavery system to contemporary problems of subregional development, such as deficiencies in public health, education and technology transfer, thus highlighting its deep and persistent historical impact.

The culture of privilege that emerged during the colonial era went through different phases in the republics of the nineteenth century and in the initial stages of twentieth century modernization, perpetuating and recreating a pattern of social asymmetries under which one part of the population (the elites in which political and economic power was concentrated) maintained privileges in terms of the appropriation of rents deriving, above all, from access to natural resources and public funding; consumption patterns that imitated those of their peers in the industrialized world; close relationships with external markets, concentration of political power (or, failing that, de facto power); and participation in networks that help to preserve privileged situations in multiple areas (employment, justice, financing, influence, communication, access to markets, concessions and exemptions).

This culture of privilege was contested by the great social movements, popular revolutions and nationalpopular leaderships; and it was also called into question by the vigorous consolidation of political democracy since the late twentieth century and the rise of social demands and rights in the first decade of the twenty-first. Other actors erupting into the democratic arena broadened the challenge to encompass privileges in the relation between capital and labour, and in relations between social classes, including other ways in which privileges are exercised in relations of gender, sex, race, ethnicity and territory.

Nonetheless, the culture of privilege continues to be reproduced and expressed by sectors of society that mobilize their networks and resources to preserve basic asymmetries, marked by birth, wealth, cultural capital and asset endowment. As with productive institutions and economic policy, this culture is also rooted in the economic structures in which the protagonism of the actors and the power they possess is defined.

The relationship between the culture of privilege and structural heterogeneity in Latin America and the Caribbean is a two-way one. Productivity gaps, asymmetric interaction with international markets, the concentrated appropriation of wealth in the exploitation of natural resources and reluctance to implement structural reforms are framed by a cultural heritage characterized by relations of privilege. A production structure that operates as an inequality factory is interwoven with a culture of privilege rooted in a history of asymmetries in productive resources, capacity development and spheres of influence.

There is also a strong relationship between the culture of privilege and rent-seeking. The use of privileged conditions to capitalize the exploitation of natural resources with little value added, take advantage of a cheap labour force to hold down production costs and compete without major innovation effort, use financialization to appropriate speculative rents or perpetuate a weak tax system and the use of public funds for private gain -all these draw from a common well. Privilege is manifested here in the form of exclusive access to these sources of rent; and it uses different guises to perpetuate the selective and concentrated appropriation of wealth opportunities with low levels of investment and innovation, and high levels of inequality.

The culture of privilege is closely related to structures of concentration of resources and institutions that concentrate power. The stronger the culture of privilege, the more dysfunctional the relationship between institutions and structures; in other words, less innovation on both sides because the system of privileges permeates structures and institutions, because de facto powers have a veto over institutional change that 
political will is unable to overturn, or because the mutual rewards existing between political and economic elites in a culture of privilege choke off any change before it can take root. In the culture of privilege, institutions also play a major role when they serve groups that hold privileges, in domains as diverse as criminal and financial justice, tax regulations and tax oversight, the land ownership regime, the control of populations at risk or considered a risk for third parties, and regulations governing treatment between genders, indigenous peoples or ethnic groups.

This is not all inevitable, however. Institutions can also generate change through politics and policies. In terms of structure, institutions can either reinforce structural heterogeneity as a factory of inequality, or else reverse it through industrial, fiscal, social and labour market policies. Institutional reforms are forged to transform structures through public action and regulation. Other institutions become necessary, for example, to move towards a knowledge society, respond to demands for greater well-being and opportunities, and change modes of production to improve integration into the international economy.

The push engendered by the creation or reform of institutions can also put a strain on structures considered outdated, unfair and dysfunctional to development. This institutional change responds both to social demands for equality and greater access to the fruits of progress, and to the emergence of public technocrats with new visions of how to steer the economy and production structures. It is not clear that these changes will undermine the culture of privilege, nor is it guaranteed; but they are a necessary condition. The dialectic between institutional change and structural change is positive, provided it is oriented towards greater acquired rights, smaller social deficits, greater control and sanction over abusive practices, better distribution of skills as demanded by the knowledge society, broader spaces for cooperation between labour and productive actors, and a clearer commitment between private initiative and public support. All these elements strengthen a culture of citizens' rights and thus undermine the culture of privilege.

In short, from the political economy standpoint, the culture of privilege is expressed through institutions and practices that are deeply rooted in the sectors where those privileges are exercised, in a way that runs counter to the direction of development proposed in this document. Such institutions and practices include the maintenance of glaring social inequalities and resistance to redistributive reforms; a productive culture with a strong rent-seeking component and little incentive to innovate; and a development model with a weak sustainability —and especially environmental — dimension. This culture of privilege operates in league with exclusionary institutions, in other words institutions that activate segregation mechanisms, discriminate against different population groups in terms of access to capacities and opportunities, and reproduce high levels of inequality and wealth concentration. Conversely, by disseminating capacities and opportunities and outlawing all types of discrimination and segregation, egalitarian institutions erode the culture of privilege and make it possible to construct a citizen culture focused on equal rights. What may seem natural at one moment - the privileges of some at the expense of others - can later be challenged through social demands and pro-equality policies and by the communication dynamics they mobilize.

\section{The domains of the culture of privilege}

The transition to equal rights has a long way to go. The culture of privilege implies denial of the social bond of reciprocity. Conversely, the absence of this link is what feeds the culture of privilege, which is based on an asymmetric relationship in various spheres: agency, power, rewards, recognitions, access, links. The following paragraphs identify some of the domains in which this culture operates.

Territorial segregation reinforces belonging in terms of income, cultural capital and relationship networks. Large cities configure genuine maps of the culture of privilege, combining aesthetic, cultural and social factors. Place defines trajectories, both physical and biographical. The large Latin American metropolises have urban areas where pockets of poverty and marginality operate as self-fulfilling prophecies of school failure, precarious employment and early motherhood. Place marks a dividing line between the fortunate and the condemned; a line that is not definitive and must not be seen as inevitable, but nevertheless implies very different life chances. 
This also extends to whole countries: in Brazil or Peru, for example, an individual born in the poorest municipalities or departments, or those with more dispersed populations, has a shorter life expectancy than someone born in the big cities or in richer areas. Geographic location as a source of privilege is multiplied by establishing differences within cities and between geographical areas. Conversely, the poor neighbourhood or community is stigmatized, which impedes inclusion.

Segmentation in education makes it a space of differentiation for the preservation of privileges. High-cost elite schools, with entry barriers associated with relationship networks, membership of specific groups and cultural capital of origin, propagate these differences from one generation to the next. School life also cultivates networks of relationships for the next generation. The effect of peers with greater cultural capital and family support for skills development produces a ring-fence effect, a positive homogeneity that marks a difference and a defines privilege relative to those who do not attend such schools.

Health care is another domain of the culture of privilege. The contrast in treatment between public and private care exacerbates the perception of privilege. Those who use the public system feel discriminated against by long waits to receive care, months to obtain a medical appointment for pathologies in which timely treatment makes a difference in terms of well-being and quality of life; the treatment they receive from professional, paraprofessional and administrative staff in health-care centres and the austere conditions they face when they are hospitalized or have to wait in crowded waiting rooms. The right to health is experienced as a hierarchy of first- and second-class citizens.

Unequal access to justice reflects socioeconomic status, geographical location and even racial or ethnic identity and gender. The culture of privilege is strengthened whenever money or contacts make the difference between being punished for a crime or not. There are also privileges in which the difference is marked by prejudices and discriminations that entrench biases in justice with respect to women, indigenous people, young people from low-income urban sectors, lesbian, gay, bisexual, transgender and intersex (LGBTI) people and Afrodescendants.

The situation in the penal system is dramatic. Latin American prisons are overcrowded, out of control and overwhelmed by violence; and part of the prison population is awaiting the resolution of their cases, often in preventive detention with cases on which no progress is being made. The contrast between this failure in judicial protection, at one extreme, and the semi-impunity of white-collar crime, on the other, reinforces the culture of privilege.

Networks of influence are decisive in matters as varied as access to high-paying public-sector jobs and enterprise boards of directors, the awarding of tenders for privatized works and services, obtaining public investment funds or subsidies, easy access to financing, asymmetries of information for investments of rapid capitalization, streamlining of procedures, obtaining of public favours and the reduction of waiting times in public services. The persistence of networks of influence as an inclusive-exclusive mechanism in multiple accesses reinforces the culture of privilege, since it ratifies a regime of differences in achievement based exclusively on systems of belonging. Just as gender discrimination gives privileges to men while offering lower pay to women with the same educational level or equal ability for a job, so a person who can harness influence networks defined by class origin or status will have a better chance of accessing a higher-skilled or better-paid job than a person who has similar educational achievements but lacks this access.

The veto power held by the business and financial world against representative powers is not new: it is a de facto power. Its practices include private and discretionary decisions that can undermine a public agenda and even jeopardize a government. The idea that a veto is possible through the play of de facto powers is part of a culture of privilege. Stronger democratic institutions help to mitigate these practices, but not suppress them. They reappear after they were thought obsolete or when those that exercise them see that they can generate financial chaos, restrict supply, discredit political leaders in the media, prompt capital flight or reduce investment, in response to policies to which they object. 


\section{Strengthening the culture of equality erodes the culture of privilege}

The mutual reinforcement of the democratic culture and the institutional framework increasingly calls into question the culture and exercise of privilege. The democratic culture must confront the culture of privilege; and it does so as described below.

Firstly, in the defence of groups or sectors of the population who are discriminated against, denied or excluded from the benefits of progress and reciprocity in treatment: the demands of movements of women, or indigenous and Afrodescendent populations, along with others in domains such as sexual orientation and gender identity, generational identity or cultural diversity in general, challenge society on a daily basis and confront secular forms of discrimination and the exercise of privileges based on gender, sex, racial or ethnic identity and generation. The right to difference goes hand in hand with equal rights, or complements it.

Secondly, the democratic culture, when reinforced and activated with democratic institutions, reduces tolerance of privileges and fosters greater empowerment to challenge them. Where that culture and institutional framework exist, they exert a demonstration effect: whenever a privilege is not only contested, but recognized as ethically inadmissible, challenged in court or politically sanctioned, it has a simultaneous effect on a specific practice and the culture underlying it. To denounce, interrupt and penalize a privilege is to challenge it as a culture.

Thirdly, in the first decade of the twenty-first century, the democratic regimes of the region implemented a wide range of constitutional, social, tax and legal reforms in response to increasing demands for well-being, effective equality of rights, State presence and non-discrimination. These reforms have a political and practical effectiveness, and also a communicational value. The issues in play are highly diverse: universal pensions, legal enforceability of social benefits, constituent assemblies of broad participation, incorporation of historical demands, recognition of peoples, laws and procedures to sanction corruption, tax reforms to tax profits and rents, systems of child care and social protection. There is a back and forth between a greater awareness of equal rights and reforms in the field of politics and justice that mobilize society with instruments to protect them from risks and abuses. The elimination of the mercantile nature of social benefits administration in some countries of the region sends a powerful signal on behalf of a culture of equal rights. This marks a turning point with respect to the preceding decades in which the accent was on privatization in the social domain or with few achievements in that area; and it goes hand in hand with a change in the citizen culture that affirms dignity and associates it with effective and not merely nominal rights.

As the other side of the coin, a progressive taxation system together with an expansionary social policy combine to institutionally penalize the culture of privilege. If pro-social-welfare reforms, especially associated with civic dignity, erode the culture of privilege, reversing such reforms instils a scepticism that revives the culture of privilege. Hence, it is also vital to preserve conquests and prevent the burden of new international restrictions or changes in national governments from rolling back the progress achieved. This would hinder the emergence of new production and consumption patterns based on effort, cooperation and technological learning. The environmental big push is also a cultural change. The culture of privilege is incompatible with a culture of effort and cooperation. 


\section{Bibliography}

Acemoglu, D. and J. A. Robinson (2013), "Economics versus politics: pitfalls of policy advice", Journal of Economic Perspectives, vol. 27, No. 2.

(2006), Economic Origins of Dictatorship and Democracy, Cambridge, Cambridge University Press.

Acemoglu, D., S. Johnson and J. A. Robinson (2004), "Institutions as the fundamental cause of long-run growth", NBER Working Paper, No. 10481.

Álvarez, J. and L. Bértola (2007), "So similar, so different: New Zealand and Uruguay in the world economy", Settler Economies in World History, C. Lloyd, J. Meltzer and P. Sutch (eds.), Brill, Leiden.

Amsden, A. (1989), Asia's Next Giant: South Korea and Late Industrialization, New York, Oxford University Press.

Arthur, B. (1994), Increasing Returns and Path-Dependency in Economics, Ann Arbor, Michigan University Press.

Bértola, L. and J.A. Ocampo (2012), The Economic Development of Latin America Since Independence, Oxford University Press.

Bowles, S. (2012), The New Economics of Inequality and Redistribution, Cambridge University Press.

(1998), "Endogenous preferences: The cultural consequences of markets and other economic institutions", Journal of Economic Literature, vol. 36, No. 1, March.

Cardoso, F.H. and E. Faletto (1977), Dependencia y desarrollo en América Latina, Buenos Aires, Siglo XXI.

Cecchetti, S. and E. Kharroubi (2012), "Reassessing the impact of finance on growth", BIS Working Papers, No. 381, July.

Chong, A. and M. Gradstein (2007), "Inequality and institutions", The Review of Economics and Statistics, August, vol. 89, No. 3.

Cimoli, M. and G. Dosi (2017) "Industrial policy in learning economies", Efficiency, Finance and Varieties of Industrial Policy, A. Norman and J. Stiglitz (eds.), New York, Columbia University Press.

Cohen, M., N. Lupu and E. Zechmeister (2017), The Political Culture of Democracy in the Americas, 2016/17: A Comparative Study of Democracy and Governance, United States Agency for International Development (USAID)/Latin American Public Opinion Project (LAPOP) Americas Barometer.

Corporación Latinobarómetro (2017), "Data Bank" [online] http://www.latinobarometro.org/latContents.jsp.

Doner, R. and B. Ross Schneider (2016), "The middle-income trap: more politics than economics", World Politics, vol. 68, No. 4.

Dooley, M.P., D. Folkerts-Landau and P. Garber (2003), "An essay on the revived Bretton Woods System", NBER Working Paper, No. 9971, September.

ECLAC (Economic Commission for Latin America and the Caribbean) (2017), CEPALSTAT database [online] http://interwp. cepal.org/sisgen/Consultalntegrada. asp? IdAplicacion=38\&idTema=882\&idlndicador=3126\&idioma=e.

(2016), Horizons 2030: Equality at the Centre of Sustainable Development (LC/G.2661/Rev.1), Santiago, May.

(2015), The New Digital Revolution: From the Consumer Internet to the Industrial Internet (LC/L.4029(CMSI.5/4)/

Rev.1), Santiago, August.

(2010), Time for Equality: closing gaps, opening trails (LC/G.2432(SES.33/3)), Santiago, May.

(2002), Globalization and development (LC/G.2157 (SES.29/3)), Santiago, April.

Evans, P. and P. Heller (2015), "Human development, State transformation and the politics of the developmental State", The Oxford Handbook of Transformations of the State, S. Leibfried and others (eds.), Oxford, Oxford University Press.

Fajnzylber, F. (1983), La industrialización trunca de América Latina, Mexico City, Nueva Imagen.

Frieden, J.A. (2015), Currency Politics: the Political Economy of Exchange Rate Policy, Princeton University Press.

Hirschman, A.O. (1986), "The political economy of Latin American development: seven exercises in retrospection, Working Paper, No. 88, Kellogg Institute, December.

(1968), "The political economy of import-substituting industrialization in Latin America", Quarterly Journal of Economics, vol. LXXXII, No. 1, February.

Jaitman, L. (2017), Los costos del crimen y la violencia. Nueva evidencia y hallazgos en América Latina y el Caribe, Washington D.C., Inter-American Development Bank (IDB).

Kahn, M. and S. Blankenburg (2009), "The political economy of industrial policy in Asia and Latin America", The Political Economy of Capabilities Accumulation: the Past and Future of Policies for Industrial Development, M. Cimoli, G. Dosi and J. E. Stiglitz (eds.), Oxford University Press.

Kim, I. (2016), "Land Reform in South Korea under the U.S. military occupation, 1945-1948," Journal of Cold War Studies, vol. 18, No. 2.

Lo Vuolo, R. and L. Goldberg (2006), Falsas promesas. Sistemas de previsión social y régimen de acumulación, Buenos Aires, Miño y Dávila.

Moore, B (1966), The Social Origins of Dictatorship and Democracy: Lord and Peasant in the Making of the Modern World, Boston, Beacon Press. 
Moretti, E. (2004), "Human capital externalities in cities", Handbook of Regional and Urban Economics, J. V. Henderson and J. F. Thisse (eds.), 1, vol. 4, Elsevier.

Nochteff, H. (1996), "The Argentine experience: development or a succession of bubbles?", CEPAL Review, No. 59 (LC/G.1931-P), Santiago, Economic Commission for Latin America and the Caribbean (ECLAC), August.

North, D.C., J.J. Wallis and B.R. Weingast (2009), Violence and Social Orders: A Conceptual Framework for Interpreting Recorded Human History, New York, Cambridge University Press.

Ocampo, J.A. (2013), “Balance of payments dominance: its implications for macroeconomic policy," Working Paper, No. 268, Initiative for Policy Dialogue (IPD), October.

O'Donnell, G. (1978), "State and alliances in Argentina, 1956 - 1976", Journal of Development Studies, vol. 15, No. 1.

O'Donnell, G., P. Schmitter and L. Withehead (eds.) (1991), Transitions from Authoritarian Rule: Comparative Perspectives, The Johns Hopkins University Press.

Palley, T. (2017), "A theory of economic policy lock-in and lock-out via hysteresis: rethinking economists' approach to economic policy", Economics, vol. 11, No. 2017-18.

Palma, J.G. (2012), "How the full opening of the capital account to highly liquid financial markets led Latin America to two and a half cycles of 'mania, panic and crash'," Cambridge Working Papers in Economics, No. 1201, January.

Prebisch, R. (1963), Hacia una dinámica del desarrollo latinoamericano, Mexico City, Fondo de Cultura Económica.

Poo, D. (2014), "China's development trajectory: A strategic opening for industrial policy in the South", Discussion Paper, No. 218, United Nations Conference on Trade and Development (UNCTAD), December.

Rodríguez, O. (2007), El estructuralismo latinoamericano, Mexico City, Economic Commission for Latin America and the Caribbean (ECLAC)/Siglo XXI.

Stalling, B. and W. Peres (2000), Growth, Employment and Equity: The Impact of Economic Reforms in Latin America and the Caribbean, Washington, D.C., Brookings Institution Press.

Stiglitz, J. (2014), "Leaders and followers: perspectives on the Nordic Model and the economics of innovation", NBER Working aper, No. 20493, September.

(2013), The Price of Inequality: How Today's Divided Society Endangers Our Future, New York, Norton.

Sunkel, O. and P. Paz (1970), El subdesarrollo latinoamericano y la teoría del desarrollo, Mexico City, Siglo XXI.

Turner, A. (2016), Between Debt and the Devil: Money, Credit and Fixing Global Finance, Princeton University Press.

United Nations (2015), "Statistical Annex", The World's Women 2015: Trends and Statistics [online] https://unstats.un.org/ unsd/gender/worldswomen.html.

Wade, R. (1992), "East Asia's economic success: conflicting perspectives, partial insights, shaky evidence", World Politics, vol. 44, No. 2, January.

Wilkinson, R. and K. Pickett (2009), The Spirit Level. Why More Equal Societies Almost Always Do Better, Bloomsbury Press.

World Bank (2017), World Bank Open Data [online] https://data.worldbank.org/. 

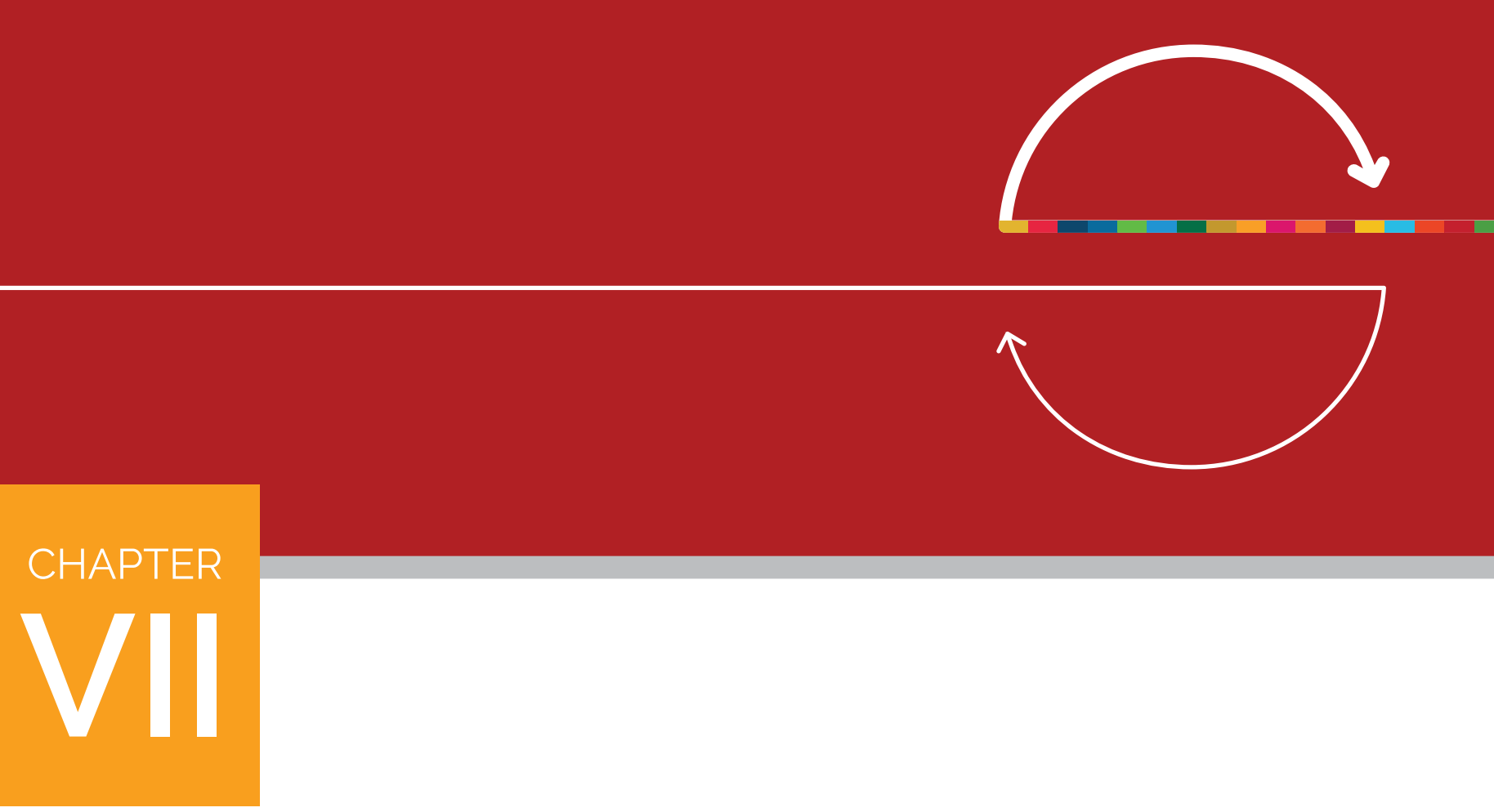

\section{Strategic orientations}

Introduction

A. A macroeconomy for development

1. From monetary stability to financial stability

2. Fiscal policy for growth and equality

B. The welfare State: exercising rights and increasing productivity

1. Protecting public social spending through progressive taxation

2. Adapting education to the new technological context

3. Strengthening social protection and care systems

4. Basic income: an option?

C. Three pillars of decarbonization: digitalization, sustainable cities and renewable energies

1. An environmental big push for progressive structural change

2. Industrial and technological policies for the digitalization of production

3. Sustainable cities as drivers of development

4. The energy sector, a driver of change

D. Transparency and trust in institutions facilitate the implementation of policies to promote the environmental big push

E. Concluding remarks

Bibliography 



\section{Introduction}

Inequality is inefficient. The culture of privilege and the prevailing pattern of development produce disparities that increase the differences between the centres and the peripheries, rather than reduce them, while generating unsustainable income polarization. Macroeconomic uncertainty, the geopolitical emergence of China, the technological revolution and the worsening environmental crisis are additional factors that make the international scenario more complex. Responding to these changes requires cooperative strategic decisions at the global, regional and national levels, under a multilateral approach engaging all stakeholders. In this framework, the Economic Commission for Latin America and the Caribbean (ECLAC) reaffirms its belief that the countries of the region need to launch a new development paradigm based on an environmental big push.

The technological revolution and the environmental crisis shorten the time horizon for action. The current generation is the first that cannot deny the scale of these changes; and it is also possibly the last that can lay the foundations for, and launch, a new economic, social and political regime capable of making more egalitarian economic growth compatible with environmental stewardship. Accordingly, the 2030 Agenda for Sustainable Development sets forth three key lines of action for the new model: a macroeconomy for development, a welfare State based on rights and productivity growth, and decarbonization of the economy and society.

The 2030 Agenda and the Sustainable Development Goals are a response by the international community to the tensions that have built up in the current phase of globalization. Growing inequality within many countries, the persistence of global financial imbalances, the impact of international migration and climate change cannot be addressed by national policies alone. Their very nature means they require a context of international cooperation that supports these policies and addresses issues that affect all countries across the board. A financial crisis in one country generates negative externalities that quickly spread to the rest of the world; although $\mathrm{CO}_{2}$ emissions are generated by the whole planet, they are felt more intensely in certain regions; and poverty and instability in an economy generate sudden and large-scale migratory flows that can have disruptive effects on other economies. None of these problems can be resolved by any one country alone; international cooperation is essential for moving towards a more stable and sustainable international economy.

In the document presented by ECLAC at the first meeting of the Forum of the Countries of Latin America and the Caribbean on Sustainable Development, held in Mexico City in 2017 (ECLAC, 2017a), several forms of international cooperation were discussed as a necessary complement to national policies aimed at fulfilling the 2030 Agenda and attaining the Sustainable Development Goals. The application of expansionary fiscal policies (together with investments targeting low-carbon development paths) in countries with international trade surpluses would help balance this trade without serious repercussions on employment and growth in deficit countries, while at the same time enhancing global growth and sustainability. Multilateral cooperation would make it possible to restore the ability of governments to act in coordination to stabilize global finances and control their effects on the national economies, which would avoid speculative bubbles and an accentuation of the business cycle, with their serious consequences for employment. Moreover, the adoption of international agreements on labour rights and the welfare State would reduce the risks of predatory competition in which wages would be the key adjustment variable for increasing exports and attracting foreign capital. Strategies based on wage cuts represent the predominance of a spurious competitiveness over approaches aimed at closing gaps, and they erode the tax base needed to build the public goods that are essential for the functioning of democracy. A multilateral system open to trade, working to narrow production and technological asymmetries, would foster job creation in less developed countries and reduce the political tensions associated with migration. Only by creating jobs and opportunities in developing countries - currently overwhelmed by income and wealth inequalities and rapid population growth — will it be possible to stem migration to the developed world.

Against this backdrop, this chapter sets forth strategic guidelines for the design of sustainable development policies in different domains in Latin America and the Caribbean. In macroeconomic terms, it reaffirms the need for a development-oriented policy that, in addition to controlling inflation, strengthens countercyclical instruments, and links the objectives of economic growth and financial stability with other equally important goals, such as production restructuring and improvements in the income distribution. In relation to social policies, the rights-based approach and the pursuit of substantive equality are pillars of the new welfare 
regimes, with a view to forming a development style centred on equality and sustainability, achieving the Sustainable Development Goals, and tapping synergies between equality and growth. On environmental issues, the chapter focuses on three pillars of decarbonization: the digitalization of society and production, particularly of micro, small and medium-sized enterprises (MSMEs) given their importance for job creation and wages; the development of sustainable cities; and the promotion of renewable energies.

Implementing these strategic lines of action and advancing towards fulfilment of the 2030 Agenda requires an approach in which the ranking of objectives, timing of actions, mobilization of resources and coordinated policy implementation are at the heart of decision-making processes at the global, regional and national levels.

\section{A. A macroeconomy for development}

Macroeconomic stability is necessary for sustainable and inclusive growth. The 2008 global crisis highlighted the close links that exist between external cycles, the economic dynamics of the countries of the region and their room for macroeconomic policy manoeuvre. Although average global growth rates are currently below those recorded during the "great moderation" (which lasted from the mid-1980s until 2007), the international economy is showing signs of recovery, and the terms of trade are expected to improve slightly; this will boost the performance of the natural-resource-producing countries of South America. Moreover, more vigorous growth in the United States should have positive effects in Central America and Mexico and the Caribbean, but this could be hindered by political decisions. International interest rates look set to remain at historically low levels despite the unwinding of quantitative easing policies by the United States Federal Reserve. ${ }^{1}$

This context provides an opportunity for the region's countries to adopt a more proactive stance and steer their policies towards promoting progressive structural change. Such a response is all the more urgent given the uncertainties surrounding the recovery of the global economy. This section therefore offers a framework for a critical analysis of the prevailing macroeconomic paradigm and for designing macroeconomic policy to foster more equal and inclusive growth. ECLAC proposes a pro-development macroeconomic policy that combines countercyclical policies with a production diversification strategy, and emphasizes the need for fiscal policies that support the generation of public goods and services and promote the creation of a welfare State.

\section{From monetary stability to financial stability}

As argued throughout this document, faster growth is needed to regain investment momentum and improve conditions in the labour market, while also diversifying the economy to enable the region to take advantage of the full potential of external demand.

With a positive interest rate differential with respect to the rest of the world, there is more room to keep nominal and real interest rates low, as several of the countries in the region have already done, without jeopardizing price stability. Since the region also recorded historically low growth rates between 2012 and 2017, and inflation is below the tolerance thresholds in most countries, the preservation of nominal stability can be combined with the thrust towards growth, structural change and equality.

One of the key challenges is to improve the transmission of looser monetary policies from the central banks to the rest of the financial system and thence to the real economy. Monetary authorities in the developed economies face constraints in achieving this objective; yet the transmission mechanism is even further restricted in the region's countries by the local financial systems' excessive exposure to international liquidity cycles, owing to the absence or weakness of macroprudential policies in a context of capital account liberalization.

Keeping a domestic interest rate structure aligned with external rates provides the liquidity needed to promote progressive structural change, while avoiding the arbitrage and carry-trade operations that have proliferated in

External interest rates have been trending down in real terms for a decade and a half (Summers, 2016). 
some of the region's countries and which intensify financialization and thus obstruct investment (see chapter III and Shin, 2015). The countries of the region need to move from a monetary policy aimed primarily at controlling inflation, towards a broader and more comprehensive approach which, while fostering financial stability, is also compatible with a higher growth rate. This means making liquidity management more flexible as circumstances require, and adopting more active financial regulation that dynamically adjusts the regulatory parameters to maintain the desirable strength in the financial system and thus minimize systemic risk. ${ }^{2}$ If these objectives were achieved, the interest rate and money supply would be relatively less important for aggregate demand management.

This group of instruments - together making up macroprudential policy - is intended to limit the accumulation of fragile financial structures and prevent asset and credit bubbles. Systemic risks are not limited to the dynamics of financial assets and liabilities, however. Today there is a possibility that climate bubbles could be intensifying; in other words, there are environmental systemic risks that are not reflected in asset values and which the financial system does not consider properly. Climate risk should be internalized in the interest rates and premia that distinguish between high-carbon investments (higher-risk from the climate point of view) and low-carbon investments (lower-risk). The preference for low-carbon options in investment decisions should be stimulated by means of a more favorable discount rate.

The region's history shows that the dynamic of short- and long-term growth is related not only to the behaviour of real variables, such as productivity and investment, but also to credit and financial stability. Moreover, the financial sector tends to exacerbate fluctuations in aggregate demand and real activity.

As argued in chapter III, in a context of mounting private sector indebtedness, maintaining financial stability is a prerequisite for sustained long-term growth. On the one hand, the increase in household debt in several countries of the region raises the possibility that indebtedness could impose a disproportionate financial burden relative to income, which can generate unsustainable situations over time. This could have negative consequences for equality, since low-income households are those that bear the heaviest financial burdens and face the worst borrowing conditions; and they are also the most vulnerable to changes in credit conditions. On the other hand, greater indebtedness in the non-financial business sector could trigger retrenchment in production and investment; this would have adverse macroeconomic effects on a group of firms that accounts for large shares of production and investment, which could in turn hurt long-term growth, job creation and the income distribution.

Maintaining financial stability requires, as a sine qua non, protecting the economies from the vagaries of the international financial cycle. Economies with greater financial depth and market liquidity attract more capital and are more exposed to abrupt changes in financial markets (Eichengreen and Gupta, 2014). Accordingly, financial openness is acknowledged to be associated with limitations and vulnerability (see chapter III and Marcus, 2016). Even when the international financial cycle is not driven by short-term investments or subject to sudden stops in financial flows, swings in international credit markets can generate significant financial and real distortions. In the developing world, this dynamic was clearly visible in the impact that non-conventional monetary policies (quantitative easing) had on exchange-rate volatility and raw material prices.

For this reason, international organizations such as the International Monetary Fund (IMF) have added their voice to the historical recommendation by ECLAC that cross-border capital flows be managed to maintain stability and as a precondition for countercyclical policymaking. In a financialized global context, the possibility of creating new tools to manage aggregate demand depends largely on the regulation of international capital flows.

Nominal exchange rates become more volatile in institutional contexts of unfettered international capital flows; they behave like a financial asset by reacting to expected returns in futures markets, which have major speculative components. In this context, managing the exchange rate is crucial, but also increasingly challenging. The typically procyclical dynamic of international financial flows tends to influence these prices, inducing sharp revaluations (devaluations) in booms (crises) that unbalance the current account. The management of cross-border capital flows would give the monetary authorities greater room for manoeuvre than they currently have to adopt managed floating regimes and align exchange-rate policy with the requirements of the real economy.

Systemic risk is the risk of interruption to financial services caused by a total or partial disruption of the financial system, which can have major negative repercussions on the real economy. 


\section{Fiscal policy for growth and equality}

Developing fiscal policies that support progressive structural change and equality requires a framework of financial stability and greater predictability. Fiscal policies need to play a more active role if the region is to follow a path of high, sustainable and inclusive growth. Thus, the current slow-growth context requires policies that not only smooth cyclical fluctuations but also correct the features of the cycle that harm growth and the production structure. Achieving these objectives entails a major mobilization of domestic resources, and this will require more vigorous steps to combat tax evasion and avoidance.

Fiscal policy is important because it is a key tool for managing aggregate demand. In particular, it is essential to shield public investment from the ups and downs of economic activity and prevent it from being used shortsightedly as an adjustment variable during downswings. The region's common propensity for procyclicality diminishes the capacity to undertake investment projects, and it prolongs the intensity and duration of slowdowns, thereby making it difficult to restore macroeconomic equilibria. Accordingly, fiscal consolidation criteria should not —and cannot— be gauged on nominal thresholds alone, which are, in any case, hard to verify empirically. ${ }^{3}$

The State's influence in the physical capital accumulation process goes beyond its direct intervention. In this connection, ECLAC advocates the establishment of inclusive, pro-investment fiscal frameworks. Among other things, these frameworks should foster investments that facilitate territorial integration, by coordinating initiatives to enable localized activities and overcome poverty traps. The State often tends to prioritize large infrastructure projects instead of coordinating inclusive investments, in areas such as urbanization, housing construction or renovation, drinking water and waste treatment, or development in rural areas.

As was suggested in chapter $V$, integrated territorial investments are essential to support joint actions in certain geographic areas. While these localized initiatives represent smaller amounts than large national projects, they are important for attaining development objectives and can have a significant effect on long-term growth. They also promote the inclusion of the rural population, which is still very large in many countries.

Publicly managed investment plans can reverse the fall in investment rates, ensure long-term productivity and competitiveness gains in areas that are strategic for structural change and reduce infrastructure gaps. Such plans can combine ventures that interact with each other, mobilize both public and private financing, foster growth and employment with a strategic and territorial perspective, and promote clean and renewable energies.

Fiscal policy contributes to building a more inclusive society through the provision of public goods and services that increase material well-being and equal rights. Public spending on education and health has a positive impact on the income distribution, as shown by the fall in the Gini coefficient; but results in the region have been less satisfactory than elsewhere. Greater efforts are needed to increase and improve the provision of quality public goods and services. On the other hand, the efficiency and effectiveness of public spending remain very mixed across the region: in many countries the same results could be achieved with fewer resources. Expenditure quality issues notwithstanding, in most of the region's countries insufficient spending constitutes the main limitation on providing public goods. In reality, the problem is twofold: little is spent, and what is spent is often spent unwisely.

The fulfilment of fiscal policy objectives will require sufficient domestic resources to be mobilized —not only as a means to finance sustainable development, but as an endogenous component of the development process itself. Mobilizing funds, especially from the public domain, is not neutral in terms of its impact on society or the evolution of the economy. The region's development is hampered by a tax structure that is biased towards regressive indirect taxes, with high levels of tax evasion and highly dependent on income derived from the exploitation of non-renewable natural resources.

Although there is a consensus that the continuous accumulation of public debt has adverse effects on economic growth, there is no agreement on the debt threshold above which growth is compromised. Rather than focusing on the level of the debt (which would be a static approach, and therefore unsuitable in an economic growth context) it is important to consider the path of the public debt. In fact, its trajectory may be as or even more important than its level for future growth prospects. Countries with high but declining debt levels tend to grow as fast as countries with lower levels. 
Innovative policies and new fiscal covenants are needed to face these challenges, especially in a lowgrowth context. Many countries in the region have adopted tax reforms in recent years, many of which include measures to increase equity and progressiveness. Many countries are also taking steps to combat tax evasion and avoidance, and to improve the administration of tax systems. These initiatives have been supported by increased regional and international cooperation on fiscal and financial issues.

As noted in ECLAC (2016a), "in an agenda for progressive structural change, fiscal policy must be understood in dynamic terms and in relation to the other areas of the economic system". This implies, first, coordinating it with the other economic policies, especially industrial and technological ones. Not only the countercyclical nature of fiscal policy matters; so do the sectors that it targets, and there is a wide margin for strategic selectiveness. Second, fiscal policy needs to be coordinated with environmental policy to change profitability incentives between sectors (increasing the relative profitability of the most knowledge-intensive and least polluting sectors), internalize negative externalities and reduce the rate at which non-renewable resources are being exhausted. A first step in this direction would be to gradually reduce subsidies on fossil fuel consumption and to introduce environmental taxes. As emphasized below, government-funded soft financing for activities linked to the supply of energy from renewable sources is another step in that direction (ECLAC, 2016a). This is what ECLAC has in mind when it calls for an environmental Keynesianism for supporting the environmental big push, i.e. the establishment of fiscal incentives that will sustain activity and promote the transformation of the production structure.

The implementation of a strategy such as the environmental big push needs a social and political coalition aligned with its main objectives, in other words a political big push. The institutional design and the priorities that inform the implementation of macroeconomic policy are not immune to this problem. Increasing room for macroeconomic manoeuvre would require re-addressing the measures and the regulatory context that fostered financialization, which has amplified the swings in the international financial cycle and exacerbated the effect of balance-of-payments shocks on the macroeconomic dynamic. Building a new financial institutional architecture requires global and regional actions based on social and political partnerships to promote and sustain them over time.

\section{B. The welfare State: exercising rights and increasing productivity}

The changes that the world economy is going through have major repercussions on welfare regimes. These risk becoming more precarious and losing protective power as a result of new forms of work, compounded by the effects of population trends such as ageing and the intensification of migration flows. In the region, this is occurring in a context of weak economic growth, especially in the South American countries.

In this situation, the debate on social issues is unavoidable. Despite the persistence of approaches that emphasize the need for a minimal State, the subsidiarity principle, pre-eminence of the market and the promotion of residual social policies, there is growing evidence that this route does not close equality gaps or eradicate poverty on a sustained basis; and that new social institutional arrangements are needed to address the problems of the current development pattern and the challenges posed by the global changes analysed in chapter II.

The most orthodox approaches treat social policies are compensatory mechanisms. In recent years, however, the long-term beneficial effects of equalizing policies have become increasingly clear; and views on the role of these policies and their effects have changed. The synergy between equality and growth has been reconsidered, since many social policies serve to increase individuals' productivity through their impact on human capabilities, thus serving as a stimulus to economic growth.

Equal rights remain more an aspiration than a reality. Not only are there disparities between and within private sector services and those provided by the public sector, but also a marked inequality between people 
who access contributory services and transfers and those who access non-contributory ones. These differences are exacerbated by gender, age, ethnic and racial origin, territory of residence or disability status. In order to move towards a style of development that places equality and sustainability at the centre and attain the Goals of the 2030 Agenda, it is therefore necessary to base new welfare regimes on rights and the pursuit of substantive equality.

\section{Protecting public social spending through progressive taxation}

Although the main objective of social policies is fulfilment of the population's economic, social and cultural rights, public social spending is also an investment in human capacities throughout the life cycle and a key component of the environmental big push. Better levels of education, health, protection and care for the population (achieved through a solid institutional framework and effective management), stimulate innovation, growth and sustainable development. ${ }^{4}$

A new mode of interaction is needed between the production structure and the welfare regime, recognizing the fact that social issues are not played out in the social sphere alone, nor are economic issues resolved only in the economic sphere: the two are mutually interdependent. Inclusive social development policies that are capable of providing quality, difference-sensitive social services and benefits help to increase worker productivity, improve environmental stewardship and strengthen resilience to natural disasters (ECLAC, 2017b).

The experience of the Nordic countries illustrates how redistributive policies and a higher growth rate can go hand in hand. Denmark, Finland, Iceland, Norway and Sweden all have high degrees of equality, as well as welfare States and labour markets of similar development levels. In the Nordic model, efficiency and equality reinforce each other. Although institutions and policies have emerged to facilitate solutions for social and labour market problems, they are aligned with the efficient allocation of resources and economic growth (Vartiainen, 2014; Dølvik and others, 2015). Institutionalized wage-setting that is not governed exclusively by the market, one of the Nordic model's main innovations, results in higher average productivity and a smaller gap between more and less productive firms (Moene and Wallerstein, 2006). ${ }^{5}$

In the 1980s and early 1990s the welfare State retreated in Latin America and the Caribbean. This has been partially reversed in the last decade and a half by stronger public social spending that has permitted progress in the coverage of education and health services, as well as expanded pension system coverage and cash transfers for families with children and for older adults (see figure VII.1). New labour market regulations and standards were also adopted, along with active employment policies (Filgueira, 2015; ECLAC, 2017c).

The growth of public social spending in the region — sustained by higher tax revenues - is aligned with the pattern seen in member countries of the Organization for Economic Cooperation and Development (OECD) (see figure VII.2). Nonetheless, the region still lags far behind the developed countries in terms of expenditure and taxation levels and their redistributive impact (ECLAC, 2017a). To redress this situation, the region must make tax systems more progressive, tackle tax evasion, reduce tax incentives that erode tax bases and make social spending more effective (ECLAC, 2017b). This entails forging compacts for equality that give a strategic orientation to development and undermine the culture and practices defined by privileges. Covenants for equality, sustainability and structural change — such as the fiscal compact and social and labour compacts (ECLAC, 2014) — form the social and political foundations needed to make progress on public policies capable of reducing gaps and challenging the culture of privilege.

In terms of economic efficiency, social policies targeting early childhood and childhood generally — critical stages of the life cycle, which lay the foundations for personal development— have much more marked effects on capacity-building than similar efforts at later ages (Heckman, 2012). Although their fruits are not evident in the short term, these investments are essential for laying the foundations for the structural change needed to progress along the path of sustainable development, and take advantage of the demographic dividend (Rofman, Amarante and Apella, 2016).

5 Moene and Wallerstein (2006) draw attention to the Rehn-Meidner wage bargaining model in Sweden, which levels the wages of comparable workers across different firms. 
Figure VII.1

Latin America (19 countries): a public sector social spending by function, ${ }^{\mathrm{b}}$ 2000-2015

(Percentages of GDP)

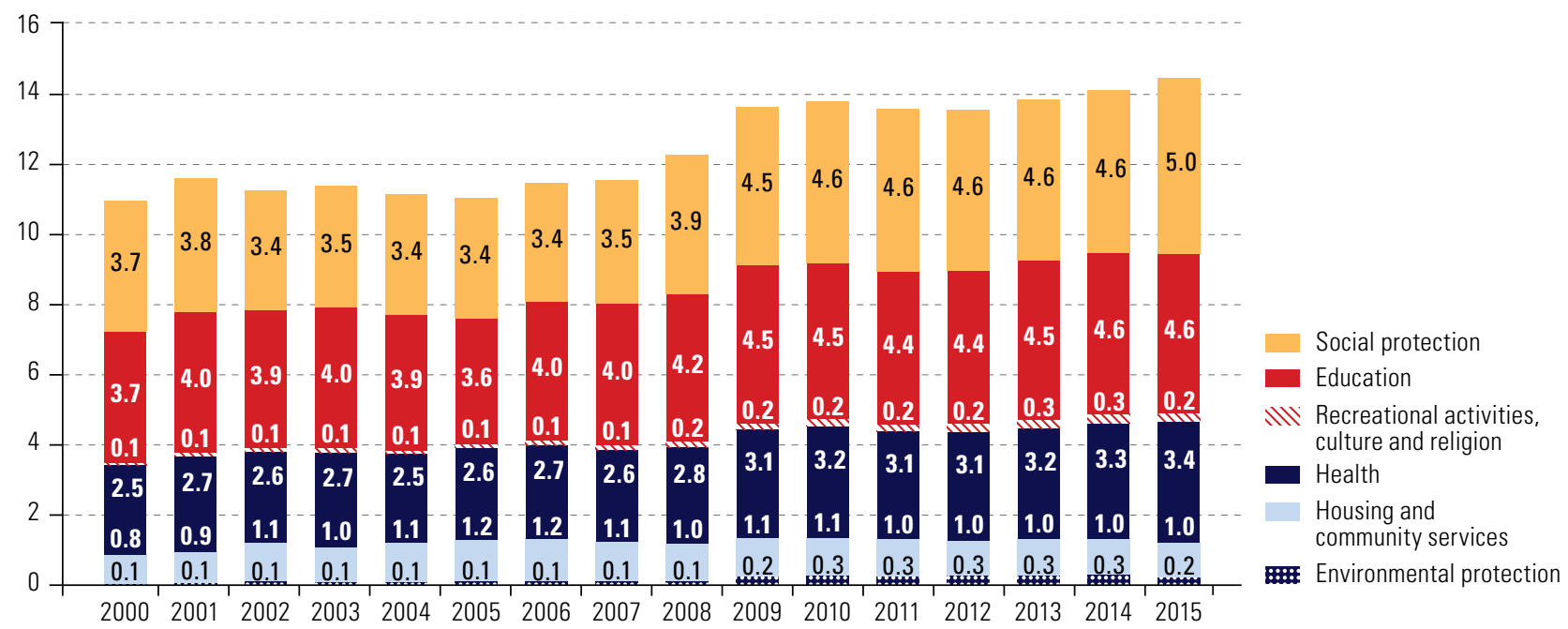

Source: Economic Commission for Latin America and the Caribbean (ECLAC), Social Panorama of Latin America, 2016 (LC/PUB.2017/12-P), Santiago, 2017.

a Simple average for 19 countries: Argentina, Brazil, Colombia, Costa Rica, Ecuador, El Salvador, Mexico, Peru and the Plurinational State of Bolivia, where coverage extends beyond the central government domain; and the Bolivarian Republic of Venezuela, Chile, Dominican Republic, Guatemala, Haiti, Honduras, Nicaragua, Panama, Paraguay and Uruguay, for which the figures cover central government. Data for the Plurinational State of Bolivia and Panama are available up to 2014 and for the Bolivarian Republic of Venezuela until 2009.

b This functional classification provides information on all government functions and does not necessarily coincide with the information generated through satellite accounts of specific functions.

Figure VII.2

Latin America and countries of the Organization for Economic Cooperation and Development (OECD): public social spending, tax burden and per capita ${ }^{a}$ GDP, 1990-2015

(Percentages of GDP and purchasing power parity dollars at 2010 prices)

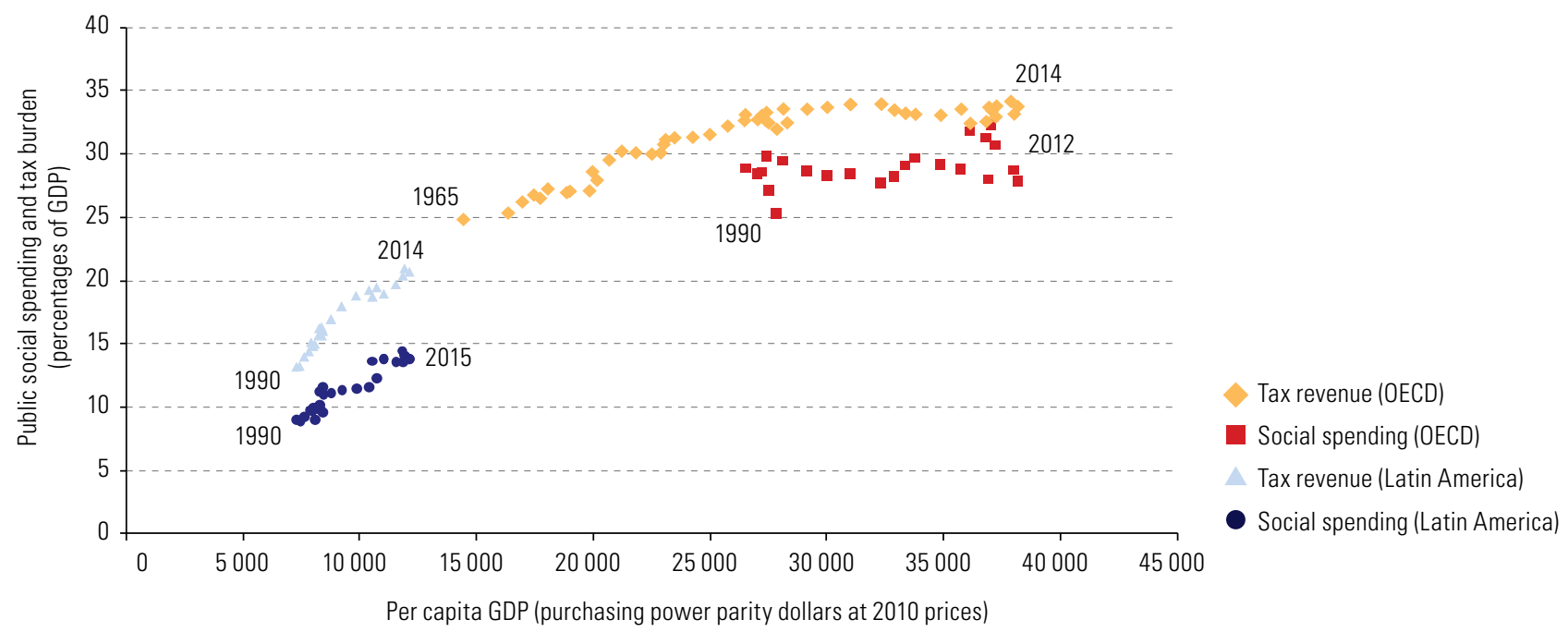

Source: Economic Commission for Latin America and the Caribbean (ECLAC), Social Panorama of Latin America, 2016 (LC/PUB.2017/12-P), Santiago, 2017.

${ }^{a}$ In both the Latin American and the OECD series, the following functions are classified as social: (i) environmental protection; (ii) housing and community services; (iii) health; (iv) recreational activities, culture and religion; (v) education and (vi) social protection. 


\section{Adapting education to the new technological context}

Education is a condition for full participation in economic, political and social life. Throughout the world, one of the main policy responses to the potential adverse effects of automation on employment is to invest in education. Innovation is considered a key part of the teaching strategies and capacity-building that will enable children to interact in the society of the future (OECD, 2016). Rapid technological changes and automation in production systems pose challenges not only for school curricula, but also for higher education and continuous training systems. Given the fast pace of technical change, it is necessary to generate the new skills that will be required in the labour market.

Mercadante (2017) argues that a high-quality, relevant education must provide students with solid training in language, mathematics and digital technologies, but also in broad-ranging skills. More general skills are needed to enable people to pose, analyse and solve increasingly complex problems and adapt to learning and reskilling processes throughout life. In particular, the ability to "learn to learn" and "learn to unlearn" (Morin, 1992) enables people to evolve and adapt to the new requirements of a world in the throes of rapid technological change. It is also necessary to move towards a concept of education that recognizes the importance of equality and rights and takes on board sociocultural and ethnic diversity and the demands of broader training for citizenship (ECLAC, 2017b).

The following, in particular, need to be prioritized: (i) regular training in science, technology, engineering and mathematics (STEM disciplines) in the school system; (ii) the development of social and behavioural skills, along with leadership and management capabilities, since the skills least susceptible to automation are perception, the manipulation of complex problems, creativity and social intelligence; (iii) the development of critical thinking, problem solving and creativity, which require curiosity, imagination and critical skills, among other capacities; (iv) the skills to operate in a digitized world; 6 ( $v$ ) increased hours of training and experience in companies and workplaces, and (vi) capacities for active learning throughout life.

Education systems also need to become less segmented, because they separate technical courses from those providing general or academic training at an early stage and tend to perpetuate training for women in feminized and lower-income job categories. Reducing segmentation would enable progress towards integrated models that promote gender equality. A new rationale is needed in the curriculum, infrastructure, teacher training and cultural fields, to overcome prejudices towards specialties and roles considered feminine, and also towards technical and vocational education, which generally represents the conclusion of education, does not offer a path towards continued studies at the university level and is therefore perceived as being of lower quality and prestige (ECLAC, 2017b). Moreover, students in the region who opt for technical and vocational training have accrued deficits in their general education that cannot be remedied at this stage in their studies. Efforts to construct pathways for technical and vocational learning between the secondary and higher levels will not bear fruit if that situation cannot be corrected (Sevilla, 2017).

\section{Strengthening social protection and care systems}

To facilitate the transition to occupations, production activities and sectors that respond to progressive and environmentally sustainable structural change requires defending historically acquired labour rights and forging new rights that allow access to a minimum level of security and well-being that is independent of labour market participation. This means enhancing the connection between contributory social protection, based on formal employment, and non-contributory social protection. Adequate mechanisms and institutions are needed, including the provision of basic and universal welfare levels and access to quality services; insurance against unemployment and loss of income; access to contributory pensions; minimum wage policies; effective rights to trade union organization and collective bargaining, and forums for negotiation and social dialogue between the public sector and stakeholders in the world of work (employers and trade unions) (ECLAC, 2017b).

6 Such as the ability to search, discriminate, synthesize, analyse and represent information in a digital environment, and also to use digital tools to share and collaborate with others. 
Another area of action is the creation or strengthening of a care system which, from a rights standpoint, requires a new social reproduction rationale that supports due provision of public goods and services in order to spotlight and redistribute the unpaid day-to-day work shouldered by women. There is a particularly urgent need for a care system to provide children and older persons, as well as the chronically ill and persons with disabilities, with better living environments, greater possibilities for development and access to higher levels of well-being; to defeminize and share out social reproduction tasks to free up women's time and enable them to access the labour market and pursue life plans; and to transform gender roles and achieve a more equitable distribution of care work between men and women in the home.

The care pillar is not only about making up for shortcomings and meeting urgent needs; it also includes the aim of developing people's abilities and allowing them to enjoy a decent life. This contributes to closing the economic participation gap between men and women and to overcoming the sexual division of labour that results in most care work falling to women.

\section{Basic income: an option?}

In developed and developing countries alike, the introduction of a basic income - to complement and strengthen social protection systems - is increasingly being discussed as a way of addressing persistent poverty and inequality and the uncertain impact of technological change processes. The basic income is a regular, unconditional universal payment that the State pays to the country's inhabitants to enable them to meet their basic needs. While it may be thought of as a recent policy option, the concept of basic income is not new: it was debated in the United Kingdom in the early nineteenth century and in the United States in the 1960s and 1970s; and it has already been applied as a pilot experience in some countries (Van Parijs and Vanderborght, 2017). What is new, however, is the extent of the debate on this idea, especially since the global crisis of 2008-2009. ECLAC has begun a process of analysis and reflection on basic income, in relation to proposals on the characteristics and pillars of the new rights-based social regime or welfare States required by the unfolding demographic, labour market, technological and production changes.

By freeing people from the most serious consequences of material dependency, a basic income could lead to a rearrangement of social hierarchies, increase the bargaining power of women, young people and other groups in situations of discrimination and subordination, and open up spaces of greater autonomy and freedom for all people.

It is particularly important for young people, who experience high rates of joblessness or precarious employment amid increasing disconnect between education, employment and income, to have a basic economic security floor enabling them to pursue their life plans. Moreover, as indicated at the second meeting of the Regional Conference on Social Development in Latin America and the Caribbean, a basic income would be an important tool for developing women's economic autonomy. It would increase workers' bargaining power, since they would no longer be forced to accept any job, pay level or hiring conditions. In other words, a basic income can serve as a tool not only to eradicate poverty and reduce inequality, provide economic security and act as an automatic stabilizer, but also to trigger processes of social emancipation and expansion of freedoms.

Basic income is conceptualized on the basis of diverse and sometimes conflicting notions of the principles that should govern society and the role of the State and the market (ECLAC, 2017b). In some cases, it is considered a tool that could monetize benefits and social services and reduce the burden and scope of welfare regimes. The repercussions of basic income on wage negotiations are also a topic of discussion. While there is concern about the risk of instituting a type of subsidy to capital, since part of workers' income would no longer depend on their wages, the opposite point is also made: a basic income would increase workers' bargaining power, particularly in the case of women and sectors with lower pay or in which organized labour is weaker.

Far from being a way to dismantle the welfare State, a basic income is in fact exactly the opposite: it represents an expansion and accrual of rights, not the replacement of social conquests and benefits. In other words, it is a new and additional pillar of the welfare State, which does not replace the services and benefits to which people are already entitled. It is from this perspective that ECLAC explores the relevance and viability of this proposal. 
In Latin America and the Caribbean, the debate on basic income stems from the relatively recent expansion of non-contributory social protection. ${ }^{7}$ In particular, from the rights standpoint, the implementation of basic income would represent an evolution of the conditional and targeted cash transfers applied in the past 20 years, which, over time, have legitimized cash transfers and the possibility —or, in some cases, the right- of accessing income through a different route than that of asset ownership or employment.

In the countries of the region, a guaranteed universal basic income could only be implemented gradually, progressively and with a long-term perspective. The possible modalities for implementing such an income are highly varied (by age group, by territory, by income level) and would depend on the conditions prevailing in each country; but it is not impossible and it could become a tool to achieve the Sustainable Development Goal of ending poverty.

Extending a basic income guarantee would require a tax system capable of making it possible. Unlike conditional cash transfers, which involve modest resources in GDP terms - both because of both their focus and their small amounts ${ }^{8}$ - a guaranteed basic income would represent a major mobilization of resources. This is not unattainable for the region's development level, but it does require taxation with much greater receipts, progressiveness and redistributive capacity.

Given the varying economic and demographic situations of the region's countries, following analysis of the costs and benefits of universalizing government-funded non-contributory cash transfers to older persons and families with dependent children, ${ }^{9}$ Filgueira and Espíndola (2015) conclude no single benefits model can be proposed for all countries. Each one would have to have the discussion and adopt strategies to expand basic income guarantees according to its fiscal capacities, social needs and economic possibilities.

Beyond income differences, unequal ownership of physical and financial assets is a structural condition that deepens and perpetuates inequality, since it is more lasting, intense and rigid than the inequalities that originate in labour markets. It is therefore worth considering the proposal that the new welfare regimes should be based on a more equitable distribution of asset ownership, which can be achieved by strengthening public ownership, the commons, and policies to promote access to asset ownership by the lower-income sectors.

Policies aimed at improving asset distribution seek to strengthen social and solidarity-based economies. Associativity, cooperativism, fair trade initiatives and, in general, the production initiatives of social and community organizations, have not received the policy backing they would need to expand, even though they create a large share of jobs and employment and can boast success stories in terms of innovation, productivity and equitable distribution of results and benefits. Access to credit and financial services under conditions of equality and with a progressive logic —in other words financial inclusion - is another important tool for moving towards a style of development that closes economic and gender gaps. ${ }^{10}$

\footnotetext{
Some modalities of monetary transfers are related to the philosophical foundations of guaranteed basic income (individuality, universality, unconditionality), such as the citizen pension for older persons in Mexico City and, to a large extent, the Pension for Older Adults programme in Mexico, the Renta Dignidad programme in the Plurinational State of Bolivia, and the Universal Child Allowance in Argentina.

8 Cecchini and Atuesta (2017) estimate that expenditure on conditional transfers in Latin America and the Caribbean amounted to $0.33 \%$ of regional GDP in 2015, and expenditure on non-contributory pensions accounted for about $0.40 \%$.

9 Around 2011, the cost of universalizing a monetary transfer equivalent to a poverty line for households with children and members aged over 65 years varied from a minimum of $1.5 \%$ of GDP in Argentina and Chile to a maximum of $13.7 \%$ of GDP in Guatemala.

10 Given the barriers that women face in accessing the financial system, financial inclusion policies can enhance their autonomy and gender equality (Rico, 2017; ECLAC, 2017b).
} 


\section{Three pillars of decarbonization: digitalization, sustainable cities and renewable energies}

\section{An environmental big push for progressive structural change}

Moving towards environmental sustainability within the framework of the 2030 Agenda for Sustainable Development, the Paris Agreement and the New Urban Agenda requires implementing policies and creating and strengthening institutions that allow for an economic development leap aimed at diversifying the production structure and managing natural heritage more efficiently, without violating ecological limits for the reproduction of life. Industrial and technological policies are fundamental for achieving these objectives, since the development of activities and sectors based on new technologies, materials and business models depends on them. These policies need to be integrated and coordinated with actions in the tax and regulatory, public investment, financing, infrastructure and education fields. The ranking and coordinated implementation of instruments is an essential condition for the effective application of these policies.

The big push proposed by Rosenstein-Rodan (1960) is an economic growth strategy that consists of the coordination of a large number of investments that need to be undertaken simultaneously in different sectors, as part of a coordinated and investment-driven public process. ${ }^{11}$ One of their arguments is that there are indivisibilities in production functions -in either the inputs or the outputs- which means that there is a minimum scale for producing the goods in question. Within a framework of multiple investments that must be carried out simultaneously in order to be viable and whose scale requires broad markets, the returns to be had from the combined set of actions depend on their complementarity.

Another characteristic of those investments is that they occur in markets subject to imperfect information, where there are no prices, or where prices do not supply the information needed for optimal decision-making. Because they provide no information on the social benefits or costs that stem from positive or negative externalities, for example, market prices cannot be used as the sole basis for calculating investment decisions: i.e. public policies are necessary to play a guiding and coordinating function. A coordinated investment package can be used to make the different activities viable in a scenario in which it is risky to take the first step. This push can take different forms and be based on different types of instruments, ranging from subsidized financing and tax incentives to the regulation of technological standards and the promotion of capital formation.

The investments that make up the big push and generate growth in the economy as a whole entail strong State activity in innovation processes that involve general-purpose technologies. ${ }^{12}$ The benefits of innovation in those technologies are difficult for the initial investor to capture, since they can be used profitably in many other activities. This means that the pre-investment stages in those technologies tend to fall to the public sector, which has historically financed and created opportunities in the market by setting standards, creating institutions and even coordinating and supervising their commercialization. This notion of the big push becomes more comprehensive if State intervention is characterized by the vision-mission-plan trinomial (Mazzucato, 2011 and 2015). ${ }^{13}$

11 "There is a minimum level of resources that must be devoted to a (...) development programme if it is to have any chance of success. Launching a country into self-sustaining growth is a little like getting an airplane off the ground. There is a critical ground speed which must be passed before the craft can become airborne (. . .) Proceeding 'bit by bit' will not add up in its effects to the sum total of the single bits. A minimum quantum of investment is a necessary (though not sufficient) condition of success" (Rosenstein-Rodan, 1961, p. 57).

12 These technologies are characterized by their widespread impact on products and markets and by their ability to reduce production costs and facilitate the development of new products and processes. This involves high-risk innovations since they require large initial investments and long maturation periods.

13 The "vision" defines the technology being investigated and foresees its applications and effects in production and consumption. A vision that is a sociopolitical pronouncement and defines a direction allows for the convergence of actors, sectors and investments and promotes innovations and synergies between supplies, skills, equipment, services, distributions, networks and demands (Mazzucato and Pérez, 2014). The notion of "mission" refers to the organization of an agenda according to the vision, the coordination of the public bodies that must invest in the creation of that agenda, and coordination of the institutes and organizations that will participate in the research process. Lastly, the "plan" covers coordination of the initial investments, the creation of conditions for the market - including its interaction with the public bodies responsible for establishing production and consumption standards - and private sector engagement in key moments and phases. 
The ECLAC proposal gathers these ideas together and adapts them to the specifics of the region. It seeks to coordinate the change of production and consumption patterns with production restructuring, putting industrial and technological policies at the centre of the development agenda based on environmental sustainability. This means implementing consistent and continuous public policies; otherwise, investments, regulations, prices, taxes and other components of State action would not lead to an innovation path, but would remain isolated initiatives.

New opportunities for production restructuring can arise from the application of digital technologies to production, and from an increase in the density of the industrial fabric as a result of a redefinition of the technologies in use and of the energy matrix. Examples of this include the management of smart cities; the expansion of mass transportation; the management of biodiversity; the recovery of rural territories; the management and sustainable use of fresh water; the development of biomaterials, and the production of renewable energies and consequent development of their value chains. Each one of these activities is an option for diversifying production in a transformative agenda that generates the material conditions for social inclusion, while guiding investments along a low-carbon growth path.

\section{Industrial and technological policies for the digitalization of production}

Promoting economic growth and employment with environmental sustainability means designing and implementing industrial and technological policies that support investment in the production of goods and provision of services associated with low-carbon production and consumption, and with a material footprint that does not put natural heritage at risk. Channelling investments in the desired direction and making them viable requires instruments and institutions that generate the right incentives. These range from tax and regulatory policies to policies on public financing and investment, including infrastructure development, the provision of public goods, the promotion of MSMEs and encouragement of public-private partnerships. The aim is to replace activities that have a high environmental impact and low technological dynamism and generate relatively few productive linkages and jobs, with a production structure based on activities that are technologically dynamic and generate strong productive linkages, quality jobs and a small environmental footprint; in other words, a progressive structural change based on an environmental big push. The international experience provides lessons for shaping the framework in which such policies should operate (Cimoli and others, 2017):

- Economic and social objectives have to be met: policies must be more than tools to increase productivity, improve competitiveness and promote structural change. They should also form part of a broader social aim to attain and balance goals such as job creation, greater equality and the fight against global warming, as proposed in the 2030 Agenda.

- Active policies for structural change are needed: policies must be conceived in a dynamic context and focus on learning paths and outcomes in terms of productivity and competitiveness. These paths rely on markets and competition, with public policies guiding and encouraging private investment.

- Industrial policy and the market are not mutually opposed: good industrial policy practices should coincide with the defence of competition and the dynamism of the private sector. There are many examples of how to design policy strategies to develop competitive mechanisms. For example, regulated prices based on competitive bidding processes, environmental standards for products and processes based on private sector bids and best practices, or the granting of subsidies for research and development only after having received and evaluated bids from conglomerates or regions.

- It is necessary to provide a long-term direction: modern policies trace a long-term development path and are maintained over time while simultaneously offering necessary flexibility. It is possible to create markets for green investments (for example, through regulated tariffs to foster renewable energies) which generate technological learning, exploit economies of scale and produce with lower unit costs.

- What distinguishes countries is the ability to implement policies, not to formulate them: implementation failures weaken or nullify policy signals that seek to boost investment and innovation. 
The region still has a proliferation of programmes that remain unimplemented owing to insufficient human and financial resources, or because of a lack of political commitment to overcome the problems of managing complex policies that need to be sustained over the long term.

- Implementation is complex and risky: the costs of possible failures can be reduced by increasing the transparency of the process, stakeholder participation and agreements between them, with continuous monitoring and evaluation of progress towards systematic policy learning.

In short, when well formulated, industrial and technological policies make up a strategic framework with indicators for facilitating firms' decision-making on long-term investments, as part of a process that stimulates competition and offers guarantees for the adoption of corrective measures. In the region, the focus should be on the institutional arrangements needed for effective implementation.

\section{(a) Policies and instruments for the digital transformation of production activity}

The main challenge of structural change in the face of the technological disruption analysed in chapter II is to build in digital technologies and the shift from the consumer Internet to the industrial Internet (ECLAC, 2016). The digitalization of industry is a powerful force for decarbonization and sustainability. Its expansion in the economy and throughout society increases the weight of services and intangible (digital) goods, whose material and carbon footprints are much smaller than those of physical goods, especially in terms of the use of plastics and transport costs. In this sense, process virtualization - for example, in the design, prototyping and testing phases - reduces or eliminates physical inputs.

In relation to market operation, digitalization enables a remarkable process of disintermediation, whereby the number of stages or links in value chains is reduced, thereby saving energy and inputs. Secondly, data analytics allows for better market segmentation, since it reduces unsaleable stocks and wastage of materials and efforts. Lastly, firms operating in the gig economy, which is built on the basis of digitalization, make better use of fixed and movable capital. For example, they increase the supply of accommodation services without building more hotels; and they increase the supply of urban mobility services by making use of the idle time of capital embedded in vehicles, without increasing the demand for vehicle units, with the savings in materials and energy that this entails. In addition, urban navigation applications (for example, Waze) reduce transport times and emissions. Digitalization is thus a powerful instrument for moving towards sustainable cities.

Virtual banking and financial technology (fintech) ${ }^{14}$ firms extend financial services without the huge costs of construction, operation and displacement, thereby affording access to these services by lower-income population groups and by microenterprises and small businesses -in other words a financial inclusion process. ${ }^{15}$ To realize the full potential of the emergence of high-tech firms, they need to operate within a flexible infrastructure (including legal framework, regulation and taxation) that reflects their business dynamics and enhances their complementarity with the banking system. Moreover, greater and more fluid access to financial services through digital technologies has created direct links between financial inclusion and the objectives of central banks, in the form of efficient payment systems, improvements in the functioning of the financial system and protection of consumers and users (BIS, 2015).

In the production sphere, the most advanced activities combine innovative technologies, such as additive manufacturing, augmented and virtual reality, the Internet of Things, data analytics, robotics and artificial intelligence. These technologies support the development of new processes, production systems and smart connected products. They also make processes more flexible and facilitate adjustment at different production scales, decentralize decision-making and allow for the manufacture of personalized products. These advances

14 Innovation in technology-facilitated financial services (FinTech) "may have a positive impact on several aspects of financial inclusion including loans and credit scores for the unbanked households and firms. (...) Distributed ledgers are perhaps the most game-changing innovation for central banks, centralized exchanges, and interbank markets (...). Regulations and policy making will need to adapt to overcome the challenges posed by modern technologies (...)" (Furche and others, 2017).

15 Financial inclusion encompasses aspects related to the use and quality of these services, the universalization of financial education, the implementation of a suitable regulatory framework and the quality of its infrastructure. Financial inclusion smooths consumption paths, increases the effectiveness of the interest rate and decreases the volatility of output with respect to inflation (Marcel, 2017) 
are present in various manufacturing industries and in mining and agricultural activities, but also in sectors such as finance, health (examples include emotional technology, ${ }^{16}$ care technology, monitoring applications and telemedicine) and in cities (for example, the optimization of energy trading processes).

These new dynamics require an ecosystem that exploits digital technologies efficiently to promote new ventures and business models that result in greater growth and competitiveness. Given the relatively high level of access to digital technologies in Latin American and Caribbean countries, the region has the possibility to use these technologies in its development strategies with less delay than in previous technological paradigms. Taking advantage of this transformation potential requires a data-driven innovation ecosystem that integrates new technologies and the processing and use capacities of both people and organizations.

Integration between technologies is also necessary to reduce the environmental footprint of digitalization and develop renewable energy sources. The demand for electricity from digital technologies, particularly from large data centres, has a significant and growing weight in total energy demand; and the scope of its environmental effects will depend on what type of sources are used to satisfy it. Moreover, the development of renewable sources will depend on advances in the digitalization of their production systems and both short- and long-distance transmission networks. Harnessing the potential of digital technologies in production requires new policy approaches and public incentives, together with strategies to steer investment decisions towards high value added activities that promote the spread of productivity gains throughout the economy. A digital industrial policy in the region should prioritize three areas of development:

- Broadband infrastructure, both fixed and mobile, to attain penetration levels close to OECD-average-income countries and qualities close to international standards in terms of speed and latency, as well as competitively priced services.

- The information technology industry (hardware, platforms, applications or data), to increase the quality supply of products and services for digital modernization among firms.

- Business capabilities for the digital transformation of business models, products and services.

This industrial policy needs to exploit synergy between government programmes (national, subnational and local), promote public-private partnerships and ensure transparency and evaluation and accountability mechanisms in the areas of investment, innovation and regulation. The institutional challenge consists of:

- Expanding digital development strategies (digital agendas) with policies focused on production restructuring and specialization, training and technological innovation that include MSMEs.

- Moving towards regulatory models that generate incentives to encompass the new needs for investment in networks, and take account of the characteristics of the industrial Internet in terms of new models of deployment, interoperability, security, data protection and privacy.

- Developing a regional digital market that allows scale and network economies to be exploited, through the harmonization of spectrum and national regulations.

The policy proposals lie in the areas of international positioning, infrastructure and regulation, and actions to support supply and demand.

Policies to promote international positioning need to connect the region to international technology networks and support the transfer of knowledge and skills in areas such as equipment, high-speed networks, digital platforms and market integration. The aim is to attract the new technological and business skills needed to implement priority specialization programmes through international cooperation instruments, training, technology transfer, investment attraction and entrepreneurship networks.

16 Emotional technology refers to the measurement of biometric data associated with different emotional states (such as heartbeat, perspiration or muscle tension) and the use of these inputs in applications that help the user achieve certain behaviours or emotional states. Examples include applications that respond to states of stress — and can calm a driver who is irritated by traffic — or which collaborate in the care of children or older persons. 
The key objective of the infrastructure policy and regulation is to create conditions that expand investment in infrastructure to increase the penetration and quality of fixed and mobile broadband. Delays in investments in new generation networks can cause network saturation as a result of the continuous growth of data traffic.

This policy should enable compatibility between investment, competition and innovation, in an environment of growing convergence and hyperconnectivity. It is increasingly necessary to redefine the scope of competition policies and focus their effects on new markets, which are increasingly oriented towards the supply of intangibles. Traditional categories, such as market power or abuse of a dominant position, should be reconsidered, taking into account dynamics such as winner-takes-all markets, which leads to greater concentration, or, conversely, markets with significant entry of new firms owing to technological disruption that eliminates barriers and creates new sectors. This means strengthening regulatory bodies and instruments to ensure competitive frameworks for business activity under these new technological conditions.

Firms have adopted two approaches to the changes that have occurred in legal and institutional frameworks. In one, disruptive firms build a critical mass before participating in regulatory discussions, which puts pressure on the regulator and represents a direct call to action by all stakeholders. In the other, they participate with regulators in drafting legislation, even in deregulated environments, such as the sandbox regulation model or testing environment. ${ }^{17}$

Supply-side policies - the creation of Internet-based technological production capabilities — and demand policies - the development of digital capabilities in firms - are closely related. A recurrent failure in policy implementation in the region is the lack of coordination between instruments to support supply and demand. The proposals point in two directions. Firstly, to strengthen technological capabilities through research centres and the promotion of technology-based firms; and, secondly to develop capacities and promote digital innovation in the production sphere, mainly in MSMEs, which are fundamental in terms of skills demand and job creation.

Industrial policy for the digital economy should start by strengthening the software and applications industry, including open-source software, to create new high-productivity sectors. Its relevance lies in what it contributes to technological development through the transfer and diffusion of new technologies, the creation of skilled jobs and the export of services. Although some countries, such as Argentina, Brazil, Chile, Colombia, Mexico and Uruguay, have had success in promoting the industry, there are still gaps in the dissemination of the use of their products and their appropriation in business activities, particularly in MSMEs.

\section{(b) The digital transformation of micro, small and medium-sized enterprises}

The digital transformation of MSMEs requires these firms to become digitally literate and change their business models, relationship systems and internal capacities. This entails re-organizing production to create a model that is structured and managed on the basis of the new technological platforms. This process needs to take account of scale economies related to the development of key skills and knowledge that require collective responses and configure new service networks for firms, such as testing and certification laboratories, specialized research and development centres or vocational and technical training firms.

Support strategies and policies must take two essential elements into account. First, specific measures to support MSMEs must be coordinated with enabling policies, to create the basic conditions needed to compete in domestic and international markets. These relate, firstly, to actions aimed at strengthening the technological base — such as the expansion of high-speed networks, access to and use of cloud computing, the generation of interoperability standards, cybersecurity or access to financial instruments— and, secondly, strengthening social capital and rules aimed at regulating competition to prevent large firms from abusing a dominant position.

17 This concept refers to the creation of a temporary secure and limited space in which firms can experiment with products, services, business models or distribution mechanisms; and they can trial new regulatory models and instruments, in dialogue with the regulators. 
Second, it must be kept in mind that the impact of digitalization is not neutral in the MSME universe. The firms that make up this business group have very different strategic capacities, capitals, knowledge, relations and economic resources; accordingly, their reactions to digital transformation vary. Firms' competitive positioning can worsen or improve as a result of the effects of digital technologies in the scenarios in which they operate. Promotion policies need to take these differences into account and develop specific and diversified measures to support MSMEs, including in particular those related to the access and use of cloud computing (see table VII.1).

Table VII.1

Measures to support the integration of MSMEs in the digital economy

\begin{tabular}{lll}
\hline Type of MSME & Measures \\
\hline $\begin{array}{ll}\text { Firms integrated into dynamic production } \\
\text { systems (clusters or districts) }\end{array}$ & $\begin{array}{l}\text { - Definition of production standards to strengthen the strategic positioning of dynamic clusters } \\
\text { - Strengthening networking with technology centres specialized in advanced technologies }\end{array}$ \\
\hline $\begin{array}{l}\text { High-end firms not integrated into clusters } \\
\text { or districts }\end{array}$ & \begin{tabular}{l} 
- Creation of local public goods for testing \\
\hline - Support for business training to generate new competitive strategies
\end{tabular} \\
\hline Non-specialized suppliers & - Promotion of the creation of firms that provide digital services \\
\hline $\begin{array}{l}\text { Non-specialized firms operating } \\
\text { in local markets }\end{array}$ & - Strategic support to identify competitive opportunities \\
\hline
\end{tabular}

Source: Economic Commission for Latin America and the Caribbean (ECLAC).

The two keys to this strategy are, firstly, to ensure the convergence of enabling policies and specific measures; and, secondly, to identify catalysts that accelerate and reinforce the impact of the measures implemented, such as:

- Large firms integrated into MSME production chains: support policies may include specific incentives for large firms to encourage their suppliers to incorporate digital technologies and thus develop a more efficient, transparent and durable supply relationship.

- Demand from the Government and public procurement policy: government procurement of goods and services can also speed up the processes of absorption of digital technologies. It must also calibrate its requirements in line with the potential and capacities of the MSMEs in question -in other words, whether they already have a technological and operational base or if they are taking the first steps in digital production and organization.

- Technology and business development centres: business support centres offer a range of services spanning management support (business development centres) to the promotion of innovation projects and the application of new technologies (technology centres). These centres can be catalysts for disseminating the new technologies, as they become integrated into the respective production systems and consolidate their capacity for dialogue and reciprocal interaction.

- Sustainable cities and new business partnerships: cities' industrial ecosystems, with their ability to attract knowledge and capital, are melting pots for opportunities and enterprises. A growing number of medium and large cities have recognized and started to value this function, launching their own local strategies to steer their growth path towards more sustainable and inclusive development models. The recovery of physical spaces, the generation of new collective services and the construction of local frameworks oriented towards innovation and production diversification combine to make up ideal ecosystems for MSMEs.

- Develop synergies between MSME productivity growth, the production and consumption of renewable energies and the electrification of urban transport: these will facilitate progress towards sustainable, low-emissions cities. Accordingly, they form part of the environmental big push based on decarbonization. 


\section{Sustainable cities as drivers of development}

Cities are open economic systems with inflows of materials and energy and generation of entropy and waste; they shape metabolisms that depend on the interaction between citizens and modes of governance. The ways citizens interact with each other, the participation mechanisms in place and the definition of priorities, the relative sizes of social groups, and the role of the culture of privilege or democratic conviction determine the need for standards, the targeting of infrastructure investment, the slant of local fiscal policy, and the quality of life and the environment.

Urban sustainability is one of the pillars of decarbonization and diversification policies, owing to the current unsustainable patterns of energy consumption and pollution, on the one hand, and the opportunities to overcome urban problems by using emerging technologies and industries, on the other. ${ }^{18}$

The growing diseconomies in cities, together with challenges in terms of quality of life, social inclusion and the radical improvement of public services, open up investment opportunities in which urban policy, the New Urban Agenda and the Sustainable Development Goals all converge. Solutions to problems such as congestion and pollution require engagement by multiple sectors; and, according to the Rosenstein-Rodan proposal discussed above, they entail solving important indivisibilities through investments in enabling infrastructures (referred to as overhead investments), which depend on public policy decisions. The city can thus serve as an innovation and investment hub to steer the development pattern towards a progressive structural change based on an environmental big push in specific sectors and territories.

Urban sustainability can benefit from technological advances in the energy sector, the automotive industry, construction and digitalization. Public policy should guide and accelerate innovation in these activities through quality and performance standards in urban goods and services. The coordinated application of regulations, ${ }^{19}$ sector-level public policies, private investments and technological innovations can change production patterns. Furthermore, land-use and urban inclusion policies can reinforce the positive effects of the new technologies.

\section{(a) Sustainable mobility as a decarbonization strategy}

Urban mobility should be a focus of action, given its large contribution to $\mathrm{CO}_{2}$ emissions, air pollution and disparities in terms of quality and travel times (see chapter V). It is also an area where public policy can stimulate changes in production patterns and strengthen innovation through regulations geared towards sustainability.

Owing to the increase in motorization and private travel, efficiency gains in the automotive sector and the change in the energy matrix have not been sufficient to meet international health standards on air quality or make headway towards climate targets. Some cities in the region, such as Mexico City and Santiago, have amended regulations to specify limits on pollutant load capacity. When this capacity or the pollutant concentration thresholds are exceeded, environmental alerts are activated that lead to certain activities being restricted. This gives governments broader scope to induce technical changes in land monitoring, combustion and mobility systems. Regulatory arrangements have been too slow to change and there is room for more stringent requirements in order to achieve compliance with air-quality health standards and speed up innovation processes. Several countries and cities have amended regulations to eliminate diesel from the urban fossil fuel mix by restricting and banning diesel-fuel vehicles, spurred on, as well, by scandals involving the manipulation of technical tests by the automobile industry. ${ }^{20}$ All this has increased the interest in electric vehicles, which

18 Cities are responsible for between $60 \%$ and $80 \%$ of global energy consumption and $70 \%$ of $\mathrm{C} 02$ emissions. They are also where inequalities and pollution are concentrated (see chapter V and UN-Habitat (2016) World Cities Report, Nairobi).

19 In Brazil, the vehicle emissions standard cut emissions from light and heavy vehicles almost tenfold between 1989 and 2013 (CETESB, 2014).

20 Diesel is set to be banned in Paris and Mexico City by 2025; in Germany, India and the Netherlands, by 2030; in London and the State of California (United States), as from 2040. In China all fossil fuels are to be restricted, albeit with no specific date yet. In Norway political support has been expressed for speeding up the transition, by banning the sale of vehicles with gasoline and diesel engines from 2025. In 2017, the German cities of Stuttgart, Munich and Düsseldorf issued rulings against the circulation of diesel vehicles (see El País, "El diésel pone al límite a la industria más grande de Alemania", August 28, 2017 [online] https:// elpais.com/economia/2017/08/25/actualidad/1503687596_501203.html). 
have pollution reduction, energy diversification and climate-change mitigation benefits, in addition to lower operating costs than vehicles that use internal combustion engines.

Its regulation role has given urban policy a more important role in changing production patterns and defining the location of technologically advanced firms. ${ }^{21}$ The most flexible firms willing to speed up technical change target their innovation efforts on areas such as the environment and energy efficiency. Thus, electromobility and the use of new materials in light vehicles acquire greater prominence, generate major changes in the industry value chain and substantially improve these technologies' acceptance in the market (see box VII.1).

\section{Box VII.1}

Urban environmental regulation and technological development

An ambitious and comprehensive initiative has been launched in Copenhagen with a view to attaining the city's 2025 carbon neutrality target. Eight lines of action towards a green economy for production restructuring, mobility and spatial organization were agreed upon, in an effort that may be considered in the nature of an environmental big push. This transformation is accompanied by a realignment of the city's public policies -especially those relating to mobility (public transport and cycling) and infrastructure, to avoid high-carbon lock-in - and the maintenance of a technological cluster by supporting innovation and endogenous growth. The success of this policy, which stems from the rapid elimination of the use of fossil fuels, could encourage replication of something similar in Latin America and the Caribbean.

In the business world, the city of Campinas (Brazil) has decided to stop certifying internal combustion vehicles for public transport as from 2018 and has formed a partnership with BYD (a Chinese firm that makes electric vehicles, among other things) and the local assembly industry to produce vehicles for the public transport system. Also in Brazil, in São Paulo the firm Eletra launched Dual Bus, a hybrid vehicle, in anticipation of restrictions on diesel. In Santiago, 15\% of vehicles in the public transportation system must be electric as from 2017. In Mexico City, by contrast, natural-gas-powered vehicles continue to be purchased, despite the availability of development bank financing for more environmentally friendly options.

Source: Economic Commission for Latin America and the Caribbean (ECLAC), on the basis of presentations made during the Cities Conference: Implementing the New Urban Agenda in Latin America and the Caribbean, Santiago, 2-6 October 2017, and the forum National Development Banks and Green Banks: Key Institutions for Mobilizing Finance towards the Implementation of Nationally Determined Contributions (NDCs) and the Accomplishment of the Sustainable Development Goals (SDGs), Mexico City, 26-27 June 2017.

Several firms have announced the intention to eliminate diesel engines from their production line, in order to concentrate on electric and hybrid vehicles. ${ }^{22}$ Between 2014 and 2017, annual global sales of electric vehicles increased from 320,713 to nearly 1.2 million units, bringing the number in circulation worldwide to over 3 million. The steep fall in the prices of batteries (which represent about a third of the production costs of such vehicles), the increase in autonomy, and the rapid expansion of recharging infrastructure, especially in developed countries, have played a key role in this.

Technological advances, cost reduction and regulatory changes are key factors driving the spread of electromobility. In developed countries, there are also generous (and, thus far, highly socially regressive) subsidies for the purchase of electric vehicles. Changes are expected to gather speed in the middle of the next decade, and electric vehicles will become the dominant technology in the long run. By 2040, long-range electric vehicles should cost the equivalent of about US\$22,000 today, and 35\% of new vehicles worldwide will have a power socket. Moreover, the possibility of vehicles being able to store or generate energy, both efficiently and on a considerable scale, will further blur the boundary between the automotive and energy sectors, and they could become part of the same generation, storage and distribution system.

21 Several companies have announced plans to launch electric vehicles, including General Motors (20 electric models by 2023, two of which as early as 2018); Ford (13 models in the next few years); and also Volvo, Nissan, Volkswagen, Daimler and Tesla (The New York Times, 2017).

22 The Swedish-Chinese manufacturer Volvo will only produce cars with electric or hybrid engines from 2019; and the French group PSA —owner of the Peugeot and Citroën brands - expects to have $80 \%$ of its production electrified by 2023 . 
Aside from innovation in propulsion systems, the panorama of mobility for people and goods is changing rapidly as a result of converging technological and sociocultural trends: the mass spread of connected and, ultimately, autonomous vehicles, and changes in consumption patterns such as the rapid growth of shared mobility (carsharing and ridesharing), where automobile ownership begins to decline. A great deal of uncertainty remains about the speed of this transition, but a paradigm shift is unfolding, from owner-used vehicles towards a mobility model centred (albeit not exclusively) on autonomous vehicles and shared mobility. Thus, a degree of convergence between private and public mobility can be anticipated, especially in certain social segments.

The adoption of a decarbonization strategy for urban mobility requires priority electrification of mass transit systems and better multimodal articulation - a field in which progress has been made in the past 15 years. ${ }^{23}$ To innovate in this area, it is important to speed up decarbonization, decontamination and improvements to operational performance. Vehicle electrification and the increase in the use of digital technologies are opportunities to improve the service. ${ }^{24}$

\section{(b) Decarbonization and energy efficiency in the construction industry}

Major changes and opportunities for industrial policy, digitalization and intersectoral coordination are also anticipated in the construction industry. Electrical input/output meters and the application of digital technologies in the administration of smart distribution networks erase the boundaries of traditional sectorial industrial policy: building, the development of building materials for power generation, ${ }^{25}$ individual electric mobility, the electrification of mass urban road transport systems, and the large-scale transmission and generation of electricity are gradually becoming components of a new expanded energy sector.

Although the prevailing view is that the profitability of the construction and housing industry and regulatory improvement as a driver of innovation are opposing factors, countries and cities have considerable space to innovate in relation to the regulations on energy labelling. Similarly, the standardization of funding for these new activities through development banks would boost innovation in the domain of construction and public service infrastructure. At the same time, it would be advisable to establish minimum energy and thermal efficiency requirements for buildings and homes, and also for the operation of mass transport, water treatment and waste management systems.

\section{(c) Digital technologies and sustainable cities to boost diversification}

Digital technologies can play an important role in rationalizing resource use in cities, improving the quality of services, strengthening participatory processes and supporting virtuous links between urban policies and production restructuring initiatives.

Technological innovation has always been a key factor in defining the type of urban development, from electrification, which facilitated the verticalization of construction at higher altitudes, to the universalization of the automobile, which continues to have an impact on investment decisions in infrastructure, both to encourage its use, or -in innovative cities such as Helsinki or Seoul — to reduce it. Digitalization has transformed modes of production, consumption and mobility and has created opportunities for more efficient resource use in cities, including the reduction of urban travel times. Digitalization provides an opportunity to link the challenges of production restructuring and urban sustainability.

23 The initial virtues of some of these mass transit systems have been undermined by the growth in private motorization and the fact that some urban administrations, taking a short-term view, have stinted on investment to expand and modernize the systems.

24 Investment in transport modes, such as cable cars or infrastructure suitable for bicycle travel, and drafting the corresponding regulations (CAF, 2016) are also being increasingly prioritized; and there is ample scope to improve policy formulation and increase the investment in cycle lanes and their multimodal combination.

25 While implementing its green growth policy, the Republic of Korea decided to manufacture transparent solar cells for use in windows and power generators. Tesla has advanced in the same direction with the construction of roofs for photovoltaic generation and domestic-scale batteries, which could displace Germany's leadership in the installation of solar panels in building projects. 
The term "smart cities" is often used to refer to the integration of digital technologies in urban management. Nonetheless, the definition of this concept and the types of urban management and governance models it entails are hotly debated. ${ }^{26}$ However, the term increasingly implies the use of digital technologies not only in material domains — such as construction, energy networks, water management, waste management, mobility and logistics - but also in the way these domains are integrated with cities' human, social, cultural and economic issues (Hollands, 2015). For the same reason, the impact of digital technologies depends on the quality of urban policy, on governance and management and on the objectives prioritized. The challenges are to integrate technological solutions into city functioning, from infrastructure to participatory processes, and to take advantage of opportunities to foster changes in production.

Smart grids, which integrate electricity grids through digital technologies, are a strategic innovation for promoting decarbonization. Smart grids are made up of various elements, including smart meters, mobile applications, bi-directional energy flow grids, energy efficiency systems and the availability of information on the use of energy, its price and ways to optimize consumption. They offer the possibility of creating distributed energy grids, in which consumers can become "prosumers", in other words, users who own small power generation units - potentially linked to non-conventional renewable sources, such as wind and solar power-and are, simultaneously, both consumers and producers of energy, either by consuming the energy they produce themselves, or by feeding their surplus energy into the grid. Distributed generation is the means by which the technologies developed by smart power grids could have a greater impact on power, stability and energy efficiency, and also on economic efficiency and welfare (Bonetto and Rossi, 2017).

In addition to infrastructure innovations, increased access to the Internet and the use of smart mobile devices also create opportunities to facilitate decision-making or democratic processes. Examples of this are virtual voting on projects financed by municipalities, or participation in the formulation of urban regulatory plans. ${ }^{27}$ Citizens can also provide information on the quality of infrastructure and services, and on security or emergencies, among other aspects of urban life. These tools are particularly useful in contexts where official information is not always available, such as informal settlements.

The large amounts of data generated from users' activities also offers both people and firms the possibility to propose creative solutions to improve aspects of urban life, through the development of knowledge-based technology firms (Perera and others, 2013). ${ }^{28}$

Public policy can promote the application of digital solutions to enhance urban sustainability and provide opportunities for production development; and local governments have considerable room for manoeuvre in this regard. In fact, a growing number of cities in the region are becoming more involved in the design and implementation of local policies to foster innovation (OECD, 2015). ${ }^{29}$ To achieve this, it is important to consolidate a system of educational, training and research institutions.

Public-private partnerships can promote better use of digital technologies. Many local governments make efforts to strengthen labour intermediation, create jobs and promote education and training aligned with the production structure of their territory. As they are in direct contact with firms in the local production system, they can take advantage of this proximity to strengthen ties between production agents, urban sustainability and production diversification.

The diversification of local production systems involves strengthening production chains between large firms and MSMEs, and also within the universe of MSMEs and between them and public sector institutions

26 The conceptualization of the smart city, promoted mainly by telecoms firms, involves the increasing use of devices connected to the Internet and to each other, and the ability to collect large amounts of data on urban operations to manage the city in a centralized and efficient manner (Greenfield, 2013). In this formulation, urban management is conceived as an apolitical, neutral and technical process. Experience, however, suggests that digitized management can reinforce the control of certain interest groups, under the pretext of this supposed neutrality (Paschoal and Wegrich, 2017). This top-down view assumes that centralized control of city management is possible, which contrasts with the understanding of the city as a system shaped by the interaction and conflicts among its citizens -in other words an essentially political and complex space, which generates the innovative and creative potential that cities have demonstrated throughout history.

27 Such as strategic regulatory plan of São Paulo, adopted in 2014

28 Patiño (2014) analyses cases of virtuous relationships between open data and municipal governments in Montevideo, Buenos Aires and Lima.

29 These include Medellín (Colombia), which, through its Strategic Plan for Science, Technology and Innovation of Medellín 2011-2021 and under the leadership of Ruta N (a local innovation and business organization created in 2009), seeks to strengthen innovation and enterprise creation (Pineda Serna and Scheel, 2011). These innovative practices have gained international recognition. 
or anchor institutions rooted in the community (CLES, 2017). Public procurement is another instrument for promoting the diversification of the local production fabric. This requires creating and strengthening public and private networks of entrepreneurs and employers in the city, with common visions and medium- and long-term action plans.

\section{(d) Urban taxation and rationalization of land use for more sustainable investments}

The implementation of new technologies does not guarantee more sustainable results and must be framed by public policy objectives. Cities display territorial specificities related to land-use patterns, connectivity and inequalities that require specific policies. Urban and land-use planning are important for channelling the benefits of technological change, particularly given the considerable effect that physical configuration and connectivity patterns have on the efficiency with which resources and energy are used (Rode and others, 2017). As noted in chapter $\mathrm{V}$, a segregated city that tends towards disorderly territorial expansion exacerbates the deterioration generated by motorized modes of mobility. For this reason, the implementation of new technologies needs to be accompanied by sustainable urban and territorial policies, backed by urban taxation that prioritizes reducing inequalities.

With few exceptions, little use is made in the region of urban tax instruments which, in addition to generating resources, rationalize land uses and promote inclusion. Property tax is one of the most common local taxes in developing countries (Bahl, Linn and Wetzel, 2013). Nonetheless, it represents only between $3 \%$ and $4 \%$ of local tax revenues in most cases, compared to between $40 \%$ and $50 \%$ in cities in Australia, Canada, France, the United Kingdom and the United States (UN-Habitat, 2016). In contrast, property taxes in Latin America only represented $0.33 \%$ of GDP in 2012 (De Cesare, 2016), compared to 1\% in OECD countries in the same year (Blöchliger, 2015).

In addition to raising additional local revenue, stronger urban taxation, including property taxes, acts as a tool for tackling urban inequality, by reorienting land-use patterns, capturing capital gains from public investment and combating real estate speculation (De Cesare, 2016). Similarly, the use of urban policy tools based on the city's social functions can generate significant revenue and finance infrastructure investments. ${ }^{30}$

Linking fiscal instruments with land-use policy is also a mechanism for combating the culture of privilege. The scant and irregular collection of taxes on urban property and privatization of the profits generated by public investment in a context of weak capture of capital gains are also symptoms of that culture's rationale. In cities, this rationale is clearly manifested in inequality and segregation; and it is expressed physically in the nature of urban development.

In this universe, emerging technologies, such as blockchain, can help improve urban registers, which must be properly managed to implement effective urban policies and taxation and to increase administrative transparency. The digitalization of registers through satellite and georeferencing tools can form part of an urban strategy of technological innovation.

National regulations on urban development can make a significant contribution to empowering cities and other levels of government to apply taxation and inclusion instruments. Innovations in taxation and inclusion tools have occurred mainly in countries that have an advanced regulatory framework for urban development. ${ }^{31}$ Accordingly, building objectives compatible with the right to the city into a consistent urban legislation framework represents a strategic challenge for building sustainable cities and taking better advantage of the benefits of new technologies. ${ }^{32}$ One way to promote legislative progress in this area is to design a national urban policy that treats sustainable urbanization as one of the nation's development objectives.

30 Examples include the certificates of additional construction potential (CEPAC) in São Paulo or the transfer of building rights in Porto Alegre. Betterment levies are applied in some Colombian cities, including Bogotá and Barranquilla (Smolka and Furtado, 2014).

31 The City Statute, of Brazil (2001), and the Urban Reform Law (1989) and Law No. 388, on Territorial organization (1997) of Colombia, provide the regulatory framework for numerous initiatives in these countries.

32 Civil society participation in coordinating urban legislation and insisting upon its implementation is essential, particularly in the presence of irregular application of instruments and shortcomings in tax collection, even in contexts where advanced regulations are available. 


\section{(e) Enabling conditions for urban sustainability and production change}

The following proposals are aimed at decarbonizing universal public services and the appropriating technological change in urban areas:

1. Radically strengthen regulations on the environmental performance of public services and emissions from urban vehicles, to speed up innovation in the production sector, particularly in mobility and construction.

2. Strengthen local finances by rationalizing urban land use to decarbonize production activity and reduce inequality.

3. Foster the appropriation of digital technologies to improve urban operation through the virtualization and, consequently, the rationalization of travel demand, greater and easier access to all types of services and the optimization of public services -including records and registers - and local finances. Digitalization must also strengthen and deepen informed and timely participation in key decisions to steer the style of development.

4. Develop national urban policies —one of the objectives of the New Urban Agenda adopted at the United Nations Conference on Housing and Sustainable Urban Development (Habitat III), since this provides an opportunity to achieve sustainable development - and coordinate them with industrial and technological policies at different levels of government.

\section{The energy sector, a driver of change}

The international experience shows that the environmental big push is possible. Examples from outside the region include the development of photovoltaic energy in China and wind power in Germany. Both cases involve investments that needed time to mature before being able to deploy their full potential and change production and consumption patterns.

China's strategy is structured in five-year plans that envisage investments equivalent to $5 \%$ of GDP in energy-saving systems and environmentally-friendly technologies, biotechnology, new generation information technologies, new materials, alternative fuels and electric cars. Within this framework, substantial investments have been made in solar and wind technologies. The China Development Bank (CDB) contributed the necessary financing to private companies, ${ }^{33}$ and tariff and regulatory instruments were implemented to reduce uncertainty, such as lower regional tariffs on food from the energy produced by solar projects (Liu, 2011). These initiatives quickly placed their manufacturers among the leading players in the world market, especially in the case of solar panels. ${ }^{34}$

In Germany, the Federal Ministry of Research and Technology launched a wind power development programme in 1989, based on the combination of a regulated tariff system ${ }^{35}$ and a $70 \%$ tax credit for smallscale producers. Subsequently, in 2011, the German Development Bank (KfW) announced that it would put up 100 billion euros (between US\$120 billion and US\$130 billion) over the following five years to promote renewable energies and contribute to a transition aimed at decommissioning all the country's nuclear power plants by 2022. The 20-year investment horizons provided by the German government's incentives reduce uncertainty and bolster investor confidence.

In contrast to the Chinese and German experiences, Latin America and the Caribbean have only recently started to combine instruments to promote the development of these sectors. Solar and wind energy sources barely top $1 \%$ of supply in some countries —a situation that belies the region's great energy potential. ${ }^{36}$ In

33 The investments made by the China Development Bank were crucial to the success of the development of solar energy. Between 2007 and 2012 , this bank lent US $\$ 78$ billion to clean energy projects. After 2010, it granted US\$ 47 billion to some 15 leading Chinese photovoltaic panel manufacturers (Mazzucato and Penna, 2015).

34 The development objectives of solar energy in China were integrated with those of wind energy. The target is to attain 1,000 GW of wind power by 2050 (Liu, 2011).

35 In feed-in tariff (FiT) systems, the administration sets rates for each type of renewable energy.

36 Some countries, such as Chile, Costa Rica, Ecuador, Mexico and Nicaragua, have medium-term energy plans involving greater penetration of renewables; but they have neglected their role as an endogenous driver of development based on industrial policies. 
particular, energy use by the small island States of the Caribbean continues to depend on fossil fuels. Among the member States of the Caribbean Community (CARICOM), Dominica has the largest share of renewable sources in electricity generation (28\%), as a result of a strategy to achieve energy self-sufficiency by 2020. There is an acknowledged need in the Caribbean to coordinate better in formulating and implementing sustainable energy policies; CARICOM has implemented various initiatives in recent years, such as designing energy-efficiency standards and promoting renewable sources in its member States (ECLAC, 2016d).

Primary energy demand in Latin America and the Caribbean overall is expected to grow by at least $80 \%$ by 2040 , and by over $91 \%$ in the case of electricity (Balza, Espinasa and Serebrisky, 2016). This will require planning, building and maintaining the equivalent of 18 new hydroelectric plants the size of Itaipú (the largest hydro project in the region and the third largest in the world). This unprecedented level of investment provides an opportunity to make the diversification of the energy matrix an endogenous and sustainable driver of the creation and development of low-carbon activities and jobs.

Progress in wind and solar energy in the region has tended to occur in the form of turnkey contracts with transnational firms. Although this does diversify the energy matrix and reduce the environmental impact of power generation, it does not provide opportunities for domestic production restructuring or incorporate new skills and knowledge into the economies, except in a few cases thanks to industrial policy implementation (see box VII.2).

\section{Box VII.2}

Policy coordination to foster renewable energies in Brazil

To promote renewable energy technologies, the Brazilian Development Bank (BNDES) used its Climate Fund Programme to offer long-term loans at low cost ( $2 \%$ per annum in real terms) to about half of all new projects in this area, covering up to $70 \%$ of the necessary capital (BNDES, 2015). Although in 2016 it reduced its contribution to the Alternative Electric Power Source Incentive Programme (PROINFA) owing to the recession, BNDES allocated US\$ 1.8 billion and took an $80 \%$ stake in investment in projects with repayment terms of up to 12 years, involving the direct and indirect creation of 150,000 jobs.

The financial architecture adopted to promote wind energy formed part of the country's industrial policy. PROINFA promoted this type of energy on a large scale, along with the installation of related industries and the testing of new technologies, and assigned it more attractive prices. Tariff and tax policies were coordinated to stimulate expansion in the sector and reduce its costs. Auctions were launched in 2007, which set market shares for the wind power contract awards. In 2011 and 2012, the prices of this type of energy rivalled those of hydropower, the most competitive in the country. In the area of fiscal policy, to increase the profitability of renewables, the government exempted project revenues from federal taxes, lowered the rate of merchandise and services (ICMS) tax on equipment and components produced in some states, and offered discounts on fees for the use of transmission and distribution systems (BNDES, 2016). ${ }^{a}$

In terms of the use of government regulation to leverage innovation and investment, BNDES applies a standard for the accreditation of wind turbines, which has facilitated the financing of projects and domestically produced components. In 2016, the six accredited manufacturers (Alstom, Vestas, Wobben Windpower, WEG, Acciona and Siemens Gamesa) had a production capacity of over 2 GW per year (BNDES, 2016). According to the Brazilian Wind Energy Association (ABEEólica, 2017a), 80\% of its production chain was domestic, and its investments totalled US\$ 5.4 billion. As a result of the support for domestic production between 2012 and 2015. while the supply of wind energy increased, equipment imports for wind power generation decreased. This helped to increase domestic technological capabilities and ease pressure on the external sector.

Although the economic slowdown in Brazil in recent years reduced the awarding of wind energy contracts (in 2015 and 2016 there were no tender), as of February 2017, 10.8 GW of installed capacity had been built up in 433 wind farms, representing a $7 \%$ share of the electricity matrix (ABEEólica, 2017b).

Source: Economic Commission for Latin America and the Caribbean (ECLAC), on the basis of Brazilian Development Bank (BNDES), "0 desenrolar da energía eólica no Brasil", Rio de Janeiro, 2016 [online] http://www.bndes.gov.br/wps/portal/site/home/conhecimento/noticias/noticia/energia-eolica-brasil; BNDES, "Fundo Clima - energias renovaveis", Río de Janeiro, 2015 [online] https://www.bndes.gov.br/wps/portal/site/home/financiamento/produto/ fundo-clima-energias-renovaveis.

a Nonetheless, Brazil still applies fossil-fuel subsidies, which should be eliminated as part of the industrial policy in the energy sector and replaced by support for targeted population groups. On average, between 2011 and 2013, fuel subsidies in the region represented $1.4 \%$ of GDP per year, while subsidies for electricity represented $0.8 \%$ (Di Bella and others, 2015). 


\section{(a) Strategic guidelines for decarbonizing the electric matrix}

To diversify the energy matrix, the countries of the region need to adopt policies that combine regulatory changes with incentives for local production of the equipment and services needed to develop investment projects in renewable energy and energy efficiency. This may include the creation of systems for storing the large volumes of energy produced intermittently by renewables, taking advantage of the abundant natural resources available to the region and generating production linkages linked to their production and technological applications. Such storage systems can be expanded to reservoirs, vehicles and buildings, thereby blurring sectoral boundaries.

To promote the decarbonization of the electricity matrix (as distinct from the energy matrix, which includes the consumption of liquid fossil fuels for transport), that is, to increase the penetration of renewable energies in electric power generation, the following guidelines are important:

- Harmonize regulations throughout the region - thus far applied only in Argentina, Brazil, Chile and Mexico- to allow bidding for time blocks. This would avoid requiring renewable sources (solar, in particular) to supply power during the hours of darkness, which would increase their profitability. The harmonization process should be run by ministries of energy, in dialogue with the private sector.

- Substitute imports in production chains. Until now, non-conventional renewable energies have generally been introduced through turnkey projects. The Brazilian experience analysed in box VII.2 illustrates the potential of an industrial policy geared towards this objective. There is great scope for innovation in wind and solar energy, and in other sources, such as geothermal, biodiesel and tidal energy, as well as the supply of buses for public transport systems, an area in which the region already has domestic manufacturing experience. In this connection, it is worth analysing the possibility of supporting trans-Latin firms in the sector in the transition towards electrification of the public transport fleet. Responsibility for these actions lies with the ministries of energy, ministries of science and technology, and universities and firms in collaboration.

- Gradually internalize real social costs in the economic calculus. Among other things, this means phasing out subsidies on fossil fuels, taxing emissions, assigning a price to $\mathrm{CO}_{2}$; or, conversely, rewarding investment in renewables. These actions are the responsibility of ministries of finance and local governments, especially in the case of the social costs of automobile use and local $\mathrm{CO}_{2}$ emissions.

- Gradually reflect the systemic risk of high-carbon paths - due to their physical, technological and reputational effects, among others - that could turn financial assets into financial liabilities (unsaleable or stranded assets) through the dynamic of climate bubbles. Examples include over-investment in areas that will be adversely affected by climate change (where, for example, agriculture faces drought risk) or in areas where technical progress will change the pattern of production or consumption (if, for example, electric cars or boats start to replace vehicles that use fossil fuels and, therefore, these become unsaleable or unpayable). Central banks, the banking sector, insurers and public sector procurement will all have key roles to play in these policies.

- Regulate or standardize bank financing for renewable energies by harmonizing risks and opportunities and rates of return, with a view to flattening the learning curve. Development banks, in partnership with private banks and ministries of energy, are key players in this.

Complementarity among the countries of the region could drive large-scale investments. Projects that use wind and solar energy are on a smaller scale than hydroelectric projects ${ }^{37}$ and those based on fossil fuels, which tend to be geographically dispersed. On the other hand, they have a smaller environmental impact, they gain authorization more easily and can be rolled out within shorter time horizons. This increases flexibility for installing new renewable capacity; it also offers an attractive solution for providing electricity to isolated communities.

37 Compared to large-scale hydroelectric projects, such as Belo Monte (11,233 MW) in Brazil, or Pescadero-Ituango (2,400 MW) in Colombia, and potential projects such as HidroAysén (2,000 MW), in Chile. 
The pursuit of complementarities between and within countries can also generate virtuous technical and political processes for regional energy integration. This means evaluating national and international technologies and regulations to promote sustainable change in the energy matrix of the region's countries. The region can learn from experiences in other systems, anticipating challenges and adapting regulatory designs as it designs solutions. For this reason, in various circles energy - a resource that is recognized as having strategic attributes and geopolitical connotations - is considered a vector of the environmental big push towards regional integration and a pillar of a more inclusive and sustainable form of development. Once again, this speaks to the need to make headway towards energy policies coordinated with industrial and technological policies, as all three are necessary components of an environmental big push.

\section{Transparency and trust in institutions facilitate the implementation of policies to promote the environmental big push}

Changes in public policies to promote the environmental big push need a base of support and public legitimacy. Transparency, accountability, evaluation of the impact of policies and programmes, citizen participation in decision-making and recognition of information and power asymmetries are key elements of the environmental big push. Initiatives in Latin America and the Caribbean to improve access to information, participation and access to justice on environmental issues are part of the effort to advance towards implementing the 2030 Agenda and attaining the Sustainable Development Goals.

The environmental big push can thus help broaden the role and meaning of social policy, which, until now, has focused on just two components of well-being: people's income and the social protection system. It thus tends to disregard the importance of collective consumption based on public services, which forms part of families' indirect income and fosters the condition of citizenship and the sense of belonging.

By contrast, resources are being allocated in ways that contribute to the deterioration of public services and increase environmental degradation, as the consumption pattern of the elites becomes entrenched. This is causing a mass flight from public education and health services to private providers. The process is also reproduced in the mass abandonment of public transport — given that the poor service quality and safety levels encourage private vehicle use - as well as the absorption of public space for shopping centres, the growth of private security services, self-segregated neighbourhoods and even discrimination in access to drinking water. The cumulative effect of these phenomena erodes the sense of belonging to a political community and of equal citizenship in the public sphere.

In short, the provision of quality public services, with operating standards that attract sectors with the greatest resources yet do not discriminate against the poorest, is key to the reconstruction of coexistence and democratic trust, inclusion and progress towards a development model with a smaller environmental footprint and greater well-being. A developed country is one in which the rich use public transport, are educated in public schools and drink tap water; and where the social gaps between high- and low-income groups are less gaping. Advocacy for collective consumption places the rights perspective at the heart of the debate about the new welfare regimes; and it is an essential part of the environmental big push.

\section{E. Concluding remarks}

The quality of democracy depends both on the institutions that promote equal rights and on the modes of coexistence that reflect a society's sense of belonging. The technological alternatives with the smallest carbon footprint and the change in the energy matrix must also strengthen this collective belonging. Hence the importance of strategies and policies that facilitate the transition to more sustainable ways of producing, 
inhabiting and consuming and, at the same time, enhance the provision of public goods and better-quality services. This will make it possible to move towards a new style of development, with fewer social gaps and spatial segregations, and to achieve growth based on innovation and the dissemination of clean technologies.

The exponential spread of innovation and the digital revolution is penetrating all areas of life; and Latin America and the Caribbean cannot be left behind. It is time to take advantage of the technological innovation fields that offer tools for the environmental big push. These encompass areas as diverse as urban management and transport, biodiversity management, conservation, water use and recycling, the quality and timeliness of social protection systems, training for the new generations in strategic capabilities for the new world of work, the development of biomaterials and the production of renewable energies.

The environmental big push thus links the macroeconomic, the industrial, the social and the environmental. Given this interdependence, the region is facing either the risk of perpetuating a vicious circle of low productivity, volatile growth, high inequality and serious environmental costs; or the opportunity to transition to a virtuous circle with synergies between a proactive macroeconomy, a low-carbon production and energy matrix and a better quality of life.

In this document, ECLAC has sought to gauge both the magnitude and the urgency of the challenge of the environmental big push. Its magnitude is evident in the acknowledged and growing interdependence of the different domains of development. Its urgency reflects the sword of Damocles that is climate change, and the opportunities and risks arising from the speed of technological change. It is not a question of postponing the attainment of equality, but of recognizing that increasing equality in order to achieve more robust growth — growth with a better production base, capable of ensuring a sustainable future for the coming generations - is a matter of efficiency.

\section{Bibliography}

ABEEólica (Brazilian Wind Energy Association) (2017a), "Brasil sobe no ranking mundial de capacidade instalada de energia eólica", São Paulo, February [online] http://www.abeeolica.org.br/noticias/brasil-sobe-no-ranking-mundial-de-capacidadeinstalada-de-energia-eolica/ [date of reference: March 2017].

(2017b) "Dados mensais: fevereiro de 2017", São Paulo, February [online] http://www.abeeolica.org.br/wp-content/ uploads/2017/02/Dados-Mensais-ABEEolica-02.2017.pdf.

Bahl, R., J. Linn and D. Wetzel (eds.) (2013), Financial Metropolitan Governments in Developing Countries, Cambridge, Lincoln Institute of Land Policy.

Balza, L., R. Espinasa and T. Serebrisky (2016), Lights on?: Energy needs in Latin America and the Caribbean to 2040, Washington, D.C., Inter-American Development Bank (IDB).

Blanchard, O. and others (2016), Progress and Confusion: The State of Macroeconomic Policy, Cambridge, MIT Press.

Blöchliger, H. (2015), "Reforming the tax on immovable property: taking care of the unloved", OECD Economics Department Working Papers, No. 1205, OECD Publishing, Paris, April [online] http://dx.doi.org/10.1787/5js30tw0n7kg-en.

BNDES (Brazilian Development Bank) (2016), "O desenrolar da energía eólica no Brasil," Rio de Janeiro [online] http://www. bndes.gov.br/wps/portal/site/home/conhecimento/noticias/noticia/energia-eolica-brasil.

(2015), "Fundo Clima - energias renovaveis," Rio de Janeiro [online] https://www.bndes.gov.br/wps/portal/site/home/ financiamento/produto/fundo-clima-energias-renovaveis.

Bonetto, R. and M. Rossi (2017), "Smart grid for the smart city", Designing, Developing, and Facilitating Smart Cities, V. Angelakis and others (eds.), Cham, Springer.

CAF (Development Bank of Latin America) (2016), Observatorio de Movilidad Urbana: informe 2015-2016, Caracas.

Cecchini, S. and B. Atuesta (2017), "Programas de transferencias condicionadas en América Latina y el Caribe: tendencias de cobertura e inversión", Social Policy series, No. 224 (LC/TS.2017/40), Santiago, Economic Commission for Latin America and the Caribbean (ECLAC).

CETESB (Environmental Sanitation Technologies Company) (2014), Plano de Controle de Poluição Veicular 2014-2016, São Paulo [online] http://cetesb.sp.gov.br/wp-content/uploads/2014/12/pcpv-2014.pdf.

Cimoli, M. and others (eds.) (2017), Políticas industriales y tecnológicas en América Latina (LC/TS.2017/91), Santiago, Economic Commission for Latin America and the Caribbean (ECLAC).

CLES (Centre for Local Economic Strategies) (2017), Community Wealth Building through Anchor Institutions, Manchester, February. 
De Cesare, C. M. (ed.) (2016), Sistemas del impuesto predial en América Latina y el Caribe, Cambridge, Lincoln Institute of Land Policy.

Di Bella, G. and others (2015), "Energy subsidies in Latin America and the Caribbean: stocktaking and policy challenges", IMF Working Paper, No. WP/15/30, Washington, D.C., International Monetary Fund (IMF), February.

Dølvik, J. E. and others (2015), The Nordic Model Towards 2030: A New Chapter?, Fafo Institute for Applied International Studies [online] http://www.fafo.no/images/pub/2015/20412.pdf.

ECLAC (Economic Commission for Latin America and the Caribbean) (2017a), Financing the 2030 Agenda for Sustainable Development in Latin America and the Caribbean: the challenges of resource mobilization (LC/FDS.1/4), Santiago. (2017b), Linkages between the social and production spheres: gaps, pillars and challenges (LC/CDS.2/3), Santiago.

(2017c), Social Panorama of Latin America, 2016 (LC/PUB.2017/12-P), Santiago.

(2016a), Horizons 2030: Equality at the Centre of Sustainable Development (LC/G.2660/Rev.1), Santiago.

(2016b), The social inequality matrix in Latin America (LC/G.2690(MDS.1/2)), Santiago.

(2016c), The new digital revolution: from the consumer Internet to the industrial Internet (LC/L.4029/Rev.1), Santiago.

(2016d), Report of the Regional Dialogue and Training Workshop on Energy Efficiency and Renewable Energy Initiatives in the Caribbean (LC/CAR/L.505), Port of Spain, ECLAC subregional headquarters for the Caribbean, 15 September.

(2014), Compacts for Equality: Towards a Sustainable Future (LC/G.2586 (SES.35/3)), Santiago.

(2010), Time for Equality: Closing Gaps, Opening Trails (LC/G.2432(SES.33/3)), Santiago.

ECLAC/UN-Habitat/MINURVI (Economic Commission for Latin America and the Caribbean/United Nations Human Settlements Programme/General Assembly of Ministers and High-level Authorities of the Housing and Urban Development Sector in Latin America and the Caribbean) (2018), Regional Action Plan for the Implementation of the New Urban Agenda in Latin America and the Caribbean, 2016-2036 (LC/TS.2017/77/Rev.2), Santiago, February.

Eichengreen, B. and P. Gupta (2015), "Tapering talk: the impact of expectations of reduced Federal Reserve security purchases on emerging markets", Emerging Markets Review, vol. 25.

Filgueira, F. (2015), "Models of development, the welfare State matrix and Latin American social policy tools", Towards universal social protection: Latin American pathways and policy tools, ECLAC Books, No. 136 (LC/G.2644-P), S. Cecchini and others (eds.), Santiago, Economic Commission for Latin America and the Caribbean (ECLAC).

Filgueira F. and E. Espíndola (2015), "Toward a system of basic cash transfers for children and older persons: an estimation of efforts, impacts and possibilities in Latin America", Social Policy series, No. 216 (LC/L.3934), Santiago, Economic Commission for Latin America and the Caribbean (ECLAC).

Florida, R. (2017), The New Urban Crisis: How our Cities are Increasing Inequality, Deepening Segregation, and Failing the Middle Class_-and What We Can do About it, New York, Basic Books.

Freeman, C. (2008), Systems of Innovation: Selected Essays in Evolutionary Economics, Cheltenham, Edward Elgar Publishing. Furche, P. and others (2017), "FinTech and the future of central banking", Economic Policy Papers, No. 63, Santiago, Central Bank of Chile, August.

Greenfield, A. (2013), Against the Smart City, New York, Do Projects.

Hanni, M., R. Martner and A. Podestá (2015), "The redistributive potential of taxation in Latin America", CEPAL Review, No. 116 (LC/G.2643-P), Santiago, Economic Commission for Latin America and the Caribbean (ECLAC).

Harris, J. M. (2008), "Ecological macroeconomics: consumption, investment, and climate change", Working Paper, No. 08-02, Medford, Global Development and Environment Institute, Tufts University.

Heckman, J. (2013), Giving Kids a Fair Chance, Cambridge, MIT Press.

Hollands, R. (2015), "Critical interventions into the corporate smart city", Cambridge Journal of Regions, Economy and Society, vol. 8, No. 1, March.

IFC (Irving Fisher Committee on Central Bank Statistics) (2016), IFC Report. Measures of Financial Inclusion: A Central Bank Perspective, Bank for International Settlements (BIS), June.

Innerarity, D. (2011), La democracia del conocimiento: por una sociedad inteligente, Barcelona, Paidós.

IRENA (International Renewable Energy Agency) (2017), Renewable Energy Auctions: Analysing 2016, Abu Dhabi.

(2016b), Renewable Energy Market Analysis: Latin America, Abu Dhabi.

Jacobs, J. (1986), Las ciudades y la riqueza de las naciones: principios de la vida económica, Barcelona, Editorial Ariel.

Jordán, R., L. Riffo and A. Prado (coords.) (2017), Desarrollo sostenible, urbanización y desigualdad en América Latina y el Caribe: dinámicas y desafíos para el cambio estructural (LC/PUB.2017/19), Santiago, Economic Commission for Latin America and the Caribbean (ECLAC), September.

Lavarello, P. (2017), “¿De qué hablamos cuando hablamos de política industrial?", Manufactura y cambio estructural: aportes para pensar la política industrial en la Argentina, ECLAC Books, No. 149 (LC/PUB.2017/21-P), M. Abeles, M. Cimoli and P. Lavarello (eds.), Santiago, Economic Commission for Latin America and the Caribbean (ECLAC).

Liu, C. (2011), "China uses feed-in tariff to build domestic solar market", New YorkTimes, 14 September [online] http://www. nytimes.com/cwire/2011/09/14/14climatewire-china-uses-feed-in-tariff-to-build-domestic-25559.html?pagewanted=all [date of reference: 24 June 2014]. 
Marcel, M. (2017), “Inclusión financiera, innovación tecnológica y estabilidad macroeconómica", document presented at the Third Conference on Banking Development, Stability, and Sustainability, Santiago, 3 November [online] http://www. bcentral.cl/web/guest/consejeros?p_p_id=cl_bancocentral_buscador_anual_portlet_BuscadorFiltroAnualMVCPortlet_ INSTANCE_uyttqsfK65KE\&p_p_lifecycle=0\&p_p_state=normal\&p_p_mode=view\&_cl_bancocentral_buscador_anual_ portlet_BuscadorFiltroAnualMVCPortlet_INSTANCE_uyttqsfK65KE_anio=2017.

Marcus, G. (2016), "Remarks on the future of monetary policy", Progress and Confusion: The State of Macroeconomic Policy, O. Blanchard and others (eds.), Cambridge, MIT Press.

Mazzucato, M. (2015), “The green entrepreneurial State," SPRU Working Paper series, No. 2015-28, University of Sussex, October [online] www.sussex.ac.uk/spru/swps2015-28.

(2011), "The entrepreneurial State", Soundings, No. 49, London, Lawrence and Wishart.

Mazzucato, M. and C. Penna (2015), "The rise of mission-oriented State investment banks: the cases of Germany's KfW and Brazil's BNDES", SPRU Working Paper series, No. 2015-26, University of Sussex, September [online] http://www. sussex.ac.uk/spru/swps2015-26.

Mazzucato, M. and C. Pérez (2014), "Innovation as growth policy: the challenge for Europe", SPRU Working Paper series, No. 2014-13, University of Sussex, July [online] https://www.sussex.ac.uk/webteam/gateway/file.php?name=2014-13swps-mazzucato-perez.pdf\&site $=25$.

Mercadante, A. (2017), "Educación y capacitación técnico-profesional en Brasil", unpublished.

Moene, K. O. and M. Wallerstein (2006), "The Scandinavian model and economic development," Development Outreach, vol. 8, No. 1, World Bank Institute (WBI), February [online] http://documents.worldbank.org/curated/en/404591468165872122/ pdf/372500NEWSOREP10Box311126B01PUBLIC1.pdf.

Mora, L., R. Bolici and M. Deakin (2017), "The first two decades of smart-city research: a bibliometric analysis", Journal of Urban Technology, vol. 24, No. 1.

Morin, E. (1992), El método 2: la vida de la vida, Madrid, Editorial Cátedra.

OECD (Organization for Economic Cooperation and Development) (2016), Innovating Education and Educating for Innovation: The Power of Digital Technologies and Skills, Paris, OECD Publishing.

(2015), Promoting the Development of Local Innovation Systems: The Case of Medellin, Colombia, OECD Publishing, April.

Paschoal, B. and K. Wegrich (2017), "Urban governance innovations in Rio de Janeiro: the political management of digital innovations", Journal of Urban Affairs [online] https://www.tandfonline.com/doi/abs/10.1080/07352166. 2017.1310561?journalCode=ujua20.

Patiño, J. A. (comp.) (2014), "Datos abiertos y ciudades inteligentes en América Latina: estudio de casos", Project Documents (LCM.621), Santiago, Economic Commission for Latin America and the Caribbean (ECLAC), September.

Patton, D. (2012), "Further huge boost to solar target 'not on China's agenda'", Recharge News, 12 September [online] www.rechargenews.com/news/policy_market/article1298370.ece [date of reference: 24 June 2014].

Perera, C. and others (2013), "Sensing as a service model for smart cities supported by Internet of Things", Transactions on Emerging Telecommunications Technologies, vol. 25, No. 1.

Pérez Caldentey, E. (2017), "Quantitative easing (QE), changes in global liquidity, and financial instability," International Journal of Political Economy, vol. 46, No. 2-3.

Pineda Serna, L. and C. Scheel (2011), "Plan Estratégico de Ciencia, Tecnología e Innovación de Medellín 2011-2021", Medellín, Corporación Ruta N [online] https://www.rutanmedellin.org/images/programas/plan_cti/Documentos/Plande-CTi-de-Medellin.pdf.

Polanyi, M. (1966), The Tacit Dimension, London, Routledge.

Pollin, R. (2012), Back to Full Employment, Cambridge, MIT Press.

REN21 (Renewable Energy Policy Network for the 21st Century) (2016), Renewables 2016: Global Status Report, Paris [online] http://www.ren21.net/wp-content/uploads/2016/05/GSR_2016_Full_Report_lowres.pdf.

Rico, M. N. (2017), “Presentación del informe 'Género en el sistema financiero', SBIF. Chile. CEPAL, 10 July 2017" [online] http://www.cepal.org/sites/default/files/news/files/inclusion_financiera_para_las_mujeres.pdf.

Rode, P. and others (2017), Resource Urbanisms: Asia's Divergent City Models of Kuwait, Abu Dhabi, Singapore and Hong Kong, London, LSE Cities, London School of Economics and Political Science.

Rofman, R., V. Amarante and I. Apella (eds.) (2016), Cambio demográfico y desafíos económicos y sociales en el Uruguay del siglo XXI (LC/L.4121), Santiago, Economic Commission for Latin America and the Caribbean (ECLAC)/World Bank.

Rosenstein-Rodan, P. (1960), "Notas sobre la teoría del 'gran impulso'," El desarrollo económico y América Latina, H. S. Ellis y H. C. Wallich (eds.), Mexico City, Fondo de Cultura Económica.

Sepúlveda, L. (2017), "La educación técnico-profesional en América Latina: retos y oportunidades para la igualdad de género", Gender Affairs series, No. 144 (LC/TS.2017/13), Santiago, Economic Commission for Latin America and the Caribbean (ECLAC).

Sevilla, M. P. (2017), "Panorama de la educación técnica profesional en América Latina y el Caribe", Social Policy series, No. 222 (LC/L.4287), Santiago, Economic Commission for Latin America and the Caribbean (ECLAC). 
Shin, H. S. (2016), "Global liquidity and procyclicality", paper presented at the conference "The state of economics, the state of the world", Washington, D.C., World Bank, 8-9 June.

Smolka, M. O. and F. Furtado (eds.) (2014), Instrumentos notables de políticas de suelo en América Latina, Cambridge, Lincoln Institute of Land Policy.

Summers, L. (2016), "Rethinking secular stagnation after seventeen months", Progress and Confusion: The State of Macroeconomic Policy, O. Blanchard and others (eds.), Cambridge, MIT Press.

Sunkel, O. (2006), “En busca del desarrollo perdido," Problemas del Desarrollo, vol. 37, No. 147, October-December.

Ter-Minassian, T. (2016), Fiscal and Financial Issues for 21st Century Cities: Background and Overview, Brookings Institution, April.

The New York Times (2017), "G.M. and Ford lay out plans to expand electric models", 2 October [online] https://www. nytimes.com/2017/10/02/business/general-motors-electric-cars.html.

Tiebout, C. M. (1956), "A pure theory of local expenditures", The Journal of Political Economy, vol. 64, No. 5, October.

Toynbee, A. (1971), Ciudades en marcha, Madrid, Alianza/Emecé.

Trajtenberg, L., S. Valdecantos and D. Vega (2015), “'Los determinantes de la inflación en América Latina: un estudio empírico del período 1990-2013", Estructura productiva y política macroeconómica: enfoques heterodoxos desde América Latina, ECLAC Books, No. 138 (LC/G.2653-P), A. Bárcena, A. Prado and M. Abeles (eds.), Santiago, Economic Commission for Latin America and the Caribbean (ECLAC).

UN-Habitat (United Nations Human Settlements Programme) (2016), World Cities Report 2016. Urbanization and Development: Emerging Futures, Nairobi.

United Nations (2017), "Resolution adopted by the General Assembly on 23 December 2016: 71/256. New Urban Agenda" (A/RES/71/256).

(2015), "Battle for sustainable development will be won or lost in cities, Deputy Secretary-General tells Mayor's Forum", 9 June [online] https://www.un.org/press/en/2015/dsgsm874.doc.htm.

(2013), A New Global Partnership: Eradicate Poverty and Transform Economies through Sustainable Development, New York.

(2012), "'Our struggle for global sustainability will be won or lost in cities,' says Secretary-General, at New York event", 23 April [online] https://www.un.org/press/en/2012/sgsm14249.doc.htm.

Van Parijs, P. and Y. Vanderborght (2017), Basic Income: A Radical Proposal for a Free Society and a Sane Economy, Cambridge, Harvard University Press.

Vartiainen, J. (2014), To Create and Share - The Remarkable Success and Contested Future of the Nordic Social-Democratic Model, Fafo Institute for Applied International Studies [online] http://www.fafo.no/images/pub/2014/20372.pdf. 



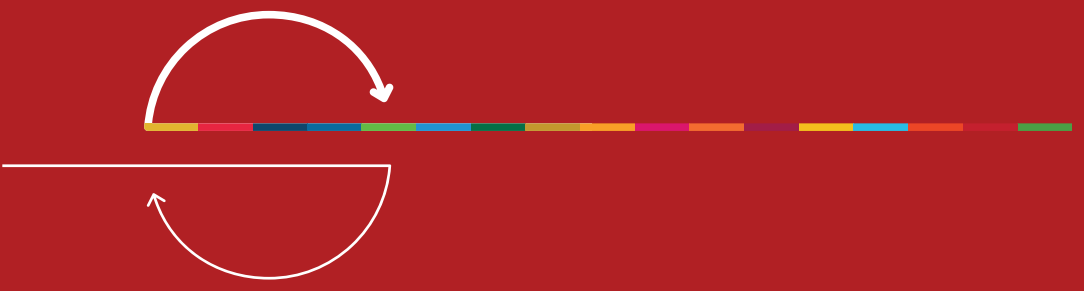

Inequality is inefficient because it hinders learning, productivity, innovation and growth. Equality is, then, not only an ethical principle inherent to development, but also a key tool for achieving it.

Consistently with the emphasis that the Economic Commission for Latin America and the Caribbean (ECLAC) has placed on equality since 2010, and in keeping with the purpose of leaving no one behind enshrined in the 2030 Agenda for Sustainable Development, this document examines the mechanisms by which inequality erodes dynamic efficiency in the Latin American and Caribbean economies. It analyses and measures the productivity and income effects of unequal access to health and education, as well as the consequences of inequality of opportunities arising from gender-, race- or ethnicity-based discrimination. It also examines how these inequalities play out at the level of territory, infrastructure and urban dynamics, where their costs not only weigh on productivity, but also worsen energy inefficiencies and environmental degradation, thereby compromising the development possibilities of present and future generations.

Inequality imposes constraints on innovation and creativity that are all the heavier because they are embedded within the culture of agents, which creates a culture of privilege in which many public goods and rights are not universal, but denied to much of the population. This weakens trust in social interactions and in democratic institutions.

Here, ECLAC proposes strategic guidelines for increasing the dynamic efficiency of the Latin American and Caribbean economies on the basis of equality. Capacity-building and the construction of welfare States are at the heart of a new development paradigm that puts the technological revolution at the service of low-carbon, technology-intensive growth. In this regard, and in view of the rapid transformations and mounting uncertainties in the global economy, the region urgently needs stronger public and private investment revolving around an environmental big push in order to diversify its production structure and even out its structural disparities 